AFTERLIVES
OF CHINESE
COMMUNISM 



\section{AFTERLIVES OF CHINESE COMMUNISM POLITICAL CONCEPTS FROM MAO TO XI}

Edited by Christian Sorace, Ivan Franceschini, and Nicholas Loubere 


\section{ANU PRES S

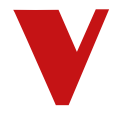 \\ VER S O}

First published 2019 by ANU Press and Verso Books

The Australian National University

Acton ACT 2601, Australia

Email: anupress@anu.edu.au

Available to download for free at press.anu.edu.au

ISBN (hardback): 9781788734790

ISBN (paperback): 9781788734769

ISBN (online): 9781760462499

WorldCat (print): 1085370489

WorldCat (online): 1085370850

DOI: 10.22459/ACC.2019

This title is published under a Creative Commons Attribution-NonCommercial-NoDerivatives 4.0

International (CC BY-NC-ND 4.0).

\section{(9) $(1 \otimes \Theta$}

The full licence terms are available at creativecommons.org/licenses/by-nc-nd/4.0/legalcode

Note on Visual Material

All images in this publication have been fully accredited. As this is a non-commercial publication, certain images have been used under a Creative Commons licence. These images have been sourced from Flickr, Wikipedia Commons and the copyright owner of each original picture is acknowledged and indicated in the source information.

Design concept and typesetting by Tommaso Facchin; Illustrations by Marc Verdugo Lopez.

Cover design by No Ideas. Cover artwork by Marc Verdugo Lopez.

Proofreading by Sharon Strange and Evyn Chesneau Papworth.

This edition @ 2019 ANU Press and Verso Books 


\section{Table of Contents}

Introduction - Christian SORACE, Ivan FRANCESCHINI, and Nicholas LOUBERE

1. Aesthetics - Christian SORACE 11

2. Blood Lineage - YI Xiaocuo 17

3. Class Feeling - Haiyan LEE 23

4. Class Struggle - Alessandro RUSSO 29

5. Collectivism - GAO Mobo 37

6. Contradiction - Carlos ROJAS 43

7. Culture - DAI Jinhua 49

8. Cultural Revolution - Patricia M. THORNTON 55

9. Datong and Xiaokang - Craig A. SMITH 63

10. Dialectical Materialism - PANG Laikwan 67

11. Dignity of Labour - WANG Ban 73

12. Formalism - Roy CHAN 77

13. Friend and Enemy - Michael DUTTON 81

14. Global Maoism - Fabio LANZA 85

15. Immortality - Gloria DAVIES 89

16. Justice - William J. HURST 97

17. Labour - Covell MEYSKENS 103

18. Large and Communitarian - Luigi TOMBA 111

19. Line Struggle - Yoshihiro ISHIKAWA and Craig A. SMITH 115

20. Mass Line - LIN Chun 121

21. Mass Supervision - Joel ANDREAS 127

22. Mobilisation - LI Zhiyu 135

23. Museum - Denise Y. HO 141

24. Nationality - Uradyn E. BULAG 149

25. New Democracy - Marc BLECHER 155

26. Paper Tiger - Judith BALSO 161

27. Peasant - Alexander F. DAY 169

28. People's War - GUAN Kai 175

29. Permanent Revolution - Matthew GALWAY 181

30. Poetry - Claudia POZZANA 189

31. Practice - Aminda SMITH 197 
32. Primitive Accumulation - Jane HAYWARD 201

33. Rectification - Andrew MERTHA 207

34. Red and Expert - Sigrid SCHMALZER 215

35. Removing Mountains and Draining Seas - Anna LORA-WAINWRIGHT 221

36. Revolution - CAI Xiang 225

37. Self-reliance - YANG Long 231

38. Semifeudalism, Semicolonialism - Tani BARLOW 237

39. Sending Films to the Countryside - Tong LAM 243

40. Serve the People - Rebecca E. KARL 247

41. Socialist Law - Susan TREVASKES 251

42. Speaking Bitterness - Jeffrey JAVED 257

43. Sugarcoated Bullets - Benjamin KINDLER 263

44. Superstition - John WILLIAMS 269

45. Surpass - William A. CALLAHAN 275

46. Third World - TENG Wei 281

47. Thought Reform - Timothy CHEEK 287

48. Trade Union - Ivan FRANCESCHINI 293

49. United Front - Laura DE GIORGI 303

50. Utopia - OU Ning 309

51. Women's Liberation - WANG Lingzhen 315

52. Work Team - Elizabeth J. PERRY 325

53. Work Unit - Kevin LIN 331

Afterword - Jodi DEAN 335

Acknowledgements 343

Contributors $\quad 345$

References $\quad 355$ 


\section{Introduction}

Christian SORACE, Ivan FRANCESCHINI, and Nicholas LOUBERE

H ere we are in the twenty-first century, among the shipwrecks of utopian voyages, with faded maps to places that no longer exist. Maoist China seems like one such place, with its dreams, aspirations, and terrors, erased under the shimmering miracle of capitalist development. But contemporary China is also a place of state-backed exploitation of labour that produces cheap commodities for global markets, including the electronic goods that have become the prostheses of modern life. The language of communism and class struggle has long been relegated to the past. When discussions of the staggering inequalities of wealth, corruption, and other adverse consequences of post-Maoist capitalism gain momentum, they are censored. Moreover, to read Marx and debate the legacy of Maoism in China is not permitted outside of highly circumscribed official channels-recently, it has even led to the repression and harassment of idealistic students who took Maoism at its word. The Chinese Communist Party (CCP) carefully guards its legacy and vocabulary of legitimation. Against what it labels as 'historical nihilism' (lishi xuwuzhuyi) - that is to say, the rogue circulation of concepts with the potential to inspire and incite new ways of being in the world-it presents a story of China's triumph under CCP rule.

This edited volume argues that there is much we can learn by revisiting the complicated and contested legacies of Chinese communism. The dogmatic reification of Chinese communism in China, and its Cold War vilification in liberal democracies, makes this critical excavation all the more necessary. We refer to Chinese communism in the volume's title, and not to Maoism, because we want to acknowledge that emancipatory ideas in Chinese thought have always been collectively produced. These ideas are the result of countless energetic debates that have taken place in different times and places in China, across the twentieth century and since. It is precisely because of the massive influence Mao has exerted over political thought and discourse in modern China that we must remind ourselves all the more not to confine the ideas, aspirations, and 
promises of Chinese communism to an individual or a time. In this volume, Maoism transcends Mao and refers to new ways of thinking, speaking, and practicing politics that involved the participation of hundreds of millions of people. And as is well known, Mao did not author all of the texts signed in his name. Maoism was the shape Chinese communism took for a time, without the two ever fully coinciding.

This book engages with the idea of communism as it was imagined, promoted, preached, and practiced during China's 'revolutionary century'-encompassing the decades from the 1910s (which culminated in the May Fourth Movement of 1919 and led to the establishment of the CCP in 1921) to the onset of the Reform and Opening Up era announced in December 1978. The period from 1949 to 1976, during which Mao Zedong led the People's Republic, is a central focus of this book.

When the CCP obtained control of the state in 1949, China had a predominantly agrarian society lacking in developed industry. The political violence of the Republican period was exacerbated by Japan's occupation of the country from 1937 to 1945, and by the ensuing Civil War, which ended with the defeat of the Nationalist Party in 1949. In the 1950s, China was reliant on Soviet bureaucratic communism, as the fledgling People's Republic struggled to develop economically in the hostile environment of the Cold War. What came to be known as Maoism can be understood as a conceptual vocabulary and way of thinking about, and putting into practice, the idea of communism in the conditions inherited and navigated by the Communist Party during this stretch of time. Responding to its context, Maoism was not an abstract doctrine, but a living body of 'thought' (sixiang) requiring the deployment of theory in practice, and the reformulation of theory based on the lessons generated by practice. In its attempt to translate and adapt Marxist doctrine to rapidly changing Chinese contexts, Maoism invented new ways of thinking and practising politics - of being political—which circulated far beyond China's borders.

People have not stopped trying to enlist Mao's discourse for their own cause-to selectively cite, interpret, and invoke Mao. Perhaps the most obvious example of a selective reading of Maoism is Deng Xiaoping's historical conclusion that Mao was 70 percent correct and 30 percent wrong (a verdict that mirrors Mao's assessment of Stalin). In the new era ushered in by Deng after 1978, the Party was unable to reconcile the bifurcated image of Mao implied by this 70 to 30 split. On the one hand, Mao was to be revered as the founding father of the People's Republic. That his embalmed corpse has been carefully maintained and displayed in a mausoleum on Tiananmen Square is indicative of his ancestral significance for the post-Maoist Party. Indeed, people are daily reminded of Mao as his visage now appears on Chinese banknotes (and has done so since 1999). On the other hand, post-Maoist Party leaders in the late 1970s and throughout the 1980s also allowed some public space for critical discussions of the Cultural Revolution. Thus, Mao found representation as the provocateur/saboteur who during the Cultural Revolution nearly destroyed the CCP through his injunction to the people to 'bombard the headquarters.' To date, however, the Communist Party has proven unable to monopolise how Mao is remembered, as he continues to lead countless afterlives in China and abroad. ${ }^{1}$ As an iconic image, Mao has become a contradictory symbol. For his admirers, he stands for mass emancipation, while for his detractors he is a cause of mass deaths. Mao has also become a pop culture icon rendered in bright colours on Warhol's silkscreens and even tattooed on the boxer Mike Tyson's 
right bicep. Others celebrate Mao as a signifier of youthful rebellion. In the lyrics of American Indie band The Mountain Goats: 'Put on your Chairman Mao coat, and let me clear my throat, let's turn this whole town upside down, and shake it 'til the coins come falling out of its pocket.' A Mao for all seasons.

\section{New Interpretive Possibilities}

This book seeks to open up interpretive possibilities regarding the Chinese Revolution as it was envisaged by the Chinese communists. Put simply, they sought to create a new world by destroying an old one. Under Mao's leadership, the CCP set about establishing new modes of organising political, economic, social, and cultural life down to the minute details of people's habits of perception and manners of speaking. How China's revolutionary century is viewed depends to a large degree on one's mode of relation to it: does one look back on it with nostalgia, horror, or ambivalence? Does one turn to it out of political fidelity, historical curiosity, or morbid fascination? To approach the Chinese Revolution is to stand in relation to it, and to feel something toward it.

As an edited volume, each author in the book takes up the question of Chinese communism from their own perspective and in their own idiom. Even the editors of the volume constantly argue with each other about the legacy of the Mao era. We suggest that this is one of the book's strengths. But like every other book, whether edited or single-authored, this volume is constructed on the basis of parameters of inclusion and exclusion. As editors, we are interested in critical perspectives on the Maoist legacy that take it seriously as a revolutionary project. This criterion still leaves a wide room for disagreement, but rules out perspectives on Maoism that are presumptively dismissive and ideologically entrenched in Cold War mentalities that pass themselves off as objective social science.

Inspiration for the volume comes from a range of positions along the political spectrum with regard to Mao's legacy: from Simon Leys at one end to Alain Badiou at the other. Simon Leys - the literary alias of the late Pierre Ryckmans-was one of the earliest and most stringent critics of the Cultural Revolution, an attitude that exposed him to vicious attacks by other scholars throughout the 1970s. To cite only a brief passage from his much-discussed 1974 book Chinese Shadows:

If the destruction of the entire legacy of China's traditional culture was the price to pay to insure the success of the revolution, I would forgive all the iconoclasm, I would support them with enthusiasm! What makes the Maoist vandalism so odious and so pathetic is not that it is irreparably mutilating an ancient civilisation, but rather that by doing so it gives itself an alibi for not grappling with the true revolutionary tasks. The extent of their depredations gives Maoists the cheap illusion that they have done a great deal; they persuade themselves that they can rid themselves of the past by attacking its material manifestations; but in fact they remain its slaves, bound the more tightly because they refuse to realise the effect of the old traditions within their revolution. ${ }^{2}$ 
Leys' unsparing condemnation of Maoist communism can be understood as a mode of taking the revolution at its own word. In Leys' despair at the methods used by the Maoists we can nonetheless discern a disappointment in which a trace of the communist promise still lingers.

Despair and disappointment do not exhaust the range of reactions that the Cultural Revolution has elicited. Many authors have also tried to see fragile revolutionary gains that were made and that were then undone by countertendencies within the dynamic process of the Revolution's unfolding. For Alain Badiou, the Cultural Revolution marks the end of a sequence of the revolutionary process: a Leninist Party organisation, formed as a vehicle of emancipation, descends into extreme violence and chaos in a failed transition of power from the hands of the Party bureaucracy into the hands of the people. The impasse that has resulted opens up a space of critical questioning. As Badiou puts it: 'What problems do we and Mao still have in common? In what sense is a reading of his texts anything more than an exercise in nostalgia or critique? To what extent can Mao's texts still be a point of reference in our search for a new direction for emancipatory politics ... ?'3 Badiou's questions presuppose that we are inescapably inheritors of emancipatory traditions with uncertain futures.

There is no reason why one cannot feel both inspired and disgusted by different aspects of Maoism. The legacies of the Chinese Revolution are far-reaching and entwined, impossible to unknot into a verdict of 'for' or 'against', no matter how tempting it is to simplify the world into reassuring positions. Rather than discuss Mao from a given position, or even enlist Mao to support a given argument, this volume seeks to generate an open-ended project of Chinese communism that allows Mao's legacy to be questioned from different interpretive possibilities.

The book contains chapters by more than 50 China scholars from different disciplines and continents. Each chapter discusses a concept or practice from the Mao era, what it signified in its historical context, and what has become of it since. The authors each respond to the legacy of Maoism in their own way, to consider what lessons Chinese communism can offer today and whether there is a future for the egalitarian politics that communism once promised. The book is structured to encourage a diversity of views. Instead of grouping the essays according to loosely framed thematic sections, we opted for a lexicon-style approach, listing the contributions in alphabetical order. We hope that this mode of organisation will invite readers to find their own theoretical paths among the various chapters and make sense of it according to their own needs.

\section{Reinvention}

There is an unspoken pressure that any hint of a positive regard for Maoism must be qualified by an acknowledgment of its violence and the untimely deaths of millions of people. This obligatory self-criticism dooms communism to appear as a discredited ideology rather than as an arc of possibilities yet to be more fully imagined, let alone realised. As Jodi Dean argues: 'Only by supposing such an impossible, invariant, constant, unchanging communism can the appeal to history turn a single instance into a damning example of the failed and dangerous communist experience. ${ }^{4}$ We typically do not hear people say that Christianity is solely reducible to the crusades, and American liberalism to the lynching of black people in the South. But the insistence 
that communism is the violent excesses of its first attempts at realisation, which emerged under improbable and embattled conditions, is often asserted by detractors of communist thought as an article of blind faith.

So how do we move out of the present impasse of living amidst a dysfunctional capitalism that will sooner or later destroy the planet, insofar as we frequently find ourselves being ideologically discouraged from imagining a way out of capitalism? Several of today's prominent philosophers have addressed how our political imaginaries are being held hostage to discursive blackmail in which the threat of totalitarianism always has the final word. ${ }^{5}$ But the act of registering this fact also means that we must no longer submit to it: that we recognise the urgent need to reinvent egalitarian organisations of political and economic life. The present volume is interested in fostering this endeavour and is guided by numerous authors who have sought to imagine and theorise life beyond capitalism.

Thus, we refuse to be confined to discussing communism under Mao as a case of being either for or against it. This way of structuring things is a setup. You are either for Mao and are blamed for ignoring the atrocities that occurred under his name, or you are against Mao and already on the side of the capitalists and reactionaries. Kristen Ghodsee and Scott Sehon have shown that anti-communist arguments generally rest on the hidden premise that if any ideology 'did many horrible things, then that ideology should be rejected.' ${ }^{\prime}$ Their response is not to deny the atrocities committed in the name of communism but to extend the same logic to all ideologies, including capitalism. Nothing in Ghodsee and Sehon's argument requires countenancing the wanton violence of twentieth-century communist regimes. In fact, they suggest quite the opposite: that leftists should be the most critical of these betrayals. Their argument helps to level the playing field by allowing us to more clearly see the grip that anticommunism continues to have on our political imaginations and discourses. If one can talk glowingly and reverently of the principles of the Constitution of the United States with the latter's history of slavery and genocide, one should also be able to approach Mao's writing as a dynamic blueprint for political organisation.

Communist afterlives are potentialities as much as they are historical realities. On this point, the philosopher Alfred North Whitehead is illuminating: 'A feeling bears on itself the scars of its birth; it recollects as a subjective emotion its struggle for existence; it retains the impress of what it might have been, but is not .... The actual cannot be reduced to mere matter of fact in divorce from the potential."7 In a communist sense, these potentialities are a free inheritance of thought to anyone who wants to seize and use them.

\section{Difference and Repetition}

We hope that this edited volume will become a reference for people seeking to understand contemporary Chinese politics and society. In discussing concepts and practices of the Mao period, each chapter also traces how they have evolved into present governance mentalities and techniques. In the spirit of Maoism as a practice-oriented theory, its components have been reassembled and updated to fit present circumstances and needs. Several Maoist ideas and turns of phrase lacking a place in the present world of capitalist development and social harmony have disappeared from the map (but not 
without leaving behind traces and virtualities in the present). Just as it was impossible to reify Maoism in the Mao era, it is even harder to draw a direct line of causality from the Mao era to the present-that is, unless you are the Communist Party and in charge of writing and policing official history and orthodoxy.

Increasingly, scholars in Chinese Studies have argued that it is wrongheaded to see Communist Party governance as having changed entirely in the early 1980s with the advent of Reform and Opening Up. The ostensible break from Maoist political campaigns, ideology, and class struggle was widely celebrated in the international media then, at the expense of heeding the ways in which CCP rule continued to rely on institutional practices established under Mao. To see Xi Jinping today as dragging China back to the dark ages of politics and ideology is to reduce China's economic transition to a caricature and to assume, egregiously, that capitalism is ideology-free. We do not need critical theory to unmask the hypocrisy here-even the Chinese government publicly describes market transition as a process of 'engineering' (gongcheng) and 'construction' (jianshe) in a way that would have made Karl Polanyi blush. ${ }^{8}$ The CCP views the world and everything in it as an artefact of the political. Its guiding documents unabashedly refer to political, economic, cultural, and ecological 'construction' as its main tasks, positing a world of malleable processes rather than fixed categories.

More often than not, anti-communist argumentation presupposes a state-phobic framework-one not shared by most people in China-in which state intervention is perceived as undesirable rather than unavoidable, a violation of individual life, rather than its infrastructure of support. Critics of communism often cherry-pick which instances of state intervention to denounce, and which to dress with pleasant-sounding phrases and justifications. The question of intervention on behalf of whom and in pursuit of what vision is generally given short shrift.

A new vocabulary for the analysis and discussion of Chinese politics is necessary. Since 2017, China's state media and CCP propagandists have been talking up the 'New Era' (xin shidai) of Xi Jinping. In Xi's attempt to reestablish Party legitimacy in a postrevolutionary form of ideology that combines Confucian traditions, civilisational pride, and socialist core values, the CCP's language has undergone significant change. Nonetheless, there are distinctive ways in which one-party rule under $\mathrm{Xi}$ today remains guided by modes of communicating and governing that developed under Mao. To the extent that the institutional and discursive resources available to $\mathrm{Xi}$ and his administration are a direct legacy of the Maoist period, we need a basic 'literacy' in Communist Party discourse to appreciate how the Party-state governs and Chinese citizens experience and negotiate the political realities of China's one-party system. Each chapter in this edited volume contributes to this literacy by offering an interpretive key to how China has become what it is today. That said, the chapters do not add up to a determinable totality. Instead, they trace a fluid set of relations and evolving practices over time.

\section{Message in a Bottle}

This volume began as a special issue of the open-access quarterly Made in China Journal, of which we are the editors. However, as it took shape, and as more people became involved, the project grew into a full-length book exploring the origins, lives, 
and afterlives of the main concepts underpinning Chinese communist thought. It was at this point that we were helped by a generous joint publishing arrangement between ANU Press and Verso Books, which has enabled the book to appear in two formats. It can be downloaded for free and is also available for purchase as a paperback.

The ethos of the Made in China project is rooted in accessibility. We are committed to open-access publication for the simple reason that not everyone can afford to purchase books from commercial academic publishers. The business model of academic publishing, which involves the repackaging and sale of publicly funded research, has reached a critical juncture in an increasingly competitive market. The publishing model we have chosen indicates that we are both in and outside this market. Moreover, we felt compelled to think outside the confines of traditional academic publishing as we want our readers to imagine new political possibilities beyond the capitalism we know.

Our modest hope is that the volume will help to revive the reading public's interest in what was one of the twentieth century's most radical, and fraught, undertakings to transform and emancipate humanity. We do this in the belief that, as the twentyfirst century portends climate catastrophe, a resurgence in authoritarianism, and obscene disparities of wealth, a revival of the communist perspective, freed from any dogmatism, is necessary to fight for what remains of the world we hold in common. 
8 AFTERLIVES OF CHINESE COMMUNISM
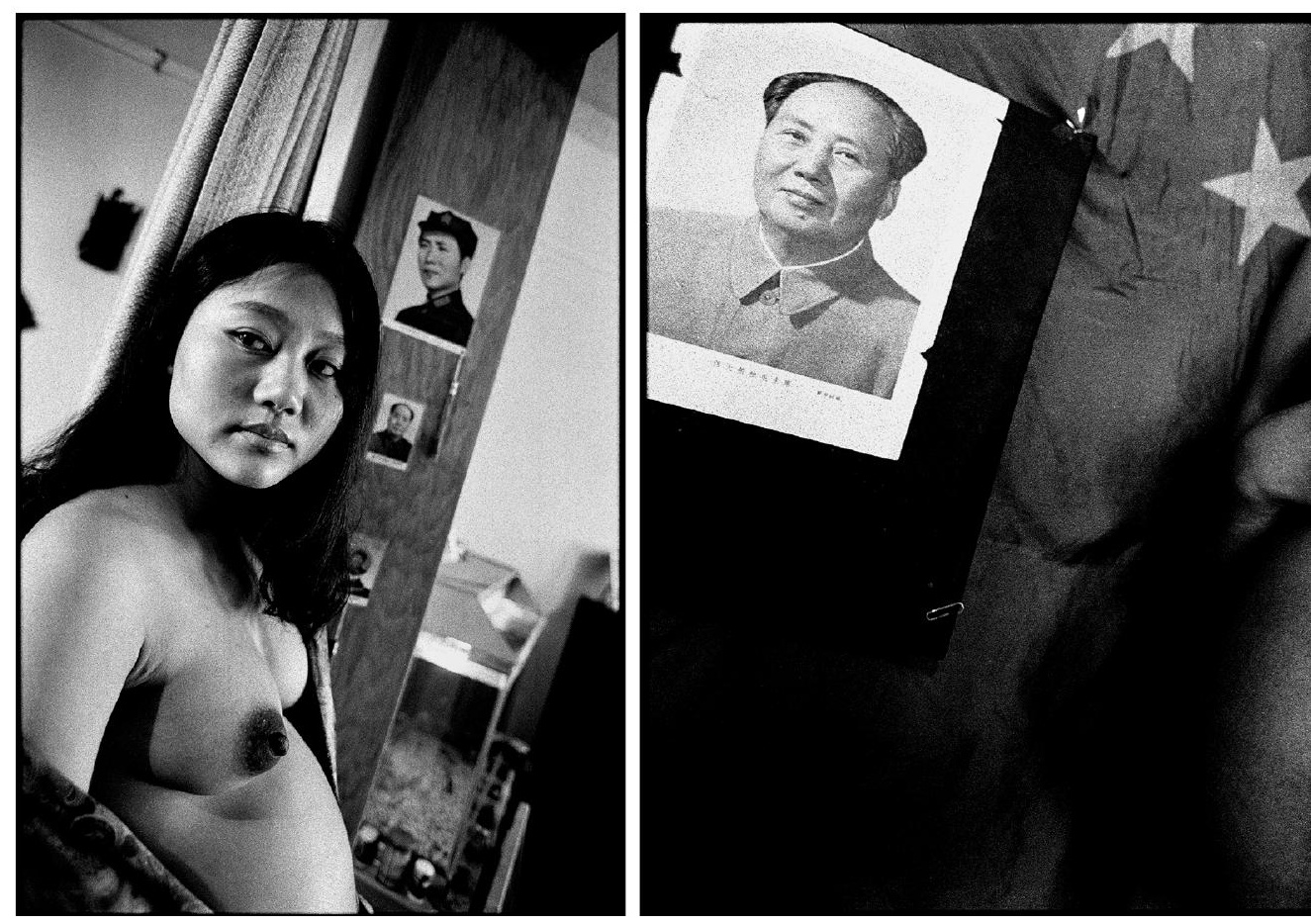
The world is yours, as well as ours, but in the last analysis, it is yours. You young people, full of vigour and vitality, are in the bloom of life, like the sun at eight or nine in the morning. Our hope is placed on you. The world belongs to you. China's future belongs to you.

Mao Zedong, 'Talk at a Meeting with Chinese Students and Trainees in Moscow, 17 November 1957 


\section{1 \\ 美学 \\ Aesthetics}

Christian SORACE
Great plans are afoot: A bridge will fly to span the north and south, Turning a deep chasm into a thoroughfare; Walls of stone will stand upstream to the west

To hold back Wushan's clouds and rains Till a smooth lake rises in the narrow gorges.

The mountain goddess if she is still there Will marvel at a world so changed.

Excerpt from Mao's poem ‘Swimming,' June 1956

M ao's poem 'Swimming' is a poetic evocation of the glorious changes that were intended to transform the Chinese nation through the collectivisation of agriculture and accelerated industrial production. Written before the suppression of the Hundred Flowers Campaign (1957) and the launch of the Great Leap Forward (1958-62), the poem signals the way ahead with a sublime utopian vision. 'Great plans are afoot'-natural chasms will be transformed into human thoroughfares. These scenes of industrious beauty obscure all traces of the destruction, rubble, displacement, and violence of transformation.

In Chinese, the word for 'aesthetics' (meixue) is, literally, the 'study of beauty.' Still, as Haun Saussy points out, this term is misleading for many reasons. ${ }^{1}$ First, it was imported into China only in the nineteenth century by way of Japanese readings of German aesthetic philosophy. Further, in the vast skein of traditional Chinese thought, there was scant consideration of an aesthetic realm outside of the sovereign jurisdiction 
of the state. In this sense, Mao Zedong's famous 1942 'Talks at the Yan'an Forum on Literature and Art', in which he subordinates the aesthetic to the political, represents another faithful iteration of this tradition, with a Marxist gloss.

In this speech, Mao outlines the relationship between politics and art in the context of revolution, arguing that there are no absolute criteria for judging the value of art, only contextual and pragmatic ones. For Mao, art transforms reality in the process of reflecting it:

\begin{abstract}
Although man's social life is the only source of literature and art and is incomparably livelier and richer in content, the people are not satisfied with life alone and demand literature and art as well. Why? Because, while both are beautiful, life as reflected in works of literature and art can and ought to be on a higher plane, more intense, more concentrated, more typical, nearer the ideal, and therefore more universal than actual everyday life.
\end{abstract}

Although everyday life is 'incomparably livelier' than art, it is also more chaotic and complex. Art, so conceived, projects a better version of the everyday present, by which the masses can see a likeness of their future. The cultural sphere consists of models of behaviour, narratives, colours, sounds, and scenes which awaken revolutionary feelings. For Mao, the masses do not need art to remind them of their daily experience of 'hunger, cold, and oppression.' They need art to visualise the possibility of transcending their suffering.

On these grounds, Mao advocates combining political and aesthetic criteria when judging a work of art. Revolutionary content with lacklustre form does not stir the heart; conversely, an enchanting work of art can be a siren song of reactionary politics. For Mao, exemplary art fuses revolutionary content with high artistic quality. In addition to touching their souls, revolutionary works of art provide the people with representations of their own collective power and future. In this configuration, the fate of art and politics are inextricably bound together.

What falls out of the picture is what Fredric Jameson describes as the implacable and sometimes even intolerable negativity' of modern art, which is a necessary antidote to the pragmatism, empiricism, and common sense of daily life, not to mention the aesthetic rituals of state legitimation. ${ }^{2}$ This logic is absent from Mao's Yan'an Talks. In 1942, revolutionary energies were too new and vulnerable to dissipation. They needed to be safeguarded by the correct 'standpoint' (lichang) and 'attitude' (taidu) of the artist:

From one's standpoint there follow specific attitudes towards specific matters. For instance, is one to extol or expose? This is a question of attitude ... . Many petty-bourgeois writers have never discovered the bright side. Their works only expose the dark and are known as the 'literature of exposure.' Some of their works simply specialise in preaching pessimism and world-weariness.

It is a slippery slope from aesthetic 'exposure' to nihilism to counterrevolution. To prevent this slippage, Mao limits art to a positive incarnation of political categories. Exposure is permissible, and encouraged, only when it is directed at enemies: 'With 
regard to the [enemies] ... the task of revolutionary writers and artists is to expose their duplicity and their cruelty and at the same time to point out the inevitability of their defeat.' Toward allies, 'our attitude should be one of both alliance and criticism,' encouraging their achievements and chastising their apathy. 'As for the masses ... we should certainly praise them' and patiently educate them to overcome their shortcomings.

After the victory of the revolution, art will continue to be a source of political intensity and inspiration for the masses, but similar to the victims of Pompeii, will also fossilise them in the representational forms of state power.

\section{Antonioni's China}

In 1972, Italian filmmaker Michelangelo Antonioni was invited to China to film the sublime achievements of the Cultural Revolution. When it was released in 1974, Antonioni's three-hour-and-forty-minute documentary film Chung Kuo triggered a virulent campaign of denunciation in China. Party leaders viewed the documentary as a 'reactionary' (fandong), 'anti-Chinese' (fanhua) attempt to humiliate China and denigrate the Chinese Revolution. People were encouraged to pen letters denouncing the film, even though it was banned from public circulation and only a handful of leaders had actually seen it. Discussion of this anti-Antonioni campaign has since been seldom raised. When it is mentioned, it is typically dismissed as a time-capsule of Maoera fanaticism. However, I suggest that the discursive rationality and affective energies of this campaign offer an interpretive key to official attitudes toward representations of China today.

CCP leaders at the time accused Antonioni of 'making China ugly' (chouhua) by filming what they regarded to be the embarrassing blemishes of everyday life. For them, Antonioni's film was anything but a beautiful contemplation of the ordinary-it was a form of national humiliation. In an editorial published in the People's Daily on 30 January 1974, the authors argue that Antonioni's purpose was 'not to understand China' but to 'humiliate it.' In response to Antonioni's defence that he only intended to provide an 'objective recording' without judgement, the People's Daily retorted that 'each scene itself is a judgment.'

The main indictment against Antonioni's documentary was not what it filmed, but what it did not film. Despite China's revolutionary victory and massive transformations, in Antonioni's film, China seemed to have changed very little, if at all. The lives of workers and peasants appeared to have barely improved since the prerevolutionary era; they toiled in similar conditions under different masters. According to the People's Daily editorial, in Antonioni's portrayal, 'it seems as if China's revolution has not changed the status of Chinese people and has not liberated them spiritually'-a direct challenge to the CCP's legitimating narrative that it freed China from its feudal past. During the Mao era, campaigns were organised in which people would 'speak bitterly' (suku) about the past, and 'recall past bitterness in order to savour the sweetness of the present' ( $y i \mathrm{ku}$ si tian) (see Javed's essay in the present volume). People were enjoined to remember and be thankful for their new lives provided to them by the Party. Antonioni's scenes of China's past haunting its present challenged this logic of legitimation. 
According to an editorial that appeared in the Guangming Daily on 13 February 1974: 'In this way, in the movie, the Chinese Revolution is missing (bu jian), the extraordinary changes brought about by the Revolution are missing, the radiant glory of new China is missing; instead, all that people can see is only the old China of last century. ${ }^{4} \mathrm{I}$ have rendered bu jian in English as missing to make the translation smooth; however, in Chinese $b u$ jian literally means to disappear from sight, implying that Antonioni's camera intentionally did not record the positive aspects of China that were directly in front of his camera. The author accused Antonioni of shierbujian, which means to not see what is plainly there.

Framed in the unflattering light of Antonioni's camera, rural China appeared full of people for whom the passage of revolutionary teleological time had stopped. In the words of the People's Daily editorial, instead of filming revolutionary advances, Antonioni 'spares no effort to find a withered farmland, lonely old man, weary beast of burden, and shabby building.' What in reality is a 'poor village', in the voice-over narration is labelled 'a desolate and abandoned place.' In the Guangming Daily editorial, the writer is baffled over Antonioni's scene selections: 'Instead of displaying industrial prosperity, [Antonioni's camera] is transfixed on the backdrop of an elderly women sitting on the ground eating a popsicle.' Why would he want to film a scene that is entirely foreign to Mao's injunction that art must distil idealised forms of life?

From the CCP's perspective, the only possible answer was that Antonioni's aesthetic decisions were politically motivated technical manipulations to humiliate China. What could not be imagined was an aesthetic appreciation of the beauty of ordinary life. As Mao put it in his 1942 Yan'an Talks: 'There is in fact no such thing as art for art's sake, art that stands above classes, art that is detached from or independent of politics.' It was impossible for the CCP to consider Antonioni as engaged in anything other than aesthetic sabotage. From the CCP's perspective, Antonioni's aesthetics were an 'imperialist way of seeing' (diguozhuyi de yanguang). Ironically enough, after the ban on publicly screening Antonioni's film in China was lifted in 2004, the movie has received praise by Chinese audiences, especially of that generation, for its depictions of a simpler and more beautiful life. ${ }^{5}$

\section{Reactionary Formalism}

What is perhaps most interesting about these denunciations is their political critique of Antonioni's formal techniques. 'Anything good, new, or progressive, he did not film, filmed very little, or at the time pretended to film and then later edited out; any inferior, old, or backward scenes, he would film without turning the camera away. Even when Antonioni filmed what the CCP would have regarded as positive aspects of China, the editorial accused him of doing so from an unflattering angle. For instance, the footage he filmed of the bridge over the Yangtze River in Nanjing was said to have undermined this 'magnificent' and 'modern' structure. This was because the camera was 'unsteady and swayed back and forth' and even strayed to film someone's 'pants drying underneath the bridge.' These intrusions of everyday life disrupted the monumental, revolutionary, and romantic longings of the Maoist aesthetic. ${ }^{6}$ 
The CCP was enraged by more than just the 'erratic' style of camera-work. In their eyes, Antonioni meticulously edited scenes in a way that obliterated China's revolutionary transformation. In the Imperial Palace's Exhibition Hall, after filming sculptures of 'oppressed workers rebelling' during the Ming era (1368-1644) and describing their 'miserable' living conditions, the 'camera shot cuts to a scene of young students sent down to the countryside to participate in labour' insinuating that not much has changed between then and now. The voice-over narration concluded that there was no 'paradise' in the Chinese countryside. This statement probably struck a nerve, as it was quoted in several of the essays denouncing Antonioni. However, it is also worth considering the European context in which Antonioni's film was made and received. Across Europe at the time groups of young self-styled Maoists fetishised the Cultural Revolution as an answer to their political desires (see Lanza's essay in the present volume). As Jacques Rancière reflected: 'There can be no doubt that we were bending the manifestations of the Maoist revolution a bit too quickly to our own desires for a communism radically different from the Stalinist one." For the Chinese Communists, however, Antonioni's statement could only be understood as a negation of revolution.

For the CCP, each aspect of Antonioni's documentary was reactionary. The People's Daily editorial complained about the 'drab lighting and gloomy and cold tone.' The film lacked the bright colours of revolutionary passion, and instead gave off a 'gloomy, depressing, and unfeeling impression.' On top of that, the musical score was also found to be offensive. Rather than highlighting China's revolutionary model operas, Antonioni used Chinese music to 'wantonly mock' the revolution. In one a scene, a pig shakes its head in sync with lines from a revolutionary opera that said 'lift up one's head and stick out one's chest' (tai qi tou, ting koutang). Scenes such as this one are marshalled as evidence of Antonioni's malicious political intentions.

Antonioni's camera recorded China in a way that challenged the official discursive and aesthetic frame of representation. The CCP's response was to denounce the film as evidence of Antonioni's imperialist gaze: you can't see China because you only see what you want to see. He had failed the People's Republic.

\section{Ridiculing the Sublime}

On 15 October 2014, in an unmistakable emulation of Mao's 1942 Yan'an Talks, China's leader Xi Jinping gave a 'Speech at the Forum on Literature and Art.' ${ }^{8}$ Despite China's rapid transformations over the last several decades, the CCP continues to vigilantly guard over-and censor-representations of China that challenge its idealised version of itself. Without the larger-than-life figures of revolution and communism as their horizon, Xi's guidelines reduce art to the celebration of Party-sanctioned morality, cultural heritage, and nationalist sentiment.

In Xi's version, the main purpose of art is to infuse reality with optimism for the future:

If literary and artistic creations merely write an account of the current situation, reveal an unmediated display of the repulsive side of things, and do not extol their bright side, if they do not express ideals and guide morality, then they cannot inspire the people to advance. 
For $\mathrm{Xi}$, art must marry 'a spirit of realism' and a 'mood of romanticism,' 'use light to disperse darkness,' 'use the beautiful and good to defeat the repulsive,' with the ultimate aim of 'allowing people to glimpse the beauty, hope, and dreams that are in front of them.'

This definition of art prefigured Xi Jinping's speech at the Party's Nineteenth Congress, held in October 2017, during which he announced the arrival of a 'New Era' (xin shidai) shaped by a new 'principal contradiction' (zhuyao maodun) facing Chinese society. This contradiction results from the nation's 'unbalanced and inadequate development and the people's ever-growing needs for a better life." Xi used the term meihao when referring to a 'better life, thus evoking the idea of an aesthetically pleasing and morally ordered life. For Xi, the duty of the artist is to produce visions of the good life, and the responsibility of the CCP is to create the socioeconomic conditions for its realisation. What his account cannot accommodate are representations that might diminish people's optimism or call into question the CCP's ability to engineer the future.

Xi's speech continues the Party tradition of using political criteria to judge the value of works of art, and criticises alternative modes of valuing artistic creation. Like Mao, $\mathrm{Xi}$ argues against formal aesthetic criteria and the mentality of 'art for art's sake' (see also Chan's essay in the present volume). In his words, 'the ultimate goal of all creative techniques and methods is to serve content ... . To depart from this principle, technique and method are utterly lacking in value, to the extent of producing negative effects.' Unlike Mao, however, Xi must also contend with the art market as a source of value for art as a cultural commodity. Unsurprisingly, Xi saves his harshest remarks for marketdriven sensationalist works of art that 'ridicule the sublime' and 'exaggerate society's dark side' in the pursuit of profit. He described these works as 'cultural garbage.' Without formal aesthetic and market criteria to judge the value of a work of art, Xi submits that an artwork's significance must derive from its ability to contribute to the 'rejuvenation of the great Chinese nation' (zhonghua minzu de weida fuxing). Here, the negative-or critical function of art-is conflated with the anti-social, and often interpreted as being anti-Chinese.

\section{Politics of Sight}

The politics and contradictions surrounding Antonioni's documentary film are still relevant today. Where is the truth in this melee of representations and mutual recriminations of misrecognition? Does one see the material successes of China's economic miracle, its skyscrapers and high-speed rails, or its concentration camps in Xinjiang and environmental devastation? In an age of globalisation, the CCP asserts its 'discursive rights' (huayu quan) to 'tell China's story well' (jianghao zhongguo gushi). ${ }^{10}$ It dismisses negative representations of China as the invidious attempts of China's enemies to 'damage the nation's image' and the 'Party's image.' To be sure, there are negative representations of China that arguably harbour lingering colonialist desires and cold war animosities. However, what the Chinese Party-state is increasingly demanding is that the world defer to its control over how China is represented, thought about, and discussed as the price of doing business with it. What the CCP offers is a future in which the spark of Maoism, which has always been the power of the masses, is reduced to the cinders of history. 


\section{2 \\ 血统 \\ Blood Lineage}

YI Xiaocuo

B loodline, or lineage, has been a political ideology of many monarchical regimes and aristocratic societies throughout history. The rise of nationalism in Europe in the seventeenth and eighteenth centuries paralleled the discourse of purity and authenticity of one's blood/race. In the context of national formation, blood is a metaphor for race, ethnicity, and sexuality that enacts loyalty, belonging, and national consciousness. Blood lineage can be a malleable narrative explaining Self and Other, a rigid disciplining tool reinforcing hierarchy, or a fluid signifier for social groups seeking belonging and protection.

In imperial China, rulers adopted blood-based ties to clarify the hereditary rights of power and property, and as a tool for social management in order to distinguish between royalty, civilians, and slaves. For example, the imperial Chinese punishment of collective responsibility-zhulian jiuzu, literally 'guilt by association of nine of a group/clan'-and the politics of lineage, or blood relation, played an important role in moulding, disciplining, and confining people to the social roles prescribed for them. People were expected to stay in their place in society, and transgression of the boundaries of their socially or politically ordained bloodlines could be met with severe punishment. In Chinese, shizu or zongzu represents a group tied by blood relationships as a family or a clan, led by lineage heads (zuzhang), with its family history and genealogy recorded as $z u p u$. In the late nineteenth and early twentieth centuries, $z u$ took on a nationalistic turn when the founding father of the Nationalist Party, Sun Yatsen, indicated that Chinese people of the Han or Chinese race (zhongzu) had 'common blood,' and they should stand together as zhonghua minzu (Chinese nationality) as they were facing the threat of national extinction under Western imperialism. ${ }^{1}$ Following the turn of the century and the May Fourth Movement in 1919, the Republic of China was founded under the famous slogan-'Five Races under One Union' ( wu zu gonghe)—to unify Han Chinese people and Manchus, Mongols, Tibetans, and Muslims, the major 
non-Han groups of China as perceived by the Nationalists. Following the Communist victory in 1949, the state ethnologists classified 55 non-Han peoples and stressed the importance of a unified nationality comprised of the Han as the majority ethnicity and non-Han as minorities (shaoshu minzu) (see also Bulag's essay in the present volume). Official discourse aside, popular memories and heroic narratives centred on blood lineage also thrived. For example, the Han nationalist imagination proposes a linear history of ancient China in which an immutable Han racial identity continually existed by virtue of descent from the mythological Yan and Huang emperors (yan huang zisun).

\section{The 1950s: A New Nation-building}

After the Chinese Communist Party (CCP) took control of mainland China in the 1950 s, the discourse of blood lineage temporarily shifted away from national or racial concerns to struggles over class identity, but the notion of heritability remained. Under Mao's guideline of class struggle, each individual was labelled with a class identity by birth or by family relationships. Despite contradicting the socialist goal of eradicating imperial practices, reckoning by blood was effectively institutionalised by those in power through the practice of class struggle (see Russo's essay in the present volume), as it inverted and brought into being new categories of people who would benefit from the revolutionary order, and those who would be its victims.

During the early 1950s, Mao's land reform and class-motivated purge of landlords virtually removed the authority of reproductive ties between powerful lineage groups within rural communities. Throughout China, previous ruling classes saw massive socialist transformations: land was confiscated from landlords and distributed to landless and poor peasants, and private merchants and capitalist industries gradually became state-owned. Blood became a form to assess one's revolutionary subjectivity through family background (chushen) or class labels (jieji chengfen). The 'good ones' were reproduced and circulated as revolutionary agents within the national body, and the 'bad ones' were identified as reactionary or bad blooded and outcast. A person's class or family background not only haunted his or her own life, but the lives of their spouse, children, and relatives. In Michael Dutton's words, class-related political problems on personal dossiers spread 'like a virus' and were inescapable like a 'blood-borne disease.' These unfavorable classes were labeled 'Four Black Categories' (hei si lei), which included landlords, rich farmers, counterrevolutionaries, and bad-influencers. After the Anti-rightist Campaign in 1957, 'rightist' was also added to the list, making 'Five Black Categories.'

In non-Han peripheral regions such as Inner Mongolia, Tibet, and Muslim-populated Xinjiang, local political groupings, religious authorities, and hereditary leaderships were also dismantled during the socialist reform. Following Western intellectual traditions of social evolutionism, Party cadres and ethnologists depicted Inner Asian pastoral aristocratic houses of power as primitive kinship tribal society (in Chinese buluo, or shizu), but also denounced them as 'capitalist' since the rich herders were accused of accumulating capital in the form of livestock, thereby reproducing oppressive class relations in pastoral production. State power materialised in omnipresent institutions in these native communities, such as the 'pastoral office' and the 'pastoral production cooperative,' with Han administrators promoting the Party's work and policies in non- 
Han regions. The discourse of blood lineage operated on the basis of two contradictory and yet compatible claims: that pastoral people were backward and in need of developmental assistance, and that pastoral political economy was advanced enough to create its own capitalist class that could be subject to persecution.

When necessary, the Party-state was tactical and flexible in instrumentalising lineage as a political tool among the pastoralists; at other times, the state obliterated those lineages when they threatened perceived national interests. As the denunciation of local non-Party authorities continued, Party cadres also reflected on their lack of understanding of pastoral social structure, especially the great social power and influence endowed to lineage heads. They realised pastoral lineage heads were crucial targets for cooptation after careful indoctrination. This method effectively assured the mobilisation of powerful local leaders to assist in the dissemination of Party policy, propaganda, and new modes of socialist animal husbandry. For example, in northern Xinjiang, Han ethnologists surveyed the Chinggisid lineage of the Kazakh noble Tore clans in detail and evaluated their productivity, eventually restructuring them into major production brigades as a form of state 'socialist primitive accumulation' (see also Hayward's essay in the present volume). ${ }^{3}$ On the eve of Mao's Great Leap Forward, interethnic relations became tense as increasing areas of pastoral lands irreversibly became agricultural with a huge influx of Han settlers into traditionally non-Han regions. As the overwhelming scale of socialist transformation in ethnic minority borderlands led to resistance in these regions at the end of the 1950s, the Party simply denounced the resistance as 'local nationalism' (difang minzu zhuyi), a 'counterrevolutionary' crime to be purged. The ever-shifting target of blood lineage in pastoral regions exemplifies the fluid nature of blood in twentieth-century Chinese politics.

\section{The Politics of Communist Lineage in the Cultural Revolution}

During the Cultural Revolution, the idea of blood lineage (xuetong) was revamped and gained a sinister level of national popularity. At the same time, Mao's notion of the class line (jieji luxian) opened a path out of one's background on the basis of one's revolutionary devotedness and political behavior. Those from good family backgrounds, called the 'Five Red Categories' (hong wu lei) including poor and lower-middle peasants, workers, revolutionary soldiers, revolutionary cadres, and revolutionary martyrs, declared that they were the legitimate successors of the socialist revolution and 'red by birth' (zi lai hong). The 'Five Black Categories' were expanded to 'Nine Black Categories' (hei jiu lei) with new additions being capitalists, capitalist roaders, traitors, and spies. In 1966, a couplet began to circulate after appearing in the Beijing Aeronautical Engineering Institute. It read: 'A hero's son is a real man; a reactionary's son is a rotten egg' (laozi yingxiong er haohan, laozi fandong er hundan).

At first, high officials in the CCP criticised this blood lineage idea and stressed that one's political behaviour or expression (zhengzhi biaoxian) was also important. However, in practice, the hierarchal categorisation and political naming prompted discriminatory policies aimed at innocent individuals with bad family backgrounds or class labels. It stamped indelible institutional marks on the countless bodies of the 'Nine Black Categories', whose children were euphemistically referred to as 'teachable offspring' (ke jiaoyu hao de zinü). In fact, they were deprived of any political and social 
participation rights. Under this regime, they had to earn leniency or better treatment through good 'political behaviour' such as making a clean break with their reactionary parents and family backgrounds. Some cases resembled the imperial penal style of 'implicating associates' in scrutinising the class labels of up to three generations. The 'teachable offspring' were often excluded from opportunities, such as joining the army or acceptance to schools. They were subjected to unequal pay and reform through labour, and their unbearable humiliation and torture led to numerous unnatural deaths.

Yu Luoke, a young worker from Beijing, made a powerful counterargument to the Red Guards' principle of blood lineage. Having suffered enough from the negative impact of his father's 'rightist' background, in 1967 he published the essay 'On Family Background.' Quoting Marxist and Maoist theories, Yu pointed out that one's family background should not be equated with political identity and revolutionary consciousness. Moreover, the principle of blood lineage could not justify violence against people without a good family background-in this sense the so-called 'Five Red Categories' were actually the oppressors. Yu's argument shook the foundation of the Party's revolutionary legitimacy by rendering illegible the categories of class struggle. Without a clearly identified set of heroes and villains, the machinery of class struggle would break down. The Party became desperate for a consolidation of self-identity, ideological control, and epistemological certainty. The principle of blood lineage came in handy because it isolated people into different categories and stratifications and screened the political disloyalties of those who could challenge the Party's status quo. As a result, top officials chose not to follow through with their criticism of blood lineage but instead exploited it as a social governing mechanism. Yu's call for equal human rights as intrinsic to socialism eventually touched the sensitive nerves of Party authority. In 1970, he was executed for the crime of 'organising counterrevolutionary groups.'

For non-Han pastoral societies in the Cultural Revolution, the system of class labelling established new hierarchical political categories that replaced previous ones and significantly frayed the fabric of society and family. Mongol landlords who leased land to Han peasants were denounced and disenfranchised in the name of class struggle. In Tibet, class struggle heightened internal divisions and led to tens of thousands killed in struggle sessions and sent to reform through labour. In northern Xinjiang, pastoral nomadic nobility formerly protected their lineages by disallowing their women from marrying men of lower statuses, at least in principle. This was reversed after Party cadres conducted struggle sessions denouncing landlords and aristocrats, and they went as far as forcing marriage across class differences.

\section{Ghosts of Blood Lineage Today}

After the Cultural Revolution, the CCP abandoned the principle of blood lineage, but the generation who benefitted from it had already attained high positions in powerful national-level political and economic organs. Many of them have gone on to earn profits for their entire family from corrupt practices and abuses of power capturing the prosperity produced through the privatisation of public goods during the reform era. Numerous cases have been exposed illustrating the ways in which these secondgeneration elites and bureaucrats enjoy above-the-law lifestyles and hold billions of 
dollars in offshore accounts. It has been an unspoken rule in China that the offspring of elite groups inherited their fathers' privilege, as people have given them nicknames such as 'officialings' (guan er dai), 'red second generation' (hong er dai), or 'princelings' (tai zi dang).

The ghost of blood lineage continues to haunt the non-Han regions in the twentyfirst century as a new era of state racism dawns. While pseudotraditional symbols of 'Chinese culture' such as the Han costume movement, Confucian rituals, and virtue training schools for women mushroomed in mainland China, Tibet and Xinjiang have been increasingly subjected to state-led exploitative development projects at the expense of native peoples and lands. A temporary pluralism and multiculturalism in the reform era has given way to Han-centred empire-building aiming to root out ethnic, religious, and cultural differences as social deviancy and disease. This is simultaneously shaped by Western discourses fostered by the US 'War on Terror' and global Islamophobia. China's use of this discourse has fostered its own industrial complex of 'terror capitalism'-high-tech Orwellian social control targeted mainly at Turkic Muslim and Tibetan populations. ${ }^{5}$ Up until now, over one million Uyghurs, Kazakhs, Kyrgyz, and other ethnic minorities have been detained indefinitely in 'concentrated reeducation and transformation centres' (jizhong jiaoyu zhuanhua zhongxin), without indictment or fair trial. On Chinese social media, they are portrayed as 'terrorists' or 'religious extremists' to justify their detention, and their religion as an ailment in need of a cure. An official was quoted saying: 'You can't uproot all the weeds hidden among the crops in the field one by one-you need to spray chemicals to kill them all. Reeducating these people is like spraying chemicals on the crops. That is why it is a general reeducation, not limited to a few people.' ${ }^{6}$ The CCP initially shifted away from the racial/nationalist discourse of mid-twentieth-century political movements, but it has rekindled those flames by explicitly combining the discourse of blood lineage with ethnicity in places like Xinjiang.

This hypercriminalisation process is unprecedentedly aided by cutting-edge technologies of biodata collection and surveillance networks. Since the end of 2016, a military technology used in national defence was applied in Xinjiang under the name 'Integrated Joint Operation Platform' (yitihua lianhe zuozhan pingtai). Its security system instantly gathers data on an individual from multiple sources such as banking, medical, and travel histories to analyse, make predictions, and generate lists of suspects. Human Rights Watch reports that on this system Uyghurs who have been arrested before or deemed 'unsafe' are differentiated and their personal dossiers are tagged in a different colour.7 Xinjiang residents also have been required to fill out a 'Population Data Collection Form' and report whether they are Uyghurs, whether they are 'persons of interest' (beyond a scale of one to five, there exists an extra te, or special security level), whether they are relatives of a detainee, relatives of someone being subjected to crackdown and punishment, whether they are tagged by the yitihua platform, and whether they have contacts abroad and how they are related. ${ }^{8}$ They also must submit detailed information including religious habits, whether they have passports, have travelled abroad, and so on. The Party-state's population control measures have metamorphised into a highly organised blood lineage classification system with layers of class, political, racial, and geographical inputs. Based on the collected data, officials 
then categorise people in terms of reliability into three groups: safe, average, and unsafe. The collected family information enables the authorities to track down and terrorise people even when they are out of China.

While Uyghur and Kazakh masculinity is ostensibly tamed through carceral governance in Xinjiang, women's bodies are turned into the next frontier for the state to deploy its settler politics in sexuality and reproduction. In its initial nationmaking process in the early 1950s, in order to solve the gender ratio imbalance, the paramilitary settlers of the Xinjiang Production and Construction Corps recruited thousands of female students, soldiers, and prostitutes from Hunan and Shandong provinces to populate the settlements. Following Mao's dictate of 'anti-Han chauvinism' and maintaining border stability, inter-ethnic marriage between Han settlers and local Muslims was strictly prohibited. Though the Han population kept rising in the past decades, low rates of Han-minority marriage are seen as an indication of ethnic tension in Xinjiang, while Uyghurs view the avoidance of such interethnic marriages as a type of resistance. ${ }^{9}$ The state turned a hard line in 2014 and started to offer incentives to encourage interethnic marriage. ${ }^{10}$ From 2015 onward, propaganda depicting secularised, mass weddings as 'new fashion weddings' to illegitimise Islamic nikah ceremonies and other native marriage customs as a form of 'counterterrorism' work has become prevalent.

From the debate on blood lineage and class labelling, to today's detention of Muslim minorities in Xinjiang, blood is a powerful symbol used by the Party-state to envision and sometimes cleanse its political and national body. As the CCP no longer needs to mobilise ethnic minorities as a united front (see De Giorgi's essay in the present volume), it has embarked on a mission to establish itself as an ever-expanding Chinese nation focussed on Han interests. From imperial China to revolutionary movements to the war on terror, the discourse of blood lineages remains a flexible political tool for the state. As the marriage of biotechnological surveillance techniques with Mao-era political ideas about blood lineage in Xinjiang suggests, the principle of blood lineage is still an important concept for understanding Chinese politics and society, and will remain so for the foreseeable future. 


\section{3 \\ 阶级感情 \\ Class Feeling}

Haiyan LEE

$\mathrm{t}$ is a truism that the Communist Revolution that convulsed Chinese society in the twentieth century effected radical transformations not only in the realm of political economy, but also in the realm of consciousness, beginning with the Chinese language itself. The revolution invented a lexicon that midwifed a new worldview and a new way of organising social relationships. As the century drew to a close and the Chinese Communist Party (CCP) retreated from radical politics, this lexicon-also known as Mao-speak-quietly exited public discourse. Among the vanished lingo of the Mao era is 'class feeling' (jieji ganqing). To a millennial in China today, it may well be Martian-speak. What is class feeling?

Like all things Maoist, class feeling needs to be grasped dialectically. On the one hand, it is comradely love for brothers and sisters from one's class. It is a horizontal, fraternal feeling that extends equally to all members of the proletariat, but finds its most intense and sublime expression in the love for the supreme leader, Mao Zedong. On the other hand, it is hatred and resentment for the class enemy, usually belonging to the former propertied classes. The Party was well aware that neither feeling came naturally to the broad masses. Specifically, it had to contend with three rivals: kin loyalty, romantic love, and pity for the down and out. Much of the socialist-era cultural production was geared toward combatting the powerful hold of these competing sentiments and engineering a new structure of feeling that elsewhere I have called the 'socialist grammar of emotion.' Underlying this new grammar of emotion was a utilitarian ethics that forthrightly rejected bourgeois humanism. Good and evil were defined entirely with reference to whatever served to further class struggle and the dictatorship of the proletariat (see Russo's essay in the present volume). Ends always justified the means and substantive goals always outweighed procedural niceties. In what follows, I invoke three examples 
from the socialist 'red classics' repertoire, as well as a documentary account of land reforms to illustrate how class feeling was alternatively pitted against or grafted onto moral sentiments that the Party deemed passé, philistine, or reactionary.

\section{Beyond Biological Ties}

'The Red Lantern' (hongdeng ji) is one of the eight 'revolutionary model operas' (geming yangbanxi) personally shepherded and curated by Mao's wife, Jiang Qing. The plot centres on a communist cell's effort to deliver an encrypted message to anti-Japanese guerrilla fighters while evading enemy detection and pursuit. The core member of the cell is Li Yuhe who poses as a railway worker. He lives with his mother Granny Li and daughter Li Tiemei. When he is betrayed by a turncoat and arrested, Granny Li consoles the grieving Tiemei with an account of their family history. It turns out that the three of them are not blood relations at all and were instead brought under one roof by Yuhe after each was left behind by their martyred kin. Having adopted Granny's surname, they form a fictive family-cum-underground cell united by unswerving devotion to the communist cause. Between them there are recognisably familial feelings, such as Tiemei's filial love for her father and Granny's tender affection for Tiemei. But these feelings spring from shared political zeal and commitment, not elemental instincts. They are voluntary, reciprocal, and egalitarian, thereby belonging to the realm of freedom, not the realm of necessity. They rest on respect, not submission; they recognise authority, but abjure tyranny; they inspire sacrifice, not subjection. These are the basic ingredients of class feeling. As such, it is imperceptibly injected into the domestic sphere, in effect displacing kin-based sentiments from their centrality in Chinese moral life. Biological ties were rendered optional, and comradely fealty was the only prerequisite for family life under socialism. The corollary is that when a family member erred politically or was exposed as a hidden enemy, there should be nothing that stood in the way of casting him or her out of the bosom of the family, via the scripted act of 'making a clean break' (huaqing jiexian).

If the family as the quintessential realm of necessity can be made a voluntary political unit, then love and marriage, a hybrid of freedom and necessity, are considerably more susceptible to the conquest of class feeling. Romantic love, especially when motivated by sexual attraction, is a horizontal feeling that rivals class feeling in intensity and yet runs a nearly opposite course. Instead of being diffuse and infinitely expandable, it is concentrated and exclusive; instead of honouring shared and publicly celebrated ideals, it is driven by inchoate yearnings and private urges; instead of being amenable to topdown direction, it is obdurate and can be utterly deaf to reason and material principles; instead of looking outward (toward comrades) and upward (toward the supreme leader), it is oriented inward (toward each other) and downward (toward the progeny). At the same time, insofar as it is capable of inspiring the ultimate sacrifice-the giving of life itself-it threatens to displace class feeling from supremacy; and insofar as it seeks fulfilment in sexual union, ideally sanctioned by marriage, it threatens to dislodge the lovers from the fraternal collective, engross them in the business of reproduction, and return them to the traditional realm of necessity. The offspring born of their union would have to be indoctrinated from scratch and inducted into the fraternal order amid all the uncertainties attendant to such an undertaking. 
The Party responded to this challenge by coopting a narrative formula popular in the Republican era called 'revolution-plus-romance' (geming jia lianiai) that typically sends a disappointed lover to the battleground as a mechanism for healing and redemption. The socialist version demands a more synchronous melding of the twin pursuits, in that the lovers must be brought together by political passion rather than erotic attraction in the first place. One of them, at the very least, must clearly embody the communist spirit, so that the other falls in love as much with a person with idiosyncratic traits as with an abstract, lofty ideal. ${ }^{2}$ Such is the premise of Yang Mo's celebrated novel Song of Youth (qingchun zhi ge, 1958). When the heroine Lin Daojing chooses the communist fighter Lu Jiachuan over the bourgeois intellectual Yu Yongze, she is also choosing communism over capitalism and aligning herself with the historically inevitable. Freedom and necessity are reconfigured to render romantic love almost perfectly compatible with class feeling.

\section{Turning Over}

Note that in these stories revolutionary couples rarely settle down to domestic life, to preoccupy themselves with rice porridge and diapers. This is because, as an insurance against the danger of love nests breaking up the fraternal collective, communist love stories are wont to kill off the object of love once the heroine is sufficiently proselytised and can stand on her own as a bona fide communist acolyte. Thus Lu Jiachuan is martyred mid-plot, so is Hong Changqing, the love interest of Wu Qionghua in The Red Detachment of Women (hongse niangzi jun), another revolutionary model opera. ${ }^{3}$ The latter work is equally memorable for its archvillain Nan Batian, an evil landlord and local tyrant who is the target of Qionghua's raging hatred and revenge attempts. The plotline of a former slave girl who 'turns over' (fanshen) by joining the Communist Revolution and learns to sublimate her private vengeance into the collective enterprise of class struggle is the tried-and-true antidote to the third obstacle to fostering class feeling: sympathy or pity for the weak and helpless. Once the former exploiting classes are dispossessed, disenfranchised, and subjected to the dictatorship of the proletariat, they have the potential to elicit pity in their pathetic state, especially if they happen to be one's neighbours, relatives, colleagues, or teachers. The liturgical drama of fanshen ensures that one does not feel sorry for them by keeping alive memories of their ruthlessness in the bad old days.

Fanshen is a communal ritual, street theatre, and people's tribunal all rolled into one. ${ }^{4}$ It is fundamentally a participatory melodrama that cleaves the world into good and evil, virtue and vice, victim and victimiser. No one is a mere spectator: everyone has to play a part, on either side. Fanshen dramaturgy consists of narrating past pain and suffering ('speaking bitterness' or suku; see also Javed's essay in the present volume), pinpointing and confronting the human author of that suffering, accusing and denouncing in unison, and sentencing and sometimes executing the villain at the finale. The denouement of all fanshen drama is an ecstatic state of purity, liberation, and rebirth. It sutures individual peasants into the collective by inscribing contingent, heterogeneous grievances and miseries with overarching ideological significance and absorbing them into a grand narrative of injustice and redemption. The ideal socialist subject is thus not an individual with a private vendetta, but a crusader with a mission, 
burning with rage and hatred against all enemies of the people. This wrathful class subject will not be in danger of wavering or relenting, having completely jettisoned the bourgeois notion of universal humanity. In his/her eyes, across the friend/enemy (diwo) line there can only be a demon, vermin, or malignant tumour, not a vulnerable human being (see Dutton's essay in the present volume). Lei Feng, the paragon soldier canonised for his selfless service ethic and uncompromising love and hate (aizeng fenming), gives the most poetic gloss to what it means to have class feeling in his diary: 'One ought to treat comrades with spring warmth ... and to treat enemies with wintry severity'.

\section{Class Feeling and Worldliness}

Red classics like those mentioned above are still beloved by a broad spectrum of audiences in contemporary China, and are periodically revived on stage and screen. How is it then that class feeling seems to have become thoroughly illegible? For this we need to seek not just psychological, but also institutional explanations. In the Mao era, by way of a class-based public goods provision regime, the 'mass line' and all-pervasive propaganda apparatuses (see Lin Chun's essay in the present volume), the CCP was able to build powerful institutional scaffolds to support and sustain class feeling and class solidarity against all odds. ${ }^{5}$ But once these scaffolds fell away as the Party shifted its priority from class struggle to economic development, class feeling lost its armature and yielded to structures of feeling that meshed better with both traditional family-centred values and the resurrected market economy and consumer society. But the reason that the Party even succeeded at all in fostering a transcendent structure of feeling that held its ground against the countervailing forces of kin attachment, romantic love, and humanist compassion is because it managed to subtend it with tribal forms of feeling, particularly cryptonationalist ones, while also repudiating and supplanting them. Observers have been taken aback by the ferocious eruption of nationalist fervour in the post-Mao decades, but they should not be.

Preternaturally cognisant of the difficulty of forging strong emotional bonds on the basis of objective economic interests, the Party grounded class identity in a quasiracialised typology of friend/enemy through the system of 'class designations' (chengfen) that were patrilineally heritable (see Yi Xiaocuo's essay in the present volume). An iconography (posters, sculptures, exhibits, picture books, films) and a dramaturgy (model operas, fanshen rituals, mass rallies) were then mobilised to exaggerate and intensify the us/them difference at a visceral level (see Ho's essay in the present volume). ${ }^{6}$ In particular, the Party made abundant use of the political drama of fanshen to fuse private sentiments and experiences into abiding hatred for the class enemy and boundless gratitude for the saviour, so that no one loved or hated without a reason, as Mao intoned. ${ }^{7}$ Instead of relying exclusively on the rational and the calculating faculties, the Party tapped into the spontaneous and primordial depths of mass psychology and succeeded in rallying the broad masses to its millenarian vision. Without this brilliant emotion work and the groundswell of popular support it produced, Mao's rag-tag army could not have defeated the far better financed and equipped Nationalist forces, nor could his regime have hurtled the newly minted People's Republic through one tumultuous campaign after another without fundamentally vitiating its own legitimacy. ${ }^{8}$ 
William Hinton, the American chronicler of the land reform movement in which communist cadres led landless peasants to overturn landlord domination and exploitation, posed the puzzle of what motivated the activists to fight on when there was little material gain for them:

My own reaction to the Party Day meeting was one of wonder-wonder at the perseverance of these people, especially the stubborn perseverance of the local men. What kept them working under such conditions? Why didn't they give up and go home? Certainly it had nothing to do with money. Right there in the middle of the meeting the county clerk had come around to ask them to sign their monthly vouchers. I knew exactly what each received for his work ... . At home on the land they could easily earn more. No, they had no material incentive to be cadres. Nor was their chosen road a path of glory. Only a stubborn devotion to the cause of fanshen made sense as a motive. I had never known men who consistently put principle above self-interest as these men appeared to do. ${ }^{9}$

A few pages later, the remarks of Secretary Ch'en of Lucheng county at another meeting suggested a fuller answer:

He swept the room with a long glance and looked straight into the eyes of one man after another. 'I want to ask you a question', he said, warming up for battle. 'Why do we live in this world? Is it just to eat and sleep and lead a worthless life? That is the landlord and rich peasant point of view. They want to enjoy life, waste food and clothes, and beget children. But a Communist works not only for his own life. He has offered everything to the service of his class. If he finds one poor brother still suffering from hunger and cold, he has not done his duty. Anyone who is concerned only with himself lacks the fundamental standards necessary for a Party member. Right now several comrades are thinking, "Life is easier at home. Why not leave this work and go home?" But think it over. Who led your fanshen? From where did the "fruits" come? Such thinking is typical of those who have forgotten their class. A good Communist, whenever he meets personal difficulties, thinks of others' difficulties. If you haven't understood that during the purification meetings, you should understand it now. If you want to go home, you can go home. But give some thought to your future. Where is the man so benighted he no longer has any political needs? Anyone who has no political demands cannot be said to be fully alive. Even the most abject villager is upset when he cannot join the Poor Peasants' League. But you Communist Party members, have you no political demands?' [Emphasis added].

As the Party secretary puts it plainly, man does not live by bread alone, and there is such a thing as 'political needs', or what Hannah Arendt calls 'worldliness'-that is, the ability to act in the world among one's peers as a free agent, a political being, beyond one's private existence in the realm of necessity. ${ }^{10}$ This is fundamental to the 
meaning of being human ('fully alive'). However, the Party's campaign-style politics ultimately warped the realm of freedom and action by clothing it in the language of devotion and selfless service, failing to recognise that the opposite of selfishness was not altruism, but worldliness. The upshot is that that no one was above the suspicion of self-interest, hence the repeated crackdowns on corruption, graft, embezzlement, and treason during the most heady and idealistic period of communist rule. If initially class feeling thrived on the longing to distinguish oneself and make a difference in the world, in grafting itself onto tribal feelings and resorting to a racialist logic, it ultimately smothered worldliness, thus feeding into post-Mao disillusionment and weariness of politics.

There is a great deal we can learn from the CCP's experiment in class feeling and class politics. At best it provides a historical lesson on how to mount a social movement: appeals to the pocket can only go so far if the heart is not stirred. Liberal democracy is rightly distrustful of mass mobilisation built on tribal feelings, and strains to balance identity politics with the Habermasian model of rational communicative action. But it risks losing the masses to demagoguery that promises something far more visceral and seductive and galvanising-something akin to the religious experience of transcendence (see Davies's essay in the present volume). Relying solely on material interests leaves ample room for populist agitators who know how to stoke righteous resentment against all manner of outsiders. We are now daily rattled by the aftershocks of a right-wing triumph of mobilisation in the wake of decades of liberal disengagement from substantive questions of sentiments and values. It is what Wang Hui has forcefully critiqued as the 'depoliticisation of politics.'11 The question that haunts the progressive among us is this: is politics possible without passion? Can we have class solidarity without class feeling? 


\section{4 \\ 阶级斗争 \\ Class Struggle \\ Alessandro RUSSO \\ (Translated by David VERZONI)}

$\mathbf{T}$

he concept of 'class struggle' (jieji douzheng) was one of the principal paradoxes of the Cultural Revolution (see also Thornton's essay in the present volume). As a slogan, it was unfailingly spoken and printed at every turn of that tumultuous decade in China; yet, any attempt to examine those events in the light of 'classes in conflict' encounters insurmountable aporia. No less complicated is the problem of how to assess the role of 'classist' categories in the Chinese government's official discourse today. In its recently amended Constitution, the Chinese Communist Party (CCP) reiterates its hallowed role as 'the vanguard of the working class' (gongren jieji de xianfengdui). Both issues-a critical reappraisal of the Cultural Revolution, as well as an analysis of the role and relevance class plays in CCP ideology-are cut from the same cloth. The thread that stitches them together is the notion of the dictatorship of the proletariat' (wuchanjieji zhuanzheng), which I will elaborate in this essay.

\section{Smashing the State}

The conceptual origins of class struggle certainly predate Marx. Indeed, not only did Marx candidly admit that he had borrowed the phrase from 'bourgeois historians and economists', but even Lenin later pointed out that 'not a single educated liberal' would have trouble admitting the existence of class struggle. ${ }^{1}$ What was new in the Marxist view was how to do away with 'society divided in classes' through a specific process called the 'dictatorship of the proletariat.' This conception of dictatorship was not a new form of permanent rule, but a transition to an altogether different political horizon that would end class conflict and lead to the extinction of the state itself.

The question of how to assess the discourse of class struggle during the Cultural Revolution requires a close examination of the concept of the dictatorship of the proletariat. In particular, in this essay I will consider the Cultural Revolution as 
a laboratory of mass politics that attempted to test this key concept of revolutionary culture. It was definitely not a coincidence that the revolutionary decade that had started in 1966 drew to a close in 1975 with a political campaign that focussed on the theoretical study of this concept, in a reckoning pursued with tenacity but never completed.

What was the dictatorship of the proletariat? Drawing a line of thought from Marx to Lenin and then Mao, this phrase designated a space of invention within which organised communists attempted to implement the goal of downsizing the state's bureaucratic-military machinery. Far from being a particular 'form of government'Marx was notably critical regarding the idea of a 'future state'-the dictatorship of the proletariat indicated the set of political experiments aimed at dismantling-or 'smashing' (zerbrechen), as Marx put it - the state apparatus as an entity separated from society, and dispersing its functions among the people. ${ }^{2}$

When, in the early months of the Cultural Revolution, Mao told the Red Guards that all of them had 'to be concerned about the affairs of the state' (guanxin guojia dashi), he expressed the spirit of the dictatorship of the proletariat perfectly. One of the fundamental components of the original agenda of the Cultural Revolution was initiating a series of political inventions that would entrust the carrying out of state functions to the 'concern' (guanxin) of the masses. Yet, putting the dictatorship of the proletariat into practice as a form of mass politics required a critical rethinking of what the socialist states, starting with the Soviet Union, had become. More specifically, the Cultural Revolution called into question the fact that in all the dictatorships of the proletariat of the twentieth century, state functions had become the prerogative of a special echelon of Party officials instead of being dispersed among the common people.

Although the Cultural Revolution never managed to complete this exhaustive account and reinvention of the dictatorship of the proletariat as a historical enterprise, it articulated a set of questions that recasted older problems in a new light, requiring further conceptual investigation and practical experimentation. A core issue among these was that of the relationship between the abolition of private ownership of the means of production and the prospect of the extinction of the state.

\section{Principles of Authority}

I define 'authority' in the elementary sociological sense of the ability to command obedience. Viewing the state as a set of 'apparatuses' obscures its essential role as the crystallisation of the general principle of authority in a given socio-historical world. ${ }^{3}$ While Marx was surely right in describing different modes of production-slavery, feudalism, and capitalism-all modes of production are held together by a bond of authority by which subordinates obey their superiors. The state is better conceptualised as the form of authority that is dominant within a society, rather than a set of discrete 'places' and bounded institutions. Although the form and phenomenology of authority vary depending on the society, authority installs the general principle of obedience.

Authority has assumed a variety of dominant forms in human societies-personal, transcendent, charismatic, and so forth. Yet the relations of authority dominant in the modern world differ from all previous others because they are based on a singular tenet of capitalism - the buying and selling of labour power as commodity. Labour 
power as a commodity - and the subsequent freedom of the capitalist to buy it or not depending on the self-valorising demands of capital-is the foundation of the relationship between command and obedience in the modern world. In this sense, private ownership of the means of production is first and foremost the exercise of an unconditional authority over the masses of wage earners. In other words, it is the ability to have decision-making power over the lives of those who are valued only as sellers of labour power. In the historical bourgeois society the buying and selling of labour power is the atom of authority's elementary structure. The current trend towards an increasingly precarious workforce aims at restoring the unconditional authority of the wage relation by eliminating the vestiges of constraint a century of working class politics imposed on the domination of capital.

Given this modern form of authority, what did Marx mean when he argued that abolishing private ownership of the means of production would not only signal a break with capitalist society but also play a preliminary role in the process of dissolving the state? Abolishing private ownership of the means of production entails not only an end to the commodification of labour power, but also the disappearance of the general principle of authority in bourgeois society. Thus, if the state constitutes the set of powers needed to command obedience in given socio-historical conditions, abolishing the commodification of labour power deprives the state of an essential function by suppressing capital's unconditional authority. Marx, Lenin, and Mao saw that abolishing private ownership of the means of production was a prerequisite for every communist political strategy. In fact, the abolition of capitalist private property inherent in every proclamation of the dictatorship of the proletariat in the twentieth century bore the seeds of the process that, according to Marx, was supposed to 'smash' the state and eviscerate a crucial pillar of authority of bourgeois society. Once deprived of the freedom to purchase labour power in the marketplace, that entire system of governance would be irreparably altered.

\section{Filling the Void}

What are we supposed to think of the socialist 'exception' to capitalism that lasted approximately two-thirds of the twentieth century, especially now that the 'rule' of labour power commodification has been fully reinstated globally? The current discourses of totalitarianism and despotism that dominate most historiography of socialism provide little help in understanding what socialism was in its aspirations, victories, and failures. The crux of the matter is how to assess, without a blueprint, the actual consequences produced by the dictatorships of the proletariat that appeared in the twentieth century-the abolition of private ownership and the ensuing end to the commodification of labour power. Given that the very conceptual coordinates that supported this abolition have been undone, such a reassessment is no easy task.

Yet, it is surely inadequate to dismiss the entire enterprise as unrealistic, as a mere utopian impulse, and violent imposition on reality destined to deliver only disastrous results. True, the results were more than equivocal. However, the abolition of private ownership was underpinned by a detailed analysis of the real conditions of capitalism and informed by an open-ended logic that would lay the groundwork for political 
experimentation on a grand scale. The decision to do away with labour power as a commodity was, in fact, a risky and challenging endeavour, the results of which should be assessed vis-à-vis the aims of the political project to which it belonged.

Abolishing the commodification of labour power was not an end in itself-it was only the first step of a project aimed at drastically reducing the functions of the state. Indeed, without pursuing or extending experimentation that would limit the state's machinery, the results produced by that first step could not but turn into the opposite of what it aimed to accomplish. Yet, this is a conclusion that can be drawn only ex post facto, and only if we take into account the experimental nature of these processes. In this context, our categories are still provisional. The assumption that we can make, however, given the historical record of the dictatorships of the proletariat in the twentieth century, is that the evisceration of the state due to the abolition of private property released a kind of 'reactive' energy that filled the very void left by this process. The 'halved' state was in turn 'duplicated' by the Communist Party, with the latter replacing the former principle of authority based on the commodification of labour power with a new authority to command obedience as the party that represented the 'vanguard of the working class.'

\section{Working Class and Vanguard}

This new principle of authority, however, was as much 'ideological' as it was 'organisational', in the meaning that Franz Schurmann gave to both concepts. ${ }^{4}$ It was grounded in a thorough restructuring of industrial organisation whereby the factory became a fundamental element of state administration and the worker a kind of entrylevel functionary. The role of the institutional paradigm of the industrial work unit (danwei) - based on the model of the Soviet kombinat-is well known (see also Kevin Lin's essay in the present volume). A Chinese hospital, university, even a department store, shared the same administrative structure as a factory, because they all were modelled on it.

The interrelationship between working class and vanguard played a key role in the reorganisation of industrial production. It was also a notably ambivalent relationship. Installing industrial labour in the sphere of state administration was envisaged as a way to dissolve capitalist authority over wage slavery. Yet, labour's very inclusion in that sphere, and the substitution of capitalist authority with that of the vanguard of the working class, ended up reconstituting the entire apparatus of the state that the abolition of private property was supposed to have smashed. Indeed, the new organism was even more inflexible than the previous one, since it had to fill the void that the abolition of commodified labour power had left in the general principle of authority. Once we account for these peculiar circumstances, it is possible to reassess the references to 'class' (jieji) during the Cultural Revolution, as well as their reiteration in the current discourse of the Chinese authorities.

The persistent references to class during the Cultural Revolution can be taken as a symptom of the insurmountable impasse that had arisen between the working class and its vanguard in the socialist state. The obsession with the concept symptomatically masked the questioning of its real political value by the people who were supposedly 
its subject. The proletariat-which, along with its dictatorship, was supposed to be the political subject leading to the dissolution of the state-had become an integral part of a process of reconstructing the state's bureaucratic machine.

It is remarkable that during this revolutionary decade the issue of the working class was approached from the perspective of critical reappraisal of the very organisation of industrial labour. One of the most significant political questions posed during the Cultural Revolution was what made the socialist factory different from a capitalist one. True, authority was no longer invested in the commodification of the workforce. Yet, the question that Mao and the Maoists raised ever since the late 1950s-the 1960 'Constitution of Anshan Iron and Steel Company' being one example-was that the workers themselves should be able to devise new forms of political experimentation, otherwise the industrial danwei would simply end up reiterating subordinate workplace relations just like those of the capitalist factory.

At stake was precisely what Marx had argued at length in his anatomy of the organisation of the modern workplace in chapters 14 and 15 of Capital: how to subvert the 'technical division of labour' whereby the factory command subsumes the 'intellectual powers of production' expropriated from the workers, who are then relegated to mere 'socio-functional detail' as simple accessories to the array of machine tools. That fundamental structure of factory despotism in the industrial danwei relied on the ambiguities in the relations between the working class and its vanguard, instead of converging in the unconditional authority of the capitalist.

As a result of these unresolved tensions, the political import of the issue came explosively to the fore with the 1967 January Storm in Shanghai. All the ambiguities in the relationship between the CCP and the working class emerged when the Headquarters of Revolutionary Rebel Workers (geming zaofan gongren silingbu) announced that they had organised themselves independently of the Party-state apparatus. For this reason, the Shanghai Party Committee fiercely opposed their very existence. No real analysis of that crucial episode can be formulated in the terms of class conflict. There was no deepseated division of social condition between Rebels and Scarlet Guards, the loyalists that supported the Party authorities. The real divide was to be found in the concept of the working class itself. While the January Storm still calls for much research, it was undoubtedly the episode that smashed the preceding principle of authority under which the CCP was the only political organisation possible, as the self-proclaimed vanguard of the working class. At that point the industrial danwei could not continue to operate as before-it had lost its ability to command obedience.

How to deal with the decline of authority from that moment on became a crucial issue that marked the entire revolutionary decade. For the Maoists, the way forward was to organise a series of experiments aimed at a political rethinking of the socialist factory, an agenda that included the need for a thorough transformation of its technical organisation. Wherever they were strong and well-organised-as in Shanghai and in the Northeast-they promoted remarkable experiments like the 'worker universities' (gongren daxue) and the 'theoretical contingents of workers' (gongren lilun duiwu). ${ }^{5}$ One such model was the University of the Machine Tool Factory in Shanghai. Set up in 1968 to close the gap between executive responsibilities and shop-floor duties, it trained worker engineers to design components as well as work on the production 
lines. By 1973, theoretical contingents appeared in factories where the Maoists were most active. They argued that theoretical work, including the study of philosophy, history, and economics, should be an integral part of shop-floor duties.

The Party apparatus responded to these experiments with lukewarm detachment that soon turned into passive resistance. The executive cadres of the industrial danwei no longer possessed the stature needed to assert their unconditional authority and were at a loss about what to do. Any pretence of reestablishing the former order was impracticable and a new order had yet to be invented. Lacking a clear principle of authority in the factories, the political system wobbled on unstable foundations.

\section{Putting Things Back in Order}

The coup d'état of 1976 imposed a solution. 'Put things back in order' (zhengdun) the keyword of Deng Xiaoping's programme from 1975 on-was code for the suppression of political experimentation of any kind in the factories, labelling it as 'disorder', 'anarchy', and 'factionalism.' Yet, this first preliminary step towards the 'new order in China' in no way restored the former principle of authority that the Cultural Revolution had smashed. Deng's strategic acuity was to grasp immediately that such a restoration was impossible and that new approaches had to be found in order to command obedience. In truth, the means employed were anything but new. In the end, capitalism's main principle of authority was revived: the exploitation of commodified labour power. The lives of millions of migrant workers in the 'world's factory' is now regulated by the principle of buying and selling labour power as a commodity in one of the world's most flexible labour markets.

What is new about the 'Chinese miracle' of the past four decades is the fact that the CCP has maintained its claim to be 'the vanguard of the working class' alongside the often brutal exercise of capitalist authority. Obviously no one really believes this claim, let alone the ones who proclaim it loudest. Yet, it is not just a litany. It is an assertion with a precise organisational thrust-an injunction that the CCP remains the only legitimate political organisation in China, and that no independent political organisation of wage-earning slaves can be tolerated. The category 'working class' is an essential component of the government's discourse, albeit shorn of its political value. It is clearly retained as cautionary principle of interdiction, a warning prohibiting any incipient form of worker political existence.

We can even predict that the stability of the Chinese government is assured as long as the dualism holds: on one side, the capitalist principle of authority regulates the lives of wage earners; on the other, the self-styled 'vanguard of the working class' acts as a preemptive censor to prevent the emergence of any political organisation independent of the Party. The former is, to a certain extent, a given in that it reiterates the basic rule governing the modern global social condition; the latter, however, is a fiction that can retain its grip only with subsequent developments of more or less esoteric formulas that amplify its hold-such as the Three Represents (san ge daibiao), Scientific Development (kexue fazhan), Harmonious Society' (hexie shehui), and the latest, China Dream (zhongguo meng). It is hard to imagine how China's political elite 
can craft a governing discourse without resorting to enlarging, and emptying, the range of slogans. To pretend that the dreams of a billion and a half people can coincide with any unifying dream is a perversion that would make the Marquis De Sade blush.

For a new politics for workers to emerge in China, workers themselves will have to invent original forms of independent organisation and critically reappraise the political value of the entire history of modern labour politics. If the main barrier against the political existence of workers is the reference to a mummified working class enshrined in official discourse, nothing that is politically novel will be able to come into being unless there is an explicit, conscious effort to keep this fiction at bay. 



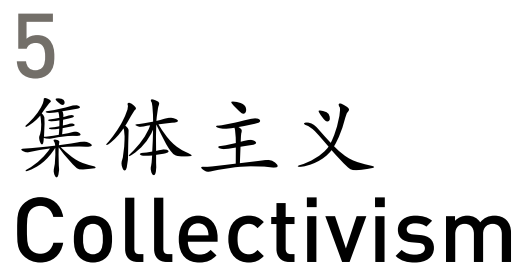

GAO Mobo

D

espite collectivism's maligned and misunderstood status today, at the time of its implementation in the Mao era, it was seen as a necessary solution to achieve a scale of food production that could feed China's massive population. Collectivism was a revolutionary idea and a potential solution to underdevelopment. To understand this, it is important to grasp the background conditions of China's complicated land-tenure system inherited by the Chinese Communist Party (CCP) when it came to power in 1949. First, China has been forced to rely on just 7 percent of the world's arable land to feed between one fourth and one fifth of the world's population. Second, in most of southern China, mountains and hills were cultivated to grow food in terraced plots not suitable for large-scale mechanised farming. Third, in large areas of rural China, communities had been (and continue to be) based on lineage or clan villages. ${ }^{1}$ Finally, although land reform in the early 1950s allocated land equally on a per capita basis, it was feared that without collective reinforcement, this equality might revert to well-trodden historical disparities between landowners and the landless-a prospect that was anathema to communist ideology. Collectivism was viewed as an attractive option with which to overcome these constraints, develop agricultural production at a scale that could feed China's masses, and evengenerate a surplus for industrial development.

\section{Land Reform in the Mao Era}

Land reform involved confiscating land from larger landowners-identified as the class categories of landlords and rich peasants-and redistributing it to households on a per capita basis. Land reform was central to the CCP's ideology, and the violence of the land seizures and struggle sessions was justified by the need to emancipate the peasantry from their oppressive landlords (see Javed's essay in the present volume). ${ }^{2}$ 
Due to the existence of lineage villages, the implementation of these ideals was not homogeneous. As a result of historical heritage, villagers in one village could end up controlling more, or less, land than their neighbours.

In spite of widespread mass support, this form of household ownership of land did not last long. Immediately after 1949, China faced two grave structural challenges: how to look after the poor and the disadvantaged in rural areas and how to obtain enough food to feed the increasing urban population while at the same time accumulating capital for industrialisation. Based on their understanding of the current conditions, and their conceptualisation of how development should unfold, the Chinese leadership in the mid-1950s came to the conclusion that collective farming was the most rational approach to address macroeconomic development and serve the needs of the peoplethe majority of which were poor, illiterate peasants struggling for survival. A collective could look after the poor and disadvantaged, and provide essential services such as health care. It was hoped that collective land ownership would guard against the recreation of unequal class dynamics in the countryside by making it impossible to transfer land from the poor to the better off. It was also seen as a way to mobilise labour power in order to achieve large-scale infrastructural projects-such as irrigationdespite the limited technology available at that time, while also increasing the state's capability to extract food to feed the urban sector, as well as capital surplus from farmers to develop industry at a faster rate.

It could be argued that collective farming succeeded in fulfilling all of these tasks. By the end of the Mao era, the Chinese people were reasonably healthy and educated. Life expectancy increased from a mere 39 to 68 years. Though life remained spartan, inequality had been reduced dramatically. Irrigation infrastructure had been improved beyond the CCP's wildest expectations. By the end of the 1970s, China had become the sixth largest industrial power in the world, whereas in 1949 the country's industrial capacity was on par with that of a small nation like Belgium. But these successes were not achieved without costs. There was a constant shortage of daily necessities and living standards remained low. The most disastrous cost was the famine that followed the Great Leap Forward (1958-62), when the Chinese authorities rapidly organised the 'people's commune system' (renming gongshe zhidu) across the country and encouraged people to put into practice many fanatical ideas, such as setting up backyard furnaces to make iron and steel. ${ }^{3}$ Although the famine resulting from the Great Leap Forward is used by many to discredit collectivism tout court, this is an unfair reduction of the possibilities of collective organisation to one of its most extreme manifestations.

\section{Life in the Commune}

When the commune system was initiated in 1958, it was organised according to the logic of 'the bigger, the better', based on the assumption that larger communes were better equipped to mobilise resources to achieve large-scale projects, and that disputes among villages would disappear in the vastness of collective life (see Tomba's essay in the present volume). A commune was set up by combining several villages into one administrative unit. These assumptions were flawed. In a large commune of several thousand households or more, it was difficult to manage and supervise production activities. This administrative failure was largely responsible for the decrease in food 
production during the crucial planting season of 1959. In the early 1960s, having learned a costly lesson, the commune system was downsized, a change that led to certain improvements in management and supervision. The system in this new form lasted until the early 1980s. Within one 'commune' (gongshe) there were ten or so 'production brigades' (shengchan dadui), each one of which was comprised of ten or so production teams (shengchan xiaodui). A team would normally consist of ten to twenty households, depending on the size of a village. A village of more than thirty households would most likely be divided into two teams. Each team would have a fiveperson leadership group, usually composed of a team leader, an accountant, at least one woman member, a person responsible for the granary, and a work point record keeper.

In this structure, the production team would be in charge of managing the land under its control. Everything produced on this land was shared by team members after deduction of taxes and levies paid to the state, and all the production activities were arranged by the team leadership. With this system, supervision and monitoring were easier and more transparent. Within one team, the contributions of each member to the collective were recorded and rewarded according to a so-called 'work point system' (gongfenzhi). All villagers received an equal amount of staple food on a per capita basis, with the only difference being between adults and children. To those households that contributed more than the worth of what they had received, the leadership applied the principle of 'to each according to one's work' (anlao fenpei) by either giving cash converted from the value of the earned work points at the end of the year, or by distributing non-staple food like oil, sugar cane, or fish from public ponds. The households that had contributed less would not be able to receive these products. Every year, all team members would assemble to evaluate each other's contribution to the collective, taking into account age, strength, work attitude, and gender. This evaluation would then be quantified through a ten-point system. Those villagers who received the highest score would usually be assigned the hardest work, but women were usually assigned less arduous manual labour, like pulling a wheel barrel or ploughing the paddy fields.

The commune leadership would not intervene in day-to-day production activities. Usually, they enforced policies and disseminated political messages from the centre. They were also responsible for the promotion of specific programmes-such as those on health and hygiene, and on how to use new technologies. As a result of reforms of collective structure and management, by the end of the 1970s, there were already signs of improvement in the life of Chinese farmers. By the middle of the 1970s, another development also contributed to improving the rural situation: the establishment of 'commune and brigade enterprises' (shedui qiye). Contrary to mainstream historical narratives of a lost decade of economic stagnation, companies of this kind actually originated during the Great Leap Forward and increased during the Cultural Revolution (1966-76). These Mao-era experiments in rural production were precursors to the creation of township and village enterprises (TVEs) developed in the 1980s after decollectivisation. Although TVEs are praised by scholars for contributing to lifting China's rural areas out of poverty, their origin in Mao-era collectivism is often conveniently erased from the historical narrative. 


\section{The Afterlife of the Collective}

As a rural development model, collective agriculture was a mixture of success and failure. According to William Hinton, one third of the communes of the Mao era performed well, one third did very badly, and the rest fell in between. ${ }^{4}$ Nowadays, however, communes are painted with the brush of failure, erasing the differences between them and their underlying potentials. It is almost entirely forgotten that the practice of combining collective life with private initiatives, such as the household contract responsibility system' (jiating lianchan chengbao zeren zhi), originated in different parts of the country in the Mao era. ${ }^{5}$ Praised for bringing about the end of the collectives and initiating rural economic reform, the contract responsibility system did not necessitate the undoing of the collective system. The outcome was not historically inevitable and, in hindsight, was perhaps lamentable. In fact, there are still a few hundred villages that have resisted the pressure to dismantle the sources of their power, and remain collective until this very day. ${ }^{6}$ While the end result of the economic reforms initiated by Deng Xiaoping was in fact the restoration of household farming and land redistribution, it has to be pointed out that the dismantling of the commune system has not entailed the total abandonment of collective agriculture. Land is still collectively owned, and households only maintain the land use rights distributed to them.

Those who pushed for dismantling the commune system argue that production output during the Mao era remained low because the system of collective farming tolerated 'free riders.' ${ }^{\text {' }}$ Arguments and evidence against such an economic rationalist position are too complex to be presented here, so I will only mention two facts that in my opinion undermine such an approach. First, due to Cold War era sanctions imposed by Western powers, China was forced to 'transform itself through its own efforts' (zili gengsheng) (see Yang's essay in the present volume), and pursue the price scissors strategy of keeping the price of agricultural produce low while setting the price of industrial goods high in order to accumulate capital to invest in industrial development and modernisation efforts. Second, technology, such as hybrid rice crops and chemical fertilisers, was not available at that point in China. Without the technology of industrial agriculture, collectivisation attempted to increase food production on limited arable land for a massive population.

\section{The Collective Roots of Today's Economic Miracle}

It is easy to dismiss collectivism without understanding its political economic goals and the circumstances under which it was developed. The economic development and wellbeing of China's rural population today were built on a foundation of collectivism. Ironically, China's economic 'miracle' of the reform era can also be explained as a result of its collective past. The collective ownership of land has provided a large well-educated but cheap labour force that has allowed China to become the 'factory of the world' over the past three decades. And it is this very same collective land ownership that to this day supports the families of hundreds of millions of migrant workers. In China, there are hardly any urban slums because collectively owned land acts as a social security net. If there is no work to be found in the cities, migrant workers can always return to their hometowns. They can also leave their families, children, and elderly relatives on the 
familial plot of land. If farmers were dispossessed from their land and without jobs in the city, today's China would face the spectre of proletarianisation on a scale of which Marx and Mao could only dream.

There are two major issues today that are used as rationale for the wholesale privatisation of land. One is the prevalence of predatory rural land grabbing, a situation in which state agents and developers work together to seize land from farmers for commercial development. While this phenomenon has seen some signs of easing recently and is mainly limited to areas next to urban centres, it is often used as an argument for privatisation in the belief that once the land is privatised, the titleholder will be properly compensated. The second issue is related to efficiency and scale economy, and is based on the assumption that only privatisation can allow the market to play its full role in increasing competition, and thus boosting agricultural productivity. These two issues remain extremely controversial in China today. And it could not be otherwise, since a decision on whether land remains collective may well decide the future direction of the entire country. ${ }^{8}$ 



\section{6 \\ 矛盾 \\ Contradiction}

Carlos ROJAS

n contradistinction to Marx, who often appeared to use the concepts of 'contradiction' and 'antagonism' interchangeably, Lenin instead at times attempted to systematically distinguish between the two, suggesting that under a socialist society it would be possible to maintain non-antagonistic contradictions. ${ }^{1}$ This notion of nonantagonistic contradictions was subsequently theorised not only by Stalin but also by Mao Zedong, beginning as early as the 1930s and continuing after the founding of the People's Republic of China (PRC). First, in August 1937, a month after his seminal speech 'On Practice' (shijian lun), Mao Zedong delivered a second lecture titled 'On Contradiction' (maodun lun), which marked his first extended engagement with the topic that Slavoj Žižek suggests is 'arguably Mao's central contribution to Marxist Philosophy.' Both speeches were initially prepared for the Anti-Japanese Military and Political College in Yan'an for the purpose of promoting correct Marxist thinking and opposing 'dogmatism.' Although transcripts of the speeches themselves do not exist, a formal version of each work was subsequently published in the early 1950s and the two texts have come to be regarded as paradigmatic illustrations of Mao's status as a Marxist theoretician. In particular, 'On Contradiction' grapples with a question that would subsequently prove to be one of the biggest challenges for the Chinese communist regime itself-namely, how to handle internal dissent within a socialist society.

\section{Universal vs Particular}

The published version of 'On Contradiction' opens by citing Lenin's distinction between a metaphysical and a dialectical worldview. Mao explains that whereas a metaphysical worldview treats things as unitary, isolated, and static, a dialectical one instead views things as being in dynamic interaction with each other while also being characterised by internal contradictions. Under a dialectical perspective, moreover, 
progress is achieved through a reconciliation of external and internal contradictions (through a Hegelian dialectic), which generates new 'things' and a new set of external and internal contradictions.

In 'On Contradiction,' Mao is specifically interested in the differences between what he calls the 'universality' and 'particularity' of contradiction, noting that while the former is widely recognised and has been extensively studied, the latter 'is still not clearly understood by many comrades.' He first outlines the notion of the universality of contradiction, and particularly the contention that all development is predicated on 'a movement of opposites,' but emphasises that 'each form of matter' is shaped by its own specific contradictions. It is precisely in Mao's focus on these latter particularities that we find his attempts to apply the generalised logic of dialectical materialism-as developed by Hegel, Marx, Lenin, and others (see Pang's essay in the present volume) to the specificities of twentieth-century China's sociopolitical situation. In particular, Mao notes that what he calls China's 'bourgeois-democratic revolution' has passed through several distinct stages over the two or three decades preceding his speechincluding the 1911 Revolution, the regime of the Beiyang Warlords, the First United Front, the Revolution of 1924-27, the Second United Front, and the War against Japanese Aggression-and argues that each of these stages was marked by its own specific internal contradictions that need to be analysed on their own terms.

Although Mao initially delivered the original oral version of 'On Contradiction' at a time when he and his fellow communists were surrounded by enemy forces ranging from the Nationalists (with whom they had been engaged in a civil conflict) to the Japanese (who were attempting to invade China), by the time the piece was finally published in the first volume of his Selected Works in April 1952, the Japanese and the Nationalists had already been defeated and the PRC had just been founded. In this context, the essay's focus on internal contradictions rather than external enemies reflected the need to shift from carrying out the revolution itself, to maintaining a sense of revolutionary purpose under a socialist system. The underlying question, in other words, involves how to negotiate the transition from 'revolution' (geming) to 'continuous revolution' (jixu geming)—or, what would later come to be known as 'continuing the revolution under the dictatorship of the proletariat.' Although it was not until the beginning of the Cultural Revolution in 1966 that Mao first called for a continuous revolution-a concept closely related to, yet distinct from, the notion of a permanent revolution, as initially developed by Marx and popularised by Trotsky (see Galway's essay in the present volume) - this sentiment of wanting to maintain a revolutionary energy even after the Communist Party had seized power could be traced back to the early years of the PRC. ${ }^{3}$

\section{Two Sets of Contradictions}

On 27 February 1957-five years after the publication of 'On Contradiction' and almost 20 years after the initial oral version of that work-Mao delivered another speech titled 'On the Correct Handling of Contradictions among the People,' which noted that: 
Never before has our country been as united as it is today. The victories of the bourgeois-democratic revolution and of the socialist revolution and our achievements in socialist construction have rapidly changed the face of the old China. A still brighter future lies ahead for our motherland.

For Mao, however, the fact that China was now unified did not mean that contradiction was no longer relevant. Instead, he distinguished between what he characterised as 'contradictions between ourselves and the enemy' (diwo maodun), on one hand, and 'contradictions among the people' (renmin neibu maodun), on the other (emphases added), specifying that in this instance he was primarily concerned with the latter. He further explained that, in contrast to contradictions between the self and the enemy, which must be resolved by drawing a distinction between the two, contradictions among the people may be resolved by drawing a distinction 'between right and wrong.'

Even as it attempted to explain how to handle the contradictions that might exist within a socialist society, 'On the Correct Handling of Contradictions among the People' simultaneously pivoted around a crucial conceptual contradiction of its own. On the one hand, Mao listed various types of contradictory relationships that he claimed one might find 'among the people'-including contradictions between individuals whose thinking is characterised by right and left 'deviations', between those who are active supporters of the new cooperatives and those who are dissatisfied with them, between the working class and the former bourgeoisie, between the interests of intellectuals from the old society and the current needs of the new society, and so forth-and he suggested that in every instance one should strive to 'resolve' (jiejue) these internal contradictions, which is to say to eradicate them. On the other hand, however, near the end of the piece he offered his now-famous discussion of the need to 'let a hundred flowers blossom, [and] let a hundred schools of thought contend, stressing the importance of creating an environment in which different perspectives could productively coexist. In contrast to the preceding advocacy of the need to eliminate contradictions, this latter section instead recommended that 'contradictions' taking the form of critiques of government policies and limited strikes be permitted, and even encouraged.

In fact, in this piece Mao asked whether Marxism itself could be criticised, given that it was already 'accepted as the guiding ideology by the majority of the people in our country. He answered his own question in the affirmative:

Certainly it can. Marxism is scientific truth and fears no criticism. If it did, and if it could be overthrown by criticism, it would be worthless. In fact, aren't the idealists criticising Marxism every day and in every way? And those who harbour bourgeois and petty-bourgeois ideas and do not wish to changearen't they also criticising Marxism in every way? Marxists should not be afraid of criticism from any quarter. Quite the contrary, they need to temper and develop themselves and win new positions in the teeth of criticism and in the storm and stress of struggle. Fighting against wrong ideas is like being vaccinated-a man develops greater immunity from disease as a result of vaccination. Plants raised in hothouses are unlikely to be hardy. Carrying 
out the policy of letting a hundred flowers blossom and a hundred schools of thought contend will not weaken, but strengthen, the leading position of Marxism in the ideological field.

Mao then noted that when 'unmistakable counterrevolutionaries and saboteurs of the socialist cause' expressed 'non-Marxist' ideas, the solution was often 'simply [to] deprive them of their freedom of speech.' However, when he asked whether it would be productive or beneficial to attempt to similarly ban 'incorrect ideas among the people,' he answered his own question in the negative:

Certainly not. It is not only futile but very harmful to use crude methods in dealing with ideological questions among the people, with questions about man's mental world. You may ban the expression of wrong ideas, but the ideas will still be there. On the other hand, if correct ideas are pampered in hothouses and never exposed to the elements and immunised against disease, they will not win out against erroneous ones. Therefore, it is only by employing the method of discussion, criticism, and reasoning that we can really foster correct ideas and overcome wrong ones, and that we can really settle issues.

This emphasis on the value of discussion and of the energetic exchange of 'correct' and 'incorrect' ideas, in turn, articulated the central premise of the Hundred Flowers Campaign, in which the Chinese people were encouraged-and often were even explicitly required-to publicly voice critiques of government policies.

Deriving out of some recommendations that had been made by Zhou Enlai in early 1956, the Hundred Flowers Campaign was a bold gesture for China's nascent communist regime. Although Mao had obviously hoped that the campaign would reinforce perceptions of the strength and stability of the government and Party leadership (on the logic that only a firmly established leadership would encourage critiques of its own policies), there was nevertheless considerable internal concern about the Campaign's destructive potential. In fact, in March 1957, the Minister of Culture-author Shen Dehong/Shen Yanbing, who is better known by his aptly chosen penname, Mao Dun, which deliberately puns on the Chinese word for 'contradiction'turned the Campaign's call for critiques of government policies on its head, with an article critiquing the Hundred Flowers Campaign itself (a critique for which he was subsequently dismissed from office).

Although Mao's 'On the Correct Handling of Contradictions among the People' speech was first delivered on 27 February 1957, shortly after the launch of the Hundred Flowers Campaign in late 1956, by the time a revised version of his speech was published in the People's Daily in June 1957, Mao had already become concerned by the disruptive potential of these criticisms. He officially suspended the Campaign a month later in July. Indeed, not only was the call for dissident voices and points of view officially called off, but the Hundred Flowers Campaign was also quickly followed by its own antithesis, in the form of the Anti-rightist Campaign that actively targeted and persecuted those who had critiqued government policies when it was permitted. In this way, Mao's attempt to 
encourage an environment of 'non-antagonistic contradiction' became, instead, deeply antagonistic, and laid the groundwork for many of the regime's repressive campaigns that would follow.

Moreover, it should be noted that Mao's delivery of the original version of 'On Contradiction' in 1937 coincided not only with the CCP's establishment of the Second United Front with the Nationalists, but also with China's signing of a nonaggression pact with the Soviet Union. Although the non-aggression pact was negotiated by China's Nationalist government - which had hoped to use the pact to strengthen the nation's strategic position in response to the threat of Japanese invasion-it also ended up having important ramifications for the PRC's relationship to the Soviet Union in the early 1950s, when the Soviet Union was an important ally of the PRC. However, Mao's advocacy-not only in 'On the Correct Handling of Contradictions among the People' but also in some earlier articles dating back to late 1956- of direct criticism of the Party and the government was in direct contradiction with current Soviet policy, and was one of the factors that contributed to the subsequent Sino-Soviet split that unfolded during the late 1950s and 1960s. The Sino-Soviet split, in turn, was emblematic of a central contradiction within Maoism itself, in that even though Maoism explicitly drew on a line of theorisation that extended from Marx and Engels to Lenin and Stalin, the Chinese state nevertheless increasingly diverged, in political terms, from the model of the Soviet Union.

\section{New Contradictions}

Even after Mao Zedong's death in 1976, and the subsequent shift to a partially capitalist economic model with the launch of economic reforms in the late 1970s, the issue of contradictions has remained as relevant to contemporary China as ever. One author who has been particularly interested in examining and interrogating these contradictions is Yan Lianke. His 2004 novel Lenin's Kisses, for instance, revolves around a harebrained plot by a local Chinese official to purchase Lenin's preserved corpse from Russia, and install it in a newly built Lenin mausoleum in the official's home county in central China. ${ }^{4}$ The work's premise is that the Chinese bureaucrat has read that the Russian government is in dire financial straits and can no longer afford to maintain the corpse in its current position in Moscow's Red Square. He therefore comes up with the idea of bringing it to China and using it as a tourist attraction to raise money for the residents of his county. Through this fictional plotline revolving around an attempt to install a Lenin mausoleum in central China modelled on the Mao Mausoleum in Beijing, Yan's novel comments on the apparent contradictions not only between contemporary Maoism and a Marxist lineage leading back through Lenin to Marx himself, but also between the original Maoist regime and the trajectory that the PRC has taken in the post-Maoist era.

In addition to the fictional purchase of Lenin's remains in Lenin's Kisses (for which Yan Lianke lost his position, which he had held for years, as a professional author under the employment of the Chinese army), Yan's novels have explored topics ranging from China's rural AIDS epidemic to the Anti-rightist Campaign, the Great Leap Forward, and subsequent Great Famine in the late 1950s. The work that engages most explicitly with Mao Zedong's notion of contradiction, however, is his 2001 novel Hard 
like Water. ${ }^{5}$ Set during the Cultural Revolution and revolving around an adulterous affair between a soldier in the People's Liberation Army, Gao Aijun, and the daughter of a local bureaucrat, Xia Hongmei, Hard like Water explores the intersections between revolutionary and libidinal passion. The novel incorporates an abundant amount of Marxist and Maoist discourse, ironically redeploying it to comment on the hyperrevolutionary affair of the protagonists. One work from which the novel quotes extensively is Mao Zedong's 'On Contradiction,' and at a critical moment in the plot, just as Xia Hongmei's husband catches her and Gao Aijun in flagrante delicto, the narrator remarks:

Just as this extraordinary event was unfolding, a subtle contradiction developed out of this special condition. While the old contradiction had been resolved, a new contradiction emerged, as the earlier secondary contradiction was transformed into a primary contradiction.

Although this dialectical process of generating new contradictions through the resolution of earlier ones has a very specific meaning in the novel, it nevertheless aptly describes the general trajectory of modern China. 


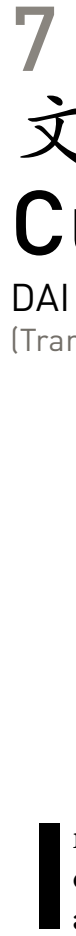

$\mathrm{n}$ the course of Chinass socialist history, during that period we are accustomed to calling the 'Mao era'-or the 1950s to the 1970s-'culture' (wenhua) was without a doubt an extraordinarily important social category of practice. It is a crucial keyword that provides an entry into or an explanation for the history of that period. Even when we take the twentieth-century history of the international communist movement as a baseline, or when we consider the various countries of the socialist camp in the postwar period, the high level of self-consciousness and the variety of practice in the creation or construction of a new culture of socialism in China's socialist history is particularly prominent and striking.

This is, of course, a result of Mao Zedong's designs for and conceptualisation of 'new China' and a 'new society.' At the same time, it follows from the fact that the Mao-era phase of Chinese socialist history coincided exactly with a crucial phase in the advancement of China's modernisation. Hence, if we see 1949 as the moment at which the establishment of the People's Republic of China (PRC) achieved a completely sovereign, modern, nation-state and also a national state committed to socialism, then we can appreciate that what this polity faced from then on was the final unravelling of a millennium of dynastic governance as well as, at the same time, the ongoing two-sided and dual task of determining a modern and a socialist culture under the leadership of the Chinese Communist Party (CCP). The enormous social transformations of the nineteenth and early twentieth centuries to a great extent underpinned Chinese society's subsequent radical turn in politics and culture. This not only is demonstrated by the fact that it was indeed the 1919 May Fourth New Culture Movement and not the 1911 Republican Xinhai Revolution that genuinely inaugurated modern Chinese history, but it is further expressed in the ways in which the practice of new culture exhibited modern China's complete rejection of and rupture with premodern culture. 
For this reason, 'new culture' (including new language) was transformed into a political practice and social rhetoric adopted by 'young China.' The practice and rhetoric were two sides of the same coin.

\section{Culture as Modern Problematique}

Indeed, the problematique of culture in the Mao era cannot be seen as a mere extension or elaboration of the democratic revolution or the processes of modernisation already in progress long before 1949. The relation of culture to the course of socialist transformation and the construction of socialism must be seen separately. That is, in the radical culture of socialism, sensuous cultural thematics were entirely rewritten through the new idioms of Mao-era Marxist emphases on class revolution and the right [of the oppressed] to rebel; class equality through the overturning of class hierarchy (represented by Mao's saying: 'the most humble are now the most noble'); and historical materialism featuring the centrality of the subjectivity of the [revolutionary] people (renmin).

To be sure, the need to promote and popularise Marxism among the people and throughout society created the ongoing importance of new rounds of state institutional involvements in translation, publication, and distribution networks. These operated at an unprecedented scope compared to the previous efforts at westernisation and modernisation. Raising the literacy of the whole populace; opening adult educational courses for peasants and workers; efforts to simplify Chinese characters: all of these were on the table and implemented to one degree or another. They all offered a foundation for the modernisation of society and culture. And yet, in the midst of all this, not only was the historical materialism of Marxism propagated, but even more importantly, the complete rewriting of Chinese history through the historical materialist method was included in school textbooks, thus producing a profound and broad impact on society. In addition, there was wave after wave of folk songs and dances popularised by the spread of education; and, meanwhile, transformed folk art and folk performances were pressed into service to help animate and mobilise political movements and social change (see also the essays by Barlow, Javed, and Lee in the present volume). At the same time as this popular culture incorporated certain aspects of the modernisation of cultural resources drawn from traditional China, a path also was opened to the creation of class culture and the new culture of socialism. Perhaps it is unnecessary to add that during the Mao era, almost every important political incident or social turning point had some single or group of cultural overtures or harbingers: from the discussions over the traditional classic Dream of the Red Chamber or the critique of the movie Life of Wu Xun and whether these texts could become important and prominent components of socialist transformation all the way to the debate over the new historical drama Hai Rui Dismissed from Office, whose critique was the opening act of the Cultural Revolution, or the discussions about the old classic The Water Margin and the criticisms of the novel The Builders. These latter discussions were part of the roll out of the Cultural Revolution and the last chapter of the Mao era.

Throughout the establishment in the 1950s to 1970s of the culture of socialism and the institutional mechanisms through which this new culture would operate, China directly borrowed the systemic structures of the Soviet Union. Among the 
more important of these were literary journals, writers' associations, and the system of movie production studios, all of which manifested the deep influence of Lenin's cultural thinking and the theory of the 'socialist new person.' ${ }^{1}$ And yet, the difference between China and the Soviet Union resides in the fact that China's new culture was also, to a certain degree, an extension of the Republican era cultural thematic of 'transforming the national character' Even if the cultural thematic of socialism extended that of the Republican period, there was also a very important difference: under socialism, new culture was not to be based upon the theme of the 'individual' derived from Euro-American logics of human nature. That was a cultural imagination that had been proposed by the modernising Republican nation-state as the alternative to the long-persistent premodern Chinese family-clan ethics. By contrast to both the premodern and the individual cultural logics, Mao Zedong and the CCP promoted socialist education, thought reform, and mass culture and art in part, of course, to disseminate socialist ideology, but also as levers intended to dislodge the hugely dominant premodern Chinese cultural disposition towards hierarchical order, or that logic that formed the class and social status basis for the production of the ideology of obedient people or slavishness. In this regard, the most exemplary Maoist expression of class consciousness was: 'Where there is oppression, there is opposition.' The simplest expression of the Maoist theory of class struggle can be encapsulated in the saying: 'The teachings of Marxism ... in the end can be summed up in one phrase: it is right to rebel!'

\section{Culture of Socialism}

The culture of socialism of the 1950s, 1960s, and 1970s was simultaneously a culture of revolution and rebellion; it was a culture aimed at undermining the value judgements on superiority and inferiority, high and low, good and bad of traditional China. It was to become a class culture; in other words, it presented an opening to an equality of practice. The focus and dynamic plotting of socialist or historical materialist historiography took the centrality of peasant revolts against dynastic rule as its narrative centre, not the rise and fall of dynasties. It was within this historical contextual gambit that new Chinese culture attempted to instantiate the social, historical, and cultural subject of 'the people,' which was concretely anchored in the just-emerging social categories named by the trinity 'worker/peasant/soldier' (see also Guan's essay in the present volume).

Perhaps we could say that in the Mao era, one of the most prominent characteristics of the CCP's state-cultural practice was its leading promotion of the art and culture of workers, peasants, and soldiers. In this regard, many highly politicised sites functioned as mechanisms to nurture producers of 'mass culture.' These included various state institutions, factories and mines, villages and people's communes, military installations and others. All of these helped introduce new writers and artists to the cultural scene, thus fundamentally altering the class composition of culture producers as well as the class nature of the audiences for art and culture. At the same time, the relationship between audiences for and producers of art and culture also changed. This can be considered as a totalising attempt to create new culture as part of the project to simultaneously create the 'new person' and vice versa. 
And yet, we could also say that, within the context of a global political perspective that takes 1989 as the historical moment at which the socialist camp disintegrated and the international communist movement was completely defeated, the reforms initiated by the Party-state in the 1980s represent not only a political failure but, perhaps primarily and at the very least simultaneously, a cultural failure. The implosion of socialism-or maybe it was just defeated without a battle-is one piece of evidence for this proposition. If we for the moment bracket a discussion of the role of political economics in this 'grand failure;' if we bracket the fact that, internal to many socialist countries (including China), the task of building socialism was at the same time and foremost the task of realising modernisation within the context of the global capitalist system; if we bracket, as well, critical reflections on Leninist theories and practices of 'state and revolution;' then I believe a precipitator of the internal combustion of socialism and the socialist camp was a dynamic within socialism which cannot be encapsulated by its lack of actual economic development or its paucity in material life, but rather, more precisely, it can be understood through the gradually accumulated tension between a revolutionary party and the realities of governing, between revolutionary culture and the requirements of ruling. China in the Mao era, with its systemic social-cultural logic of revolution/ rebellion, oppression/resistance is particularly indicative of these tensions. On one side were the uniquely broad, continuously promoted social mobilisations-'the violent and tempestuous mass movements ${ }^{2}$ - whose logic of revolution/rebellion inserted itself deeply into the hearts of the people; and on another side was the anxious global situation of the Cold War, for which the process of modernisation and industrialisation was most urgent and because of which socialist countries implemented internal order, coerced obedience, direct political pressure, and all-around surveillance policies.

In the midst of all this, the paradoxical aspect of the articulation of the culture of socialism was in its preservation of revolutionary or communist ideals, which were then 'translated' or 'transplanted' into expressions of loyalty towards the Party (the revolutionary party? the ruling party?) and the state (the national state? the socialist state?). Revolution/rebellion/overthrowing of the old society and vanquishing the oppressor were all parts of a mainstream expressive value system as well as part of a personal or social promise about the future. This promise was soon closed off by a past that receded into history even as the promise was projected into a future imaginary and vision, which then was rendered into a unique kind of suspension of reality. Continuous calls for mass movements and the uninterrupted summons to social mobilisation facilitated the accumulation of the cataclysmic capacities of society (see also Li's essay in the present volume). In these processes, both intimate social organisation and harsh social supervision coexisted as a condition of social life itself. Such social capacities, on the one hand, could be turned to serve for the requirements of modernisation, industrialisation, and other experiments in economic construction. And yet, those processes also could not completely deplete or free up the amassing of social energy, thus inevitably leading to the extremity of social (cultural) tension. This situation perhaps helps explain how the Cultural Revolution could be 'launched' from 'top-to-bottom' and then, instantaneously, burst forth from 'bottom to top', thus making it very difficult to summarise the movement exclusively as a 'top to bottom' 
event. This can also perhaps help explain how in the first year of the Cultural Revolution the young student/red guard movement exploded onto the scene with two absurdly mismatched slogans: 'the right to rebel' and 'boundless loyalty.'

\section{Culture and Future Scholarship}

In short, in the 1950s and 1960s, there was a self-contradictory and paradoxical condition to political culture and political economics that, in the end, created a huge tension within socialist countries, tugging at them and finally causing them to implode. For this reason, to encapsulate the Cultural Revolution is, in reality, to encapsulate the terminus of the Mao era. Yet, ironically, the 1976 Tiananmen Square mass protest movement deployed the classic forms of socialist mass culture and art: a movement on the Square for popular poetry and singing. Meanwhile, the cultural form of clearing accounts for the Cultural Revolution was through 'scar literature,' along with a wave of publishing whose major constituents had themselves emerged from the mass art and literature movements animated by and through the advent of worker/peasant/soldier writers.

Of course, any further discussion of these topics would need to be more complex. It would, at minimum, require a consideration of the fierce debates among cultural producers about how capitalist-bourgeois culture functions as a potential force undermining the establishment of socialist culture, not to mention an exploration into the narrative form that requires collectivist action to be undertaken by individual heroes. Ultimately, such complexity would have to deal with an investigation into the contradictory relationship between the universals of historical materialism and the particularities of China.

Chinese socialist cultural experiments of the Mao era profoundly rewrote Chinese society and culture, as well as the psychological structures of the Chinese people and their social life. These revisions have created a unique inheritance for a still-evolving modern Chinese culture. Perhaps these legacies could yet open another path towards, or another entry into, an alternative society or an alternative cultural practice. 

8

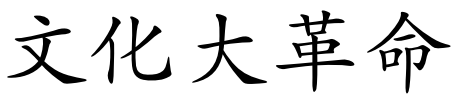

Cultural Revolution

Patricia M. THORNTON

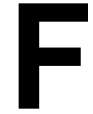

ew episodes in the history of the People's Republic of China (PRC) remain as politically sensitive as the Great Proletarian Cultural Revolution (wuchanjieji wenhua da geming, hereafter referred to as 'Cultural Revolution'). Its significance is so bitterly contested that only days before the Party's sixtieth anniversary in 1981, the Sixth Plenary Session of the Party's Eleventh Central Committee saw fit to adopt a lengthy and carefully worded resolution in hopes of sealing the book on the Cultural Revolution and Mao's role in it. To that end, the 1981 'Resolution on Certain Questions in the History of the Party since the Founding of the PRC' unequivocally declared the entire decade from 1966 to 1976 to be 'an extraordinary leftist error' initiated and led by Mao Zedong. As to his motives, the Resolution asserted that the Party Chairman had been 'labouring under a misapprehension' in his later years that propelled him into action that 'led to domestic turmoil and brought catastrophe to the Party, the state, and the whole people.'

This vehement denunciation was quickly followed by a thoroughgoing three-year campaign to not merely repudiate, but to 'totally negate' (chedi fouding) the Cultural Revolution as an aberration standing apart from, and outside of, the 'normal' course of PRC history. Individuals and collectives at every level of Chinese society were called upon to study the Resolution and related official documents, to engage in criticism and self-criticism, and, finally, to root out the 'three kinds of persons' (san zhong ren) in their workplaces and communities - those 'followers of Lin Biao and the Gang of Four, those seriously affected by factional ideas, and the "smashers and grabbers" of the Cultural Revolution.' The chief result of these strenuous collective efforts to obliterate the late Maoist past, as Alessandro Russo observed, produced 'an almost total intellectual block' that made it utterly impossible to comprehend the Cultural Revolution both inside and outside of China 'beyond the familiar "horrors of totalitarianism."'” 
But cultural revolution (wenhua geming) as a form of political practice has a history in the PRC that extends beyond the final decade of Mao's life. The term appeared frequently in Party documents and Party-run newspapers well before 1949 to denote the Party's core pedagogical mission, when the term was used interchangeably with 'cultural construction' (wenhua jianshe) to refer to the regime's efforts to eliminate illiteracy with the goal of widening political participation through reading, writing, and debating about matters of civic interest. Such references continued throughout the 1950s and mid-1960s, with the vast majority drawing parallels either between Party activists and the literati standard-bearers of the May Fourth Movement of 1919, or with the Soviet cultural revolution that had been carried out from 1928-31 under Stalin's leadership.

It was during the Great Leap Forward (1958-62) that cultural revolution emerged as a set of practices in the realm of mass politics. The previous decade of education work was roundly criticised for having neglected politics and the needs of ordinary workers, and a vast effort to eliminate illiteracy within five years was undertaken nationwide. Overtaken by the extreme deprivations of the Great Leap period, these efforts were largely abandoned and many reversed, along with the raft of equally ambitious plans for which the Great Leap is known. Yet it was this earlier project of mass empowerment through educational reform to which activists initially returned in May 1966, with Mao's support. Despite the tumultuous political upheavals of the late 1960s and 1970s, a series of grassroots experiments were nonetheless carried out in a strenuous attempt to recentre education work around the mass line (see Lin Chun's essay in the present volume), at every level of Chinese society.

Although cultural revolution has not disappeared entirely from contemporary Chinese discourse, it has been largely superseded and supplanted by 'cultural development' (wenhua fazhan), 'cultural creation' (wenhua chuangzao), and 'cultural construction' (wenhua jianshe). At the same time, the broader normative context within which the practice was undertaken has altered dramatically. Whereas cultural revolution during the Mao era aimed to transform illiterate workers and peasants into revolutionary political subjects capable of exercising the 'four great freedoms' (sida ziyou)—speaking out freely, airing views fully, holding great debates, and writing big character postersthe post-Mao project of cultural construction seems designed chiefly to refashion ordinary Chinese citizens into the compliant subjects and refined citizen-consumers of a consolidated and stable CCP-led regime. The abandonment of the term in postTiananmen Chinese political discourse represents another manifestation of how the post-Mao Party-state has successfully appropriated and transformed Mao-era methods of mobilisation in order to generate a new politics that disarticulates the Leninist power of the Party-state from a positive vision of the future based on revolutionary transformation.

\section{Culture Revolution before the Cultural Revolution}

In April 1933, following the collapse of the First United Front with the Nationalist Party, the CCP's provisional central government promulgated a set of guidelines on education policy. Party committees at all levels were enjoined to focus on cultural education, and on raising the class consciousness of workers and peasants so as to 
enable mass mobilisation and the deepening of class struggle throughout Chinese society. Cultural revolution, as it was envisaged by the early CCP leadership, entailed the dismantling of traditional Han Chinese cultural norms informed by Confucian paternalism that instilled obedience to authority. In a cultural context in which literacy had always been inextricably intertwined with political power, the project of mass education was inherently revolutionary, reversing long established patterns of authority in Han Chinese society. Grassroots Party committees at the district and township levels were tasked with designing and implementing anti-illiteracy campaigns to not only educate, but also to empower, ordinary Chinese workers and peasants by challenging traditional beliefs and assumptions. In January 1934, Mao reported that cultural revolution was successfully being carried out throughout the Communist-controlled revolutionary base areas as a key means of increasing the levels of popular mobilisation in revolutionary struggle. ${ }^{3}$

The initial appearance of the term in the People's Daily came in a 1947 editorial celebrating the May Fourth Movement of 1919 for having launched China's first cultural revolution. ${ }^{4}$ Within the span of a few months, this was followed by an article translated from Russian in which the author invoked the term cultural revolution to describe the transformation of education and leisure activities that attended collectivisation. Soviet peasants in the 1920s, the author asserted, 'began to live rich and cultured lives.' For the next several years, the People's Daily published several dozen articles each year either detailing the ongoing cultural revolution in China that was said to have begun with the May Fourth Movement, or extolling the Soviet socialist civilisational project as a model. In some cases the two themes were conjoined, as in a November 1957 editorial by Kang Sheng proposing that, following from the success of the May Fourth Movement, China's success in emulating the Soviet experience of cultural revolution depended in the first instance on the elimination of illiteracy as quickly as possible, and the cultivation of intellectuals from within the ranks of the proletariat. ${ }^{6}$ The concept, if not the actualised practice, of cultural revolution would therefore have been abundantly familiar to the readers of the People's Daily during the period of the first Five-year Plan (1952-57).

Yet, as the decade of the 1950s came to a close, the concept of cultural revolution underwent a significant shift. In his 27 February 1957 speech 'On the Correct Handling of Contradictions among the People,' Mao made two assertions important to the practice of cultural revolution moving forward. The first was that although the ideological struggle between the forces supporting socialism and those supporting capitalism would persist in China for some time, the use of 'crude coercion' to resolve such struggles would be counterproductive: it was only through 'the method of discussion, criticism, and reasoning that we can really foster correct ideas and overcome wrong ones' (see also Rojas's essay in the present volume). The second was that, in the handling of contradictions among the people, ideological and political work must be strengthened sufficiently to support the CCP's policy of educating the labouring classes within the context of both socialist consciousness and culture, so that they would be empowered to participate in that struggle in the ideological field. Both dictums quickly came to inform the Party's work of carrying out cultural revolution, which began to diverge from both past practice and the Soviet model. At a national conference convened by the Education Ministry in March and April 1958, specific 
guidelines for carrying out cultural revolution were drawn up, which included five 'great tasks:' a sweeping nationwide literacy campaign, an expansion of elementary education, the establishment of agricultural middle schools, improvement of teacher training, and a complete overhaul of the educational system to meet the needs of socialist construction. The outline determined that, moving forward, a fundamental aim of all schools would be to demolish capitalism and establish socialism while relying on the Party's leadership and following the mass line. ${ }^{7}$

One month later, at the Second Plenum of the Eighth Party Congress in May 1958, Liu Shaoqi asserted that in carrying out the simultaneous development of political, economic, and thought 'lines' in accordance with implementing socialist revolution, it was also essential to further advance a technological revolution alongside a revolution in culture. Several days later, on 9 June, the People's Daily announced 'the cultural revolution has begun,' and proclaimed that 'cultural revolution is a movement to totally transform the culture of all labouring people. ${ }^{8}$ The movement immediately shifted into high gear.

The familiar rallying cries of the Great Leap Forward included ambitious plans to not only boost both agricultural and industrial production to the extent that China would be able to catch up with Great Britain in five years, but also make equally impressive gains in the areas of education, cultural production, and the technological and scientific enskilment, particularly for workers and peasants (see Callahan's essay in the present volume). In preparation for the nationwide literacy drive, in February 1958, the National People's Congress promulgated the 'Scheme for the Chinese Phonetic Alphabetic System,' thereby reorienting the national curriculum around the use of pinyin to facilitate basic literacy. A few months later, with the Great Leap's production drive underway, groups of university students and teachers, as well as literate cadres and employees of state bureaucracies, were organised into anti-illiteracy teams and dispatched to the countryside. The teams organised intensive adult literacy and cultural enrichment classes, often directly in the fields, in order to take maximum advantage of the brief rest and meal periods taken by commune members. Communes in Guangdong's Yangjiang county pioneered a 'four cultures goes to the fields' effort that involved leading peasants in singing and acting, playing musical instruments, singing folk tunes and mountain ballads, and taking books and newspapers into the fields where they were tending crops. ${ }^{9}$ Guangdong's model Lechang county organised an all-out effort to saturate the lives of county residents with printed texts. Transcripts of morning radio broadcasts were affixed to bulletin boards alongside newspapers, and in two of the market towns in the county, anti-illiteracy activists patrolled the markets to make certain that signs were affixed to all items of produce for sale, and that all sellers produced written bills of goods, so that consumers could familiarise themselves with the characters for items of produce that they normally consumed. ${ }^{10}$

Beyond remaking ordinary workers and peasants into literate subjects, the movement further aimed to transform them into politically active and engaged agents capable of sustaining democratic and participatory politics at the social grassroots. In August 1958, the Guangzhou Municipal Party Committee insisted that, once workers and peasants had attained basic literacy skills, they apply them in the exercise of their 'four great freedoms' in order to inspire mass enthusiasm, as well as to help 'everyone understand the responsibility of each individual during cultural revolution, so that all are happy to 
teach and ready to learn.' ${ }^{11}$ In July 1958, the Southern Daily reported that Guangdong's Xifu commune had become known as a 'big character poster village' because the community had taken to resolving its social conflicts through the composing and public posting of literally thousands of handwritten texts. ${ }^{12}$ In addition, the formation of civic associations and social organisations that would enliven exchange and debate was encouraged. For example, in 1959, the Guangzhou municipal Culture Department called for an associational revolution to enrich worker's lives beyond the confines of the factory floor. The Culture Department subsequently reported a five-fold increase in the number of clubs established over the previous year-a total of 2,885 opera clubs, singing groups, dance troupes, and intellectual salons had formed in Guangzhou in 1958, and the Department anticipated that the number might increase five-fold again before the end of $1959 .{ }^{13}$

\section{The Great Proletarian Cultural Revolution}

This burst of grassroots activity was relatively short-lived: as the disastrous economic consequences of the Great Leap programme set in, cadres at all levels refocussed their attention and resources on the more pressing goal of economic recovery. At China's elite universities, the Great Leap educational reforms had involved efforts to increase student and staff participation in administrative decision-making, to favor students from worker-peasant-soldier backgrounds in the admissions process, and to strengthen the role of the Party and politics in schools (see also Schmalzer's essay in the present volume). However, beginning in 1961, universities began rolling back these efforts. Political viewpoint and class background were downplayed, both in university admissions and in faculty hiring and promotion, and the Great Leap's egalitarian aims were replaced with meritocratic policies. Beneficiaries and supporters of the Great Leap reforms were sidelined; despite their bitter disappointment, many of them continued to agitate for the reinstatement of the Great Leap's educational reforms on university campuses across the country. ${ }^{14}$

These left-leaning students and young lecturers, many of whom had participated in and benefited from the 'education revolution' (jiaoyu geming) of the Great Leap Forward, welcomed the first salvos of the Great Proletarian Cultural Revolution. The 16 May Notification issued by the Party Central Committee called once again to 'open wide' (fang) a process of radical educational reform that would allow 'all people [to] express their opinions freely, so that they dare to speak, dare to criticise, and dare to debate.' ${ }^{15}$ Familiar themes and slogans raised during the Great Leap returned: there were calls to revolutionise both the content and delivery of education, allow the formation of new groups at the social grassroots, and the waging of great debates and public discussions, often through the vehicle of the big character poster. Yet, the locus of power quickly shifted away from the orderly mobilisation of social forces by the Party in 1958 to a complete usurpation of that leading role and agenda by self-proclaimed rebel activists only eight years later. The driver behind this change was Mao himself. In 1961-62, in his reading notes on the Soviet text Political Economy, Mao noted the stubborn persistence of 'conservative strata' and 'something like vested interest groups' in socialist society-groups that had benefitted from certain institutions and would therefore resist alterations to existing arrangements. ${ }^{16}$ By 1966, Mao had determined that these 
forces formed 'a bunch of counterrevolutionary revisionists' that had 'sneaked into the Party, the government, the army, and various cultural circles,' and called for them to be criticised, repudiated, and expelled; the Party's Central Committee acquiesced, and the call went out to the grassroots to allow 'all people express their opinions freely', and for all to dare to speak, criticise, and debate, and hopefully to expose the revisionists from within their midst. ${ }^{17}$

Unsurprisingly, many of the initial targets in May and June 1966 were the so-called 'bourgeois academic' and cultural authorities that were seen to have reversed the ambitious initiatives introduced during the Great Leap. The forms in which those criticisms were delivered followed the patterns of the earlier cultural revolution, including the rapid formation of grassroots associations, the staging of vast public debates in public squares and auditoriums, and the reappearance of big character posters to criticise ideological opponents. The critical difference, of course, was that in 1966 the Party had moved from the instigator of cultural revolution to one of its chief targets, firmly in the crosshairs of the revolutionary masses.

One brief but illustrative measure of how thoroughly the practice of making cultural revolution shifted out of the hands of the Party-state in 1966 is the number of official and unofficial publications during this period. In the mid-1960s, the number of official newspapers in publication fell from 343 in 1966 to 43 in 1967; the number of official journals likewise declined from 191 to a mere 27. At the same time, however, there was an explosion of new mass media produced by independent mass organisations: between 1966 and 1969, at least 5,000 new self-published broadsheets sprang into existence to disseminate news and the political views of various grassroots groups not managed by the normal channels of Party-state control. ${ }^{18}$ Mass associations likewise flourished: although many Party-state offices and organisations had suspended their operations by early 1967, independent mass organisations of every shade and stripe flourished at the grassroots, including not only the grassroots Red Guard and rebel student groups, but also spontaneously formed poor peasant associations, workers' pickets, and Mao Zedong Thought study societies, to name a few. Enjoined by Party leaders to 'join up, over time these myriad groups pledged their allegiance to various coalitions, dispatched delegates to meetings and assemblies, and participated in congresses organised at superordinate levels in a fevered flurry of associational activity.

Despite the tumultuous political struggles that subsequently came to define the Great Proletarian Cultural Revolution, elements of the earlier pedagogical project endured not only in the form of the 'worker-peasant-soldier universities' (gongnongbin daxue) and the 'workers propaganda teams' (gongxuandui) of the 1970s (see also Russo's essay in the present volume), but also perhaps most significantly in the vast rustication campaign that dispatched 17 million urban Chinese youths into the countryside to be reeducated (zai jiaoyu) by the poor and lower-middle peasants beginning in 1968 . Reversing the pattern of the 1958 cultural revolution in which teams of students and teachers brought literacy and cultural enrichment to workers and the peasantry, the purpose of the rustication campaign was instead to teach urban youths 'proletarian virtues,' instilling in them a love of hard labour and a Spartan way of life, and an interest in politics and class struggle-in short, to transform them into 'peasants with a socialist consciousness and culture.' Most would stay in the countryside for more than a decade. ${ }^{19}$ 


\section{From Cultural Revolution to Cultural Construction}

How are we to understand the transition from the sweeping upsurge from the social grassroots in 1966 to the Party-controlled modes of cultural governance that we see today? Interestingly, references to the practice of cultural revolution in official media did not cease with Mao's death, nor even with the consolidation of Deng Xiaoping's control over the Party-state in 1978. Instead, references to the practice of cultural revolution appear in official media throughout the 1980s, albeit with far less frequency than during previous decades. This trend is even more salient after the suppression of the 1989 protests, when the term 'cultural revolution' in the sense of an ongoing process or practice all but disappears from official discourse in favor of more robustly managerial terms like 'cultural development,' 'cultural creation,' and 'cultural construction.' As Wang Hui has suggested, the suppression of the mass protest in 1989 can perhaps best be understood as the end of the political sequence that began with the 'Asian Sixties' in the PRC-a period during which people's movements across Asia challenged the Cold War and the Western-dominated capitalist world order. ${ }^{20}$ The closing off of the sequence and its more radical possibilities with the brutal suppression of the 1989 demonstrations in Beijing's Tiananmen Square and across China announced the inauguration of a new cycle characterised by a 'depoliticised or anti-political political ideology' that enervates popular political participation and forms of mass activism. The transition from mass practices and discourses of cultural revolution to the Party-managed processes of 'cultural construction' mirrors the Party's own transformation from a revolutionary to an administrative party that is absorbed into the state apparatus.

The intent of the post-Mao Party-state's project of cultural construction is detailed in the China Youth Daily Ideology and Theory Department's pivotal 1992 manifesto, 'Realistic Responses and Strategic Options for China after the Soviet Upheaval,' which laid the responsibility of creating 'a brand new, sufficiently ecumenical culture resting on Chinese traditional culture' in the hands of the Party. ${ }^{21}$ This signal document, composed by high-ranking and influential Party technocrats in the wake of the Tiananmen crisis, urged central Party strategists to regard 'creative transformation of traditional Chinese culture [as] a rich spiritual resource for safeguarding the socialist system, protecting the interests of the state and nation, and promoting the cause of modernisation.'

Historically, one chief resource of the Mao-era Party-state was its considerable power to mobilise mass participation and enlist the resources and energies of social forces to achieve ideological and practical ends. Yet in its transition from a revolutionary to a ruling party, the $\mathrm{CCP}$ has replaced Mao-era practices of cultural transformation with a broader depoliticising project of cultural governance driven by the legitimation and perpetuation of the existing state system. ${ }^{22}$ Whereas the mass mobilisations that took place under the banner of revolutionising culture during the Mao era aimed to enlist the power and creativity of the masses in the building of a revolutionary new socialist order, post-Mao efforts at cultural construction aim to maintain and consolidate the power of the contemporary Party-state, rather than to develop direct democratic and mass participatory politics. 

9

\section{大同， \\ Datong and Xiaokang}

Craig A. SMITH

$\mathrm{n}$ his epic three-hour-long speech to open the Nineteenth Party Congress on 18 October 2017, Xi Jinping emphasised the establishment of a comprehensive xiaokang shehui-which official translators rendered as 'moderately prosperous society' - as the first of four strategies for the 'new era of socialism with Chinese characteristics.' ${ }^{1}$ He repeated the term xiaokang shehui 18 times during this exceptionally long speech, making it a goal for his tenure and almost synonymous with the rise of China. Still, the concept has been in use throughout China's reform period and much earlier, as intellectuals have repeatedly raised it as a future step on the country's path to utopia.

Xiaokang and its close relative datong are distinctly Chinese terms that successive generations of intellectuals have adapted from classical Confucian discourse to fit Marxist and, subsequently, Maoist and post-Maoist teleologies. This adoption plays a role in Party-state legitimacy by forging a continuity between past Chinese traditions and a future Chinese utopia. Emphasis on the establishment of a xiaokang society highlights the success of the Chinese Communist Party (CCP) in leading China along a path that is distinctively Chinese. Although the terms have a long history in Confucian texts, intellectuals returned to and developed the concepts in the twentieth century, opening them up for adaption to define today's China. Ubiquitous in current Party rhetoric, due to their long-standing role in Chinese intellectual thought, xiaokang and datong convey messages about the role and authority of the CCP that go far beyond their classical meanings.

\section{Classical Usages}

Xiaokang and datong most famously appear in the 'Li Yun' chapter of the Book of Rites, one of the Confucian classics compiled in the Han Dynasty. As one of the most admired sections of one of the most popular books in history, the 'Li Yun' has received 
regular attention for close to 2,000 years. The concepts have managed to maintain much of their original meaning as stages on the path to utopia, yet their adoption into the contexts of modern ideologies has created new implications.

The second and third paragraphs of the 'Li Yun' describe the periods of datong and xiaokang, and are the key to their modern influence. The opening line of the section on datong indicates its importance: 'When the great way was followed, all under heaven was for the common good' (dadao zhi xing ye, tianxia weigong). The spirit of the clause is unmistakably egalitarian, as is the entire passage, but the ambiguous nature of the text allows for considerable variation in interpretation. The ' $\mathrm{Li}$ Yun' described the utopia of datong as a past world which had no borders, no crime, no waste, no need to adhere to the classical relationships, and no unnecessary suffering. It was a world in which all felt safe, secure, and provided for. Modern Chinese intellectuals interpreted tianxia weigong, or 'the world is for all', as an indication that the age of datong was a world without private possessions. ${ }^{2}$ This was an effort to draw upon the authority of a classical text to legitimise a political programme, but it was not removed from the context of the terminology.

Xiaokang was more complicated to appropriate into modern usage. It was a world in which 'all under heaven is for [private] families' (tianxia weijia). The text also explained that, unlike in the age of datong - a meritocracy in which those most worthy were appointed as officials-in a xiaokang society families maintained monopolies over government posts and, thereby, over wealth. The age of xiaokang was, however, only inferior when compared to the age of datong. Ritual and principle, walls and moats, as well as the five relationships, were necessary to maintain order and harmony in such a time, but nevertheless it was a period of relative peace. It is the comparison between datong and xiaokang that is important for our reading of the ' $\mathrm{Li}$ Yun' and for understanding the usage of the two concepts in modern China.

In translation, the terms have a number of iterations, indicating their complexity, but also revealing the assumptions and politics of the translators in their understandings of Confucian thought. James Legge's 1885 translation of the Confucian classics as part of The Sacred Books of China has had the greatest influence as a reference for later generations of translators. However, his rendering of datong and xiaokang respectively as 'the grand union' and the 'small tranquillity' has not been passed down. 'Grand unity' has come closer to being a standardised translation for datong, and remains in use.

In French, Séraphin Couvreur (1835-1919) offered a more comprehensive translation of datong as 'the grand union of universal brotherhood' (la grande union ou la fraternité universelle), but chose a judgement-laden translation of xiaokang as the imperfect tranquillity' (tranquillité imparfaite). ${ }^{4}$ This is not very different from the translation as 'lesser prosperity' favoured by Theodore de Bary in his recent renditions. ${ }^{5}$ Translating these passages in the twentieth century, it was difficult to avoid connecting the classical concepts to modern political theories of capitalism and communism. The passages lent themselves well to the politics of the time, and were crucial conceptual resources for Chinese intellectuals during that time. 


\section{The Return to Datong in Modern China}

The term datong gained new significance in the twentieth century, largely through the efforts of the extremely influential reformer and intellectual Kang Youwei. Kang reconceptualised Confucianism from a religious perspective, emphasising ren'benevolence' or 'love'-as the basis upon which to build civilisation. He saw datong as the ultimate realisation of ren. ${ }^{6}$

In The Great Unity (datong shu), Kang discussed the future datong as a utopia in which states will no longer exist; families will be completely different, as men and women will be equal and same sex marriage will be accepted; robotic birds will take the place of servants; and animals will be treated well by a world of vegetarians. Although often full of radical compassion in a way unlike other literature of his contemporaries, Kang and his book were products of their time, and included terrifying prescriptions for the elimination of the black race through a centuries-long programme of eugenics. Kang's utopia was both highly imaginative and deeply troubling.

However, although Kang was responsible for the reemergence of the terms datong and, to some extent, xiaokang in modern Chinese intellectual discourse, the concepts were larger than Kang and exceeded his own definitions of them. With the rise of communism and materialist understandings of social evolution, intellectuals preferred to see class consciousness and social change as dictated by selfishness, rather than benevolence (ren).

Although disagreeing with many of his core assumptions and conclusions, Mao appreciated Kang Youwei's vision and referenced it in his speeches and writings. In his 1949 essay 'On the People's Democratic Dictatorship', Mao explained: 'Kang Youwei wrote The Great Unity, but he did not, nor would he be able to, find a way of achieving datong. The republican states of the capitalist classes are found in foreign countries, but China could not have such a state because the country was oppressed by imperialism. The only way [to datong] is through the People's Republic led by the working class.'

The appropriation of Kang's Confucian views to a modern Chinese teleology did not happen quickly. Despite Mao's occasional use of the terms, datong and xiaokang were not key elements in early Maoism, and only became ubiquitous during the reform period that began with the rise of Deng Xiaoping after the Cultural Revolution.

Since then, Party elites have regularly invoked the terms to frame China's progress through the lens of a specific historical and economic period. The prosperity associated with xiaokang was identified as a goal through the Four Modernisations (si ge xiandaihua), the defining thought of the Deng Xiaoping period, beginning in the late 1970s. Discussing China's modernisation with Japanese Prime Minister Masayoshi Ōhira in 1979, Deng utilised the concept of xiaokang to differentiate the Chinese path of development: 'The Four Modernisations that we hope to realise are a Chinese Four Modernisations. Our conceptualisation of the Four Modernisations is not like your conceptualisation of modernisation, but is a xiaokang family (xiaokang zhi jia).'7 Although vague, this rhetoric was important as it allowed Deng to discuss capitalist modernisation while avoiding capitalist discourse, a defining moment in neoliberalism. From this moment, xiaokang became an essential part of 'socialism with Chinese characteristics.' 
At the Sixteenth Party Congress, held in 2002, Jiang Zemin announced that 'comprehensive xiaokang' (quanmian xiaokang) would be achieved by 2020 -a promise strongly reasserted by $\mathrm{Hu}$ Jintao in his speeches at the Seventeenth and Eighteenth Party Congresses in 2007 and 2012. ${ }^{8}$ This goal later became a key part of Xi Jinping Thought, definitively established at the Nineteenth Party Congress in 2017, as he has repeatedly declared a 'decisive victory in attaining comprehensive xiaokang society' as the objective for his next five years in power. Looking back through these speeches, the rise of xiaokang is striking, but its role in rhetoric outweighs the importance of its content. Alongside terms such as modernisation, marketisation, and development, Wang Hui points to the popular usage of quanmian xiaokang as an example of the depoliticisation of politics in contemporary China due to the careful avoidance of discourse related to the modern political ideologies of capitalism or communism. ${ }^{9}$

\section{An Epitome of Chineseness}

The rise of xiaokang and datong as key concepts for the CCP embodies discursive, practical, and theoretical messaging that the CCP is communicating to its domestic audience. Respectively, these messages indicate that the Party is the epitome of Chineseness; that the current priority of the Party is to address inequality; and that the Party still aspires to communist ideals, polished and sundered from the turbulent politics of the Mao era.

Discursively, the use of classical concepts indicates that China's modernisation and path through history is unique to China. The nature of this uniqueness is left unclear, but the use of a China-specific terminology is crucially supportive of the nationalist discourse and of the idea of a 'socialism with Chinese characteristics,' notions from which the Party derives much of its authority. This discourse signals that Western institutions, definitions, and practices cannot be imported into China because they will fail to take root in Chinese conditions.

Secondly, China's current affluence is a notable achievement, but it must spread to all people in all walks of life, eliminating poverty by 2020. This is what is indicated by quanmian xiaokang, and denotes the Party's resolve to significantly reduce the inequality that has increasingly plagued the country in recent decades.

Finally, xiaokang reveals the position of China on the route to the utopia of datong. Xiaokang is an imperfect society, troubled by inequality, selfishness, and a lack of public spirit, but defined by a moderate prosperity in which all are adequately provided for. The theoretically identifying feature of xiaokang, however, is its penultimate nature and subordination to datong, revealing the communist utopia as the ideal still animating Party leadership.

English-language readers of Xi Jinping's speech at the Nineteenth Party Congress may have been confused by his repeated emphasis on a 'moderately prosperous society', but for Chinese speakers the concept conveyed fundamental messages about the Party's role and authority in the twenty-first century. 


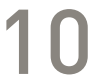

\section{辩证唯物主义 \\ Dialectical Materialism}

PANG Laikwan

$\mathbf{W}$

hile the teaching of 'dialectical materialism' (bianzheng weiwuzhuyi) is part of secondary and university curricula in the People's Republic of China (PRC), young Chinese citizens probably consider it a hackneyed, dogmatic, and fussy logic. After all, their job is simply to mechanically recite official definitions and methods instead of engaging intellectually with them. From this point of view, the ossification of the term indirectly demonstrates how Chinese communism is deprived of an afterlife in China. In this essay, I will put dialectical materialism into a historical context and explore how this once very powerful concept has degenerated into such a cliché. More importantly, I will investigate how this concept might still be productive for our current political understanding.

\section{A Brief Genealogy of Dialectics}

Dialectics as a Western philosophical concept can be traced back to ancient Greece, where good citizenship and social relations were grounded in dialogue, from which agreements and disagreements arose. The idea of dialectics gained a new life in the nineteenth century thanks to Hegel, whose dialectics of Aufhebung (sublation) describes how oppositional elements, in the forms of thesis and antithesis, engage in struggle with each other and then synthesise into a whole that in turn becomes a new thesis from which another Hegelian triad forms. Hegel believed that continual dialectical development leads ultimately to the fulfilment of absolute spirit. In his opinion, it was this 'becoming' that allows us to transform ourselves in order to reach the ultimate ideal.

Hegelian theory was then borrowed and challenged by Marx, who developed his own theory of dialectical materialism. In Marx's theorisation, until we reach a classless society, each intermediate historical stage entails the exploitation of the lower classes 
by the dominant one, a situation that motivates the former to struggle against the latter. Bourgeois capitalism is exemplary of this kind of dynamic: while the bourgeoisie needs to exploit the proletariat for its own capital accumulation, at the same time it also supplies proletarians with some education, such as general working and organisational skills, to facilitate their participation and integration in the production process. In the end, however, education enhances the political consciousness and skills of the workers, making them more likely to ultimately overthrow the dominating class. To quote the famous words of the Manifesto of the Communist Party: 'What the bourgeoisie, therefore, produces, above all, is its own gravediggers. Its fall and the victory of the proletariat are equally inevitable.' ${ }^{\prime}$ This famous statement implies that history progresses according to its own laws, which cannot be altered by anyone, no matter how powerful.

Engels further elaborated this Marxist historical view by referring to the natural sciences. ${ }^{2}$ He came up with three laws of dialectics. The first is the law of the unity and struggle of opposites, according to which opposites condition each other. The second is the law of the passage from quantitative to qualitative change, referring to the qualitative change of physical phenomena triggered by enough intensity of quantitative changes. The third is the law of the negation of the negation, which poses the controversial question of whether a negation, which still retains traces of what it negated, itself requires negation for the radically new to emerge. ${ }^{3}$ Together these laws, supposedly supported by physical and biological sciences, not only define class struggle as the engine of history, but also illustrate the universal manifestation and development of all matters.

One detrimental effect of Engel's overemphasis on the scientific dimension of Marxism is that it turns the original theory of history, which featured an important role for humanity, into one deprived of human inputs. It was when Marxism took on the halo of science that it came to claim a totalising understanding of human history. Via the combined efforts of many intermediate thinkers and the various Leninist parties of the 1920s and 1930s, Engel's laws of dialectics gradually evolved into the orthodox doctrine of dialectical materialism in the Soviet Union. ${ }^{4}$ Through Soviet-trained revolutionaries, this doctrine of linear evolutionary historical progress was then exported all over the world, including China, as a theoretical resource for legitimising the allegedly inevitable communist revolutions in other countries. The mechanical understanding of dialectical materialism being taught in the PRC over the last half century was also a result.

The notion of 'historical materialism' - which has largely been seen as interchangeable with dialectical materialism - came into being in this same historical context. It is clear that Marx developed a materialist conception of history, but he never separated society from nature. Engels deliberately provided Marxism with the additional non-humanistic dimension of natural sciences, implicitly arguing for the superiority of the studies of sciences to the studies of history. Stalin integrated this reading into official discourse. In 1938, in Dialectical and Historical Materialism, he wrote that the studies of nature and society should be clearly differentiated to become two Marxist doctrines:

Dialectical materialism is the world outlook of the Marxist-Leninist party. It is called dialectical materialism because its approach to the phenomena of nature, its method of studying and apprehending them, is dialectical, while its interpretation of the phenomena of nature, its conception of 
these phenomena, its theory, is materialistic. Historical materialism is the extension of the principles of dialectical materialism to the study of social life, an application of the principles of dialectical materialism to the phenomena of the life of society, to the study of society and of its history. ${ }^{5}$

According to this authoritative definition, dialectical materialism is the basic Marxist doctrine that should be used to understand nature-i.e., everything-while historical materialism is a branch of dialectical materialism devoted specifically to the study of human society and its history. This genealogy of the term is important for us to understand the specificity of Maoist dialectics.

\section{Maoist Dialectics}

Based on the state-commissioned work of the Chinese Marxist thinker Ai Siqi, since the 1960s most Chinese Marxist theorists have adopted the Stalinist differentiation, considering dialectical materialism as a term that encompasses all kinds of science, and historical materialism (lishi weiwuzhuyi) as specifically designated for the studies of human history. ${ }^{6}$ However, Mao Zedong, although being much more interested in history and the humanities than natural science, mostly used the term dialectical materialism. What I would like to emphasise here is that Mao's fascination with human history made his dialectical materialism a doctrine much less rigid and contained than Stalinism. If there is a legacy of Maoism which might still be useful for our current political actions, I believe it is his sensibility regarding the unpredictable nature of history.

Mao's historicism is heavily marked by a deep conviction that the wilful human subject can change history. The major structure of Mao's dialectical materialism is precisely the struggle between humans and history. The Maoist subject is 'poor and blank' (yiqiong erbai), and history is the stage on which he or she struggles. Mao announced:
Apart from their other characteristics, the outstanding thing about China's 600 million people is that they are 'poor and blank.' This may seem a bad thing, but in reality it is a good thing. Poverty gives rise to the desire for changes, the desire for action, and the desire for revolution. On a blank sheet of paper free from any mark, the freshest and most beautiful characters can be written; the freshest and most beautiful pictures can be painted. ${ }^{7}$

To Mao, it is the poverty and blankness of the Chinese people that allows them to engage in the most spectacular historical upheavals. ${ }^{8}$ Being 'poor and blank' and deprived of all identity tags, the Maoist subject becomes an empty vehicle ready to be invested with revolutionary will, so that he or she can engage in the most ferocious struggles and bring seemingly impossible historical transformation to fruition. We can understand this rhetoric as one particularly constructed for the Great Leap Forward, which therefore is highly historically confined. But we can also approach this Maoist subject theoretically as the one who performs the negation, instead of allowing negations to be performed on him- or herself. This Maoist hero is not invincible, and under Mao's dialectical materialism there is a subtle fatalism. People do not act on 
history unidirectionally, but rather engage in a dialectical struggle with it. Dialectical materialism did not provide Mao with a clear historical direction. Instead, it enlightened him to the exact opposite, so that it was the courage and the will of the people against an uncertain future that made them so heroic.

In the 1930s, when Mao's basic philosophical worldview was already formed, he clearly identified himself as a student of the orthodox Marxism developed in the Soviet Union. As he admitted to Edgar Snow, his famous 1937 lectures on 'On Contradiction' and 'On Practice' were written in response to a request from the Anti-Japanese Military and Political College in Yan'an for philosophy lectures for its students. Still, while written on commission, these lectures show that besides being interested in orthodox Soviet theories, Mao was also most invested in two notions: contradiction (maodun) and practice (shijian) (see the essays by Rojas and Aminda Smith in the present volume). In both lectures, Mao works out the core dialectical mechanism of his understanding of dialectical materialism: 'dialectical' as historical laws and 'materialism' as human practices. He made clear that it is the constant arising and resolution of contradictions that make up historical forces, and that there is undoubtedly a universal law, which is the continuous confrontation of opposing forces. However, according to him, it is impossible to predict what these antagonistic clashes will lead to, because historical reality is built up through a myriad of human practices, and is therefore unstable. What we can do is to learn from history how contradictions have formed, developed, and transformed. While we cannot predict the future, these historical patterns can still guide our future action.

Reading history was one of Mao's most devoted pastimes. He studied not only all the major historical Chinese texts, but also a variety of alternative histories, historical novels, family histories, and local gazettes. Mao was particularly interested in understanding the circumstances and fates of historical figures, and he frequently referred to historical details in his political speeches, poetic expressions, and everyday conversations. It could be argued that Mao was drawn to the dialectic because he already believed in constant transformation. The mechanical teleological view of the progression from feudal to bourgeois capitalism and then socialism is seldom mentioned in Mao's writing. Instead, he displayed more interest in the struggles of the people, whether these might or might not lead to a better future.

\section{A Distaste for Grand Narratives}

Being so captivated by history, Mao disliked any grand narrative. He frequently asserted that no 'theory' (lilun) can really explain history. The universal law, in other words, is only a form within which practice and knowledge interact, but it does not tell us where history goes. In his lecture on dialectical materialism, which is considered to be the blueprint for his two lectures on contradiction and practice, Mao emphasises that the universe is open, so that there is no end to history. ${ }^{9}$ Similarly, he never conceptualises an end to the revolution, and instead insists that revolution must be continually carried out in order to keep the power structure open. ${ }^{10}$ With so much emphasis on 'practices', Mao's history can only be an unfinished one. Mao's unyielding confidence in the human spirit rests on an awareness of the ruthlessness of historical forces. In his 'Reading Notes on the Soviet Union's "Political Economics," Mao openly 
criticises Soviet Marxist orthodoxy for focussing too much on historical laws, and Soviet textbooks for always '[starting] from laws, tenets and definitions, an approach which has all along been opposed by Marxism.'11 Instead, he argues that one must perform empirical analysis before principles and tenets can be discovered and verified.

In Western liberal societies and postsocialist countries alike, the rigidity of the concept of dialectical materialism describing historical progression as governed by universal laws has attracted many criticisms. A new generation of leftist critics, particularly those from the Frankfurt School, has challenged the teleological dimension of Marxist dialectics, claiming that such universalisation prevents us from seeing history as open and contingent. For example, Adorno has argued that the ideal formulated by Hegel can only be conceptualised retrospectively, when changes have already happened. Any attempt to theorise a universal without acknowledging particulars as unpredictable is naïve. ${ }^{12}$ At the same time, dialectical materialism as a philosophical concept continues to be discussed and explored among sympathetic critics, allowing the idea to gain new lives. ${ }^{13}$ In contrast, this has not happened in China yet, because the ruling Communist Party continues to see this doctrine as a part of its founding myth, and therefore considers any serious questioning and revamping of it to be a challenge to its ruling authority.

For this reason, one of the few available ways to reconsider the heritage of Marxism and socialism in China is to revisit Mao's understanding of history. This is not, once again, to turn Mao into a cult, but rather to critically-and strategically-engage with his struggles with, on the one hand, the imported Soviet orthodox, and on the other, the petrification of a Party corrupted by power. ${ }^{14}$ This might help us face the more insecure and authoritative Chinese Communist Party of our time. By deliberately adding physical and biological sciences to Marxism to reinforce its universal application, and by further separating dialectical materialism and historical materialism, Engels and Stalin transformed Marxism into an orthodoxy in which the current Chinese government is still deeply entrenched. Mao, instead, rescued the political dimensions of Marxism, encouraging us to be ready to face, build, and eventually be defeated by an open future. 



\section{1 \\ 主人翁 \\ Dignity of Labour}

WANG Ban

n socialist China, working people did not view their jobs as merely a means of making a living. A job meant an honourable vocation, and workers were endowed with dignity. In the 1920s, socialist thinkers Li Dazhao and Cai Yuanpei proclaimed that labour was sacred, because the working class would take control of their destiny in forging a society free from exploitation and oppression. But a look at the working conditions in China today will convince anyone that labour has fallen from grace to become a curse and a nightmare. Jia Zhangke's film A Touch of Sin (2013) offers a vignette of labour in the hellhole of a Foxconn factory. Rows and rows of workers bend over the task of assembling iPhones and submit to repetitious movement for long hours. The employees hardly have any breaks, communication, or social life. Living in a dormitory like a labour camp, roommates do not get to see each other as they work different shifts. Vibrating with jarring electronic sounds, the whole factory seems to be a huge device swallowing up workers-body and soul. This dystopia explains the despair of young workers, who jump, one after another, from the building to their death (see Pozzana's essay in the present volume). By contrast, in the socialist past, films often depicted factory workers taking pride in their work and being committed to their community. But in Zhang Meng's postsocialist film The Piano in a Factory (2010), the proud workers of a socialist steel plant disperse after the factory is shut down, scraping out a miserable living by performing in a gig band, or by trafficking or peddling.

\section{The Dream of Non-alienated Labour}

Although literary and film works depict the new wretched of China's contemporary industrial wasteland, it is difficult to find outrage or outcry. Critics and workers seem to be resigned to dehumanising labour as the norm of capitalist production. I think this resignation stems from the lack of an alternative vision, and from the forgetfulness about 
the veneration of labour in socialist China. In her fieldwork on the industrial rustbelt of northeast China, Ching Kwan Lee compares today's labourers with the working class in the past. ${ }^{1}$ The workers interviewed recall, in protest and anger against today's precarious conditions, their fond memories of socialist labour. Regarded as the leading class, factory workers enjoyed job security, relatively equal income, medical care, and a pension. Working together to solve concrete technical problems in collective projects, they developed comradeship and solidarity. The workers were equal with technicians and managers, and participated enthusiastically in work processes. Everybody was eager to contribute wisdom, experience, and energy. Equality and participation meant the sharing of power and fostered pride in being masters of the new society. Most importantly, the workers were able to see the purpose and meaning of their work. They were passionate in the belief that they were creating a new economic and social order in which individuals would thrive with all others. It is this type of meaningfulness that has the potential to give labour beauty and dignity.

Working with a purpose is distinct from alienated labour. It is not just work to feed oneself, and the fruits of this labour do not result in profits for capitalists. We can take a page from Edgar Snow's Red Star Over China to see the glimmers of what labour could be under revolutionary conditions. ${ }^{2}$ In a chapter entitled 'They Sing Too Much,' Snow depicted the workers as full of pride and joy working in factories in the township of Wuqi in Yan'an. Mostly young women from impoverished villages, the workers had little to warrant any joyful smiles: their pay was very low and living conditions primitive, their meals consisted of millet and vegetables, and their dormitory was a cave house with earthen floors. But working under the principle of 'equal pay for equal labour,' they appeared to be the happiest and proudest people the journalist had encountered. Lacking in cultural resources, they treasured the rare opportunity of learning and education. They valued their 'two hours of daily reading and writing, their political lectures, their dramatic groups.' Everybody competed vigorously for the small prizes in sports, literacy, writing, and productivity.

Puzzled by the incongruity between material squalor and mental happiness, Snow found answers by recalling child workers in foreign factories in the China ruled by the Nationalist Party: 'You have to contrast their life with the system elsewhere in China' to understand the joy of labour in Yan'an. In hundreds of factories elsewhere, 'little boy and girl slave workers sit or stand at their tasks twelve or thirteen hours a day, and then drop, in exhausted sleep, to the dirty cotton quilt, their bed, directly beneath their machine.' A Western-educated engineer, who quit his foreign firm in Shanghai to come to Yan'an, expressed similar bewilderment. Dedicated to productivity and efficiency, the engineer complained about so much 'horseplay going on' while everybody was happy, and wondered why the young women workers spent so much time singing. Constant singing, Snow writes, sums up 'a great deal about the youthful bravado of these young women workers.' The workers felt they were working for themselves and nobody was exploiting them. Compared with their past lives, the new working life was one 'of good health, exercise, clean mountain air, freedom, dignity, and hope.' It is no wonder that singing, joy, and laughter are the natural and spontaneous expression of this work ethic. Revolutionary culture aimed 'to shake, to arouse, the millions of rural China to their responsibilities in society; to awaken them to a belief in human rights, to combat the 
timidity, passiveness and static faiths of Taoism and Confucianism.' The revolutionary labour ethos encouraged the workers to work for the 'reign of the people', a life of justice, equality, freedom, and human dignity.

\section{The Joys of Collective Labour}

Fast forward to today. Zhang Meng's The Piano in a Factory recalls similar joy and beauty in collective labour. Like thousands of his coworkers, the protagonist Chen Guilin has been laid off from the state-owned steel plant. During his divorce, he seeks to build a piano with scraps of steel, so that his daughter will stay with him. The piano is more than a musical instrument. Chen's wife has ample means to purchase a piano for her daughter, who will go with whoever offers her this possession. Although the laid-off coworkers have each gone their disparate ways, they answer Chen's call and look forward to working together again. They come in order to exercise their own ingenuity and creativity, and to reconnect emotionally. An ambiance of jouissance and warm feeling suffuses the process of building the piano. In creating something new and deploying their talent and skill, the workers are rediscovering a collaborative ethos that had been previously fostered in the socialist steel plant but has since lain dormant-wasted. They experience camaraderie and solidarity. In socialist labour, workers are masters of the production process and free from alienation, a condition of estrangement from one's body and mind. They are able to exercise the essential powers, capacity, and creativity worthy of a productive human being.

In Marx's analysis, private property makes people one-sided because it exists as capital and commodity. In commodity exchange, the structure of feeling is very much truncated, confined to a one-dimensional sphere of existence. A life based on private property is about seeking possession and enjoyment of private property. Such a life has little social and emotional resonance with fellow human beings. In Grundrisse, Marx mocks Adam Smith's claim that the producer of the piano has nothing to do with the piano player: 'The piano would be absurd without the piano player.'3 If the piano as a commodity 'reproduces capital' and if 'the pianist only exchanges his labour for revenue,' where are the piano's aesthetic functions that 'produce music and satisfy our musical ear?' Marx is invoking the essential link between piano maker and pianist, worker and artist, alienated labour and the labour that fulfils the spiritual and bodily potentials of a human being. The Piano in a Factory picks up Marx's hints. The piano being built by the workers escapes the fate of being a mere commodity and a sign of capital. In its creation, the labour is unalienated, self-directed, and voluntary. In labouring, the workers rediscover their essential creative powers-their intelligence, knowledge, passion, and skills previously acquired as steel workers. Their minds and bodies are activated and emancipated from their entrapment in private possession and in labouring for capitalists. The building of the steel piano becomes a process by which the workers come together to form a new working community and to realise their human and artistic potentials. The piano is no longer a thing, but an aesthetic, affective focal point into which the workers pour their emotion and camaraderie.

Working together unites piano maker and piano player in The Piano in the Factory, which echoes Snow's episode of female workers singing at work in Red Star Over China. The film presents extended episodes of singing, dancing, and performance, intimately 
associated with the technical as well as emotional tenor of piano building. The socialist labour involved in this endeavour envisions workers with well-rounded personalities transcending the one-dimensional individual confined to a narrow sphere of activity through the capitalist division of labour, efficiency, and productivity. The socialist worker has the potential to become accomplished in any branch of the technical and cultural spheres. While the same Chinese word gang (steel) is present in both gangqin (piano) and gang de qin (a piano made of steel, as the original title of the movie reads), making steel and making music are after all very different activities. But this combination is what the workers ought to be. They are not only producers of material goods but also creators of culture: the piano maker should be a piano player.

\section{Workers as Artists}

The unity of worker and artist, of mind and body, of mental and manual work in the mix of steel and music entails a socialist motif: art is to serve working people-workers, peasants, and soldiers. It is to enrich their cultural life, foster a collective ethos, and raise their consciousness. The workers, instead of being passive consumers, should have the opportunity to actively participate in cultural activity and creation. It is by no accident that Chen Guilin, his girlfriend, and other workers are excellent amateur artists. They might have been on the steel plant's art troupe or propaganda team engaged in mass cultural activities on a regular basis.

By highlighting the workers' artistic performance, the film suggests that the socialist workplace is a site for manufacturing material as well as cultural goods. Cultural activity provides for and nurtures an ambiance that meets the emotional, aesthetic, and intellectual needs of workers. By extension, socialist culture is to serve and educate the working people by forging and spreading new ethoses, new knowledge, and new artistic forms. The film gives testament that factory workers in the past had access to musical education and actively participated in music events. In the film, the workers team up with a Soviet-educated engineer, and apply book knowledge and foreign language proficiency to piano research and building-proof of power sharing on the factory floor and cultural accomplishment. In light of this, it is worth pausing to think about factories in the present. One wonders how many of these factories have a library like the one in the film, how many talented workers have a chance to perform and sing in the workplace, and how many can tackle high-tech engineering problems and read foreign languages? Culture and education in today's China are becoming a prerogative of the privileged few, not an equal right open to all citizens, much less to labourers. The film's director Zhang Meng complained that while he made this film for unemployed and laid-off workers, they could not afford to go to the cinema to watch it.

The Piano in a Factory conjures up images and scenarios of the socialist workplace and the dignity of the workers. Swept under the rug by the neoliberal market imperative, these images stage a magical comeback in the midst of the industrial wasteland and against the ruinous effect of capitalist labour. They are a source of critique, and a gesture of protest. This invocation of the imagination alerts us to what labour could be like in a world where workers enjoy equality and dignity, possess a well-rounded personality, and are producers of material products as well as creators of artworks. 


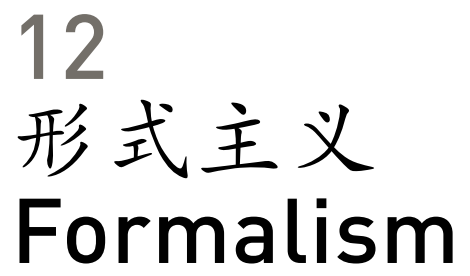

Roy CHAN

n his 1942 speech 'Oppose Stereotyped Party Writing', delivered at Yan'an, Mao Zedong critiqued Party discourse that was full of cliché but lacked concrete substance. He argued that such discourse constituted yet another kind of 'eightlegged essay' (baguwen), the formulaic standard for imperial examinations, and identified the 'formalism' (xingshizhuyi) of this discourse as being out of touch with the masses that comprised both its ostensible audience and object. Formalism in short order crystallised an objection to all manner of impertinent convention, feudalistic ritual behaviour, aesthetic ornamentalism, and empty rhetorical abstraction. In the Soviet Union, the aesthetic currents of the Russian Formalists that flourished in the early years of the Bolshevik Revolution had already been proscribed by Stalinist orthodoxy. ${ }^{1}$ Crucially, the epithet 'formalist' expressed how elitist forms of expression and behaviour often indexed social and political privilege. Mao's hostility to calcified institutional practices, and his suspicion that such attitudes only cemented elitist privilege, lent the term a strong affect of political resentment; he identified elitism not just in the old feudal ruling classes and urbanised intellectuals, but also as forming in the privileged attitude among many within his own revolutionary movement. Just a short time earlier, in another speech entitled 'Rectify the Party's Style of Work', he had criticised the Party's 'style of work' (zuofeng) for promoting selfishness and dogmatism. Formalism prevented Party members from thinking of their own endeavours as integrated with the Party's work and the people as a whole. Mao's reference to the imperial eight-legged essay to figure both stereotyped Party writing, but more essentially, forms of selfcentred conduct, implied that Party behaviour and discourse were essentially 'textual' in nature. As such, they corresponded to forms and styles whose relationship to mass politics could be assessed. 


\section{Form and Content}

Anti-formalist sentiment derives from the culture of Chinese modernity as a whole; in the late 1910s, the New Culture Movement's iconoclastic attitude toward all varieties of premodern, 'feudalistic' (fengjian) norms of ritual behaviour was in keeping with the egalitarian aspirations of thinkers and reformers of that period. Liberal $\mathrm{Hu}$ Shi and radical Chen Duxiu alike proclaimed the need for Chinese literature and art to abandon outdated classical forms and adopt styles and genres in keeping with the modern age. While drawing on this tradition, Mao nevertheless charged urban intellectuals with saying one thing and doing another-while they upheld an image as agents of change, they remained hopelessly tied to their social privileges.

However, Maoist formalism encompasses more than a critique of elitist snobbery and empty rhetoric. The question of the proper relation between 'form' (xingshi) and 'content' (neirong) constituted an epistemological problem that Mao, who was intensely studying Marxist philosophy during the Yan'an period, sought to resolve. The relationship between 'form and content' was but one of many dialectical antinomies that appears throughout Marxist parlance. Its roots stretch as far back as German idealism, in particular the philosophy of Hegel. Indeed, the spirit of Mao's critique of formalism did not consist of a disavowal of all forms, but rather an exhortation to bring form back into a productive relationship with real social content. Formalism as a philosophical problem thus brought into its orbit such categories as literature, politics, and education - to wit, all forms of knowledge and cultural production.

The philosophy of Hegel iterates time and again the dynamic unity of form and content; they are not separate entities but two aspects of a dialectical whole. Content denotes undifferentiated, immediate existence in all its potentiality, while form expresses its internal structure as an organised self-reflection. The distinction between form and content is not absolute; rather, it can be grasped as how we perceive a thing in an immediate and total manner, as an essence, but also mediated through intelligible representations, so it emerges as appearance. As knowledge of reality proceeds in a dialectical perpetuum mobile, the distinction between form and content never remains static-they always appear relative to one another in a process of endless progression. Whereas 'idealist' philosophers such as Hegel identified real 'content' with notions of universal 'Spirit,' later materialists, including Marx, dispensed with such idealism as the basis of knowledge. Ultimate reality was not to be located in universal concepts and abstractions, but within the material world. Marxist philosophy locates the roots of knowledge within the processes of human labour. Real content, then, was not to be found in abstract concepts, but within the material forms of social life.

\section{Overcoming the Domination of Form}

That form and content are but two aspects of an integrated whole strikes at the crux of the problem of formalism-what happens when forms (of knowledge, of art, of philosophy, of behaviour, etc.) become alienated from their social content? As social life constantly progresses through struggle, the forms through which we mediate knowledge of social life should also change. But what happens when abstract form, through repetition, replication, and imitation, takes on the appearance of concrete 
materiality, thus occulting the real content from which form ostensibly derives? What happens when form takes on a life of its own and forgets its very origins in the content that has been elided? To endlessly replicate forms, conventions, and institutions that have long outlived their social shelf-life can thus only serve one possible purpose: the maintenance of social privilege.

Under Mao's Chinese Communist Party (CCP), then, formalism as a term of denunciation was meant to correct the dominance of mere form over social content. Content was seen as the primary criterion against which all forms were to be judged, and all had to conform to the CCP's vision of what social content ought to be. In practice, what the campaign against formalism ensured was the prohibition against the formal autonomy of academic disciplines and cultural production. The constant need to justify all intellectual and aesthetic activity on the basis of its ostensible relation to concrete social reality constituted a political imperative that brought serious consequences to those who committed the sin of formalism.

The rise of a 'model' (mofan) culture in the aesthetics of the People's Republic, however, demonstrates how the Communists sought to align innovative aesthetic forms that not only reflected real social content, but could also shape utopian forms of social life to emerge in the future. ${ }^{2}$ In his 1942 'Talks at the Yan'an Forum on Literature and Art,' Mao himself argued that such art 'ought to be on a higher plane, more intense, more concentrated, more typical, nearer the ideal, and therefore more universal than actual everyday life.' Model types were distinct from formalism in that there was a putative organic link between these forms and real social transformation. If model forms did not reflect a current social reality, then they could potentially instigate a process by which they would eventually materialise.

The imperative that all aesthetic forms reflect an undeniable social content tended to result, ironically, in the formalisation of social life into shopworn conventions. How is it possible to encapsulate the complexities and vicissitudes of social life into a few sanctioned forms? As Jason McGrath has noted, the more rigid the ideology and aesthetics of the Cultural Revolution became, the more model operas became untethered from social life and started to 'drift' into formulaic convention. ${ }^{3}$ In the guise of resisting formalism, Maoist culture often ended up imposing its own readymade representational formulas on the social world (see also Sorace's essay in the present volume).

\section{A New War against Formalism}

The end of the Mao era undoubtedly brought fresh air into domains of knowledge and cultural production that had become moribund as a result of anti-formalist attitudes. To a certain extent, starting in the 1980s, academics and artists were granted a formal autonomy they had rarely experienced. Western modernism, with its emphasis on formal sophistication, flourished in Chinese literary and visual arts. The achievements of Chinese writers, artists, and intellectuals of the postreform period confirm that a degree of formal autonomy in their respective disciplinary domains was not only healthy for their intellectual and cultural development, but could also provide new perspectives on ever-changing social realities. 
But the reintroduction of the market economy has created class differences that exist not simply on a material level, but on a formal one as well. Urbanites and migrants, rich and poor, elite and common, have grown increasingly alienated from each other, not simply in terms of wealth, but also in terms of dress, language, and styles. Since Mao's death, education has reverted to extremely competitive modes of standardised testing which seem only to replicate the domination of elites, approximating the eight-legged essays of the imperial examination system that Mao hated so much. State bureaucrats, while nominally professing the communist creed, behave more like genteel aristocrats than committed cadres. Postmodern Chinese art garners top dollar on the market, seemingly more tied to the accumulation of cultural capital than the reflection of social conditions. Popular resentment against the emergence of a new social hierarchy has continued to spill over into outbreaks of discontent.

It is no wonder, then, that under Xi Jinping formalism has reemerged as a target. Critiquing the Party's increasing alienation from the people it serves, in $2013 \mathrm{Xi}$ declared formalism as one of the 'four forms of decadence' (si feng) to be opposed, along with 'bureaucratism' (guanliaozhuyi), 'hedonism' (xianglezhuyi), and 'extravagance' (shemi). ${ }^{4}$ His critique of formalism echoes Mao's own criticisms of selfishness within the Party's style of work. Xi has sought to channel popular discontent with a Party perceived as hopelessly out of touch; by bringing back rhetoric against formalism, he seems to suggest that the Party should return to its populist roots, and that its formal gestures correspond to a sincere commitment to social life.

But what is missing from Xi's critique of formalism is the dynamic interplay between ideological form and social content-one fuelled by the ever-churning internal roiling within social life. Mao's critique of formalism was connected to the necessity of recognising continuously changing social conditions and contradictions, and how they foster new forms of knowledge that aid in analysing them. Mao thrived upon, if not relished, the kind of social upheaval that made visible new roads of political possibility. $\mathrm{Xi}$ has abandoned class struggle in favour of consolidating national unity. However, railing against the sins of formalism while trying to tamp down any kind of grassroots social struggle ensures that this critique will remain stuck in the logic of formalisman ironic cliché. 


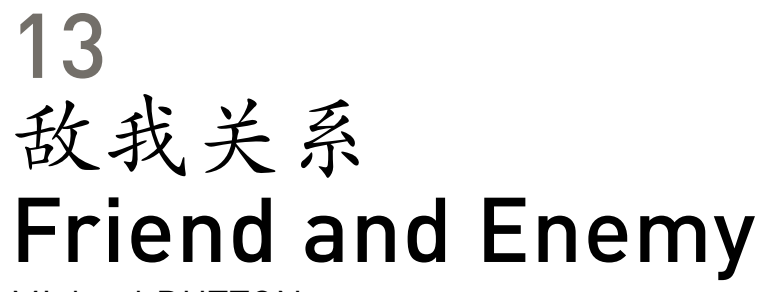

Michael DUTTON

'W ho are our enemies? Who are our friends? This is a question germane to the revolution. ${ }^{1}$ Found at the very beginning of Mao's Selected Works, these words would remain as key pillars of the thought of the Chinese Communist Party (CCP) throughout the years of Maoism. They appeared a few years before the rustication process that transformed the CCP into a distinctly telluric Maoist revolutionary force. ${ }^{2}$ They were also words written some time before Western theory discovered the centrality of the friend/enemy dyad to the concept of the political through the work of Carl Schmitt. While friend and enemy were never used by Schmitt as an exhaustive definition, he, nevertheless, came to regard it as being at the 'essence of the political.' ${ }^{3}$ In terms of understanding not only modern Chinese history but also, at a more general theoretical level, the very concept of the political, this friend/enemy dyad is, then, central. ${ }^{4}$

Schmitt may have theorised the friend/enemy binary, but Mao lived it. The Maoist years were built on this knife edge and it was not until the death of Mao and the arrest of the radical Maoists that the question of friend and enemy would give way to the binary of profit and loss. Along with this shift, attitudes toward Mao and his revolutionary ideas also changed. His fall from grace, both in China and in the West, was spectacular.

In China, Mao was brought down from his 'sacred pedestal' by a combination of official criticism of his (later) radical years and, as economic reform kicked in, by a gradual commodification and trinketisation of his image. ${ }^{5}$ If the Chinese critiques brought the Chairman back to earth, Western reassessments sent him straight to hell. 'Marx, Mao, and Marcuse' had once been a slogan chanted by Western leftist students in the 1960s and 1970s. Not anymore. By the turn of the century, that slogan was but a distant and embarrassing memory. ${ }^{6}$ Revelations of tens of millions of deaths in the Great Leap Forward, coupled with tales of fear, horror, and cruelty during the Cultural Revolution, had turned the image of Mao, even among Western radicals, on its head. As a result, 
'Marx, Mao, and Marcuse' became 'Hitler, Stalin, and Mao.' As the moral opprobrium that had once been reserved for Hitler and Stalin crept into Western understandings of Mao, in the antimony of good and evil, Mao became almost universally vilified and disdained-and depicted as evil manifest.

Translated into a political form, good and evil became freedom and tyranny, and it was in this form that it became a key dyadic pressure point of Western politics. It was this politicised moral grid that came to define who 'we' in the West were by showing us what we stood against. Faced with such an overwhelmingly powerful and morally defining binary distinction, it became almost impossible to think of Mao and Maoism outside the shadows of this unholy good/evil binary and immoral triumvirate of twentieth-century dictators.

\section{At the Heart of the Political}

Paradoxically, in Maoist China it was a similarly structured intense binary antagonism that would reduce the space to think outside the category of class struggle. In terms of political theory, however, the key difference between the Maoist binary of friend and enemy and the Western binary of good and evil is that Mao takes us directly to the heart of the political. As Carl Schmitt explains:

A definition of the political can be obtained only by discovering and defining the specifically political categories .... . Let us assume that in the realm of morality the final distinctions are between good and evil, in aesthetics beautiful and ugly, in economics profitable and unprofitable. The question then is whether there is also a special distinction which can serve as a simple criterion of the political and of what it consists. The nature of such a political distinction is surely different from that of those others. It is independent of them and as such can speak clearly for itself.

The specific political distinction to which political actions and motives can be reduced is that of friend and enemy. ${ }^{8}$

From 1927 onwards, Schmitt's theoretical work turned on this question, which he claimed, 'denotes the utmost degree of intensity of a union or separation, of an association or disassociation. ${ }^{9}$ For Schmitt, this friend/enemy dyad was not only the specific political distinction to which all political actions and motives could be reduced, but it was also a particular form that would manifest as the political in 'the most extreme antagonism. ${ }^{10}$ Indeed, according to Jan-Werner Müller, Schmitt came to think of the political as 'purely a matter of intensity', and it was at its most intense, Schmitt would later write, in the 'telluric partisanship' of Mao Zedong. ${ }^{11}$ It was Mao's telluric partisanship, derived from years of rustication, that came closer-'closer than Lenin,' Schmitt tells us-to what he called 'the core of the matter', and the core of the matter for Schmitt was always the political. ${ }^{12}$ 
In circling around Schmitt's concept of the political and a Maoist political practice predicated upon an intensification of the friend/enemy dyad, this encounter becomes not just a history of a nation-state or Party, and far more than a simple record of tyranny. Read together, Mao and Schmitt lead to broader conceptual questions as to the nature of the Schmittian political as it congeals into a form of Maoist governmentality. ${ }^{13}$

Registered in this fashion, the Maoist historical moment opens onto a radically different understanding of both Chinese political history and how to approach the concept of the political. Put simply, while this is a concrete, culturally, and temporally specific moment, creating a unique and irreproducible political form (Maoism), it nevertheless opens onto a broader conceptual question but only after (Western) political philosophy articulates it. These questions gain form in material practices rather than purely text-based conceptualisations, and focus on the affective, and not simply the rational dimensions of human life. Engendering these sorts of practices, technologies, and machinery, Maoism attempted-sometimes murderously-to develop a system based on tapping into affective energy flows and transforming these flows into political energy through a process of intensification. This is where the grid of class struggle would provide Maoism with a mechanism to intensify (see Russo's essay in the present volume).

\section{Manufacturing Emotions}

While class struggle was ever present, the state machinery operated to intermittently press forth with rhythmically pulsating political campaigns that intensified as the category of enemy was deepened and extended. Such campaigns were an attempt to harness and channel political intensity. To work with intensity is to work off affect. Hence, Maoism was attempting to design machinery to channel 'affective,' as well as cognitive knowledge forms in order to produce a revolutionary intensity which would manifest not just with words, but with the evocation of feelings registered by lumps in the throat, goosebumps on the skin, or the pounding of a revolutionary heart (see Lee's essay in the present volume). In other words, it attempted to develop technologies to focus the revolution on a process of 'touching people to their very soul' by instituting an economy of sacrifice. ${ }^{14}$

To produce this sacrifice, a form of governmentality emerged around the production, channelling, and harnessing of political intensity, which would be produced by framing the abstract question of friend and enemy in the language of class struggle. Through struggle, the abstraction of the dyadic form became an existentially felt knowledge and the machinery of the Party-state was redesigned to channel that knowledge and energy into the struggle and into personal sacrifice.

That these Maoist experiments failed-and sometimes failed spectacularly with the loss of millions of lives-is without question. Moral opprobrium is in order, but it needs to be put into context. Here was a new, revolutionary political practice (Maoism) that attempted to manage the social through the channelling of affectivity. These very early, sometimes very rudimentary, devices and technologies were attempting to harness and direct an affective flow and turn it into an intensity that would build toward an economy of sacrifice. This stands in sharp contrast to the government of flows within liberal market economy-based democracies and it took many struggles to arrive at this 
point. In its earlier manifestations, capitalist market expansion saw a litany of abuses, famines, and deaths-colonialism, imperialism, and slavery. While we seldom affix the word 'murderous' to this form of government, it must be remembered that the new technologies of capitalism spread, not just through scientific advances, but by forcibly creating new markets through imperialism and colonialism, and by producing and trading in any commodity on a mass scale, be that opium or slaves. ${ }^{15}$

Viewed in this light, the Maoist experiment needs to be recognised as a complex and fragmentary set of lessons that, despite all the problems, threw up technologies, machines, and questions about the political that are currently difficult to ignore.

\section{Faux Friends}

It would, no doubt, be tempting to try to address the complexity of Maoism by adopting the binary of tyranny and freedom. Indeed, in drawing attention to the link between Mao and Schmitt, I have possibly supplied critics with new ammunition. After all, someone could point out that Schmitt, a Nazi Party member, praised Mao, the left-wing tyrant. To suggest, however, that the two extremes are comparable is a misunderstanding based on the fact that while these 'extremes' may theoretically and practically direct our attention to the affectively based elements in the production of the political, they certainly do not share a political viewpoint. In other words, the operations of such regimes rely on the capture of political intensity, whereas liberal democracies try to extinguish these intensities or dissipate their effects through market forces. Whereas Maoism attempted a Cultural Revolution as a means to develop machines of intensification, neoliberal democracies used the Culture Industry as a means to limit or dissipate those same energy flows.

The singular intensity of Maoist class struggle was replaced by a dispersion of this energy as it was transformed into a million desires that actually took the form of one single desire for the commodity. These two distinct modes of being political still revolve around the friend/enemy distinction, but do so in different ways, taking us well beyond both Schmitt and Mao. Whereas Maoism agglutinates energy, channelling it toward an intensity, liberal democracy attempts to stave off such intensities by dissipating and transforming them into material desires. ${ }^{16}$ As this liberal agenda now gives way to a right wing populist surge worldwide, it would indeed be ironic if the use of Schmitt to explain Mao now led to an understanding of Maoist technologies that, theoretically, help us understand the emergence of the Alt-Right. 


\section{4}

\section{Global Maoism}

Fabio LANZA

$\mathrm{n}$ recent years, we have witnessed renewed scholarly attention to the phenomenon that usually goes by the name of 'global Maoism'-that is, worldwide interest and admiration for the radical politics China embraced in the 1960s and 1970s. With few notable exceptions, depictions of Maoism outside China-and especially in 'the West'-almost universally highlight the infantile fascination for a poorly understood reality, the quasi-religious pilgrimages to the land of ascetic communism, and the immediate reversal of judgments when the 'truth' was revealed and communes were shown to be, at best, Potemkin villages. Even when the study's declared intent is to take 'Western Maoism' seriously, Western Maoists still tend to be depicted as unwitting orientalists, whose fascination with China was a youthful phase in a process of development towards better, more respectable politics-human rights, feminism, gay rights, etc. ${ }^{1}$ As one former French Maoist famously quipped, that China existed only 'in our heads.' ${ }^{2}$ As a figment of the Euro-American imagination, 'that China' could point the way to more mature discoveries, but it had only a dreamlike existence.

While we should not ignore the naiveté, the ignorance, and the orientalism that characterised the reconfiguring of China in the long 1960s, there is a certain amount of smug certainty in the presumption of having now a more objective, finally uncorrupted view of Maoism. It is certainly not the case that the ideological lenses of triumphant capitalism are less thick than those which framed the rosy views of the 1960s. More importantly, I believe that the denial of any political and intellectual value in the experience of global Maoism obscures, rather than frees, our own understanding of that historical moment, in China and abroad. We should continue asking why Maoist China operated as a significant point of reference for activists in completely different situations-from Africa to South America, from Paris to Oakland-and why it was precisely Maoism that provided a vocabulary and a syntax for many of the political struggles of the long 1960s. In this essay, I will highlight what was valuable in the 
sympathetic perspective towards Maoism, and what we can learn by taking seriously people who engaged the Maoist experience on its own terms. Does it do any good to have (Maoist) China in our heads today?

\section{Pathological Alterities}

In my book The End of Concern, I trace the history of a group of young US professors and graduate students - the Committee of Concerned Asian Scholars (CCAS) - who came together in the late 1960s, united in their criticism of US policies in Asia and of the complicity of the field of Asian Studies in those policies. ${ }^{3}$ While not Maoists, most CCAS members were nevertheless sympathetic to Maoist China, in particular to the experiments of the Cultural Revolution and the Great Leap Forward, which they saw as pursuing an alternative path to both American capitalism and Soviet dirigisme-'an egalitarian development, an industrial development without dehumanisation, one that involves everyone and affects everyone. ${ }^{4}$ To that extent, they stood in radical opposition to the general academic consensus in the US.

In the late 1960s, the social sciences (as well as public opinion and, one could argue, the US government itself) were dominated by Modernisation Theory, an approach that evaluated societies according to their position along a supposedly 'typical' path of development-with contemporary US society at the pinnacle, and socialist states depicted as having embarked on a deviant, 'pathological' trajectory. Modernisation theorists like Walt Rostow joined the Kennedy and Johnson administrations and directed a foreign policy actively fostering-and often imposing - the 'correct' model onto other nations.

In this academic and political context, Asian Studies occupied a peculiar place: the field was constituted, like all area studies, in the immediate postwar period, primarily through direct government intervention, and it remained largely defined by the Cold War imperative to 'know thy enemy.' Then, immediately after its establishment, Asian Studies became one of the main targets of McCarthyism, as a first round of attacks, focussed on the 'loss of China,' was directed against the scholar Owen Lattimore and the Institute of Pacific Relations, which, since 1925, had been the most important international NGO promoting research about and relations between the countries of the Pacific Rim. ${ }^{5}$ The McCarthy purges defined the early history of Asian Studies in the US, not only through overt persecution, but more subtly, through the self-imposed silence of an entire generation of scholars, who learned to constrain their questions. Imperialism and colonialism were never mentioned as factors in the historical trajectory of Asian nations; at best, as in the work of leading China historian John K. Fairbank, 'the West' appeared as a naturally emerging challenge, to which 'the East', because of its cultural obduracy and traditional mentality, could not respond. Modern Chinese history was, according to Fairbank, the often tragic process of a civilisation divesting itself of difference to fit the needs of modernity. ${ }^{6}$ China, from the perspectives of Area Studies and Modernisation Theory, could either persist in its obstinate (and ultimately pathological) alterity, or accept reality and become 'like us.' 


\section{An Alternative Vision}

This was the regime of academic thought to which CCAS reacted, spurred not only by their opposition to the Vietnam War-which they argued was abetted by the silence of their teachers-but also by their sympathy for the Maoist experiments of the Cultural Revolution-experiments not only dismissed by, but de facto invisible to, the thencurrent academic consensus. Coherently, members of CCAS directed their criticism and, at times, their mocking derision first and foremost at the ideological assumptions behind the dominant US attitudes towards Asia. For example, they pointed out how the field was incapable of producing an analysis of Maoist socioeconomic change that exceeded the narrow focus on economic growth, thus making experiments that conceived of economic change as only ancillary to radical political transformation completely unintelligible. More damningly, CCASers showed how their opponents had actually made invisible the economic growth that was happening under socialism: because Modernisation Theory deemed socialist human relations to be fundamentally incompatible with economic growth, any economic growth taking place under Maoism had to be explained away. Similarly, they chided the field's inability to give any consideration either to the revolutionary agency of the masses or to the contents of their revolutionary effort, arguing that the dominant analyses rested on studies of elite politics and bureaucratic forms, with change coming only from the top down with the Chinese people being reduced to 'objects to be administered.'

The political biases that the CCAS uncovered were hidden under a thick ideological discourse, one that continuously asserted the neutral location of the (American) academics who studied China and the objective character of their knowledge. Thus, completely unwarranted assumptions about capitalism, modernisation, development, and the production of knowledge were peddled as objective, rational principles with which to judge Asia and Asian people. The blindness of the profession towards Maoism revealed a much more profound one towards the profession's own constitution and ideological framework. The CCAS's critique then predated-albeit in a much less theoretical fashion - that of Said's orientalism and of postcolonialism. ${ }^{8}$

CCASers did not limit themselves to a critique of the dominant ideology but also offered an alternative vision, one based on the recognition of the political reality of the Chinese experiments. This meant evaluating Maoist China in terms of its own goals and its own methods for attaining them, thus recognising their validity. Contrary to any academic pretension of political neutrality, a true understanding of Maoism could come only from a certain degree of political sympathy (in the sense of 'feeling together'), and from the acknowledgement that Chinese people were subjects with whom political and theoretical experiences could be shared. Politics, or the 'commitment to the need for revolutionary change' in Asia, was the prerequisite for a concomitant 're-orientation

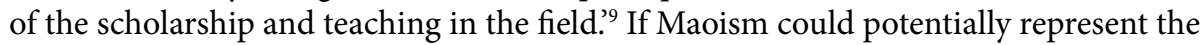
search for a more humane, more egalitarian alternative to existing forms of development, then those alternative practices could only be understood through a different scholarly approach, one that rejected the technocratic/culturalistic framework of the existing social sciences. Accepting the value of these revolutions required first and foremost a drastic shift in the very structure of intellectual thought. In that, CCAS was part of a larger movement of dissent within the academy, often framed around the same terms. 


\section{Rediscovering Maoist China Today}

That larger movement left a profound mark on academic, intellectual, and pedagogical practices, as it was connected to the emergence of postcolonial studies, gender studies, and critical theory in general. But the contemporary relevance of the approach to Maoist China in the long 1960s is much more in question. Yet, I would argue that there is plenty in that perspective-as mesmerised, fanciful, and naïve as it certainly was at times-that is still significant, or rather newly relevant, to how we study Maoist China today.

First, if, as in the case of the CCAS, we understand political sympathy not as silly nostalgia for a revolutionary era, but rather as the need to engage Maoist politics as politics, then that should in turn lead us to accept that the history of Maoist China is a history of political subjects at all levels. Despite certain recent efforts, the history of Maoism largely remains split into two parallel lines: the old, Cold War focus on the intrigues and sophistry of Party leaders at the top, and, at the bottom, the voices of 'the people,' who, it is alleged, either lived ordinary lives or were dragged into frenzied mass movements and divided into opposing camps, as either victims or perpetrators. ${ }^{10}$ One way to avoid this dichotomy might be to engage with the actors in our sourceswhether that is Mao or a lowly cadre-by taking their pronouncements, their beliefs, and their language seriously. Seriously, but not uncritically. Which means not assuming that those who professed Maoism were either duped or lying. ${ }^{11}$

Secondly, unlike the CCAS generation, historians of the Maoist period have been temporarily enjoying a relative abundance of new materials, in either archival or 'garbological' collections. This has unfortunately coincided with a resurgence of an often uncritical empiricism, where sources are mined for nuggets of facticity, allegedly capable of revealing the 'truth' of life under Maoism. ${ }^{12}$ In this context, the CCAS's attempted evisceration of our presupposed neutrality and 'objectivity', their incessant self-examination of the scholars' own projections, might be a useful reminder for a younger generation to avoid reproducing old blinders or inventing new ones.

Finally, while we have largely moved away from the Cold War discourse on China, in recent years, orientalist tropes of 'Asian values' or 'Chinese characteristics' have been deployed-in China and elsewhere-to articulate differences within a triumphant global capitalism. The CCAS's critique of Western perspectives should alert us to how China is still, in many ways, trapped between its unredeemable difference or its drive to 'become like us.' And the CCAS's recognition of political subjectivities across borders might suggest to us a more productive way of engaging with China, as well as our own relationship to that location. 


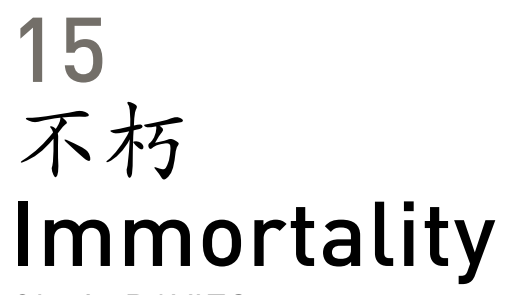

Gloria DAVIES

When I graduated from university in 1966, I sincerely believed what I was taught, that I was a brand-new bolt to be used in the construction of the great mansion of communism. I was willing to be put wherever my country needed me, and I was prepared to stay in place my whole life.

To me, Mao was like God. I believed that he was not only the great leader of the Chinese people, but also the great leader of people throughout the world. I feared the day when he would no longer be with us. I really hoped thered be a scientific breakthrough that'd enable young people like us to give up voluntarily a year of our own lives, to add a minute to his. That way the world would be saved.

Dai Qing, $1995^{1}$

have sometimes used these remarks in a course I teach on modern Chinese history to illustrate the extent to which young people were in thrall to Mao Zedong during the Cultural Revolution. They also appear as the first of three epigraphs in Frederick Teiwes's essay, 'Mao and His Followers', which I regularly set as required course reading. Echoing Teiwes, I tell my students that the epigraphs exemplify Mao's stature in a totalitarian Party-state system, in which 'virtually all members of the body politic became the Chairman's followers, willingly or not, with varying degrees of enthusiasm.'2

Reading Dai Qing's remarks this way translates her enthusiasm for Mao's revolutionary vision into a delusion. Dai Qing herself wanted to be read this way. She discussed her youthful wish to extend Mao's life to highlight by contrast how, upon regaining her senses, she 'didn't shed a single tear when Mao died. I felt I'd been cheated. I've never visited the Mao mausoleum. It is so disgusting.' Comparing Mao with Deng Xiaoping, she said: 
Mao had the personality of a romantic poet. Deng's is that of a pragmatist. $\mathrm{He}$ is not a puritanical theoretician or an idealist. He is different from Mao in that he knows that when people are hungry they need to eat. They can't live on poetry. ${ }^{3}$

While Dai wanted to convey the necessity of the reforms launched by Deng, her characterisation of Mao as 'romantic,' 'puritanical,' and 'idealistic' was not entirely negative. Moreover, there is something wistful about her comment-'They can't live on poetry'-as if she were wondering what might have happened if people could live on poetry.

At any rate, it is generally through poetry, including song lyrics and religious uses of poetic language in chants, mantras, and prayers, that senses of the sacred are given expression. Geoffrey Hartman provides the helpful observation that:

The sacred has so inscribed itself in [poetic] language that while it must be interpreted, it cannot be removed. One might speculate that what we call the sacred is simply what must be interpreted or reinterpreted, 'A Presence which is not to be put by."

What does it mean to write about 'immortality' in relation to communism, Mao Zedong Thought, and people's experiences of life under Chinese Communist Party (CCP) rule in Mao's time and since? A pat answer would be that immortality is a figment of the imagination. One could always trot out the Cultural Revolution chant, 'May Chairman Mao live ten thousand years, a hundred million years!' (mao zhuxi wansui wanwansui), as an example of how dangerous it is to believe in immortality. Yet, to dismiss the Cultural Revolution as totalitarian brainwashing prevents us from engaging with people's reverence for Mao productively, as a certain experience of the sacred, however disfigured.

As Dai Qing's remarks make plain, she wanted Mao to live longer because 'that way the world would be saved.' The 'immortal', as longevity, is bound to the 'sacred' as that which endures and grants meaning and purpose to otherwise mortal lives. A prosaic reading of Dai's remarks confines us to see how Mao was exalted and worshipped. A poetic reading allows us to dwell on how people were genuinely inspired by Mao to defend communism as a sacred cause: how communism-as interpreted by Mao through Mao Zedong Thought-became a certain 'Presence which is not to be put by.' The frequent posthumous references to Mao and his legacy in mainland public discourse as 'undecaying' (buxiu) gestures to something incorruptible that remains worthy of commemoration, despite the violence and extreme suffering of the Maoist years.

\section{Undecaying}

Hartman took his figuration of the sacred from William Wordsworth's 'Ode on Intimations of Immortality.' Wordsworth's poetic formulation of 'a Presence which is not to be put by' alludes to the sacred as a truth that commands our attention: one we cannot escape except through childlike oblivion or wilful denial. Immortality for 
Wordsworth was the spiritual dimension of human existence: 'We respect the corporeal frame of man, not merely because it is the habitation of a rational, but of an immortal soul. ${ }^{5}$ This description is akin to the Chinese idea of immortality as the 'undecaying' hence ageless truth that the sagely embody, in life and after their death. The difference is that whereas the Christian tradition led Wordsworth to intimate a godly presence in human nature, the Chinese idea of buxiu is directly focussed on human continuity. Both, however, point to immortality as an idea borne of existential reflection on death as intrinsic to life. The immortal, whether as 'a Presence which is not to be put by' or as buxiu, articulates a human preoccupation with all that precedes and succeeds us; with what is, or has turned out to be, indestructible despite mortal brevity.

The earliest extant appearance of buxiu is in the classic Confucian text Zuo Commentary (circa fourth century BCE), where the term was used to describe the sagely who are remembered for generations to come because they have 'established their virtue, their deeds, and their words' (li de, li gong, li yan). Simon Leys has observed that this ancient Chinese understanding of immortality meant that "life-after-life was not to be found in a supernature, nor could it rely upon artefacts: man only survives in man-which means, in practical terms, in the memory of posterity, through the medium of the written word.' ${ }^{\prime}$ Immortality, in the sense of an undecaying reputation, is a matter of human judgement. The Zhuangzi, a classic Daoist text, offers the following criteria for judging who among the dead ought to be remembered:

Those who come before us but who have not explored the depths of knowledge to be worthy of their years are not our predecessors. Those who do not distinguish themselves as humans do not provide a path for [other] humans to follow. Those who do not produce a human path are thus called worthless people. ${ }^{7}$

These Daoist criteria accord with the Confucian understanding of history as the ongoing textual transmission of life's lessons and moral truths. To read Mao's legacy against this longue durée context of instructive Confucian and Daoist stories (told and retold) of sagely and skilled humans is to be led to ask if there are things about Mao that have not 'decayed.' To understand immortality in these Sinophone terms requires us to consider the extent to which Mao's textual remainders remain in some way constitutive of how mainland Chinese experience their lives and articulate their feelings and goals. ${ }^{8}$

But let me first recall an influential 1919 essay by China's leading liberal thinker $\mathrm{Hu}$ Shi titled 'Immortality: My Religion' to highlight the significance of buxiu in modern Chinese thought. ${ }^{9}$ To transpose premodern buxiu into a modern democratic idiom, Hu employed two concept-metaphors, 'lesser self' (xiao wo) and 'greater self' (dawo). He described China as an 'immortal society', the permanence of an evolving 'greater self' to which mortal humans are bound and to which they must contribute as 'lesser selves' over their lifetimes:

This 'lesser self' that is me [wo zhege 'xiaowo'] has no independent existence. It has direct or indirect relations of mutual influence with an infinite number of other 'lesser selves', the whole of society and the world as a totality ... . All kinds of causalities past and present, created by an infinite number of 
'lesser selves' and an infinite number of other forces, have become a part of the 'lesser self' that is me. This 'lesser self' that is me, combined with various causalities past and present will be passed on to future generations to constitute an infinite number of future 'lesser selves.' From one generation to the next, an unbroken chain is formed, drop by drop, an incessant torrent results to become the 'greater self' ... . Although the 'lesser self' will die, the conduct of every 'lesser self,' the sum of its merits and flaws, its every word and deed, no matter great or small, true or false, good or evil, is preserved in that 'greater self.' That 'greater self' is thus the stele and the ancestral hall commemorating virtues past, the book of judgement and posthumous titles indicting crimes committed that generations of filial sons and loving descendants cannot alter. Because this 'greater self' is immortal, the endeavours of all 'lesser selves'-every word and deed, gesture and idea, merit and flaw-become equally immortal. This is none other than the immortality of society, the immortality of the 'greater self.'

Accordingly:

The 'lesser self' that I am at present must shoulder an immense responsibility not only for that eternal 'greater self' that has always preceded me but also for that 'greater self' that is eternally in the future. Thus, I must always contemplate: in what ways can I best apply myself to ensure that the present 'lesser self' is worthy of the 'greater self's' eternal past and does not bring calamity to the eternal future of the 'greater self?' ${ }^{10}$

These passages from $\mathrm{Hu}$ indicate the ease in modern Chinese intellectual discourse of reading buxiu as an ever-changing-hence never-decaying-world to which one belongs and helps to renew. A similar idea is implicit in Dai Qing's self-reference as 'a brand-new bolt to be used in the construction of the great mansion of communism' albeit far more narrowly and rigidly articulated. Whereas $\mathrm{Hu}$ conceived of an everevolving 'greater self', constituted as much by the flaws as merits of countless 'lesser selves', communism for Dai Qing was synonymous with Mao, the 'greater self' with which all 'lesser selves' must form a perfect union. The popular Cultural Revolution slogan-attributed to the soldier-martyr Lei Feng-that one must desire to be 'a revolutionary screw that never rusts', illustrates a similarly drastic reduction of the greater to mean the eternal machine of communist revolution that one must serve as a perfect cog. The more deterministic da wo becomes, the less room there is for variations in individual xiao wo agency. During the Cultural Revolution, we could say that the idea of buxiu shifted from a sense of 'never-decaying' historical change to an Orwellian 'endless present' in which Chairman Mao was always right. ${ }^{11}$

\section{Decaying}

The feverish chanting of Cultural Revolution slogans lasted for as long as the Partystate was able to devote energy and resources to sustaining Mao's vision of continuous revolution. A decade after Mao's death in 1976, with post-Maoist economic reforms 
underway, the Beijing novelist Wang Shuo became a bestselling success with his parodies of Maoist discourse in works such as The Operators (Wanzhu, 1987), 'An Attitude' (Yidian zhengjing meiyou, 1989), and Don't Treat Me as a Human Being (Qianwan bie ba wo dang ren, 1989). The farcical treatment of Maoist discourse in mainland China from the 1980s is analogous to the parodic uses of official language known as stiob which flourished in the Soviet Union from the late 1970s. Wang's characters speak in ways that echo Alexei Yurchak's description of stiob as requiring 'such a degree of overidentification with the object, person, or idea at which this stiob was directed that it was often impossible to tell whether it was a form of sincere support, subtle ridicule, or a peculiar mixture of the two.'12

Yurchak's highlighting of the ambivalence in stiob is important. In China as in the Soviet Union, playful, sardonic overidentification with the language of the Party gave people a sense of social communion and solidarity in post-Maoist times, based on their prior experience of Maoist sociality. What Wang and others parodied was the discourse taught and approved by the Party that became linguistically ordered around Mao Zedong Thought in the Cultural Revolution years. This was a discourse shaped, among others, by Lin Biao (Mao's one-time successor before Lin's purge and death in 1971), Jiang Qing (Mao's wife), and her fellow-members in the Central Cultural Revolution Small Group formed under Mao's orders in 1966. Mao's own words, conversely, have largely been spared this profane treatment. ${ }^{13}$ This distinction between the Party's Maoist formulations and actual 'quotations from Chairman Mao' (Mao zhuxi yulu) is crucial. Because the Party's formulations derived their authority from Mao, they were never and could never have been equal to the Chairman's, as it were, unique authorial voice.

The Party's foundational motto, 'Serve the People' (wei renmin fuwu) is an interesting case in point (see Karl's essay in the present volume). Its authority derives from the title of a short speech that Mao delivered on 8 September 1944 to eulogise Zhang Side, a communist soldier who had died in an accident three days earlier while making charcoal. ${ }^{14}$ Much of Mao's speech highlighted the CCP's commitment to always 'have the interests of the people and the sufferings of the great majority at heart' such that 'when we die for the people, it is a worthy death.' Today, when protestors seek to hold the government accountable on any number of issues, they invoke this motto both seriously and as a jibe. The Beijing-based writer Yan Lianke's darkly humorous 2005 novel Serve the People depicts a love affair during the Cultural Revolution in which the characters aroused each other by using 'Serve the People!' as their private code word. In doing so, Yan does not so much diminish as dramatise the affective force of the slogan as part of people's everyday communication and interaction. ${ }^{15}$ Even when parodied, the motto, as Mao's word, retains an inexorably normative rightness.

\section{Earthly Immortality}

In saying all this, I am not sacralising Mao. Rather, I want to highlight the ways in which his words have continued to enjoy a commanding presence in mainland public discourse. They are often what people reach for when they want to express their desire for a transformative politics. When student protestors at Tiananmen Square staged 
a hunger strike in May 1989, they issued a manifesto that began with lines from a 1919 essay by Mao: 'This country is our country, this people our people: if we don't speak out, who will? If we don't take action, who will?'16

When the highly regarded artist and social commentator Chen Danqing addressed a packed audience at Guangxi Normal University in 2011, he mused with stiob-like ambivalence that he 'missed Mao very much.' This was because people no longer knew how to be idealistic to the point where 'because of your foolish ideal you're even prepared to give up your life without regret and you might even laugh as you're about to die.' He continued:

Be truly fearless for there's nothing to fear. That's what Chairman Mao taught me. Don't be afraid of heaven, earth, or capitalism ... . He taught us to fear nothing. The culture today tells us to be ever fearful, to be good and obedient. ${ }^{17}$

Using Mao's language to evoke an ideal attitude is clearly different from quoting Mao Zedong Thought. In these post-Maoist evocations that render Mao's words serviceable for a variety of purposes, he has been restored, as it were, to 'lesser self' status. For this to happen, Mao had to first be adjudged as fallibly human. The Politburo's 1981 Resolution did just that by determining Mao's leadership as having been 70 percent correct and 30 percent wrong. Stories about Mao's private life and habits have also become part of this 'humanising' process. There have been stories too of his irritation with being worshipped. For instance, at the million-strong rally of 18 August 1966, Mao reportedly replied to a Red Guard's declared wish that 'Chairman Mao live forever' (zhu Mao zhuxi wanshou wujiang!) with the quip: 'Even long life comes to an end!'18

Mao, as an object of endless discussion, of stories publicly told and shared, has become demonstrably buxiu in Hu's modern sense of a 'lesser self' whose words and deeds, gestures and ideas, merits and flaws contribute to the 'greater self's' ongoing metamorphosis. Hannah Arendt's defence of 'earthly immortality' as a necessary transcendence of 'the life-span of mortal men' resonates with Hu's understanding of buxiu. In Arendt's words:

The common world is what we enter when we are born and what we leave behind when we die. It transcends our life-span into past and future alike ... . It is what we have in common not only with those who live with us, but also with those who were here before and with those who will come after us. But such a common world can survive the coming and going of the generations only to the extent that it appears in public. It is the publicity of the public realm, which can absorb and make shine through the centuries whatever men may want to save from the natural ruin of time. ${ }^{19}$

As literature, Mao's evocations of immortality are not discordant with Arendt's or Hu's. He saw unceasing change as a fundamental law of human existence. Mao expressed this idea lyrically in 1949 in his heptasyllabic classical-style poem, 'The People's Liberation Army Has Taken Nanjing.' The poem's last two lines, which draw on Daoist images of cosmic mutability, read: 
If Heaven had feelings, it too would grow old,

Seas thrice turned into mulberry fields: that's the way of the human world..$^{20}$

In 1958, he stated more prosaically: 'Disequilibrium is normal and absolute, whereas equilibrium is temporary and relative. ${ }^{21}$ Among the stories that have surfaced about Mao in recent years there is one concerning his 5 April 1954 visit to the Ming Tombs north-west of Beijing in the company of several 'democratic personages' (minzhu renshi). ${ }^{22}$ As his companions lamented the tombs' state of disrepair and recommended to Mao that the tombs be restored to their former glory, Mao reportedly replied:

The desire of these emperors to be immortal [buxiu] is both laughable and tragic. They built monuments to themselves using the blood and sweat of the labouring people, which is simply despicable. A true monument is built in the accounts of history. When established in the hearts of the people, it becomes a great monument; only then can it be called immortal. We should not be wasting our efforts on restoring ruins. That they are 'ruins' is their historical reality. People should come here to think about history and to see historical change. ${ }^{23}$

These remarks do not appear in either the collected works of Mao or the sixvolume Chronological Biography of Mao Zedong: 1949-76 published in 2013. ${ }^{24}$ Official verification, however, is not the issue here. Rather, it is that citations of Mao are not the monopoly of the Party.

Though few would wish to return to the totalitarian conditions that enabled the cult of the Chairman, in mainland public discourse, Mao's passion for revolutionary change is often fondly remembered. For a large majority of people who experienced the Cultural Revolution as children, adolescents, and young adults, their erstwhile intense identification with Mao's communist vision was, and remains, a powerful formative experience. ${ }^{25}$ Among them are senior Party officials born in the 1940s and 1950s, including the incumbent CCP General Secretary Xi Jinping, whose time in Liangjiahe village as a rusticated youth from 1968 to 1975 is presented by the Chinese state media as both character-building and shaping his leadership style. Yet like other post-Mao leaders since Deng Xiaoping, Xi has used Mao's sayings to defend CCP rule as necessary and enduring. Discipline and stability are what he favours when speaking in his own voice. For instance, when Xi addressed students at Peking University on the 95 ${ }^{\text {th }}$ anniversary of the May Fourth Movement in 2014, he said:

Living one's life is like buttoning up one's jacket. If the first button is not fastened correctly, the rest will never find their rightful place. The buttons of life should be fastened well from the very beginning. ${ }^{26}$

These words bear no trace of Mao. 



\section{6 \\ 司法 \\ Justice}

William J. HURST

$\mathbf{S}$

ince 1978, it has been fashionable, both inside China and around the world, to speak of the Maoist era as a period of near lawlessness, during which basic institutions of justice and adjudication essentially ceased to function in the People's Republic of China (PRC), whether for purposes of criminal punishment or civil dispute resolution. In this telling, China had some form of traditional or capitalist legal system prior to 1949, and later recovered from the Maoist dark ages to reestablish a new rational developmentalist legal order that could underpin a new form of socialism with Chinese characteristics, and eventually help give rise to a socialist market economy, while preserving the Chinese Communist Party (CCP) in power. The (re)construction of the legal system is thus central to the CCP's ideological narrative of the reform era, even as critics abroad continue to decry China's alleged rule of law shortcomings and pine for greater change (see Trevaskes's essay in the present volume). Both the Party and its critics base their perspectives on an assumption that whatever legal order existed prior to the Revolution was destroyed or suspended, but not replaced, during the subsequent three decades. Both narratives make this explicit in claiming that no law functioned at all during the 'long Cultural Revolution' (1966-76). Unfortunately, such breathless teleological accounts misjudge and misconstrue the Maoist legal system that actually existed and functioned between 1949 and 1978.

\section{Maoist Justice}

Maoist justice did not operate in a manner most legal scholars are trained to spot. Law was not essentially conservative, ${ }^{1}$ but rather functioned as a vehicle for mobilisation and an arena for political contestation. ${ }^{2}$ Critical to this was the fact that the polity-the set of politically empowered actors-was constantly contested and in flux, with dire or deadly consequences for any that might lose out in the high-stakes battles of Maoist 
politics. ${ }^{3}$ Indeed, we can characterise Chinese law in the Maoist era as a 'mobilisational legal regime', in which unsteady members of a divided polity regularly intervened in legal processes and adjudication in order to advance their own transformative political agendas. This stands in contrast to the 'rational pluralism' most rule of law perspectives assume ought to exist in what they define as well-functioning legal orders, where the polity is open and contested but adjudication remains free from political influence. It also differs from what I call 'rule by law' and 'neotraditional regimes' that we can observe in contexts where unified hierarchical polities either permit the formally rational adjudication of cases or intervene heavily into the legal process to protect their own interests. ${ }^{4}$

The one force that prevented any devolution into outright and open conflict over the first 30 years of the PRC's existence was Mao's periodic charismatic intervention. ${ }^{5}$ Such interventions did not render the law or the operation of courts and legal institutions predictable or formally rational in Weberian terms. Maoist law thus retained a thoroughly mobilisational character, with its unsettled polity taking an active role rather than promoting the 'rational pluralism' many legal scholars use as a touchstone (though this rarely exists, even at the times or in the places they tend to look to as rule of law paragons). ${ }^{6}$ If we recognise the law's mobilisational nature in Maoist China, with its fractious and contested polity and heavy intervention by non-legal actors into the process of adjudication, we can analyse its legal order in a more dispassionate and objective manner, without endorsing it on normative grounds or condemning it as tyrannical lawlessness.

Law and politics did not manifest the same way in all courts or institutions across all of China at all times. Instead, we see differentiated patterns in rural versus urban areas and across time. ${ }^{7}$ Further, civil dispute resolution in areas other than family law was largely neglected, though not entirely absent. ${ }^{8}$ Family law was among the first priorities for the new regime after seizing power in 1949 and the implementation of the CCP's Marriage Law has received a great deal of attention. ${ }^{9}$ Still, criminal law was the main focus of the CCP regime in its early days and throughout the Maoist period and is my main focus in this essay. ${ }^{10}$ Of course, criminal law in a revolutionary context carries some special connotations and enjoys an expansive scope. Criminals are defined as hostes to the new order, not simply 'bad elements' or 'deviants. ${ }^{11}$ Maoist mobilisational criminal law, therefore, served a critical function of rooting out and suppressing 'antagonistic' contradictions through the application of legitimate state violence or coercive force (see Rojas's essay in the present volume). Any other conception of law was at best secondary, if not reactionary or simply irrelevant.

The overall construction and reconstruction of legal institutions after 1949 was rapid. In cities, the CCP took over existing Republican courts where they existed and ensured that at least all prefecture-level cities (dijishi) had a functioning basic legal apparatus. In the countryside, there were fewer existing legal institutions to work with. The CCP often had to make new ones, more or less from scratch. In many places, only crude institutions of criminal justice could be established quickly. Chief among these were the so-called 'justice sections' (sifake) that many local governments set up for handling routine cases and 'people's tribunals' (renmin fating) that operated under the direction of land reform teams for the 'mass adjudication' (gongshen) of alleged land reformrelated crimes. ${ }^{12}$ Overall, the preferred political method for implementing the new 
system was the mass campaign (see Li's essay in the present volume). ${ }^{13}$ This proved highly destabilising to more or less intact urban institutions, but provided resources and political impetus for the construction of previously absent or moribund rural ones. $^{14}$

Eventually, all courts were regularised and brought into a nationally unified system under the 1954 Constitution and the Organic Law of People's Courts enacted the same year. This created what has become China's familiar four-level judicial system, with basic-level courts (jiceng fayuan) in every county or urban district, intermediate courts (zhongji fayuan) in every prefecture or equivalent city, a high court (gaoji fayuan) for each province or directly administered municipality, and the Supreme People's Court (zuigao renmin fayuan) in Beijing as a court of final appeal. In each court, civil and criminal sections hear each type of case and every trial is presided over by either a single judge (for petty crimes or minor disputes) or more properly a three-judge panel (heyiting), comprised of a 'presiding judge' (shenpanzhang) and two associate judges - one of whom usually acts as the 'principal adjudicating judge' (zhushen faguan) with primary responsibility for determining the verdict and legal reasoning. ${ }^{15}$ Court personnel are appointed and overseen by the CCP's political and legal affairs committee (zhengfawei) at the equivalent level, while court budgets are allocated by state fiscal organs (caizhengju/ting/bu) at the equivalent level. ${ }^{16}$ Also at each level, a procuratorate (jianchayuan) and public security bureau (gonganju/ting/ $b u$ ) were established to oversee investigations and prosecutions as well as police work and stability maintenance, respectively-resulting in the now-common acronym of gongjianfa to stand for the whole legal apparatus.

Though these institutions indeed grew into something resembling their modern forms between 1954 and 1978, their operation throughout the Mao era continued to be subjected to pervasive intervention by powerful and contending political actors-as well as by Mao and his underlings themselves, asserting his charismatic authoritythroughout the period. The manner and degree of intervention was different across specific moments over those several decades, however. Indeed, we can see a clear periodisation, in which land reform and the CCP takeover characterised legal politics between 1949 and roughly 1957, with a distinctly different pattern arising during the Great Leap Forward. This was followed by a period of relative calm and consistently harsh rectification during the early 1960s, before a decidedly new and novel framework emerged during the Cultural Revolution that remained (through various twists and turns) in place until Mao's death.

\section{Specific Manifestations}

Immediately after the establishment of the PRC, the CCP set to work building and rebuilding legal institutions in the countryside. This took place in tandem with land reform (1950-52) and the upheavals it caused. Indeed, for the next 30 years, the roots of a great many criminal cases could be traced directly to the land reform period and to issues dating back to before 1949. Many counties established justice sections by 1952 and most had seen widespread mass adjudication of land reform claims against 'counterrevolutionaries'(fangeming), 'land bandits' (tufei), and 'illegal landlords' (bufa dizhu), as well as alleged agents of the old regime. In addition to such cases, a high 
proportion of otherwise routine crimes were imbued with political content to facilitate their prosecution - for example, by calling a rapist or burglar a counterrevolutionary or bandit.

Also during this period, basic institutions of criminal adjudication and punishment grew up in the rural areas. 'Reform through labour' (laodong gaizao) camps and factories, prisons, and institutions capable of dispensing capital punishment and other penalties were all established, alongside at least proto-courts. The content of prosecutions remained overwhelmingly political and politicised. But the institutions and workings of justice began to come into being. Thus, on the eve of the enactment of the Organic Law and 1954 Constitution, most of rural China already had the makings of a legal and criminal justice system, albeit one that had grown up under the mobilisational politics of land reform and its immediate aftermath.

The situation in cities was markedly different. There, already existing courts were turned upside down through purges of judges and other officials during the many campaigns, such as those to Suppress Counterrevolutionaries, the Three Antis, and Five Antis. Without the highly skilled and experienced, if politically suspect, old regime officials, urban courts and other institutions had difficulty continuing to function. Many cities resorted to mass rallies in the early 1950s to prosecute hundreds or even thousands of criminals en masse (sometimes punishing them-occasionally even by execution-immediately afterward). Once the campaigns subsided somewhat and the new institutional framework was enshrined in foundational laws, the urban courts returned to more or less routine functioning by the mid-1950s. ${ }^{17}$

The relative calm of the First Five-year Plan period (1953-57) was disrupted, however, in both cities and rural areas, by the Anti-rightist Campaign of 1957 and especially the Great Leap Forward (1958-62). Courts in the countryside became more heavily politicised during this period than any other, prosecuting multitudes of alleged counterrevolutionaries and punishing them very harshly, quite often for crimes related to their pre-1949 conduct or alleged misdeeds during land reform. ${ }^{18}$ Also during this period, 'reeducation through labour' (laodong jiaoyang), a form of administrative detention that allowed police to detain people without judicial recourse for up to three years for minor offences, became a favoured tool of public security bureaus, and appears (particularly in the early 1960s) to have been used to deprive many newlyurban workers of their urban residency and relocate them back to their 'home' villages. ${ }^{19}$ In the cities, the Great Leap Forward years were also a time of intense politicisation and political competition in the legal system, though most of this played out in the prosecution of workers for economic crimes related to cheating or undermining the aims of the new planned economy. ${ }^{20}$ Those alleged to have stolen supplies, sold ration tickets, or shirked official duties came in for especially harsh punishments. But so did those who were accused of undermining the Great Leap's radical mobilisation through 'reactionary speech' (fandong biaoyu) - for example, in questioning unrealistic plan targets or criticising excesses-or other misdeeds or omissions of thought or ideology.

During the 1962-66 period, both city and countryside saw reduced political intervention into most cases and an increased use of reeducation through labour to handle petty crimes and send would be migrants into cities back to rural hinterlands. The lack of much political intervention during this time actually reflects a decreased 
use of formal legal processes and institutions as much as anything else. The Socialist Education Movement played out very strongly through the Chinese political system and legal apparatus, just not as clearly through direct and overt prosecution.

The Cultural Revolution years are often erroneously assumed to be a period during which law and the legal system ceased to operate or function. ${ }^{21}$ This is completely false. In both cities and rural areas, courts and other legal institutions continued to operate. Overall, the Cultural Revolution certainly led to many urban judges and officials being displaced and a much less predictable implementation of justice in cities, ${ }^{22}$ but in some rural settings it actually produced a far more professionalised legal order than might otherwise have been present, precisely because of the involvement of military cadres and 'revolutionary committees,' as well as the entry of rusticated youth and other urban intellectuals into many rural settings. ${ }^{23}$

Ultimately, by the end of the Maoist era the Chinese legal system was much more institutionalised in its form and regularised in its functioning than it had been in 1949 . This was due primarily to the consistent assertion by Mao and his allies of his charismatic authority and claims to absolute leadership of the general revolutionary direction. The persistently mobilisational character of Maoist justice, however, resulted as much from the contestation of other rival political currents fighting for power as any 'Mao in Command' ideal. In fact, had Mao's authority been more ironclad and the polity been more stable, it seems likely that we would have seen the emergence of a more settled legal order in China well before 1978. Yet, on the eve of reform, Chinese politics was as fractious as ever and the mobilisational character of Chinese law remained unchanged, despite all of the great upheavals in Chinese society more broadly.

\section{The Rise of the Reform-era Hybrid}

Importantly, the advent of the reform era in 1978 did not mean a sudden break from the Maoist order or a comprehensive embrace of Anglo-American or Western models of a rule of law. Instead, the major changes that did occur were the fixing of polity membership and a conscientious decision on the part of Deng and other leaders to foster the development of a market economy. This led to a distinctive hybrid legal regime that persists to this day, in which criminal law is characterised by neotraditionalism-in which entrenched powerholders intervene pervasively into legal processes to protect their interests-while civil law, especially in the commercial sphere, was marked by what I term 'rule by law'-in which a stable polity refrains from intervening into adjudication of specific cases. ${ }^{24}$

Once the struggle against the Gang of Four was complete and Hua Guofeng had been effectively outmanoeuvred, the new order led by Deng Xiaoping faced two essential tasks: keeping itself firmly in power, preventing any challengers, and promoting the market economic development they promised as China's salvation and pathway to modernity. The first required pervasive intervention into the adjudication of criminal cases to ensure that any potential challengers to the new market order or, more bluntly, to the power of Deng and his faction, lost and were effectively sidelined or eliminated. The second necessitated the rollout of more predictable and formally rational adjudication processes and venues for civil dispute resolution to underpin a new system of contracts and market relations. We can see this pattern from at least the early 1980s forward, with 
the imposition of campaigns like 'strike hard' (yanda) in criminal law alongside new systems of arbitration and legal clarification in areas like torts, contracts, and property law.

Indeed, without continued extralegal authority for the coercive apparatus, ${ }^{25}$ China's leaders could not be confident in their ability to maintain power in the form of a polity stabilised since 1978. At the same time, without 'tying the regimes hands, ${ }^{26}$ China could never facilitate the development of markets on the scale or of the nature envisioned by Deng and his successors. Neotraditionalism and rule by law thus went hand in glove in the reform era's particular developmentalist authoritarian order.

\section{Reassessing China's Legal Regime}

In sum, Mao's charisma helped prevent a breakdown of law or degeneration into a true bellum omnium contra omnes during the first three decades of the PRC. At the same time, his lack of total authority and the continuing high-stakes conflicts and struggles that characterised politics in the Mao era prevented any hardening of the polity's boundaries or full routinisation of formally rational legal processes or adjudication. What prevailed was a highly idiosyncratic and astoundingly long-lived mobilisational legal regime, in which law definitely existed and legal institutions absolutely functioned, but in which law was always both a tool and a venue for political mobilisation and contestation. Understanding Maoist China's mobilisational legal politics on their own terms is thus critical to avoiding mischaracterisations or assertions of lawlessness or obfuscations caused by trying to evaluate its legal order against some explicit or implied rule of law standard or template. 


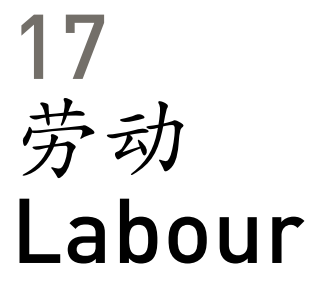

Covell MEYSKENS

mages of work were a key genre in Maoist visual culture. There were images of people smiling as they worked to build an industrial base for socialist China, but also of people whose countenance expressed total absorption in work by either focussing completely on the object they were producing or staring intently at their colleagues during meetings or training sessions. In these photos, the Chinese Communist Party (CCP) was often not immediately visible-Party members did not wear clothing that distinguished them from ordinary people-but its 'spirit' (dangxing) was present in the gaze of the workers and energy transmitted through their gestures. The accompanying texts further emphasised that the CCP was always beside them, guiding workers forward into a radiant future.

Since that promised socialist future had not yet come, people expectantly laboured away at laying railroads, forging factories, and bringing new lands under the plough. In visual representations of workers engaged in these practices, there are no traces of tensions between workers of different socioeconomic positions, backgrounds, or competences. ${ }^{1}$ The developmental process of transforming China from an agrarian country into an industrial powerhouse appears to involve absolutely no coercion. In the imagined world of Mao era labour, no government official ever forces recalcitrant workers to perform their job against their will. No administrator ever reprimands or punishes workers for being lazy, dragging their feet, or disobeying orders. ${ }^{2}$ In photographs, the CCP and Chinese workers seem to be seamlessly connected. China's socialist revolution looks to be a complete success, and as Vladimir Lenin dreamed would happen, the division between state and society had withered away. ${ }^{3}$

According to official propaganda, the will of the Chinese people and the CCP had become one and existed together in perfect harmony, as they enthusiastically walked together on an ever-triumphant developmental road towards socialism (see also Franceschini's essay in the present volume). ${ }^{4}$ Workers broke production records, 
national economic output ascended higher and higher, and Chinese socialism grew stronger and more prosperous by the day. The Party-state allocated fairly the fruits of labour, and everyone was content with what they gave and received from socialist China. The mass media, thus, contained no images highlighting the administratively managed urban-rural divide or the preferential treatment given to state-owned enterprises, such as more welfare guarantees. ${ }^{5}$ In my study of Maoist visual culture, I have rarely encountered mass media photos of Party administrators paying workers for their labour-time even though the reception of wages by urban workers and workpoints by rural labourers was a managerial ritual that punctuated everyday life. ${ }^{6}$

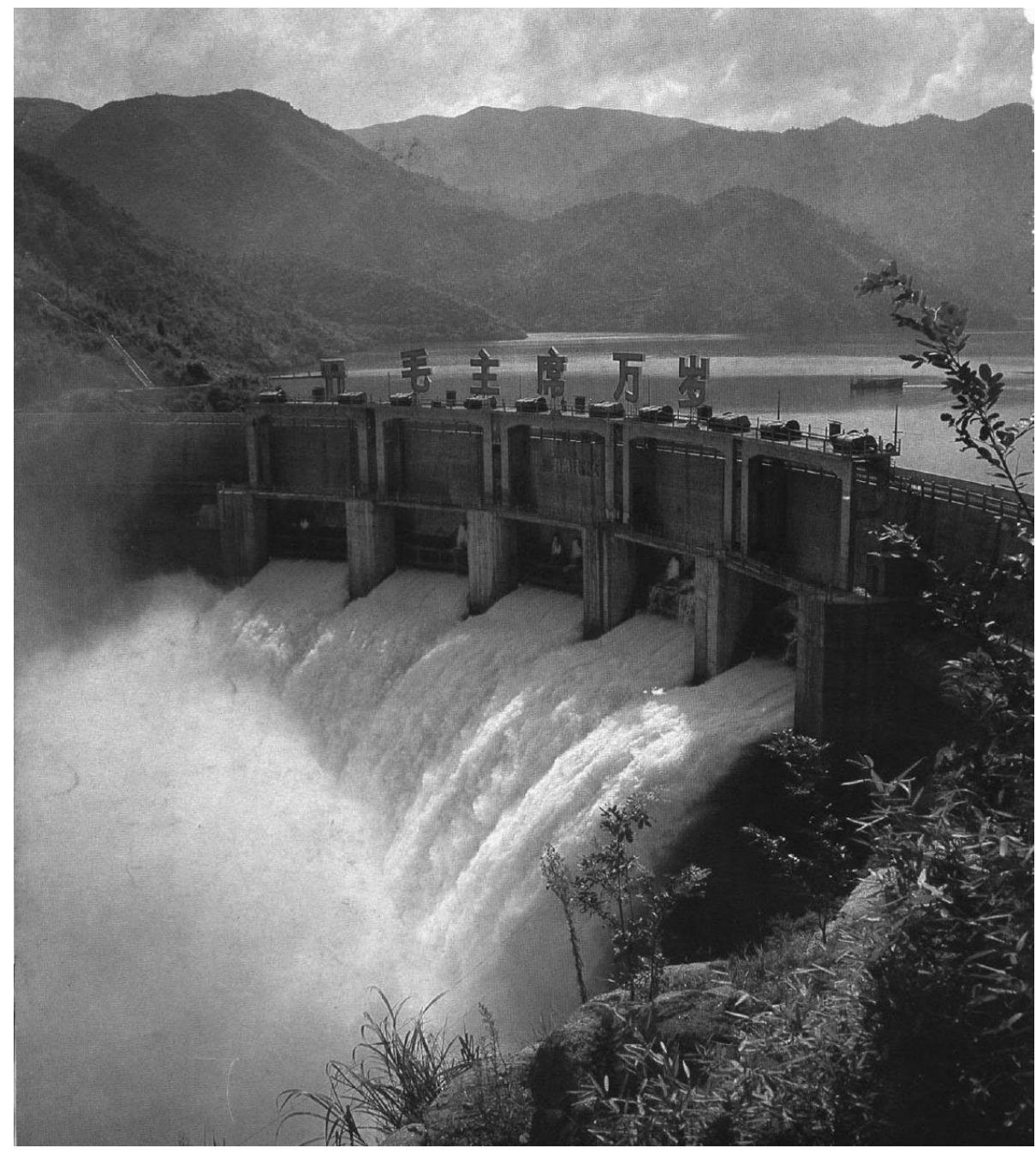

Dam, 'Long Live Chairman Mao!' (early 1970s) 


\section{Compensation, Community, and Socialist Reciprocity}

Despite attempts to erase the difference between the Party and the workers, Mao-era images still contained traces of their differentiation. This political divide is perceptible in photos of local Party representatives giving work units (danwei, see Kevin Lin's essay in the present volume) material objects, such as an apartment block, a hospital, a cultural centre, or a radio. ${ }^{7}$ More than a wage, these objects, and how they were given, resembled a gift granted to the collective group rather than to one individual or family. The Party did not bestow a work unit with a new apartment block because of a contractual obligation but on the basis of a generalised reciprocity. ${ }^{8}$ There was an expectation that the Chinese people were part of the same shared endeavour, and individual contributions would even out over time like drops accumulated in a vast ocean. The Party presented a group of workers with a new material object, not because of their economic performance but as a symbol of the Party's unconditional concern for their wellbeing and gratitude for their ardent commitment to China's socialist cause.

In line with Maoist China's productivist ethos, most images did not depict consumer goods limited to the consumption of an individual, family, or particular work unit. The Party's gifts were electrical lines bringing power to large undifferentiated areas, stockyards full of machinery laying in wait to raise national productivity, or railroads shuttling around passengers and freight for the good of the entire Chinese people.

In return for its generosity, the Party demanded altruism. People were not supposed to act like bourgeois subjects who worked only on the basis of material incentives or in pursuit of personal fame. Images in the mass media made it look as if China had already realised the communist ideal of workers motivated by their commitment to the collective good. Within the phantasmagorical realm of Maoist imagery, the disappearance of any contradictions between the Party and labour render the term 'command economy' misleading, since the Party no longer needed to give 'orders' to the Chinese people who already knew in their hearts what needed to be done.

\section{Dead Labour and the Socialist Pastoral}

But workers' power is also augmented by the prosthesis of machinery and technology. What Karl Marx called 'dead labour' are the material objects of production that are used to achieve even higher levels of economic output. ${ }^{9}$ Monumental dead labour, such as factory complexes and hydroelectric dams, was a recurrent motif in Mao-era visual culture as a testament to China's rise as an industrial power (see the image on page 104). Thanks to labour's collective efforts, new railroads were traversing mountains and linking the totality of the nation into a cohesive whole. Dams were looming high above riverbeds and pumping electricity into power grids. Factories were sprouting up all over, and assembly lines were churning out ever-larger quantities of standardised industrial goods. $^{10}$

Some images of monumental dead labour just showcased the machinery. Others depicted different relationships between labour and machinery. One kind of image staged the moment when workers began to use a machine for the first time, such as a tractor, and locals gathered around and gazed with joyous wonder at the new industrial world emerging before their very eyes. Other human-machine images depicted workers 
at home in their new machine-bodies and technologies. There were no intimations that the industrialisation of work was an alienating process that subjected labour to a disciplinary regime in which administrative personnel regularly monitored workers, evaluated both their political and economic performance, and compiled dossiers on their activities that often determined their future career trajectory. ${ }^{11}$ Visual language rendered the socialist machine-human nexus as a source of empowerment, efficiency, and productivity.

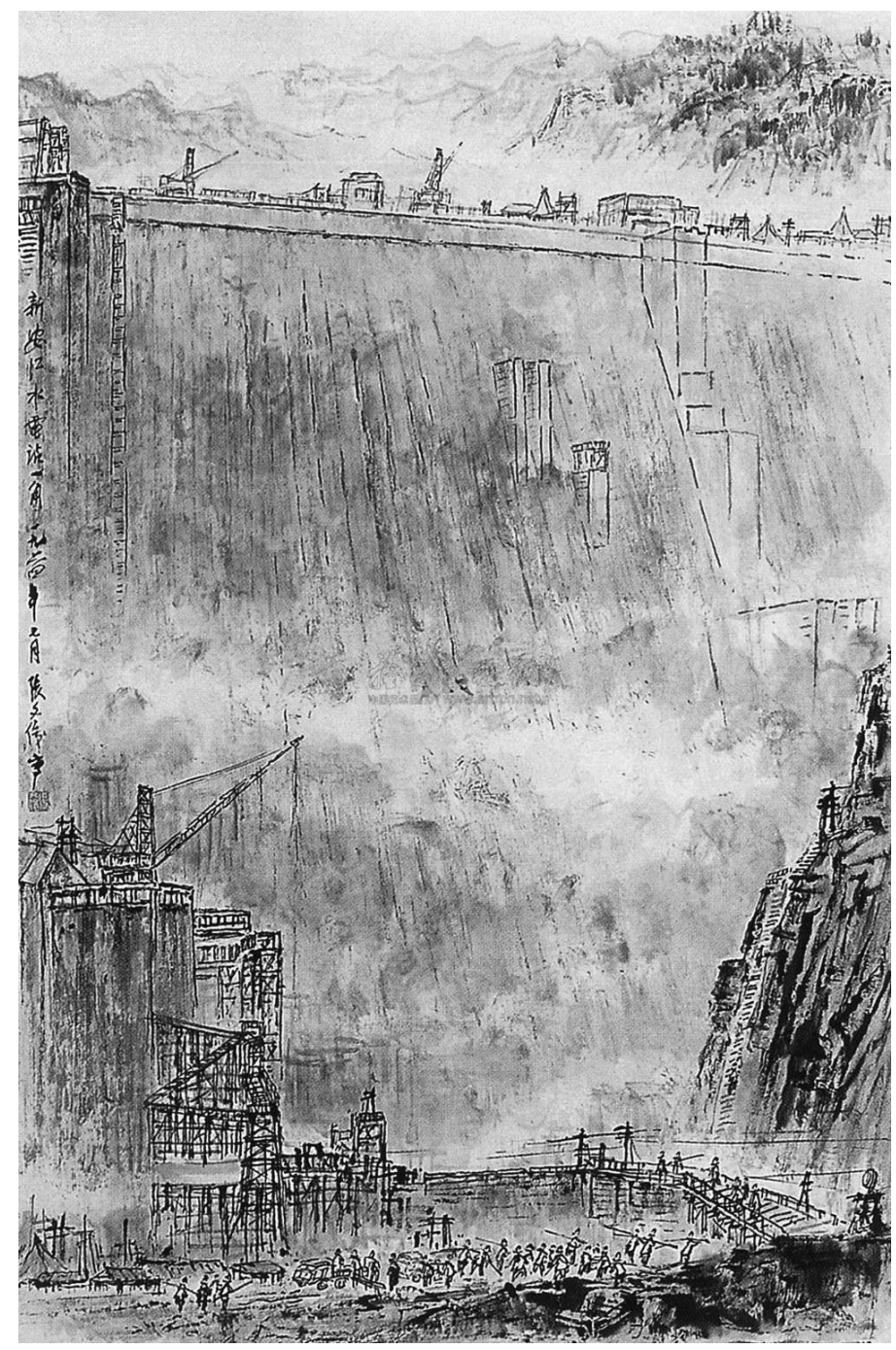

Zhang Wenjun, The Xin'an River Power Station (1964) 
But there are also more ambivalent images in which labour was dwarfed by a large piece of machinery that took up most of the visual field. The diminutive size of the workers might seem to suggest their insignificance compared to industrial machines, which tower over them and have productive powers far beyond their bodies. Yet, these images could also imply the potency and ingenuity of human labour to invent such mammoth industrial creations. Though the latter was probably the meaning the Party intended at the time, the images also registered the feeling of being crushed beneath immense industrial embodiments of dead labour.

In classic mountain-water paintings, massive mountains and rushing rivers soar above small homes and puny people, suggesting the relative triviality of human endeavours compared to the spatial awesomeness and temporal durability of the natural world. ${ }^{12}$ In contrast, many Mao period photographs were of construction sites in which the natural environment did not soar over labour. Instead, workers were in the foreground, as they 'worked hard to move forward' (lizheng shangyou) Chinese development. Photos of this sort were saturated with the Maoist view of industrialisation as a heroic militarised process in which workers were fearless soldiers whose industriousness and spirit of 'self-reliance' (zili gengsheng) enabled the Chinese people to dominate the natural environment (see the essays by Yang and Lora-Wainwright in the present volume). Even in the images of nature conquered and industrial modernity achieved, there was no tinge of the industrial gothic aesthetic, so pronounced in Western art, which revels in portraying humanity's technoscientific inventions as prying open Pandora's box and unleashing uncontrollable monsters. ${ }^{13}$

In the painting of the Xin'an River Hydropower Station (see the image on page 106), hydroelectricity is not a jarring alien force whose introduction does violence to the natural order and strikes fear into the viewer. Instead, the painting is an example of the Mao era's industrial pastoral aesthetic in which industry was not a destructive imposition on nature but a beautiful improvement, undertaken by what Zygmunt Bauman has called a 'gardening state' which removes unwanted impediments to progress from society and the natural world and cultivates what state agents see as best for the whole national community (see Sorace's essay in the present volume). ${ }^{14}$ Maoism's industrial pastoral aesthetic permeated paintings of factories too. For instance, in Xu Xingzhi's Steel Forests (see the image on page 109), smokestacks emit exhaust without causing concern. Not only was there no indication that air pollution was harmful, but factory exhaust was even seen as a visually pleasing mist that added colour to the skyline.

Tightly connected to this positive view of industrialisation was imagery of CCP leaders. Photographs in mass media figured leaders as a special kind of worker: they were the diligent political shepherds of Chinese socialism. ${ }^{15}$ Normally, central-level officials fulfilled their role as guardians of the Chinese nation from a distance and interacted with work units through the medium of documents, newspaper columns, radio addresses, and news clips. The mass media, however, made the public aware that though CCP leaders might be far away, the Chinese people were always on their minds, and they were at every moment tirelessly working to advance socialism. Newspapers and magazines were awash with photos of CCP leaders serving the socialist project. They held meetings to discuss issues of national import and hammer out policies that would improve the lives of every citizen. Another common picture of the Partyleader-as-worker was a top official going on an inspection tour of different parts of the 
country. On inspection tours, high-ranking officials incarnated the ideal of the mass line (see Lin Chun's essay in the present volume). Visiting the grassroots showed that the centre still strived to be close to the people and held the masses' interests in their hearts, despite their busy meeting schedules.

\section{The Afterlives of Maoist Labour}

With the passing of the Mao era, new ways of depicting labour emerged. One emblematic example is the photograph of a tile-making factory distributing televisions to individual workers in 1984 (see the image on page 109). Like images from the Mao period, nearly everyone in the photo is smiling and content with how Party officials are compensating the Chinese people for their labour. Mao-era slogans also still line factory walls and exhort workers to 'work hard on moving forward' the Chinese economy. But like the letters that compose this slogan the meaning it held in the Mao period was beginning to fade as China entered the reform era.

The other contents of the photo foreshadow what hard work would come to mean in postsocialist China. The viewer's eye is not drawn to the collective, as the faces in the background are blurred. The spectator's attention is instead pulled toward the individual man at the centre of the scene confidently walking forward. Local Party representatives are also not distributing goods that will be available for use by all the members of the work unit. Only the individual man is receiving a television as material compensation for his hard work. If the man wants to allow his coworkers to enjoy together the pleasures of the silver screen, it is up to him and his family because the television is theirs-it does not belong to the collective.

Here, we can see the decomposition of the public life of Mao's China, as work units transformed into capitalist companies concerned about not just maintaining their bottom line but outperforming their competitors and turning a profit in emerging markets. With this transition, work units expended fewer funds on group cultural events to fill the non-working hours of Chinese labourers. With such collective activities gradually becoming passé in the post-Mao era, the social life of labour became more privatised and centred on the family and individual. ${ }^{16}$ The man at the core of the photograph walking off with his own personal television also signals the advent of a new capitalist regime of social stratification in which it is viewed as normal that some Chinese workers earn higher wages which enable them to accumulate more material goods and attain a higher socioeconomic position than their compatriots.

The television at the heart of the photograph, however, is not only a sign of the new capitalist times coming into view in China. As a Chinese-made television, it is also a marker of what the CCP had accomplished under Mao. It had acquired the ability to mass produce televisions, and that feat depended on a variety of industries. Mines were required to extract metals needed for electrical circuits and wires. A petrochemical industry was necessary to generate plastic coverings to encase wires and enclose the television. A body of technicians and engineers was also vital to the design and manufacture of the television. This photo of a man carrying off a television to his home can thus be read as both visually representing the fruits of the Maoist developmental state, while pointing towards a future in which Chinese labour would produce the miracle of economic reform and further erase itself from the picture. 

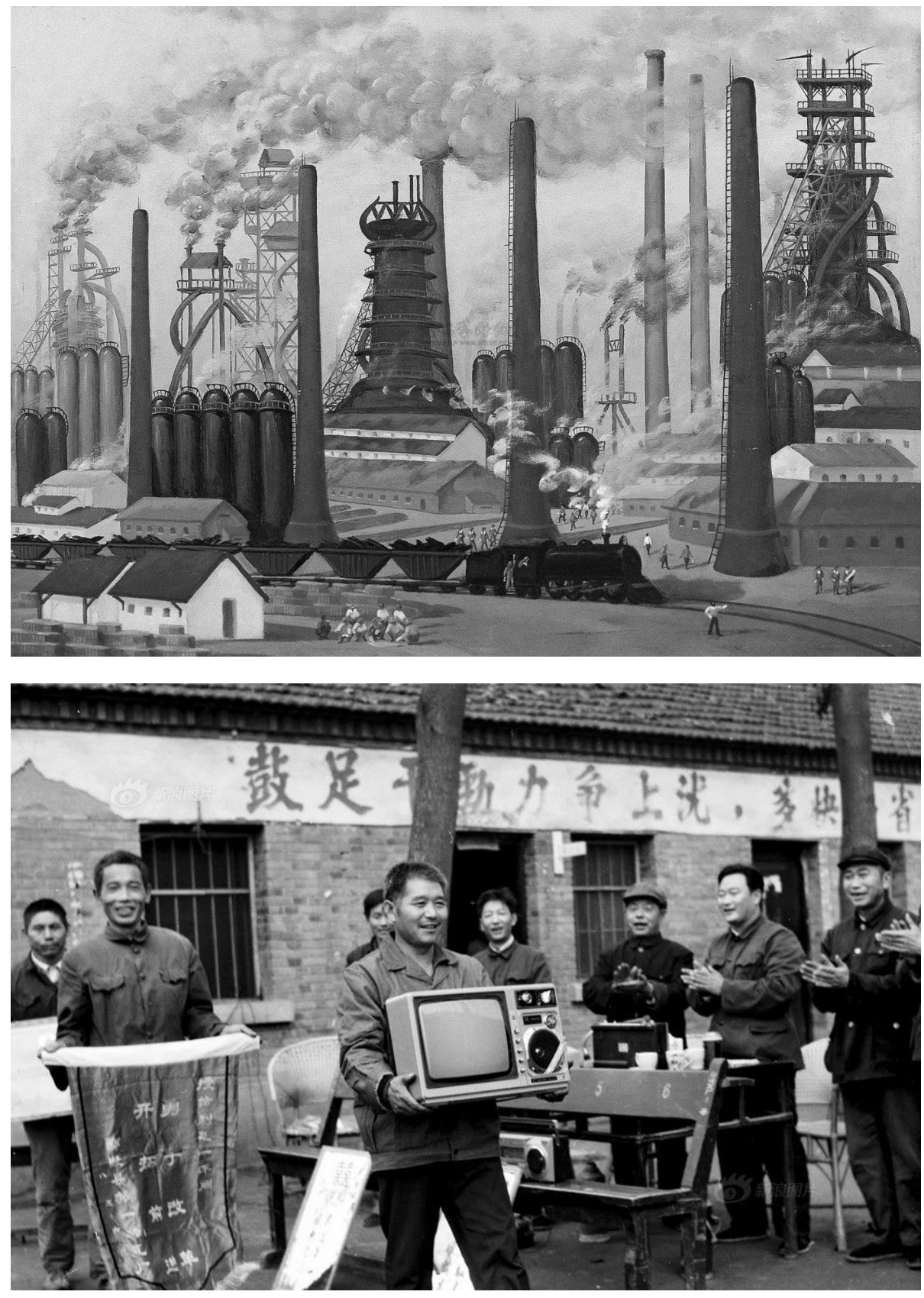

(1) Xu Xingzhi, Steel Forests (1962)

(2) A worker receives a televison at a tile-making factory in 1984 



\section{8 \\ 一大二公 \\ Large and Communitarian \\ Luigi TOMBA}

What should we call them? We can call them people's communes or not call them people's communes. My opinion is that we should call them people's communes ... . People's communes are both large and communitarian. Many people, large territory, large-scale production, large-scale services.

Mao Zedong, $1958^{1}$

$M$ ao Zedong's coining of the slogan 'large and communitarian' (yida ergong) accompanied the launch of the people's communes (renmin gongshe) in 1958. ${ }^{2}$ In the language of Maoism, collectivism had come to include a territorial aspiration, and the success of the communes depended on their size (see Gao's essay in the present volume). More than one hundred years earlier, in 1845, Friedrich Engels had instead emphasised how collectivism aimed at creating new, efficient spaces for the working class:

And then the preparation of meals-what a waste of space, ingredients, labour, is involved in the present, separate households, where every family cooks its little bit of food on its own, has its own supply of crockery, employs its own cook, must fetch its own supplies separately from the market, from the garden, from the butcher and the baker! ${ }^{3}$

In the same Elberfeld lecture, Engels was keen to call attention to Robert Owen's 1,650 square-foot residential block used to concentrate and enhance working-class labour power. 
Besides the mundanity and technicality of Engel's vision and the grandiosity and focus on the wider territory that Mao expressed from the beginning of the Great Leap Forward, this different way of thinking about how to build collectivism also signals one of the less researched ways in which Maoism diverged from Bolshevism. Mao wanted communes to be big, something that could inspire awe in the imagination of the masses. It was about conquering the territory, extending the reach of the state. Only then would it be communitarian. Efficiency was a very distant priority for the Great Helmsman. The large territorial units were to replace the artificial division between cities and countryside (yida), while a large group of people were to collectively own the means of production (ergong): this was the double engine of communist transformation. The very size of the communes, sometimes as large as a county, and where means of production where in the hands of a local government at times hundreds of kilometres from agricultural sites, became one of the reasons why they failed. Already in August 1959, after the Lushan Conference revealed the first cracks in the leadership regarding the Great Leap Forward, the Chinese Communist Party (CCP) exposed the exaggerations of the communes and suggested a prudent return to a more 'natural' collectivism-one that relied on cooperatives and production teams.

\section{Just a Leftist Mistake?}

The ideology of 'large and communitarian' went down in history as a 'leftist mistake' (zuopai сuоwu). Nonetheless, it continues to signify one fundamental difference between the two main forms of socialist organisation: the efficiency-seeking Soviet version, and the territorial concerns of the Chinese version that aimed at seizing control of the collective strengths of a largely rural society. Notwithstanding the many contradictions, when pointing our gaze at a longue durée history of socialist China's developmental ideology, it seems clear that maintaining control and shaping physical territory is still a high-priority strategy. The two most significant attempts to reshape China-the communes and the current urbanisation drive-while undoubtedly different in ideology and form, are ultimately territorial projects of a state constantly obsessed with the patrolling of the shifting geographical and human borders between cities and the countryside. Through them, the state-admittedly different states with different priorities at different historical moments-is attempting to control increasing chunks of the country's vast territory and impose a nationwide rationality.

In the 1950s and 1960s, the rationale underpinning the communes was the need to control the prices of agricultural products to facilitate industrialisation and the transfer of resources from agriculture, of which China had plenty, to industry, of which China had little. Today, it is about imposing the rationality of the planning state as a means of resolving the messy territorial, environmental, and property rights uncertainties of the still existing collectives. In both cases, it was a state-directed project that implied the advantages of control-state-owned communes were the plan then, rationalisation through state-owned land in the cities is the goal now. Both imply that, once the state becomes involved, size is increased and the larger scale allows for rational decisions taken by a higher planning authority. The traditional reliance on large ventures that project the power of the state onto the territory, and limit the wasteful private use of land, survives the otherwise obvious differences between the two campaigns. No doubt 
one was aimed at gaining control of the countryside, the other of cities; one had the goal of gathering productive forces, the other of assembling the consuming masses; one was aimed at rationalising consumption in a low-resource environment, the other to allow a growth in the value of land and the real estate built on it to support the expansion of cities. Yet, in both cases there was a reliance on 'large,' where size and scale allowed for the implementation of common priorities.

The other implication of 'large' is integration. When the CCP launched the ultimately unsuccessful extension of communes to the cities in 1959-the so-called 'urban people's communes' (chengshi renmin gongshe)-they were supposed to 'become the unifying organisation to integrate production, trade, distribution, and public services and to unify the politics of gong nong shang xue bing (workers, peasants, traders, intellectuals, and soldiers). ${ }^{4}$ When Shanghai communised in the same year, planners hailed a new era of integration with three emphatically stated goals: a) turn the isolated areas of the municipality into 'planned industrial and agricultural areas' where the two activities support each other; b) change the former separation between industrial and cultural life; and c) eliminate the existing separation of urban and rural in planning the territory. ${ }^{5}$

Talks of an integrated development of cities and their hinterland have been one of the main goals of current urbanising trends: among many urban slogans about the sustainable city, chengxiang yitihua, or the integration of the industrial periurban with the hypermodernity of the inner cities, remains one of the main-and most elusivegoals of today's planners.

\section{A Spiritual Connection}

The second objective of the original slogan was never abandoned and contributes to the CCP's grip on power today by establishing the connection between the territorial and the spiritual objectives of a policy campaign. In 1958, ergong was meant to signify a movement towards a more communitarian society, where the cohesiveness of communities would overcome their lack of resources, where nature would be the ultimate enemy, and growth a utopian benchmark that could only be achieved through struggle. Today the CCP has hardly abandoned the goal of controlling the motivation of individual citizens, and mounts campaigns in which the good citizen is a righteous, law-abiding, and high-consuming human being. The reward is no longer a utopian communist society for all, but a more ordinary place among the social elites. Faith in the Party's authority is an element of that righteousness and a condition to be part of this new elite. While gong, the public community of collective memories, may not be the ultimate goal anymore (despite attempts to revive it), controlling the definition of public good remains central to any ideological efforts of the Party.

In this process of transformation the officially promoted and reward-based conception of morality has changed radically. In 1960, the goal of the communes was described as 'reforming radically the lifestyles of the masses, ultimately eliminating the distinction between cities and countryside, between industry and agriculture, and between manual and intellectual labour.' When planning communes in the city, for example, it was imperative that the new communist way of life be inscribed in the new spaces: 
In the old cities, the design of services and residential areas was influenced by a certain idea of 'family' that still reflected capitalist privilege and focussed on individualistic lifestyle. For example, houses were planned with an apartment for each family, with each apartment featuring its own kitchen and stove. Once the door was closed, the home became a sacred, undisturbed space, where women were bound to cooking, raising children, and other home chores. Two doors faced each other or neighbours lived one above the other but they would never visit even if their chickens and dogs could hear each other's calling (jiquan xiang wen, er laosi bu xiang wanglai). These buildings of one-family-one-house where households cook meals on their own are incompatible with the collectivisation of life and the socialisation of service labour. ${ }^{7}$

The gong that this description suggested was a utopian approach to the atomisation and the alienation (see Ou's essay in the present volume). The critique often heard by voices nostalgic for a more collective life usually emerges in the context of lifestyles that can be characterised by today's gated communities and privatisation of governance in new real estate residential communities. ${ }^{8}$ It remains, however, a fact that lifestyles even today are not the expressions of individual choice but rather of individuals willingly buying into a certain aesthetic, packaged by the developer of a large community with the approval of the local state that is keen to use new residential settings to attract 'high-quality' citizens. It is not uncommon for developers to sell a specific lifestyle and even to register its trademark, and for local developers to reproduce the same language associated with campaigns of the state.

Yida ergong is a lost slogan, one that reminds us of a different age of China's modernisation. Yet, $d a$, intended as the need to shape the territory and to project the power of the state on it, and gong, a public good around which the building of a social coalition is possible that justifies the ideology of the ruling Party, are both still pervasive in today's China. 
19

路线斗争

Line Struggle

Yoshihiro ISHIKAWA and Craig A. SMITH

$\mathbf{U}$

$\mathrm{p}$ to a certain point in time, the histories of communist parties in any country can be seen as sequences of 'line struggles' (luxian douzheng). 'Line' is a specialised term that indicates a specific direction or guiding principle for political activities and is directly linked to whether or not a path is deemed revolutionary. However, it must be noted that the expression's use in politics and political movements was nowhere to be found during the time of Marx and Engels. It was not until the twentieth century that this expression became of common usage, specifically during the revolutionary activities of organisations such as the Lenin-led Communist Party and the Comintern. Moving from theory to practice, Marxist theorists saw that the success or failure of a given activity was inextricably related to its guiding principle, therefore particular political directions came to be referred to as 'lines.'

Walking the correct line was no easy task. Taking up a radical guiding principle that had drifted too far from reality would inevitably lead to tremendous sacrifices, oppression, and conflict. Conversely, accepting the status quo and following more moderate principles would be to completely lose any possibility of revolution. Generally speaking, the official histories of communist parties would record these as leftist or rightist 'deviations' resulting in an incorrect line.

China is no exception to this. The 1945 'Resolution on Certain Questions in the History of Our Party' not only established perspectives on the correct line according to Mao Zedong's revolutionary policy, but also identified left and right deviating lines. This understanding of history as line struggle continued to restrain the Chinese official representation of history until the death of Mao. Since then, the term has all but disappeared as changes to Chinese Communist Party (CCP) leadership have gradually come to be called 'power struggles' (quanli douzheng), in which lust for power, rather 
than ideological principles, appears to exert influence on the direction of the CCP. This essay outlines the appearance of the term 'line struggle, its usage, and its disappearance into the shadows of history. ${ }^{1}$

\section{A Genealogy of Line Struggle}

In China, the understanding of history as line struggle appeared in the 1930s, when the Communist Party of the Soviet Union exerted considerable influence on the CCP. Still, it was only after the establishment of the People's Republic that this view of history became dominant, achieving a prominence that would remain until the death of Mao Zedong. With the onset of the reform era, former proponents of this discourse acknowledged the terrible force that it had exerted, and the Party deliberately and expeditiously stopped all use of line in official documents.

The Chinese term luxian is a translated equivalent of the English term 'line', the Russian 'линия' (linija), and the German 'linie.' This modern Western intellectual concept is rendered into the same Sinitic characters in Japanese, in which it is pronounced rosen. It is well known that in many cases modern conceptual terminology-which was imported into China and Japan from the West-was first translated into Japanese and then flowed into China during the late Qing Dynasty. Key ideas from Marxist theory, as well as early Chinese socialism, also entered Chinese lexicons and conceptual frameworks through translation from Japanese. However, in the case of line, it was not a simple matter of the Chinese term luxian being acquired from the Japanese term rosen. First, we must outline the process of how line came to be a Sinitic concept.

The formulation of line into the two Sinitic characters of luxian did not occur in Japan, but was an effort of China's left-wing activists. Logically, before the term line could be discussed in the context of a revolutionary movement, a large movement had to exist. Although research into Marxist theory was advancing in Japan in the 1920s, the concept remained meagre and limited in practice. Japan's socialist movement was restricted and obscured by severe repression by government officials, and the idea of line failed to develop to any degree under this climate. However, for the CCP, it did have an impact upon, and power over, the degree to which leadership could be criticised during pivotal events. It exhibited considerable influence in determining the course of the revolutionary movement under Chen Duxiu's leadership and the First United Front with the Nationalist Party (guomindang, hereafter GMD). It was also prominent shortly after this, during the period in which the Party fell under Li Lisan's leadership, demonstrating power over the extent of the military occupation of Changsha in the summer of 1930. Due to these controversies, the Comintern then used line to discuss the appropriateness of developments in the CCP.

The translation of line as luxian appeared early on. One of the first instances of the usage of this term can be found in the documents from the CCP meeting that took place on 7 August 1927, which formally dissolved the First United Front with the GMD. The meeting severely criticised the leadership of Chen Duxiu for the haphazard compromise with the GMD, labelling it as an 'unprecedented, compromising, and opportunistic line. After this use of line as rebuke, the term came to be employed as a suffix after the name of the Party leader who was pushing for that specific kind of political strategy. An early example of this can be seen in the 'Li Lisan Line'-a temporary 
push for urban uprisings and attacks on cities by the Red Army in 1930. In November of that same year, the Comintern sent a letter to the Central Committee of the CCP. It said that the error of 'Comrade Li Lisan's political line' was in opposition with the Comintern's line for being 'non-Bolshevik, non-Leninist', with the Russian term linija translated as luxian. Incidentally, at that time in Japan the term rosen was only being used to indicate routes of railways or other transportation methods. In due course, the political usage of the term line would appear even in Japan, but for a long time the Li Lisan Line was referred to as the 'Li Lisan Course' (Ri Rissan kōsu). ${ }^{2}$

Therefore, it could be said that luxian was a political concept that directly entered the Chinese lexicon from Soviet Russia. As the CCP kept up its fight through shakeups and redesigns at every twist and turn of the revolutionary movement, whenever a new leadership group came into power, they would criticise the decisions of their predecessors as 'so-and-so's line.' This became a normal occurrence at every transfer of power and thus the line struggle historical perspective came to be, constructing a historical narrative based upon the validity of the line of successive leadership groups.

\section{From Stalin to Mao}

The formation of this unique historical perspective had a tremendous impact on communist movements worldwide, as can be seen in the so-called 'Stalinist encyclopedia,' the History of the Communist Party of the Soviet Union (Bolsheviks), commonly known as the Short Course. This book's most outstanding feature was its treatment of the successive internal line struggles throughout the history of the Communist Party of the Soviet Union. Those occasional struggles served to validate the righteousness of Lenin and Stalin. Although this book is now seldom discussed, it influenced not only the Soviet Union, but also the global leftist socialist movement that included China. From an intellectual perspective, it was not only the guiding principle of the communist movement, but it has also exerted influence on history, political science, and other related fields. The degree of the book's extensive influence should be revisited and reappraised.

In China, Mao Zedong's admiration for the spirit of the Short Course led to the publication of successive texts that varied markedly, starting with the adoption of the 'Resolution on Certain Questions in the History of Our Party' in the Seventh Plenary Session of the Sixth Central Committee of April 1945. No other communist party anywhere in the world adopted its historical narrative into such a resolution. The four periods of line struggle between an incorrect line represented by the Party leadership of the time and a correct line centred upon Mao Zedong have since then become well known. The four incorrect lines that were formalised through this Resolution were: a) the right-opportunist line of Chen Duxiu; b) the left-deviationist line of Qu Qiubai; c) the left-adventurist line of Li Lisan, and d) the left-opportunist line of Wang Ming. Accepted to this day, this Resolution stipulates a Chinese historical narrative that posits these four as mistakes in Party history, in contrast to the persistent advance of Mao Zedong along the correct line. Among these, Wang Ming himself was a regular user of the term line, and he even once released a pamphlet titled: 'Two Lines: The Struggle for the Further Bolshevisation of the Chinese Communist Party.' Wang Ming and his followers, known as the '28 Bolsheviks' or the 'Returned Students' due to their studies 
in the Soviet Union, were ardent followers of the dogmatism of the Soviet school. Concerning the Stalinist historical perspective on line struggle, Mao and Wang were disciples of Stalin in equal measure.

There are reports that Mao Zedong, who was effectively the author of the Resolution on History, also raised the alarm over the casual use of the term line struggle. The Resolution was being drafted at the Politburo meeting that took place in November 1943. It was the very meeting that was held to criticise the Wang Ming Line, when, according to the Chronicle of Mao Zedong Thought, the official chronology of Mao Zedong's thought and discourse, Mao was recorded as stating that: 'The History of the All-Union Communist Party seldom mentions the term "line," yet our Chinese comrades enjoy chewing over the word. It would be best if we used it sparingly. ${ }^{3}$ It is not possible to verify either the authenticity of these words or Mao's true intentions at the time, which appear paradoxical in several ways. First, the use of line as a suffix was widely popular at that time, largely because of Mao himself, and his request for people to refrain from using the term in the future was in tremendous contradiction with his own behaviour. Secondly, the Short Course that Mao referred to above, was none other than the canonical text from which the term line proliferated. Finally, in the 27,000 characters of the 1945 Resolution on History, the term line appeared no fewer than 186 times.

After this, the identification of incorrect lines in the Party history of line struggle did not decrease. On the contrary, the usage of the term only increased after 1949, with Gao Gang, Rao Shushi, Peng Dehuai, Liu Shaoqi, and Lin Biao all falling from power due to their 'incorrect lines.' By the early 1970s, there were ten such incorrect lines.

Known as the 'ten great line struggles', these incidents provided a summarised historical narrative of the development of the CCP. ${ }^{4}$ Needless to say, Mao Zedong himself was the main proponent of this discourse. During his Southern Tour in August of 1971, he explained: 'The correct or incorrect nature of the line determines everything .... The line is the guiding principle .... Problems with the line are problems of principle, and I will not allow anyone to transgress my line.' On various occasions, he declared that the line was everything. ${ }^{5}$

In his political report at the Tenth National Congress, held in August 1973, Zhou Enlai publicly detailed the discourse of the ten great line struggles. Identifying and criticising each of the embattled leaders-all former comrades of his-he avoided becoming the target of the eleventh line struggle. The ten great line struggles held such prominence after that Congress, but they would no longer be raised shortly following Mao's death three years later.

\section{Into Oblivion}

In order to summarise the disorder of the Cultural Revolution and to recompose Party history, at the Sixth Plenary Session of the Eleventh Central Committee in 1981 members adopted a second resolution on Party history, entitled 'Resolution on Certain Questions in the History of Our Party since the Founding of the People's Republic of China.' In this document, the Party recognised the mistakes that Mao Zedong had made in the final years of his life, offering evaluations of both his successes and his failures. The final text totalled 33,000 characters. Although it is considerably longer than the 
original 1945 Resolution, it employed the term line only 22 times. Using the previous conception of line that had long been overly stressed, the new Resolution asserted that: 'Normal disputes between Party comrades have been recognised as errors of line.'

Concerning this remarkable change, $\mathrm{Hu}$ Qiaomu-who was involved in the drafting of both resolutions-explained:

That [1945] Resolution had its faults ... . We can say that the perspective of historical change as the history of line struggles began with that Resolution. The history of the Party retreated behind the curtain, leaving only the history of line struggles on the stage. This was a tremendous mistake. ${ }^{6}$

Before the Comintern raised criticism of the Li Lisan Line, the CCP rarely used the term line. It did not appear in any of the documents from the Second Congress to the Sixth Congress. Beginning in the period of Wang Ming's leadership, Party members used the term abundantly, and its usage became ever sacralised and mysterious. The [1945] Party's Resolution on History cannot be reduced to the history of line struggles. It is difficult to estimate how many comrades have been harmed by the terms line error and line struggle. ${ }^{7}$

In this text by $\mathrm{Hu}$ Qiaomu, we can see that he made a mistake in his attribution of the first usage of the term, which, as noted above, can be found as early as 1927 . Also, by asserting that Wang Ming was behind the initial popularity of line, he made no reference to Mao's responsibility. In spite of these misrepresentations, the 1981 Resolution recognised that the concept and label of line had come to play a negative function in Party's history. Moreover, this text is of particular significance as it was the first to frankly state that this was due to the 1945 Resolution. Thus, in accordance with the 1981 Resolution, the Party resolutely set forth policy that no longer succumbed to the discourse of line struggle or line errors, and as a consequence, although Chinese leaders continue to mention the importance of following the correct line, now the term line struggle has all but faded from vocabulary.

However, one should not forget that in order to discount this discourse and unite the entire Party's understanding of history, the Party had to alter its historical narrative and resort to the use of yet another resolution in the post-Mao era. Once again, history was caged through a resolution of the Party. One resolution followed another, and now this history too must be locked away. To this day, what should be written about Party history, and what must not be written about Party history, remains the sole prerogative of the Party itself. 



\title{
20
}

\section{群众路线 \\ Mass Line}

\author{
LIN Chun
}

n post-Mao China, the concept of the 'mass line' (qunzhong luxian)_consulting the masses, interpreting their will, and implementing policies in their interestshas been widely reviled in public and academic discourse. As the transformative objectives of the Mao era fade into obscurity, all that is remembered is the violence of oppression and persecution, which is condemned in retrospective judgment. Still, whereas in English, with an air of elitist condescension, the term 'masses' conjures up the loss of individuality in an indistinct crowd of people, during the Mao era, to be part of the 'revolutionary masses' was to belong to a collective political subject, which amplified one's sense of individual worth and glory. Today, China's ordinary people could only dream of such substantial and symbolic respect. In addition to its association with Mao-era chaos, the mass line rings anachronistic in an age of conservative governance which, regardless of the political system, attempts to contain 'excessive' democratic desires. How do we approach the mass line in times of mass dispossession, degradation of the public, and waning belief in popular power? If by returning to the lessons from history, the true nature of the present can be accessed and transformed, then the relevance of the mass line lies in its noble conviction as an unfinished project: ordinary people can be proud of themselves as direct producers of both material and cultural wealth in the collective mastery of their own destiny.

\section{China's Lost Mass Line}

The mass line was an innovative concept and a powerful tool of the Chinese Communist Party (CCP) as it struggled to seize and consolidate power. As is typical for political ideals, it is an ideological commitment as well as a working method. By design, it entails a dynamically interactive bottom-up and top-down process of 'from the masses, to the masses', in which the leadership collects scattered views from below and turns 
them into systematic positions and experimental policies, the effects of which are then investigated, debated, and fed once again back into the system. This process of 'pooling the wisdom of the masses' (jizhong qunzhong zhihui) through solicitation, aggregation, articulation, and adjustment repeats itself in an endless cycle. Instead of the competing 'interest groups' of liberal democracies, this form of politics and governance seeks to integrate public preferences for sound policymaking while minimising cleavages and mistakes. Meanwhile, in the communist tradition of rural mobilisation, the Party must attend to every detail of the basic needs and interests of the population, as the core of its social contract with the people, described in the popular analogy of a fish-in-water or seed-in-soil relationship. Institutionally, the mass line is also a novel adaptation of the Leninist principle of democratic centralism which aims at balancing deliberation and discipline, and avoiding bureaucratic dogmatism and blind commandism. When not confined to inner-Party operations, the mass line emphasises popular input based on the premise of the sovereignty of the people. ${ }^{1}$

I have been using the present tense not because mass line politics exists today, but because it is a normative model. For the same reason, an analytical distinction between the rhetoric and utility of mass line is necessary. Historically, Party building, the united front, and armed struggle were taken as the three 'great magic weapons' of the Chinese Communist Revolution (see De Giorgi's essay in the present volume). The mass line was imperative for achieving them all-as the benchmark for Party programmes and groundwork, as the baseline and pathway to the alliance between workers and peasants at the core of a wider rallying front, and as the epitome of the people's war (see Guan's essay in the present volume). Class- and state-building in the red base areas prior to the founding of the People's Republic of China (PRC) depended on the mass line, so did the war effort in Korea in the early 1950s and the subsequent socioeconomic transitions throughout the Mao era. The effective mass movements to alleviate illiteracy, improve sanitation, eliminate endemic diseases, and so on, were good examples. Mass line-style accumulation of both capital and labour also featured in China's socialist build-up of infrastructure and industrialisation.

The CCP, claiming to have no special interest of its own, took the motto 'to serve the people' as another catchphrase to indicate the mass line (see Karl's essay in the present volume). 'We the people,' however, were not a given but had to be forged through revolutionary socialisation. It involved painstaking tasks at the grassroots fulfilled by the Party's foot soldiers, work teams, and activists mobilised by the 'mass organisations' (qunzhong tuanti), i.e. various wartime local associations and later branches of the official trade union, women's federation, and youth league as arms of state corporation (see Perry's essay in the present volume). The famous Yan'an way of raising consciousness favoured peasant art forms and networks in indigenous dialects to popularise a Sinified Marxism. The 'continuous revolution' that followed 1949 went farther ideologically: school classes should include productive and scientific labour; regular folks could become philosophers through mass learning (qunzhong xue zhexue); and 'emperors, ministers, and generals' (diwang jiangxiang) should be replaced by commoners who would then 'occupy stages of the superstructure' (see Schmalzer's essay in the present volume). Mao concurred with Marx that theory can be a material force for winning over the masses. In this sense of self-confidence and self-reliance of a liberated nation, the Chinese people had stood up in 1949 and placed their country on equal footing 
with the nations of the world, long before the so-called rise of China credited to its market economic 'miracle.' Not only did their revolutionary victory have an immense impact on the third world, but it also inspired a whole generation of intellectual rebels in the global 1968 (see the essays by Lanza and Teng in the present volume).

Still, actual tensions between centralism and decentralisation, mobilisation and participation, and guidance and spontaneity or vanguardism and populism posed a serious challenge, both conceptually and operationally. Mass line politics was often overshadowed by either increased Party control or willful voluntarism. What was designed to provide a two-way flow of information and exchange became a conduit for the imposition of the Party line or the lawless anarchism of mass movements. Such contradictions could only be partially made up for by the Maoist assertion that educators must be educated by the masses, as well as the call for constant criticisms and self-criticisms within the Party. Mao's decision to mobilise the masses to attack the Party-state itself was also doomed from the beginning. However, the belief in the entitlement and creativity of ordinary men and women in constructing socialism while remaking themselves, in the intrinsic good of their public and political participation, and in their right and ability to expel the old and new ruling classes, transcends traditional liberal hostility towards popular power, denounced as 'mobocracy' or a hotbed of totalitarianism. That is, according to the mass line, power is not handed down from above but attainable only by the masses through their own daring struggles.

The mass line is the creation and lodestar of the Chinese Revolution. The masses, like the revolutionary classes and the people, are made through revolutionary practices. If we stick to its original vision, waves of arbitrary victimisation and policy blunders would appear not as the by-products of the mass line but its very betrayal. It would thus be fair to draw the lesson, dearly paid for by countless sacrifices, that only when the Party is ideologically and practically faithful to its traditional mass line, can it triumph against all odds; otherwise it fails, regardless of how the failure might be self-deceptively packaged or perceived.

\section{From the Paris Commune to the Angang Constitution and Beyond}

Marx's visionary assumptions about the Paris Commune loom large in the background. The 'utopia' of removing distinctions between governors and governed, and the regular selection of administrators by lot with a constant leeway of their being recalled, was glimpsed in the Paris Commune as within the realms of possibility. In the legislative bodies of the PRC, for example, the people's deputies (renmin daibiao) are not professional politicians. They come from all walks of life and go back to their individual professions when the Congresses are not in session. If only the National People's Congress was truly 'the highest organ of state power' as proclaimed in the Constitution! If only the deputies who sit on it and its local bodies were truly representatives of the people and empowered as lawmakers! The relatively recent phenomenon of the superrich and bureaucrats dominating the institution violates the original design but does not nullify its promise.

What connects the Paris Commune to the mass line is self-governing or participatory governance in workplaces and residential communities, which is qualitatively superior to money-fuelled electoral politics. An active citizenry and high-intensity politics 
were indeed hallmarks of Chinese socialism. If certain 'bourgeois rights' were deemed unavoidable in a transitional period to communism, Mao nevertheless insisted on the role of labour in managing government, enterprises, cultural institutions, and public affairs. ${ }^{2}$ In his critique of Stalin's political economy textbook, Mao remarked that the right to state management was missing from the 1936 Soviet constitutional rights of workers to employment, paid leave, education, and security in old age and sickness (adopted in the United Nations' Universal Declaration of Human Rights in 1948). ${ }^{3}$ In his words, this absent right should be labour's 'biggest and most fundamental right in a socialist system.' Without it and its institutionalisation, other rights cannot be guaranteed. This point has been abundantly vindicated by the postsocialist ruins. Familiar axioms such as 'labour's dignity' and the working population as 'masters of society' have vanished under a bureaucratic-market dictatorship (see the essays by Wang Ban, Meyskens, and Franceschini in the present volume). The catastrophic consequences of losing even an imperfect workers' state are laid bare in front of our eyes.

Convinced that human agency and socialist potential had been stifled in the Soviet Union, Mao's attempted remedy focussed on curbing bureaucratisation, material incentives, and rigid divisions of labour. His alternative was social empowerment by 'walking on two legs' (liangtiaotui zoulu), which meant liberating popular energy in all sectors, at all levels. In what came to be known as Mao's '7 May Directive,' he envisioned communal socialism, in which labour would have a collective purpose, enabling each individual to perform several roles, thereby fulfilling Marx's promise of emancipated human creativity. The commune would engage in industry, agriculture, commerce, education, healthcare, and defence simultaneously. Its members would practice united labour together, freely debate politics, as well as enjoy leisure, while creating new people and society. Mao however did not elaborate on how to arrange intercommunal relationships (as a global problem), which created a major hurdle to fostering equality between local groups and workers from outside of the community.

Mao was also firmly for industrialisation and a strong advocate for economic democracy. The eminent Angang Constitution, proposed in 1960 for the Anshan Steelworks and other large state firms, introduced egalitarian approaches that required managers to join workers on the shopfloor, workers to partake in executive decisions, and technicians to contribute to both undertakings. The scheme promoted multiskilled practitioners and smooth horizontal and vertical communications. Fluid hierarchies and shared responsibilities would, in turn, boost morale and efficiency. However short-lived, the experiment pioneered a mass line managerial revolution against both statist and capitalist 'sole-head systems' (yizhang zhi) and Taylorism. Economic democracy involved democratic planning and budgeting, equal pay for equal work, and mechanisms of public control over the surpluses in a model of production for needs rather than profits. This ambition of countering capitalist primitive accumulation as 'nothing else than the historical process of divorcing the producer from the means of production' is what ultimately underscored the mass line in the sense of labour gaining freedom and power (see also Hayward's essay in the present volume). ${ }^{4}$ 


\section{Politics in Command}

In China's market transition, the conditions in which the mass line had flourished are gone. Its brief return in the official vocabulary under Xi Jinping's direction a few years ago sounded hollow and ended abruptly. A first explanation is obvious: the relationship between the Party and masses has radically changed. After all, we are talking about a different Party whose remaining communist identity contradicts its non- or anti-communist direction and conduct. The alienation of officials from the masses is now an everyday experience in Chinese society. Despite his own failures to institutionalise worker power, Mao repeatedly predicted the scenario of 'a nation-wide counterrevolutionary restoration, when the Marxist party becomes a revisionist or fascist one, and the whole of China changes its colour. ${ }^{5}$ With the masses out of the picture after the Cultural Revolution, families of the 'red aristocracy' and the new elites have enriched themselves at an unprecedented speed and scale by devouring state resources, and colluding public offices with private (domestic and foreign) capital. The early, popular enthusiasm and mandate for reform collapsed when a new 'compradorbureaucratic capitalism' (one of the main enemies of the Communist Revolution) emerged. Anti-graft campaigns have been plainly selective and left the root cause of corruption and degeneration intact. Above all, the loss of the mass line implies that the Party and government are no longer supposed to be publicly supervised (see also Andreas' essay in the present volume). Chinese rulers refuse the popular demand to transparently declare their personal assets, for example, which is routine in capitalist democracies. Deprived of their 'right to rebel' (zaofan youli), the masses cannot question or resist Party decisions in any form.

Second, by the same logic, the transformation of social and class relations renders any organised class politics a sheer impossibility. Without a 'leading working class' (constitutionally designated) in the first place, the majority of Chinese workers, who are rural migrants often on subcontracted or precarious jobs, are hardly a conscious class force. The 'labouring people' no longer signal a powerful political category. Instead, they are viewed through the lens of negative signifiers, such as 'vulnerable groups' (ruoshi qunti) prone to 'mass incidents' (qunti shijian) that threaten social stability. In Beijing's ruthless campaign to expel migrants from the outskirts of the capital in the freezing cold in the winter of 2017, the abusive reference to them as a low end population' (diduan renkou), and the violent treatment of many of them as nothing but cheap, disposable commodities sparked a national outcry.

Yet, the blurred nature of the Party-state continues to prevent class consciousness from forming by occupying the symbolic space through which it could be articulated. The Party also cracks down on any sign of collective organisation and action. Labour's dilemmas lie in whether to accept or reject the nominally communist regime and its arbitration, and whether to rely on ever distant state protection or attempt to collectively organise itself while running the high risk of being repressed. As such, labour vacillates between a waning hope of empowerment and the harsh reality of powerlessness, as shown in 2018 in the police pursuit of students supporting workers' unionisation at the Shenzhen Jasic Technology factory. The state-capital coalition severely limits the Party-sanctioned legal channels. These channels are utilised only because workers are robbed of a socialist state that functions as an institutionalised class power committed 
to their wellbeing and recognition. At best, depoliticised litigations and lawsuits seek isolated legal redress while thwarting the political representation of class interests or ferment of insurgency. The notions of judicial independence and formal procedures presume a 'normal' polity that protects capitalist private property and order, in contrast to the mass line presuppositions that subject legality to the fundamental morality of social justice (see Hurst's essay in the present volume). Given China's profound revolutionary inheritance, neither the rule of law prioritised in the state agenda nor political democratisation as a liberal yearning can be legitimately accomplished without reinstating this moral substance.

A third explanation is that the Party's current ideological position is incompatible with the mass line, as reflected in the lack of persuasiveness and cultural capital of the Party's people-centred rhetoric. Under Deng Xiaoping's interdiction against 'arguing' (bu zhenglun), decades of a state-sponsored commodification and single-minded growth have nurtured a monoculture of money fetishism, consumerism, and political cynicism. Xi Jinping's 'New Era' has so far produced no reorientation while at the same time endorsing a superficial and even deformed Marxism. Exemplary is his depiction of the contradiction facing Chinese society as 'between unbalanced and inadequate development and the people's ever-growing needs for a better life, rolled out at the Nineteenth Party Congress. ${ }^{6}$ Evaded outright is a basic class analysis of China's actual contradictions: its exploitative productive relations, structural inequalities, as well as class, gender, ethnic, and regional disparities and conflicts. The fact that 60 million children are left behind in dilapidated villages by struggling parents working faraway as urban subalterns alone taints any socialist decoration. This deliberately apolitical formulation will not revive the pride of labour but only further encourage developmentalist greed, waste, rifts, and resource depletion-both at home and abroad.

One may argue that due to the Party's suicidal departure from its founding creeds, we have witnessed a historical defeat of the CCP by capitalist global integration. But things are not all fixed. The regime is still capable of responding to popular pressure on certain issues, such as improving general welfare and government services, as shown in a few celebrated policies of 'accurately' identifying and eradicating poverty or 'greening' the environment. Such policies may have nothing to do with socialism, and their implementation is far from free of biases or mismanagement. Neither poverty nor pollution is yet treated at its root cause and hence inevitably keeps being reproduced. However, the message of 'politics in command' resonates in its absence and urgency, in the midst of China's ongoing neoliberalisation (as others are phasing it out) as seen in its virtual privatisation of land, opening the commanding height industries and the financial and security sectors to private tycoons and foreign investors, relentless overaccumulation and overseas adventure, as well as the recentralisation of personalised and repressive power. The possibility of a transformative politics in an age of illusion as well as despair depends on the most imaginative and fruitful legacies of the Chinese Revolution and experimental socialism being critically relearned. Confusions, retreats, and setbacks notwithstanding, the future is open. A new popular and historical subject could be remade in a countertransformation of society and its structure of feelings and values. The mass line is dead, but its lessons and aspirations live on. 


\section{1}

\section{群众监督 \\ Mass Supervision}

Joel ANDREAS

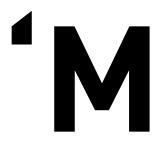

ass supervision' (qunzhong jiandu) was a central pillar of the Chinese Communist Party's (CCP) mode of governance during the Mao Zedong era. The term referred to practices designed to make individuals in positions of power accountable to those below them. Although it was used in connection with old elites from pre-1949 society, the main target was always the CCP's own cadres. The Party maintained elaborate systems of internal discipline and top-down control, but it found these to be insufficient, and so from its earliest days Party leaders mobilised rank-and-file Party members and 'non-Party masses' to monitor communist cadres, denounce violations of Party policies, and criticise malfeasance and abuses of power.

After taking power, the new regime organised an array of systems to lodge grievances and report official abuses as well as other methods to facilitate continuous monitoring of cadres from below. For the most part, however, mass supervision took place through periodic political campaigns rather than these routine channels. The Mao era was punctuated by a series of mass movements carried out under the rubric of mass supervision, culminating in the Cultural Revolution (see also Thornton's essay in the present volume). It should be emphasised that although these campaigns required the active participation of workers, peasants, and other citizens, the latter did not initiate the campaigns or determine their objectives. Mass supervision was a CCP project designed to meet Party goals.

In this essay, I will first briefly discuss the aims, targets, and forms of mass supervision. I will then provide an overview of the major mass supervision campaigns during the Mao era, before noting enduring practices today. A key focus will be on a fundamental problem entailed in mass supervision efforts-the lack of autonomy of those expected to monitor and criticise the cadres who exercised authority over them-and methods 
employed to address this problem. My understanding of how these methods were implemented and my assessment of the results are informed by a ten-year investigation into the evolution of governance practices in Chinese factories. ${ }^{1}$

\title{
Aims, Targets, and Forms
}

Mass supervision was the quintessential element of the CCP's conception of democratic participation. Mao succinctly expressed this in his famous conversation in 1945 with Huang Yanpei, a prominent education reformer. At a meeting with communist leaders at their insurgent headquarters in Yan'an, Huang presented his hosts with a pointed question about the fate of victorious revolutions in China's past:

\begin{abstract}
What I've seen conforms to the saying, 'Things flourish suddenly, but they also degenerate quickly'. At first people pay close attention to everything, they work extremely hard and are willing to go through all kinds of hardships. But later, as the situation improves, this spirit gradually degenerates and over time people develop inertia .... Throughout history, either the government falls into the hands of eunuchs, or reforms fail after a reformer is dismissed, or officials becomes corrupt, but so far no state has been able to escape this cyclical law. Gentlemen of the Communist Party ... . I hope you can find a way to escape this law.
\end{abstract}

Mao replied: 'We have already found a new road to escape this cycle. That new road is democracy. Only when the people are allowed to supervise the government, will the government not dare to become complacent.'

Mao's conception of democracy, shared by other Party leaders, was quite restricted. The CCP insisted on an absolute political monopoly; it did not allow competing political parties and it exercised tight control over all economic and social institutions. Moreover, popular participation was limited largely to the basic levels of society, far from the realm of central policymaking, which took place at higher echelons of the CCP. Within this constricted framework, however, mass supervision was expected to play a critical role, keeping communist cadres on the straight and narrow and compelling them to listen to the concerns of the population they were to govern.

The mechanisms of mass supervision were designed to elicit exposure of a wide variety of proscribed behaviours by communist cadres, including corruption, favouritism and nepotism, inefficiency and waste, privilege-seeking and selfishness, a variety of political offences, and official misconduct prompting citizen grievances. The most important target of mass supervision, however, was bureaucratic work styles (guanliaozhuyi zuofeng), which in the CCP's lexicon referred to cadres being isolated from the masses, imposing harsh rules and regulations, managing in an arrogant and autocratic fashion, stifling criticism, complaints, and suggestions from below, and refusing to attend to the concerns of masses or involve them in local governance. Party leaders recognised that the problem of bureaucratism could not be effectively remedied through the Party's systems of top-down control. ${ }^{3}$ Such bureaucratic controls were not only ineffective in 
curbing bureaucratism, but were counterproductive because they exacerbated cadres' proclivity to turn their gaze up, rather than down; to prevent cadres from becoming aloof from the masses, supervision from below was indispensable.

The CCP made workplaces - rural production brigades and urban work units (see Kevin Lin's essay in the present volume) - the main sites through which it governed the populace and fostered popular participation. These workplaces, therefore, became the principal locations for mass supervision. This was true both of the periodic mass supervision campaigns as well as the everyday mechanisms, which included reporting systems (such as anonymous letter boxes), petition and grievance systems, the election of basic-level leaders, the practice of leaders reporting to mass meetings, the creation of teams of rank-and-file representatives to monitor leadership bodies, and the election of representative congresses to supervise workplace leadership.

Efforts to make mass supervision effective confronted a fundamental problem: urban workers and villagers had little autonomy from the cadres they were expected to supervise. Local cadres enjoyed great power, which was reinforced by the Party's determination to maintain a political monopoly. Party organisations in villages and work units left little room for autonomous activity and, despite official prohibitions, raising criticisms of local cadres often brought retribution. Mao and other Party leaders were acutely aware of this problem and the purpose of organising mass campaigns was to overcome popular reticence by providing official support for raising criticisms. Mao was responsible for initiating all mass supervision campaigns, including major movements in which Party authorities dispatched outside work teams to mobilise villagers or workers to criticise local cadres (see Perry's essay in the present volume). Although outside work teams introduced a degree of autonomy from local Party officials, the Party organisation remained in charge. On two occasions, however, Mao went around the Party organisation to inspire more freewheeling criticism. In the following sections, I will review the various methods of mobilisation employed in mass supervision campaigns and assess the results.

\section{Origins and Early Campaigns}

The CCP's practice of mass supervision had both domestic and foreign roots. It was informed by the traditional Chinese system of lodging complaints (gaozhuang), in which people were encouraged to report malfeasance by 'corrupt officials' and 'evil gentry' to higher authorities through petitions that ultimately might reach the emperor. ${ }^{4}$ It was also informed by Soviet traditions, many of which were borrowed by the CCP, along with the term mass supervision itself. ${ }^{5}$ The Party's own practices were developed while it was an insurgent organisation, ensconced for decades in remote rural base areas. In order to maintain support in the villages it governed, Party leaders sought to prevent local cadres from abusing their power by conducting periodic Party rectification campaigns (see Mertha's essay in the present volume). In 1947, they experimented with 'open door' rectification, dispatching Party work teams to organise villagers to criticise shortcomings and transgressions of local Party cadres. In his classic first-hand account, William Hinton described how this campaign was carried out, with each village cadre compelled to face village-wide meetings and 'pass the gate' in order to keep his or her position. ${ }^{6}$ Li Fangchun subsequently documented the vast impact of this campaign and 
the severe psychological and physical violence to which rural cadres were subjected. ${ }^{7}$ Commenting on the campaign, a senior communist leader wrote in his diary that the Party seemed to be 'waging revolution against itself.'

After the CCP took national power in 1949, the practice of mass supervision was given prominent sanction in the new regime's first Constitution, adopted in 1954, which declared: 'All state organs must rely on the masses of the people, keep close contact with the masses, listen to the opinions of the masses, and accept the supervision of the masses. ${ }^{9}$ Starting in the early 1950s, Party leaders launched a series of mass supervision campaigns, the most important of which was the Three Antis Campaign (sanfan yundong), directed against leaders of state-owned enterprises and state agencies. Many communist cadres became targets of this campaign, but during these early years their offences were generally construed to be the product of corruption by old elites and the influence of traditional ideas and practices. As these campaigns were an integral part of the effort to consolidate communist power at the expense of old elites, it was also not difficult for central authorities to trust local Party organisations to manage them. For instance, concerns that Party cadres in charge of a particular factory had developed close ties with incumbent factory leaders or had become entrenched in local networks of corruption could readily be dealt with by sending in outside work teams to mobilise workers in the factory to investigate. ${ }^{10}$

This was no longer the case after the socialist transformation was completed in 1956. The Party Rectification Campaign carried out in the spring of the following year exclusively targeted Party cadres, who were by then fully in charge of all institutions. Under these conditions, Mao decided to unleash a more autonomous type of mass supervision that did not entail the tutelage of Party-dispatched work teams. In the 1957 Party Rectification Campaign, the culmination of the Hundred Flowers Campaign launched in 1956, he invited professionals, intellectuals, and students to organise their own meetings and activities to criticise the communist cadres in charge of schools, government agencies, and enterprises. This was a risky move that ended in disaster, as many of those who spoke up did not limit their criticisms to Mao's intended agenda, but raised more fundamental critiques of the new regime. Communist cadres responded with alarm and indignation, and Mao was compelled to support a harsh backlash, the Anti-rightist Campaign, which condemned hundreds of thousands of those who had spoken up to years of punishment and discrimination. ${ }^{11}$

In the years that followed the debacle of 1957, Mao continued to mobilise criticism of communist cadres, but he retreated to the more conventional work team method. Moreover, in order to avoid the dynamic that emerged in 1957, which pitted old elites against new elites, he never again mobilised popular criticism of communist cadres without at the same time targeting old elites. In subsequent campaigns, although Party cadres were always the main target, old elites were also subjected to attack.

\section{The Four Cleans}

In 1962, Mao launched the Four Cleans Campaign-formally known as the Socialist Education Movement - the broadest, deepest, and most protracted effort since the founding of the People's Republic of China to reign in malfeasance and bureaucratic practices among Party cadres. The Campaign lasted for more than four years and 
mobilised huge numbers of workers and peasants. The purpose, Mao declared in the initial guidelines for the mobilisation, was to criticise cadres who had been 'acting like bureaucrats and overlords divorced from the masses', compelling them 'to directly face the masses and resolve the abnormal relations that have existed between cadres and the masses for many years.' ${ }^{\prime 2}$

During the course of the Campaign, Mao's evaluation of the maladies that afflicted the CCP officialdom became more jaundiced, and in early 1965 he supervised the drafting of a new set of guidelines that identified the main target as 'those in positions of authority inside the Party who are taking the capitalist road. ${ }^{\prime 3}$ Later that year, responding to a report by the leader of a work team assigned to direct the movement in an agricultural machinery factory, Mao elaborated on the 'capitalist roader' (zouzipai) theme with startling words. 'The bureaucratic class,' he wrote, referring to officials of his own Party, 'is a class sharply opposed to the working class and poor and lower-middle peasants. These leaders who take the capitalist road have become, or are becoming, the capitalists who suck the workers' blood. How can they sufficiently understand the necessity of socialist revolution? They are the targets of our struggle and the targets of the revolution.' ${ }^{\prime 4}$

For Mao, the Four Cleans Campaign became a critical test of the work team method. The revised 1965 guidelines emphasised that 'cadres must have supervision from above and below, particularly mass supervision' adding that 'in the Four Cleans Campaign we must work together with the masses to find effective means of supervision. ${ }^{15}$ As is evident from retrospective ethnographic accounts of the Campaign in factories as well as villages, the Four Cleans work teams were, in fact, very effective in curbing cadre corruption. ${ }^{16}$ Because the teams were not under the leadership of local Party committees, they were in a position to organise villagers and factory workers to criticise their superiors, and to undertake harsh, systematic, mass-based investigations of unscrupulous behaviour by local cadres. On the other hand, the top-down nature of the work team method only reinforced the hierarchy of authority and culture of tutelage that underpinned the maladies associated with bureaucratism. As Mao became increasingly preoccupied with the latter, which he saw as fostering the development of a new bureaucratic class of Party officials, he decided to abandon the work team method.

Already in January 1965, Mao issued a sharp critique of the methods employed by the Four Cleans work teams, using language that presaged the radical approach he would take during the Cultural Revolution. 'When you go to develop a mass movement, when you go to lead a mass struggle, in the midst of the struggle the masses are going to do what they want to do, and then in the course of the struggle they'll create their own leaders', he insisted. 'In short, you have to rely on the masses; you can't rely on the work teams. The work teams don't understand the situation, or in ignorance they become bureaucrats and obstruct the movement. ${ }^{\prime 17}$ In a postmortem delivered two years later, he declared that the movement had 'failed to solve the problem because we did not find a form, a method, to arouse the broad masses to expose our dark aspect openly, in an all-round way and from below. 18 


\section{Rebel-led Mass Supervision}

The Cultural Revolution was in many ways a direct continuation of the Four Cleans Campaign, but it featured a much more radical effort to introduce autonomy into mass supervision. Although Mao allowed Party leaders to once again send in work teams when he launched the movement in the spring of 1966 , he immediately commissioned newspaper articles and radio broadcasts that called on the masses to 'educate themselves and liberate themselves.' A few weeks later, he demanded the removal of work teams, accusing them of having 'encircled and suppressed revolutionaries, stifled opinions differing from their own, imposed a white terror, and felt very pleased with themselves.'19

Mao subsequently called on students, workers, and peasants to form their own 'fighting groups' (zhandoudui) to criticise Party officials in their schools, factories, and communes. In factories, this turn of events had a polarising effect, spurring the rise of both 'rebel' (zaofan) organisations, which directed their fire at the Party organisation and pledged loyalty to no one but Mao, and conservative organisations, which defended the factory Party organisation. This led to fierce factional struggles in workplaces across China. ${ }^{20}$

The stakes of the conflict increased dramatically in January 1967 after Mao called on rebels to 'seize power' (duoquan). He first endorsed rebel efforts to take control of Shanghai's newspapers, declaring: 'The seizure of power at two newspapers is a national question and we should support their rebellion.' He cautioned, however, that the old leaders of the newspapers should not be discharged: 'I am not in favour of their dismissal; let them remain at their posts and be supervised by the masses. ${ }^{21}$ He relayed the same message a few days later after rebels, backed by his emissaries, overthrew the Shanghai Municipal Party Committee. 'Taking over is great, but those who take over should only be in charge of politics (zhengwu), not regular administrative functions (yewu),' he instructed. 'Regular administrative functions should still be taken care of by the original staff. We should only be responsible for supervising them.' ${ }^{22}$ The new 'revolutionary committee' (geming weiyuanhui) structure that Mao eventually endorsed followed this logic: 'mass representatives' (qunzhong daibiao), who were to be drawn from the ranks of rebel groups and remain at their original posts, were to supervise veteran cadres, who would occupy managerial positions. Despite Mao's insistence that seizing power should only be a means of reinforcing supervision from below, the ensuing violent factional struggles for power greatly complicated and in many ways eclipsed the original project.

His inflammatory rhetoric notwithstanding, Mao's goals during the Cultural Revolution were not as radical as many observers (and participants) imagined. He had no intention of fundamentally changing the state structure or overthrowing the CCP; his aim was to shake up the Party organisation and challenge the officious, bureaucratic airs of Party cadres. The methods he introduced, however, were quite radical considering that until then the CCP had insisted on exercising a complete monopoly on political activity. Because the rebels were self-organised and largely independent from the Party 
organisation, they were especially capable of breaking down the authority of the local Party hierarchy, and opening up Party cadres to a torrent of criticism from below. The impact was lasting; the authority of Party officials never fully recovered.

The Cultural Revolution, however, ultimately failed to establish an effective longterm model for incorporating autonomy into mass supervision. The autonomy of the rebel groups was compromised in two critical ways. First, they were compelled to operate within very narrow political and ideological constraints and the scope of the issues they were permitted to raise was limited. While they were encouraged to attack cadres' privileges, corruption, and authoritarian and bureaucratic ways, economic demands were off limits. Organisations so constrained could never truly represent the masses of workers and peasants. Second, the rebel organisations were only allowed a momentary existence. Once Mao's blessing was withdrawn, they were compelled to disband and subsequently faced a backlash far harsher than the Anti-rightist Campaign. Mao recognised that effective mass supervision required organisations that were not under Party control, but he was not willing to permit the permanent establishment of autonomous organisations.

\section{Remnants of Mass Supervision}

Today, mass supervision continues to be part of the principles formally underpinning the CCP's model of governance, but the practices associated with the slogan have changed in fundamental ways. ${ }^{23}$ This has been evident in the ongoing anti-corruption drive launched by $\mathrm{Xi}$ Jinping in 2012. The masses have been called upon to participate, but there has been little semblance of the mass movements of the past, when cadres were hauled before mass meetings in every village and factory. Instead, the Campaign has largely been carried out by the Central Commission for Discipline Inspection, and supervision from below has mainly taken the form of individuals reporting abuses. Moreover, as in all recent campaigns that have targeted cadres, the focus has been on corruption. The main preoccupation of the Mao era-the abuses of power identified as bureaucratism-are of little concern.

The dynamics of mass supervision, however, extend beyond official channels. A wide variety of other avenues for grassroots complaints about cadre behaviour have emerged, including unofficial websites on which citizens vent frustration and anger about cadre corruption and abuse of power. The resulting scandals have become a highlight of Chinese political life. One indication of the extent to which the concept of the mass supervision continues to inspire popular political thinking in China can be found in a manifesto issued by organisers of 'Jasmine' pro-democracy rallies in 2011, which featured as its central demand that the government 'genuinely fight corruption and accept the supervision of the people.'24 Thus, although the tumultuous mass movements of the Mao era are fading into the past, the idea of mass supervision, rooted in longstanding Chinese traditions and forged into a mainstay of popular participation during the first decades of the communist era, has become an enduring feature of China's political culture. 



\section{2 \\ 动员 \\ Mobilisation}

LI Zhiyu

(Translated by William SIMA)

'M obilisation' (dongyuan) is a fundamental concept in contemporary Chinese politics. It denotes the use of an ideological system by a political party or regime to encourage, or coerce, members of society to participate in certain political, economic, or social objectives, in order to achieve large-scale centralisation and deployment of resources and manpower. In China, the modern understanding of politics by mass mobilisation originated in the First United Front between the Chinese Communist Party (CCP) and the Nationalist Party (guomindang, hereafter GMD) in 1923. Believing that the success of the Chinese Revolution depended on close unity between the government and all social organisations, Sun Yat-sen, the founder of the GMD, stressed the importance of awakening the masses, advocating a policy of 'alliance with the Soviet Union, alliance with the Communist Party, assistance for the peasants and workers.' With this policy, Sun sought to fashion the GMD into a modern political party rooted in mass mobilisation. Yet, it would be the CCP that eventually came to exemplify and refine mobilisation politics in modern China. During the War of Resistance against Japan, the Civil War of the late 1940s, and in successive social movements after 1949, mass mobilisation was a critical ideological mechanism through which the CCP achieved its political ambitions.

In their classic study Politics in China, James Townsend and Brantly Womack describe the advent of a 'Chinese model' or 'Maoist model' in Western political science since the 1970s, which emerged in response to a recognised need to view China's political system as sui generis rather than with reference to 'developing country' models, the Soviet Union, and other imperfect comparative paradigms. ${ }^{1}$ They identify four key elements in the Chinese/Maoist political model. First, it aims to achieve national independence and self-reliance, avoiding economic or political dependence on other states (see Yang's essay in the present volume). Second, it seeks comprehensive development of all sectors of society and the economy, with emphasis on agriculture, through centralised planning. 
Third, it emphasises mass mobilisation and participation as techniques for achieving social, economic, and political goals. In such a context, the destabilising effects of mass campaigns on bureaucratic institutions are regarded as healthy, or at least acceptable, as is any damage to intellectual and technical skills that accompanies the glorification of mass movements. Finally, the Chinese political model insists on continuous revolution for the purpose of avoiding the restoration of capitalism, including in cases where capitalist tendencies are evident within the Party itself (see Galway's essay in the present volume). However, rather than conceiving of mobilisation as a distinct element within the Chinese model, as Townsend and Womack do, in this essay I will argue that it would be more fitting to see mobilisation as essential to all the elements of the model.

\section{Governance by Mobilisation}

The 1937-45 War of Resistance against Japan was the critical period for the ascendency of the CCP, for Mao Zedong's ideas on the people's war, and the maturation of a political system rooted in mobilisation (see Guan's essay in the present volume). Mao understood war to encompass driving away imperialism and building a new nation out of the old. For this to be realised would require nothing less than the full mobilisation of the Chinese population. In his classic treatise 'On Protracted War', first delivered as a series of speeches at Yan'an in May and June 1938, Mao described mobilisation in the following terms:

A national revolutionary war as great as ours cannot be won without extensive and thoroughgoing political mobilisation ... . [Mobilisation] is indeed of primary importance, while our inferiority in weapons and other things is only secondary. The mobilisation of the common people throughout the country will create a vast sea in which to drown the enemy, create the conditions that will make up for our inferiority in arms and other things, and create the prerequisites for overcoming every difficulty in the war. To win victory, we must persevere in the War of Resistance, in the united front, and in the protracted war. But all these are inseparable from the mobilisation of the common people .... To mobilise once is not enough; political mobilisation for the War of Resistance must be continuous. Our job is not to recite our political programme to the people, for nobody will listen to such recitations; we must link the political mobilisation for the war with developments in the war and with the life of the soldiers and the people, and make it a continuous movement. This is a matter of immense importance on which our victory in the war primarily depends.

Thus, for Mao war was a phenomenon encompassing not only armed conflict, but also national independence, political renewal, and the reconstruction of society and culture. Throughout the War of Resistance and the ensuing resumption of the Civil War with the GMD after 1946, the CCP successfully mobilised large numbers of peasants to enlist in its regular army, or to join people's militias, guerilla detachments, and local-level self-defense groups acting in concert with the regular army. From the early 1940s, the CCP launched a Production Campaign for self-sufficiency in agriculture and 
the production of common items, with rectification (zhengfeng) and thought reform (sixiang gaizao) serving as crucial political mechanisms for achieving consensus among Party members, and unity with the masses (see the essays by Cheek, Mertha, and Yang in the present volume). Self-sufficiency and ideological rectitude safeguarded the CCP's growth during wartime.

After the establishment of the People's Republic of China (PRC) in 1949, the communist regime adapted the ideology and methods of mass mobilisation it had developed during wartime to political administration, the economy, and society. From 1950 to 1953, the Land Reform Movement, the Campaign to Suppress Counterrevolutionaries, the Campaign to Resist US Aggression and Aid Korea, the Three Antis Campaign (against corruption, waste, and bureaucratism), and the Five Antis Campaign (against bribery, tax evasion, theft of state assets, cheating on government contracts, and stealing state economic intelligence) were all deeply rooted in mass mobilisation. So too were the campaigns of the late 1950s and 1960s, including the Four Pests Campaign (aimed at eradiating mice, sparrows, flies, and mosquitoes), the Great Leap Forward, and the Down to the Countryside Movement at the start of the Cultural Revolution. Indeed, it may be said that from 1949 until the beginning of the reforms in the late 1970s, the communist regime embodied a politics of governance by mobilisation. Below, I outline three key features of this model of governance.

\section{The Mechanisms behind Mobilisation}

The Party serves as the core and propellant of mobilisation politics. The late University of Chicago-based political scientist Tang Tsou famously described a 'concentric circle structure' in China's CCP-led political system, with

the Party secretary standing at the center, the Party committee forming the inner circle, and the general membership forming the next one outward. The Party as a whole ... sought to influence, guide, penetrate, and control the social groups and institutions around them, mobilising and organising the social strata, groups, and individuals which had never been actively involved in the political process or had formerly remained passive and inert. ${ }^{2}$

This concentric circle structure, Tsou writes, 'proved to be an efficacious instrument for carrying through a social revolution and reshaping the social system.'

In the early years of the PRC, the function of mobilisation in carrying out mass movements can be seen in just such terms of a concentric fanning out, from the Central Committee to cadres in provincial- and regional-level Party committees, thence downwards to activists engaging directly with the masses at the grassroots. This is illustrated in a December 1951 report from the CCP North China Bureau to the Central Committee, recommending the Three Antis Campaign to be carried out 'on a grand scale, with tenacity of lightening and the swiftness of wind.'3 Mao circulated this Report as an exemplary text on how the Three Antis Campaign should be enacted nationwide. It stipulated that policies and directives be issued in a top-down fashion throughout all Party representative committees, cadre committees, people's representative committees and in Party and non-Party political, economic, and military 
organisations. It recommended that inspection committees made up of Party and nonParty cadres and activists be established at all levels, overseen by a senior Party official; these committees should be responsible for rectifying the sort of 'erroneous thinking' that hindered the project of opposing corruption, waste, and bureaucratisation. The Report insisted that mobilisation spread ubiquitously at all levels, 'leaving out not a single small organisation or individual.'

If we survey movements and campaigns from 1949 up to the Cultural Revolution, it is evident that centre-led mobilisation generally progressed through a number of steps: a) propaganda was formulated and inculcated among the people; b) high-level cadres shaped propaganda and facilitated its spread, mobilising from the centre downwards; c) exemplars of effective political action were fostered and encouraged through intergroup competition and education sessions; d) 'psychological warfare' (gongxinzhan) was used to enforce mass education movements; e) short and longer duration political campaigns intersected and overlapped, driven by a process of continual mobilisation.

\section{Mass Mobilisation and the Mass Line}

As a mechanism of political action, mobilisation requires efficacious propaganda techniques and a constructive relationship between the Party and masses. Mass mobilisation involves working with the masses to develop the 'mass line' (qunzhong luxian), an important concept for the CCP during and after its coming to power (see Lin Chun's essay in the present volume). Mao's thinking on the 'people's war' advocates having faith in the masses, relying on the masses, mobilising and organising the masses to create the 'vast ocean' in which to drown the enemy, as he outlined in his treatise 'On Protracted War' noted above. This attitude of relying on the masses is perhaps what most strongly distinguished the CCP from the GMD in their approaches to war; the GMD, by contrast, emphasised reliance on the standing army, the government, and conventional forms of warfare. Indeed, willingness-or lack thereof-to stir up popular sentiment and mobilise the masses was perhaps the most fundamental difference in the approach to governance between the two parties.

However, having faith in and relying on the masses, learning from and returning to the masses is merely the ideal situation of the mass line. The mass line only works effectively when those in power take account of the best interests and aspirations of the masses, when the masses recognise that the Party is sincerely representing them, and respond by embracing and upholding the Party's policies. While it is the Party that stages mobilisation, the subjective position of the masses-their feeling that they really are 'masters of their own affairs' - is the essential basis for successful mobilisation politics. At numerous points in the history of the PRC, the mass line has failed to achieve this ideal.

\section{Administrative Mobilisation in the Era of Reform}

China's transformation after 1979 is often expressed in terms of a shift from 'revolution' to 'modernisation.' With the new leadership under Deng Xiaoping pursuing economic reform and bureaucratic professionalisation of the government administration, and as citizens embraced private ownership and individual self-consciousness, politics by large- 
scale mass mobilisation gradually became a phenomenon of the past. In contemporary China, the government, at such times when it requires organised popular participation on a large scale, typically issues administrative orders and offers material incentives to participants. Such 'administrative decree-style mobilisation' is especially visible in two main areas.

The first is crisis mobilisation. The state regularly mobilises the Party, government administration, and military to coordinate closely with social forces in emergency rescue and crisis alleviation. The successful response to the 2003 SARS epidemic and the May 2008 Wenchuan earthquake are notable recent examples of administrationdriven mobilisation. ${ }^{4}$ In a recent study of the Wenchuan earthquake, Christian Sorace demonstrates how the CCP claims to have engineered a secular 'miracle' (qiji) on the basis of mobilising the entire Party-state apparatus and 'Party spirit' (dangxing) of its cadres to complete the reconstruction in under two years. ${ }^{5}$ Thus, mobilisation is praised as key to the success of the reconstruction effort, while remaining a carefully controlled and orchestrated affair.

The second is education campaigns. The Party communicates developments in ideology and policy implementation to wider society through what may be termed 'mobilised education drives.' Recent examples include the 2015 Three Stricts and Three Genuines Campaign (san yan san shi yundong), which exhorted strictness in 'moral cultivation, the use of power, and in the exercise of self-discipline,' while 'planning and working in genuine ways and genuinely striving to be a decent person.' ${ }^{\text {In }} 2016$, the Two Studies and One Action Campaign (liang xue yi zuo yundong) pressured CCP members to study the Party constitution and regulations, study the serialised speeches of Party leaders, and strive to be good Party members. Designed and directed by the Central Committee and implemented downwards, these education campaigns aim to defuse pressure away from the centre; committees at all levels are required to 'maintain discipline among Party members and effectively lead the rank-and-file.' Whereas during the Maoist period mobilisation was based in mass participation, contemporary campaigns such as those outlined above rely on the media to communicate policy from the centre. While often regarded as a tiresome formality of public life, they are nonetheless an effective means for the Party to shape the behaviour of its members, and of wider society. 


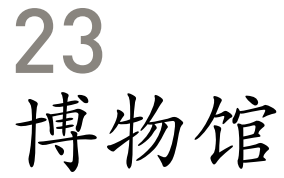

Museum

Denise Y. HO

W hat was a museum (bowuguan) in Mao's China? In 1952, a Shanghai Museum guidebook explained that New China's heightened political consciousness required attendant opportunities to study culture. ${ }^{1}$ According to its directors, there was also a demand for museum visits from an increasing number of mass organisations, such as workers' groups and schools. Citing Mao Zedong's writings on the historic greatness of the nation, the role of antiquity in building New Democracy, and the place of China in world civilisation, officials announced the Shanghai Museum's guiding principles: to teach China's cultural traditions, to utilise ancient culture to develop the new, and to cultivate patriotism in service of socialist construction. 'The museum is part of society's superstructure,' declared director Shen Zhiyu in 1960, 'the goal for establishing museums is to carry out mass education in patriotism, socialism, and communism.2 A museum in China-from the Mao era to the present-has been a political classroom.

Writing on the rise of museums in nineteenth-century Europe, sociologist Tony Bennett described 'exhibitionary culture' as a complex: a system in which knowledge projected power and in which viewers were part of the display, both subject and object of the exhibition. ${ }^{3}$ In the Mao years, the Shanghai Museum participated in all forms of exhibitionary culture-not just the fine art for which it is famous for today. While its permanent display showcased art by dynastic era, it also mounted special exhibitions to accompany political campaigns, including exhibits on revolutionary artefacts, on the history of Shanghai, and on the transformation of class from old to new China. During the Cultural Revolution, its workers collected contemporary objects like the placard of the Shanghai People's Commune, anticipating that such artefacts would be the displays of the future. In these ways, the museum encompassed many functions. It was also a memorial hall (jinianguan), a display hall (chenlieguan), and an exhibition 
hall (zhanlanguan). Its objects were mostly artefacts (shiwu), but also cultural relics (wenwu), which included a special subcategory of revolutionary cultural relics (geming wenwu).

Museums were not new to Mao's China. In the nineteenth century, foreign museums were founded in Shanghai's international settlements, and in 1905 reformer Zhang Jian established the first Chinese museum in the city of Nantong. The Nationalist Government had its own museums, including memorial halls that displayed the possessions of revolutionary martyrs. While some May Fourth intellectuals criticised museums as warehouses for old things, their Republican-era boosters explained thatas in the Soviet Union-museums could be used to spread ideology and transform the people's consciousness. ${ }^{4}$ The Chinese Communist Party (CCP) began planning for a Museum of the Revolution as early as 1930 and used small-scale exhibits in its rural base areas for mass education. ${ }^{5}$ After coming to power in 1949, the state established museums to reflect and project its political legitimacy. Beyond this, exhibitions became part of the Party's propaganda repertoire, deployed to mobilise the masses. As tools in China's Communist Revolution, museums have served politics, displays have been curated at the grassroots, and objects have served as evidence.

\section{Museums as Politics}

Museums in Mao's China were first and foremost the expression of a political narrative. In the 1950s, Chinese cultural officials followed the Soviet model of museums as 'living textbooks.' The Lenin Museum, for instance, arranged its rooms according to the chapters in Stalin's History of the Communist Party of the Soviet Union (Bolsheviks). Inspired by visits and by handbooks of Soviet museology, Chinese curators followed suit, presenting Chinese history according to Mao's 1940 essay, 'On New Democracy' (see Blecher's essay in the present volume). Further, as a 'living textbook' the revolutionary history museum would always be incomplete, a work in progress; as Wang Yeqiu of the State Bureau of Cultural Relics wrote in 1950, chapters would continually be added until the arrival of communism. ${ }^{6}$ Hence the Shanghai Museum's collection of Cultural Revolution artefacts: this was the age of permanent revolution.

In addition to the narrative of the past, museums provided a script for the current moment. Archival materials from the 1960s show that at the First Party Congress Sitethe memorial established to commemorate the CCP founding in 1921-the official imperative was to serve the present (wei dangqian zhengzhi fuwu) (see the image on page 143). Exhibits were constantly updated to accord with contemporary politics, leading to a dizzying number of exhibition texts at the height of the Cultural Revolution, when scripts were continuously revised to include the latest political enemies. Docents themselves memorised scripts according to their audience-domestic visitors vs. foreign dignitaries-and also prepared lists of typical questions and appropriate answers. Even local and ad hoc exhibits had political scripts; in campaigns such as the Socialist Education Movement and the Cultural Revolution, display boards and docent texts presented visitors with the words, slogans, and quotations to attack alleged class enemies. $^{7}$ 


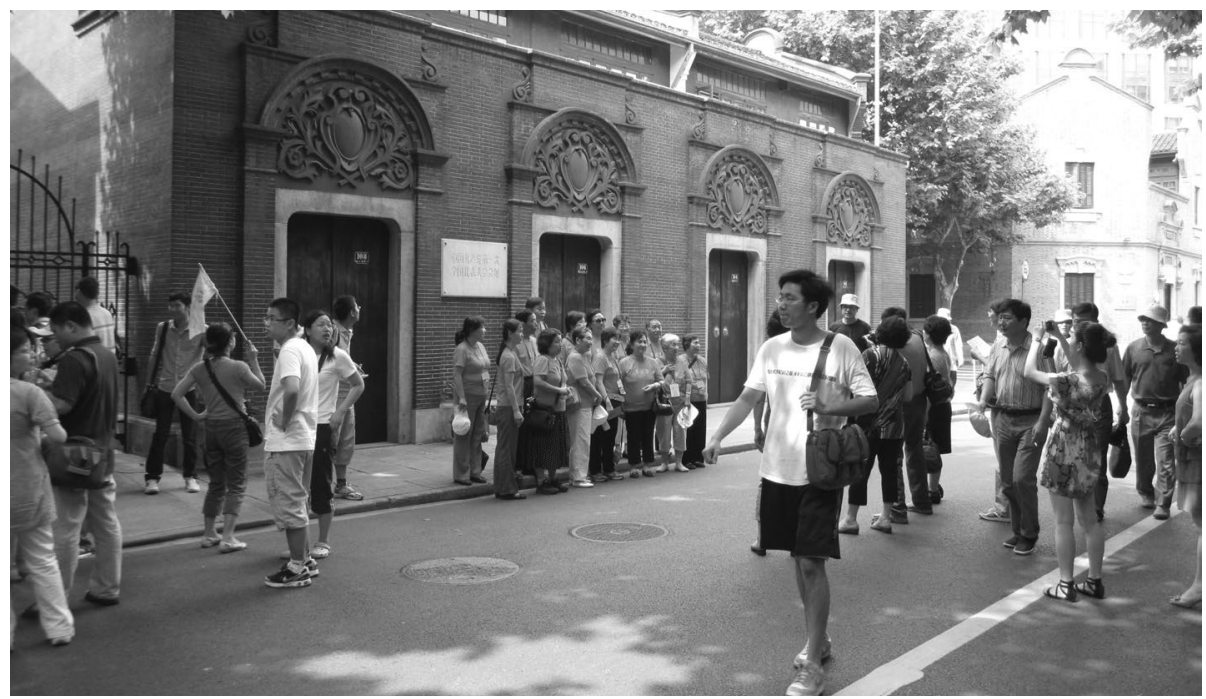

The Site of the First National Congress of the Chinese Communist Party, Shanghai (2010)

In these ways, exhibitionary culture functioned as a kind of political signalling: in an era of tumultuous politics, when words could both accuse and incriminate, museum scripts were the latest Party-approved text. No wonder that even if exhibition attendance was required, people paid attention: a visit included copying text to teach others in turn; individuals requested visits to exhibits to try to understand the Cultural Revolution as it was breaking out; and out-of-town Red Guards went first to the local Red Guard Exhibition to understand the movement at the grassroots. In Elizabeth Perry's study of the mining town of Anyuan, the Party secretary of its Chairman Mao Memorial Hall noticed Lin Biao's absence from Beijing's Great Hall of the People before news of Lin's death came out, and revised Anyuan's exhibits to his own political advantage. ${ }^{8}$ An exhibit's narrative text was a barometer for political winds: a docent script could be revised, a display backboard could be rewritten, and a cassette tape could be recorded over. As a political technology, the museum was at once an authoritative master narrative and an eminently adaptable form.

Since the end of the Mao era, the museum in China continues to be a site for political narratives. It was in 1990-one year after the 1989 Tiananmen student movementthat President Jiang Zemin chose Beijing's Museum of the Chinese Revolution as the setting to speak on the importance of patriotic and socialist education, calling on Chinese museums to take responsibility in cultivating youth. From 2004, the state has promoted 'patriotic education' by supporting red tourism (hongse lüyou), entailing visits to historic sites associated with the revolutionary tradition. ${ }^{9}$ In 2012 , President $\mathrm{Xi}$ Jinping introduced his slogan 'China Dream' (zhongguo meng) at what is now called the National Museum of China. As Timothy Cheek writes in this volume, the project of 'telling China's story well' (jianghao zhongguo gushi) is a central priority for the current regime, and museums no doubt play a role. As part of local development, municipalities have been building museums, and there is an increasing trend for companies and work 
units to each have their own museum. A tour of the museum is sometimes a stand-in for an inspection of the factory floor or an actual site visit-in other words, museums remain a way to control the script. And, in a time when China's influence increasingly reaches abroad, museums will play an important role in 'telling China's story well' for global audiences. For instance, the World War II Pacific War Memorial Hall (haiwai kangri zhanzheng jinianguan), a private museum in San Francisco, looks remarkably like a Chinese museum, featuring a sculpture 'Great Wall of Blood and Flesh' that evokes the Chinese national anthem.

\section{Museums as Grassroots}

Exhibitions in Mao's China departed from Republican and Soviet precedents in that they were a grassroots phenomenon. Neighbourhood cadres were instructed in the early 1950s to mount small-scale exhibits in alleyways that would complement the latest political campaign and the most recent propaganda. Officials were encouraged to enliven exhibits with objects and cartoons, to employ students to narrate them to those who could not read, and to even set up games; one anti-spy exhibition in Shanghai's Huangpu district presented a 'study city' in which visitors could work their way through a maze by answering questions correctly. Similarly, handbooks for rural art workers gave detailed instructions on how to put on 'class education exhibitions' (jieji jiaoyu zhanlanhui), down to how to set up display halls for the best visitor circulation and how to construct backdrops to maximise visual space. In these ways, exhibitionary culture served a historiographical trend that began in 1958: to write and display history at the grassroots. Indeed, museums also had their own Great Leap Forward, in which the Ministry of Culture called for a museum in every county.

In the era of permanent revolution, local exhibits served to mobilise the masses. They provided visitors with a narrative, but they also taught participation. At the grassroots, individuals were encouraged to provide artefacts to display: schoolchildren offered the uniforms and identity cards of their proletarian parents, workers presented the protective gloves and safety equipment of the factory in New China. During the Socialist Education Movement, which preceded the Cultural Revolution, teachers encouraged students to curate their own 'class education exhibitions' at school. The prototype for such a display was Sichuan's Rent Collection Courtyard, which showcased the threat of class enemies past and present. It also provided a stage for individuals to tell stories of class suffering, for viewers to remember their own pasts, and for visitors to shout political slogans (see Javed's essay in the present volume). Though the Rent Collection Courtyard was the most elaborate and well known, each locality had a 'class education exhibition,' some complete with a landlord manor and sculptural tableaux (see the image on page 145).

In today's China a different kind of grassroots exhibition is taking place. There has been a craze for personal collecting, ranging from retirees collecting Mao-era memorabilia to multimillionaires competing for artwork at international auctions. The former may do so for personal pleasure, with the occasional participation in a collective exhibition encouraged by the 'friends' of a local museum. The latter may see collecting as connoisseurship and investment, and build private museums on par with the most modern and professional of state museums. Grassroots exhibitions can 
even be digital, as in the case of virtual Cultural Revolution museums. ${ }^{10}$ Unable to have a bricks-and-mortar Cultural Revolution museum in China, activists wishing to memorialise the period do so online. In Hong Kong, there is somewhat more space to mount a grassroots exhibit; the territory has hosted pop-up displays on the 1989 Tiananmen student movement, and between 2014 and 2016 a privately run June Fourth Museum existed across the street from the official Hong Kong Museum of History. Yet, the long arm of the Chinese state extends far and deep; with the rise of the Xi Jinping regime's 'sharp power,' even displays outside of China-like Harvard's 2017 exhibit of Cultural Revolution 'big-character posters' (dazibao) from an anonymous private collector-can be seen as politically sensitive (see the image on page 146).

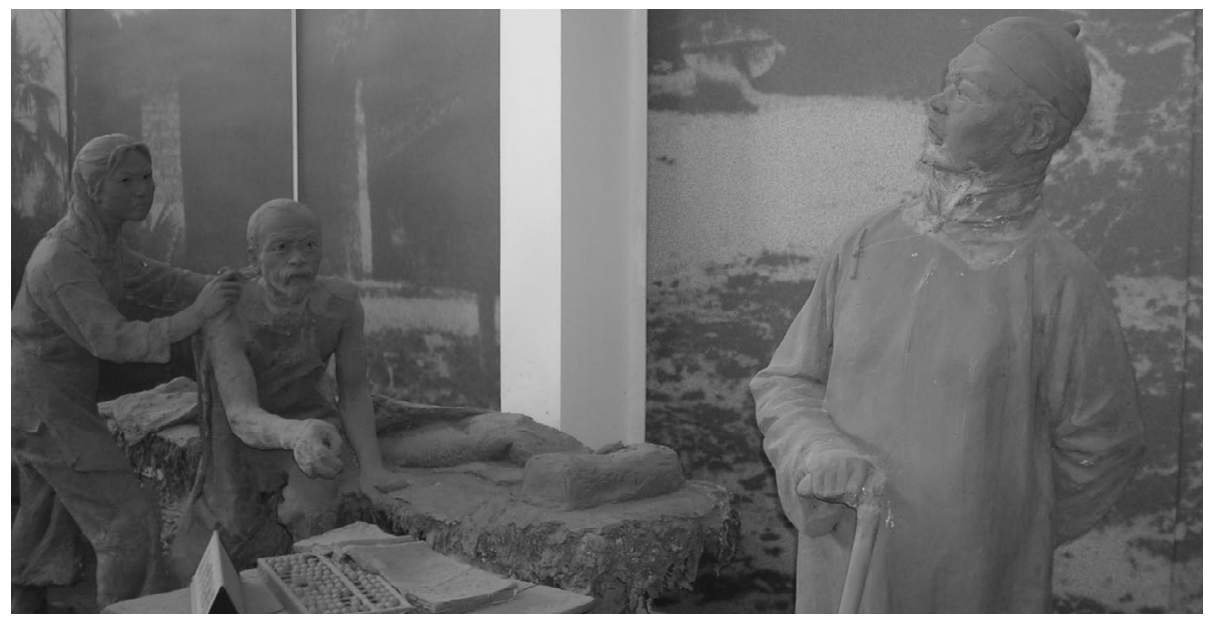

Lei Feng Memorial Hall of Hunan, Changsha (2010)

\section{Museums as Evidence}

In the Mao era, museums and exhibitions differed from other propaganda forms in their focus on the material. Officials stressed that objects-more so than pictures or text-were most attractive for the ordinary viewer. 'Every exhibition object,' they exhorted, "has in and of itself a life and the ability to persuade." ${ }^{11}$ Both accessible and arresting, material objects also fit within the ideological framework of a revolution based on Marxism: if a material object was a reflection of the historical circumstancesand class relations-that produced it, then an object was the ideal lesson. Yet curators in Mao's China departed from the Soviet model. In Soviet museums, exhibits explained class by showcasing the means of production and their ownership. In China during the Mao era-with the persistence of class struggle in the context of a 'continuous revolution' (see Galway's essay in the present volume)-curators displayed class through personal possessions: workers and peasants through patched clothing and humble quilts, landlords and capitalists through silks and furs. Like temple depictions of otherworldly justice, greed and corruption were represented by material excess. ${ }^{12}$ 
Yet 'class education exhibitions', ubiquitous during the Socialist Education Movement of the early 1960s, were more than mere morality tales. These were used to make the argument that class enemies existed in New China, threatening the socialist revolution, and that it was necessary to struggle against them; hence such exhibits used material possessions to display what were literally called 'evidence' and 'proof.' Land deeds and rent registers were called 'change-of-sky documents' (biantianzhang), supposedly saved by former owners so that after a capitalist restoration they could stage a comeback. Similarly, gold bars and foreign currency were used to identify landlords and capitalists who had 'failed to reform,' concealing their wealth for a future 'change-of-sky'. Finally, weapons and Nationalist flags were proof of counterrevolutionary intent, revealing enemies in New China's midst. So powerful at suggestion was the 'class education exhibition' that it gave the Red Guards concrete examples, things to look for when they ransacked the homes of alleged class enemies during the Cultural Revolution's notorious 'house searches' (chaojia). The discovery of such material evidence became grounds for class struggle, and the Red Guards proudly displayed the spoils of their revolutionary rebellion. ${ }^{13}$

Four decades after the conclusion of the Cultural Revolution and the Mao era, where is the material evidence of this period? Outside of China, there have been exhibitions of its material culture, but most have been limited to displaying cultural artefacts and manufactured products: folk paintings and propaganda posters, ceramics and objects of everyday use, Mao badges and other consumer goods. Within China, a few collectors have established and built private institutions that exhibit what is sometimes called the 'Red Age' (hongse niandai)_for instance, Shanghai's Propaganda Poster Art Centre

Red and Black Revolution: Dazibao and Woodcuts from 1960s China, Cambridge, MA (2017)

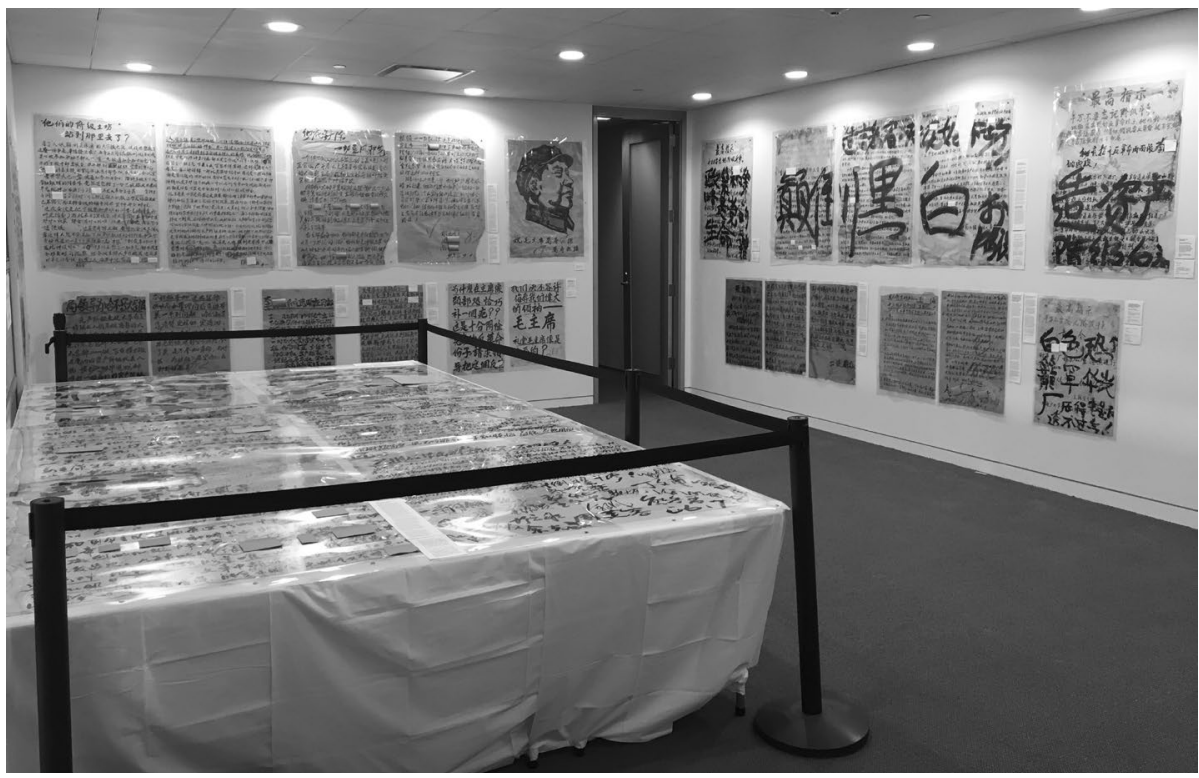


has become a niche tourist attraction, and the Jianchuan Museum Cluster, adjacent to Sichuan's Rent Collection Courtyard, boasts the largest private museum in China today. But in the main these private museums do not offer an alternate narrative to that of the state. Events like the Great Leap Forward and the Cultural Revolution are acknowledged, but their violence and tragedy are only obliquely referred to, if mentioned at all. A propaganda poster or an enamelware basin present a past that is as 'red, bright, and shining' as it was once imagined.

Ironically, the rare examples of individuals who collect negative evidence borrow a page from Mao-era exhibitionary culture. For example, the display of blood-stained shirts is a constant trope from the Nationalists' martyrs memorials to the Communists' land reform rallies to New China's 'class education exhibitions.' In Hu Jie's 2006 documentary film, Though I Am Gone, the husband of Bian Zhongyun-the first teacher beaten to death in the Cultural Revolution-saved her bloody clothing to be displayed one day in a Cultural Revolution Museum. In a similar way, some of the Tiananmen Mothers saved mementoes of their children: a death notice or a photograph of a bloodied corpse. ${ }^{14}$ Another central element of Maoist exhibitionary culture was the use of written and verbal testimony: letters and confessions, in-person recounting of suffering, and post-viewing reflection and self-criticism. Unconsciously mirroring this repertoire, the grandson of the notorious Liu Wencai-the landlord of the Rent Collection Courtyard-has spent his retirement years collecting testimonials of his grandfather's good deeds from former family servants and tenant farmers, a presentday attempt to rectify names. ${ }^{15}$

Jianchuan Museum Cluster, Anren, Sichuan (2016)

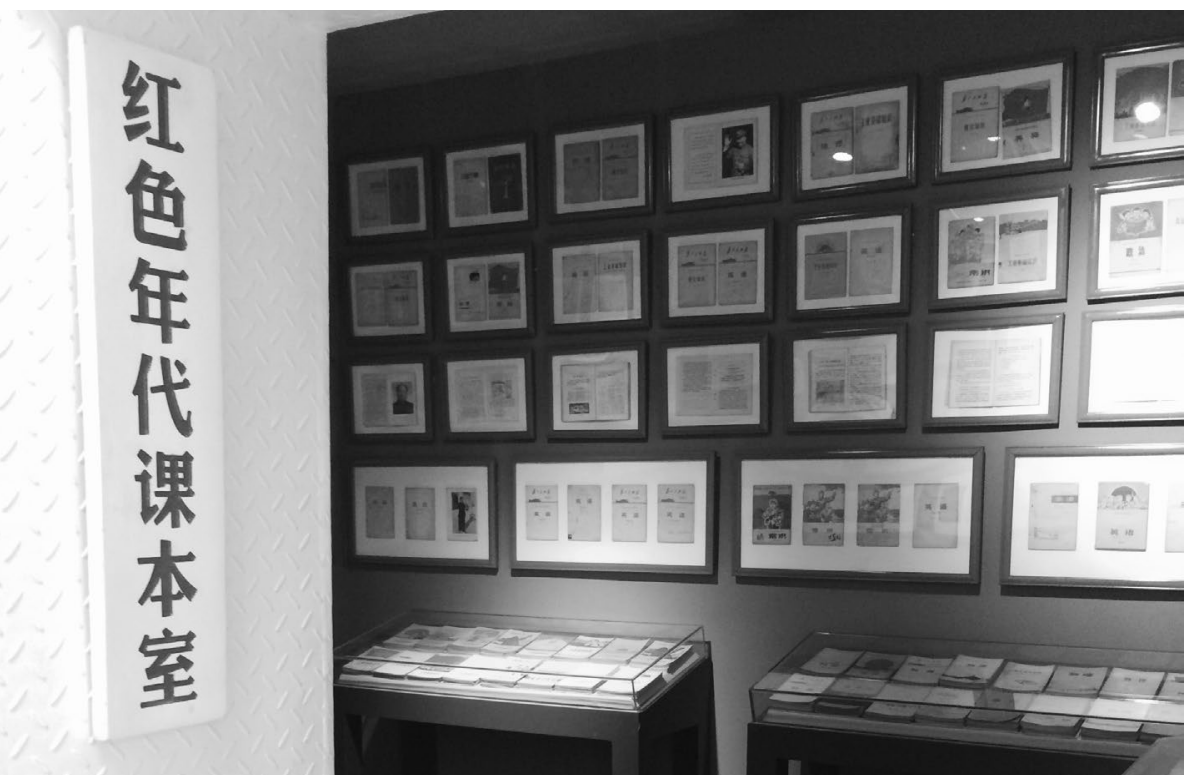




\section{The Power of Material Objects}

Material objects-in the Mao period and since-are powerful forms of evidence. To control their collection and exhibition is a priority for the state. Thus, museums in China, past and present, are repositories of official history, contemporary politics, and guides to the future. In the Mao era, a visitor could go to an exhibit and learn the script for a mass campaign as it was happening; likewise, an official could read a display's backdrop for clues on political reshuffling. Today, one can still read Chinese museums and note revisions to the displays. In 2016, subtle changes to the private Jianchuan Museum Cluster's 'Red Age' Exhibition Halls were observed. What was once to be a separate building devoted to the Cultural Revolution now exhibits the Red Army in Sichuan. A previous ambition to have a hall simulating the terror of the 'house search' was replaced with a digital collection of documents relating a house search account, erasable with the flick of a switch. In a series of glass cases, archival materials about property confiscation disappeared in favour of collectible cards featuring Mao Zedong quotations and revolutionary songs. Finally, a provocative side gallery consisting of the 'wanted circulars' of political enemies has been remade into a room for Mao-era textbooks (see the images on page 147-48). From official exhibition to private museum, the state continues to control the political narrative, the grassroots collection, and the material evidence of the past.

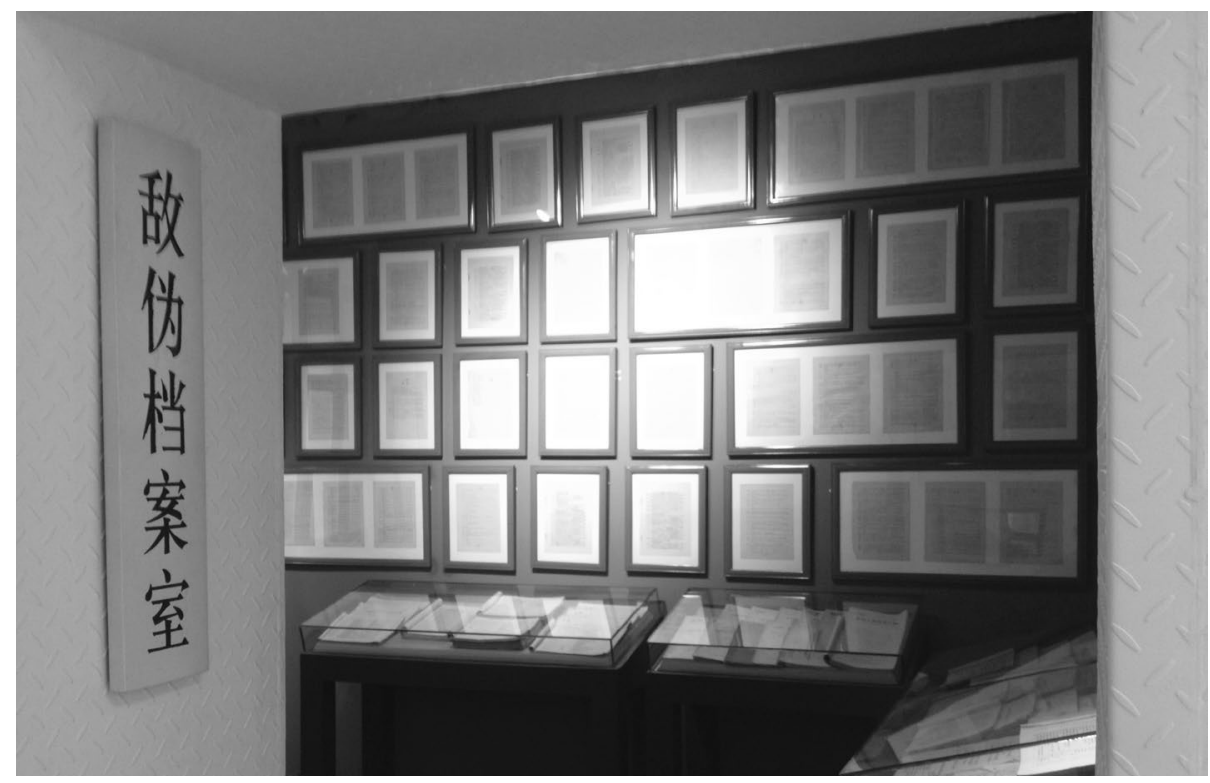

Jianchuan Museum Cluster, Anren, Sichuan (2013) 


\section{4 \\ 民族 \\ Nationality}

Uradyn E. BULAG

M

odern China has inherited not only a large territory but also many ethnic groups from the Manchu Qing Empire it overthrew in 1912. How to 'stretch the short, tight, skin of the nation over the gigantic body of the empire' has been a question confronting the successive governments of the Republic of China and the People's Republic of China (PRC). ${ }^{1}$ In 1912, Chinese revolutionaries came to power with an anti-Manchu rage vowing to 'drive out barbarians to restore China to the Chinese' (quchu dalu, huifu zhonghua), but settled with the last emperor, who issued an abdication edict handing over the non-Chinese dominions of the Manchus, Mongols, Tibetans, and Muslims to the new Chinese state, thereby inaugurating it as a 'union of five races' (wuzu gonghe). ${ }^{2}$ This multinational settlement was only a temporary compromise by Chinese nationalists whose foremost goal was to build a 'Chinese' nation-state in which the nation and the state were congruent. The imagined nation was zhonghua minzu (Chinese nation) to match the state name zhonghua minguo (Republic of China). Thus, the Chinese Nationalists who established a National government (guomin zhengfu) in Nanjing in 1928 scrapped the Five-colour Flag of the Republican government (minguo zhengfu or beiyang zhengfu) based in Beijing, which symbolised the five races, and replaced it with a Blue Sky with a White Sun Flag (qingtian bairi qi) signalling a desire for a national unity.

The PRC founded by the Communists in 1949 had a different vision for the new state. Since the Communists' legitimacy lies in 'the people' (renmin), the PRC Constitution defines China not as a nation, but a 'unitary multinational state created jointly by the people of all its nationalities' (quanguo gezu renmin gongtong dizao de tongyi de duo minzu guojia). And yet, with the waning of communist ideology, in the recent decade the discourse of the nation-zhonghua minzu-has come to the fore, thereby raising 
the question not only of how to refer to its diverse constituent nationalities, but also whether they should have any place in the newly imagined Chinese nation now openly embraced by the Communists.

\section{Pre-communist Ethnopolitics}

At the turn of the twentieth century, as the empire was transformed into a nationstate, China's ethnopolitics centred around how to name the diverse ethnic groups and the nation itself. The Chinese borrowed the concept of minzu from the Japanese minzoku (written with the same characters), which translated the English terms nation and nationality in the original Western sense of a civilian class opposed to aristocracy. In China, though, minzu came to denote a genealogical group with a racial connotation. In his oath of office as the provisional President of the Republic, and his reply to Sun Yat-sen's congratulations on 10 March 1912, Yuan Shikai referred to the 'five great nationalities' (wuda minzu), thanking them for elevating him to the supreme position and swearing to work for their happiness. ${ }^{3}$ The nationalist vision espoused by Sun Yat-sen and his successors was, however, to blend these five groups into a single minzu, which was called zhonghua minzu-the Chinese nation. The adoption of the term minzu to refer to two different categories faithfully reflected the built-in structural tension of the Republic. Not surprisingly, as the Nationalists overthrew the Beijingbased Republican government in 1928 to build a national state centring on the Han, they attempted to resolve the tension by changing the designation of the five national groups from minzu to zongzu (lineages). In this schema, minzu was reserved for the Chinese nation, while zongzu was used to designate the five groups as lineages descending from the same ancestors as the Han - the Yan and Huang emperors-with a hope to bind them into a single large Chinese nation-cum-family. ${ }^{4}$ Such a genealogical gerrymandering to assimilate non-Han peoples into the Han was prompted by a national crisis in the 1930s, when the Japanese invaded China and supported non-Han nationalist 'dissent' by restoring their own sense of 'descent.'

The conflict between the Chinese Nationalists and the four non-Han groups was masterfully exploited by the Chinese Communist Party (CCP), which was in need of any support it could muster to fight the Nationalists who were bent on annihilating them in the 1930s. The CCP adopted a different concept for the non-Han peoples, calling them 'shaoshu minzu' - in its original Western sense of 'national minorities' whose anti-imperialist national self-determination was deemed legitimate. Initially, the CCP couched the 'nationality question' in class terms, seeing national minorities as exploited and oppressed by the Chinese Nationalist regime, and their struggle for liberation a just cause. Pursued by the Nationalist Army on their Long March (1934-35) to safe haven, the Red Army passed through the Yi, Tibetan, and Muslim territories, and found in the non-Han peoples natural allies. Presenting themselves as 'good Han' (hao hanren), the Communists forged alliances with political leaders of the non-Han groups, pledging to help fight against their 'bad Han' (huai hanren) common enemies, and support their demand for autonomy. ${ }^{5}$ This 'united front' strategy proved to be effective in winning them over to the CCP and the new state it later built-the PRC. The Chinese Nationalists, in their zealotry to assimilate non-Han peoples, inadvertently pushed minorities into the embrace of their enemies, resulting in their own demise in 1949. 


\section{Conceptual Contradictions}

However, the communist class-nation principle had a built-in contradiction. The communist support for national minorities and their nationalist aspirations was predicated on the existence of exploitation and oppression by 'the enemy. It operated not in binary opposition, but in a triadic relation, with the Communists and the minorities forging an alliance against their common enemy-the Nationalists. But the victory in defeating the enemy and the termination of exploitation and oppression rendered any continued nationalist demand on the part of minorities illegitimate, for not only had they lost their basis for grievance, but any nationalist demand was perforce an indictment against their former ally, the CCP, casting it among the ranks of the 'bad Han.' Thus, the recognition of shaoshu minzu after the founding of the PRC was not so much a concession to minority nationalism as it was the adoption of a different logic pertaining to state-building.

The Qing Empire, ruled by the Manchu from 1644 to 1912, and the two Chinese republics built by the Chinese after 1912, were all composite states divided into two large components: China proper and Inner Asia. They were also conquest states, the Manchu conquering Inner Asians and the Chinese, and in turn the Chinese conquering the Inner Asians who had their separate territories and whose loyalty to the Chinese regime had little historical precedent. Ruling Inner Asians and their territories required conquests, which were euphemistically referred to as 'liberations' (jiefang). The friendship and alliances forged earlier during the Long March certainly helped make the liberation a relatively easy process, but the new government faced the task of both knowing the peoples it had incorporated into the new state and ruling them through appropriate representations.

The PRC thus launched a nationality identification (minzu shibie) project in the 1950s, which resulted in the recognition of 55 shaoshu minzu groups. The project followed both the Chinese genealogical principle and the Stalinist definition of nationality, which is based on four criteria: common territory, common economy, common language, and common culture. Each identified and approved group was granted territorial autonomy at various administrative levels depending on the size of their population and that of the territory they occupied. Shaoshu minzu now acquired a different connotation than the previous understanding as 'national minorities;' they were instead understood as 'minority nationalities,' whose identity was to be set against the 'majority nationality', the Han, and were to enjoy rights only to territorial autonomy but not to secession. As a communist state, the PRC represented itself as a radical rupture from the previous regimes, thus it did not define itself as a nation-state, but as a unitary multinationality state, comprising 'the Chinese people of all nationalities' (zhongguo gezu renmin).

The autonomy granted to minority nationalities was, thus, not national autonomy as originally demanded by minorities. Nor were minorities recognised purely for their own sake. Rather, the classification was an act of statecraft to recast minorities in a way that was legible for the state to solve the 'nationality question', i.e. to achieve the twin purposes of both winning their loyalty to the regime and integrating them into 'the Chinese people.' The territorial autonomy granted to each minority nationality was defined as 'regional national autonomy' (minzu quyu zizhi) rather than 'national autonomy' (minzu zizhi). The term quyu has two sets of connotations: first, as 'local', 
i.e. a lower administrative level, and second as a region, whose raison d'etre was to accommodate other nationalities, especially the Han, in the autonomous area which is named after a specific minority nationality. The combination of the regional and nationality principles then effectively rendered an autonomous quyu a local-level multinationality administrative area. Moreover, a minority nationality would not be granted autonomy until there was a significant Han Chinese presence in the designated autonomous area, and autonomous leadership was firmly in the hands of the CCP.

\section{Governance Innovations}

One key area of innovation by the CCP in governing autonomy was the creation and training of minority cadres; they were to replace the traditional leaders who were removed after they had delivered their people to the PRC through the war-time Second United Front (see also De Giorgi's essay in the present volume). They were deemed politically suspect because they were elites, hence belonging to the category of 'enemy', whose rule must be overthrown. Minority cadres, recruited from lower classes and owing their political life to the CCP, were to serve the twin roles of both Partystate agents ruling their own respective nationality, and members of their nationality providing representation to the Party-state. To the extent that the degree of autonomy is measured by the number of minority cadres proportionate to the percentage of their nationality vis-à-vis other groups in their designated autonomous quyu, these cadres embody a conflict of interest. However, although the CCP is supposed to be transcendental and above ethnicity, the communist ideological authenticity is to be more faithfully maintained by Han cadres in an autonomous quyu, because the CCP subscribes to social evolutionism, which treats the Han as more 'advanced' than the minorities. Thus, with the exception of Ulanhu, a Mongol who served as the Party secretary of the Inner Mongolia Autonomous Region from 1947 to 1966, all Party secretaries in all the five provincial-level autonomous regions have been Han. In most cases, the Party secretaries also served as chairmen of the local People's Congresses, which represent the 'state', leaving only the chairmanship of the people's government to a member of the nationality exercising autonomy. In the Chinese political hierarchy, the government chairmanship is the third position, and it has the duty to implement Party policy and state laws-both the prerogative of the Han.

The Party and state control of minority autonomy is supplemented by the presence of the Han population in an autonomous area. In addition to the principle of what may be called 'joint autonomy' (gongzhi), i.e. the combination of regional and nationality principles, the Han are also assigned the task of 'uplifting' minorities to the level of the Han. Culturally, this means assimilation as minority languages are deemed an obstacle to progress. Economically, it means Han 'replacing' minorities in the development of the autonomous area's economy. The Chinese development model of 'partner assistance' (duikou zhiyuan) since the launch of the Great Western Development (xibu dakaifa) policy starting in 2000 , whereby numerous coastal provinces and municipal cities are to provide 'aid' to corresponding counties and departments in Tibet and Xinjiang only exacerbates the economic conflict in the frontiers. In the face of massive and rapid economic development initiated and carried out by forces from outside of the autonomous regions, minorities have begun to shy away from the public domain, and 
have moved into their private domain - that is, seeking refuge in religions or traditions. There they hope to run their 'internal affairs' (neibu shiwu), rights actually prescribed by the Law on Regional National Autonomy passed in 1984, but never fully implemented.

\section{Fears of Disintegration}

The collapse of the Soviet Union in 1991, and the partial Chinese attribution of its cause to nationality conflict, have led to open calls from both within the CCP and Chinese academia not only to abolish the regional national autonomy system, but also to change the minzu category. ${ }^{6}$ In their diagnosis, the system of autonomy has not led to minority integration in China; instead, minorities are alleged to have treated the autonomy under their ethnonym as their patrimony, and regarded the Han as alien invaders. Minority separatism is said to have been undergirded by the very category of minzu. From this perspective, the sin of the concept of minzu for minorities is that it competes with zhonghua minzu, the Chinese nation. The proposed solution to this apparent contradiction is to change minority as a minzu to minority as a 'zuqun', the latter being a direct translation of the English term 'ethnic group.' In their prognosis, minzu, with its allegedly misleading overtone of territorial autonomy, has led minorities to distance themselves from the Han and China, while the concept of zuqun is both relational and cultural, but not territorial, and the adoption of such a conceptual category would be conducive to interethnic intimacy, and eventually a consolidation of the Chinese nation.

What this amounts to is an attempt not only to 'depoliticise' minzu by replacing it with zuqun, but also to 'securitise' it in order to mitigate the minority tendency for splittism, terrorism, and extremism - the three crimes allegedly prevalent in minority regions. ${ }^{7}$ Such calls, as proposed in the so-called Second Generation Nationality Policy to replace the current nationality policy, effectively rendered the current system as 'abnormal.' However, such a desire to make China a 'normal' country would mean scrapping the Regional National Autonomy System, which the CCP has defined as one of the three basic political systems of China, along with the system of multiparty cooperation and political consultation under the leadership of the CCP, and the system of community-level self-governance.

Although the CCP seems to have rejected such calls and stayed the course, fundamental changes have already taken place at multiple levels. For one thing, Xinjiang and Tibet are already 'states of exception.' Not that minorities there have more rights to enjoy, but quite the opposite, as the two autonomous regions are now under tight security control (see also Yi Xiaocuo's essay in the present volume). Some of the measures adopted, such as the outright banning of minority languages in schools in Xinjiang, not only as a medium of education, but as a language in its own right, clearly violate the Chinese Constitution, which stipulates that 'all nationalities have the freedom to use and develop their own spoken and written languages and to preserve or reform their own folkways and customs' (Article 5). For another, zuqun is now deemed a scientific concept in Chinese ethnology or anthropology, which has shunned the term minzu as too political. And the English phrase 'ethnic group' has long been used to translate minzu in official documents, even though the official English translations of the Constitution and the Law on Regional National Autonomy still keep 'nationality' 
The academic and popular 'rectification of names' (zhengming) by using zuqun and 'ethnic group' instead of minzu or 'nationality' is a déjà $v u$ that reminds us of the Chinese Nationalist rendition of minzu to zongzu or lineages of the Chinese nation in the 1930s and 1940s. Although zuqun or ethnic group does not entail geneaologism as in zongzu, it is made subordinate to minzu, which is now reserved for the larger Chinese nation-zhonghua minzu. However, both zuqun and zhonghua minzu are unconstitutional concepts.

\section{On the Steppes of the Mongol Empire}

This does not mean that these challenges should be dismissed. For they have been framed as a warning to the CCP that unless it gives up on the current nationality policy and the term minzu for minorities, there is a risk of demise for both the Chinese state and the Party. The argument is seductive as it is conceptualised academically: minority nationalities are said to have been invented out of nothing, a result of blindly following the Soviet model. Invented or socially constructed 'nationalities' are deemed as being creatures akin to Frankenstein's monster, who have developed desires for independence and, when denied, begin to attack their very inventor: the CCP and the Chinese state.

Such a discourse mirrors the postcolonial criticism that often denounces Europe's arbitrary demarcation of ethnic boundaries in its colonies for having caused interethnic violence and even genocide. The opponents of this view have argued, however, that it is not the implementation of the current nationality policy or the state's Law on Regional National Autonomy that has led to minority splittism, but rather the lack of a good faith to put it into practice. ${ }^{9}$ They warn the CCP not to forget the solemn oaths it made to minority leaders when the Party was in dire need and urge the Party to keep its promise not to discriminate against minorities. Reversing the policy would be tantamount to returning to the position of the Nationalists, against which the Communists and minorities fought in alliance.

The notion of zhonghua minzu has come to centre stage in China's imagination of its identity in recent years. The current Party leadership has set the goal of achieving the rejuvenation of the Chinese nation as one element of the China Dream. This version of zhonghua minzu is different from the Chinese Nationalist rendition, the purpose of which was to assimilate non-Han into the Han, giving no place to their culture and history in the Chinese nation. Instead, in this iteration the impetus comes from the new ambition of Chinese leadership for global recognition of China's big power status. This dream has compelled China to present itself not as an inward-looking Han nationalist state, but as a big power in the image of the Mongol empire, as evidenced by China's Belt and Road Initiative. This has meant broadening the scope of China to embrace its former conquerors, such as Chinggis Khan and Kublai Khan, as Chinese, and even as national heroes. The new notion of zhonghua minzu actually challenges the Han historical and cultural sensibility and pride, for the Chinese tradition of resistance to Inner Asian conquests is now redefined as petty isolationism. The question now is whether the Chinese celebration of the Inner Asian 'minority' contribution to China's greatness and glory as embodied in the new zhonghua minzu will do justice to and improve the fate of its Inner Asian minority citizens. The situation in the frontiers does not, however, give any room for optimism, at least for the foreseeable future. 


\section{5 \\ 新民主主义 \\ New Democracy}

Marc BLECHER*

‘

ew Democracy' (xin minzhuzhuyi) was a theory, an overarching revolutionary strategy, and a period of the Chinese Revolution that lasted from the 1930s until the first half of the 1950s. Mao Zedong explained it in his classic 1940 essay 'On New Democracy.' He argued most centrally that:

The Chinese revolution must go through two stages, first, the democratic revolution, and second, the socialist revolution, and by their very nature they are two different revolutionary processes. Here democracy does not belong to the old category-it is not the old democracy, but belongs to the new category-it is New Democracy.

Shaped by the material forces of the class struggle at the time, New Democracy involved specific economic, political, and cultural forms to be elaborated by the Chinese Communist Party (CCP). It stood as a 'necessary' bridge between 'the old European-American form of capitalist republic under bourgeois dictatorship, which is the old democratic form and already out of date' and 'the socialist republic of the Soviet type under the dictatorship of the proletariat which is already flourishing in the Soviet Union.'

Politically, 'a system of really universal and equal suffrage, irrespective of sex, creed, property or education, must be introduced,' though Mao was careful to add immediately that it would be part of the Party's 'system of democratic centralism.' In economic terms, large industrial, financial, and commercial enterprises would come under state ownership, but under New Democracy 'the republic will neither confiscate capitalist private property in general nor forbid the development of such capitalist production as does not "dominate the livelihood of the people," for China's economy is still very backward.' Landlords' holdings would be distributed to farmers as private property. 
'In general, socialist agriculture will not be established at this stage, though various types of cooperative enterprises developed on the basis of "land to the tiller" will contain elements of socialism.' Culturally, Mao identified it with the breakthroughs of the May Fourth Movement of 1919 and with 'native legacies, especially popular culture' and in contrast to the immediately preceding 'imperialist'-inflected ideas of the bourgeoisie. Under New Democracy, the Party's ideology and propaganda would place communist ideas decidedly on the back burner, 'prepar[ing] the ground' by emphasising instead attacks on feudalism and imperialism. ${ }^{1}$

\section{Hidden Controversies}

Between 1949 and 1953, a controversy among the top leadership began to bubble below the surface about whether to shift to what Mao had always said was going to be the subsequent phase of socialist revolution. According to Arlen Meliksetov, a Moscow State University scholar who has analysed Soviet archives, Mao began to abandon New Democracy, while Liu Shaoqi, Zhou Enlai, Chen Yun, Bo Yibo, Deng Xiaoping, and others continued to support it. At a June 1953 meeting of the Party's Politburo,

Mao came down heavily on those [Party] members who sought 'to establish firmly the new democratic social order ... ? 'There are some', Mao Zedong said, referring to Liu Shaoqi and his supporters, 'who, after the victory of the democratic revolution, are still marking time. They do not realise that the nature of the revolution has changed, and instead of socialist reforms they continue to dabble at their precious "new democracy."

Between 1953 and 1956, as the socialist transition got underway, Mao continued to relegate New Democracy to the past. In 1957, the Communist Youth League, which in 1949 had been renamed 'New Democracy Youth League,' reverted to its original name. With the onset of the Anti-rightist Campaign, also in 1957, and the following Great Leap Forward and Cultural Revolution, New Democracy would not play a significant role in the Party's policy for the next two decades.

\section{Legacies}

Yet it left some legacies. Saloth Sar-who changed his name to Pol Pot-was first attracted to Mao's thought by the theory of New Democracy, though by the time the Khmer Rouge finally came to power, any trace of it had vanished to say the least (see Mertha's essay in the present volume). ${ }^{3}$ New Democracy did leave a more lasting impact on China's own nationality policy (see Bulag's essay in the present volume). On the one hand, it kept Han chauvinism in check; on the other, it presupposed that the Party would lead the country's minority nationalities (as it did all classes and groups), thus precluding any movement toward national self-determination. ${ }^{4}$

New Democracy began to stir from its coma with China's turn to structural reform starting in 1978. Arif Dirlik has observed that: 
there was much in common initially between reform policies after 1978 and policies of New Democracy that had brought the Communist Party to power [including] a mixed economy blending private national capital and state management and direction (bureaucratic capital) ... and a culture policy that sought to integrate a new Communist culture with native legacies, especially popular culture.

The Mao Zedong Thought the Party restored in 1978 returned it to its 'true' spirit, that of New Democracy, premised upon class alliance (united front) and development of the forces of production as the primary goals. ${ }^{5}$

The landmark 1981 'Resolution on Certain Questions in the History of Our Party since the Founding of the People's Republic of China, which comprised the Party's decidedly mixed verdict on the Maoist period, did not finish its second sentence before it mentioned New Democracy, going on to argue that it was one of Mao's major achievements. But leading Party ideologues Feng Wenpin and Hu Qiaomu were quick to contend that China was certainly not returning to New Democracy, partly because it had been so closely associated with the Chairman, and partly to assert that structural reform was forward- rather than backward-looking. ${ }^{6}$

But structural reform was, of course, politically contentious. In 1999, no less a figure than Hu Sheng-a long-standing revolutionary, Chair of the Seventh and Eighth National Committees of the Chinese People's Political Consultative Conference, member of the Twelfth Party Central Committee, and President of the Academy of Social Sciences-weighed in:

A reexamination of Mao Zedong's theory of New Democracy and his integrated theory of correctly handling the relationship between capitalism and socialism under Chinese historical conditions and with Marxist principles will be of great help to us in correctly understanding Deng Xiaoping Theory, the theories of reform and opening up, and the primary stage of socialism and relevant policies. ${ }^{7}$

He backed up his argument with Mao's own words: 'There will be a need, for a fairly long period after the victory of the revolution, to make use of the positive qualities of urban and rural capitalism as far as possible, in the interest of developing the national economy. ${ }^{8}$

\section{New Democracy and the Chongqing Model}

The most politically intriguing effort to resuscitate New Democracy came in 2011, as the $\mathrm{Hu}$ /Wen government was winding down and China was in the run-up to the accession of the new leadership. Zhang Musheng is a prominent Party intellectual whose father, Li Yingji, was a secretary to Zhou Enlai and Dong Biwu during the Maoist era. The publication of his book Transforming Our Cultural Perspective on History attracted the attention of no less a figure than General Liu Yuan, the son of Liu Shaoqi, who 
wrote a foreword to it and brought five senior military officers to the April 2011 book launch. ${ }^{9}$ Zhang was a supporter of Bo Xilai and his so-called 'Chongqing Model,' both eventually crushed by Xi Jinping.

What Liu Yuan and Zhang Musheng considered to be the Chongqing Model is similar to the Socialist New Democracy Movement of the early 1950s in three main ways: rural land reforms that aim to please peasants; an urban socialist welfare economy with a strong presence of state-owned enterprises that claim to protect the interests of workers; and a moral and authoritarian government that takes a strong stance against corruption. ${ }^{10}$

Zhang's stunning position is worth quoting at length:

Only the CCP can save China; only New Democracy can save the CCP.

If China hopes to roll with the globalisation trend of 'democracy', I'm afraid it will be like drawing a tiger and ending up with the likeness of a dog, not getting at all what we expected. Rather than bringing in a stone that might shatter the jade [i.e., result in chaos], why don't we just have confidence and just use our native-born New Democracy, which CCP member Mao Zedong raised and Liu Shaoqi put into practice?

There will be constitutionalism, there will be different parties within the Party, and opening up and freedom of public opinion, including freedom and independence of thought, can all ultimately be resolved within a single party.

If we had trade unions and farmer's associations, even under the leadership of the CCP, and their anti-corruption and balancing mechanisms went further in using the law to check the ruling Party itself, unlike today where everything is bound up together-could [the Party] not develop in this direction [toward greater democracy]? I believe it is entirely possible. We could surely proceed slowly, step by step. What Hong Kong and Singapore have accomplished, the CCP can surely accomplish.

If the CCP does not recover its leadership and control as principally a representative of workers and farmers, then there is no way out for you [the Party] whatsoever, and no legitimacy. So you cannot regard them (the workers and farmers) as [weak and] disadvantaged groups. Today, what kind of farmers are our farmers? On average they have 13.5 years of schooling, and for workers it goes without saying [that this is even higher]. Go back to the past, go back to the era of Mao, and they all belong to what you would call the intellectuals. So these masses aren't such fools [as you might imagine]. We are talking about 800 million mobile phones sending out short messages, and 460 million notebook computers exchanging ideas. 
There's no way of comparing this to your so-called staging demonstrations, airing views and writing big-character posters, or to the great networkingit is so much freer than it was at that time. ${ }^{11}$

Zhang offers an extraordinary vision in which the Party maintains its monopoly but opens itself up to vigorous, public debate and greater press freedom. It locates itself squarely within the educational and communicative advances of the twenty-first century, mindful, unusually and most significantly, that these belong not just to middleclass urbanites but also to farmers and workers. It would, indeed, comprise a new kind of democracy never seen in history, but inspired by Mao's theory and practice of New Democracy. With the fall of Bo Xilai a year later, and the rise of the increasingly hardline Xi Jinping, Zhang's ideas went nowhere. Yet with such powerful supporters as Liu Yuan, his trial balloon, and New Democracy, may yet float again. Chinese politicians play the long game, and such a development would not be the first profound political innovation by the CCP. 



\section{6}

\section{纸老虎 \\ Paper Tiger \\ Judith BALSO}

ike many other statements of Mao Zedong, the description of imperialistsor even all reactionaries-as 'paper tigers' (zhi laohu) became famous beyond China through the Little Red Book, where it features as the title of its sixth chapter. In fact, if one closely reads the chapter, only the first quotations deal with this term. ${ }^{1}$ Elsewhere we find a different imaginary, such as 'lifting a rock only to drop it on one's own feet' referring to the persecutions of revolutionary people by reactionaries; 'nooses round the neck of US imperialism' to describe American invasions and aggressions all over the world; or 'the East Wind is prevailing over the West Wind,' as a characterisation of the international conjuncture at that time. Amidst these passages, the paper tiger, far from being a trompe loeil in which the fragility of the enemy would be masked by a belief in its appearance of ferocity, reveals the double nature of any class enemy.

\section{Classical Roots}

Paper tigers made their first appearance in Maoist discourse during the Civil War. When Chiang Kai-shek's offensive began against the small communist bases scattered throughout China, Mao had to invent a way of framing their difficult situation so that communist soldiers could imagine their own possible victory. After its initial usage, the term came back into fashion in 1950 and 1951-years marked by the threat of a new world war linked to the atom bomb and precipitated by the US operation in Koreaand appeared once again at the outset of the so-called 'Sino-Soviet Controversy' in 1957. What these different situations had in common was the perceived danger that the Chinese Communist Party (CCP) and the international communist movement would lose courage in the face of disproportionate enemy military forces, and fall prey to the temptation to capitulate or accept futile compromises. 
The origins of the metaphors that appear in Mao's writings are often ancient and literary. In this specific case, the image probably comes from a classic of Chinese fiction that is known for having greatly inspired Mao: Water Margin by Shi Naian. This is the story of 108 rebels guided by Song Jiang, who fight against powerful and corrupted people and defy imperial troops through inventive stratagems. In the $23^{\text {rd }}$ chapter, one of these outlaws, $\mathrm{Wu}$ Song, proves able to kill a terrifying tiger with his bare hands. Tigers, animals that represent both courage and cruelty, are omnipresent in the novel. The names of at least ten rebels contain the character for 'tiger' $(h u)$, and throughout the book, the rebels' courage is continuously challenged in these terms: 'When the time comes for action, what good are you? Seeing a paper tiger, you cry out in fright!' In Mao's writing, it seems that the exploits of the incredible tiger-killer Wu Song and the fear of the cowards in front of simulacra of tigers combined to give birth to a new image that represented both the refusal to overestimate powerful enemies and the ability of overcoming the most terrifying threats.

\section{From Paper Tigers to Contradictions among the People}

Some people mock or despise statements of this kind-metaphors like paper tigers concentrating a political vision-taking them as an expression of a purely idealistic or even cynical position. But in Mao's thought, such formulas are never hazardous inventions. They are rather meant to condense experience, or enhance experimentation.

In 1946, Mao's rhetoric about paper tigers was clearly aimed at giving courage to the revolutionary army facing Chiang Kai-shek's Nationalist Party (guomindang, hereafter GMD) forces. The GMD was allied to the greater power of the time, the United States, then inflated by its victorious involvement in World War II. In 1950 and 1951, the injunction to not fear the enemy was still confidently rooted in the Marxist concept of History-who needs to be afraid when History is on their side? At the end of the 1950s, another conception emerges, introducing a displacement from history to politics: the crucial distinction between 'contradictions among people' (renmin neibu maodun) and 'contradictions with the enemy' (diwo maodun) (see Rojas's essay in the present volume).

This formula laid the foundation for a historical experiment that was confirmed by the final and complete victory against the GMD. A few years later, in a new threatening conjuncture, confronting the risk of a third world war, the victorious experiment was enlarged to a global philosophy of history. But the true power of the concept cannot be thought in separation from new political categories. It became clear to Mao that the solution of contradictions among people had been all along the key to the previous military victories and required being thought of in its own terms. What we can do today with paper tigers cannot be decided without a full examination of the conditions prevailing when it was invented.

\section{A New David against Goliath?}

Returning to the Civil War period and the origin of the Maoist usage of the term, in 1946 Chiang Kai-shek had a professional army with more than four million soldiers. As Mao described in 'Farewell, Leighton Stuart!' (18 August 1949), immediately after 
the barbaric atom bombing of Nagasaki and Hiroshima, and the following Japanese surrender, the armed forces of the United States were deployed to help the GMD fight the Civil War in China. In Mao's words, the US government '[supplied] the money and guns and Chiang Kai-shek the men to fight for the United States and slaughter the Chinese people.' By the end of June 1946, the United States had equipped 45 GMD divisions, trained 150,000 GMD military personnel, and landed 90,000 Marines. According to Mao: 'There were US naval bases in Qingdao, Shanghai, and Taiwan. US troops were stationed in Beiping, Tianjin, Tangshan, Qinhuangdao, Qingdao, Shanghai, and Nanjing. The US air force controlled all of China's air space and took aerial photographs of all China's strategic areas for military maps.' In different places, US troops and other military personnel clashed with the People's Liberation Army (PLA) and the American air fleet took part in the war on Chiang Kai-shek's side.

Mao's immediate conclusions were that the American policy against the revolutionary bases in China was a major component of 'the US imperialist policy of worldwide aggression since World War II. From his perspective, in 1946 not only did the war continue, but a new world war seemed possible-maybe unavoidable-based on the military superiority of the US and their expansionist tendencies. It was the beginning of what would later be called the 'Cold War,' a period marked by the obsession over the possibility of conflicts between the US and the Soviet Union with global repercussions.

To face the GMD and American forces, the PLA had 900,000 guerrillas isolated and scattered throughout China. By the end of June 1946, Chiang Kai-shek and his allies launched an all-out offensive against the liberated areas, opening six major theatres of war. The PLA was outnumbered by its enemy. It is no surprise, therefore, that a pessimistic appraisal of the situation gained traction within the CCP, with some people showing weakness in the face of enemy assaults and superior military strength.

Mao tried to counter pessimism, first through the diffusion of inner-Party documents that excluded the possibility of any new short-term compromise between the Soviet Union on one side, and the United States, Britain, and France on the other. The point was to reassure CCP members that there was no possibility of an AmericanSoviet agreement, which would leave the Chinese revolutionaries isolated and alone. It was a hard task, considering that in August 1945 Stalin had already recognised Chiang Kai-shek's government as the central government of China and negotiated a partial occupation of Manchuria, choosing the Nationalists over the Communists as interlocutors.

\section{Courage or Recklessness?}

In the face of Stalin's desertion, Mao's statement on paper tigers was deliberately addressed to Anna Louise Strong, who was a freelance American journalist, already linked to revolutionary Russia. This meant that Mao's words were aimed at a global audience, including the American government and the American people. It was August 1946, only one year after the terrifying destruction of Nagasaki and Hiroshima, and two months after the beginning of the GMD offensive in China. In this context, Strong asked a question that was far from rhetorical: 'Suppose the United States uses the atom bomb? Suppose the United States bombs the Soviet Union from its bases in Iceland, Okinawa, and China?' To which Mao responded: 'The atom bomb is a paper tiger which 
the US reactionaries use to scare people. It looks terrible, but in fact it isn't. Of course the atom bomb is a weapon of mass slaughter, but the outcome of a war is decided by the people, not by one or two new types of weapon.' And he went on: 'All reactionaries are paper tigers. In appearance, the reactionaries are terrifying, but in reality they are not so powerful. From a long term point of view, it is not the reactionaries but the people who are really powerful.'

In other words, Mao subordinated the power of weapons to the conduct of the war. But how long would it take for the CCP to defeat the GMD armies? Strong asked this exact question: 'Suppose the United States gives Chiang Kai-shek no help, besides that already given, how long can Chiang Kai-shek keep on fighting? Mao: More than a year. A.S: Can Chiang Kai-shek keep on that long, economically? Mao: He can. Here Mao firmly opposed the long-term reality to the immediate perception of powers. On one side the GMD could keep going for a long time, more than one year, at least 'economically', and even without US help. On the other side, Mao was confident that recent historical facts were going to vindicate his apparently adventurous statement about Chiang's fragility. He quoted the fall of the tsar in Russia, the smashing of Axis allies (Hitler, Mussolini, and Japanese imperialism) as elements supporting his faith in a communist victory, in spite of the initial disproportion between forces. And he did not hesitate to announce the impending defeat of Chiang Kai-shek before its time: 'We have only millet plus rifles to rely on, but history will finally prove that our millet plus rifles is more powerful than Chiang Kai-shek's aeroplanes plus tanks.' This last sentence sums up Mao's belief in the power of the masses, and people's war, to defeat those on the wrong side of the people and therefore on the wrong side of history (see Guan's essay in the present volume). For him as for Marx, although articulated in different conceptions, progress remains a driving force of history: reaction has no future in the face of progress, and people are on the side of progress.

\section{Victory over Paper Tigers}

Six months after Mao's talk with Anna Louise Strong, the GMD's offensive was halted, and a counteroffensive began. This eventually would lead to the victory of the communist forces in 1949, less than three years after Chiang's violation of the truce agreement and in spite of all his American support. Mao's statement had been submitted to experiment and proved right, at least in the context of the Chinese Civil War.

In fact, in that case, the conditions-'progress' and mass support-that made victory possible were anything but abstract or metaphysical. They consisted in the minute care with which the war of self-defence was organised and guided, including decisions and strategies such as accepting mobile warfare and the temporary abandonment of specific places and cities; developing close cooperation with the masses of the people; moderating policy towards middle peasants and landlords; and working to increase production in protected areas in order to become self-sufficient.

In an inner-Party directive entitled 'On some Important Problems of the Party's Present Policy' (18 January 1948) produced a few months before the CCP's final victory, it is possible to find some honest reflections stemming from the paper tigers notion: 'We have reason to despise them and we are confident and certain that we shall defeat all the domestic and foreign enemies of the Chinese people. But with regard to each 
part, each specific struggle (military, political, economic or ideological), we must never take the enemy lightly; on the contrary we should take the enemy seriously and concentrate all our strength for battle in order to win victory.' Here a new distinction appears, between strategy and tactic, between the whole and the part: there must be no strategic overestimation, but also no local imprudence or tactical eagerness. Everything depends on specific circumstances. In other words, non-adventurist policies always require a clear identification of the real process.

\section{From Circumstantial Statement to Political Concept}

Ten years later, Mao brought up paper tigers again in three different contexts: a talk with two Latin-American public figures ('US Imperialism is a Paper Tiger', 14 July 1956); a speech at the Moscow Meeting of Representatives of the Communist and Workers' Parties ('All Reactionaries Are Paper Tigers', 18 November 1957); and a publication in his Selected Works ('On the Question of Whether Imperialism and All Reactionaries are Real Tigers', 1 December 1958). In each text, Mao went back to the period of the Civil War, emphasising its victorious outcome. In his mind, victory remained tightly linked to the correctness of a strategy that minimised the power of the enemy. He henceforth elevated what originally was only a circumstantial statement to a proper political concept. 'We have developed a concept over a long period for the struggle against the enemy,' he wrote in 1957, 'namely, strategically we should despise all our enemies, but tactically we should take them all seriously.'

To broaden and find potential value for this concept in other situations and countries, Mao produced new arguments belonging to what we might call 'historical dialectics,' insofar as these arguments take the form of historical laws. In his 1956 Talk, first he presented an extension of the Marxist vision of History: 'History as a whole, the history of class society for thousands of years, has proved this point: the strong must give way to the weak. In so writing, Mao introduced a dialectics of the strong and the weak, still related to the Marxist vision of the transformation of ruling classes-first vigorous, revolutionary, and progressive, like the bourgeoisie itself-into backward, decaying classes. He then added his own optimistic theory of universal change and becoming: 'Everything is subject to change. The big decadent forces will give way to the small newborn forces.' Or again: 'Bigness is nothing to be afraid of. The big will be overthrown by the small. The small will become big.'

The philosophical ground for these affirmations is what Mao calls 'the law of the unity of the opposites', which he expounded in his 1958 Essay: 'Just as there is not a single thing in the world without a dual nature (this is the law of the unity of the opposites), so imperialism and all reactionaries have a dual nature-they are at the same time real tigers and paper tigers.' This law is defined in these terms: 'This basic concept of Marxism, the concept of the unity of opposites ... is the concept of the dual nature of the development of the universe, the concept of the dual nature of the development of things, the concept that a thing invariably manifests itself in a process and that every process without exception has a dual nature.' 


\section{The Return of Real Tigers}

Nevertheless, in 1956, Mao warned his interlocutors that, if it was true that 'all oppressed nations want independence ... the day will come when the paper tigers will be wiped out. But they won't become extinct of their own accord, they need to be battered by the wind and the rain.' And in 1958, again:

They are at once real tigers and paper tigers, they are in the process of being changed from real into paper tigers. Change means transformation. Real tigers are transformed into paper tigers, into their opposite ... . Hence, imperialism and all reactionaries, looked at in essence, from a long-term point of view, from a strategic point of view, must be seen for what they are-paper tigers. On this we should build our strategic thinking. But they are also living tigers, iron tigers, real tigers, they can devour people. On this we should build our tactical thinking.

Mao's dialectics is the subject of another essay by Pang Laikwan included in this volume. What I would like to underline here is this: first, reactionaries have to become what they are in essence, but they do not reveal what they truly are without a political catalysation of the process. The historical process of change never works alone, this is what no one should miss, or forget. No great progressive transformation may happen without the invention of a new fair and real policy. Yes, Mao in 1956 claimed: 'Small forces linked with the people become strong.' And again in 1957: 'All allegedly powerful reactionaries are merely paper tigers. The reason is that they are divorced from the people.' But the true question, the crucial question, is: what kind of processes may create such progressive links with the people? Or rather, which processes nowadays, can give birth to 'the people'?

Of course, popular movements advancing claims such as 'We are the 99 percent' or even to represent entire countries-such as the use of the slogan 'We are Egypt' in Tahrir Square-were far from being able to answer this question. The problem is: were they even aware of these underlying issues: what does it mean today to organise the existence of something durably solid, which we may name 'the people', or rather a piece of 'generic humanity'?

\section{A New Starting Point}

Mao in 1958 reminded us that 'the destruction of the rule of imperialism, feudalism, and bureaucrat-capitalism took the Chinese people more than one hundred years and cost them tens of millions of lives before victory in 1949.' In other words, to be victorious takes time. Because this kind of war 'can only be fought one by one' (1957). But Mao himself did not entirely elucidate how the victory becomes possible, at least not until he wrote one of his most influential and significant essays: 'On the Correct Handling of Contradictions among the People' (27 February 1957). My own hypothesis is that this text represents the true political development of the paper tigers concept. It contains not only the theoretical aftermath of the vast former sequence-the Long March, the War of Resistance against Japan, and the War of Liberation-but also decisive elements 
for a break with Stalin's policies. It begins by departing from a traditional notion of class struggle and opening to a non-classist definition of the category of 'people:' one belongs to the 'people' not strictly by virtue of one's objective class; more important is the subjective position towards revolution. To cite Mao's own words: 'The concept of "people" varies in content in different countries and in different periods of history in a given country.'

Even more important is the distinction between two kinds of contradictionsyou will notice the name itself, which is not equivalent to 'struggle' or 'conflict'those 'between ourselves and the enemy' and those 'among the people.' No need to be Chinese to understand these categories: they take the opposite course of Stalin's conceptions-anyone likely to be an enemy who could then be eliminated-and try to place the contradiction with the enemy under the rule of the contradictions among the people. The weight of emphasis is shifted entirely. For the first time, such distinction and the correlative assertion that 'the two are totally different in nature' allow the development of multiple policies, multiple treatments, depending on the antagonistic or non-antagonistic character of a contradiction. It was a turning point in the history of revolutionary politics, because it put an end to the exclusive bilateral face to face between the people and the enemy. It allowed a political work enlarging the existence of the people and diminishing the existence of the enemy. Henceforth, the departing point of any progressive politics had to be the ability to give existence to the people itself. When Mao claimed that real tigers-living tigers, iron tigers, tigers that devoured people-could be changed into paper tigers, he rested his claim on repeated political experiences of how the CCP had been able to constitute a Chinese people in the face of haunting odds and seemingly inevitable defeats and disasters.

The dialectics between real tigers and paper tigers may still be true, but remains of no use for us, as long as we do not connect the question of the enemy to the question of how a piece of 'generic humanity' today can exist, under which political conditions, through which local processes. Do real tigers and paper tigers still roam the world and haunt social space? This may very well be the case, but we wander among them blindly as long as we do not connect the question of the enemy to the circumstances in which people today live. Especially when we believe we understand the world around us, we are at our most ignorant. The production of knowledge no longer fully takes place within the university but depends on people's political capacity to speak about their lives as sites in which the present is contested and new futures are promised. One of the most enduring promises of communism is the egalitarian capacity of speech for all, regardless of national identity or traditional markers of belonging. In the words of a Malian worker in France and member in an organisation called Workers of the World/Architects of Peace, these conditions begin to be realised when 'those who have read all the books and those who have passed a hundred countries meet and work

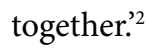





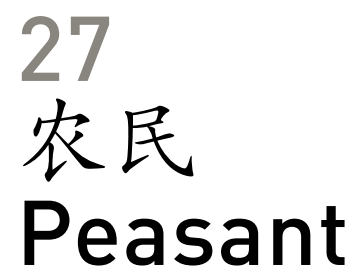

Alexander F. DAY

'P

easant' (nongmin) is a modern historical and political category in China, and Mao Zedong had more to do with its construction than any other individual. At the turn of last century, nongmin emerged as a translation of the English term peasant. While the category usually had negative connotations-such as backwardness, superstition, and ignorance-some took nongmin to be a positive category. For instance, in the first decade of the twentieth century, a moment in which the capitalist transformation of China was leading to a more pronounced rural-urban divide and worsening conditions for peasants, early Chinese anarchist Liu Shipei saw rural rebellion as having revolutionary potential and the peasant as a revolutionary subject. ${ }^{1}$ Liu took a populist position on the peasantry, in the belief that rural revolution implied a resistance to capitalist transformation by a unified peasantry in a way that would significantly transform rural social relations.

While Liu mapped a potential historical transformation, in his narrative the peasant was largely an essentialised figure. Others followed a similar, though less anarchistinflected, populist view of the peasant. Li Dazhao, one of the founders of the Chinese Communist Party (CCP), believed that the peasantry was a singular, if disorganised, class. $^{2}$ A less revolutionary populist vision of the peasantry emerged with the Rural Reconstruction Movement of Liang Shuming, Y. C. James Yen (Yan Yangchu), and others, who believed that rural education and governance reforms could lead to a unified rural sphere immune to class differentiation, and to a stronger China safe from capitalist and imperialist intervention (see also Ou's essay in the present volume). ${ }^{3}$ Nonetheless, the dominant image of the peasant in early twentieth-century China was negative, portraying the peasantry as holding China back from progress and in need of modernisation. For example, Chen Duxiu, an intellectual of the New Culture Movement 
and another founder of the CCP, viewed peasants as petty-bourgeois reactionaries who at best stood on the sidelines of revolution, if not in its way. In his opinion, they would never play a progressive role in history.

These dichotomous images of the Chinese peasant, however, were brought together into a new dynamic unity within the Maoist theory and practice of rural revolution, a result that was achieved by paying particular attention to the question of class differentiation. During the revolution, Mao came to understand the political inclinations of peasants as two-fold, depending on the local material and political conditions: as potentially tending towards rebellious activity, on the one hand, or towards the protection of their individual petty-bourgeois land holdings, on the other. The task of revolutionaries then became to investigate why certain peasants-especially 'middle peasants' (zhongnong)-would become revolutionaries instead of conservative defenders of the status quo. This 'revolutionary peasant dialectic' formed one of the most important and influential political inventions of China's short twentieth century (from 1900 to the 1970s), and has been referred to by historian Philip C. C. Huang as the 'dialectic of rural revolution.' ${ }^{4}$ Yet this dialectic began to disintegrate soon after the CCP victory in 1949, devolving into the earlier incongruous and static images of the peasantry. With China now undergoing rapid capitalist agrarian change, the question of class is returning in a new form.

\section{The Peasant Dialectic of the Chinese Revolution}

The methodology of the revolutionary peasant dialectic that emerged in China in the first half of the twentieth century did not seek a true comprehension of the essential nature of the peasantry. Rather, it sought a historical grasp of rural class differentiation aimed at understanding which classes of peasants would most likely become revolutionaries, and under what material and political conditions this kind of change could occur. In 1926, Mao argued that rural China at that time had eight classes, 'each having different economic positions and living conditions. This in turn influences their psychology, so that their attitudes towards the revolution also differ. ${ }^{5}$ The 'attitude' (taidu) of the petty-bourgeois landholder class, the middle peasant of later analysis, was decisive for revolutionary strategy, and the turning of the richer and middling landholders towards revolution was a crucial moment in the unfolding of revolution. The petty-bourgeoisie was, thus, a wavering class. ${ }^{6}$

Mao came closest to a populist vision of the peasantry in his famous 1927 'Report on an Investigation of the Peasant Movement in Hunan', in which he went so far as to claim that the Hunan uprising was a fulfilment of the 'historic mission' (lishi shiming) of the peasantry to 'overthrow the forces of rural feudalism.' Yet Mao quickly returned to focus on rural class analysis, and in the sober 1930 'Report from Xunwu' gone was the spontaneity of the revolutionary peasants of the previous 'Hunan Report,' replaced by more in-depth investigations and interviews that contained a far greater amount of sociological detail. ${ }^{8}$ In this later writing there was no abstract peasantry. Rather, the peasantry was riven with class divisions, and it was acknowledged that only detailed social investigations would lead to proper revolutionary practice. For Mao and the CCP, who, following Stalin, viewed China as a semifeudal and semicolonial society (see Barlow's essay in the present volume), the primary axis of class in rural areas was 
landownership. Chinese Trotskyists such as Ren Shu, Yan Lingfeng, and the Chinese Economy group, on the other hand, believed that society was already capitalist, and that the main rural class contradiction was between capital and labour. ${ }^{9}$ Organisationally, the CCP dominated, even if the debate on the nature of rural Chinese society was inconclusive.

By the late 1930s, the revolutionary peasant dialectic had become the CCP's orthodox position. There was a consensus around the idea that the peasant had a 'dual nature' (liangchongxing). ${ }^{10}$ As Mao stated in 1939, 'the positive or negative attitude of the middle peasants is one of the factors determining victory or defeat in the revolution, and this is especially true after the agrarian revolution [land reform] when they become the majority of the rural population.' ${ }^{11}$ But as the Party began to contemplate victory in the Civil War, the increasing fear that the conservative side of 'peasant consciousness' (nongmin yishi)-which derived from a petty-bourgeois class of small property owners-might prevail led to worries that, after liberation, the defensive attitude of the peasants towards their property would eventually block socialist development. In such a context, in 1948 Mao argued that the Party had to be vigilant against agrarian socialism' (nongye shehuizhuyi), a 'reactionary, backward, and retrogressive' form of rural socialism based on the principle of an absolute egalitarianism of landholdings. ${ }^{12}$

With the establishment of the People's Republic of China in 1949, the CCP turned to socialist modernisation, within which agriculture was to play an important but subordinate role. Party leaders saw a high level of accumulation from agriculture as the only way to underwrite the industrialisation process, which focussed on heavy industry. ${ }^{13}$ To feed industrialisation, the agricultural economy had to be developed, but under the conditions of a high and growing level of surplus extraction. Within this situation, the more conservative view of the peasant as a potential block to socialism and industrialisation, and as an object in need of modernisation, took precedence. ${ }^{14}$ The revolutionary peasant dialectic, which had brought the dual images of the peasant into dynamic unity, thus began to break down.

\section{Dialectical Breakdowns and Theoretical Reversals}

This process of dialectical breakdown accelerated in the early 1960s, following the demise of the Great Leap Forward, and is especially visible in historical debates on peasant revolution from that time. ${ }^{15}$ As political stances became increasingly rigid, the image of the peasant bifurcated into a revolutionary actor that carried the seeds of socialism, on the one hand, or a conservative and reactive class of small property owners that could never escape their own conditions without outside help, on the other. For example, the historian Bai Shouyi, interpreting peasants from a class viewpoint, argued that peasants could create their own 'peasant dictatorship' (nongmin zhuanzheng) to represent their interests just as a proletarian dictatorship represented the interests of the proletariat. ${ }^{16}$ Cai Meibiao, representing the orthodox Marxist stance of more senior Party historians such as Guo Moruo, Fan Wenlan, and Jian Bozan, argued to the contrary, that peasant rebels could not be revolutionary because they did not have the political consciousness necessary for the revolutionary overthrow of feudalism, and that their rebellions were simply spontaneous outbursts, largely without historical significance. ${ }^{17}$ In his view, peasant wars were neither real social revolutions 
nor the prime motor of history under feudalism, and it was only with the appearance of the bourgeoisie or proletariat that the conscious overthrow of feudalism could be accomplished.

During the Cultural Revolution, the more orthodox stance was attacked as conservative, and many of its proponents lost their academic positions. Nonetheless, from the early 1960s on, the peasant revolutionary dialectic that had guided the revolution was at a standstill. Diagnoses of the peasant inclined either to one side or to the other, depending largely on political engagements rather than concrete analysis of class, interests, and material conditions.

These debates reemerged and were reframed in the post-1978 reform period. As rural policy shifted to support the Household Responsibility System (jiating lianchan chengbao zerenzhi), effecting a return to household farming, the conservative side of the peasant's dual nature was initially emphasised, and peasants were portrayed as a conservative block to modernisation. As the 1980s proceeded, however, the valence of the dichotomy reversed. From then on, in the dominant discourse peasants could become a subject of modernisation only if they became more entrepreneurial. In a remarkable reversal, it was exactly their petty-bourgeois nature-which, within Maoist discourse had been the cause of their conservatism - that now made them progressive. Under this new formulation, class and class differentiation disappeared as problematic elements. It was rather the risk-taking individual farmer who became the motor for rural economic development. In an influential text, reformist intellectuals Wang Xiaoqiang and Bai Nansheng argued that the transformation of the rural economy-rather than simply its quantitative growth-depended on the 'quality' (suzhi) of individual peasants, with suzhi denoting 'the quality of engaging in commodity production and management' highlighted by an individual entrepreneurial attitude. ${ }^{18}$

This discourse on the low quality of peasants was central to the controversial television documentary River Elegy, which aired in China in the months preceding the 1989 protest movement. The series blamed China's lack of development on the peasantry, which with its low quality stood as a block to modernisation.

In the vast, backward rural areas, there are common problems in peasant [quality] (suzhi) such as a weak spirit of enterprise, a very low ability to accept risk, a deep psychology of dependency (yilai sixiang) and a strong sense of passive acceptance of fate ... . It's not the lack of resources, nor the level of GNP, nor the speed [of development], but rather this deficiency in the human [quality] that is the essence of this so-called notion of 'backwardness.' ${ }^{19}$

In other words, the rebellious side of the nature of the peasants was chaotic and disruptive to social progress, and only petty-bourgeois self-interest could lead to entrepreneurial progress. ${ }^{20}$

\section{From Peasant to Low-end Population}

This reformulation of the peasant comprised the basis for both the liberalism of the reform-period and the state's view of rural modernisation. ${ }^{21}$ But it was not long before this formulation was challenged by the reemergence of a populist politics of the 
peasant around the turn of the millennium. Growing out of the New Left critique of market utopianism in the early 1990s, pro-peasant scholars such as Wen Tiejun and He Xuefeng took a Polanyian stance, arguing that free market policies and the invasion of the countryside by the forces of capital would destroy peasants and rural society, destabilising China as a whole. ${ }^{22}$ In their writings, only a unified peasantry built through cooperative villages and protective state policies could prevent this dire outcome. These ideas developed in relation to rural activist and cooperative practices that came together under the name of 'New Rural Reconstruction' (xin xiangcun jianshe), a label that drew from the populist movement of the 1930s mentioned above. ${ }^{23}$ While the Movement generated considerable innovative practices, it had less influence on state policy. From the pro-peasant perspective, the policies of the $\mathrm{Hu}$-Wen administration were a mixed bag for rural society: on the one hand there was the abolition of the agricultural tax in 2005 , but on the other, those years saw an acceleration of the entrance of capital into the countryside, a facilitation of land transfers, and a limitation of cooperative relations. ${ }^{24}$

With the rapid growth of agribusiness and the formalisation of land transfers allowing for the accumulation (and dispossession) of rural land, it is more and more difficult to talk of a unified peasantry. In response, newer scholars are paying more attention to class differentiation and capitalist agrarian transition in China, although it is less clear what political stances much of this new academic work presents. ${ }^{25}$ At the very least, however, peasants today are being treated less as an essentialised, general abstraction, and more as a historical formation or process that requires explanation (i.e. de/ repeasantisation, class differentiation, new spatial formations, etc.). One might even question whether the category nongmin does the analytical and political work it used to do. The rural-urban divide, so central to the Mao years, now plays a much different role in structuring social relations, everyday life, and political economy, with so many rural residents no longer living in the countryside or, in many cases, not even knowing how to farm. Responses to the evictions of 'low-end population' (diduan renkou) at the edges of Beijing at the end of 2017 point to some possibilities, with the extent of public outcry against and debate concerning the evictions seeming to surprise the Chinese state. While many see the term 'low-end population' from a liberal viewpoint as a form of discursive discrimination, the analyses of others suggest its importance in reviving discussions of class in the Chinese context. ${ }^{26}$ With the acceleration of capitalist transformation in China, especially in the agricultural sector, class analysis and historical inquiry are as necessary as ever. 

28

人民战争

People's War

GUAN Kai

(Translated by Christian SORACE)

The richest source of power to wage war lies in the masses of the people.

It is mainly because of the unorganised state of the Chinese masses that Japan dares to bully us. When this defect is remedied, then the Japanese aggressor, like a mad bull crashing into a ring of flames, will be surrounded by hundred of millions of our people standing upright, the mere sound of their voices will strike terror into him, and he will be burned to death.

Mao Zedong, ‘On Protracted War', 1938

I

n 1938, as Japan's war machine and total invasion of China clearly advanced, and the Chinese army suffered defeat in every battle, the entire country was pervaded by the anxiety and premonition of defeat. Given the conspicuous lack of national and military strength at the time, China seemed to have no other road than surrender.

In May 1938, Mao published 'On Protracted War', rich with a vision of the future that firmly predicted China's ultimate victory in the War of Resistance against Japan (1937-45). According to him, the 'magic weapon' (fabao) that would deliver victory to China was guerrilla warfare. But the ability to engage in guerrilla warfare for an unknown duration of time depended on the support of the people in the countryside. In Mao's words, 'the [people] may be likened to water, the [guerrilla soldiers] to the fish who inhabit it'-later aphorised as 'the people are the sea that the revolutionary swims in. The metaphor of a fish in water describes an intimate political relationship and ecology in which the Communist Party (CCP) lives among the people. Thus, 'guerrilla war' (youji zhan) and 'protracted war' (chijiu zhan) were more than mere military strategies, as they constituted a broad outlook that Mao referred to as 'people's war' (renmin zhanzheng). For Mao, people's war was not only a blueprint for victory against the Japanese but a source of political legitimacy. In August 1946, after the victory against Japan, Mao said to the American reporter Anna Louise Strong: 'The outcome of a war is decided by the people.' ${ }^{1}$ One does not have to strain too hard to hear echoes 
of Mencius's political philosophy: 'The time is not as important as the terrain, and the terrain is not as important as having unity with the people ... [A]n unjust cause finds little support.'

\section{Who Are the People?}

To understand people's war, it is imperative to raise the conceptually thorny question: who are 'the people' (renmin)?

In China's history, there has never been a concept of the people-only the binary structure of government officials and ordinary people. In traditional Chinese thought, the minority of rulers-'officials' (guan) — and the majority who are ruled-'people' ( $\mathrm{min}$ ) - are both separated and connected by a material force, which confirms the truth that people are the material foundation of rule. This idea is articulated in the wellknown Chinese expression that the 'water can carry the boat or overturn it.'

The concept of the people originated from the French Revolution (1789-99) and the transformation of monarchical subjects into the subject of popular sovereignty of the nation-state. ${ }^{2}$ After the emergence of the modern nation-state-alongside other basic factors, such as territory, sovereignty, population, and government-the vague concept of the people was elevated to the ruler of the nation. Marxist theory was suspicious of such a slippery concept. From a Marxist perspective the state is an instrument of the ruling class; in this light, the people function as a vague concept that conceals class antagonism. The Marxist worldview of class antagonism between the proletariat and the bourgeoisie does not include the category of the people. So how did the people arrive on the stage in China?

The people is a fundamentally abstract concept-what Ernesto Laclau referred to as an 'empty signifier,' the meaning of which is determined by how it is inserted into a particular context. ${ }^{3}$ Under the ideological control of the Leninist political party, the people can be transformed into a flexible and pliable object of political manipulation. On the one hand, the people is the faintly discernible trace of revolutionary practice, a slogan that can be found everywhere, but the meaning of which is constantly changing. On the other hand, the people takes on particular meanings in different contexts in order to satisfy the needs of political reality. For example, in the War of Resistance against Japan, the revolutionary objective was the country's independence and national liberation: the Chinese people (zhonghua minzu) as a national category were equivalent to the people of China as a political category. After the CCP obtained political power, the category of the people was reformulated. Anyone who endorsed the socialist path belonged to the people, and anyone who opposed it became an 'enemy of the people.' The fulcrum of internal political struggle was the distinction between 'contradictions among the people' (remin neibu maodun) and 'contradictions between ourselves and the enemy' (diwo maodun) (see the essays by Rojas and Dutton in the present volume). The differentiation of political community is the foundation and prerogative of the CCP's leadership.

The abstract concept of the people always requires a supplement to make it concrete. For this reason, it is necessary to examine in fine-grained detail the different historical moments and discourses in which the name of the people was invoked. 


\section{People's War or Peasant's War?}

Under the conditions in which military strength was insufficient for victory, the CCP's army did not solely rely on military strategy, but simultaneously applied a political strategy. A slogan of this strategy was 'to win the war, rely on the people for support.' Due to its dependence on the people for victory, the army of the CCP referred to itself as 'the people's army' (renmin zidi bing) - a term that semantically implies that the army is the child of the people-and proclaimed its mission to fight on behalf of the interests of the 'the broad masses of the people' (guangda renmin qunzhong).

But in China at the time, the peasantry was the country's largest demographic. The CCP won the peasantry's support by identifying, addressing, and resolving their needs and aspirations, at the same time as it set up military encampments in the countryside. If communism is said to be a utopia, the CCP's revolutionary policy of land reform was far from an ideologically misty affair. Rather, it was a practical political endeavour, which severed the roots of the existing social system. The CCP's Marxist message and promise of the communist future was enthusiastically received by the peasantry who understood it through a Confucian framework of social equality in which the elite and the lowly, the rich and the poor are [treated] the same.' Confucian morality was draped in the attire of modernity and Marxist social equality. The majority of Chinese people fully supported the CCP's War of Resistance against Japan because they saw the land reform being carried out in communist-controlled areas as containing the seeds of their emancipation-a potential future when they could become the masters of their own lives. To defend the land parcels allocated to them by the CCP, the masses were willing to risk and sacrifice everything, and 'give their last grain of rice for army provisions, last piece of cloth for military uniforms, last bed frame as a coffin lid, and send their last son to the troops.' ${ }^{\text {' }}$ Under the historical magnifying glass, the people were revealed to be none other than the peasantry.

Mao realised that the Chinese revolutionary war depended on the correct handling of the peasantry and the ability to resolve their problems (see Day's essay in the present volume), and could not rely on the classical definition of the proletariat. From the earliest periods of his thinking, Mao's call to 'strike local tyrants and redistribute the land' ( $d a$ tuhao, fen tiandi) became the basis of revolutionary policy. Whereas this practice was successful in the early years in the base of operations in the Jinggang Mountains and Jiangxi Soviet (1931-34), it later had to be modified to fit the changing political situation.

After arrival in Yan'an in 1935, the CCP adjusted its land policy to call upon the peasantry to 'pay rent and interest' (jiao zu jiao $x i$ ) and for landlords to 'decrease rent and interest' (jian zu jian $x i$ ) in order to ameliorate the impact of class contradiction. This was because Mao regarded the War of Resistance against Japan as a historical mission of national liberation, and wanted to mobilise the political capabilities of the entire nation. In other words, class warfare had to take a backseat to national liberation. The results of this decision were fruitful. To synthesise the precarious balance between class and national objectives, the CCP invented different political forms, such as: the democratic regime of the 'three-thirds system;' the absorption of 'enlightened gentlemen' (kaiming shenshi) into the struggle for national liberation; the invention of a ballot mechanism based on the 'selection of representatives by the casting of bean 
shoots; and the establishment of a democratic system of government that was a bright lantern in the darkness. ${ }^{5}$ In all of China at that time, the mountain pagoda of Yan'an was the most politically attractive place.

Mao's people's war was conducted by the peasantry-but this fact is often obscured by the common definition of the peasantry as narrow-minded and incapable of class consciousness and class affection. But the CCP's concept and practice of people's war and the united front (see De Giorgi's essay in the present volume) supplemented the limited scope and class exclusivity of the original principles of Marxist-Leninist theory, while maintaining the organisational structure and mobilisational character of the Leninist political party. The inclusion of the peasantry expanded the CCP's social base of mobilisation, and formed unique political traditions, such as the centralisation of power to achieve major goals and the ability to launch political movements to solve political and social problems, which deeply influenced modern China.

\section{People's War or National War?}

The war of national liberation was considered a stepping stone on the road to class emancipation. But could these logics be so neatly disentangled?

The interests of the oppressed classes and oppressed nations are the motor of the development of human history. People's war came into being as part of the resistance against oppression. Mao traced the concept of people's war along a lineage of resistance, including examples from Chinese history, the slave revolt led by Spartacus against the Romans, and the early nineteenth-century wars of national resistance across Europe against Napoleon. In communist ideology, for the true nature of people's war to be revealed, it needed to first separate itself from the category of national war and transcend the principle of national self-determination-only then could the people obtain a class basis, and gain the long-term support of the oppressed classes of the world-the dream of international communist solidarity.

But for the CCP to achieve victory over the Japanese, it needed to mobilise the support of the entire nation, and not just the industrial working class (who barely existed as a class at that time). The category of the people was expanded to ventilate the contradictions of Chinese society. Mao invoked the name of the people to transform the CCP into the core leadership of the Chinese Revolution, construct the political party itself through the 'mass line' (see Lin Chun's essay in the present volume), and establish itself as the founder and leader of the emancipation of the Chinese peopleand not only serve as a local branch of the Comintern. Although the CCP called itself a class party, people's war transcended the narrow boundaries of class and popularised the revolution as a project of national liberation.

People's war was grounded in two fundamental premises. First, all of the material and spiritual wealth of human society is created by the large majority of the labouring people who are the natural masters of society ('the people, and the people alone, are the motive force in the making of world history'); second, all social phenomena and processes, including war, must conform to the fundamental interests and aspirations of the masses in order to be just and reasonable. On these grounds, all wars can be divided into two categories: 'righteous wars' (zhengyi zhanzheng) that serve the people's interests and 'unjust wars' that harm them. Righteous wars will obtain the endorsement and support 
of the people. Not only will people throw themselves into non-military struggle, but also energetically participate in military struggle. In this way, people's war possesses a mass quality and totalising quality. Conversely, people often resist and oppose unjust wars. For example, in both Korea in 1950 and Vietnam in 1973, the United States finally had to withdraw from these unfinished wars as a result of the popular belief at home that they were unjust.

In its own revolutionary struggle, the CCP and the People's Army attempted to preserve maximal distance and independence from the command of the Republican government. They did this by engaging in people's war, i.e. investing in the people's lives, infrastructure, and productive capabilities in its base areas. Under army leadership, the large production campaign at South Muddy Bend (nanniwan) significantly improved the living conditions, and reduced the burdens of people living there. ${ }^{6}$ The contrast with the Nationalist Party could not be clearer: the People's Army was more than just a fighting unit, but also a propaganda team, a production team, and a tractor planting the seeds of the future rolled into one. By establishing a relationship of flesh and blood with the local people, the People's Army was full of vital force. The Japanese invaders found themselves trapped in a people's military struggle behind enemy lines. As Mao said in 'On Protracted War:' 'The mobilisation of the common people throughout the country will create a vast sea in which to drown the enemy, create the conditions that will make up for our inferiority in arms and other things, and create the prerequisites for overcoming every difficulty in the war.'

This discourse of people's war supplied the CCP with an explanation for its victory over both the Japanese and the Nationalist Party, and a source of legitimacy. It was able to defeat armies with superior military and technological support on the basis of its magic weapon-the support of the people (see Balso's essay in the present volume). In political propaganda, the CCP accused the Nationalist Party of 'representing the reactionary classes' and 'opposing the people', and labelled Chiang Kai-shek an 'enemy of the people.' Mao's theory of people's war contrasted the Nationalist Party's corruption and alienation from the people with the political superiority and mass-based support of the CCP.

\section{Political Legacy}

People's war was not only a military strategy, but also a theory of political party organisation and ideology. Ultimately, the theory of people's war determined the nature of the CCP.

From the Communist Manifesto onwards, socialist revolutionaries have explored how to establish a revolutionary party organisation. In What is to be Done?, Lenin expounded the idea that the Communist Party must control the machinery of public opinion to impart proletarian consciousness to the proletariat, and transform disparate workers into an organised force aware of their own power. Mao's theory of people's war was developed on the basis of his insight into the conditions faced by the CCP. As early as Mao's 1927 'Report on an Investigation of the Peasant Movement in Hunan' he realised that the crucible of the Chinese Revolution was the education of the peasantry and that the revolutionary process depended on an alliance between peasants and workers. From Mao's first mention of his famous phrase 'political power grows out of the barrel of 
a gun' at the emergency meeting of the CCP Central Committee to address the question of agrarian revolution and armed struggle on 7 August 1927 in Hankou, the theory of people's war began to ferment until it achieved final form.

During the revolutionary process, Mao gradually realised that the CCP could not separate itself from the practical conditions of Chinese reality. Although the CCP came into being as part of the international communist movement, it became a distinct party by absorbing into itself the cultural traditions of Chinese civilisation. In retrospect, it is clear that the CCP did not mechanically replicate the definitions of Marxism, Leninism, and Stalinism, but supplemented and refashioned them through Confucian moral norms and China's dynastic historical experiences. Mencius's phrase 'whoever wins the people's hearts, wins the world' (de minxin zhe de tianxia) was proven in the victory of people's war. For Mencius and Mao, the people's heart is the most formidable weapon.

To this day, people's war is one of the historical foundations of the legitimacy of the CCP government. In the revolutionary years, the Communists who engaged in people's war cultivated an exceptional work style, disciplined themselves through arduous struggle, and behaved with integrity and honesty. But without the motivational horizon of people's war, this moral resource has been gradually lost. Armed with the concept of the people, Mao Zedong transformed the CCP, achieved Revolutionary victory, blazed a new path for China, and created history. But the world has changed since Mao's death. In China today, who is still capable of mobilising the people in their exalted name? 


\section{9 \\ 不断革命 \\ Permanent Revolution}

\section{Matthew GALWAY}

Our revolutions come one after another. Starting from the seizure of power in the whole country in 1949, there followed in quick succession the anti-feudal land reform, the agricultural cooperativisation, and the socialist reconstruction of private industries, commerce, and handicrafts ... . Our revolutions are like battles. After a victory, we must at once put forward a new task. In this way, cadres and the masses will forever be filled with revolutionary fervour instead of conceit.

Mao Zedong, $1958^{1}$

$\mathbf{T}$ he Chinese Communist Party's (CCP) victory and proclamation of the People's Republic of China in 1949 was a watershed moment in communist history. The Party had defied all odds and defeated a numerically and technologically superior foe in the Nationalist Party (guomindang, hereafter GMD). The victory, however, was not the end of the Chinese Revolution, but its beginning. As CCP Chairman Mao Zedong intimated in 1948:

The question now facing the Chinese people ... is whether to carry the revolution through to the end or to abandon it half-way. If the revolution is to be carried through to the end, we must use the revolutionary method to wipe out all the forces of reaction resolutely, thoroughly, wholly, and completely; we must unswervingly persist in overthrowing imperialism, feudalism, and bureaucrat-capitalism; and we must overthrow the reactionary rule of the [GMD] on a country-wide scale and set up a republic that is a people's democratic dictatorship under the leadership of the proletariat and with the worker-peasant alliance as its main body. ${ }^{2}$ 
Mao's call for China's revolution to persist-what became his theory of 'permanent revolution' (buduan geming lun)—was a reminder that new contradictions would inevitably emerge along China's path to socialist development, and even old contradictions could reemerge, thus necessitating a persistent revolutionary fervour. Permanent revolution also meant that revolution had to pass through stages and achieve specific goals at each stage before progressing to the next. As a concept, permanent revolution raises important questions: when does a revolution end, if ever? How does one know that enemies have been defeated? Are enemies of class struggle ever truly defeated? Is there a threshold of exhaustion when permanent mobilisation becomes unsustainable? Mao believed that social change still necessitated and demanded revolution even after the defeat of imperialism and the reactionary classes. Permanent revolution thus represented a response to the fact that revolution can never truly be complete because of the persistence of contradictions in socialist society (see Rojas's essay in the present volume). The incessant emergence, development, and resolution of contradictions are ultimately integral to socialist and communist development. ${ }^{3}$

Permanent revolution may consist of charismatic leadership, mass mobilisation, and an oppositional force against which revolutionary classes can struggle. ${ }^{4}$ It also contains spatial and temporal dimensions: spatially, the revolution must extend globally, as we see in the case of global Maoism (see Lanza's essay in the present volume); and temporally, it must become a duration of the present, as a way of making and sustaining revolution after seizing state power. To extend revolution in space and time, thereby making it permanent, became a central theoretical dispute of twentieth-century communism. The temporality of permanent revolution in China also led to a form of post-Cultural Revolution exhaustion and dissipation of revolutionary energies. But outside China, for instance in the case of Peru's Partido Comunista del Perú-Sendero Luminoso (Communist Party of Peru-Shining Path, hereafter CPP-SP), permanent revolution found new life.

In what follows, I trace this conceptual lineage from Mao's initial formulation to its invocation and experimentation in the highland territories of central and southern Peru, where the CPP-SP recruited students and peasants to fight incessantly across 'a river of blood' to punish exploiters and establish communism. ${ }^{5}$

\section{Genealogy of Permanent Revolution}

First coined by Karl Marx and Friedrich Engels in the mid-nineteenth century, and developed later by Leon Trotsky, the term permanent revolution has evolved significantly. Marx and Engels initially discussed a 'revolution in permanence' in The Holy Family in anticipation of social upheaval and a proletarian uprising after the national bourgeoisie's failure. Permanent revolution came to mean the proletariat's continued pursuit of its interests despite its political domination by another class; in the face of class hostility from above, this idea gave rise to an independent militant approach whereby the proletariat organises autonomously. ${ }^{6}$ Trotsky drew from this conception, emphasising the proletariat's role in leading an 'uninterrupted' revolution, surpassing the bourgeois democratic revolution to implement socialism. ${ }^{7}$ The 'socialist revolution,' he elaborated, 'begins on the national arena, it unfolds on the international arena, and is completed on the world arena, thus transforming domestic political 
change into an international affair. In 1927, the CCP made permanent revolution its political line, which at this stage was 'an uninterrupted series of armed uprisings [in the countryside] until final victory was achieved.' This earlier approach was hardly the final formulation; indeed, on the eve of the Great Leap Forward in January 1958, Mao announced his theory of permanent revolution, which offered a new strategy to guide the Chinese Revolution's transition to socialism. The ubiquity of contradictions in any society, even a socialist one, required permanent proletarian struggle, passing through necessary stages, to prevent a lapse in revolutionary progress.

\section{From Permanent to Continuous Revolution}

Rhetorically indebted to Trotsky's formulation, and to Sun Yat-sen's view that the Chinese Revolution 'has not yet been completed' and 'comrades must still bend every effort to achieve it,' Mao's theory of permanent revolution grew out of the CCP's struggle against the GMD. ${ }^{9}$ Pre-revolutionary China, Mao diagnosed, was semifeudal and semicolonial (see Barlow's essay in the present volume). The bourgeois democratic revolution's failure meant that only proletarian revolutionary action in an unbreakable alliance with the peasantry 'as its main body' could bestow the revolution with a permanent character on the path towards socialist development. New contradictions, however, required 'revolutionary zeal' to realise China's modernisation, economic development, and socialist unity. ${ }^{10}$ Mao's theorisation thus regarded the entire revolutionary process predating and anticipating communism as 'an endless series of social contradictions and struggles [that] can be resolved only by radical revolutionary breaks with existing reality. ${ }^{11}$ Progress to higher stages, he urged, 'must necessarily be in a relationship between quantitative and qualitative changes. All mutations, all leaps forward are revolutions [that] must pass through struggles. The theory of [the] cessation of struggles [in a socialist society] is sheer metaphysics.' ${ }^{12}$ The persistence of contradictions would remain given the permanent possibility of a reactionary class attempting to restore its power, and undermine the revolution. The Chinese Revolution would therefore pass through 'many stages and many revolutions' to safeguard the revolutionary gains and protect against the reemergence of bureaucratic, reactionary tendencies. ${ }^{13}$

Mao's theory of permanent revolution departed from Trotsky's conclusion that the bourgeois democratic revolution (the Republican government) had succeeded in China on the grounds that the latter had failed to eradicate feudalism, enact land reform, develop and augment productive forces, resolve national questions, and safeguard national sovereignty. The CCP, by contrast, sought to accomplish such tasks, stage-bystage, on the path towards socialist construction and proletarian dictatorship. As Mao noted, the Communists were 'exponents of the theory of the transition of the revolution, and not of the Trotskyite theory of "permanent revolution" ... for the attainment of socialism by going through all the necessary stages of the democratic republic. ${ }^{14}$ He elaborated on this break from the Trotskyite approach in 1958:

I stand for the theory of permanent revolution. Do not mistake this for Trotsky's theory of permanent revolution. In making revolution one must strike while the iron is hot-one revolution must follow another, the 
revolution must continually advance .... After Liberation in 1949 came the Land Reform; as soon as this was completed there followed the mutual-aid teams, then the low-level cooperatives, then the high-level cooperatives. After seven years the cooperativisation was completed and productive relations were transformed; then came the Rectification. After Rectification was finished, before things had cooled down, then came the Technical Revolution. ${ }^{15}$

In Mao's version, permanent revolution rationalised the CCP's economic and political rectification campaigns (see Mertha's essay in the present volume). 'Our revolution, he urged, 'is like fighting battles. After winning a battle, a new task is at once put forward. In this way, the cadres and the masses can be made to uphold their revolutionary enthusiasm to the full extent. ${ }^{\text {'6 }}$ Contradictions would indeed be present even beyond the 1949 victory, and new contradictions would emerge as the CCP developed China into a socialist society with a modern socialist economy. Such 'continually emerging contradictions' required accomplishing objectives that corresponded to each stage and revolutionary enthusiasm to stamp out bourgeois tendencies seeking to reverse revolutionary gains. ${ }^{17}$ Hence the CCP moved from Land Reform and the First Fiveyear Plan to the mutual-aid teams, cooperatives, the 1956 Hundred Flowers Movement, the 1957-59 Anti-rightist Campaign, the Great Leap Forward, and lastly, the Cultural Revolution.

During the Cultural Revolution, permanent revolution metamorphosised into the concept of 'continuing the revolution under the dictatorship of the proletariat' (wuchanjieji zhuanzheng xia jixu geming). Continuous revolution was an innovation introduced by the Gang of Four to theoretically justify the most radical features of the Cultural Revolution. ${ }^{18}$ 'Continuing the revolution' first emerged in People's Daily in 1967 and eventually constituted a theory of sorts. ${ }^{19}$ Consisting of quotes from Mao's earlier writings, continuing the revolution was a necessary ingredient of proletarian political power and the establishment of socialism. The enduring nature of class conflict in socialist society required continued infusions of revolutionary energy and enthusiastic action to ensure its perpetuity (see Dutton's essay in the present volume).

The debate over the difference between the earlier buduan geming and jixu geming was never definitively resolved. On one hand, the shift from the predicate adjective buduan to the transitive verb jixu stresses that positive action was essential to the revolution's continuation; on the other, jixu also implies continuity with the CCP's bureaucratic establishment, whereas buduan contains the possibility of rupture. ${ }^{20}$ The first reading is supported by Zhang Chunqiao's warning of a resurgence of the 'bourgeois right' unless the revolution was fortified under the dictatorship of the proletariat. ${ }^{21}$ The fear was that the bourgeoisie would reverse the positive gains of the revolution and reroute the Chinese path towards capitalism. Enthusiastic action ultimately took the form of a revolutionary culture that upheld the path towards socialism in all fields and stood steadfast against 'capitalist roaders.' Intrinsic to the revolutionary promise at the core of the Cultural Revolution was the formation of a new culture for a socialist mode of production, which necessitated continuous reinvention, i.e. revolution, to prevent it from deviating along a capitalist or Soviet bureaucratic path. To achieve the type of socialist society that Mao envisioned, the Cultural Revolution aimed at transforming 
high culture and everyday culture into a new type of revolutionary culture, and removing rightist tendencies that presented potential obstacles (see the essays by Thornton and Dai in the present volume). ${ }^{22}$

There were, ultimately, consequences to making revolution permanent in China. As Mao once said, 'the straw sandal has no pattern, its shape evolves as it is woven.' ${ }^{\text {. }}$ This phrase evokes the need for a constant reassessment and recalibration of the shape revolution takes as it unfolds. Yet the result of this approach had disastrous consequences, ranging from the Great Leap's unrealistic production quotas and pace to the Cultural Revolution's iconoclastic fanaticism, both of which disfigured the 'pattern' of revolutionary politics. Such misshapen sandals were not suitable for China's postMao leadership, in its attempt to 'cross the river' of economic modernisation and leave revolution on the shores of history. The lessons and inspiration from China's permanent revolution, however, spread beyond its own borders and found new life elsewhere. ${ }^{24}$

\section{Exporting the Revolution to Peru}

The Cultural Revolution struck a chord with foreign visitors to China, notably a Peruvian Marxist named Abimael Guzmán. His visits to Beijing between 1965 and 1967 led him to adopt Mao Zedong Thought as the CPP-SP's guiding ideology and regard the Chinese Revolution as pregnant with lessons for Peru. He studied Mao's works closely, trained in the CCP's military techniques, and received small arms training at a Chinese cadre school. Upon his return to Peru, he founded the CPP-SP as a Maoist party, avowing Maoism in his claim that the Shining Path's armed struggle required peasant mobilisation 'under the infallible banners of Marxist-Leninist-Mao Zedong Thought.' ${ }^{25}$ Now convinced to launch a people's war from Ayacucho, Guzmán adopted the nom de guerre 'Presidente Gonzalo' and followed Mao's example in waging a permanent revolution in Peru. ${ }^{26}$ The CPP-SP's ideological foundation contained four central pillars on which its revolution rested: a) the universality of people's war (see Guan's essay in the present volume); b) the Party's militarisation of the worker-peasant alliance; 3 ) the personality cult; and d) a permanent cultural revolution.

In addition to Mao, Guzmán drew inspiration from Peruvian Marxist José Carlos Mariátegui's (1894-1930) anti-imperialism and diagnosis of Peru as a semicolonial, semifeudal society. The name 'Sendero Luminoso' derives from Mariátegui's axiom that 'Marxism-Leninism will open the shining path to the future.' After Guzmán's trips to China between 1965 and 1967, he discovered ideas in Mao that resonated with Mariátegui, and also went beyond them. Mao's strategies of protracted war and revolutionary violence provided tactical elements that were absent in Mariátegui's thought. ${ }^{27}$ Together, Mariátegui and Mao's respective writings from the 1920s are reflected in CPP-SP assessments of the nature of Peruvian society in the 1970s. Mao's call to apply Marxism-Leninism creatively, Guzmán admits, allowed him to appreciate the contributions of Mariátegui as a 'first rate Marxist-Leninist who had thoroughly analysed our society.'

Mariátegui had applied Marxism as an interpretive paradigm to Latin American realities with Indigenismo, which called for socialism to end the racial marginalisation of indigenous peoples. Since his death, however, every leftist Peruvian political party failed to address the 'ethnic question' and the state's pauperisation of its indigenous 
population. ${ }^{28}$ Frustrated over issues of political line, strategy, and revisionism of leftist currents in Peru, Guzmán broke from the Mariátegui-founded Partido Comunista Peruano (Communist Party of Peru) and, later, the pro-Chinese Partido Comunista Peruano-Bandera Roja (Communist Party of Peru-Red Flag). These schisms were justified as an unfolding of the principle of permanent revolution, which was venerated as a fundamental pillar of the CPP-SPP. Under these auspices, the newly formed Party declared its intention to surround the cities from the countryside in an unrelenting, continuous peasant revolution. ${ }^{29}$ Guzmán's CPP-SP sought to conquer 'three mountains' before it could succeed where others had failed: a) US imperialism; b) semifeudalism; and c) bureaucratic capitalism. The 'three mountains' metaphor shows the centrality of Mao's permanent revolution in Guzmán's thinking: Mao's April 1945 invocation of the fourth-century story of the 'Foolish Old Man Who Moved the Mountains', a tale about persistence and human will in removing a mountain, had become one of the seminal essays of the Cultural Revolution (see also Lora-Wainwright's essay in the present volume). ${ }^{30}$ As Mao intimated:

Today, two big mountains weigh down on the Chinese people. One is imperialism, while the other is feudalism. The CCP has long made up its mind to dig them up. We must persevere and work unceasingly [buduan de gongzuo], and we, too, will touch God [hui gandong shangdi de]. Our God is none other than the broad masses of the Chinese nation. If they stand up and dig together with us, why can't we dig these two mountains away? ${ }^{31}$

The only way to conquer these mountains, Guzmán urged, was through protracted struggle, an alliance between urban and rural proletarians (notably the Andean peoples), and a perpetual struggle against reactionary forces, both local and global. ${ }^{32}$

A philosophy professor at a university in Peru, Guzmán declared himself the 'greatest living Marxist-Leninist' and intellectual successor to Marx, Lenin, and Mao. His 'mastery of Maoist text' granted him total authority over the CPP-SP as its supreme theorist, with 'pensamiento Gonzalo' ('Gonzalo Thought') constituting a 'Fourth Sword of Marxism. ${ }^{33}$ A Mao-like personality cult developed around him that employed Cultural Revolution agitprop methods of wall posters and fervid acolytes singing Mao songs 'memorised in Mandarin. ${ }^{34}$

Peru's need for a 'permanent' or 'continuous' revolution is most explicitly stated in a 1988 interview by El Diario with Guzmán:

This democratic revolution [of ours] must be followed uninterruptedly by a socialist revolution, on this we would like to specify, taking what President Mao taught us with a lot of foresight thinking about what could arise; he tells us that the democratic revolution ends on the same day that power is taken in the whole country and the People's Republic is founded, and on that same day and hour the socialist revolution begins, and in it, we have to develop a dictatorship of the proletariat and, thus, initiate the basic transformations to develop socialism. ${ }^{35}$ 
Guzmán's perspective on permanent revolution was clearly informed by his close reading of Mao's texts during his time in China, as he echoes the Chinese leader's emphases on world revolution, the peasantry's potential under Party leadership, and waging a people's war. By studying Mao and the CCP, Guzmán came to regard the Cultural Revolution as 'a continuation of the revolution under the dictatorship of the proletariat and its indispensable character; without it the revolution cannot continue its march to communism.' But in no way was the Cultural Revolution-its Chinese or Peruvian version-to be a single-step towards socialism; rather, as Guzmán makes clear, there were to be 'successive culture revolutions' responsive to 'our own reality.' The Peruvian revolution, he concludes, is linked inextricably to the world revolution; that is our final goal, the others are stages, steps, moments and we believe that the road to reach communism is long. ${ }^{36}$

CPP-SP's brand of Maoism took the form of broad recruitment among rural workers, organising peasant patrols (rondas campesinas), military encroachment, and continuous mass violence. Recruits were either students from Ayacucho's countryside, or from the margins of urban society. Despite its self-proclaimed vanguard status, however, the Party organisation reproduced rather than eradicated Peru's top-down 'colonial stratification,' as a Central Committee of white Peruvians oversaw a largely poor youth of indigenous or mixed ancestry. The CPP-SP nonetheless won over many students and peasants, as millenarian promises of radical upheaval in a continuous armed struggle struck a sympathetic chord with a disaffected base. By 1977, young militants were hosting Maoist-style 'education sessions' and 'recruiting fighters in mountain villages. ${ }^{37}$ The ouster of corrupt authorities and punishment of criminals and counterrevolutionaries by rondas were also positive changes.

But when military forces moved in to eliminate Party influence in the 1980s, the CPP-SP response was mass violence, often at the expense of the impoverished villagers and respected local leaders that it purported to help. This was all part of Guzmán's grand scheme and represented, ultimately, an extension of his adaptation of permanent or continuous revolution in fervour and scope. Mao's tactic of a people's war also guided the CPP-SP. Between 1980 and 1988, the Party nearly completed all stages of its revolution, expanding its peasant revolution by 1989 in preparation of seizing Lima. As the movement progressed, however, the Party initiated brutal internal purges to ensure longevity and loyalty. The personality cult around Presidente Gonzalo and the view that the Russians, Cubans, North Koreans, and even Chinese were 'weak and not true communists' led it to change its official ideology to 'Marxism-Leninism-MaoismGonzalo Thought. ${ }^{38}$ Government forces captured Guzmán in 1992, and although the people's war persisted, Guzmán's imprisonment effectively ended the CPP-SP revolution.

Abimael Guzmán's thinking on permanent revolution was responsible for some of the CPP-SP's strategic blunders. A faithful adherent to the Gang of Four's dogmatic Maoism of the Cultural Revolution, his emphasis on ideological purity ultimately pigeonholed his movement and squandered its emergent momentum. The Party's fixation on its own revolutionary purity sacrificed another vital aspect of Maoism and reason for the CCP's longevity - its pragmatism and adaptability. As a result of the Party's betrayal of its base, it ended up decapitated from its body politic. ${ }^{39}$ 


\section{Permanent Revolution Today}

Today, both in China and Peru, permanent revolution is all but dead. The planted seeds of global capitalism in both nations have grown into deeply rooted trees. The afterlife of permanent revolution, or versions thereof, outside China is a different tale. Maoist parties-some of which have ruled, others somewhat marginal-have emerged in several far-flung polities in Europe (Italy and Turkey), South Asia (India, Nepal, Afghanistan, and Bhutan), and Peru's South American neighbours (Bolivia and Colombia). Although the Peruvian Maoists failed, both the theory and concept of permanent revolution remain relevant to those still seeking redress in a world increasingly dominated by global capitalist imperialism. Even in Peru, where most believe that the Maoist movement is over, the insurgents who continue the fight do not see it this way. CPP-SP acolytes revere Presidente Gonzalo, and hold firmly that permanent revolution against imperialism and contradictions will never die. 'This will demonstrate to the world that what we have in Peru is a people's war, not a central committee's war,' stated director of the pro-CPP-SP London-based Sol Peru Committee Adolfo Olaechea. 'The war has more to do with a class struggle than with personalities. ${ }^{40}$ So long as class struggle remains, then, revolution will permanently be necessary. 


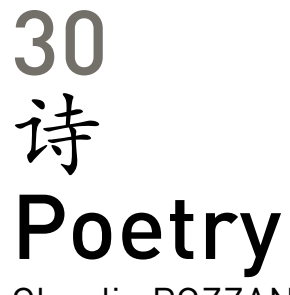

Claudia POZZANA

$\mathbf{T}$

o situate contemporary Chinese poetry among the afterlives of Maoist China is problematic, above all due to the very nature of the poetry, which is like a karst river surfacing erratically at unpredictable points and moments, making it difficult to locate its springs and tributaries. Added to this is the complication that the main novelty in the field of Chinese poetry is the wave of excellent poems written by migrant workers. Such a sociological phenomenon reopens a crucial political problem of modern China: what has been, and what could be, the role of the workers in a project of collective emancipation beyond capitalism? The permanence of a simulacrum of the 'working class,' mummified in the insignia of power (see Russo's essay in the present volume), clashes with the lyrical realism of these new worker poets, who are fully aware of the radical political inexistence of workers in China today. A close source of inspiration is certainly the Misty poetry that emerged at the end of the 1970s, which brought to light the deadly ambiguities of the role played by poetry and art in revolutionary culture (see Dai's essay in the present volume). Another hidden source, and perhaps the most paradoxical, is that Mao himself was one of the great poets of the twentieth century, although he wrote in classical regulated verses.

Finally, one could say that the richest source of the contemporary appearance of this karst river is still the immense Chinese poetic tradition, whose most authentic voices were driven by a sense of profound introspection about the place of poetry in China's cultural space. In fact, the best Chinese poets and writers have always illuminated key dilemmas of 'China's identity'. In the last 40 years, poetry has shed a peculiar light-a 'glitter among the interstices,' as Xiao Kaiyu, one of the most important Chinese contemporary poets, put it-on the very meaning, past, present, and future of 'China.' For Chinese writers and poets, 'China is a big question mark' and a vast unexplored territory accessible to poetic exploration. ${ }^{2}$ 
In the words of Meng Lang, a poet who recently passed away: 'The poet stays in the blind places of history. ${ }^{3}$ These places are perfectly inhabited by the new migrant poets. Despite the rhetoric of twentieth-century state communism, which praised the worker as the brightest historical figure, today the worker toils away in the dark shadow of history. The intersection of artistic creation and wage slavery in the new wave of migrant worker poets must resist its own obscurity and bring to light the conditions of life at the bottom of the global capitalist production chain.

This path of poetic investigation was opened by an artistic group labelled the 'Misty Poets' (menglong shiren), which was first formed in 1978-80 by the editors of the underground journal Today (jintian). ${ }^{4}$ This generation of young poets had grown up during the Cultural Revolution, which had given them a chance to taste a sense of equality (see Thornton's essay in the present volume). In the aftermath of the Cultural Revolution, however, the political language of Maoism had become anaemic and impoverished, emptied of its revolutionary intensity and emancipatory promise. Following Mao's death, the poets began to sense the risk of their own creative experimental enthusiasm being annihilated. In response, they dedicated themselves to a bold exploration of hidden possibilities within the Chinese language, creating new openings for thought, which reverberated across the entire Chinese intellectual horizon, not only in poetry and novels, but also in cinema, visual arts, architecture, music, and much more.

Misty Poets and the migrant worker poets are two distinct poetic configurations that, although born three decades apart, are engaging in a significant dialogue. The main ground of convergence is the concept of poetry as an independent intellectual space distant from the dominant culture and governmental discourse. Moreover, both groups share a peculiar sensitivity towards labour. Most of the early Misty Poets had experiences as ordinary labourers, as 'educated youth' (zhishi qingnian) sent to work in the countryside, or as workers in factories during the Cultural Revolution. Famous poets such as Bei Dao and Shu Ting were factory workers, Mang Ke worked in a fishing village, and Yang Lian was in the countryside-experiences through which they find resonance with migrant poets.

\section{Living the Changing Chinese Workplace}

Through these biographical experiences of contemporary Chinese poets one can glimpse the epoch-making changes of factory life in China after 1949. Chinese industrial workplaces have witnessed at least three eras: the early period of socialist construction in the 1950s; the intermediate, experimental period of the 1960s and 1970s; and the post-Maoist period with its neoliberal factories.

The poems written by workers during the era of socialist construction expressed a positive attitude and optimistic participation in the socialist project, as in 'Factory Morning,' a poem written by Li Xue'ao in 1957:

The valiant chimney is like the mast of a ship, it rises high at the centre of the factory.

The towering plant is the ship cabin, the Party secretary here is our red pilot, 
when all around all still sleeps quietly,

we sound the siren and set sail

bringing millions of heroic hearts we enter one wider day. ${ }^{5}$

These were poems that glorified labour (see also Ban Wang's essay in the present volume). However, the meaning, practice, and organisation of labour all radically changed during the Cultural Revolution. The Misty Poets who lived during this intermediate period witnessed and participated in a variety of experiments, such as attempts to mitigate the division of labour; remould the relationships between workers, technicians, and managers; and produce 'theory' through the existence of 'worker theoretical groups' active in the factories, as well as 'worker universities.'

These experiments in emancipation from factory despotism and the unprecedented space for intellectual pursuits among the workers contributed to the overall atmosphere in Chinese factories during the Cultural Revolution. Yu Jian captures this multifaceted situation in a recent reflection on his decennial experience as a worker before becoming a professor of literature and one of the greatest contemporary poets:

In my factory there were figures of the past who had been labelled rightists, ex-movie actors, painters, dancers, a variety of owners of the old society, descendants of capitalists, and intellectuals. These were highly educated people, a sort of living textbook, and they became my teachers. I remember well the time in the plant, the funniest thing was the storytelling-many people told stories and putting them together seemed like novels in which they all spoke. In that factory there were frequent power outages, so we had plenty of time to tell stories. Now when I think about it, the factory was like a secret art school .... I remember that in the factory I had time to write poetry, sing, play the flute, there was painting, writing of ancient poetry, studying philosophy of science, we listened to the Voice of America ... even Western literary works from the eighteenth and nineteenth century circulated in private. I even read Shi Zhi's poems, the brochures by Robespierre, and also Herzen and Chekhov. ${ }^{6}$

From this point of view, certain factory spaces in the Cultural Revolution functioned as 'communist heterotopias' in which traditional factory logic and temporality were suspended, and new capacities, relations, and senses of the world could take place.

For today's migrant poets, the subjective condition of life in the factory is radically different from both the classic socialist era and the experimental interval of the Cultural Revolution. The collective 'us' has blotted into 'a massively single number' (pangda de danshu), to borrow a line from the poet Guo Jinniu. ${ }^{7}$ It is a poetic description of the radical absence of sociality, the boundless eradication of identity and belonging in which the only relationship with the 'motherland' is 'my payment for the temporary residence permit.' As Guo writes with bitter sarcasm:

A person crosses a province, another province, another province

A person takes a train, then a truck, and then a black bus again

Next stop 
The motherland has given me a temporary residence permit.

The motherland accepted my payment for the temporary residence permit. $\ldots$

Sister Li of the north, stands alone facing south in untidy pajamas

Sister Li of the north, embraces a broken chrysanthemum

Sister Li of the north, hangs from a banyan tree

Lightly. As if her flesh and bones did not weigh.

Alas, I could not arrive to help her. ${ }^{8}$

\section{Strangers to Themselves}

'Sister Li of the North, hangs from a banyan tree' and the author is devastated for arriving too late to help her. Strange destiny for a poet to arrive in the place where someone has just killed oneself! In another poem, 'Going Home on Paper' (zhishang huanxiang), Guo portrays himself as a worker charged with putting up the nets on the top floor of the factory (this was a well-known measure taken by Foxconn managers to prevent the reoccurrence of suicides among young workers). For the poet it is an excruciating job that cannot but remind him of those who have jumped. The poem is like a funeral that brings the young boy back home, though only 'on paper.'

1.

The boy, at dawn, counts from the first to the thirteenth floor ends up counting and arrived on the top floor

he

flies, oh, flies

he cannot imitate the birds' movements

$\cdots$

3.

Thirteenth floor, I'm putting the anti-jump nets, this is my job to earn a payday with force turn clockwise, tighten the screws bit by bit, fight and resist in the darkness the more I use force, the more dangerous it is ... .

The poet searches in verse for a way to survive and resist the self-destructiveness of wage slavery.

Another migrant poet, Xing Huangtian, points out that 'we do not know anything' about workers today and their depressing labour in the deadly repetition of the factory life. ${ }^{10}$ How far from the Chinese Dream is the verse 'Dreams decreasing, slowness increasing?"11 In a poem simply titled 'He', the worker is unidentifiable, not only 
outside the factory, where 'he' is virtually invisible, but even inside the factory. 'He' is the stranger-even to himself-who works at the next machine. Everyone is locked in their own obsessions:

It is always like this, day after day, month after month year after year, time going by,

machinery wearing out, physical strength running out dreams decreasing, slowness increasing.

It is always like this, always

feeling blue, except for labour,

except for love. It is like innate that

we do not know anything about him

we do not know what

this person is grounded on, neither

his obsession, but is this the obsession

that we do not have. ${ }^{12}$

\section{Fatalism}

What it means to be a worker in the modern world constitutes an intellectual enigma, which requires renewed conceptual inquiry. Previous theoretical-political attemptsMarxism above all-to explain the worker as a political subjectivity and not merely an economic reality have fallen into a period of confusion and disorientation. It is unclear what a worker's existence can be grounded in beyond mere survival.

In this era, when political visions of labour have become rarefied, the poetry of migrant workers can be read as a symptom of unmoored subjective existence. Surely, they are a 'massively single number,' but can this number become a collective entity? My tentative answer is to consider the 'us' of the 'worker' in these poems as animated, at least temporarily, by a 'rational fatalism,' ${ }^{13}$ condensed in the following lines by $\mathrm{Xu}$ Lizhi: 'I cannot accuse, I cannot complain/I can only suffer my exhaustion.' ${ }^{14}$ Though this statement is written in the first person, I suggest that it should be read as an 'us' representing any worker.

As young Marx wrote: 'To call on them to give up their illusions about their condition is to call on them to give up a condition that requires illusions.' ${ }^{15}$ This lucid understanding of the conditions of wage labour generates an intense realistic lyricism. This lyrical power of unflinching insight can be felt in the portrayal of the radical social inexistence of migrant workers in the following two poems by Ji Zhishui-a remarkable woman poet. ${ }^{16}$ While migrants generally come from rural areas to work in the cities, they neither reflect peasant characteristics nor fit into the urban 'Chinese dream.' They are merely 'rocks piling up by the side of the road;' leaves of grass that, on encountering a gust of wind, are 'stripped of a rippling smile/stripped of the most basic respect;' and finally, 'leaves falling down into the dust.' 


\title{
Rocks by the Road
}

\author{
A gust of wind \\ blows us up from the land \\ and down onto machines in a strange place, down onto the assembly line \\ plunged into noise, machine oil, red and black gum, white lead, rust \\ beaten, screwed tight, nailed up \\ our quick spinning \\ flings off our accents and shouts and warm tears \\ until we can't squeeze out another droplet of sweat \\ and we harden into rocks \\ left by the side of the road \\ even if we go home we don't know how to farm \\ these rocks piling up by the side of the road \\ lean against one another, cold against cold

\section{Migrant Workers} \\ These grasses often \\ encounter a kind of wind \\ like a basin of cold water being sprinkled out \\ stripped of a vibrating heartbeat, stripped of a rippling smile \\ stripped of the most basic respect \\ we head down \\ like leaves falling down into the dust \\ looking for food in the dirt, in garbage piles \\ these people still want to run, still want to escape \\ but that only brings them into the trap \\ others rush onto the knife's point \\ these grasses are often \\ thin and weak
}

The last five verses expose the internal weakness of 'rational fatalism.' While insight is a necessary prerequisite for the emergence of subjective existence, it is not enough to prevent self-destruction. The same movement 'to run' and 'to escape' ultimately leads to a trap, and even pushes some of the 'grass leaves' to 'rush onto the knife's point.'

To consistently maintain the 'line' of not hoping for anything and not complaining about anything is extremely difficult-a titanic endeavour requiring an ascetic-heroic attitude, which constantly risks transforming into its opposite. Under these constraints, as soon as one gives in to the poetic urge to lament one's own sufferings, one risks succumbing to the 'hope' of recognition from the society which they ostensibly reject. Since every desire for recognition involves the frustration of misrecognition, this ambivalence ends up annihilating the starting point of not hoping and not complaining. 


\section{The Tragedy of Xu Lizhi}

In 2014, Xu Lizhi, a 24-year-old migrant worker at one of the Foxconn factories in Shenzhen, committed suicide, leaving behind a vast poetic body posthumously published by his worker friends. Any suicide is always an enigma that cannot be reduced to a single cause, even less, I would argue, to an act of resistance. Even his biographic details cannot explain his tragic decision, as they are no sadder than those of the other migrants. Regardless of the reasons for his suicide, we should consider his verses independently from his tragic fate. An example is 'I Swallowed an Iron Moon', which has become the emblem of Chinese migrant workers poetry.

I swallowed an iron moon

they called it a screw

I swallowed industrial wastewater and unemployment forms

bent over the machines, our youth died young

I swallowed the hurry and the displacement

I swallowed bridges for pedestrians and this rusty life

I cannot swallow any more

everything that I swallowed flows back to my mouth

I spread across my motherland

a poem of shame ${ }^{17}$

Other verses by Xu Lizhi offer chilling descriptions of the condition of workers in the despotic atmosphere of the factory:

\section{Fell Asleep Standing like That}

The sheet of paper in front of the eyes yellows slightly

I use the pen to mark over with various shades of black

it is full of a worker's vocabulary

workshop, assembly line, platform machine, work sheet, overtime, wage ...

by these words I was trained to be submissive

I cannot scream, I cannot resist

I cannot accuse, I cannot complain

I can only suffer my exhaustion in silence

when I first arrived here

I was only hoping for the grey pay check of the tenth of the month that gives me a late consolation

for this I have to grind off the edges and corners, grinding the language never skipped work, never a day of illness, never a day of personal break 
never arrived late, never left early

I'm standing like iron next to the assembly line, my hands as if they were

flying

how many days and how many nights

I fell asleep standing like that. ${ }^{18}$

Such intense verses leave us with much to meditate on. The existence of poems written by migrant workers affirms the infinity of poetry against the oppression of any finitude. Clearly the way out of the hell in which these poems were written is still to be invented, but it will depend on the possible affirmation of creative subjectivities. How can this migrant proletariat of the contemporary world unite to abolish wage slavery? We can glimpse at least one sign of trespassing towards a new political capacity. Mi Jiuping, a worker from Shenzhen Jasic Technology, a factory in the southern metropolis, was arrested in July 2018 for spearheading a protest in which he and his colleagues demanded, among other things, the establishment of an independent workplace union. At the time of writing, he still remains under detention, but this poem, which he wrote while in jail, has been shared across several blogs and websites, becoming famous among the workers and generating its own collective force:

I am with us

I stand atop a hill,

Seeing beyond the highest heavens,

The mountains crisp green,

The red sun rising.

I stand on the banks of a great river,

taking in the sight of the water,

the rolling waves

surging on endlessly.

I am a crane in a crowd of people,

I am silent beyond the outskirts,

I have lost family, love, and friendship,

I have lost all,

I have lost everything.

I will have family, love, friendship,

I will have all,

I will have everything.

Not today,

But in the not-distant future,

I am not me,

I am with us. ${ }^{19}$

Xiao Kaiyu observed, with a touch of skeptical irony, that for Mao poetry would be resurrected only when everyone in China became poets. Is not the new wave of migrant workers poets a 'Maoist' signal? ${ }^{20}$ 


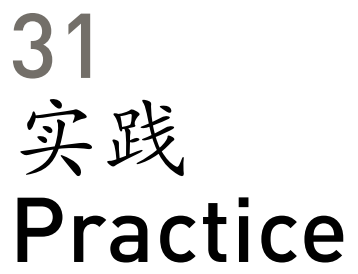

Aminda SMITH

n Yan'an, the wartime base area of the Chinese Communist Party (CCP), there were a number of dogmatists in the Party. They tried to impress people with their knowledge of Marxist texts and saw Marxism as an unquestionable and timeless truth, rather than a guide to action. Conversely, there were also a number of Party members who were empiricists. Those people based their thinking on their fragmentary, individual experiences. They failed to understand the bigger revolutionary picture and did not see the importance of theory at all. To correct these comrades' divergent but equally erroneous, subjectivist ideas-especially those of the dogmatists, who had already caused the Chinese Communist Revolution to suffer several losses-Mao Zedong wrote 'On Practice' in 1937. Or so says the introduction to the essay in the official collection, Selected Works of Mao Zedong.

'On Practice'-subtitled in the Selected Works as 'On the Relation between Knowledge and Practice, between Knowing, and Doing' - was not the first time Mao had written on the importance of practice. In his 1930 essay 'Oppose Book Worship', he excoriated the 'disgraceful' comrades who 'always keep their eyes shut and talk nonsense,' insisting that 'unless you have investigated a problem, you will be deprived of the right to speak on it' because 'when you have not probed into a problem, into the present facts and its past history, and know nothing of its essentials, whatever you say about it will undoubtedly be nonsense' and 'talking nonsense solves no problems, as everyone knows'. The claim that a core feature of Maoism is anti-intellectualism is often evidenced by Mao's insistence that all knowledge comes from engaging in actual practices, especially those of labour. In fact, Mao was only anti-intellectual in the specific sense that he distrusted bourgeois intellectuals and their exploitation-abetting methods and pursuits. Mao was deeply devoted to some of the defining tasks of intellectual work: producing knowledge 
and verifying it, which also required critiquing and evaluating methods of knowledge production (see Schmalzer's essay in the present volume). He did not want to halt the pursuit of knowledge; he wanted to pursue revolutionary knowledge. ${ }^{1}$

\section{A Technology for Revolutionary Knowledge}

Mao offered a technology for revolutionary knowledge production and truth verification: the 'mass line' (qunzhong luxian, see Lin Chun's essay in the present volume). Encapsulated in the shorthand phrase 'from the masses, to the masses' (cong qunzhong zhong lai, dao qunzhong zhong qu), the mass line was premised on the Marxist claim that ordinary working people were best positioned in terms of class perspective to most clearly see objective realities, produce the best analyses of problems, and point the way to the best solutions. Why were the masses so ideally positioned to know? For Mao and other Marxists, it was because the masses engaged in labour:

Man's knowledge depends mainly on his activity in material production, through which he comes gradually to understand the phenomena, the properties, and the laws of nature, and the relations between himself and nature; and through his activity in production he also gradually comes to understand, in varying degrees, certain relations that exist between people. None of this knowledge can be acquired apart from activity in production. ${ }^{2}$

The most successful revolutionary praxis would produce knowledge by beginning with that practice of participating in the concrete daily experiences of production and paying attention, observing, and investigating the concrete conditions created by those practices, while listening very closely when other labourers describe their own practices and conditions. According to Mao, when you come to see through that mass perspective, through the viewpoint of the people who labour, you will know some of the truest truths about the concrete conditions of the world.

Crucially, however, Mao's insistence on practice was not a dismissal of theory. For him, the dogmatists were worse than the empiricists, but both were guilty of subjectivism. All truth came from the concrete conditions of the masses, but not every interpretation of those conditions was true. Members of the masses, and the Communists who observed and worked with them, could hold incorrect views, or correct views that were 'scattered and unsystematic.' It is rarely possible for any individual to see fully the broader implications or imperatives contained in their own experiences. Mao famously likened the role of the Party to that of a processing plant for the ideas of the masses: the Party's responsibility was to 'listen attentively' to the masses; to engage in the practices they engage in; to use Marxist-Leninist theory to help identify the correct ideas that emerge from concrete work; to show the masses how to apply Marxist/Leninist/Maoist theory to understand the full scope of their ideas in a 'concentrated and systematic' form; and then to propagate the systematised ideas until 'the people' came to understand and accept them as their own. ${ }^{3}$ The mass line knowledge production and truth verification technology operates through an open-ended and recursive process of new truths becoming lived realities and new sets of practices, the results of which are observed, discussed, and recalibrated. 


\section{Anti-intellectualism?}

Mao was not anti-intellectual. He did not deny that we must produce knowledge about the world. But he also argued that we ought not simply seek to interpret the world when the point, of course, is to change it. He envisioned the dialectical method as ideally being able to produce new, verified knowledge, which could be used to change practice in revolutionary ways, to reshape the very conditions of the world (see Pang's essay in the present volume). Nevertheless, from Mao's perspective no revolutionary should become too invested or too certain about new practices, or the knowledge that informed them, or they would be vulnerable to those subjectivist ideas of empiricism or dogmatism. Revolutionaries must think in an 'infinite way'-from practice, to theory, to practice, to theory, to practice-in an endless 'ascending spiral' of mass line knowledge production. ${ }^{4}$

Some worry that the Party's recent attempt to revive the mass line means a return to the disasters of the Mao era, but the mass line also offers the possibility for Maoism to transcend Mao. ${ }^{5}$ In the official Party view, Mao Zedong Thought is alive. It did not die with him, nor must it be killed to prevent repeating his mistakes, as its method can improve and disprove its founder's preliminary conclusions. A recent article in a Party theory journal claimed that the CCP's continuous use of the endless 'ascending spiral' of mass line knowledge production 'is precisely why socialism is still flourishing, vibrant and alive in China, and why the Chinese nation is still walking along the road of socialism with Chinese characteristics toward its great rejuvenation.' ${ }^{\text {a }}$

Many observers find 'socialism with Chinese characteristics' or 'market socialism' to be little more than cynical attempts to preserve the legitimacy of a Communist Party working with practices and theories that are seemingly far removed from the ideas Marx advocated and the practices he observed. Yet those phrases could be entirely logical within a mass line epistemology, if the progression from Marxist thought to Maoist praxis to Deng Xiaoping's economic reforms to Xi Jinping's efforts to tie it all back together is the path lit by practice. Infinite practice-theory-practice processing could certainly take a party and a society in unexpected directions; if Marx could have set the course for revolution from his armchair, there would have been no need for a praxis of ongoing investigation and evolution. Of course, practice is not the sole criterion of truth, and the appearance of having been borne from experience does not, alone, make knowledge Marxist or emancipatory. It is only through the dialectical method of considering practice in light of theory and vice versa that one can approach truth and the possibility of revolutionary change.

\section{Marxist Futures}

What might Mao say on the debate over the nature of China's economic and political system in the twenty-first century? He would probably be unsurprised that dogmatists still want to impress others with their knowledge of Marxist texts and thus attempt to falsify the 'socialism' in 'socialism with Chinese characteristics' by pointing to the way the practices of Chinese communism have failed to correspond with Marx's nineteenthcentury theory. Yet Mao might also instruct empiricists to remember that their 
fragmentary, individual experiences and practices must always be contextualised with theory. And that theory cannot be one that takes us farther away from the promises of equality, liberation, and communism. The present progress toward those revolutionary goals can only be judged by engaging in the practices of material production, observing the relations between people, and investigating the concrete realities of the people's daily lives. 


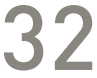

原始积累

Primitive Accumulation

Jane HAYWARD

$\mathbf{T}$

he creation of wealth is often ascribed to hard work and dedication by those who have it. Yet, '[i]n actual history,' wrote Karl Marx, 'it is a notorious fact that conquest, enslavement, robbery, murder, in short, force, play the greatest part.' Primitive accumulation (yuanshi jilei) is the transfer, often by violent means, of formerly common resources into the hands of a privileged few so that they can be utilised for the creation of private profit, thus depriving everyone else of an autonomous means of existence. Chronologically, primitive accumulation is precapitalist-it is the process by which the exploitative class relations inherent to capitalism come into being. Marx called it the 'original sin' of the capitalist mode of production.

Historically, the basis of primitive accumulation is the centuries-long process of the peasantry being driven off the land. This process takes different forms in different countries during different historical epochs. ${ }^{2}$ The classic account of this is the enclosure movement in feudal England. As common lands were taken over for sheep pastures by the aristocracy in response to the rising demand for commercial wool, the English peasants, deprived of their means of subsistence, had no choice but to sell their labour in order to survive. Over time, the peasantry was transformed into a propertyless class of industrial workers-a proletariat-providing the cheap labour which eventually came to fuel the British industrial revolution. Such processes, as they unfolded in various ways across the countries of Western Europe, were accompanied by parallel forms of primitive accumulation overseas, as the rising colonial powers seized foreign lands and enslaved native peoples, providing ever more resources and cheap (or free) labour to perpetuate the cycle of capitalist expansion.

The Chinese Communist Party's (CCP) relationship with the concept of primitive accumulation has been conflicted. In that it signifies the founding moment of exploitation of one class by another, it is considered the root of all capitalist evil. Thus, the presence or lack of primitive accumulation was a defining marker of difference between 
unjust capitalism and morally superior, egalitarian socialism. The Chinese socialist state under Mao was therefore organised in such a way that nation-building should take place without the occurrence of primitive accumulation, through the creation of-at least in aspiration-non-exploitative forms of social and economic organisation. This meant no accumulation externally via colonisation-an impossibility in any case, given the hostile international environment of the Cold War-and no private property domestically.

Production was to be organised on the basis of communal ownership, based on a system of work units (danwei), and via the collectivisation of agricultural production in the countryside (see the essays by Gao and Kevin Lin in the present volume). The relationship between urban and rural, industry and agriculture, was thus organised on the basis of an alliance between workers and peasants, under which grain produced by agricultural communes was cheaply supplied to industrial workers in the cities. With both workers and peasants as the owners of their respective means of production, primitive accumulation was rendered impossible-in theory, at least.

\section{The Search for Primitive Accumulation}

Yet, while primitive accumulation was to be avoided at all costs in the building of the new socialist state, paradoxically, it continued to be regarded as a necessary component for the realisation of socialism. Since primitive accumulation was the process by which two antagonistic classes emerged-those with property and those without-it was the very thing that produced class struggle (see Russo's essay in the present volume). In the somewhat simplistic version of Marxist theory to which many Chinese communists subscribed - based on a universalist, stagist version of historyclass struggle was the basis of social dynamism and of revolutionary possibility. ${ }^{3}$ For centuries, European thinkers from Hegel to Weber had conceived of China as a static and unchanging society which, under absolute despotic rule, was incapable of historical progress. For Chinese communist intellectuals, China's apparent stagnation in comparison to European capitalist development likewise caused concern. In the late 1950s and early 1960s, debates flourished on questions such as: why had capitalism not developed in China as it had done in Western Europe? Was there something lacking in Chinese society? And, most importantly, where lay the potential for socialist revolution predicted by Marx, on which the CCP had pinned its hopes as well as its legitimacy?

With these questions in mind, Chinese economists and historians scoured China's past to uncover moments of primitive accumulation. These efforts often corresponded with a search for the 'sprouts of capitalism' (zibenzhuyi mengya) in Chinese history. This term refers to moments of early commodification that scholars attempted to locate in order to disprove the common depictions of developmental stagnation, which, besides being factually inaccurate, contradicted the stagist version of history underpinning CCP doctrine. ${ }^{4}$ For many intellectuals, however, these 'sprouts' on their own were not synonymous with actual primitive accumulation and were therefore insufficient to demonstrate the sundering of Chinese society into two antagonistic classes.

The discussions on whether or not primitive accumulation had taken place at some point in Chinese history are usefully summarised in an article published in 1962 in the People's Daily by the economist Peng Zeyi. ${ }^{5}$ For some, according to Peng, these moments 
were evident in commercial activities dating as far back as the mid-sixteenth century, under the Ming Dynasty. Others argued that it was not until after the Opium Wars, with the violent impact of invasion from foreign capitalist powers in the mid-nineteenth century, that China's entrenched feudal social structure was shattered enough to kickstart processes of primitive accumulation. There were others for whom even colonial invasion could not bring about real primitive accumulation. For these scholars, China's lack of a strong monarchical regime meant it was incapable of enacting political violence of sufficient potency to reconfigure China's social structure. They compared Chinese history to that of England, where the monarchy had acted in alliance with the British bourgeoisie, forcibly reshaping society to forge a class structure-including a large labour force-conducive to profit-making and capitalist expansion.

Under Mao, these discussions remained sensitive, however. The implication of the historical failure of Chinese society to produce class struggle was taboo, as was any reference to primitive accumulation actually occurring during the Mao era. ${ }^{6}$ Indeed, a number of scholars were purged during the Anti-rightist Campaign of the late 1950s for daring to suggest that China's unequal economic system, founded on the cheap extraction of grain from the rural communes in order to feed industrial workers in the cities at low cost, was, in fact, a form of state primitive accumulation based on the exploitation of China's peasantry. ${ }^{7}$ Further discussions concerning such matters were supressed during the Cultural Revolution.

\section{The Return of Primitive Accumulation}

After the death of Mao, primitive accumulation reappeared in policy discussions of the reform period as the regrettable, but necessary, starting point by which China was to reclaim its rightful place in a universalist world history through successful participation in the global capitalist economy. ${ }^{8}$ After a tentative reemergence in scholarly literature in the early 1980s, its passage to widespread acceptability was assisted by an article in 1989 by Wen Tiejun, a well-known left-wing scholar of China's peasantry and agricultural economics. ${ }^{9}$ Wen published what he claims was the first article to openly recognise the role of primitive accumulation as an essential aspect of Chinese socialist modernisation under Mao. The article concerned Wenzhou-a city famed for its early and hugely successful adoption of market policies in the reform period. In the article, Wen's reference to 'state primitive accumulation' during the Mao period implicitly referred to-without stating explicitly - the extraction of capital for industry from the countryside via the rural communes. Wenzhou's economy, Wen argued, had stagnated under Mao due to a lack of investment because of its location across the strait from Taiwan. Yet, with the new sense of economic freedom that came with the reform era, the Wenzhou inhabitants began to take full advantage of their only abundant resource, low-cost manpower-in other words, cheap industrial labour. According to Wen, it was this 'human capital primitive accumulation' that led to the extraordinary levels of economic growth for which Wenzhou is famed.

This article was significant for two reasons. The first was Wen's use of the term 'primitive accumulation' with reference to industrialisation under Mao. This helped pave the way for other scholars and policymakers to use this concept when referring to various elements of China's modernisation in the contemporary era which were deemed 
unfortunate, but necessary. The second was Wen's description of fully marketised labour as a source of primitive accumulation. Wen appeared to be hinting that-now that the period of state-managed industrial growth via rural communes was over-primitive accumulation in a different form, based on the extraction of cheap labour for industry, was the new foundation of China's economy. The peasantry would continue to be the primary resource fuelling national economic growth, he was suggesting, but now in the form of industrial migrant labour in the cities (see Day's chapter in the present volume).

Shortly afterwards, Wen published another influential article which explicitly discussed primitive accumulation both as central to Chinese modernisation, and as founded on an unequal urban-rural relationship. ${ }^{10}$ Wen portrayed the Chinese state under Mao as unexceptional in its use of primitive accumulation, viewing it as different from Western capitalism only in terms of its 'Eastern-style:'

The main differences between societies of the East and West originate in their different resource environments and their different historical processes of state capital primitive accumulation .... China is a typical state which carried out Eastern-style primitive accumulation. It did not, as did Western states, carry out plunder and expansion externally, but mainly deployed internal 'self-exploitation' ... extracting accumulation from the countryside[.] ${ }^{11}$

By accounting for China's difference from Europe by virtue of it being Eastern as opposed to Western, rather than framing the difference as one of socialism versus capitalism, Wen normalised primitive accumulation as a universal process deployed by modernising states globally, thus avoiding the prior association of primitive accumulation with capitalist states in particular. Stripped of its political baggage, the term could then be applied freely to Chinese development processes without the ideological rupture which would have occurred from deploying an 'evil' capitalist concept within a nominally socialist state.

\section{The 1990s Onwards: Back with Abandon}

Wen claims that his repeated advocacy since the mid-late 1980s that primitive accumulation is a normal and necessary process for modernising states and, as such, was central to Maoist industrialisation, led to this position being 'accepted by the majority of scholars' by the late 1990s. ${ }^{12}$ It is hard to avoid the irony that this conceptual shift in the language of Chinese socialism in favour of a mode of development situated right at the heart of classical capitalist transition theory was ushered in through a positive appraisal of Mao, for whom this very notion would have been anathema. Yet, it was no doubt Wen's associating of primitive accumulation with Maoist, rather than capitalist, development which facilitated its passage into mainstream socialist discourse. ${ }^{13}$

In fact, in a discursive double movement, just prior to primitive accumulation's return to the mainstream, the term 'class' (jieji) had been dropped from the official lexicon of Chinese socialism, replaced by the far more anodyne phrase 'social strata' (shehui jieceng). ${ }^{14}$ This allowed the term primitive accumulation to roam free in public discussions while rendering silent, and invisible, its negative association with class 
exploitation, which was, in fact, inherent to it. According to Qin Hui, another wellknown scholar of China's peasantry, by the late 1990s the term primitive accumulation was being bandied around quite casually by local officials and in the media, sometimes used in a positive sense to denote rapid economic development. ${ }^{15}$ Qin also observed that the common occurrence of the term 'capitalist primitive accumulation,' a phrase never used by Marx, likewise stemmed from a misunderstanding of the concept. For Marx, primitive accumulation was a precapitalist phenomenon, but in postreform China it had become naturalised as a feature of early capitalism - the first stage of the market economy, and therefore something to be embraced.

This important shift in the available language of policy, therefore, was not limited to rhetoric but reflected what had come to be considered acceptable in terms of how society and the economy were organised. The widespread embezzlement of public assets, often by dubious legal means and/or force while taking the appearance of the legitimate privatisation of state-owned enterprises, for example, was viewed as simply part of a universal historical trend of 'transition' to modernity-and whether that meant a socialist or a capitalist modernity was increasingly irrelevant. ${ }^{16}$ The promotion of urban industrialisation by redirecting central state budget allocations to the cities, leaving lower-level rural governments to fend for themselves, similarly normalised the countryside as a legitimate target of capital extraction, now by means of excessive taxation and often illegal fees imposed on rural households. ${ }^{17}$ With the concept of class excised from discussion and primitive accumulation consequently defanged, the formation of a proletariat-both via layoffs from state-owned enterprises and in the form of rural migrant workers flooding into the cities (in large part to escape the decimation of rural living conditions) now seemed entirely coherent with socialism, albeit 'with Chinese characteristics.'

Meanwhile, the spate of rapacious land grabbing in the countryside, enacted by real estate developers in cahoots with local officials, and facilitated by the somewhat nebulous system of collective ownership over rural land, appeared all too similar to the enclosure movement of medieval England from which capitalism had originated. ${ }^{18}$ Although widely condemned by scholars on the left, many people tolerated, and some even welcomed, these occurrences, which were perceived as unfortunate but necessary steps on the elusive universal path along which China would finally join the rest of the developed world. ${ }^{19}$

\section{The Road Ahead}

Today, while it is difficult to consider China as being 'precapitalist' (let alone socialist), the restructuring of Chinese society in the interests of capital expansion continues apace. While the countryside remains a primary resource for national capital accumulation, the focal point appears to have shifted from people to land. Although rural land ownership remains collective, policies of land transfer have produced a quasiland market which is efficiently performing the work of class differentiation, gradually transforming a relatively egalitarian society of smallholder farming households to one of larger farms and employed labourers. ${ }^{20}$ In the name of 'civilising' the countryside, meanwhile, a variety of state policies are geared towards the removal of villagers from their homesteads and their relocation into dense tower blocks, either on the outskirts 
of their villages or in far off townships, freeing up their land for use by incoming agribusinesses or other more profitable enterprises. ${ }^{21}$ Meanwhile, as expanding urban metropolises are branded 'world cities' to attract international investment, urban land encroaches further into the countryside.

These days, however, low-cost migrant labour is being evicted from China's cosmopolitan urban areas, no longer welcome in these increasingly exclusive playgrounds for wealthy global elites. ${ }^{22}$ Marx would have recognised these social upheavals as the long process of reconfiguring China's class structure as the Chinese state is transformed into a component within the global capitalist economy. These epoch-defining historical transformations are neatly packaged, explained, and justified in official language as 'the primary stage of socialism' (shehuizhuyi chuji jieduan). 


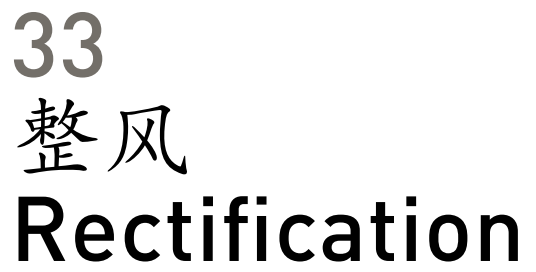

Andrew MERTHA*

But our aim in exposing errors and criticising shortcomings, like that of a doctor curing a sickness, is solely to save the patient and not to doctor him to death. A person with appendicitis is saved when the surgeon removes his appendix. So long as a person

who has made mistakes does not hide his sickness for fear of treatment or persist in his mistakes until he is beyond cure, so long as he honestly and sincerely wishes to be cured and to mend his ways, we should welcome him and cure his sickness so that he can become a good comrade. We can never succeed if we just let ourselves go and lash

out at him. In treating an ideological or a political malady, one must never be rough and rash but must adopt the approach of 'curing the sickness to save the patient,' which is the only correct and effective method.

Mao Zedong, 'Rectify the Party’s Style of Work,' 1942

There is a sickness within our Party ... . As our socialist revolution advances, however, seeping more strongly into every corner of the Party, the army and among the people, we can locate the ugly microbes. They will be pushed out by the true nature of socialist revolution. We are encouraged to expel treacherous elements that pose problems to the Party and to our revolution. If we wait any longer, the microbes can do real damage.

Pol Pot, $1976^{1}$

A 11 revolutionary regimes confront a decision of life and death: to kill or reeducate the enemy. This has not only determined the fates of countless people, but also shaped the rise to power and approach to governance of revolutionary movements. There is a tendency to blur the distinctions between Stalin's eliminationist approach and the Maoist norm of 'curing the sickness to heal the patient' (zhibing jiuren). Distinct contexts and organised applications of violence are painted with the 
same brush of communist terror. This indiscriminate conceptualisation of violence, in turn, leads to faulty comparisons between Maoism and the methods of the Communist Party of Kampuchea (CPK, the so-called 'Khmer Rouge') in Cambodia. Despite superficial similarities, the main difference-one that shaped two fundamentally distinct movements-is that China found a way to break out of the vicious cycle of purge and counterpurge while the Khmer Rouge swiftly and inexorably went down the dark path of liquidating any and all perceived opponents.

Despite key commonalities in the rise to power of the Chinese and Cambodian communists, their subsequent trajectories deviated from one another so much so that non-superficial comparisons are untenable. Specifically, these two movements embraced fundamentally different doctrines and methods about how to handle vanquished political opponents. China eventually settled on coopting them through the mechanism of rectification (zhengfeng), which remains built into the machinery of governance that functions up to the present day, while the Cambodian communists were unwilling or unable to move away from a single-minded obsession with eliminating the opposition, eventually cannibalising themselves into oblivion.

This essay is divided into three sections. The first describes the 'Anti-bolshevik' purges that are commonly referred to as the Futian Affair (futian shibian) of 1930-31 within the larger context of political bloodletting in the Jinggangshan and Jiangxi Soviet era, in which thousands died and scores of military and political organisations vanished because of political infighting. The second describes the rectification doctrine that emerged in Yan'an in the mid-1930s as the antidote to the kind of open-ended purges at Futian, which transformed the Chinese Communist Party (CCP) into a durable, selfmoderating organisation. The third shows how the absence of a rectification doctrine left the Khmer Rouge bereft of a mechanism to prevent a Futian-esque model of governance on a national scale that eventually killed millions, accomplished nothing, and ultimately brought down the regime.

\section{The Futian Affair (1930-31)}

Prior to 1930, violent measures adopted by the CCP and the Red Army targeted individuals and groups outside the Party. However, this key norm was broken by Mao in the 'Conclusion of the Joint Conference and Announcement of the Establishment of the Front Committee' of 16 February 1930:

There is a severe crisis in the Party in western and southern Jiangxi ... the local leading organs of the Party at all levels [are] filled with landlords and rich peasants ... . The Joint Conference calls on all revolutionary comrades within the Party to arise, overthrow the opportunist political leadership [within the Party], eliminate the landlords and rich peasants from the Party, and see to it that the Party is rapidly bolshevised. ${ }^{2}$

The reasons for this are debated by scholars-land reform, conflict between the Jiangxi and Hunanese wings of the Party, disagreements over the Li Lisan Line, and seepage of Stalinism into the Party ranks being just a few explanations that have been put forward-but the result was an intense factional struggle that began in October 
1930 and led to the widespread torture and execution of CCP members identified as part of an 'AB' (Anti-bolshevik) 'League' (tuan). ${ }^{3}$ A lack of institutional 'checks on both the leadership and the security organisations contributed greatly to the ... [subsequent] expansion of the purges' which completely bypassed judicial process ('except as theatre') with execution as the only possible outcome. ${ }^{4}$ Dutton concurs, arguing that within the binary logic of the time, 'there could be no "soft option" when dealing with the enemy." Over the course of a week, some 4,400 First Front Army officers and men confessed to having ties to the $\mathrm{AB}$ tuan; 2,000 or more were shot. ${ }^{6}$

These confessions provided information targeting leaders in the Jiangxi Provincial Action Committee and officials in the Twentieth Army allegedly opposed to Mao. Five weeks later, in the Futian Affair, these officials were tortured with the goal of forcing them to provide the names of their coconspirators. This continued well into 1931:

The overall death-toll from the purge in the summer and early autumn of 1931 can only be guessed at. Four hundred officers and men from the $20^{\text {th }}$ Army perished, and probably several hundred from the $35^{\text {th }}$ Army... . From other Red Army units, there were many more. In the local Jiangxi Party, 3,400 were killed in just three of the more than twenty counties. By the beginning of September, a CCP Central Inspector reported that ' 95 percent of the intellectuals in the south-west Jiangxi Party and Youth League' had confessed to $\mathrm{AB}$ tuan connections. Today the best-informed Chinese historians say merely that 'tens of thousands died.'

Given the small number of active Chinese communists, those figures mask the proportional scope of the massacre: 'By the end of 1931, virtually all of the countyand regional-level Party cadres who had collectively been involved in accusing Yuan Wencai and Wang Zuo of becoming counterrevolutionaries-and in killing them-had themselves suffered the same fate.8 Guo finds that in mid-1931, '90 percent of CCP cadres in southwestern Jiangxi were killed, imprisoned, or dismissed.'

Futian occurred in the context of the ongoing 'counterrevolutionary suppression' (sufan) campaigns, borne out of an inherently dark view of revolutionary parties under duress, an atmosphere in which 'the purges went to such extremes because there were no mechanisms to check potential abuses of power ... [moreover] the sufan campaigns did not always benefit those leaders who initiated the campaigns [because of the] overwhelming terror they induced and widespread purges. ${ }^{\prime 10}$ And they were to continue through the years leading up to the Long March in the Minxi (1931), the E-Yu-Wen (1931-32), and the Xiang-E'xi (1932-34) base areas. ${ }^{11}$

To the scholar of Cambodia, these campaigns are virtually indistinguishable from actions undertaken deliberately and enthusiastically by Pol Pot. Yet the Futian incident continued to weigh heavily on the post-1949 Chinese leadership: Mao considered the incident a mistake, and subsequently moved away from this type of bloody political manoeuvring by adopting rectification doctrine-a decision that would ultimately, and fundamentally, separate the two revolutionary movements in China and Cambodia. ${ }^{12}$ 


\section{Yan'an and Rectification}

Mao introduced a number of innovations to the Chinese approach to Marxist revolution and governance by emphasising peasants over proletarians, privileging spatial alongside vertical governance, and establishing Party rectification. Teiwes defines rectification as:

The distinctive approach to elite discipline developed by the CCP leadership under Mao Zedong in the early 1940s, [that] occupies a key position in the Party's organisational norms. It embodies several principles which quickly became basic Party doctrine: the vast majority of officials are 'basically good' and their mistakes can be corrected, discipline must aim at achieving reform and utilising the talents of such officials for the CCP's cause, and disciplinary methods on the whole should be lenient and limit purges to exceptional cases. ${ }^{13}$

Rectification doctrine arose in Yan'an in tandem with Mao's rise to supremacy in the Party as an attack on the twin evils of 'subjectivism' (zhuguanzhuyi) and 'sectarianism' (zongpaizhuyi), and alongside the goal of eliminating the differences between individuals, particularly intellectuals, on the one hand, and workers and peasants, on the other. ${ }^{14}$ Rectification proved to be an exceptionally useful political tool which created a set of genuine incentives for politically vulnerable targets to demonstrate fealty to the regime and for leaders who, instead of liquidating the opposition, were able to coopt a grateful, relieved, and softened new, mobilisable political resource. The crushing of individualism was not universally celebrated (see below), but it was also not a completely foreign concept, tapping into deeper, Confucian principles: that thought can be purged of incorrect elements and reset to align with (in this case) Maoist doctrine (see Cheek's essay in the present volume). Finally, in addition to the substantive normative conditioning, the purely strategic effect of rectification as a demonstration of the Party's supremacy provides a signalling device to keep potentially errant cadres in line. ${ }^{15}$

Rectification facilitated the establishment of core tenets of organised governance, such as minority rights in collective decisionmaking, and in particular the norm of democratic centralism (minzhu jizhong zhi), as a way of preempting factionalism and extra-Party manoeuvring. ${ }^{16}$ One need not establish a causal link between the Futian Affair of 1930-31 and rectification doctrine 12 years later; one need only to demonstrate the vastly different political outcomes that accompany choosing one over the other. That said, Mao reportedly did make an 'indirect' self-criticism during the Yan'an rectification specifically about the brutality of the sufan campaigns. ${ }^{17}$

There are several possible reasons why rectification doctrine emerged under Mao at this time in Yan'an. Organisationally, it was a necessary response to the unmanageable growth of CCP membership from 40,000 in 1937 to 800,000 in 1940. Fully 95 percent of CCP members were new and thus required ideological conditioning to absorb them as trustworthy partners within the revolutionary ranks. The differences among and across these groups were vast. As Bonnie McDougall argues, it is difficult for Westerners to appreciate the depth of the distaste for manual labour that the new intelligentsia 
inherited from the old gentry class' and most of the new CCP recruits making their way to Yan'an held this view. Even the May Fourth Movement intellectuals were referred to by Mao as 'heroes without a battlefield, remote and uncomprehending,' a phrase that richly invokes the spirit and goals of rectification. ${ }^{18}$ And all of this was taking place as Mao was being enshrined in a position of absolute leadership, where developing a governing programme distinct from the Soviet Union, in terms of both substance and practice, was becoming a political imperative. Rectification was thus not something that happened in the absence of agency; it was a conscious decision to shift governance from one identifiable form to another.

At the same time, lest rectification seem overly benign, it should be noted that, quite apart from the intellectually horrific notion of externally 'controlling one's thought,' the process could be physically and mentally excruciating. This was particularly true in its more severe iterations, as in the case of 'brainwashing' (xinao) in the late 1940s and early 1950s. ${ }^{19}$ Moreover, it was not completely separate from purges and violent struggle, as the 1942 Rescue Campaign (qiangjiu yundong) and subsequent excesses by Kang Sheng (who was enabled by Mao) made clear. At the time Yang Shangkun observed:

We can see that the Rectification movement contains two kinds of struggles. One is the inner-Party struggle ... to remould the ideological methods of both cadres and Party members ... . The other struggle is the one that exposes and opposes those Trotskyites and dissidents who snuck into our Party to destroy and undermine it. ${ }^{20}$

Clearly, the ghosts of Futian were difficult to exorcise. Nonetheless, even as rectification doctrine itself was not immune to the more violent side of revolutionary governance, it fostered leadership norms that allowed the CCP to evolve from a revolutionary organisation into the wards of a mature state borne from the fires of revolution. Rectification emerged and evolved as an important tool that to this day provides the necessary institutional 'give' for the CCP to continually recast and recalibrate itself as new challenges arise, avoiding the excesses of non-institutionalised political struggle while simultaneously eschewing the 'transfer of power' of contested elections. ${ }^{21}$ The longevity of the CCP in exceptionally changing circumstances arguably owes a great deal to rectification doctrine.

\section{The Khmer Rouge Rise to Power}

Rectification's 'curing the patient' metaphor was fundamentally at odds with the Stalinist idea of the rusty screw that needed to be eliminated for the machinery of the state to operate more efficiently, which was the tacit political logic underlying the events encompassed by the Futian Affair. ${ }^{22}$ Pol Pot used the metaphor of the microbe (merok), but his view was fully consistent with Stalin's. ${ }^{23}$ If after Futian, the CCP rejected Stalinist purges, the CPK embraced them.

The ubiquity of the Khmer phrase 'no gain in keeping, no loss in weeding out' in describing their subjects provides a window into the stark Khmer Rouge worldview. ${ }^{24}$ The doctrine-and certainly the practice — of the Khmer Rouge had an extremely dark 
view of human nature. Describing in aspirational terms the purity of the hill people in the northeastern highlands, they deemed that anyone who had deviated from upland purity-'lazy' lowland rice farmers, ethnic Chinese and especially Vietnamese, Muslim Cham, urbanites, artists, intellectuals, politicians, and beneficiaries of the ancient regime-had no claim to innate goodness or even utility. As Ta Mok said of Pol Pot after his death: 'He is nothing more than cow shit. Actually, cow shit is more useful because it can be used as fertiliser. This provides an apt description of the Khmer Rouge's view toward potential enemies, real or imagined. ${ }^{25}$

Second, the fact that people could be rehabilitated was dismissed almost completely out of hand. Rectification, insofar as it existed under the Khmer Rouge, was in the form of 'tempering' - hard labour mixed with torture. More often, people who were accused by the authorities, or named in three or more confessions of others being tortured, would be brought into the national processing centre of Tuol Sleng (or a local counterpart) with the sole purpose of confessing under brutal torture before facing inevitable execution. ${ }^{26}$

Indeed, as in Futian, attacking elements within the Party was a key feature of Khmer Rouge governance. During the CPK rise to power in 1973, its united front strategyadopted in 1970 as a way to offset their initial weakness vis-à-vis the government in Phnom Penh-came to an abrupt end, when it turned on its erstwhile allies, killing many of them or expelling them from the country. And this continued after they gained national power in 1975. After the initial killing of elements from the Khmer Republic regime that had just been overthrown, the CPK shifted to targeting its own cadres: zone commanders of the North, Northeast, East, and Northwest Zones were all killed, as were several generations of ministry heads. ${ }^{27}$ Torture was widely used to uncover networks (khsae) of often imaginary conspirators. During Futian, Jiangxi Provincial Action Committee Member Li Bofang gave up the names of a thousand cadres perhaps to confuse his accusers; former CPK zone secretary and minister of commerce Koy Thuon similarly named thousands who were subsequently brought in for torture. ${ }^{28}$ All this was used as evidence to build the narrative that the respective leaders' political line was correct, and to utterly vanquish their opponents (see Ishikawa and Smith's essay in the present volume). Leniency-a central tenet of rectification-was simply not part of the Khmer Rouge vocabulary.

This rectification-free political environment fostered a necropolitical culture of distrust and secrecy, of preempting one's enemy by attacking him first. As a result, loyalty to other individuals, let alone the regime, was a luxury that was not only unaffordable, but one that made no sense. Such an environment formed an extremely brittle regime bereft of legitimacy, which collapsed spectacularly in only a matter of days following the Vietnamese invasion of 1978 after being in power for less than four years. Indeed, some two decades after this, ragtag Khmer Rouge remnants along the Thai-Cambodian border had not learned this lesson. Suspecting his number three lieutenant, Son Sen, of conspiring against him, in 1997 Pol Pot had him and his extended family (including grandchildren) killed and ordered a truck to repeatedly run over the corpses and leave them there for public viewing to deter others from doing the same. ${ }^{29}$ This led his hitherto loyal commander Ta Mok to preemptively rout Pol Pot's forces and arrest Pol Pot himself, bringing the Khmer Rouge to an ignominious end. 


\section{Seeds of Authoritarian Resilience}

To sum up and reiterate, the Cambodian communists self-destructed after proving unable to advance beyond the same political dynamic exemplified by the Chinese communists in and around the Futian Affair. Had they been able to adopt a model of rectification like the $\mathrm{CCP}$, the $\mathrm{CPK}$ may well have strengthened their ability to govern and enjoyed the longevity of their erstwhile Vietnamese allies. Had the CCP not adopted the doctrine of rectification, it may have easily have been snuffed out before Chiang Kaishek's troops ever got near them. Instead, China witnessed multiple instances in which rectification doctrine was developed (early post-1949 campaigns), debased (the Antirightist Campaign, the 1959 Lushan Conference, the Cultural Revolution), resuscitated (the 1983 Rectification Movement, the 1998-2002 Three Stresses Campaign), and brought into the twenty-first century (Xi Jinping's current anti-corruption measures). Taken together, this essay provides a first cut, a soft, comparative-historical engagement with the hypothesis that such internal rectification is an important explanatory variable which helps account for regime stability in the absence of external accountability, contributing to what is commonly referred to as 'authoritarian resilience, a key preoccupation within the field of Chinese politics scholarship today. 



\section{4 \\ 又红又专 \\ Red and Expert}

Sigrid SCHMALZER

n 1957, leaders of the Chinese Communist Party (CCP) began calling on students and intellectuals to become 'both red and expert' (you hong you zhuan or hong $y u$ zhuan)-that is, to combine revolutionary politics with technical expertise. By 1958 , the slogan had ramified, taking on new kinds of significance for other social groups. Its influence was due to the definition of two crucial relationships: the political relationship between intellectuals and the socialist state, and the epistemological relationship between knowledge and the revolutionary society. The first of these has been of particular concern to liberal critics of authoritarianism, who recognise the call to be 'red and expert' as an effort, first and foremost, to discipline and control intellectuals. The second has excited radical critics of technocracy, who share the Maoist perspective that science and politics are inseparable, and who often also appreciate Maoist efforts to engage in inclusive and class-conscious forms of knowledge production (see Aminda Smith's essay in the present volume). Both politically and epistemologically, the 'red and expert' concept continues to speak to enduring questions in the history of science, society, and the state-in China and around the globe.

\section{Intellectuals and the State}

The 'red and expert' slogan emerged in 1957 during the early months of the Antirightist Campaign, an especially wrenching episode in the tortured history of the CCP's relationship with China's intellectuals. As with the Rectification Campaign (1942-44) of the Yanan era (see Mertha's essay in the present volume), and following on the heels of the massive national criticism campaign against the literary figure Hu Feng in 1955, the Anti-rightist Campaign facilitated Party authority over the political expression of intellectuals. Those labelled 'rightists' were publicly criticised and often imprisoned 
or 'sent down' to the countryside for reeducation, removing them from academic and political influence for years or even decades. This was the political context within which the 'red and expert' slogan gained meaning. ${ }^{1}$

Already in 1957, and repeatedly for the next two decades, Party leaders took pains to emphasise that for intellectuals the 'red' half of the 'red and expert' equation boiled down to loyalty to the CCP and the proletariat it represented. In a December 1957 article, the People's Daily specified that the call to be both red and expert by no means entailed an expectation that 'every expert would at the same time be a political activist or political theorist,' because this would be 'very difficult' and a requirement 'only a small number of people could achieve.' Rather, the question of whether one was red would be 'resolved with respect to whom one serves.' The article quoted Liu Shaoqi as explaining: 'China's staff members and various types of experts must all commit to transforming themselves to wholeheartedly serve the workers and peasants, and to serve socialism, placing the benefit of the individual within, and not above, the collective benefit of the masses. This is what being a red expert means.' A few months later, Mao himself underscored the significance of loyalty: 'Red is politics; expert is one's job. To be only expert and not red is to be a white expert .... If we are to overtake Britain in 15 years, then we must mould millions upon millions of intellectuals whose loyalty is to the proletariat.' ${ }^{3}$

In fact, during the Anti-rightist Campaign and subsequent Great Leap Forward, demonstrating such loyalty frequently involved intensive political reeducation and work alongside the masses in manual labour. In 1961, science policy leader Nie Rongzhen spearheaded the 'Fourteen Articles on Scientific Work', a policy document which dialled back the standard: loyalty to the Party and placing one's expertise in the service of socialism were again deemed sufficient to earn the label 'red and expert.' In 1978, following the Cultural Revolution, Deng Xiaoping reaffirmed this position. ${ }^{4}$ Both of these cases involved 'moderate' political leaders resetting expectations after intense periods of attacks on 'bourgeois' intellectualism. Defining redness as political loyalty thus represented a kind of minimum expectation that CCP leaders across the spectrum shared; we may also say that defining it as merely political loyalty represented a perspective on the relationship between intellectuals and the state held especially by 'moderate' (or technocratic) Party leaders like Liu Shaoqi, Nie Rongzhen, and Deng Xiaoping.

The highly charged and dangerous politics surrounding intellectuals during the Mao era was grounded in a tension between intellectuals who held cultural capital and cadres who held political capital. These two groups gradually came to overlap as children of intellectual families gained access to channels of Party membership, and children of Party cadres gained access to elite schools. By the time Deng Xiaoping rose to power in 1978, a new, more powerful, and stable class had emerged that wielded both forms of power. ${ }^{5}$ In one sense, the underlying contradiction between red and expert would seem to have been largely resolved; the decisive blow to dissident intellectual voices of June Fourth 1989 contributed still further to this resolution.

Nonetheless, the 'red and expert' slogan has continued to trickle through official discourse during the post-Mao era, and recently resurfaced in a way that provoked significant public discussion. In May 2017, Education Minister Chen Baosheng gave a speech on undergraduate education in which he proclaimed the need to cultivate 
'reliable successors' to further the construction of socialism with Chinese characteristics. These graduates would be 'both red and expert,' possessing 'both integrity and talent,' and boasting a 'well-rounded development.' The phrase 'red and expert' attracted special attention, with some netizens using discussion boards to declare their 'disgust' and point ominously to what one called the "imprint of the Cultural Revolution.7

A report in the US-based online newspaper The Diplomat picked up on the buzz and elaborated on the concerns that Chen's rhetoric signalled a return to Mao-era policies on education and intellectuals. ${ }^{8}$ Taking the other side of the issue, an article by Lin Aiyue on the left-patriotic Chinese website Chawang considered it 'unsurprising' that 'rightist public intellectuals' should be up in arms over Chen's statement, and further emphasised that the Minister's evocation of 'red and expert' surely reflected policy decisions from far above and was a welcome direction. Lin traced the origins of the 'red and expert' slogan to Mao in 1957 and noted the widespread support for the concept among other leaders, including Deng Xiaoping. However, reflecting the highly nationalistic perspective of Chawang and many-though by no means all-other leftists in China today, Lin narrowly interpreted 'red' to mean 'deeply loving the nation-state and its people' ( guojia minzu). ${ }^{9}$ This takes the emphasis on loyalty advanced by moderates like Nie Rongzhen and Deng Xiaoping in a new direction: loyalty to the Party is now tied more to the interests of an ethnically defined nation-state than to a class-based national or even global proletariat (see Bulag's essay in the present volume). The use of a Maoera slogan to buttress such nationalism and state power certainly deserves attention and criticism. However, this is not the only legacy 'red and expert' carries.

\section{Knowledge and Society}

The repeated calls to understand 'red and expert' as fundamentally about political loyalty is in some sense evidence that the slogan also stands for something else. During the Mao era at least, 'red and expert' was one of a set of concepts related to the nature of knowledge itself, intended to change what people were supposed to know, how knowledge was supposed to be produced, and who might be deemed an expert. This was the side of 'red and expert' that leftists around the world found inspiring. Fundamentally anti-technocratic, it declared all knowledge-including that of the natural world-to be political; in a class society, this meant that knowledge has class character. Such a proposition attacked intellectual elitism and thus could still result in attacks on intellectuals themselves. However, when the emphasis is on epistemology, the threat posed by intellectual elitism is not that of a class poised to translate cultural capital into political capital, but rather that of a concept of knowledge divorced from the experiences and perspectives of labouring people. What is required is thus notor at least not merely-loyalty to the Party-state, but rather a sincere commitment to recognising and engaging the value of knowledge possessed by labourers.

The epistemological aspect of 'red and expert' is found in the influential 'Sixty Points on Working Methods', drafted by Mao on 31 January 1958: 'There is no question that politics and the economy must be unified, and that politics and technology must be unified. It has always, and will always, be so. This, precisely, is the meaning of red and expert. ${ }^{10}$ An article appearing in the People's Daily two weeks later-'Plant Experimental Fields: The Road of Red and Expert'-offered one of many concrete examples. ${ }^{11}$ 
The article opened by describing a scene in which two local officials 'wearing shoes and socks' stood at the side of a rice paddy ostensibly 'inspecting production.' A commune member loudly scolded them: 'Quit strutting around like lords! You're going to wreck the embankment!' The People's Daily declared the scolding justified and applauded the eventual outcome in which one of the local officials ceased standing on the side waving his hands and giving orders, and began working with the peasants and technicians to plant 'experimental fields.' The article called on all cadres similarly to shed their 'aloof and remote' attitudes and plunge deep into the grassroots-to 'integrate intimately with the labouring masses and technological experts, and diligently study necessary industry and technological knowledge, in order to become proletarian experts in their fields.' In this way China would be able to establish a mighty contingent of 'red and expert' cadres.

To be 'red' was thus not merely to be 'loyal,' but to be proletarian in consciousness. More broadly, to be 'red and expert' was not only to be both loyal and skilled, but rather to develop knowledge through a process of engagement with both peasants and technological experts. It was an ideal to be achieved not just by intellectuals, but by political cadres - and by the labouring masses themselves. Indeed, beginning in 1958 some communes began establishing 'red and expert universities', where peasants could learn to become 'technicians possessing socialist consciousness; scientific knowledge in the areas of agriculture, forestry, and irrigation; and the ability to participate in labour.' ${ }^{12}$ Two years later, Chinese Academy of Sciences Vice-president Zhang Jingfu gave a speech proclaiming the need for 'all people to do science,' turning science into a 'mass movement' and 'cultivating a red and expert, mighty, proletarian scientific and technological contingent.' ${ }^{3}$

It is easier to appreciate the epistemological challenge presented by 'red and expert' if we place it in the broader context of related slogans and programmes of Maoist science, including the unity of practice and theory; the joining of peasant/native $(t u)$ and elite/ foreign (yang); the principle of 'walking on two legs', i.e. employing existing, indigenous methods, while also developing new, modernised methods; the effort to transcend the barrier between mental and manual labour; and the formation of 'three-in-one' scientific experiment groups combining cadres, labourers, and technicians. ${ }^{14}$ Several of these concepts emerged prior to 1949 , but they came to new prominence along with 'red and expert' during the Great Leap Forward and continued to develop over the next two decades. The common theme undergirding all of them was the harnessing of different forms of knowledge to produce a revolutionary programme of science and technology.

In some cases, the goal of such programmes appeared to be dissolving contradictions by weakening the difference between elite and popular forms of knowledge-for example by requiring intellectuals to engage in manual labour and learn from peasants and workers, while simultaneously encouraging peasants and workers to engage in the arts and sciences. The 'red and expert' paradigm similarly envisioned individuals who would combine previously separate characteristics to become living embodiments of the 'all-round communist' ideal.

Other programmes, however, organised people who represented different perspectives and types of experience to work together in the production of revolutionary scientific knowledge. In agriculture, 'scientific experiment groups' were formed on a 'three-in- 
one' (san jiehe) basis, integrating the practical, experiential knowledge of old peasants with the political knowledge of revolutionary cadres and the technical knowledge of educated youth (and/or agricultural technicians, where available). The three-in-one model did not promise to produce individuals who transcended divisions between mental and manual labour, or between technical and political knowledge. Rather, it preserved specific epistemological identities for different social groups and attempted to create a mechanism where each could contribute to a collaborative project of knowledge production.

The broad epistemological implications of 'red and expert', understood as a representative slogan within Maoist science, encountered widespread enthusiasm among leftists and left-leaning intellectuals around the world, who saw in China a living example of a politically conscious and socially revolutionary scientific practice. For example, the 'Knowledge and Power' course, offered by Deakin University in Australia, included a book by historian of science David Wade Chambers entitled Red and Expert: A Case Study of Chinese Science in the Cultural Revolution. ${ }^{15}$ Bringing together a range of primary and secondary sources, Chambers presented the 'red and expert' paradigm, and Mao-era science more generally, as an example from which Westerners could and should learn. Among the questions Chambers saw Mao-era science addressing were: 'What is the nature of expertise?' 'What role can the interested amateur (or nonprofessional) play in the actual practice of science?' 'What constitutes an appropriate education for scientists and engineers?' and 'Will politics always continue to influence scientific judgements?'16

Though the slogan 'red and expert' in current discourse is undoubtedly dominated by the Party-loyalty definition discussed in the previous section, the more radical, epistemological implications are also sometimes evoked. Examples are collected and circulated on leftist websites-both those critical of the state, like Red China, and those supportive of the state, like Chawang. ${ }^{17}$ In one recently circulated article, literature scholar Yan Zuolei portrays the significance of 'red and expert' precisely as the joint efforts to 'make labourers into intellectuals and intellectuals into labourers' in order to create 'new people, both red and expert.' ${ }^{18}$ Similarly, Peng Guangcan, a professor of philosophy at Guangxi University's School of Public Management, praises Maoera factory movements for allowing 'cadres to participate in labour, and workers to participate in management,' and bringing cadres, technicians, and workers together in 'three-in-one' combinations: he sees this as a model for Chinese industry today and consistent with the teachings of influential Harvard University management scholar and systems scientist Peter Senge. ${ }^{19}$ The anti-elitist, anti-technocratic challenge of Maoera radical epistemology lives also in some ongoing rural development projects: the 'participatory action research' approach adopted from the West was itself shaped by Maoist theories of knowledge. ${ }^{20}$ For example, in terms strikingly reminiscent of Maoist epistemology, the Participatory Plant Breeding Project run by an interdisciplinary group of scholars and scientists explicitly rejects 'top-down' methods divorced from rural realities and peasant knowledge, and instead brings peasants and researchers together in mutually respectful collaboration. ${ }^{21}$ Although the political and economic contexts have changed dramatically, we may still imagine these researchers-like that cadre featured in the 1958 People's Daily article-stepping down from the field embankments to 'integrate intimately with the labouring masses.' 


\section{Long-lasting Political and Epistemological Questions}

The principle of 'red and expert' emerged from the anti-elitist politics of the Mao era and served two closely related but nonetheless distinct political projects. Emerging within the specific historical conditions of the Anti-rightist Campaign, it without question worked to rein in intellectuals and prevent them from using their cultural capital to wield political power. However, it quickly became integrated into the broader Maoist epistemological universe, which sought to transform scientific knowledge and practice along revolutionary lines. Today, 'red and expert' is sometimes invoked to promote loyalty to the Party-state among an increasingly wealthy professional class and in ever more nationalistic terms. But it also survives in ongoing efforts to highlight the inseparability of science and politics, and on the basis of that understanding, to forge scientific knowledge and practice that respects the contributions and priorities of labouring people.

In closing, I would suggest that our assessment of the 'red and expert' concept hinges on such highly charged questions as the legitimacy of the state in representing the people, the value of intellectual freedom, and the neutrality or objectivity of scientific knowledge. Just as David Wade Chambers predicted more than three decades ago, the political and epistemological questions raised by the 'red and expert' concept have far outlasted its glory days in the Mao era. 

Draining Seas

\author{
Anna LORA-WAINWRIGHT*
}

$\mathbf{T}$

he expression 'removing mountains and draining seas' (yi shan dao hai) first appeared in the sixteenth-century classic novel Journey to the West to refer to the attitude one should adopt in the face of difficulties. Taken a little more literally, it encapsulates rather well the promethean attitude to nature-conceiving of the environment as a resource to fulfil human needs and interests-during the Mao years. It embodies a celebration of the capacity of humanity to overcome natural obstacles and mould the environment to its benefit. It goes hand in hand with a broadly adversarial disposition towards nature exemplified in the militaristic language often adopted during that period, involving humans conquering nature (ren dingsheng tian) or waging a 'war' against it. ${ }^{1}$

At first glance, this vision of nature may seem completely at odds with the ethos of Xi Jinping's 'New Era' (xin shidai). Upon visiting China today, one is struck by the frequent exhortations to 'build an ecological civilisation' (shengtai wenming jianshe) and equally frequent references in official speeches and policy documents to Xi's statement that 'clear waters and green mountains are as good as mountains of gold and silver.' ${ }^{2}$ But are the Party-state's approaches to nature in these two periods so radically at odds? In this essay, I will argue that the promethean attitude still continues into the present, even if it supports different representations of and engagements with nature.

\title{
Tracing the Changing Lives of 'Removing Mountains and Draining Seas'
}

The ideology of 'removing mountains and draining seas' is rooted in a Confucian vision of nature at the service of humans. The various forms of environmental deterioration which result from this stance-including deforestation, loss of biodiversity, and soil erosion-have a similarly long history. ${ }^{3}$ Nonetheless, representations of nature promoted in Mao's thought enhanced this promethean attitude towards the environment. 
Reference to exemplary tales and local success stories became the ideological support structure for megaprojects aimed towards building a socialist paradise which, however, accelerated concomitant environmental degradation. ${ }^{4}$

An illustrative example is the tale of the 'Foolish Old Man Who Moved the Mountains' (yugong yi shan). Originally attributed to an ancient Daoist text, Mao reinterpreted this story in a famous 1945 speech in Yan'an, where he used it to refer to the metaphorical mountains of imperialism and feudalism which needed to be removed by the masses organised by the Chinese Communist Party (CCP). But this tale was also used to suggest that human will and perseverance can alter anything, even nature. It was promoted as part of a related propaganda campaign known as 'In Agriculture, Learn from Dazhai.' Dazhai was the name of a production team in Shanxi province which was elevated to a national model in 1964 because of its success in turning infertile soil into productive land allegedly through sole reliance on the physical efforts of the farmers who cleared mountain land and created terraced fields.

A number of other campaigns were promoted in this spirit during the Mao period, including massive hydropower projects such as the Three Gorges Dam, plans for which began before the Mao era and continued well after its end; the backyard smelter campaign during the Great Leap Forward, designed to accelerate steel production; and sweeping deforestation and dredging to 'open the wilderness to plant grain.' Encouraging people to follow in the footsteps of the foolish old man who moved mountains, campaigns paid little attention to local topography and climate, following the conviction that with hard work and socialist spirit, anything could be achieved, despite any natural obstacles. The effects of these campaigns were mixed to say the least. In the case of efforts to intensify agriculture at all costs, for instance, the result was in some cases extreme soil depletion and deforestation without the intended growth in agricultural production. ${ }^{5}$

Following the death of Mao in 1976, the early reform period was characterised by a rather different ethos, with development and profit being prioritised at the expense of communitarian ideology. Indeed, Deng Xiaoping-who is often described as the architect of China's social and economic reforms-is best known for the dictums 'let some get rich first' and 'it doesn't matter if the cat is black or white as long as it can catch the mice.' Nevertheless, the utilitarian approach to the environment exemplified by 'removing the mountains and draining the seas' carried on with renewed vigour despite the ideological shift. Rural industrialisation-and particularly the creation of Township and Village Enterprises (TVEs) - was a key feature and encapsulates how the natural environment was treated in the early reform period. ${ }^{6}$ Although individually these TVEs were relatively small, taken collectively their development amounted to a megaproject rivalling those of the Mao era. Given that profit considerations determined investment in industrial infrastructure and methods of mining and processing, longer-term environmental impacts were substantial. ${ }^{7}$ However, due to the fragmented nature of rural industrialisation and the short-term horizon implicit in the immediate profit orientation of the TVEs, these impacts are difficult to measure.

The grave environmental consequences of this development model soon became apparent and the early reform mindset-'pollute now, clean up later' (xian wuran hou zhili)-came under growing scrutiny. Since the late 1970s, concerns about preserving the natural environment-rather than exploiting it—began to take shape, and China's government developed a growing body of environmental protection policies and 
legislation. ${ }^{8}$ However, megaprojects led by a promethean spirit have continued into the late reform period, including the South-to-North Water Transfer, a massive project first conceived during the Mao era and still ongoing which is intended to divert over 40 billion cubic meters of fresh water through three separate routes from southern rivers into the notoriously arid northern China.

Under the leadership of Jiang Zemin and Zhu Rongji (1998-2003) a campaign to 'Develop the West' was promoted in order to tackle regional differences between the eastern seaboard and the less-developed western interior. ${ }^{9}$ This includes massive projects which are, in some cases, the literal manifestation of 'removing the mountains and draining the seas' in terms of their intended reach and effects. Some of these projects are directed towards preserving, restoring, or even creating ecological environmentssuch as reforestation and the establishment of ecocities-alongside others which are much less about natural protection than about industrialisation and infrastructure development.

Many of these projects have tended to prioritise economic gain over a slower and more sustainable version of development. This is particularly the case in historically poor regions where local governments depend on polluting firms to raise tax revenue necessary to support public services and villagers rely heavily on them for employment. ${ }^{10}$

While under the leadership of Jiang and Zhu the focus remained on relatively unbridled economic development, the tide began to change with the ascendance in 2003 of the subsequent administration, led by President Hu Jintao and Premier Wen Jiabao. They made Scientific Development (kexue fazhan) and Harmonious Society (hexie shehui) the cornerstones of their leadership, and emphasised the need to build an 'ecological civilisation.'

The concern to protect the natural environment was further expanded by Xi Jinping who has made ecological civilisation a leading principle for his vision of a 'New Era.' In a similar spirit, and in recognition of the gravity of China's environmental situation, at the opening of the annual session of the National People's Congress in March 2014 Chinese Premier Li Keqiang stated that China would declare 'a war on pollution.' The difference between Mao's war against nature and the current war against pollution is striking, of course, but it is significant that in both cases a militaristic language convergent with the ethos of 'removing the mountains and draining the seas' is employed in approaching the environment.

Just as during previous leadership periods, less developed areas (particularly in China's interior) have continued to feel the pressure to catch up with the rest. For instance, in Langzhong county, Sichuan province, where I lived in 2004-05 and which I visited frequently since, a new 'development zone' was established in the early 2010 s to further expand infrastructure and boost the local economy. This included building new roads and a new railway line and station, as well as providing space for investors to open businesses. Much of this area was hilly, and in order to create the new development zone many hills were literally removed, making parts of the landscape unrecognisable. In the words of an elderly villager which uncannily resemble the Maoist promethean spirit, 'opening and developing mountains' (kaifa shan) was an important resource for the local economy, particularly because hill land is less valuable than prime agricultural land and therefore cheaper to compensate. This anecdote illustrates a situation that is unfolding across much of rural China as it urbanises at breakneck speed. For all the 
emphasis on environmental protection, the allure of economic development remains alive and well in poorer areas. Conversely, removing mountains to enable development is no foolish endeavour, just as Mao maintained.

\section{A New Era for the Environment?}

If we take the expression 'removing mountains and draining seas' literally-to mean exploitation of nature with no regard for the consequences-then there are clear signs in rhetoric and policy under $\mathrm{Xi}$ that this approach is no longer applicable. Humans are not seen as entirely separate from nature, there is an emphasis on harmony between them, and the language of warfare is reserved for pollution rather than nature per se. However, if we take it to stand for megaprojects and prometheanism, various examples come to mind that betray an attitude to the natural environment led by a vision in which humans are at the centre and nature serves as nothing more than a resource. For instance, the Belt and Road Initiative, embraced with vigour in recent years, is a development strategy to build infrastructure connecting China and its neighbours and involves, among other things, resource extraction and the development of new coal power plants outside of China's borders. China's renewed push to urbanise is one of the fastest in human history, and the functional zoning at the heart of integrated ruralurban planning protects certain areas while targeting others as objects of exploitation. The ongoing campaign to develop the western areas of the country involves plans to extract resources from China's interior. Hydropower projects may be construed as efforts to protect the environment by reducing reliance on coal, but they may also negatively impact biodiversity. Most representative of the enduring promethean ethos of the current leadership are weather modification and geoengineering projects, whereby the weather itself becomes an object of intervention and human innovation.

Crucially, the extent to which the increasing attention to the natural environment under Xi trickles down to localities, especially poor and remote localities which regard development at all costs as desirable, will not be equal everywhere. The notorious implementation gap, whereby central government policies and national laws are often not well enforced in the localities is likely to be addressed in different ways and to different extents in different parts of the country. ${ }^{11}$ This may result in reinforcing existing environmental and social inequalities between regions and between rural and urban areas. ${ }^{12}$

While the balance overall may be shifting in favour of more emphasis on nature protection, this is likely to affect some regions more than others-as the principle behind functional zoning suggests-and could well result in the safeguarding of areas designated as national parks while mineral-rich areas are subject to ongoing exploitation. Rural areas are under contradictory pressure to perform as an ecological resource and as a resource for extraction and industrialisation. ${ }^{13}$ In conclusion, the question is not so much whether the promethean ethos of 'removing the mountains and draining the seas' is still applicable but rather where it is applicable and in what guises. 


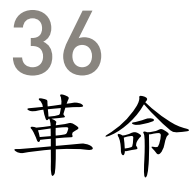

\section{Revolution}

CAl Xiang

(Translated by Rebecca E. KARL)

n contemporary Chinese discourse, what is called the 'Chinese Revolution' (zhongguo geming) usually indicates the socialist revolution led by the Chinese Communist Party (CCP). The core content of this revolution is Marxism, primarily Leninism, dominated by the injunction to eliminate private property. For this reason, the Chinese Revolution is seen as forming a constituent part of twentieth-century world history while, in its realisation, it can also be seen as having temporarily disrupted the developmental logic of nineteenth-century capitalism. And yet, the Chinese Revolution also possessed its own local characteristics, namely in its anti-imperialist and antifeudal aspects (see Barlow's essay in the present volume). Anti-imperialism indicates anti-colonialism, which means that the Chinese Revolution also had a nationalist component. Its anti-feudal aspect means that theories of enlightenment were also a special constitutive part of the revolution. In this sense, Marxism, nationalism, and theories of enlightenment comprised the complex structure of thought informing the Chinese Revolution-although, of course, after the establishment of the People's Republic of China (PRC), we must add the dimension of developmentalism (as Lin Chun has argued). ${ }^{1}$

The modernity of the Chinese Revolution is produced in this structure, even as the structure also produces the particularities of the theory of its historical stages, from New Democracy to socialism (see also Blecher's essay in the present volume). At the same time, the abundant experiences and complex content of the revolutionary process contributed to, while also helping produce, numerous particular revolutionary theories-for example, theories of the countryside surrounding the city, the united front, the mass line, etc. ${ }^{2}$ Yet, by the same token, communism was always the ultimate horizon and the end goal of the struggle. The self-negations and theories of 'continuous revolution' characteristic of the Chinese Revolution can be attributed to the essential particularities of this ultimate goal. 


\section{Rupture and Continuity}

The modernity of the Chinese Revolution meant that inherent to it was a strong antitraditional tendency; for this reason, it constituted a genuine rupture in Chinese history. This rupture is responsible for much of the creativity of the twentieth century. And yet, from a different perspective, at the same time as the Chinese Revolution decisively parted from tradition, it also consciously or unconsciously utilised tradition to enhance its own creative content. For example, the CCP required its own members to 'first eat bitterness [endure hardship], and then to enjoy themselves.' This could be seen as akin to the spirit of the adage attributed to the ancient sage Fan Zhongyan (989-1052), a Song Dynasty statesman credited with being the founder of neo-Confucianism, who said: 'Be the first to bear the world's hardship, and the last to enjoy its comforts.' Historian John King Fairbank once encapsulated modern Chinese history into an 'impact [of the West]-response [of China]' paradigm, yet, with regard to the Chinese Revolution, this paradigm could perhaps be more precisely expressed as impact-appropriationresponse. ${ }^{3}$ Even so, in the normal course of affairs, the appropriation of resources from Chinese tradition usually congealed around the requirement to effect an absolute break from tradition.

From the late 1920s, when the CCP was mostly based in the Jinggangshan area of Jiangxi province, along with the gradual growth of the consciousness of the need for revolutionary bases, rudiments of the new nation emerged, which later came to maturity during the Yan'an period. For this reason, inherent in the Chinese Revolution was a strong commitment to institution building, which simultaneously produced a serious critique of anarchism. However, this certainly did not spell the end of discussions over where power resided; to the contrary, whether power belonged to the state or to society was consistently one of the arenas of potential trouble throughout the revolutionary years. This trouble reached its climactic theoretical and experiential limits during the Cultural Revolution and was expressed in the Paris Commune-like principles that informed the January Revolution of 1967 in Shanghai, one of the high points of the proletarian commitment to the Cultural Revolution in the city (see also the essays by Russo and Thornton in the present volume). ${ }^{4}$ The most pragmatic choice for restoring social order was that power belonged to the state, and yet the idealistic or even romantic yearning that power could belong to society remained a strong sentiment. Understanding this point is essential to grasping the internal theoretical contradictions and paradoxes of the Chinese Revolution.

\section{Beyond the Political Revolution}

The Chinese Revolution was never only a political revolution, but rather it was always also a social revolution, with the ultimate goal of fashioning a more egalitarian social order. After 1949, the PRC underwent a sea change to become a collective society. In the rural villages, there was a gradual transformation from a small peasant private property regime to the collective property regime of the people's communes (see also Gao's essay in the present volume). In the urban areas, there was a gradual nationalisation of industry and manufacture through unitary purchasing policies. In the end, these comprised the planned economy. Forbidding individuals or any kind 
of interest group from putting themselves above society was one of the core ideals hidden in the background of these socialist transformations. That is, in addition to valorising the broad proletariat-peasant masses, radicalising political campaigns were used to smash the formation of any possible power blocs. Restraining bureaucratisation was about preventing the emergence of special power factions; the vigilance against markets and its corresponding commodity economy was about rejecting privatisation and the possibility of the reemergence of capitalist classes; the remaking of intellectuals to one degree or the next was about the transformation of intellectuals as a class into a form of cultural capital, whose 'red and expert' mastery could help control social anxiety about the future of communism in China (see Schmalzer's essay in the present volume). This radical socialist transformation reached a climax during the Cultural Revolution; its ultimate failure can be attributed to many different factors.

Socialism retained the nation-state form and at the same time it also retained the bureaucracy, in particular the system of cadres which not only included bureaucrats but also absorbed intellectuals. Essentially, there was no way to break through the laws of the salary-wage system, so that the problem of distribution continuously tilled the fecund soil of special privileges. In the context of the modern world system, it was almost impossible for China, in reality, to return to any autarkic form of economicsself-reliance, rich harvests, and self-sufficiency (see Yang's essay in the present volume) - even while, of course, this impossibility simultaneously is attributable to the Cold War geopolitical patterns. ${ }^{5}$ Even more important, perhaps, is that after 1949 there was never a pure socialist system in China. Because of nativist elements, the Chinese Revolution was at once both radical and incrementalist, and was always oscillating between compromise and struggle. This embodied the strategic spirit of the Chinese Revolution at the same time as it also formed the internal complexity comprising its socialism.

In the rural villages, what actually existed was what can be called a semiplanned, seminatural economic formation, where the small peasant economy (including its corresponding ideology) could never have been completely eradicated. The system of 'three-level ownership with production teams as the base' of the people's communes was a formation that integrated the production team, the production brigade, and the commune. The production team in many essential aspects was merely the continuation of a traditional natural village formation, with, in particular, the system of individual plots substantively retaining the idea of a private economy along with its cultural connotations. By the same token, in the cities, once socialist nationalisation had been completed in 1956, there nevertheless remained a host of consolidated ownership forms (state-owned enterprises, collectively owned enterprises, individual economy). In the midst of such a complex socioeconomic structure, exchange obviously became extremely important; at the same time, the reality of the pattern of a 'private economy in the midst of the collective' became particularly evident. In this light, we can say that the socialist revolution from 1949 to 1976 did not really cope with these problems completely.

As for the transformation of intellectuals, in addition to the clear challenges presented to professionals, the popularisation of education also produced new problems. In 1950, the horizons of this issue began to become evident, and by 1960 the problem of 'successors' drew huge political attention. ${ }^{6}$ On the one hand, the popularisation of education gave 
rise to tense relations between intellectual youth and villagers, with a conflict between peasant children 'entering the cities' and urban intellectual youth 'returning to the villages." On the other hand, modern education, particularly the expansion of university education, included the movement of university graduates into work environments with relatively well-paid salaried positions and social welfare provisions. This led to the gradual formation of a socialist middle class, with corresponding newly arising middle class lifestyles and cultural desires. The reforms of the 1980s in China derived from the impetus provided by the alliance of the three social strata that was forged in this period between bureaucrats, urban entrepreneurs, and the petty bourgeoisie. In the middle of this kind of socialist transformation was a continuation of conflict in Chinese tradition over the relationship between xiaokang and datong (for an exegesis of the interpretation and translation of these terms, see Craig A. Smith's essay in the present volume). That is, should one pass through xiaokang so as to achieve datong (socialism), or should one achieve datong in order to reach xiaokang? This debate continues to this day.

\section{A Social Enlightenment}

The difficulties encountered in the political or economic arenas often found their way into the cultural sphere, so that training the so-called 'new socialist person' became an urgent task (see Dai's essay in the present volume). Political scientist Tang Tsou has called Chinese society an 'all-round society', but from a different perspective we could say that the ambition of new China was to build an 'education society.' This intention was fully expressed and contained within Mao Zedong's 1966 '7 May Directive.' Literature and arts were to throw themselves wholeheartedly into the social fray, where their goal was to transform society and to help mould the new socialist person. For this reason, these practices were far from the older (individualised) practice of literature, and rather were intended to produce a literature of society or the collective with the aim of creating the conditions of possibility for a richer public life. The design of this 'education society' clearly mobilised to a great extent ancient Chinese resources on social 'enlightenment' (jiaohua); in its aspirations to cover all of society, it was close to the neo-Confucianism of the Song-Ming period, and particularly the idealism of Wang Yangming (1472-1529). ${ }^{10}$ The idea that every person could achieve the perfection of the ancient sages Yao and Shun was directly cited in Mao Zedong's poetry: 'Our six hundred million Chinese can all be Yao and Shun.' ${ }^{11}$

This education society naturally has a social disciplinary aspect, but, by the same token, it also retained classical educational aspirations for the cultivation of social morality: for example, excellence, brilliance, loyalty, devotion, selflessness, courage, etc. For this reason, the sublime was always the most prominent aspect of socialist aesthetics (see Sorace's essay in the present volume). Through this type of learning, which emphasised intrinsic quality (moral fibre), the hope was that the new socialist person would reject material rewards and ambitions for power so as to carry out revolution to the very end. What the Chinese Revolution sought to accomplish was the popularisation of the ancient aristocratic ideal of the 'gentleman' (junzi), ${ }^{12}$ although, truthfully, this was not the innovation of the Chinese Revolution alone. For, aside from the aesthetic influences of the former Soviet Union, this also came from an internal aspect of the Song-Ming idealist school, even though the Chinese Revolution relied 
upon the strength of the Party-state to realise it. However, the difficulties this education society encountered also derived from the structure of state coercion: for many people, this form of the sublime steadily created a kind of pressure which, by the 1980s, produced the beginning of the trend towards 'avoiding glory', in the words of Wang Meng. ${ }^{13}$

\section{Advocating Datong}

In the twentieth century, the Chinese Revolution experienced a cycle of radicalismretrenchment-radicalism, of temporary compromise followed by a new move on the chessboard. This makes conspicuous the fact that difficulties were not just the province of prerevolutionary activity, but that in the postrevolutionary era, the difficulties of realising socialism in one country were multisided and emerged from everywhere. Yet, the core issue, I still believe, is that the revolution was never able to resolve the problem of private property in the midst of the regime of public property. This also encompasses the problem of how to preserve individual autonomy in the context of collective life. Despite this, the Chinese Revolution has left behind a mighty legacy, inclusive of its errors and failures. Today, China has reaffirmed the system of market economy and is trying to resolve the inverse problem of 'public property in the midst of the system of private property.' This encompasses the problem of how to 'embed' the market into social structures rather than allowing the market to dominate or control society. ${ }^{14}$ For this reason, I believe renewed calls for datong as an ideal able to surmount the society of xiaokang will only become more important in the future. ${ }^{15}$ 



\section{7 \\ 自力更生 \\ Self-reliance}

YANG Long

he Chinese Communist Party (CCP) first referred to 'self-reliance' (zili gengsheng) in the late 1930s. The meaning of the term shifted over time, reflecting the Party's economic capacity and changes within official ideology. In English, self-reliance is defined as a 'reliance on one's own powers and resources rather than those of others.' ${ }^{1}$ In Mandarin, self-reliance has an additional connotation of regeneration through one's own power and effort. It is a dynamic phrase that entwines power, economic, and spiritual growth, and has lent itself to continuous redefinition. ${ }^{2}$ This essay traces how self-reliance came to have a precise meaning in official Party discourse in response to economic constraints during the War of Resistance against Japan (1937-45) and describes how it was redefined to justify Mao's radical isolationist policies between the late 1950s and early 1970s. Despite China's integration into the global capitalist economy, the phrase has retained conceptual flexibility in its adaptation to the changing economic policies and political landscapes of the 1980s and 1990s. Tracing the fluid meanings of self-reliance provides a lens through which we can more clearly understand how China politically conceptualises the economy and its own position in the world.

\section{Historical Origins}

Although the concept of self-reliance predated the conflict with Japan, it was the War of Resistance against Japan which made the need to practically implement policies aimed at self-reliance a concrete reality. The Party's efforts to turn the term into a precise formulation-a so-called tifa, i.e. a term that was, and still is, used by the CCP to encapsulate its political ideas and important policies 3 - began in the late 1930s. After the surviving the treacherous Long March and prolonged economic blockade, the Party was on the verge of fiscal collapse. The outbreak of the war with Japan and the 
economic isolation of the communist base in northwest China further exacerbated the woes of the CCP. In order to increase self-sufficiency in food and living necessities, in February 1939 Mao launched a series of production campaigns in the area controlled by the CCP by encouraging all students and soldiers to engage in agricultural and industrial production. ${ }^{4}$ The concept of self-reliance was first formulated in precise terms in a speech that Mao gave to senior Party officials in June 1939 to mobilise all CCP members to make mental preparation for the most adverse conditions. In his words: 'The Party and its military force need to prepare for the harshest [survival] environments. ${ }^{5}$

In the following years, the Party's fiscal situation worsened due to two factors. First, the CCP's continuous success in territorial expansion and military recruitment threatened and provoked the Nationalist Party into an attempt to isolate the CCP nationwide. Second, the Rectification Campaign, launched by Mao in 1941, not only created many internal enemies but also distracted Party members from agricultural production (see Mertha's essay in the present volume). The dramatic increase of the burden on peasants in 1941 left the Party with no choice but to accentuate the importance of self-reliance through production campaigns. ${ }^{6}$ These underlying tensions came to a head on 3 June 1941, when the acting governor of Yanchuan county, northern Shaanxi, was struck dead by lightning while he was attending an administrative meeting in an open-air square. At the same event, a peasant whose donkey had also been killed by lightning publicly put a curse on Mao, asking why the heavens did not strike him dead instead. In the next few days, the peasant told anyone who was willing to listen about the curse he had put on Mao. The local public security agency investigated the peasant's outburst, and acknowledged that his discontent arose from the Party's policies that had led to the high agricultural tax burden. Mao himself also acknowledged that the excessive burden imposed on the peasants had pushed them to the verge of subsistence. This incident served to strengthen the CCP leadership's resolve to implement the policy of self-reliance through further production campaigns aimed at increasing agricultural output. ${ }^{7}$

The CCP's ability to overcome scarcity during the War of Resistance depended on its ability to mobilise the masses in production campaigns and 'regenerate' its own conditions of existence. After the victory over the Japanese, self-reliance became cemented as an official formulation within official Party discourse. On 13 August 1945, Mao delivered a speech in Yan'an, in which he summarised the lessons from the war that was then ending, underscoring the importance of self-reliance in the following way:

On what basis should our policy rest? It should rest on our own strength, and that means 'regeneration through one's own efforts' (zili gengsheng). We are not alone; all the countries and people in the world opposed to imperialism are our friends. Nevertheless, we stress regeneration through our own efforts. Relying on the forces we ourselves organise, we can defeat all Chinese and foreign reactionaries. ${ }^{8}$ 
In this sense, the war with Japan provided the historical basis and justification for the ideological framing of self-reliance as a political and economic concept. The continued survival of the CCP, against overwhelming odds, meant that the Party had self-confidence that it could rely on itself to overcome dangerous times ahead. Mao's statement strove to attach revolutionary spirit and significance to 'regeneration through one's own efforts', thus embedding the concept deep within Party symbolism.

\section{Self-reliance in China's Era of High Socialism}

In the 1950s and 1960s self-reliance gradually evolved from a symbolic commitment and mark of loyalty to China's socialist project into a Maoist principle of development and foreign relations. In the early 1950s, the CCP discarded the wartime policy of self-reliance and instead adopted the socioeconomic development model of the Soviet Union. The CCP's dependence on Soviet aid-including technical specialists-was vital for the promotion of the industrial sector. However, commencing from around 1955 fissures started forming in the Sino-Soviet alliance. In 1957, the Soviet Union began withdrawing experts from China in response to the escalation of the diplomatic feud between the two countries. The conflict between the remaining Soviet experts and Chinese officials in 1958 and 1959-when the Great Leap Forward was in full swinggave the Soviet Union an excuse to pull back even further. ${ }^{9}$ As a result of the Sino-Soviet split and the loss of technical expertise, Mao revitalised the concept of self-reliance as the fulcrum of domestic development strategies and relations with the international community. Unfortunately, this approach did not accelerate industrialisation as envisioned, but rather facilitated and fed into the utopian economic experiment turned disaster of the Great Leap Forward (1958-62). ${ }^{10}$

During the early years of the Cultural Revolution, the commitment to self-reliance was bound up with radical revolutionary values, which in practice resulted in selfimposed isolation. In the domestic sphere, the emphasis on self-reliance at all levels through continuous propaganda campaigns resulted in a dramatic decline in both the supply of light industrial products in cities and state support to rural areas. ${ }^{11} \mathrm{~A}$ case in point was the national campaign to 'Learn from Dazhai in Agriculture' (nongye xue dazhai) which emerged in 1963 and became the model for revolutionary agriculture based on the practices of Dazhai, a village in Shanxi province. Dazhai villagers placed a great deal of effort in the policy of self-reliance, and refused support in the form of state grain, state funds, and other outside relief materials. Their attempts to sustain themselves were showcased by the central government to compensate for its own limited ability to provide Chinese people with the life necessities they badly needed. ${ }^{12}$ In the international sphere, the Party's excessive commitment to self-reliance resulted in the breaking off of diplomatic ties with other countries and the reduction of foreign imports, particularly of industrial equipment. ${ }^{13}$

By the late 1960s, the international isolation and rigid insistence on self-reliance had caused the Chinese economy to lag behind a large number of European and Asian countries, which had experienced rapid economic growth during this period. ${ }^{14}$ Its economic anxieties compelled the CCP to modify its policies by seeking rapprochement with both the United States and Japan in the early 1970s. ${ }^{15}$ 


\section{Contemporary Transformation}

At the onset of the reform period, the Party leadership under Deng Xiaoping paid enormous attention to repairing and renovating the institutions and norms of political life. At the same time, the Party shifted its focus from continuous revolution to economic reform and the country's integration into the global economy. Against this backdrop, the concept of self-reliance was hollowed out leaving behind only a name, akin to a museum piece in the shrine of the Chinese Revolution. That being said, it was a source of pride and glory within and legitimation of Party history. In the CCP's decisive 1981 'Resolution on Certain Questions in the History of Our Party since the Founding of the People's Republic of China, the relationship between self-reliance and the victory of the Chinese Revolution was highlighted in these terms:

It must be said that, fundamentally, victory in the Chinese Revolution was won because the Chinese Communist Party adhered to the principle of independence and self-reliance and depended on the efforts of the whole Chinese people, whatever their nationality, after they underwent untold hardships and surmounted innumerable difficulties and obstacles together.

The postreform articulation of self-reliance reformulated the term from a pillar of Maoist revolutionary thought and action, to a Dengist conceptualisation that saw selfreliance as a means to an end in the struggle to ultimately reclaim China's rightful place on the world stage.

The transformation of the concept of self-reliance into a historical artefact was further confirmed by Deng Xiaoping's opening address at the Twelfth National Congress of the CCP in September 1982. In his speech, Deng specified that 'China's affairs should be run according to China's specific conditions and by the Chinese people themselves. Independence and self-reliance have always and will always be our basic stand. The objective of his speech was, however, to emphasise the importance of economic development through 'unswervingly following a policy of opening to the outside world and increasing our exchange with foreign countries on the basis of equality and mutual benefit. ${ }^{16}$ In the following seven years, Deng, mentioned the term self-reliance on at least four separate occasions, but all in the context of policies aimed at accelerating economic reform and integrating China into the global economy. ${ }^{17}$

In the late 1980s and 1990s, when Chinese economic reform gained momentum, the term self-reliance was gradually discontinued in official Party documents and speeches by Party leaders. It was only in the late 1990s that a debate over the revision of the state-sponsored Chinese Dictionary of Etymology (cihai) brought the term back into the public discourse. This dictionary, updated on a ten-year basis, is roughly equivalent to the Britannica Concise Encyclopaedia. At that time, the editors of the Dictionary succeeded in removing 'self-reliance, alongside hundreds of existing entries related to revolutionary discourse, such as 'independence and self-reliance,' 'criticism and self-criticism,' and 'the Chinese Revolution and the Chinese Communist Party.' These changes immediately provoked heated controversy among Chinese scholars, with leftwing intellectuals lashing out against the editors of the Dictionary and accusing them of denying the legitimacy of the Chinese Revolution, as well as Mao's historical merits. 
As a belated response to the above criticism, at a conference in 2005 the Dictionary's editor-in-chief explained that the controversial updates had aimed to 'get rid of the stale and take in the fresh.' More specifically, old-fashioned words were no longer included in the new version of the dictionary because they were not deemed useful for the Chinese people, as they did not describe the current socioeconomic and political circumstances. ${ }^{18}$

Fast forward two decades to today, and self-reliance suddenly seems to be having a resurgence. Between September and November 2018, Chinese President Xi Jinping frequently used the term in his speeches during visits to several high-tech companies. A number of observers of China have interpreted this as Xi's attempt to revitalise Maoist political rhetoric. ${ }^{19}$ However, we should be careful not to hear Mao's voice in Xi's words. A closer look at the context and usage reveals that Xi's main concern is not about the revival of Maoist revolutionary rhetoric, but about the development of a number of key technologies in response to accusations that China engages in technology and intellectual property theft coming from the United States. The current Chinese leadership is of course keenly aware of the importance of technological development for the economy, as well as the vulnerability of Chinese companies that rely on global supply chains for high-tech components, many of which originate in the United States. While Xi's use of the term self-reliance may evoke memories of Mao's isolationism, in actuality it is a reflection of the Dengist interpretation of self-reliance as a means to an end-in this case China's continued rise within the global economic order. 

38

半封建社会，半殖民地

Semifeudalism,

Semicolonialism

Tani BARLOW*

$\mathrm{n}$ his treatise Imperialism, the Highest Stage of Capitalism, Vladimir Lenin inserts the term 'semicolonialism' to describe China under global capitalism's industrial and financial imperialism. 'Theories sharpen and clarify conditions that are neither clear nor consistent; the addition of the prefix 'semi' refined the strategic understanding of colonialism as a matter of degrees and historical conditions that are permanently in flux. This reformulation also expanded what global imperialism/colonialism (or capitalist imperialism in the Soviet tradition) meant strategically. After 1917, in Internationalist Comintern politics, semicolonialism indicated relative subordination to imperialist powers. Translated as banzhimindi in Chinese, this latent, formulaic category in European internationalism was given new life in the writing of Chinese Marxists in the 1930s, such as Chen Hongjin and Mao Zedong. ${ }^{2}$ Mao particularly interpreted Marxism to address conditions facing the Chinese Communist Party (CCP) in the 1920s and 1930s. In the 1930s and 1940s, key ideas inherited from European traditions of revolutionary thought and party organisation were retooled to fit Chinese conditions under the banner of Mao Zedong Thought. One resulting category was 'semifeudal, semicolonial' (banfengjianshehui, banzhimindi), which was both a conceptual innovation of Maoist dialectics and a strategic approach to people's war (see Guan's essay in the present volume). The power of the concept of semicolonialism and semifeudalism was due to its proximity to local conditions and availability to strategic praxis; because it was close at hand, the concept had predictive value. ${ }^{3}$

\section{The White-haired Girl}

The coded simplicity of the term semifeudal, semicolonial was widely communicable and routinely transmitted to the masses. Transforming a backward society into a progressive one during the War of Resistance against Japan involved both disciplining 
intellectuals and also raising the consciousness of the ordinary people so they, too, understood the difference between emancipation and oppression. Among the massive number of syncretic cultural texts that appeared in the mid-century, the 'White-haired Girl' story shows most obviously how the reality of history in China could be coded into a story about China's semicolonialism and semifeudalism.

Beginning in 1945 and in direct response to Mao's 'Talks at the Yan'an Forum on Literature and Art,' the CCP authorised a story about Xi'er, a peasant girl, her beloved fiancée Dachun, her father, her godmother, and her fellow villagers. Based on the vicissitudes of village girls abused by landlord families, 'White-haired Girl' was staged in various versions but the core story remained the same. The narrative takes place in a small village in Shaanxi province, and revolves around the life of Xier who is engaged to a poor peasant named Wang Dachun. Because of his debt from a phony interest charge, Xier's father commits suicide (in the ballet version, he is killed by the debt collector). As a result, the father's 'creditor, the local landlord Huang Shiren seizes Xier to pay her father's debts. This exchange transforms Xi'er into a commodity subject to the abuse of her owners; she is forced to work day and night, and becomes pregnant after being raped by the landlord's son. Alerted to the fact that she will be sold to a brothel, she escapes to a mountain shelter where she gives birth to a stillborn baby. Xier lives in a cave in the mountain where she learns to be free and self-sufficient, and survives by stealing food from a local temple. In another version of the story, an angry mob believes that Xier is a spectral apparition threatening their community with harm and attempts to desecrate her body until they are stopped by Wang Dachun, who recognises his lover (this version was intended to help eradicate superstition; see Williams's essay in this volume). In the mainstream version, Dachun uses his revolver to flush out the supposedly supernatural 'white-haired spirit' only to find that it is his beloved. Despite the different variations and art forms, the tunes are still familiar. Peng Liyuan, spouse of China's leader Xi Jinping, starred as Xier in the People's Liberation Army song and dance troupe during the 1980s, and more recently, served as artistic director of a revival tour, which opened in the hallowed revolutionary site of Yanan in November $2015 .^{4}$

Decoding this cultural phenomenon is by-the-book. Each figure embodies elements of semicolonial, semifeudal, backward village society. Old Zhao, who advises Wang Dachun not to seek revenge on the landlord but to join the Eight Route Army, typifies the honest but culturally illiterate poor peasant. Dachun, the poor landless peasant and his mother, Wang Dashen, live in permanent indebtedness to the Huang family whose scion, Huang Shiren, and Dowager, Madame Huang, inflict pains small and large on their indebted workers. Each character performs a range of predictable activities that identify them as archetypes. Huang Shiren, for instance, is a tool of the Nationalist Party and a leader of the rural bourgeoisie. He is a rapist and unredeemable criminal who relies on imperialist and international capital to extract surplus value and labour from villagers until they die. Similarly, scenes showing Xier, abandoned and pregnant, milling wheat like a water buffalo, convey how semicolonial, semifeudal sociology truthfully represents reality. The feudal setting where peasants incur debt just to stay alive and where landowners are usurers, armed with bourgeois pistols is contrasted with the white-faced, red-lipped Eighth Route Army soldiers, whose solemn and operatic visages signal that the time has come for poor peasants who are seeking revolutionary vengeance to take action. Before he is reunited with Xier, Wang Dachun returns to 
the village and teaches his old cohort how to stage an uprising. He has learned to read and has become a politically aware, revolutionary cadre. The strategic logic that Party members bring to the village merges into revolutionary indignation and vengeful rage as the villagers overthrow the semifeudal, semicolonial old order.

\section{Fierce Debates}

Despite its seductive appeal and simplicity, Maoist terminology-semifeudal, semicolonialism, colonialism, feudalism - has provoked savage historiographic debate. First, these terms cannot be subsumed into theories about colonialism in India and British capital accumulation known under the rubric of 'postcolonial theory.' Postcolonial theory is a portmanteau of related techniques for theorising England-to-India relations including: a) magical inversions ('provincialising' imperial power); b) disputing class and class consciousness (incommensurability, subalternity); c) conflicts over the status of capital as such in colonisation (othering or otherness); and d) post-Althusserian disregard for the historical limits of culture. There is some doubt that postcolonial theory even supports its alleged intention, to comprehend colonialism in India. ${ }^{5}$ Second, in the last several decades, China historians have struggled to distinguish universal elements of Marxism from localisms. In US debates, some scholars argue that Maoism, a field of praxis, has no bearing on Marxism, which consists of Marx's critique of capitalist logic and history of capitalism's rise out of conditions in Europe. ${ }^{6}$ Others say that Maoism is a utopian offshoot of Marxism, its potential lying in voluntaristic effort and a praxis for changing social relations of production outside Marxism's Europeoriented universalism. ${ }^{7}$ The Adelaide School suggested Maoism was a future Marxism that could bridge national differences and unevenness in the relations of production internationally. ${ }^{8}$ A few have refused to admit Maoism into the Marxist Pantheon at all, declaring instead that Maoism is a 'discourse,' a localist category without universal significance. ${ }^{9}$

How Maoists sculpted the phrase 'semicolonialism, semifeudalism' is a legitimate historical question. Marxism, Maoists observed, was universally true. Marx, they argued, discovered the 'universality of the contradiction between the productive forces and the relations of production in class society in general. ${ }^{10}$ Singularity (Chineseness) and utility lie in Marx's emphasis on praxis or what Maoists particularly valued, i.e. method. Their explanation was as follows. Universally without exception, Marxism makes material and social process visible. Intervening in reality requires flexibility, however. Practitioners of Marxism find truth in circumstances in order to choose the best course of action. A good strategist must understand immediate process, embrace dynamic contradiction, and anticipate where human action can influence outcomes. In semicolonial China, Marxists realised that while the principal contradiction is class society as such, there are singular or 'Chinese' non-principal contradictions.

\section{Universalism and Localism}

The 'semi' in semicolonialism opens the way to recognising what is a singular and non-principal contradiction while holding onto the universal or principal contradiction stated above. It turns out that semicolonial and semifeudal offers a way 
into given conditions through specific instances. The determinate difference between colonial and semicolonial spaces, for instance, gives analysts the key to grasp how the concrete universal appears in the world under specific temporal and geographical conditions, such as the pursuit of irregular guerilla warfare in a border region in 1938 . On the basis that China was semicolonial and semifeudal, Maoist battle strategy was both regular and irregular, relying on ground troops as the main force, and guerrilla warfare to drain Japanese imperialist military power. ${ }^{11}$ As Nick Knight has long pointed out, the difference between the Maoist and orthodox Leninist-Stalinist approach to contradiction lies in the Maoist mandate that analytic terminology proliferate around singularities and specifics. ${ }^{12}$

If China was understood to be a semicolonial, semifeudal social order, and not a colonial, feudal state-i.e. distinct from India-planners could see warfare in a new way. This understanding of concrete universality allowed for battle plans to be designed on the basis of real conditions. These were not cerebral exercises but high-stake analyses, such as Mao's 1938 essay 'On Protracted War', in which he wrote that: 'The Sino-Japanese War is none other than a war of life and death between a semicolonial and semifeudal China and an imperialist Japan in the 1930s. Herein lies the basis of the whole problem.' 'On Protracted War' explained what semicolonial meant in that context, on the way to addressing why protracted war was the strategy needed to defeat Japan. ${ }^{13}$ The essay reasoned that China was no longer a feudal society in great part as a consequence of European and Japanese imperialism. Therefore, in a global context, with the Soviet Union on the one hand and the example of a failed Ethiopian war of independence against Italy on the other, Marxists could locate China's singular 'identity.' ${ }^{\text {' }}$

The bigger point was to demonstrate how semicolonial, semifeudal conditions were ripe for politically defining identity and mobilising the masses in a protracted war that drained the enemy's relatively stronger position. Under real conditions and correct theoretical work (theory and praxis in relation to identity) attacking an enemy requires using a feedback mechanism, such as the mass line, that puts into constant circulation political, military, cultural, and mobilisational resources. Protraction means only that no one yet knows what amount of time will be needed to unbalance the enemy. It is a temporality that exists within an uneven spatiality composed of different topographies, resources, populations, and shifting real conditions. Not only thatengaging in protracted struggle expedites the transformation of the very conditions that make possible the protracted warfare. Consciously understanding the reality around us makes it possible to decide strategy and tactics.

\section{The Truth of the Singular Moment}

The historical task of the Chinese nation-in-process during protracted war against Japanese imperialism was to overthrow semicolonial, semifeudal relations of production and to set in motion a dialectic-theory and praxis-that would transform national identity and readjust class struggle. The CCP's long experience of battle had demonstrated that the sine qua non for the Party was to grasp the 'unity between the theory of Marxism-Leninism and the practice of the Chinese Revolution. ${ }^{15}$ As this essay has shown, that was not an abstraction. To initiate praxis on the basis of theory, one can extract from Mao Zedong Thought the contemporary historical moment 
(the Second Great Imperialist War, emergence of the Soviet Union, etc.) and the truth of that singular moment. This method provides clarity about momentary configurations of identity, topography, sociology, economics, and suggests a range of good policy options. When Maoists use the term semicolonial and semifeudal this way, it is not a description but a representation of the realities that theoretical Marxism can, when used properly, actually illuminate.

The power of representation is certainly a reason why in December 1939 the collective group of writers associated with Mao published an official textbook about society, revolution, and Party building (the latter chapter was never completed) for incoming intellectuals and CCP members. ${ }^{16}$ The Chinese Revolution and the Chinese Communist Party starts with the history of a space that originated, like all places, as a classless society, and had emerged into slave and then feudal social relations, but was currently a weak semicolonial, semifeudal country. In simple language the text explained that because imperialism introduced foreign capital, the feudal economy began to crumble, and the landlords, bureaucrats, and bourgeoisie turned toward capital investment in modern industries. There is nothing particularly Chinese about the concluding argument:

It is clear that by penetrating into China the imperialist powers have on the one hand accelerated the disintegration of China's feudal society, caused factors of capitalism to emerge in China and transformed the feudal society into a semifeudal one, and on the other hand imposed their ruthless rule on China and reduced an independent China into a semicolonial and colonial China. ${ }^{17}$

My essay consequently demonstrates how central to Maoism the phrase semicolonial, semifeudal turns out to be. And yet, it also turns out that unsnarling claims about Chinese singularity does not make Maoism into a 'Sinicised' or discursive Marxism. As Mao Zedong Thought emerged, it claimed only that all situations and societies where Marxism prevails are singular. No two sites of class struggle will ever be the same: however, no amount of difference alters Marxism-Leninism's universal truth. 

39

电影下乡

Sending Films to the Countryside

Tong LAM*

$\mathbf{T}$

he idea of delivering education, health care, and technical knowledge to the countryside has always been an important part of China's nation-building effort. In the early twentieth century, many intellectuals argued that such initiatives would be crucial to the production of modern citizens in China's vast rural areas. They also maintained that the suffering and hardship that they had to endure in the process would be the key to converting themselves into new political subjects. ${ }^{1}$ By the time of the Cultural Revolution, the idea of 'going down to the countryside' took on yet another significance, as it became associated with the relocation of millions of urban youths to the rural regions for reeducation by a supposedly ideologically pure peasantry. In spite of the strong resentment harboured by these so-called 'sent-down youths' (xiafang qingnian) or the 'Lost Generation,' the programme-which was officially called 'up to the mountains, down to the villages' (shangshan xiaxiang) - did help to address many of the deficiencies suffered by the rural communities.

Nevertheless, xiaxiang as a cultural and political trope encompassed a wide range of practices that served to reduce the unevenness between rural and urban areas and populations. Among them was the project known as dianying xiaxiang, or 'sending films to the countryside.' Like other projects that sought to overcome the rural and urban economic and social disparity, a primary purpose of bringing films to China's rural communities was to deliver entertainment to remote and underdeveloped areas. At the same time, not unlike similar mobile cinema projects around the world, openair film screenings also allowed the Chinese rural population to experience the shockand-awe of the cinematic spectacle for the first time. Moreover, the magic quality of outdoor films did not just disrupt the harsh reality of the everyday, but also projected the utopian fantasy of the socialist future. In doing so, the state effectively presented itself as the cultural broker of modernity, strengthening its legitimacy and authority. 


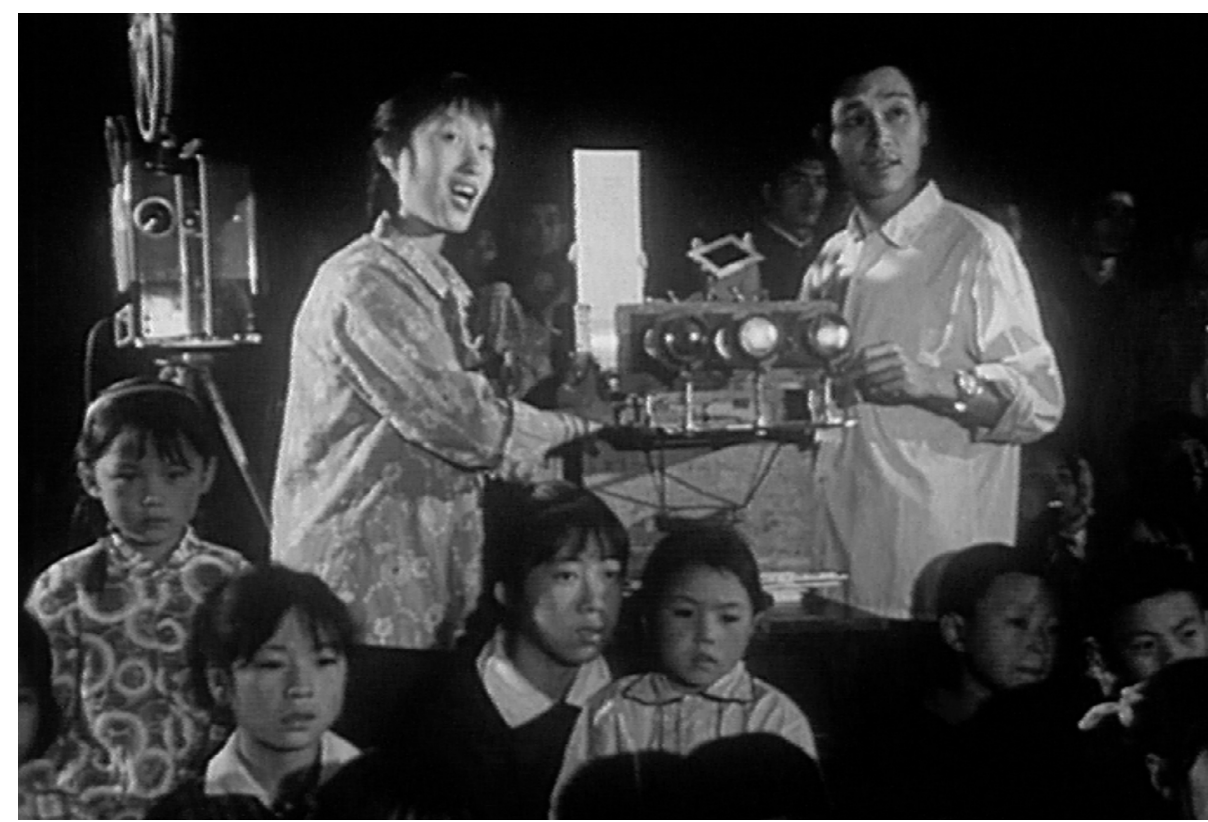

In television footage from 1965, a female projectionist is seen singing a revolutionary song while her male colleague is showing a slideshow prior to a feature presentation. The same machine is also projecting the lyrics that she is holding in her left hand. (Inner Mongolia, c. 1965; Central Studio of News Reels Productio archival footagel

Mobile film screening was indeed tremendously popular in the socialist era. Since such screening events reached a village only once every few years, many villagers walked for hours and even days from nearby villages in order to catch a film. Projectionists, many of whom were young men and occasionally women-including a large number of sentdown youths during the Cultural Revolution-were well respected by rural residents as they were seen as intellectuals and agents of the state. Their jobs entailed the endurance of hardship as they needed to cross formidable mountains and rivers with heavy equipment in tow. Projectionists were also often required to do live performances, such as puppet shows and singing, as part of the practice of delivering revolutionary messages to the rural masses. Not surprisingly, by the late 1980s, mobile films sponsored by the government ceased to operate as the magic of outdoor propaganda films was increasingly challenged by other forms of popular entertainment, such as television, karaoke, and foreign films.

Yet, significantly, in 1998-an era of rising rural and urban disparity as well as social discontent - the Chinese government reactivated the programme of rural outdoor film screenings with much greater coverage and intensity, promising that it would deliver at least one film in each village every month. Known as Project 2131, the programme has shown how digital technology can be mobilised to augment the already powerful propaganda machine in the postsocialist era. At the same time, contemporary mobile film screenings also operate in a different visual economy and political register. Instead 


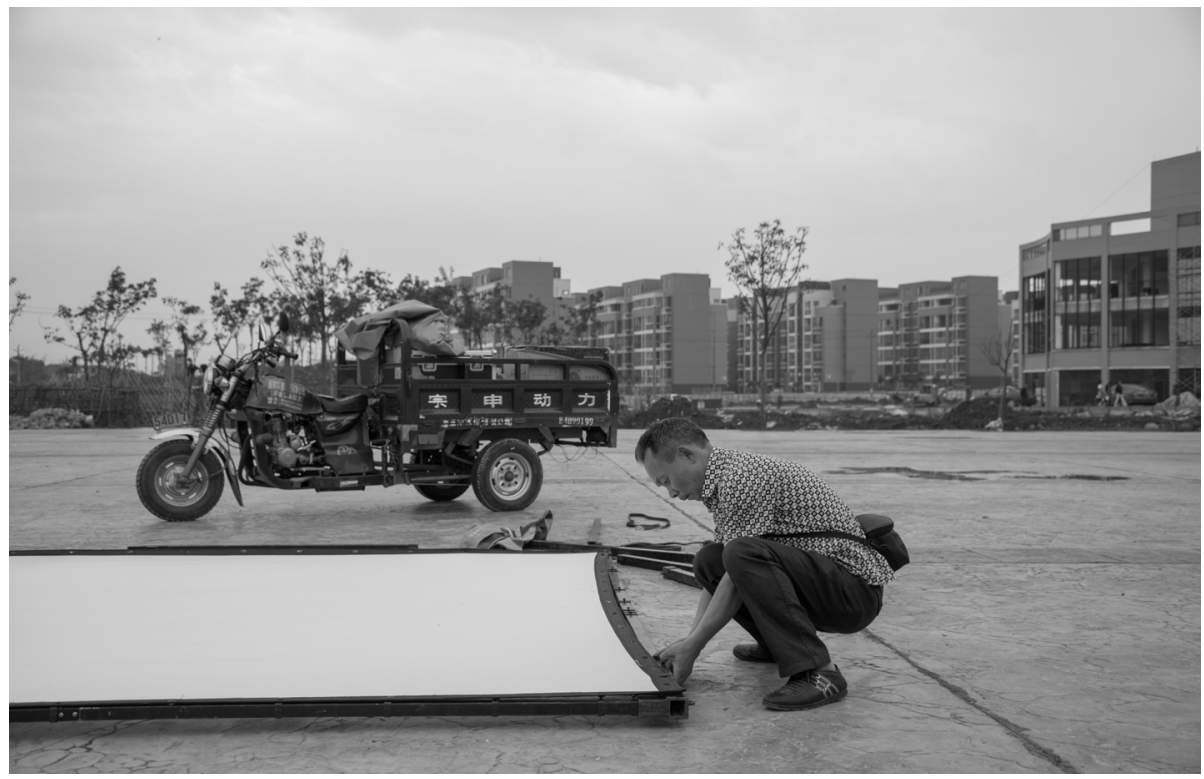

A projectionist setting up the screen for the evening in a so-called Socialist New Village, which is often a combination of several old villages with villagers being housed in mid-rise and occasionally high-rise buildings. (Mumian new village, Sichuan province, 2013; Tong Lam)

of just screening the popular old revolutionary films, the mobile screening programme uses newly developed propaganda films that are specially made for the rural audience. With the assumption that the rural viewers are simple-minded and unsophisticated, these are mostly war and revolutionary films set in the World War II and Civil War times. While these new films, like their predecessors, tell the familiar stories of the liberation of the peasantry under the leadership of the Communist Party, their emphasis is more often about the triumph of the Party and the nation rather than class struggle. Moreover, the sheer quantity of these films is enormous, as an entire segment of the Chinese film industry is now devoted to their production and digital delivery for the government-sponsored rural mobile cinema.

Of course, the Chinese countryside today is different from that of the socialist era in some fundamental ways. Decades of rapid urbanisation have not merely transformed China into an urban nation, but have also uprooted many of its rural citizens. In most villages, those who are being left behind are the elderly and their grandchildren, since young and middle-aged men and women have often become migrant workers in the city. If these peasant migrant workers, who mostly work in factories, construction sites, and other service industries, have become precarious labourers in the postsocialist economy, so are the new generation of projectionists. The improvement of technology and infrastructure means that film projection has become straightforward, effortless, and a highly disciplined affair. Projectionists can now drive directly to the screening site with their government-issued vehicle and digital equipment. From the downloading of films to the uploading of audience tallies, screening events are constantly being tracked 


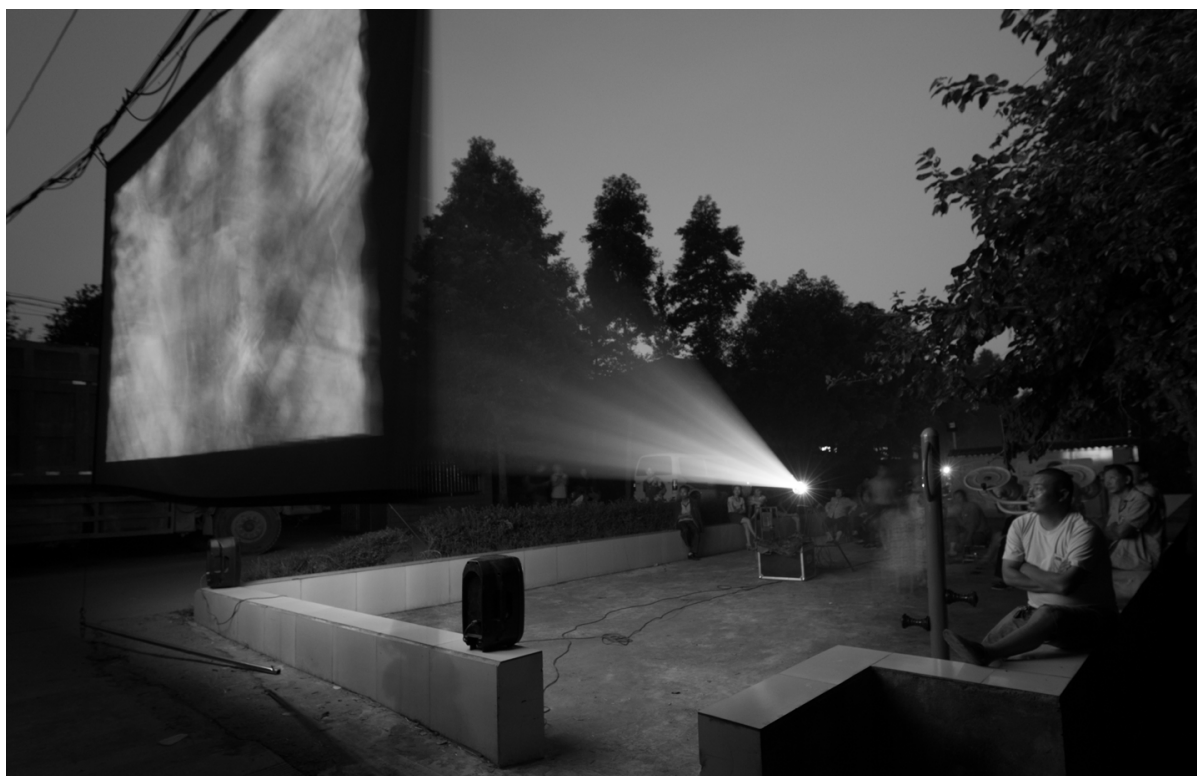

An anti-Japanese war film is being screened next to a village road. Aside from a few classic films, most of the films used in the new mobile cinema programme are tailormade for such purposes. (Yuhe village, Sichuan province, 2014; Tong Lam)

and tabulated. Gone, therefore, are the days when delivering films to the countryside was seen as admirable and heroic. In fact, these days, projectionists are generally poorly paid, part-time and subcontract workers with few benefits.

More importantly, the new generation of propaganda films are no longer about celebrating and sustaining the socialist revolution. Quite the contrary, they are now used to promote patriotism in order to ease any potential social discontent amid the country's enduring, if not widening, urban and rural divide. In this respect, it seems that the latest 'sending films to the countryside' programme is nothing but an ironic reminder of its phantom past. Meanwhile, in the new visual economy, as flashy skyscrapers and mobile devices have become ubiquitous, these open-air propaganda films, even with their updated audiovisual effects, can hardly offer the same level of enchantment and satisfaction that they once did. Behind the sound and fury generated by special effects are the unresolved tensions between the socialist ideal and the postsocialist reality. Hence, if some viewers nonetheless find these films captivating, it is not because of the projected future imagined by these films, but the nostalgic feelings evoked by them. 


\section{0 \\ 为人民服务 \\ Serve the People}

Rebecca E. KARL

0

n 8 September 1944, in China's far northwest communist base headquarters of Yan'an, Party Chairman Mao Zedong eulogised a just-deceased soldier, Zhang Side, as a paragon of 'serving the people' (wei renmin fuwu). ${ }^{1}$ While a common soldier's death in wartime is always tragic, it is usually not the cause for a major tribute, much less for the coining of a vital phrase that, after a half-century of earnest usage, has now devolved into a commodified cliché. Yet, in this small piece of oratory-the speech is no more than a few paragraphs long-we find a text that called into being, and now can recall, an entire kind of history: a prospective and prescriptive socialist history of China. In the deceptively simple locution 'serve the people' is embedded a political injunction, a social ideal, a cultural expectation, and an economic norm, which, in the several decades after its initial articulation, summoned a form of common sense-an ideology-that once was lived as a concrete social practice.

In China's official historiographical understanding, 'serve the people' is primarily an ethical demand. It names a requirement for pure selflessness and individual sacrifice, ideally through death, for the already constituted revolutionary collective. As it turns out, Mao's tribute became one of the three 'constantly read articles' (lao san pian) of subsequent socialist education campaigns - the other two texts being Mao's tribute to a Canadian surgeon, Norman Bethune, who devoted his life and skills to global leftist causes from the Spanish Civil War to the Chinese Communist Revolution; and the mythical figure of the foolish old man who moved the mountains, whose legendary perseverance despite impossible odds was given a new positive spin. Indeed, by the time of the Cultural Revolution in 1966, 'serve the people' had become a mostly empty incantation, and its prescriptive and inscriptive scope narrowed to the sole demand to 'wholly and entirely... live or die for the people.' While the modifying 'wholly and entirely' (quanxin quanyi) was a later addition (1945) to the basic phrase (1944), the narrowed Cultural Revolution era attitudinal directive-as well as the narrowed 
definition of 'service' to a willingness to sublimate the self in death-stuck, as if original to the pronouncement. It is this rigid dogmatic version of the phrase that is thoroughly lampooned in Yan Lianke's scandalous 2005 novel, Serve the People. ${ }^{2}$

Yet, in its time and in its more immediate afterlives, the simple text contains several interpretive levels that should not be so readily ridiculed. On the surface, the tribute was penned for a beloved comrade: a man who had worked his way from poor peasant obscurity in Sichuan province into the Chinese Communist Party (CCP) as a soldier in an elite armed division; who had completed the arduous Long March in 1935, becoming quite close to Mao and other Party leaders; and who had died at the age of 32 in 1944, when a charcoal kiln collapsed on him during the process of mining, just as the armies of the Nationalist Party were besieging the communist base that housed their ostensible allies in the ongoing War of Resistance against Japan. At a more abstract level, Zhang Side was rendered through Mao's tribute into a repository of all the elements of an emulative model of socialist becoming, a so-called bangyang. In this process of abstraction, his particularities came to be dissolved into a universal type-a dianxing - through which the timelessness of service/labour and the timeliness of socialism could be coproduced. In this play of temporalities, the phrase inspired by Zhang's death proposed a new form of social relation, a socialist organisation of time and society that was at once abstract and concrete, lived and 'yet to be made,' remembered and 'not yet existing.'

\section{Heavier than Mount Tai, Lighter than a Feather}

When Mao Zedong first spoke the phrase on 8 September 1944 at the mass meeting to commemorate Zhang's death, 'serve the people' indicated a method through which the enduring and repetitive fact of human death in war could be wedded to the ethical imperative and materially spontaneous creation of the revolutionary unity called 'the people.' Hence, the injunction to 'serve' can be understood as a method in the widest Marxist sense: it is a 'practice of theory.' The locution wei ... fuwu (serve for...) had been used by Mao in his 1942 'Talks at the Yan'an Forum on Literature and Art', when he proposed that the purpose of socialist culture was 'to serve the masses' (wei dazhong $f u w u$ ) (see Sorace's essay in the present volume). It was thus initially used for promoting the welding of all cultural production, as a form of abstract intellectual labour, to the very concrete and lived historical materialist creation of revolutionary culture in China that 'service' came to be elevated to the pinnacle of expectation for the definition and realisation of socialist social relations.

With the eulogy of Zhang Side, this creative principle was expanded and deepened to speak to the production not only of the masses as a cultural concept, but of the 'people as unity' who were the very objects and subjects of socialist revolution itself. Thus, in 'serve the people', the objects and subjects of service are merged into the same revolutionary productive process: one is to become properly part of the people by serving and being worthy of being served. 'To serve' becomes a concrete abstraction: a form of labour indifferent to space/time but also productive of a determinative space/ time; even while 'the people' is the everlasting but concrete revolutionary 'unity in formation' appropriate to a particular historical moment-socialism. 
In this sense, the locution 'to serve' pertains and appeals to a kind of enduring history different from, and yet made to engage with a socialist one. So, while 'the people' is a peculiarly revolutionary formulation that is politically specific to the socialist era, the durational 'service' ethic must be embedded in socialism in very particular ways. Let us note briefly that an important prior history of the injunction 'to serve'-as an ethic but also as a form of labour-resides in filiality, where service is labour performed with the proper expression, or attitude. That is, in the Confucian classics, labour is not merely the performance of an atomised task, but rather also an attitude commensurate to the project of producing and maintaining a form of social relations. 'Labour as service' is an embedded form of social relation. For Confucius and the tradition that follows from his teachings, the social relations sought after through the appropriate performance of service were those defined by and through the family. That is, for example, the son serves the father by labouring as a son for the father as a father, where each of those social positions is predetermined by relation to the other in a social hierarchy. By contrast, the desired social relations in Mao's China were intended to produce a very different social formation altogether: one defined by and through egalitarianism and social equality in pointed opposition both to the hierarchies of the Confucian past and to the global capitalist inequities of China's midcentury present (see Lee's essay in the present volume). Thus, for Mao, 'service' would create the conditions not for the mutually binding reproduction of hierarchical social relations, but rather the possibility for their undoing.

In this regard, in Mao's speech, the meaning oflabour/service (or sacrifice) is historically contextualised and productive. This historicity is dependent on the individual attitude of the performer and the moment of her performance. Specifically, Mao says: 'People die, yet the meaning of their deaths is variable.' How is one to understand the meaning of death? Paraphrasing ancient historian Sima Qian, Mao indicates that the meaning of death can be heavy or light depending on the dialectical relation between personal intention/expression (attitude) and historical situation. From that older principle, Mao derives the concrete meaning of the moment in which the sacrifice (service) occurs: specifically in the eulogy, to die for the benefit of 'the people' (revolution) is as weighty as Mount Tai, whereas to die on behalf of fascism, exploitation, or oppression is featherlight. The contrast between 'the people' as a revolutionary concept, whose existence and equality is created at the same time as it is being secured, and 'fascism/exploitation/ oppression' is thus established as the historical specificity required to materially produce the particular meaning of Zhang Side's death and the nature of his service. While the people will have been-as a predicated future-created as revolutionary, they also will have led that revolution through the weighty service rendered to one another as masters (zhurenweng), shaping and realising their own histories.

It is evident, then, that at the same time as it extols the merits of a soldier who died in the course of the anti-Japanese war, this speech is already looking forward to the end of the war against Japan and to the coming civil conflict with the Nationalists. Much of the organising in the base areas from this point onwards was thus aimed at transforming rural society into ideological and military bastions of socialism in preparation for the imminent domestic showdown. Part of this transformation included the expansion of popular education movements focussed on literacy and economic skills. Thus, for example, the 1944 directive to 'develop production, expand 
the schools' was never merely a technocratic problem, but rather-as with 'serve the people' - it was an ideological imperative to reformulate social relations along the lines of socialist equality. ${ }^{3}$ In other words, the creation of revolutionary unity through the dual emphases on production and education was not just a sociological problem of a class alliance between workers and intellectuals, where each readymade constituent part of society occupies its proper place; rather, it was a materialist-ideological problem of producing a new social formation altogether (see Dai's essay in the present volume).

\section{End of Politics}

In Mao's 'serve the people' the practice of theory is precisely the realm of politics. That is, it is the realm of the futurity whose glance back towards the present calls into being the necessity for an ethical form of social relations in the here and now. Unlike any Confucian notion of filial service, aimed at transhistorically reproducing social hierarchy, Mao's 'serve the people' names a revolutionary political unity as the historically mandated form of ethical social formation, whose creation will be accomplished through the labour of service and the service of labour. The imperative to serve is thus an injunction to properly pursue class struggle (see Russo's essay in the present volume); yet perhaps more important, it is an imperative to create out of the contingent historical moment marked by the spontaneous potential of the people as a revolutionary subject the possibility for socialism. This revolutionary unity could never be free of conflict-for, as Mao theorised earlier, contradictions would persist into whichever social formation eventually took shape-but it would always be the site of concrete politics aimed at its own realisation through labour as service.

The retreat of Maoism from the social field of substantive ideology and social practice has meant the erasure of the original embedded capacity of 'serve the people' to produce socialist meaning. Thus, today, if and when it is evoked-as in the 2012 ill-fated and much-mocked 'Learn from Lei Feng Day' - the topos of service is entirely instrumentalised and mechanically reproduced as a hierarchical desire for popular obedience. ${ }^{4}$ This is not service in the Maoist sense of producing a new collective lifeworld of socialist equality; this is Party injunction nakedly appropriating resources for their opposite use. 'Serve the people' today can only be communist kitsch or empty Party blandishment. Its life as a socialist text has gone the way of socialism itself: dead, gone, buried. 


\section{1 \\ 社会主义法 \\ Socialist Law}

Susan TREVASKES

ocialist law, both in the Soviet Union and in Mao's China, emerged as a system of legal principles based on the historical realities of socialist revolution. The role of the Communist Party in both nations was to lead over all aspects of the law in order to bring about the realisation of communism. In his Law of the Soviet State, Soviet legal theorist Andrei Vyshinsky theorised Soviet law as a system of norms of conduct based on relations of domination. Soviet law, he stated:

$\ldots$ is the aggregate of the rules of conduct established in the form of legislation by the authority of the toilers and expressive of their will. The effective operation of these rules is guaranteed by the entire coercive force of the socialist state in order to defend, to secure, and to develop relationships and arrangements advantageous and agreeable to the toilers, and completely and finally to annihilate capitalism and its remnants in the economic system, the way of life, and human consciousness-in order to build a communist society. ${ }^{1}$

The theory of socialist law that developed in the People's Republic of China (PRC) borrowed heavily from Vyshinsky's theory of the law and the state. In a Maoera dictionary of jurisprudence, socialist law is defined as the aggregate of rules of conduct enacted and approved by the state, expressing the will of the dominant class, the application of which is guaranteed by the coercive force of the state." Of utmost importance to the theory of socialist law in both China and the Soviet Union, was the prominence given to the normative nature of the law, an emphasis which had its roots in political principles taken directly from the philosophy of Marxism. Legal scholar Phillip Chen notes the following in relation to Vyshinsky's theory of law: 
The 'theory of law' Vyshinsky has in mind is evidently not a theory of positive law. It is a theory which has to produce 'legal principles.' But these legal principles are not the positive law that is to be established on the basis of these principles. If they are to be 'legal' principles, they are legal not in the sense of positive law, but in the sense of norms of an ideal law, the law that ought to be established in a socialist society. It stands to reason that these principles are the ideal norms of a socialist law. ${ }^{3}$

China's socialist legal system developed out of this defining principle: that the Party utilises state law to regulate social relations in order to advance the cause of the dominant class and ultimately for the realisation of communism. As such, law had to be flexible and open to the vicissitudes of socialist development and class struggle, not bound by the strictures of detailed positivist legal statutes. Throughout periods of state bureaucracy and legal system-building (the mid-1950s) and in the age of mass campaigns (from the late 1950s to the late 1970s), socialist law continued to be conceived of as a system of norms of human behaviour based on the relations of domination; that is, the Party dominating on behalf of the people, with the application of the law open to constant change based on the requirements of Party policy. ${ }^{4}$

\section{Socialist Rule of Law from Jiang to Xi}

The concept of a socialist rule of law (shehuizhuyi fazhi) emerged as a defining reform-era ideology after the Mao period. It developed along the same principles as those observed by Chen and Keller above in relation to socialist law: it was conceived as a strategy to realise the broad governance agendas of the Party. The Deng Xiaoping leadership of the 1980s promoted it as a way of differentiating their reformist regime from the chaos of the Party's Mao-era 'rule by man' (renzhi) governance style (see Hurst's essay in the present volume). In the 1990s, Jiang Zemin sought to improve Deng's notion of rule of law by coining a new phrase, 'governing the nation in accordance with the law' (yifa zhiguo). First put forward by Jiang in the mid-1990s, yifa zhiguo refers to the institutionalisation of law-based governance across all areas of the state. It was inserted into the Constitution in 1999 and declared China's governing strategy for reform.

The vagaries of core Party policy priorities, which shift each decade or so as the Party leadership group changes, means that yifa zhiguo contains a level of ambiguity and flexibility that can accommodate different nuances of meaning, apt for political leverage. ${ }^{5}$ The formula was used to promulgate and validate legal reforms through the $\mathrm{Hu}$ Jintao era of the 2000s but it was not the central discursive tool employed to define the Hu leadership's overall agenda of 'Harmonious Society' (hexie shehui). In contrast, yifa zhiguo has come to the ideological foreground in the present Xi era.

Xi Jinping's leadership group has endowed yifa zhiguo with a more compelling Partycentric stance, by giving its Jiang-era focus an ideological upgrade in late 2014. Yifa zhiguo is now an integral part of Xi's ambitious ideological plan for a rejuvenation of Chinese Communist Party (CCP) governance and supervision over the state through law. The new administration's theoretical contribution to socialist legality has been to assert the idea that 'socialist rule of law' and 'Party leadership' (dang de lingdao) are two entirely complementary concepts, and that given this truism the Party must exercise 
its rule through all processes of yifa zhiguo. As is explicated in more detail below, this assertion is important for strategic reasons, as it further embeds the Party into the state through law, in order to maintain the supremacy of Party rule so that the people remain masters of the nation.

\section{Party Leadership as the Core Mechanism of Accountability}

Political discourse frames the parameters of governance in China. In the Xi era, the Party's governance discourse of yifa zhiguo operates conceptually and in practice as a key ideological lever to identify and affirm power relationships for governing the nation. In Xi's new era of socialism, given the corruption epidemic and the Party's response to it, the Chinese leadership claims that the need for virtuous governance-or 'governing the nation through moral virtue' - is even more crucial now than ever before. ${ }^{6}$ Building on Jiang Zemin's original interpretation of yifa zhiguo, the Xi-era claim is that the Party's role should be to focus on monitoring and supervising government employees in a much more comprehensive way than in previous years. Hence, in this thinking, Party leadership itself is the core mechanism of accountability. Given the idea that the government must be accountable to the people through the conduit of Party leadership, the $\mathrm{Xi}$ administration declared in 2017 that an all-encompassing new mechanism for greater accountability is required, and moved to expand the parameters of the authority of Party leadership to incorporate routine supervision and monitoring of the activities of all employees of the state. Among other innovations, the upshot of this political upgrade of yifa zhiguo is the establishment of the National Supervision Commission (NSC), a behemoth supervisory and prosecutorial structure that was piloted in some provinces in 2017. This is supposedly a state- (rather than Party-) based mega anticorruption and national surveillance body that effectively merges state and Party surveillance structures by integrating same-level Party commissions for disciplinary inspection, government corruption prevention agencies, and state prosecution offices. ${ }^{7}$

Broadly speaking, the NSC monitors and inspects all state civil servants across China to ensure that they comply with laws such as the National Civil Service Law and the Criminal Law. In this respect, the Commission has the power to monitor, investigate, and, where necessary, detain any personnel working for any enterprise-including a school or university, cultural, medical or sports institution, or mass organisationthat is effectively operated or owned by the state. ${ }^{8}$ A new State Supervision Law passed in March 2018, gives the NSC a total of 12 main powers. Notably, these include the power to investigate (diaocha) and detain (liuzhi) any China-based government employee (both Party members and those without Party membership) for any workrelated infringement, illegal behaviour, or suspected crime as defined by administrative, civil, or criminal law. Xinhua News Agency boasts that merging state and Party anticorruption apparatuses 'will overcome longstanding rule of law problems in China,' since it will 'improve rule of law thinking and yifa zhiguo methods in the state's capacity to punish corruption.' The NSC will exercise much greater surveillance and supervisory power over the nation's legislature, judiciary, police, and procuratorate than any previous organisation. 
Since the Fourth Plenum in 2014, Xi Jinping has repeatedly declared that for $y$ ifa zhiguo to be effective, the Party must be able to exercise its legitimate leadership over all government activities, including those of the legal and security systems. ${ }^{10}$ Party supervisory power over all functionaries including both Party and non-Party members, concentrated with $\mathrm{Xi}$ at the helm in Beijing, now sits above any claim to supervisory authority or accountability that might be made by military, legal, or security institutions or personal. ${ }^{11}$ We saw the first signs of this bold move in 2015 with the promulgation of the State Security Law, which 'grants a Party authority state powers and allows such powers to be exercised directly by a Party authority - a practice that only existed during the Cultural Revolution in the PRC. ${ }^{\prime 2}$ Further moves were made again in late 2017 with the announcement that amendments to the People's Armed Police (PAP) Law now place the PAP under direct control of the Central Military Commission run by Xi himself.

\section{The Party Leads Over Everything}

The opening paragraph of this essay gives us the necessary clues to understand from whence this ideological rationale for Xi's bold new era of the Party 'leading over everything' is derived: it comes from the Soviet and Mao-era idea that the Party must dominate through a system of norms of conduct based on relations of domination. In refocussing Jiang-era yifa zhiguo to pay much greater ideological attention to Party leadership, Party theorists now claim that Xi's yifa zhiguo is an advancement on both Deng and Jiang's thinking on law. ${ }^{13}$ The historic decision of the Fourth Plenum of the Eighteenth Party Congress in late 2014 contains two key assertions about the Party and the law that are new to the theorising of law in China. The first assertion relevant to this claim is that the authority of the leadership of the Party is entirely compatible with the rule of law. The second is the imperative that 'the authority of the leadership of the Party must be implemented across the entire process of governing the country in accordance with the law.' ${ }^{\prime 4}$

Xi's revised interpretation of yifa zhiguo rests on the assertion that there is a fundamental harmony between three key conceptual elements of power in China: the 'rule of law,' 'Party leadership', and the idea that 'the people are the masters of the nation. ${ }^{\prime 15}$ The rationale thus becomes as follows: it is only through Party representation of their interests that the people of China can claim their place as the rightful masters of the nation. ${ }^{16}$ A so-claimed harmony of interests between the people and the Party legitimates the Party's right to represent the people. Bringing the Party and the people together under the yifa zhiguo umbrella allows Xi to promote the idea that the Party, as the vanguard of the people, must always and forever remain present and supreme throughout the entire process of the law. This includes not only the making of law but also the process of enforcement of the law. ${ }^{17}$ To leave no one in doubt of its ambitions, in late 2017, the phrase 'the Party leads over everything' (dang shi lingdao yiqie) was inserted into the Party's Constitution. ${ }^{18}$

By reworking Jiang Zemin's original interpretation of yifa zhiguo, the Party has codified its leadership of everything. The 'New-style Party Political System' (xinxing dangzheng zhidu) announced in March 2018 rests on two main political truisms: first that 'the Party leads over everything' and second that the Party's main government 
accountability mechanism is in fact the Party leadership itself. The underlying ethos behind this new style of governance is that concentrated power under the core leadership of the Party in Beijing is a more effective accountability mechanism than Westernliberal dispersed power-type arrangements. This is justified by dint of the ideological assertion that the Party that holds this concentrated power is the purist representation of the people. ${ }^{19}$ It is its representational status that makes the Party virtuous and thus most capable of leading: it leads over governance in China because its leaders possess an advanced nature, capable of representing the will of the people.

Among other strategies, the Party aims to achieve its ambition to 'lead over everything' in Xi Jinping's China by 'organically unifying' (youji tongyi) intra-party law with state law-that is, by directly governing the nation through all processes of the law. The Xi administration's ideological focus on 'comprehensively integrating' (yiyuanhua) the Party into the state through law reconstitutes the Chinese governance landscape through a reassertion of, and renewed focus on, the idea of Party-dominated governance over everything, an ideal which was first espoused by communists in Yan'an during the $1930 \mathrm{s.}^{20}$ This integration of Party and state law is, to date, most evident in the supervisory ethos and laws that govern the NSC, particularly those relating to the investigatory powers of officials. ${ }^{21}$ It is also evident in the intention, announced in May 2018, to fully incorporate the Party's 'socialist core values' into all legislation over the next five to ten years, and in so doing, making accountability based on socialist values 'the core' of the legislative system. ${ }^{22}$

\section{New Thinking, Old Roots}

The focus of this essay on Party dominance enables us to discern how Mao-era socialist law and Xi-era yifa zhiguo are from the same ideological family tree: the latter derives its basic precept-that is, the idea of law being a system of norms of conduct based on the relations of domination-from the former. Hence, a consistent legitimising rationale in Xi-era Party propaganda has been the claim that for the Party to exercise leadership effectively, it must both supervise and remain supreme over the institutions that administer the law-that is, it must be above the law-so that it can effectively represent the people. Party supremacy over and via the law is based on the assumption that since it is the people who are the masters of the nation, the Party does not need to build overall structures of law that protect 'the people' from the people's very own manifestation of power: the Party. ${ }^{23}$ On the contrary, the Party's effective supervision of state officials confirms the claim that China is governed by the Party in 'accordance with the law. This does not mean that the Xi leadership has in any way-so the narrative goes-ignored the importance of government accountability. On the contrary, it is seeking to redefine how accountability operates. To this end, to a much greater extent than in previous decades, accountability is now provided through supervision by $\mathrm{Xi}$ Jinping, the Politburo Standing Committee, and the Party-run NSC in a manner that protects the people against individual illicit behaviour within the Party-state at the lower levels. Therefore, Xi Jinping has Mao-era socialist legal ideology to thank for his 'Party leads over everything' ambitions since his yifa zhiguo is indeed a system of norms of conduct based on the relations of domination-Party domination. 



\section{2 \\ 诉苦 \\ Speaking Bitterness}

Jeffrey JAVED

$\mathbf{T}$

o relate abstract ideologies to the lived experiences of ordinary people is the great task of all revolutionaries. How do we then explain the Chinese Communist Party's (CCP) remarkable success in mobilising workers and peasants, many of whom had little interest in Marxism-Leninism, to join its fervent, violent cause? One of the key foundations of the CCP's successful mobilisation was its ability to tap into human emotions, which it did most notably and effectively through a practice known as 'speaking bitterness' (suku) - the public expression of an individual's woes with the intent to cultivate sympathy toward the speaker and outrage against those who caused his or her suffering. ${ }^{1}$ As one of the foremost strategies the CCP used to build the revolutionary subjectivity of the masses, its principal purpose was to leverage morality and emotion to inculcate in the populace new mass identities that accorded with the Party-state's ideology of class struggle. Operating through outrage and sympathy, it sought to build hostility towards an outgroup of class enemies and solidarity among an ingroup of ordinary villagers (see also Dutton's essay in the present volume). By the time of the Chinese Civil War, speaking bitterness had become a mainstay of the Party's repertoire of mobilisation techniques to incite villagers to pursue land reform, a tool for 'soliciting tales of suffering for mobilising the masses.'

\section{Mobilising Outrage and Sympathy through Suffering}

Although speaking bitterness was always a public act, it occurred at many different scales: cadres guided villagers to speak bitterness in both small, face-to-face settings and large mass rallies-e.g. struggle sessions and public sentencings. Early on in the course of land reform mobilisation, work team cadres met with local villagers, often in the homes of the poorest in the village, to discuss their concerns and grievances in 'small groups' (xiaozu) and 'informal chats' (mantanhui) (see also Perry's essay in the present 
volume). These meetings provided safe spaces for poor peasants and farmworkers-and middle peasants - to speak bitterness in focus group-like settings before their fellow villagers. Officials designated those who spoke suffering as 'the aggrieved' (kuzhu) literally, 'masters of bitterness.' Not everyone at these meetings spoke bitterness, but for both the speaker and the listener such affectively charged words 'construct[ed] the old order as oppressive, inherently violent, and immoral by recalling instances of social antagonism between individuals who occupy very different positions within hierarchies of power in Chinese society. ${ }^{3}$ In this way, speaking bitterness unified various strata of peasants - the landless, the land-poor, and even the average landholder-as 'oppressed class subjects.'4

Speaking bitterness, particularly when performed in front of large audiences at struggle sessions, was a highly organised process. Officials cautioned against speaking bitterness 'recklessly', and instructed cadres to use it 'at a proper time and against a proper target. ${ }^{5}$ At struggle sessions, cadres organised the aggrieved to take turns speaking against their alleged oppressors. To heighten the efficacy of their storytelling, cadres coached speakers on their dramatic delivery, and even arranged the lineup of speakers to frontend those who were the best storytellers, had the most pitiful stories, and had the most damning and colourful evidence against their targets. As one eyewitness remarked, speaking bitterness at struggle sessions was 'ordered and methodical' and 'rich in theatricality.'

Speaking bitterness in small groups and informal chats sought to generate ingroup solidarity among 'the masses' (qunzhong) by eliciting villagers' sympathy toward those who were suffering (see also Lee's essay in the present volume). Sympathy is a powerful method for building ingroup solidarity: empathising with another's pain triggers the same affective responses in an individual as if he or she were the recipient of pain. ${ }^{7}$ In The Theory of Moral Sentiments, Adam Smith defines 'sympathy' as a 'fellow-feeling' that 'does not arise so much from the view of the passion, as from that of the situation which excites it ... . [W] hen we put ourselves in his case, that passion arises in our breast from the imagination.' Indeed, it was seeing one's own suffering reflected in the stories told by others that forged this collective bond among villagers. Cadres viewed collective sympathy as a sign of successful speaking bitterness. Township cadres in Fengyang county, Anhui province, reported that speaking bitterness succeeded to the extent that when 'a single person spoke bitterness, everyone sympathised' ( $y i$ ren suku, dajia tongqing). ${ }^{9}$ Elsewhere in Fengyang, a township's small group meeting had 13 people speak about their plight and how they lived on the brink of starvation without land or draft animals. Touting the success of this session, the report notes that 'there were three people at the meeting who "spoke bitterness" until they were in tears. Class consciousness, therefore, greatly increased." ${ }^{10}$

To facilitate the cultivation of sympathy, work teams specifically tried to recruit women and the elderly to speak bitterness at struggle sessions because they believed they could better attract sympathy from the masses. In Liyang county, southern Jiangsu province, cadres, in their collection of speaking bitterness material, discovered that nearly 200 local women had been raped by Japanese soldiers. They used these women's stories to 'educate the broad masses' about the evils of the old feudal order, but, more importantly, to help locals 'understand the roots of their own suffering.' From this, the Southern Jiangsu Regional Party Committee concluded that in the struggle against 
feudal "evil tyrants" ( $e^{\prime} b a$ ) and landlords, women are the most powerful force in sparking the class consciousness of the masses.'11 These sympathetic figures helped create feelings of commiseration that cadres could shape into violent outrage. In a striking example of this, an elderly woman in Baoxi township, Chongming county, cried herself hoarse, prompting others to break down sobbing, after which they subjected the evil tyrant landlord to ferocious struggle. ${ }^{12}$

Inextricably tied to the cultivation of sympathy for the aggrieved was the elicitation of outrage against those who were claimed to have caused their suffering, with the ultimate intent to justify and mobilise violence against them. The link between outrage and violence is well established: outrage is an emotion that 'motivates people to shame and punishes wrongdoers' in response to perceived violations of moral norms. ${ }^{13}$ Importantly, speaking bitterness used individual instances of landlord malfeasance to elicit outrage and establish hostility towards landlords as a group. These individual examples of moral transgression were often deployed in speaking bitterness conducted at struggle sessions, where the theatrical retelling of stories of suffering could most effectively generate outrage and instigate violence. During the public sentencing of evil tyrant and landlord Chen in Huaining county, southwestern Anhui province, an old couple entered the stage, sobbing, to tell the crowd their story of how Chen had beaten their son to death while attempting to settle a debt owed to him, hounded their daughter-in-law to death, and rendered them destitute, causing their newly born grandson to die of starvation. The crowd of over 2,000 people were so enraged by the couple's story that they began to yell: 'Down with the evil tyrant landlord, a blood debt must be repaid in blood.' ${ }^{\prime 4}$

That the Party used speaking bitterness within the People's Liberation Army (PLA) illustrates its utility as a tool of ingroup consolidation for mobilising outrage and violence. Wu Guo's thoughtful and fascinating exploration of the PLA's use of speaking bitterness shows how the Party used it to recruit soldiers, build camaraderie, and forge a violent hatred of internal 'class enemies' as well as the Nationalist foe. ${ }^{15}$ The Speaking Bitterness and Seeking Vengeance (suku fuchou) handbook, published in 1947 by the PLA, contains a collection of 'classic' speaking bitterness materials that the Party used as templates for PLA soldiers. With colourful titles like 'How Vicious Are the Hearts of the Landlords!' (dizhu laocai de xin duo hen ya!), 'When Will Two Generations of Hatred Be Avenged, Setting One's Mind to Eliminating Chiang Kai-shek' (liang dai yuan chou he shibao, lizhi xiaomie Jiang Jieshi), and 'Tell My Bitterness to the Party' (ba wo de ku gaosu gei dang), these stories were designed to conform to generic narratives of suffering that could trigger the righteous indignation of soldiers before battle. Some of these stories of exploitation were even written in verse. ${ }^{16}$ Because speaking bitterness was used to provoke outrage against both the Nationalists and landed elite and strongmen who allied with them, cadres drew on examples of injustice from members of the local community to mobilise soldiers. To an audience of soldiers at the battlefield of the Qingcang Campaign in 1947, an elderly man surnamed Liu spoke of his abuse at the hands of the region's notorious strongman-a 'traitor-evil tyrant' landlord named Gao Hongji-who beat Liu senseless after failing to extort money from him: 'As the soldiers heard this, they became moved, one by one, [until] everyone shouted, "Resolutely avenge Old Man Liu!'” After hearing more stories of how Gao Hongji raped women, ordered the demolition of people's houses, and otherwise oppressed locals, one of the 
army commissars led his troops to yell the slogans 'Avenge the people!' and 'Resolutely exterminate Gao Hongji!', after which the soldiers 'through gritted teeth, avowed to avenge the people.' ${ }^{17}$

\section{The Historical and Cultural Foundations of Speaking Bitterness}

What were the origins of speaking bitterness? Considering the Western roots of the CCP's mobilisation tactics, Frederick Yu remarked that '[the Chinese Communists] appear as such veterans of what seem to be psychiatric and psychoanalytical practices that one could even suspect that they had read Freud and Jung along with Marx and Lenin in their early revolutionary days. But there is no evidence that they did so. ${ }^{18}$ It is more plausible that the Party developed speaking bitterness into a structured technique by drawing upon cultural norms regarding the public expression of suffering and storytelling traditions. ${ }^{19}$ The goal of making its audience sympathise with suffering resembles the neo-Confucian idea that one can cultivate virtue through witnessing and being upset by suffering. As De Bary explains: 'For the neo-Confucians it was the mark of the humane man that he could not endure the sufferings of others, but felt compelled to take action to remedy them. ${ }^{20}$ The use of suffering to elicit sympathy appears to have been widely practiced in various contexts in pre-communist China. In an intriguing anecdote from his memoir of life during the Taiping Rebellion, Zhang Daye writes of how ferryboats often hired 'one-headed women'-childless widows-to wail and tell their stories of suffering to defuse brawls among passengers by making everyone cry or feel deep pity. ${ }^{21}$ Shi Jianqiao, who infamously shot and killed the warlord Sun Chuanfang in public, disseminated pamphlets to onlookers detailing how Sun had murdered her father; the Nationalist media used Shi's tale of filial vengeance to solicit the public's sympathy and successfully pressured the government to acquit her. ${ }^{22}$ These various cultural precedents could possibly explain how the Communists came to see this technique as a legitimate and effective form of political education and why ordinary villagers may have accepted it as a practice.

The structure of speaking bitterness and its attentive focus on public performance appears to be inspired by China's folk operatic tradition. The Party did not simply find those who were aggrieved to serve as accusers, they actively guided them to understand their suffering and trained them to deliver their stories in the most effective way possible. Speaking bitterness, as Anagnost notes, was 'not the spontaneous flow of pentup sorrow but the careful reworking of perception and experience into the narrative frame of Marxist class struggle. ${ }^{23}$ The ways in which cadres coached 'accusers' to speak bitterness resembled acting lessons. In his research on the use of speaking bitterness during land reform in Shandong and Hebei during the Civil War, Li Lifeng observes that speaking bitterness participants received a great deal of instruction on how to deliver their tragic stories: speakers needed to learn how 'to summarise several [of the landlords'] most heinous crimes that could make the masses feel a high degree of hatred and thus a desire to join the struggle. ${ }^{24}$ Cadres treated accusers like actors playing before an audience. A cadre would push an accuser, when delivering his or her stories, to 'wear a sad facial expression' and to 'become an actor who can move the people.' In fact, when the Party introduced speaking bitterness to the PLA during 
the 1947 Speaking Bitterness Campaign, it used an opera-'Wang Keqin's Squad'to demonstrate the technique: at one point in the opera the titular character literally performs speaking bitterness on stage..$^{25}$

\section{The Legacy of Speaking Bitterness after Mao}

Speaking bitterness, as a mobilisation practice, disappeared with the ascendancy of Deng Xiaoping, but the use of suffering to legitimise and justify state repression quickly resurfaced in the campaigns of the early reform era. Though the Party claimed to continue to draw on the experiences of the masses, it now spoke bitterness on their behalf. The Anti-spiritual Pollution Campaign of 1983, aimed at attacking intellectuals who were 'polluting' China with bourgeois liberal ideas, linked degenerate intellectual thought with societal decay-i.e. rising rates of rape, murder, and corruption. The ensuing Strike Hard Campaign of 1983 to 1986 used sensational, morally abhorrent acts, such as sexual crimes and murder, to rally public enthusiasm for a broad crackdown on criminals who were harming society. As Thaxton writes:

In city after city, top CCP and Public Security personnel stoked public indignation toward accused criminals, often issuing calls for quick, violent revenge against the accused .... [P]eople were sentenced and shamed in mass public meetings and alleged wrongdoers were paraded through the streets with derogatory signs around their necks while scores of police cars, sirens screaming, were dispatched to seize 'criminals' reported by 'the masses. ${ }^{26}$

Although speaking bitterness was never a spontaneous grassroots practice, it still succeeded in creating a form of mass politics that vocalised suffering that had long been mute or met with resignation. Today, such places have again fallen silent, as the masses have been moved off the stage of history, relegated to passive spectators of their own suffering.

Under Xi, the anti-corruption drive and the Eliminate Crime and Purge Evil Campaign (saohei chu'e) again resorted to sensationalised accounts of criminal activity to teach the masses the nature of their suffering and to provoke outrage against corrupt officials, drug dealers, and those who threaten social order, and to rally sympathy for the Partystate's harsh repression of them. Instead of the masses, it is the alleged agents of suffering themselves who speak. Even when it is the Party that is responsible for the suffering of the masses, it ventriloquises and individualises guilt through the confessions of fallen cadres. In the resurgence of televised confessions under $\mathrm{Xi}-\mathrm{a}$ more contemporary manifestation of the age-old communist practice of self-criticism-allegedly corrupt cadres enumerate their sins to a national audience who can only applaud or remain silent. ${ }^{27}$ And so the Party continues to speak bitterness-to quote the title of the hit anti-corruption television series-'in the name of the People.' 



\section{3 \\ 糖衣炮弹 \\ Sugarcoated Bullets}

Benjamin KINDLER

$\mathbf{T}$

he political debates of the period 1945-49, although spanning a variety of subjects, were underpinned by the question of how to comprehend the imminent realisation of power by the Chinese Communist Party (CCP) within the larger historical frame of the Chinese Revolution. By 1949, the victory of the Communists was no longer in doubt, and yet Mao and other leaders showed themselves curiously resistant to any premature triumphalism. They were, rather, concerned about how the Party might maintain the élan and heroic commitment of the war period after the beginning of socialist construction.

It was against this historical and theoretical backdrop that Mao developed the concept of 'sugarcoated bullets' (tangyi guozhe de paodan) a formulation that first appeared in his 'Report to the Second Plenary Session of the Seventh Central Committee of the CCP', issued in March 1949. In the conclusion of this speech, in which he argued against an immediate transition to socialism and warned against policies that would endanger the careful coalition and reform strategy that the Party had developed under the name of New Democracy (xin minzhuzhuyi) (see Blecher's essay in the present volume), Mao alluded to the impending change through a series of theatrical metaphors. The revolutionary process up to the present, Mao said, had only been 'a brief prologue to a long drama, of which the climax-the realisation of socialism-lies yet in the future, and would require many years of arduous work. In this frame, Mao warned revolutionaries of the challenges and temptations following the initial seizure of power, that is, the possibility that the Party might succumb to 'love of pleasure and distaste for continued hard living. The bourgeoisie, having failed to defeat the revolution, might resort to flattery and temptation as the means by which to undermine revolutionary morale. They might, in other words, make use of 'sugarcoated bullets' in order to destroy the system of revolutionary morality that had been developed through the struggle of the preceding decades. 
Mao's insistence on the continuation of arduous struggle after the formal seizure of power amounted to a new conception of revolutionary temporality. For Mao, the end of the war against the Nationalists marked the culmination of a process of revolutionary war and state construction in which the Communists had been engaged since the 1920s. Therefore, for him, the task of unifying mainland China under the leadership of a revolutionary government could not be understood solely within the Leninist or Bolshevik temporal framework. For Lenin, cleaving to a pre-Maoist revolutionary temporality, revolution was a concentrated moment, the hour at which history strikes, or that singular moment which must be grasped lest the opportunity for transformation slip. ${ }^{1}$ For Mao, revolution is a moment of rupture within continuity and continuity amidst rupture - a transformation of the strategic terrain in which the nature of both the possibilities and the dangers undergo a marked change from one state to another, but where the conquest of power by no means marks the end of the revolutionary process.

\section{Shifting Terrains of Revolution}

Closely tied to this epochal change was a shift in the geographical terrain of revolution. Over the course of the Chinese Revolution, Mao juxtaposed the urban and the rural as two contending zones of political struggle, noting that the period of 'the city leading the village' (you chengshi lingdao xiangcun) had begun. It was in the cities that the problem of sugarcoated bullets first presented itself, as cities were the locations in which the rhythms of commodity production and consumption had most radically established themselves during the preliberation period. The problem of the city did not refer uniformly to all urban centres across China, but more specifically Shanghai, with which the concept of sugarcoated bullets was always most closely associated. Immediately after Mao's address, the People's Daily borrowed directly from his formulation of the Party entering the cities in order to lay out a vision of 'transforming cities of consumption into cities of production.' ${ }^{2}$ The cities of the past, the authors argued, were cities of consumption because of the unequal and exploitative relationships they enjoyed with the rural periphery, whereby the countryside provided both goods and a supply of cheap labour in order to meet urban needs. As such, socialism would involve the development of heavy industry in Shanghai and elsewhere, so that these cities would cease to play the role of exploitative centres of parasitic consumption or sites where the bourgeoisie would target sugarcoated bullets against the revolution.

Hence, the political history of sugarcoated bullets from the moment of liberation onwards reveals a process of expansion, with Shanghai at the centre of this political imaginary. It began with a set of specific concerns directed against cadres who were entering the city for the first time, coming into contact with forms of consumerist pleasure that had so far been unknown to them in their rural locales. The formulation was also employed in the context of the Three Antis Campaign of 1951, which sought to eliminate problems of corruption amongst cadres. With the progression of the first decade of socialist construction, the formulation of sugarcoated bullets entered into the language of an influential propaganda drive launched in 1959 during the Great Leap Forward, namely the Campaign to Emulate the Good Eighth Company of Nanjing Road, in reference to a People's Liberation Army detachment that had been stationed on 
the main shopping boulevard of Shanghai at the moment of liberation. This company, in the language of the campaign, had succeeded in overcoming the sugarcoated bullets of metropolitan Shanghai by refusing to bow to the temptations offered by the city. The dissemination of the campaign crucially took the form of a series of plays, later adapted into one of the socialist period's most enjoyable films, Sentinels Under Neon Lights (1964).

In his own reporting on the campaign in his capacity as a cultural journalist in Shanghai, Zhang Chunqiao, who would later emerge as a member of the Gang of Four in the Cultural Revolution, extended Mao's language to emphasise the problem of sugarcoated bullets as one of visibility and exposure. Whereas 'enemies with guns' can 'be seen at a moment's glance,' he argued, the 'fragrant breezes' of sugarcoated bullets require a wariness that goes beyond that of the violent battlefield. ${ }^{3}$ Significantly, for Zhang, the heroism of the Eighth Company under peacetime conditions was demonstrated through everyday forms of asceticism and attention to the self rather than singular acts of heroic bravery. He says that 'we must not neglect such "small affairs" as handing over a lost penny, using a wash basin for eight years, and wearing clothes that have been patched up thirty-eight times.' Through these everyday acts, the Campaign sought to impart revolutionary élan among the younger generation as a defence against sugarcoated bullets. The everyday itself emerged as the site at which the revolution was fought through the demand to produce new modes of behaviour, above all amongst the young.

Here too, there was a temporal consciousness, but of a different kind from that posed in Mao's speech. While Mao had directed his warning against seasoned cadres about to enter the city, the problem of sugarcoated bullets in the late 1950s was bound up with the problem of revolutionary succession, which was articulated in terms of the problem of 'revolutionary successors' who would maintain the spirit of the pre-1949 period as the first generation born under the People's Republic (PRC). The problem of how to mould those who had not personally experienced the Civil War into revolutionaries became one of the enduring problems of the Chinese Revolution in ways that resonated with the larger problem of the cultivation of the 'new person' (xin ren) as the appropriate mould of the human for a socialist society. The Maoist envisioning of the new person was in many ways modelled on those virtues that Mao had associated with seasoned revolutionaries prior to the seizure of power-a resistance to material corruption, heroism, and a sense of responsibility to the Party and the collective. The Maoist envisioning of the new person in these terms informed the emergent critique of the Soviet model of socialism from the late 1950s onwards, whereby radical intellectuals, Zhang Chunqiao among them, called into question the Soviet reliance on the technical division of labour, the continued role of commodity production under socialism, and above all the use of material rather than spiritual incentives to regulate labour and productivity. In the 1960s and 1970s, this aspiration to maintain revolutionary succession and resist sugarcoated bullets provided the rationale for the Cultural Revolution, which carried injunctions to avoid material corruption to a yet higher level, as the whole of Chinese society was enjoined to conduct a revolution to the depths of their soul (see Thornton's essay in the present volume). Significantly, the Cultural Revolution would also borrow from Zhang's language of visibility and exposure by emphasising the enemy as he who is not visible to the naked eye or at 
a moment's glance, but must be exposed through a violent moment of revelation in order to overcome the threat of sugarcoated bullets. In much the same terms, the remaking of the self also invokes a language of depth, whereby revolution demands a transformation of the innermost depths of subjectivity. The revolutionary, therefore, is called upon not only to remake their own subjectivity but also to pierce beyond visible surfaces in order to identify failures of revolutionary discipline wherever they may present themselves.

\section{Pleasure and Play under Socialism}

The problem of sugarcoated bullets recurs across this entire period as a way of marking the deleterious effects of material consumption on revolutionary morale. It highlighted the danger of a counterrevolutionary reversal not by armed defeat but by the gradual corruption of revolutionary vigour. As Mao's formulation marked the continuing threats to revolutionary morale after the seizure of power, it seems to leave little room for the utopian optimism normally associated with a revolutionary process. It might be read together with Mao's more philosophical notion of 'contradiction' (maodun) as the ontological status of all being, and the failure of the dialectic to ever truly resolve itself into a stable synthesis, in order to argue that no revolutionary victory is ever truly definitive, and that history always encompasses the possibility of reversals (see the essays by Pang and Rojas in the present volume).

Already in his 1937 essay 'On Contradiction', Mao had declared that 'without contradiction, there is no world.' Perhaps this sense of tragedy is necessary, particularly in a postsocialist era such as our own. At the same time, however, Mao's critique of the corrupting influence of the bourgeoisie contains a hidden utopian imperative that may yet prove useful in future revolutionary projects, which is the demand that socialism also produce new modes of pleasure and happiness, ones which can assist in the process of forming new human beings who are no longer bound to the seductions of the commodity form (see Dai's essay in the present volume). If there is a dimension of Mao's injunction that might be made meaningful in our present context, therefore, it is that a socialist alternative be grasped not only as an amelioration of the pressing crises of gross inequality and environmental catastrophe, but also as a society that will invent modes of enjoyment and pleasure that exceed the banalities of the capitalist present. Taking socialist pleasure seriously also compels us to attend to the liberatory aspects of the history of the PRC that have otherwise been obscured by prevailing discourses of vulgar anti-communism, in which all socialist experiments are characterised as a monotone of grey.

The history of pleasure and play across the socialist period marked an attempt to wrest pleasure away from the atomised limitations of commodity consumption through the formation of new cultural practices that would produce new modes of human collectivity and aesthetic experience. This took place above all in the cultural sphere. Less often appreciated is the fact that these cultural practices were radically popular because they opened the possibility of aesthetic enjoyment to those who had previously been denied a recognised cultural universe, and because they also sought to orientate the aesthetic tastes and spiritual sensitivities of their participants towards a radical vision of a new human being. The cultural activities of the revolution were 
developed over the long process of revolutionary mobilisation from the People's War of the 1930s through the postliberation period. ${ }^{4}$ Over the course of the People's War, when the Party's primary locus was in the countryside, this meant the Party working through existing cultural forms and seeking to meld them with new radical content, most clearly actualised in the traditional peasant dances known as 'rice sprout songs' (yangge). From 1949 onwards, as its cultural activities turned towards the cities, and as the problem of sugarcoated bullets became a key part of the Party's political project, socialist pleasure was prioritised through an emergent infrastructure of factory recreation and a new film system (see also Lam's essay in the present volume). Whereas once workers would have been marginalised within the commodity system of an urban metropolis such as Shanghai, socialism sought to open up a new world of pleasure that would offer a definitive break from the atomised consumerism of the colonial past.

A recovery of the Maoist conception of pleasure and play may draw not only on the institutional history of workplace recreation or the details of these socialist cultural texts themselves, but also in the ways that the question of pleasure became a site of explicit theoretical articulation at some of the most pressing moments of the revolution. The use of 'theory' here should be understood with its full range of connotations and as a recognition of how the Chinese Revolution threw existing categories into contestation and produced its own modes of self-reflexion, rather than being a mechanical repetition of prior socialist experiments. The development of socialist pleasure received explicit theoretical articulation in 1964 through a discussion series held in the Southern Daily titled 'How Should One Live in Order to Be Happy', subsequently published as an edited collection. ${ }^{5}$ This discussion serves as an appropriate bookend to the early socialist period and the present discussion because it recapitulates the positions and experiments of the preceding phase of experimentation, but did so in terms that anticipated the Cultural Revolution.

The editors of the collection argued in their conclusion that the divergent classes of bourgeoisie and proletariat possessed their own distinct 'conceptions of pleasure' (xingfuguan), with the proletariat being endowed with a conception of pleasure that is 'collective' (jiti) and 'spiritual' (jingshen) rather than individualist and material. ${ }^{6}$ This experience of pleasure is explicitly counterpoised to the atomised form embodied in sugarcoated bullets. For these editors, the foremost experience of happiness in a socialist society consisted of nothing less than the practice of 'arduous struggle' (jianku fendou) itself, understood as the transformation of the world through labour and the ongoing overturning of oppressive social relationships. In this conception, revolutionary praxis itself becomes pleasurable, engaged in an ongoing battle against the bourgeois notion of pleasure as material consumption, and envisioning a society in which labour itself would become life's first form of pleasure. It is, perhaps, in the very struggle against sugarcoated bullets as the bourgeois mode of pleasure that socialism also discovers and engenders its own experience of collective pleasure.

\section{Life beyond the Commodity Form}

The formulation of pleasure in these terms provides suggestive connections with other dimensions of the Chinese Revolution, including the glorification of labour (see the essays by Wang Ban and Meyskens in the present volume). There is also much 
that is absent in this theorisation of pleasure, above all the question of sex and sexuality, which fared poorly throughout much of the revolution due to the state reification of heterosexual reproduction. Yet most suggestive and powerful of all is the celebration of insurrection as a site at which a new conception of pleasure might also present itself, and the understanding of insurrection as continuing after the seizure of power. The revolution may not, strictly speaking, be a dinner party, but for the Maoists it can and should be pleasurable in order to befit the name of revolution at all. The pleasurable contents of insurrection, and the insurrectionary contents of pleasure, are most closely in accord with the larger grammar of Mao's thought, which, from its earlier beginnings and through the decades of high Maoism, offers an affirmation of the legitimacy of insurrection, even against the Party-state itself.

The collective euphoria experienced by the Red Guards during the early years of the Cultural Revolution, when they witnessed Mao on the rostrum of Tiananmen Square, can, in these terms, hardly be dismissed as simple evidence of a personality cult, or even as violent revolutionary fanaticism, but must be taken seriously as that collective pleasure of insurrection based on the promise of a better world born through struggle. The intensification of the struggle against sugarcoated bullets during the Cultural Revolution coexisted with a new collective experience of pleasure as insurrection.

More relevant to the present, perhaps, is how the celebration of arduous struggle and insurrection as pleasurable connects with the reappearance of an insurrectionary politics in our own time. From Tahrir Square to the varied articulations of the Occupy Movement, these moments of collective struggle and euphoria may as of yet offer glimpses of a society based on a different and more expansive notion of pleasure than the banality of the present. Just as the heady days of insurrection in revolutionary China sought to strike a blow against the dangers of sugarcoated bullets, so too, in our present moment, as we grasp for a life beyond the commodity form and its atomised forms of pleasure, may we glimpse in our own insurrections the possibility of a different way of living and playing together. 


\section{4 \\ 迷信 \\ Superstition}

John WILLIAMS

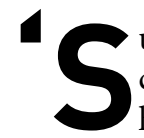

uperstition' (mixin) and 'heterodoxy' (xiejiao) are related concepts in contemporary Chinese political discourse, although the terms' scope has continued to fluctuate from the time of the founding of the Chinese Communist Party (CCP) in the early 1920s through the present. As in the West, the notion of superstition in China emerged from earlier antecedents to assume a central role in the discourse of modernity. Like many other terms associated with modernityincluding xianfa (constitution), kexue (science), and even the term xiandai (modern) itself-mixin (literally 'confused belief') was probably a Japanese loanword, as was 'religion' (zongjiao), another neologism with which superstition has a complicated relationship. ${ }^{1}$ Although the earliest cited usages of mixin appear during the last decades of the Qing, the word was in common use by 1920. By 1930 the eradication of superstition was an essential component of the revolutionary programmes of both the Nationalist Party (guomindang, hereafter GMD) and the CCP.

\section{Imperial Antecedents}

The term from late imperial political usage that provides the clearest discursive antecedent for mixin is xiejiao, literally 'heterodox teaching.' Xie can also be rendered as perverse, evil, or heretical, and thus the state's preferred translation for the heterodox organisations (xiejiao zuzhi) banned today is 'heretical cult.' Legal codes from the Ming Dynasty (1368-1644) established statutes criminalising 'sorcerers and black magic' (xieshu, literally 'heterodox arts') and became the precedent for legislation under the Qing Dynasty (1644-1912), which adopted them verbatim. The codes banned 'fraudulent summoning of evil spirits' (jia jiang xie shen), creation and use of charms, spirit writing, membership in illegal groups like the millenarian Buddhist sect of the White Lotus, and secret meetings of worshippers organised by those who 'feign 
virtuous deeds to incite the people' (yang xiu shanshi, shanhuo renmin). Conducting or organising any of these activities was a capital offense, and adherents were punishable with 100 blows of the heavy bamboo. ${ }^{2}$ Though the word superstition was not yet in use, its core concept is reflected in the discourse of fraudulence that the codes' architects used to frame these crimes. The gods were always false, leaders always charlatans, and believers always deluded. These assumptions remain central to superstition discourse in the People's Republic of China (PRC), though today they are articulated in a way consonant with Marxist theory.

Even before the fall of the Qing, however, superstition in the form of popular religion was targeted by reformers who saw it as antithetical to the construction of a modern state. The first campaign against popular religion was mounted in north China under the auspices of Yuan Shikai, Governor-general of Zhili. Forcible transformation of local temples into schools and other measures curtailed ostensibly malignant forms of religious practice, and reformers also discovered the fiscal advantages to be gained from confiscating real estate and other material resources. Though many of the targeted practices resembled the illicit behaviour labelled as 'xie' in the Qing code, the early campaigns eschewed the terminology of heterodoxy in favour of superstition. This reflected more than semantics, for the discourse of heterodoxy left space for many popular religious practices that, however unseemly from the point of view of Confucian orthodoxy, remained acceptable, or least legal. Superstition, by contrast, encompassed virtually all forms of religion, popular or otherwise, and pointed to a fundamental distinction between the scientific and modern on the one hand, and the primitive and irrational on the other. As a pejorative, superstition was less sinister than heterodoxy and, for the time being, had fewer criminal implications; but its use signified a fundamental epistemological shift in the thinking of early twentieth-century political elites. Discursively, superstition was a far more categorical and absolutist term than heterodoxy, and its deployment signalled the unprecedented and eventually permanent intrusion of the state into local society. ${ }^{3}$

\section{Superstition in the Republican Era}

As the discourse of superstition came into wide use in the first decade of the Republic, intellectuals, revolutionaries, and state-builders used it to attack elements of traditional belief systems seen to impede the modernisation of the state, in particular those linked to popular religion and the mantic arts. New Culture Movement (xin wenhua yundong) intellectuals made superstition a main target. For example, Chen Duxiu wrote in 1918 that standing at the crossroads of modernity, China had to choose between the 'path of light that leads toward republicanism, science, and atheism, or the less attractive 'path of darkness leading toward autocracy, superstition, and theism.' ${ }^{4}$ Though socialism would soon replace republicanism in Chen's hierarchy of values, science and atheism remained indispensable components-and superstition was the enemy of both.

By the end of the 1920s, positive scientism had become the dominant epistemological paradigm of revolutionaries and intellectuals, and the legitimacy of any new political order depended on its ability to mobilise the cognitive and moral truth claims of scientific modernity in service of nation-building. In this context, superstition's modern associations with backwardness, irrationality, and political ignorance combined with 
traditional connotations of crime and disorder to make it a fundamental oppositional category against which the modern Chinese state-and in particular the then newlyfounded CCP-defined itself. ${ }^{5}$

Superstition was also a distinctly political problem for GMD and CCP cadres in the 1920s. In the north China countryside, loosely organised, religiously inspired rural militias had arisen in response to the depredations of militarist forces, demonstrating an ability to coalesce into ever larger confederations-as happened in 1926 when an uprising in northern Henan threatened the control of militarist Wu Peifu. The CCP's mobilisation efforts in rural north China depended on the cooperation or tolerance of these groups, called 'spear societies' (qianghui) after the long pikes with red tassels that were their trademark weapon. Though in communist iconography the tasselled spear came to symbolise rural uprisings in general, their actual use reflected the poverty of the poorly armed militias, who made up for lack of firepower with rituals believed to grant invulnerability from the bullets of more heavily armed warlord troops. These ranged from spirit possessions to the ingestion of written charms, taught by itinerant and often charismatic martial arts masters. ${ }^{6}$ Heterodoxy, in other words, had outlived the imperial state and now posed a distinct challenge for those vying to succeed it. Indeed, Republican news media continued to describe such movements in just these terms. For instance, one article in Beijing's Morning Post (chenbao)-one of the most widely read Chinese language newspapers of that time-called the invulnerability rituals 'heterodox arts' (xieshu), while another decried the 'heterodox language' militia leaders used to dupe ignorant commoners. ${ }^{7}$

Though all agreed the militias represented a 'stubborn and chronic superstition' (wanjiu mixin) that was, in the words of Chen Duxiu, part of the intrinsic nature of primeval rebellion among a backward peasantry, opinions varied on whether and how to mobilise them. ${ }^{8}$ Ultimately, the CCP issued a resolution at its July 1926 Plenum recognising that the infiltration of rural society might require cadres to 'go along with the superstitions of the masses in order to further develop our work.'

\section{Mao's Early Views on Superstition}

It was in this context that Mao equated superstition and popular religion in his 1927 'Report on an Investigation of the Peasant Movement in Hunan.' In it, he posited four meshed systems of authority that oppressed Chinese society and thus needed to be overthrown: the state, the clan, religion, and patriarchy. Elites exercised religious authority (shenquan) via the system of ghosts and spirits (guishen xitong), the panoply of popular deities spanning the overlapping pantheons of Buddhism, Daoism, and local popular religion. Mao reported that nascent peasant associations had appropriated local temples for offices and income, terming the seizures 'public revenue from superstition' (mixin gongkuan); Liling county was particularly notable for the popularity of iconsmashing and proscriptions on superstition (jin mixin). Mao's analysis operated in a materialist-functionalist frame: it was not so much that peasants were liberating their minds from irrational religious beliefs-although their political awakening certainly implied that too-but rather seizing the means of religious cultural production (and thus the income it produced) from local elites who used it to maintain the class system. 
It was in keeping with Mao's theme of rural awakening that the peasant associations became the architects of these campaigns, but the modus operandi he described and the discursive frame he employed actually resembled the Nationalist government's campaigns against superstition in the lower Yangzi delta in 1928 and 1929. The latter also sought to seize revenue streams - in this case to aid the fiscal consolidation of the Nanjing regime-but the agency lay with the Nationalist government, whose modernising reformers held that peasants must be shown the way to demolish the religious authority that obstructed progress, since a 'religious society' was incompatible with a 'new society based on the Three People's Principles.'10

Contemporaneous with the anti-superstition campaigns, the GMD suppressed the Red Spears and similar groups with varying degrees of success. Spear societies became active again during the War of Resistance against Japan, along with other popular salvific movements like the Way of Pervading Unity (yiguandao). All were outlawed with the establishment of the PRC in 1949. Though superstition in all its guises remained anathema to the Party-state, the mode and target of discussion (and suppression) shifted over the course of the Maoist and reform eras.

\section{The Fight against Superstition in Maoist China}

Anti-superstition efforts in the early PRC employed activist cadres and mass campaigns to limit or eradicate local religious practices. Combat Superstition Teams dispatched to the village in the 1950s represented the first wave. ${ }^{11}$ Their targets most often were local religious customs associated with annual festivals and rites of passage. Theoretically, this brand of superstition represented the persistence of a false consciousness that stymied political awareness in the countryside. As a vestige of the sociocultural structures underlying class exploitation in the old society, such customs remained a threat to the new one. More concretely, they represented an economic drain on local society-a misallocation of resources badly needed for industrial development and poverty alleviation, which was a view that had much in common with the classic Confucian and Mohist critique of extravagant funerals.

In the aftermath of the Great Leap Forward and accompanying famine, media reports of 'superstitious rumours' proliferated. In 1962, for example, talking toads in Jilin were said to prophesy widespread death among the elderly; in 1963, tales of chinless ghosts roaming the streets of Shanghai allegedly kept nervous textile workers from leaving the mill at night. These disturbing phenomena, along with the apparently limited success of earlier anti-superstition efforts, contributed to the inclusion of 'feudal superstition' (fengjian mixin) in the list of corrupt practices targeted by the Socialist Education Movement. ${ }^{12}$

The height of the Cultural Revolution brought widespread attacks on all forms of religious practice. Superstition was, of course, a central characteristic of the Four Olds (si jiu)_customs, culture, habits, and ideas-first enunciated in Chen Boda's 1966 People's Daily editorial 'Sweep Away All Monsters and Demons' (hengsao yiqie niugui sheshen). ${ }^{13}$ The 'monsters and demons' of Chen's title, in fact, derived from traditional Buddhist demonology, and the rhetorical potency of the metaphor itself demonstrated 
the ways in which superstition remained the Party's cultural bogeyman. This is perhaps nowhere more apparent than the designation of Mao's personality cult as a 'modern superstition' in the early reform era. ${ }^{14}$

\section{Superstitious Revivals in the Reform Era}

The reform era transformed superstition discourse in a number of ways. The loosening of control over religious and economic life permitted the revival of folk religious customs while increasing opportunities for charlatanism. In the early 1980s, the state recognised three broad categories of superstition. 'Religious superstition' (zongjiao mixin) referred to all forms of religious belief, in particular those of the universal organised religions practiced in China: Buddhism, Islam, and Christianity. 'Common superstitions' (yiban mixin) were those conducted at the individual or household level, such as ancestor worship or the eudaemonic practices associated with holidays and festivals. 'Feudal superstitions' (fengjian mixin), on the other hand, were those related to traditional mantic practices such as divination, geomancy, exorcism, and healing, or unauthorised forms of communal popular religion that were often distinguished by charismatic leadership and seen as threatening to social order. ${ }^{15}$ This formula retained an overall theoretical consistency with earlier understandings, while essentially narrowing the range of activities to be actively suppressed as feudal superstition to those covered under the late imperial rubric of heterodoxy.

Current PRC criminal law reflects this shift. The three times superstition appears in the criminal code, it is accompanied by the term 'heterodoxy'. These all occur in Article 300, one of 27 provisions in the section on 'Crimes of Disrupting Public Order' (raoluan gonggong zhixu zui). Article 300 prohibits the organisation and utilisation of 'superstitious sects, secret societies, and heterodox organisations', but distinguishes between acts that 'sabotage the implementation of the state's laws, that result in death; or that defraud money, property or result in sex crimes.' The first two instances are punishable by up to life in prison, while sexual exploitation through the use of superstition is punished according to the article on rape (Article 236, qiangjian zui), and the illegal procurement of property or funds is prosecuted according to the article on fraud (Article 266, zhapian zui).

Expanding upon these laws, on 30 October 1999 the Standing Committee of the National People's Congress adopted a 'Resolution on the Suppression of Heterodox Organisations, and the Prevention and Punishment of Heterodox Activities' in order to facilitate the suppression of the increasingly popular spiritual movement Falun Gong, whose rapid growth the state found threatening. ${ }^{16}$ This resolution resembled the late imperial legal codes in terminology and approach. The measure also emphasised the distinction between organisers and adherents, ordering that the former be prosecuted harshly. Followers, on the other hand, were assumed to be unwitting dupes and thus should be 'differentiated from the criminal elements' leading heterodox organisations or activities. Article 300's distinction between activities that threaten the state and those that materially defraud its citizens, moreover, is analogous to that made in the two substatutes appended to the law on heterodoxy in the Ming and Qing codes. 
Nevertheless, the resolution was thoroughly couched in the discourse of socialist modernity, and reflected social and cultural dynamics unique to late twentieth-century China. It ordered 'all corners of society' to mobilise against the illegal sects in a manner reminiscent of the mass campaigns of the Maoist era (see Li's essay in the present volume). It also emphasised ideological work, stipulating a long-term educational and propaganda effort to raise awareness about illegal cults while at the same time promoting scientific and technological literacy. One result was the Campaign to Revere Science, Leave Heterodoxy Behind (chongshang kexue, yuanli xiejiao yundong). As a 2005 reader issued by the Shanxi provincial anti-heterodoxy association explained, even though Falun Gong had been soundly defeated, 'various heterodox cults acting in the name of false religion have reappeared in certain parts of the country, particularly the countryside. ${ }^{17}$

The reader laid out ten major differences between proper religion and heterodox cults, ranging from millenarian theory to supernatural belief to social function. Not surprisingly, these differences establish xiejiao as a negative category of religion: everything that religion does, xiejiao perverts. More remarkable is the construction of religion as a positive category in which the word superstition does not appear once. Though the tract concedes that there are negative aspects that require correct government policy to control, orthodox religion in general serves a positive social function by promoting social order and harmony in interpersonal relationships, and by 'upholding the leadership of the CCP and the socialist system.' It serves as a 'spiritual support and expression of the people's respect and reverence of supernatural forces'in wholesome contrast to the fraudulence of heterodox teachings. ${ }^{18}$

The absence of superstition in this discussion reflects the ironic truth that there is currently more tolerance for popular religious belief and practice than an an other time in the history of the PRC. Returning to the formula of the early reform era cited above, 'common superstition' is often criticised in the media but is no longer recognised - at least publicly-as false consciousness signifying the reemergence of the class system or a threat to New China. 'Religious superstition' is not only tolerated but, if the Shanxi tract is any indication, openly endorsed as beneficial to social and political order. 'Feudal superstition,' a category whose definition had already narrowed substantially in the early 1980s, is now largely limited to the illegal religious organisations that the late imperial and modern Chinese states have endeavoured, with varied success, to eradicate. 


\section{5 \\ 超越 \\ Surpass}

William A. CALLAHAN

W

here is China going? How will it influence world politics in the twentyfirst century? Such questions currently vex commentators not only in the West, but within the People's Republic of China (PRC) as well. ${ }^{1}$ In his first month as China's leader in 2012, Xi Jinping addressed this concern when he proposed the 'China Dream' (zhongguo meng) as his vision of the PRC's future direction. Such discussion of directions and dreams is actually part of a broad and ongoing debate about the 'moral crisis' that China faces after four decades of economic reform and opening up. Public intellectuals from across the political spectrum, thus, are engaged in 'patriotic worrying' (youhuan yishi), where they feel that it is their job to ponder the fate of the nation, and to find the 'correct formula' to solve China's problems. ${ }^{2}$

Curiously, in this broad discussion, the concept of 'surpass' (chaoyue or chaoguo, also translated as 'overtake') keeps appearing to inform the 'correct formula' for saving China. Such surpass-speak characteristically invokes a quotation from Mao Zedong's 1956 speech on 'Strengthen Party Unity and Carry Forward Party Traditions:'

Given 50 or 60 years, we certainly ought to surpass the United States. This is an obligation ... . [I]f after working at it for 50 or 60 years you are still unable to overtake [ganguo] the United States, what a sorry figure you will cut! You should be read off the face of the earth. Therefore, to surpass the United States is not only possible, but absolutely necessary and obligatory. If we don't, the Chinese nation will be letting the nations of the world down and we will not be making much of a contribution to humanity. 
This essay will do two things. It will conduct a textual analysis of this quotation, first to locate it in its original context, and then to examine how it has been rejuvenated as a guide for the future. It will argue that surpass-speak is part of what can be called a 'nostalgic futurology' that looks back to key events, like the Great Leap Forward, in order to look ahead to Chinese success in the twenty-first century.

\section{Mao's Strategy to Surpass America}

To imagine China's future, Mao employs a quantitative strategy measured by material metrics, as opposed to a qualitative strategy that invokes normative ideas. Earlier in the Speech, Mao stated that 'a country like ours may and ought to be described as "great." Our Party is a great Party, our people a great people, our revolution a great revolution, and our construction is great, too.' 'Greatness' (weida) here is not measured in terms of the normative measures of cultural achievement, economic equality or social justice, but in terms of the material metric of steel tonnage. 'Great,' thus, is the quantitative measure of 'big' (see also Tomba's essay in the present volume). Big-ness is not absolute, but relative, and for Mao, relative to the United States:

The United States has a population of only 170 million, and as we have a population several times larger, are similarly rich in resources and are favoured with more or less the same kind of climate, it is possible for us to catch up with the United States. What are your 600 million people doing? Dozing? Which is right, dozing or working? If working is the answer, why can't you with your 600 million people produce 200 or 300 million tons of steel when they with their population of 170 million can produce 100 million tons?

Surpassing the United States is not simply a national goal for China, but is seen as the PRC's responsibility to the world. Otherwise, as we saw above, Mao feels that China would be letting the world down, and therefore would not deserve any respect.

This was the first time that Mao spoke of his goal of surpassing the United States. The speech 'Strengthen Party Unity and Carry Forward Party Traditions' was delivered at a preparatory meeting for the Communist Party (CCP)'s Eighth Party Congress that was held in September 1956. At that time, Mao was fighting against Zhou Enlai and others who wanted to consolidate the economic and social gains of land reform and move forward with the nationalisation of industry. They criticised Mao's more radical economic ideas as a 'rash advance' (maojin) that was 'proceeding too rapidly without due consideration of actual circumstances and likely consequences.'3 Mao's 1956 Speech was, thus, an early expression of his push for what would later be called the Great Leap Forward (1958-62).

Drawing on Khrushchev's 1957 prediction that the Soviet Union would surpass the United States in 15 years, 'surpass Britain and catch up to America' (chao ying gan $\mathrm{mei}$ ) became Mao's key slogan for the Great Leap Forward. According to Bo Yibo, 'the stated goal of the Great Leap Forward movement was to overtake Britain in iron and steel production within just two years, overtake the Soviet Union within four years, 
and overtake the United States within ten years. ${ }^{3}$ As we can see, Mao became more ambitious as the movement developed. ${ }^{5}$ But as is well-known, this ambition eventually led to humanity's greatest famine, killing more than 30 million people. ${ }^{6}$

\section{Public Intellectuals Revive 'Surpass America'}

Why then would this passage about surpassing America, which exemplifies the key ideas of the disastrous Great Leap Forward, continue to be popular? Actually, according to CNKI-China's largest academic database-Mao's 1956 'Strengthen Party Unity' speech was not regularly cited in the 1970s, 1980s, or 1990s. It regained currency in the 2000s as a way of explaining China's dramatic economic expansion, in the context of predictions that the gross domestic product (GDP) of the PRC would soon surpass that of the United States. In the past decade, Chinese confidence has grown, with Chinese futurologists no longer just speaking of the 'rise of China', but also of the impending 'fall of the West.' For many, Mao's dream of a strong China that could beat America was coming true, and even according to his 1956 timetable of ' 50 or 60 years'-i.e. between 2006-16. ${ }^{7}$

For instance, military intellectual Colonel Liu Mingfu, development economist $\mathrm{Hu}$ Angang, and political scientist Zhang Weiwei each come from very different institutional backgrounds and pursue quite divergent approaches to China's future. But they all appeal to Mao's surpass-speak to make similar arguments about China's unstoppable rise. For Colonel Liu, China is in an era of strategic opportunity, where it is incumbent to seize the day to become the 'world's No. 1' superpower (shijie diyi). To describe why Mao is the top ideologist of 'world No. 1-ism,' Liu conducts a close textual analysis of the surpass quote from Mao's 1956 Speech. Mao is heroic for Liu because he dared to craft a grand plan to surpass America, stating again that beating the United States would be China's great contribution to humanity. Liu is fascinated by the Great Leap Forward, seeing the outrageous ambition of this Maoist mass movement as the key to China's success in the twenty-first century. He admits that the Great Leap Forward 'suffered defeat', and that 'a large population met an irregular death', but concludes that 'the "Great Leap Forward" is the roadmap for surpassing Britain and catching up to the United States' in the twenty-first century because it shows that in order to create a new path one has to destroy old rules. ${ }^{8}$ Liu thus understands Deng Xiaoping's post-Maoist reform and opening policy as a continuation of Mao's Great Leap Forward plan. China's current and future success, here, is the upshot of Mao's ambitious aspirations from the Great Leap Forward era. Colonel Liu's ideas and arguments are important because his China dream of the PRC as a strong military power has been largely adopted by Xi Jinping.

$\mathrm{Hu}$ Angang also quotes the 'Strengthen Party Unity' speech at length to argue that Mao and the Speech are important because they created 'the strategic concept of catching up to, and then surpassing the United States.9 He elaborates on Mao's materialist quantitative way of measuring power and status, quoting him to explain that because of its large territory, large population, and superior socialist system, China is the only country in the world that is capable of catching up to and surpassing the United States. ${ }^{10}$ Like with Liu Mingfu, Mao is important for Hu because he dared to dream of China as the 'world's No. 1' power. ${ }^{11}$ Hu's understanding of China's future direction is important 
because he is a very influential public intellectual. He leads Tsinghua University's China National Conditions Research Centre, which writes important reports for the Chinese government and consults for the PRC's Five-year Plans.

In asides and footnotes, $\mathrm{Hu}$ actually acknowledges the problems with Mao's 'leapforward' economic policy, and is quite critical of the negative economic impact of the Great Leap Forward: 'By 1965, GDP was 41 percent less than it would have been had the Great Leap Forward not taken place.' ${ }^{12}$ Former World Bank Chief Economist Justin Yifu Lin explains that Mao's 'leap-forward strategy' did not lead to sustainable economic growth because its capital-intensive development model defied the country's comparative advantage of abundant cheap labour. ${ }^{13}$ Since Mao's political campaigns to develop heavy industry-i.e. steel production-actually retarded China's economic growth, Mao's grand political goal of surpassing the United States could only be achieved by discarding Mao's economic policies. Like most economists, Lin contrasts the problematic first three decades of the Maoist planned economy with the successful three decades of Deng Xiaoping's reform and opening policy. Hu, on the other hand, follows China's New Left to rehabilitate the Maoist period, arguing that 'China's pre1978 social and economic development cannot be underestimated.' ${ }^{\prime 4}$

\section{Back to the Future}

It certainly is odd to imagine China's future in terms of the audacious aspirations and disastrous results of the Great Leap Forward and the Cultural Revolution. But this is not simply a historical lesson-Mao's 'great leap strategy' is back in vogue. China's recent 'great leap forward mentality' can be seen in the leadership's demands for rapid and glorious achievements, such as the PRC's high-speed train network, a domesticallybuilt aircraft carrier, and a Chinese space station. This rush to greatness, critics argue, has led to a rash of accidents, including a major train accident in 2011, as well as to broader social and environmental problems (see Lora-Wainwright's essay in the present volume). ${ }^{15} \mathrm{Hu}$, however, is unconvinced, reasoning that Mao's 1956 'Strengthen Party Unity' quotation is actually the origin of the economic reform plans unveiled by Deng Xiaoping in 1979. Hu thus concludes: 'It now seems that Mao Zedong's grand strategy for China is on the verge of being realised. China overtaking the United States in terms of GDP, regardless of how it is calculated, is inevitable. ${ }^{16}$

While Colonel Liu focuses on military power, and $\mathrm{Hu}$ focuses on economic power, Zhang Weiwei emphasises political power. His main goal is to show that China's political system is better than the (Western) democratic system. To do this, he cites many Western sources to 'prove' that China will soon surpass the United States economically, politically, and culturally-and even argues that his native Shanghai is already better than New York. In a section called 'To the Top' of The China Wave, Zhang reviews British economist Angus Maddison's predictions of the PRC's surpassing the United States by 2015, before noting: 'This reminds many Chinese of a famous observation made by Chairman Mao in 1956.' Zhang then reproduces the surpass quotation in full, to conclude that 'Maddison's prediction seems to tally well with Mao's forecast back in 1956. ${ }^{17}$ After citing predictions from PricewaterhouseCoopers and Goldman Sachs that China soon will overtake the United States, Zhang concludes the chapter by stating that 'like it or not, China has risen, or to say the least China is now being held by many 
as the "No. 2" in the world economy. Taking a longer-term view, China will eventually be "No. 1" in the future. ${ }^{18}$ Once again, Mao's 1956 surpass-speak is applied alongside current economic analysis to explain how the PRC is destined to become the world's top power. Once again, the huge differences between Mao's method of analysis and those of Maddison, PricewaterhouseCoopers, or Goldman Sachs are effaced simply because they come to similar conclusions. In a later book, China Surpasses: The Glory and Dream of a 'Civilization-State,' Zhang combines Mao's 'surpass America' trope with Xi Jinping's China Dream to argue that China has already overtaken 'the West and the Western model,' and will soon be at the top of the world. ${ }^{19}$ Zhang is important because his books sell millions of copies in China, are assigned readings for CCP study sessions in Shanghai, and were reportedly read by Xi Jinping in the summer of 2012, just before he became China's leader. ${ }^{20}$

\section{Misreadings}

Certainly, it is not strange for China's public intellectuals to think about how the PRC could be a great power, while looking to previous predictions of when China would be the world's No. 1 power. What is remarkable, however, is the 'correct formula' China's patriotic worriers invoke to guide their national and global aspirations: they all choose a reference to the Great Leap Forward, which employed such a different path from the reforms that facilitated China's rejoining the world in 1978. In fact, employing Mao's surpass-speak does not make sense in the twenty-first century because it embodies two serious misreadings: a) rather than being an example of causation (i.e. Mao's Great Leap Forward idea led to China's current economic success), it is actually an example of correlation (Mao's prediction of success in 50-60 years came true in spite of his tragic policies that retarded China's economic growth); and b) Mao's notion of national power measured in terms of steel production does not make sense in the context of the current global political-economy, which is characterised by transnational production chains in a knowledge-based innovation economy. Indeed, China's massive production of steel is now not seen as a strength, but is taken as a sign of the weakness of domestic overcapacity that has to be exported through state-subsidised projects like the Belt and Road Initiative. ${ }^{21}$

The attraction of Mao's surpass-speak, thus, is not economic, but political. Liu, Hu, and Zhang all stress the ideological and conceptual value of the 'Strengthen Party Unity' speech. For the New Left, this is part of a campaign to rehabilitate Mao, the Great Leap Forward, and the Cultural Revolution in order to confirm the continued relevance of socialism and the CCP in China. In many ways, it is an example of nostalgia for the imagined equality and order of the Maoist period, which is figured as the antidote for China's current money-worship society. Mao's 1956 Speech continues to strike a chord because it was memorised by a whole generation of Chinese who grew up during the Cultural Revolution. Its currency also benefitted from the rise of Maoist websites like Utopia in the 2000s, which further publicised such radical thought. Thus, surpassspeak is a key example of what could be called China's 'nostalgic futurology'. 

TENG Wei

(Translated by Craig A. SMITH)

7 he revolutionary origins of the term 'third world' (di san shijie) in China are now buried under a litany of developmental discourse. After all, as Deng Xiaoping famously said: 'Development is the only hard truth' (fazhan shi ying daoli)-everything else is fanciful utopianism. In China in the twenty-first century, belonging to the third world is not a source of pride and revolutionary potential as it was in the Mao era, but a stigmatised and shameful mark of backwardness. The changing connotation of the concept-from the starting point for revolution to the beginning of a technocratic development path-registers a profound sense of the abandonment of China’s revolutionary potential.

\section{Mao's Theory of Three Worlds}

The fluidity of the concept of the third world has posed conceptual conundrums. These questions were further refracted through the perspective of those asking them. Did China belong to the third world, the Soviet bloc, or was it something else entirely? Early on, Mao wavered on this question, and even into the early 1960s had not yet formalised a theoretical answer to the problem.

In this period, Mao experimented with different ideas such as an 'extremely expansive ... intermediate zone' (zhongjian didai) between the United States and the Soviet Union. This shifting zone included a 'great many capitalist, colonised, and semicolonised countries in the three continents of Europe, Asia, and Africa.' He also detected contradictions among imperialist powers, and between imperialist nations and oppressed nations. As Mao's thinking developed over time, these different formulations and experimental lines of thought developed into the Theory of Three Worlds (san ge shijie de lilun). 
In the early 1970s, the concept of the third world became a regular part of CCP discourse and self-identity. In November 1971, Zhou Enlai described China by saying: 'We are also very poor and very backwards. As a developing nation, we are a part of the third world.' Also, in the same month, at the 26th Session of the General Assembly of the United Nations, China regained its seat in the assembly. In his first speech as the leader of the Chinese delegation to the United Nations, Qiao Guanhua stated: 'Just as the vast majority of Asian, African, and Latin American nations, China is a third world country.' In January 1974, the People's Daily published the Xinhua News Agency's authoritative interpretation of the third world:

The third world is the new power progressively forming after World War II. The countries of the third world suffered under the oppression of imperialism and colonialism for extended periods of time, and still face the aggression, bullying, and intimidation of the superpowers today. Economically, these countries are all developing countries. The vast majority of Asian, African, and Latin American countries are in the third world. ${ }^{3}$

This was followed by the unequivocal statement:

Socialist China is part of the third world. China is also a developing country and shares a common [fate] with the countries and peoples of the third world, facing a common enemy and a common struggle. With mutual sympathy and mutual support, they unite to advance in the struggle to oppose imperialism, oppose colonialism, and oppose hegemony.

However, the CCP had yet to formulate an integrated understanding of the divisions that defined the three worlds.

The Theory of Three Worlds was formally announced on 22 February 1974. In a meeting with Zambian president Kenneth Kaunda, Mao Zedong explained:

I see the United States and the Soviet Union as the first world .... The United States and the Soviet Union have many nuclear bombs and are both quite wealthy. The second world, including Europe, Japan, Australia, and Canada, have fewer nuclear bombs and are not as wealthy, but remain wealthier than the third world. We are the third world, and the population of the third world is very large. Apart from Japan, all of Asia is in the third world. The entirety of Africa is in the third world, and so too is Latin America. ${ }^{4}$

Three days later, Mao also said to the leader of Algeria: 'China is part of the third world. Due to politics, economics, and various other aspects, China cannot be compared to the rich and powerful nations, but must be grouped among the relatively poor countries.'5

However, Mao Zedong did not expand upon this issue with a detailed analysis. Rather, on 10 April 1974, with Mao's approval, Deng Xiaoping related the Theory of Three Worlds in an address to the Sixth Special Session of the UN General Assembly. He spoke in a formal language to clearly and succinctly express Mao's theory: 


\begin{abstract}
Regarding the transformation of international relations, there are three sides or three mutually integrated and mutually contradicting worlds existing under the real conditions in today's world. The United States and the Soviet Union are the first world. Asian, African, and Latin American developing countries, as well as the developing countries of other regions, make up the third world. The developed countries that lie between these two comprise the second world. ${ }^{6}$
\end{abstract}

As a representative of the Chinese government, Deng continued: 'China is a socialist country and a developing country, and therefore is a part of the third world. China is not nor ever will be a superpower' This principled refusal to become a superpower did not mean that China did not desire nor reflect on power; quite the contrary, its aim was to fight alongside oppressed nations and bring about a new way of conducting international relations and thinking about one's place in the world.

\title{
Cold War Politics
}

In the Cold War system that took shape following World War II, the competition for supremacy between the United States and the Soviet Union delivered the world into a precarious situation. In order to gain a peaceful and safer environment, the newlyestablished People's Republic of China (PRC) endeavoured to unite those outside of the spheres led by the United States and the Soviet Union. Postwar leaders such as de Gaulle and Tito were also searching for roads to development that could transcend Cold War thinking and maintain independence. Historical events such as the 1955 Bandung Conference, the 1961 Conference of Non-aligned Countries, and the 1964 establishment of the Group of 77, all pointed to the efforts of a growing number of nations to engage in new forms of united and peaceful development.

Furthermore, beginning in the 1960s, the divisions and discord between the PRC and the Soviet Union grew deeper by the day. A series of activities by the Soviet Union, including the deployment of troops to Czechoslovakia, the Sino-Soviet border conflict at Zhenbao island, and the amassing of millions of troops along China's border, all prompted Mao to increasingly consider the Soviet Union as a social-imperialist state. In order to check and balance the Soviet threat, China began to contact, engage in negotiation, and finally establish official relations with its ideological enemies-the governments of the 'counterrevolutionary' United States, West Germany, and Japan, as well as the non-socialist or even anti-communist countries of Asia, Africa, and Latin America.

Naturally, Mao's introduction of the Three Worlds Theory in this complicated and fluctuating historical context was informed by the diplomatic survivalist strategy of 'making friends with distant states and attacking those close by' (yuanjiao jingong). However, as a plan born of necessity, this strategy in no way implied that Mao was willing to renounce his revolutionary perspective. On the contrary, to act according to the real situation, to act from practical experience, and to be flexible in distinguishing the enemy, ourselves, and friends according to the time and place, were all in complete accordance with the theories he expressed in his essays 'On Practice' and 'On Contradiction' (see the essays by Aminda Smith and Rojas in the present volume). 
Although Mao never published an article specifically dealing with the Three Worlds Theory, his judgement of the world situation and China's position in it clearly emerged from his discourse and practice. First, he based his division of the three worlds upon military and economic strength. Second, this division transcended ideology and Cold War mentality, placing both the United States and the Soviet Union in the same world. Third, by situating socialist China in the third world, he indicated his willingness to occupy the same camp as Asian, African, and Latin American countries, bridging differences and establishing an extensive united front to oppose the hegemonic rule of imperialism and colonialism.

Although Mao's Three Worlds Theory divided the world into three, it was by no means a hierarchical structure. The first world was not superior to the third world, just more powerful militarily and more developed economically. From this position of strength, it dominated the weak, attempted to rule the world imperialistically, and threatened to undermine world peace with its war bases. It was, therefore, an unjust and immoral world. In his words:

We are the third world! I support the countries of the third world engaging in mutual support. The people of the third world must unite. Just as humans fear mosquitoes, so too shall the powerful nations fear the small nations. ${ }^{7}$

It is clear that Mao did not consider the three worlds to be a standard diplomatic strategy of the 'horizontal' or 'vertical' schools. ${ }^{8}$ The theory still maintained his belief in world revolution and internationalism, amassing strength to push through the low tide of revolution that plagued the 1970s by striving to unite anti-imperial and anti-colonial power. Despite the Sino-American Shanghai Communiqué of 1972, he also asked for Zhou Enlai to resolutely convey the position that 'wherever there is oppression there will be resistance. Countries must be independent, nations must be liberated, and the people must revolt. This has become the irresistible tide of history'

\section{Post-Maoist Interpretations}

After Mao passed away, the Cultural Revolution soon ended and the Party restored Deng Xiaoping. Deng then had Hu Qiaomu organise a writers group to draft an article discussing the topic of 'Mao Zedong's Theory on the Division of the Three Worlds.' Deng himself repeatedly revised this article during the writing process and recommended multiple discussions in the Politburo, in each province, and in the military divisions. Finally, the article was published in the People's Daily, People's Liberation Army Daily, and Red Flag. This was the first important theoretical document in which the CCP addressed the international situation since the nine criticisms of the Soviet Union in 1963-64. It established the basis for the fundamental diplomatic policies of the Deng Xiaoping era. However, unlike Mao, Deng did not emphasise world revolution, instead favouring peace and development.

Current Party theorists generally praise Deng for this revision, seeing this as a useful development of the Three Worlds Theory to overcome the limitations of Mao Zedong's version. ${ }^{10}$ Deng attributed the East-West divide to a difference in politics and the South-North divide to an economic difference, which transforms the latter 
into a developmental issue. Particularly in the final stages of the Cold War, when the outcome was inevitable, and amidst the discourse of judging the defeated and bidding farewell to the revolution, the Chinese people gradually became accustomed to examining the history and present conditions of the third world through the lens of economic development. All that remained of the third world was poverty, backwardness, underdevelopment, and a lack of civilisation-a position to be escaped from with increasing haste. In today's China, the division of the three worlds is possessed of a concrete hierarchical meaning, with the third world occupying the lowest substratum as the 'other' of the entire world structure.

In the past, the third world was the locality of the Chinese self in the Cold War. It was the place of China's subjectification. However, in the post-Cold War world China's subjectivity is consciously being shifted to a position above that of the developed countries of the West. At the same time, the third world has been other-ised while its stereotype has been internalised within the Chinese episteme. This transformation is even clearer when seen alongside the neoliberal global order indicated by China's entry into the World Trade Organisation, and China's rise to become the second largest economy in the world.

In Empire, Michael Hardt and Antonio Negri categorically assert that the spatial division into three worlds is already an outmoded paradigm, as 'we continually find the First World in the Third, the Third in the First, and the Second almost nowhere at all. Capital seems to be faced with a smooth world-or really, a world defined by new and complex regimes of differentiation and homogenisation, deterritorialisation and reterritorialisation.' ${ }^{11}$ Although it may be tempting to give in to the thought that 'empire has no outside,' this position excessively stresses the homogenous nature of today's world structures. In contrast to Hardt and Negri's conception of the empire/ multitude, the Maoist discourse of the 'third world' retains powerful insight into the constant reterritorialisations carried out through globalisation. ${ }^{12}$ It is only in those places which span or fracture borders that there is the possibility of the emergence of new political thought and practice.

The third world is not necessarily located only in Asia, Africa, and Latin America, but may be close at hand-as every place of poverty and every destitute person is the third world. We must strive to recover the third-worldism that Mao formulated through the dialectical relationships of 'world peace, national liberation, people's democracy, and socialism.' ${ }^{13}$ Despite global capitalism's unceasing self-renewal through reliance on technological advancement, and despite the relentless tightening of hegemonic rule, we must strive to reunite, through mutual assistance, deliberation, and the fight against capitalism, the entirety of the third world across all of its oppressed and exploited countries, classes, societies, and individuals. In the third world we find a uniqueness, subjectivity, and unity that, although weak, cannot be ignored. 



\section{7 \\ 思想改造 \\ Thought Reform}

Timothy CHEEK

'T

hought reform, or ideological remoulding, has been and remains a key tenant of leadership in the Chinese Communist Party (CCP). The standard phrase in Chinese is sixiang gaizao, the reformation or refashioning of sixiang - a term that is difficult to render into English in a way that captures its range of meanings, which span from 'thought' to 'ideology' to 'way of thinking.' Thought reform in the CCP has a cultural affinity with deeper pathways in Chinese thought, most notably the Confucian commitment to self-cultivation (xiuyang) and the mandate of dynastic rulers to transform the people through state-sponsored education (yili jiaomin or jiaohua). Nonetheless, communist thought reform is substantially different from these traditional norms and expectations in Chinese statecraft for two reasons. First, technological and geopolitical changes of the nineteenth and twentieth centuries brought the model of, and the communication technologies for, mass politics. Second, China's father of the nation, Sun Yat-sen, adopted the sinews of Bolshevik organisation, including the commitment to an ideological Party-in his case, the Nationalist Party (guomindang)-under a supreme leader whose thought should guide all political activity. Then, beginning with the purge of its early leader Chen Duxiu in 1927, the CCP embraced the Stalinist version of a text-based, ideological Party in which thought errors' (sixiang cuowu) or 'erroneous line' (cuowu luxian) could spell political defeat and personal demise (see the essay by Ishikawa and Smith in the present volume). This model was perfected, if we can use that word, by the Yanan leadership under Mao Zedong in the 1940s, and it remains a political technology much valued by China's current leadership under Xi Jinping. Thought reform remains a key component of the 'pedagogical state' that Chinese governments since Sun Yat-sen have required of their cadres and have tried to enforce on an unruly and generally disinterested public. 
In his now famous 1942 'Talks at the Yan'an Forum on Literature and Art', Mao Zedong gave what has become the canonical example of revolutionary thought reform-his own:

I started off as a student at school, and at school I acquired student habits, so I felt ashamed about performing any manual labour, such as carrying my own bags, in front of all those students who were incapable of carrying anything for themselves. I felt that intellectuals were the only clean people in the world and that workers, peasants, and soldiers were in general rather dirty. I could wear clothes borrowed from an intellectual, because I considered them clean, but I would not wear workers', peasants', or soldiers' clothes, because I thought they were dirty. When I joined the revolution and lived among workers, peasants, and soldiers, I gradually became familiar with them, and they got to know me in return. Then and only then the bourgeois and petty-bourgeois feelings taught to me in bourgeois schools underwent a fundamental change. Comparing intellectuals who have not yet reformed with workers, peasants, and soldiers, I came to feel that intellectuals are not only spiritually unclean in many respects but even physically unclean, while the cleanest people are workers and peasants; their hands may be black and their feet soiled with cow dung, but they are still cleaner than the big and petty bourgeoisie. This is what I call a transformation in feelings, changing over from one class to another. ${ }^{1}$

Thought, in Mao's testimonial, is more than an idea, it is a fundamental attitude, what in modern Chinese is often called one's taidu, which in English corresponds to concepts such as 'orientation,' 'value assumptions,' 'commitments,' and 'judgment.' Most recently, on 29 July 2018 the Organisation and Propaganda Departments of the Central Committee of the CCP announced a new campaign for local Party branches to lead in 'Promoting the Spirit of Patriotic Struggle and Making Great Contributions in the New Era.' 2 Their instructions to local Party units reflect the core assumptions of thought reform-implementing government policy (in this case promoting a spirit of patriotism among intellectuals) through propaganda and explanations carried out in small group study under the watchful eye of the local Party officials.

This essay offers an introduction to this key concept from the Mao era with some reflections on its relevance in Xi Jinping's China. What is thought reform in practice? Why does it matter for Party leaders in the commercialised, globalised, politicallysecularised China of the twenty-first century? Is there a life beyond the Party for thought reform? For instance, could thought reform have a role in progressive politics? To address these questions, I offer an introductory history of thought reform in four scenes: prehistory, intentions, experiences, and legacies. This deeper historical perspective exposes the cultural and historical weight of thought reform in China's modern political culture and suggests alternatives to Xi Jinping's version that live on from that historical experience. 


\section{Reforming the People through the Rites: A Prehistory of Thought Reform}

The political application of thought reform, or the modification of assumptions, habits, and values to suit the norms of a cultural or political elite is not new to China. 'Transform the people through the Rites' (yili jiaomin) is a political maxim recorded in the ancient Classic of Rites. ${ }^{3}$ It endorses the transformative power of correct models. Its constant repetition by Chinese governments and leading thinkers for the past two thousand years reflects a shared belief in the educability of humans to achieve good governance. By the eve of the twentieth century, Chinese scholar-officials continued to 'reform the people through the Rites' by propagandising the sacred edicts of the Kangxi Emperor and later Qing monarchs in xuanjiang lectures elaborating on the emperor's moral maxims. ${ }^{4}$ These maxims included general moral injunctions, such as 'filial piety and brotherly submission' and 'instruct sons and younger brothers' to avoid wayward behaviour, and practical advice to 'cultivate peace and concord in your neighbourhood' and 'show that you prize moderation and economy'. The maxims included political reminders, as well, to 'pay your taxes promptly' and 'combine in collective security groups (baojia) in order to put an end to theft and robbery.'

These lectures were not simply in books. Local magistrates were instructed to recite the maxims and expound upon their meaning in monthly public meetings. Handbooks, such as Li Laizhang's 1705 Explanations of the Sacred Edict Lecture System, literally mapped out how to hold these meetings, down to diagrams showing the placement of the tablets with the maxims and altars, and the locations where both scholars and townsfolk should stand, as well as instruction on how to hold the meeting and fill out the registers of good and bad behaviour. ${ }^{5}$ This was basic political thought reform in Qing China: public education or jiaohua. That it was not particularly effective by the end of the nineteenth century did not diminish the appeal or the collective impulse to find and inculcate correct thought to produce good governance.

\section{The Intentions: Awakening the Leaders, Then the Cadres, Then the People}

The intentions of thought reform in the CCP leadership have deep cultural resonances about the educability of people, as well as clear and coherent goals and practices suitable to an ideological party. Thought reform in its modern political form emerged in Sun Yatsen's constitutional idea of 'political tutelage' (xunzheng). ${ }^{6}$ This was Sun's explanation for putting democracy off for another day, because by the 1920s he had come to feel that the Chinese people were not ready for democracy and required instead a period of political education during which his one-party state would inculcate modern civility in the masses. This responsibility (or presumption, depending on one's point of view) was enthusiastically embraced by his successors-Chiang Kai-shek and his Nationalist Party, as well as the CCP, most famously under Mao Zedong. Chiang's efforts were unsuccessful-spectacularly so in the desultory New Life Movement (xin shenghuo yundong) of the 1930s. ${ }^{7}$ Mao's efforts at public thought reform, on the other hand, were effective. 'Rectification' (zhengfeng) was the political education and reform movement to train Party leaders and rank and file members that Mao perfected in Yan'an in the $1940 \mathrm{~s}^{8}{ }^{8}$ When undertaken seriously, this form of political training resembles nothing so much as Bible study in small groups run by your local police department (with officers 
from the intelligence service and military on hand when needed). Individual study, public confession of your sins, review of your personnel record, and public propaganda about role models (and a few negative role models to show what is to be avoided) define a CCP rectification campaign (see Mertha's essay in the present volume). Rectification was taken to absurd and tragic extremes in the Cultural Revolution, but it has been a staple of political life in the CCP since the 1940s. Xi Jinping's current anti-corruption drive belongs to this lineage of rectification. ${ }^{9}$

Rectification is a political process that Frederick Teiwes has documented as being a 'persuasive-coercive continuum. ${ }^{\text {'0 }}$ That is, the CCP version of political tutelage always ranges from warm and fuzzy advertising and efforts to persuade individuals to change how they think about themselves and the world along with incentives and penalties designed to encourage correct behaviour, to straight up use of force in censorship, arrest, public humiliation, and imprisonment. Thought reform is considered to be part of Party 'thought work' (sixiang gongzuo) and operates as much through the Party's public propaganda system as through small group study sessions for Party cadres and government leaders. To see Xi Jinping sitting down at a 'study session' (xuexi xiaozu) with senior leaders may look ludicrous to outside observers, but it makes sense to Party leaders as part of a successful model of political training, discipline, and motivation. It worked to bring the CCP to power 60 years ago, so why not now?

\section{Experience: Promise, Penitence, and Punishment}

The reality of thought reform naturally varied over time and in diverse contexts, but we can trace a general arc, both for elites and common folk. Early experience suggested something of the promise of thought reform to build consensus, explain revolutionary change, and create a sense of hope and purpose. By the mid-1950s the experience of penitence, of being humiliated and corrected outweighed the promise of thought reform as it became clear that to survive one had to submit. In short, the corruption of power began its work on what had been, at least potentially, a redemptive and community-building technique. When it was voluntary (even with a fair amount of peer pressure), the techniques and goals of thought reform could have a salutary role in a political community. However, when applied with the direct threat of force, and especially by a leadership in a hurry-up mode unwilling to invest the time it takes to make such fundamental changes in one's psychology, thought reform transformed into a particularly nasty form of punishment. By the late 1950s it had already become a tool of political oppression-effective in shutting down unwanted speech (and, to some degree, unwanted thought itself), but useless in building community or coordinating productive effort.

Recent literature on Mao's China, especially the experience of intellectuals, is replete with examples of the political misrule and personal abuse that came in the form of thought reform. Even those who embraced thought reform in the early 1950 s as a way to expiate the sin of enjoying a bourgeois life at university while the Chinese working class had suffered and who loyally served changing Party lines, such as the historian Zhou Yiliang, had to submit to the humiliating public criticism and painful denunciations of their own teachers and friends. ${ }^{11}$ For many others, thought reform under Mao was much worse. Fang Lizhi, the notable astrophysicist who became famous after the 
1989 Tiananmen demonstrations and their violent suppression, discovered his faith in democracy and hatred of Party dictatorship precisely through the thought reform 'labour' to which he was subjected during the Cultural Revolution. Unlike Zhou, Fang was a product of CCP-controlled universities and had no bourgeois guilt to expiate. When he saw the miserable lives of the coal miners among whom he was thrown at his '7 May Cadre School,' Fang concluded that the Party had flat-out failed to serve the interests of the workers and peasants (see Karl's essay in the present volume). He gave up on the Party and turned instead to the open scepticism of international science as a better tool with which to judge policy. ${ }^{12}$ Ironically, Mao's vision of thought reform through living and working with China's labouring masses had also worked in Fang Lizhi's case, though the revolutionary 'change in feelings' produced by the thought reform was not what Mao would have prescribed.

Thought reform has not been limited to intellectuals and Party elites. Stories of local teachers and village officials, and even of urban layabouts and prostitutes brought in to be reeducated by the Party likewise reflect the range of experiences and responses to thought reform. ${ }^{13}$ As was the case with intellectuals, when applied carefully and with some sensitivity to local conditions, this form of political mobilisation could produce positive results, but when applied inflexibly, quickly, and without concern for local conditions, it was little more than personalised tyranny.

\section{Legacies: Public Transcripts and Progressive Potential}

Thought reform is still with us in China today. At the National Propaganda and Ideology Work Conference in August 2013, Xi Jinping issued a directive to 'tell China's story well' (jianghao zhongguo gushi). ${ }^{14}$ That means teaching the 'correct' version of China's history and values according to current Party policy. This story not only appears in the public media and propaganda in China, but also forms the content of thought reform study sessions for Party members and government leaders today, as we saw in the July 2018 announcement at the beginning of this essay. Nevertheless, thought reform in contemporary China is inextricably tied up in the persuasive-coercive continuum that has marked it since Yan'an, and even the most reasonable and mild suggestions carry the shadow of the 'big stick' that can be brought to bear as needed. The sharp end of the thought reform stick has been tragically demonstrated in the reeducation camps across Xinjiang in which hundreds of thousands of PRC Uyghur and Kazakh Muslims have been forcibly detained over the past year (see also the essays by Yi Xiaocuo and Bulag in the present volume). On 9 October 2018, the Xinjiang Uyghur Autonomous Region government produced regulations legalising 'anti-extremist ideological education' ( $q u$ jiduanhua jiaoyu) at various 'education and training centres' (jizhong jiaoyu zhuanhua zhongxin). ${ }^{15}$ Party thought reform now extends to ethnic relations in a troubled region.

Given that many Chinese people do not embrace the Party's version of the 'China story,' why does Xi Jinping keep talking about this? The answer, we have seen, is that thought reform is an irreplaceable constituent part of the ideological Party. Such political organisations can no more do without ideological remoulding than the theology of the Church or Uma can do without prayer. The compelling question about thought reform 
in China today is: does anyone care? Never mind China's politically secularised society, one can reasonably ask: do the majority of China's some 90 million CCP members take thought reform seriously?

The pervasive corruption in the Party and the brutality of Xi Jinping's anti-corruption drive suggest that thought reform in the CCP has failed to produce the desired 'noble attitude' among Chinas Party cadres. Nonetheless, thought reform, study sessions, and punctilious attention to ideological phrasing (tifa) are all part of what James Scott identified as the 'public transcript' elites tell each other to bolster their self-confidence and to justify their privileges. ${ }^{16}$ More importantly, the fundamental assumptions undergirding thought reform remain vibrant across Chinese society today: that behaviour can be fundamentally shaped by moral education, that the common people broadly lack such a moral compass, and that some elites have the cultural learning and awareness (often couched as suzhi, or 'personal cultural refinement') that entitle them to offer guidance in practical ethics to their social inferiors. On the other hand, it is not impossible for an inspired and capable figure outside the elite to harness the mobilisation potential of thought reform to help create a social movement. This possibility alone explains the current CCP leadership's commitment to censorship and intellectual repression. 


\section{8 \\ 工会 \\ Trade Union}

Ivan FRANCESCHINI*

D espite Lenin's preliminary misgivings about trade unions as bulwarks of economic conservativism only concerned with improving labour conditions under capitalism, he also saw them as sites of revolutionary potentiality, akin to tinder across which the Bolshevik message could be ignited and spread. After the October Revolution, Lenin considered trade unions to be 'an indispensable "school of communism" and a preparatory school that trains proletarians to exercise their dictatorship, an indispensable organisation of the workers for the gradual transfer of the management of the whole economic life of the country to the working class (and not

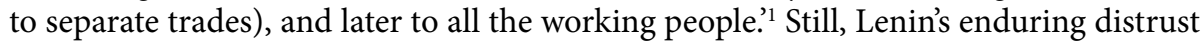
of trade union's spontaneous and 'conservative tendencies toward economic demands' carried over from the revolutionary era to postrevolutionary governance. Unions could not be trusted to act on their own. They were powerful bodies without a head to guide them. For this reason, in his early writings from the prerevolutionary period, he demanded that all Party members be active in the unions, seeking to influence their membership. ${ }^{2}$ After the establishment of the Soviet Union, he further argued that the proletarian dictatorship 'cannot work without a number of "transmission belts" running from the vanguard to the mass of the advanced class, and from the latter to the mass of the working people."

As a transmission belt, the Leninist union was supposed to convey the directives of the Party leadership to the workers, and feed the opinions and reactions of the latter to the Party, implying a circular movement that stands in marked contrast with the linearity of production lines. One century later, this canonical interpretation of Lenin's words remains crucial to understanding the role of the All-China Federation of Trade Unions (ACFTU, zhonghua quanguo zonggonghui), the only union legally allowed to exist in China. To this day, the ACFTU-which currently has more than 300 million members-remains structured according to the Leninist principle of 'democratic 
centralism' and continues to function as a transmission belt between the Chinese Communist Party (CCP) and the workers. The current leadership of the CCP has made abundantly clear that it does not intend to reconsider its relationship with the union. At the Sixteenth National Congress of the ACFTU, held in October 2013, Prime Minister Li Keqiang expressed the hope that the trade unions at all levels continue to develop their role of bridge and link [qiaoliang he niudai] between the Party and government and the masses of the workers and employees, rallying these broad masses to the cause of the modernisation of the country.4 Such expectations were confirmed almost verbatim five years later, in October 2018, when both Prime Minister Li Keqiang and Politburo member and Party chief-ideologist Wang Huning took the stage at the Seventeenth National Congress of the ACFTU to reiterate the CCP's view of the union. ${ }^{5}$

Nevertheless, these formulaic statements, common among both Party and union leaders, do not tell the whole story. In line with the ambivalence in Lenin's conceptualisation, they hide a history of contention about what the role of a union should be that spans the entire existence of the People's Republic of China (PRC). Through the voices of union and Party leaders of times past, in this essay I will show how, beyond the apparently smooth surface of orthodoxy, the relationship between the CCP and ACFTU has often been marred by seething tensions, ready to explode at critical economic and political junctures.

\section{1}

Founded in May 1925 as a coordinating body for the activities of leftist unions nationwide, by the early 1930s the ACFTU had fallen into irrelevance due to the deteriorating political situation in the wake of the falling out between the CCP and the Nationalist Party. The CCP decided to revive it in the summer of 1948, when victory in the Civil War was in sight. ${ }^{6}$ In those early years of consolidating political power, the Party saw the organisation of the Chinese labour movement into a rigid and exclusive hierarchical structure as being instrumental to mobilising and controlling the human resources needed to rebuild the national economy. ${ }^{7}$ At the same time, the Chinese leaders were wary of the political risks involved in allowing the existence of a strong, organised national union. The compromise-encapsulated in the 1950 Trade Union Law-entailed a national union built on the basis of the Leninist principle of 'democratic centralism' (minzhu jizhongzhi), a structure that required the minority to submit to the will of the majority and the lower levels to obey the higher levels. The ideological assumption was that the ACFTU, a 'mass organisation voluntarily formed by the working class' (gongren jieji ziyuan jiehe de qunzhong zuzhi), shared exactly the same interests as the Party, which was the vanguard (xianfengdui) of that same working class. $^{8}$

According to Mark Frazier, in the first months after the foundation of the PRC:

thousands of private-sector employees left unemployed by the collapse of industrial activity during the Civil War returned to their factories to demand their jobs back. They wanted higher wages, improvements in benefits and working conditions, and guarantees of full-time employment. In the state- 
owned factories, Communist military cadres who had been placed in certain critical factories to 'supervise' factory directors often seized power from them, with predictable upheavals in basic operations. ${ }^{9}$

This led to a situation in which 'workers struck at will and frightened capitalists closed their factories. ${ }^{10}$ The necessity to restore production and regain control over the economy led the Party to strengthen the political role of the ACFTU, a move that caused widespread mistrust and even hostility among the workers, who came to perceive the union as a tool in the hands of management. In response, in August 1950 the authorities launched a campaign against 'bureaucratism' (guanliaozhuyi) within the ACFTU, encouraging it to be more open and responsive- and less formal and rigidto the needs of workers. ${ }^{11}$

It was against this uncertain background that, in August 1950, the People's Daily and Workers' Daily published a speech by a Party cadre named Deng Zihui on the work of the ACFTU in southern and central China. ${ }^{12}$ According to Deng, the union had become detached from the masses. Going even further, he argued that, although in the public sector the union and the Party were both working for the wellbeing of the workers and the country, some differences between the functions of the union and those of the Party could not be avoided. For this reason, he reckoned that it was necessary to admit that, in certain circumstances, it was possible for the union to adopt a 'standpoint' (lichang) different from the Party.

This apparently mild assertion triggered a heated debate. Li Lisan, a prominent Party leader and labour organiser during the Republican era who was then concurrently serving as ACFTU Chairman and Minister of Labour, intervened in support of Deng's thesis. In a speech given in March 1951, he affirmed that, although under the new government, the administration and the working class converged, it was inevitable for 'some small contradictions' (xie xiao de maodun) between workers and management to survive. For instance, even in the state sector there could be differing views regarding wages. ${ }^{13}$ Still, Li was careful to express his disagreement with Deng Zihui regarding the existence of different standpoints between the union and the administration. Such a distinction was substantially wrong because 'under the "New Democracy," public and private interests overlap and therefore the standpoint of the union and the administration also overlap. Wherever there is a difference, it can just be said that it is a matter between "fundamental standpoint" [jiben lichang] and "concrete standpoint" [juti lichang].' In other words, while the Party still determines the fundamental standpoint, this may require modification to suit concrete situations.

In a draft official document written on behalf of the ACFTU in September 1951, Li further distinguished between two sets of potential contradictions that could affect the work of the union: the contradiction between 'general interests' (zhengti liyi) and 'individual interests' (geren liyi), and that between 'long-term interests' (changyuan liyi) and 'ordinary interests' (richang liyi). ${ }^{14}$ In his view, while 'in the state enterprises the workers are the owners and there are no class conflicts nor exploitation, therefore the effects of the development of production are always beneficial for both the individual and general interests of the working class, as well as for its long-term and ordinary interests,' it was impossible to deny that 'there remain some contradictions in the practical problems of workers' lives, on issues regarding labour conditions.' On this 
basis, he argued that it was of the utmost importance that even state enterprises be equipped with a union strong enough to represent the workers and protect their interests.

In October 1951, Li Lisan repeated his views in a report directly addressed to Mao Zedong, urging him to take a position in the debate. ${ }^{15}$ No official reply was given. However, months later, on 20 December 1951, during an enlarged meeting of the Party group of the ACFTU, Li was subjected to ferocious criticism. ${ }^{16}$ In strict Party jargon, he was accused of having committed three fundamental mistakes: first, he had 'completely misunderstood the nature of state enterprises,' confusing the relations between workers and enterprise under the new socialist government with the previous situation under the rule of the Nationalist Party; second, he had 'denied the role of the Party as a guide of the union, considering the latter as the highest representative of the working class;' and third, he was guilty of 'subjectivism' (zhuguanzhuyi), 'formalism' (xingshizhuyi), 'routinism' (shiwuzhuyi), and 'paternalism' (jiazhangzhi de zuofeng). This attack not only put an end to Li's political career but also crystallised the discursive boundaries for the role of the ACFTU in communist China for years to come.

\section{7}

As the Party-state prepared to launch the First Five-year Plan in 1953, the priority of the ACFTU shifted even further towards boosting production. In the winter of 1955, the Chinese authorities decided to nationalise industry, a development that required a major restructuring of industrial relations. Although the nationalisation was presented by the official propaganda as a historical step forward towards the end of capitalist exploitation, many workers formerly employed in the private sector experienced a deterioration in labour conditions. In particular, while in the past workers had at least felt that they were morally entitled to fight their employers, with the entrance of the Party-state in the ownership of their enterprises, they lost even that discursive right. Paradoxically, the symbolic claim that the workers had become the 'master of the state' ended up weakening their practical power. The union cast off the pretence of representation and shifted 'from a unionism of class struggle aimed in fact against the employers to a state unionism, dedicated to nothing else than production growth and the management of social services.' ${ }^{\text {'17 }}$

As if this was not enough, a reform of the wage system launched in 1956 took a heavy toll on the workers, causing a wave of strikes. ${ }^{18}$ Mounting labour unrest in those months led the Chinese authorities to reconsider the right to strike, which had been omitted from both the Common Program of 1949 and the Chinese Constitution of 1954. Mao Zedong was the first to bring up the issue during a meeting of the Central Committee in March 1956:

It is necessary to allow the workers to go on strike, allow the masses to protest. The demonstrations have their basis in the Constitution. If in the future the Constitution is to be amended, I suggest adding a freedom of strike, it is necessary to let the workers go on strike. This can benefit the resolution of the contradictions between the workers, the directors of the factories, and the masses. ${ }^{19}$ 
Mao reiterated his stance in February 1957, in his famous speech 'On the Correct Handling of Contradictions among the People.' In his opinion, the contradictions among workers and those between workers and the national bourgeoisie had to be considered 'contradictions among the people' (renmin neibu maodun) and therefore had to be solved through the method of 'unity-criticism-unity' (tuanjie-piping-tuanjie) (see also Rojas's essay in the present volume). According to Mao, the episodes of labour unrest that had taken place the previous year had three different roots: the failure of the Party to satisfy the economic requests of the workers; a bureaucratic and formalistic approach by the leadership; and the inadequate political and ideological education of the workers.

After less than one month, the Central Committee of the CCP adopted a 'Directive on How to Handle Strikes by Workers and Students. ${ }^{20}$ This document-which to this day constitutes the only public official statement by the CCP leadership on how to manage strikes-espoused Mao's point of view, claiming that in the event that the masses had been deprived of their democratic rights and had no other choice than adopting extreme measures such as strikes or protests, these actions 'were not only unavoidable, but also necessary,' and therefore had to be allowed. Moreover, the Directive stated that these actions did not go against the Constitution-and there was therefore no reason to forbid them - but at the same time suggested that Party committees infiltrate the strikes in order to take the lead and prevent the masses from being 'stranded on the wrong way by some bad elements.'

Where did this leave the ACFTU? The Directive mentioned the union only three times, twice in passing, and once just to emphasise that Party committees had to lead the union and the youth league to actively reflect the opinions and the requests of the masses.' Facing irrelevance, when the CCP launched the Hundred Flowers Campaign, the union leadership saw an opportunity to reaffirm the role of the ACFTU on the national stage. On 8 May 1957, the Workers' Daily ran a long interview with Lai Ruoyu, the official who had replaced Li Lisan at the helm of the organisation. ${ }^{21}$ In this exchange, Lai tackled the thorny issue of the position of the union vis-à-vis the Party-state, arguing for a more complex view that contemplated the possibility of contradictions arising not only between union and company managers, but also between the union, workers, and authorities. His words are worth quoting in full:

From the point of view of the union, one of the main problems at the moment concerns democracy. Only when there will be democracy, it will be possible to prove that the union is an organisation of the masses ....

For what concerns the relations with the administration, in the past the issue of the identity [of interests] has been emphasised and not much attention has been paid to the differences, so in dealing with problems we always stood by the leaders, it was not possible to represent the interests of the masses. This simplistic view of the contradictions among the people has often led the union to adopt bad work methods, preventing it from carrying out its function of mediator between the leaders and the masses. This will have to change. 
For what concerns the relations with the Party, in the past it has been settled that the union has to accept the leadership of the Party. This is correct, but not enough attention has been paid to the fact that, being an organisation of the masses, the union also has to carry out independent activities, though being subject to the guidance of the Party for what regards policies and thought. Only by carrying out its own independent activities will the union be able to fulfil its functions. ${ }^{22}$

In the interview, Lai went so far as to assert that in the event of strikes or other worker protests, the ACFTU had a duty to stand by the masses, because otherwise it would have lost credibility and the workers would have had no other choice than to establish autonomous organisations.

The following day, the Workers' Daily published another critical piece, a report on a long investigation undertaken in the previous months by Li Xiuren, Deputy Director of the ACFTU General Office. ${ }^{23}$ The trip had taken Li into a dozen cities along the railway lines Beijing-Hankou and Hankou-Guangzhou. In every city, Li had found clear hints of a 'crisis of the union', with enraged workers blaming the ACFTU for being nothing more than a 'tail of the administration' (xingzheng de weiba), a 'department for the management of the workers' (gongren guanlike), or a 'tongue of bureaucratism' (guanliaozhuyi de shetou), and striving to establish their own autonomous organisations. Many union cadres complained about the difficulty of their position: even if they wanted to support the rightful requests of the masses, they could not do so because of the imperative of respecting Party discipline. They were particularly concerned about being accused by Party leaders of 'syndicalism' (gongtuanzhuyi), 'tailism' (weibazhuyi), and 'independence from the Party' (dui dang nao duli), risking their Party membership.

The publication of these two articles triggered a heated debate about the role and the functions of the union in China. In May and June 1957, the Chinese press published a great number of articles that dealt with the perceived impotence of the union. Confronted with such criticism, the Party once again stepped in. In September 1957, at an enlarged meeting of the ACFTU Party Group, Lai Ruoyu delivered a long speech in which he substantively gave up any demand of independence for the union. ${ }^{24}$ From that moment on, the ACFTU stopped playing any meaningful role in industrial relations. At least 22 high-level cadres of the ACFTU were purged in the following months, while Lai Ruoyu himself died of illness in May 1958. Relegated to irrelevance, the organisation was completely dismantled at the outset of the Cultural Revolution. ${ }^{25}$

\section{9}

The ACFTU was reestablished in 1978 in concomitance with the launch of the reforms. Even then, the CCP lost no time in making it clear that they maintained a purely instrumental view of the union. In his opening speech at the Ninth National Congress of the ACFTU in October 1978, Deng Xiaoping declared that the role of the union was 'to protect the wellbeing of the workers, [which] can only increase gradually following the increase in production, especially in labour productivity. ${ }^{26}$ To achieve this task, the union was supposed to take a leading role in the 'democratic management of the enterprise' (qiye minzhu guanli), which in Deng's words was the only way for the 
ACFTU not to become 'that kind of organisation whose existence does not make any difference' (na zhong keyou kewu de zuzhi). In practice, this led to the establishment of workers' congresses in hundreds of thousands of state companies. This development was due not only to the need to reinforce the legitimacy of the Party among the workers, but also to the necessity of gaining credibility on the international front in the wake of the PRC's entrance into the International Labour Organisation in $1983 .{ }^{27}$

It took ten more years for the CCP to begin to contemplate the possibility of a substantial reform of the union. In his opening speech at the Eleventh National Congress of the ACFTU, held in Beijing in October 1988, then CCP General Secretary Zhao Ziyang conceded that a real divergence existed among the general interests of the Party-state and the specific interests of the workers:

\begin{abstract}
Under socialism, the working masses have not only interests in common with other sectors of the society-the general interests of the state-but also their own specific interests. In the past, the fact that the union had to protect the specific interests of the workers has been neglected and this has had a negative influence on the edification of the union organisation. We have to ... ensure that putting the construction of the economy at the centre, protecting the general interests of the people but also, at the same time, guaranteeing the specific interests of the working masses become fundamental guiding principles of the Chinese labour movement and of the union's activities, making sure that the union carry out its social role in a better way. ${ }^{28}$
\end{abstract}

The reformist bent of the Chinese leadership was confirmed by the release at the Congress of a Basic Plan for the Union Reform, a document that candidly admitted the weaknesses of the ACFTU-a lack of internal democracy, despotism of the cadres, scarce coordination between local and industrial unions, and alienation from the workers-and sought to trace a path for future reforms. ${ }^{29}$ If implemented, these reforms would have laid the foundations for a truly democratic union, instituting a system in which lower unions would form associations of higher unions, along with a delegate system in which lower levels would send their delegates to higher levels. ${ }^{30}$

These hopes for a top-down reform were dashed in 1989. Although the quality of life of Chinese workers by then had significantly increased, the morale of the workforce had sunk due to galloping inflation, a sense of uneasiness caused by the ongoing dismantling of the welfare system, and complaints about widespread managerial corruption. ${ }^{31}$ The death of beloved Party leader Hu Yaobang in April 1989 acted as a catalyst for the widespread discontent that was already brewing in Chinese society, triggering massive student demonstrations and an occupation of Tiananmen Square. Workers were also eager to join the protest, and between April and May 1989, independent unions sprang up in several cities in China, the most famous of them being the Beijing Workers Autonomous Federation (gongzilian).

The ACFTU also decided to take action. ${ }^{32}$ On 14 May, a union delegation marched on Tiananmen Square to express its support for the students. ${ }^{33}$ Two days later, 400 pupils of the Labour Movement Institute, a union think tank, marched to the union headquarters and presented the union leadership with a petition that asked the ACFTU to intervene as a 'representative of workers and employees' to call on the Party-state to 
recognise the patriotic nature of the student movement, guarantee freedom of press and association, fight against corruption, adopt a new legislation on trade unions, and acknowledge the fact that the union had to speak and act on the behalf of the workers. ${ }^{34}$ As more staff and students from the Labour Movement Institute participated in various demonstrations, on 18 May the ACFTU headquarter donated 100,000 yuan to the Red Cross to cover medical expenses for the students on hunger strike. ${ }^{35}$ That very day, the ACFTU put forward three new requests to the authorities: that they start a real negotiation with the students; that they open an early session of the National People's Congress Standing Committee; and that they initiate a dialogue with the workers under the aegis of the union. ${ }^{36}$

Some sources report that the ACFTU had decided to proclaim a general strike for 20 May, an unprecedented step that could be one of the reasons why the Chinese authorities opted to declare martial law. ${ }^{37}$ After martial law was declared, the conservative side of the ACFTU took over and in the following months an internal purge stripped the union of most of its reformist cadres. That marked the end of any attempt at a structural reform of the ACFTU to this day.

\section{Suspicious Emphasis}

The moves of the ACFTU during these dramatic stages in contemporary Chinese history can be considered attempts at an 'institutional conversion' aimed at ensuring the survival of the organisation. ${ }^{38}$ At the same time, they were not entirely inconsistent with the role of the union as a transmission belt. If anything, they were attempts by part of the union leadership to make the ACFTU live up to the Leninist ideal of a union able to act as a real intermediary between the Party-state and the workers.

Although much has changed in the landscape of industrial relations in China since 1989, the ACFTU has never relinquished its role as a transmission belt. Three main developments are worth noting. First, in 1992 the Chinese authorities passed a new Trade Union Law. Although this Law, amended in 2001, reaffirmed the control of the Party over the union and reiterated the ACFTU's monopoly over labour representation in China, it was nevertheless a timid attempt to pick up the broken threads of the reforms. For instance, for the first time since 1956 it reintroduced the possibility for the union to stipulate collective contracts on behalf of workers. Second, in the wake of the drastic restructuring of the state sector in the late 1990s, the membership of the ACFTU plunged from 104 million members in 1995 to the less than 87 million in 1999, a drop which pushed the Chinese leadership to pursue a new unionisation drive among previously neglected targets: private companies and migrant workers. Third, since the mid-1990s the core focus of union reform has shifted from the ideological realm to the more technical aspects of legal reforms. The promotion of the 'rule of law' in the field of labour relations has become an important feature of union activity, with the ACFTU involving itself in the drafting of new laws and regulations on labour and in providing legal aid to its constituency.

Nevertheless, none of these changes have been successful in boosting the reputation of the ACFTU among the Chinese workforce. Constrained by a Party that to this day sees it as transmission belt, the Chinese union is still struggling to gain recognition among the workers. In surveys that I carried out in China over the years, I consistently 
found significant percentages of workers who had no idea whether they were union members or not, nor whether there was a union in their factory. In one survey that I conducted in 2016 in garment factories in Dongguan, as many as 28 percent of 250 interviewees had never heard the word 'trade union' (gonghui) before. ${ }^{39}$ In light of this widespread irrelevance, the calls of the CCP leadership for the union to keep playing its role of 'bridge and link' could be deceptive. If history teaches us anything, it is that just under the smooth surface of orthodoxy, trouble might be lurking. The ambiguousness of the union's role-and the fact that Mao's speeches were supportive of strikes-means that the union, either officially or simply the idea of it, remains a place that is ripe for contestation and a potential Achilles' heel for the Party. 



\section{9

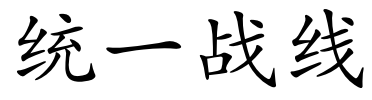 \\ United Front}

\section{Laura DE GIORGI}

$\mathbf{T}$

he notion of 'united front' (tongyi zhanxian), originally formulated by Lenin, was first adopted by the Chinese Communist Party (CCP) in the early 1920sa period of strong Comintern and Soviet influence. At that time, it referred to the Party's need to consider the historical stages of social revolution, and consequently to be able to set class contradictions aside and seek for more inclusive alliances in order to support what was then supposed to be nationalist revolution. As the military nature of the term reveals, the idea of united front was originally connected to the tactic of cross-class mobilisation against a target on a temporary basis, and it assumed the differentiation between friends and enemies according to this goal as its rationale (see also Dutton's essay in the present volume).

In time, the original concept took on a broader meaning, coming to refer to the CCP's ability to work with, unite under its guidance, and manipulate other political parties and social forces, eliminating possible sources of opposition by means of cooptation and control. From this perspective, throughout the history of global communism, the CCP is the communist party that has most comprehensively developed the united front in both theory and practice. ${ }^{1}$

\section{Origins and Development}

The history of the CCP before 1949 has seen two important configurations of united front activity, both of which mainly concerned the relationship with other political parties, and the Nationalist Party in particular (guomindang, hereafter GMD). The First United Front was the alliance between the CCP and the GMD which was initiated in 1923 with the aim of fighting foreign imperialism and the warlords in order to carry on a national revolution, and tragically ended in 1927 with a bloody purge of the Communists commonly referred to as the 'White Terror.' Since at that time the CCP was 
just a small political organisation, the First United Front permitted the Party to expand and gain political and cultural recognition outside the circles of radical intellectual and labour elites. It was, however, a short-lived experiment. The Second United Front (1937-41) was destined to have a stronger and more lasting impact on the CCP's political strategy and theory. Historically it consisted of an alliance with the GMD and other minor patriotic and intellectual parties to fight the Japanese occupation of China. While in 1923 the members of the CCP had entered the GMD, on this occasion they maintained their separate political identity and worked in Nationalist-controlled areas and institutions to engage in patriotic resistance against the enemy. At the end of the war, this united front formation had become a distinctive feature of the CCP's political strategy, as was demonstrated by the alliances that the Party revived with the so-called 'minor parties' during the Civil War with the GMD in 1946-49, and then again after 1949.

The wartime period was also pivotal to a first theoretical elaboration of the notion of the united front, and to its institutionalisation within the structures of the CCP and, subsequently, the new Chinese state. First, war experiences shaped Mao's attitude towards the united front, making him appreciate its importance for the final victory of the CCP. In 1939, he defined it one of the three 'magic weapons' (fabao) wielded by the CCP, along with people's war and Party-building (see Guan's essay in the present volume). ${ }^{2}$ In his view, the united front implied the choice of the proletarian class to temporarily suspend class struggle in order to lead and unite the Chinese people. Patriotism and nationalism were fundamental to this end. The final goal was to establish the political and ideological hegemony of the CCP, laying the foundations for the Communist Revolution. At that time, the united front was considered to be a specific transitional stage rather than a permanent feature of the political and ideological identity of the CCP. Mao also emphasised how one core issue in a successful united front had to be the ability of the CCP to interact with several political, cultural, and social constituencies within an apparent win-win strategy, but without jeopardising its ability to take autonomous political action.

The institutionalisation of the united front work within the CCP also dates from the wartime years. It was in this period that the United Front Work Department was established under the direct supervision of the Central Committee, with branches at the local administrative level. During the Civil War, the CCP made extensive use of the united front-as an alliance with the other minor parties-to distinguish itself from the GMD and to win the political and symbolic battle as the best representative of the interests of the Chinese nation.

After 1949, the notion and strategy of united front found an embodiment in the socialist state with the establishment of the Chinese People's Political Consultative Conference (CPPCC), which mirrored similar institutions created by the GMD during the War of Resistance against Japan. The CPPCC was instrumental in the adoption of the so-called 'New Democracy' that, as an interclass alliance, constituted the basis for the birth of the People's Republic of China (PRC) and characterised the early years of the new socialist state (see Blecher's essay in the present volume). Though initially conceptualised as a representative and consultative institution useful for the transition towards the new Constitution, the CPPCC remained active as a symbolic element of the united front even after 1954, when the National People's Congress was established. 
The importance attributed to the united front has changed over time. As its premise is the CCP's acknowledgment of the complexity of social and cultural differentiation and interests, it has reflected not only the political priorities but also the ideological shifts within the Party. Until 1957, the United Front Work Department of the CCP was quite active, especially in seeking the cooperation of non-Party intellectuals, experts, and exbusinessmen. In exchange, it granted them access to material and symbolic resourcesfor instance, privileged information about policies, participation in political events, positions in the state bureaucracy, and direct relationships with the CCP leaders. ${ }^{3}$ Cooperation was, at any rate, carefully managed by ideological education and criticism of individual personalities and groups. From 1957, it began to lose importance as the shift towards radical policies centred on the primacy of class struggle implied the demise of the 'magic weapon' of the united front. During the Cultural Revolution, until 1978, the United Front Work Department remained practically inoperative. It is worth noting that although it was downplayed in the domestic arena, in that period the doctrine of the united front continued to play a role in the theory and practice of international relations of the PRC with third world and European countries (see Teng's essay in the present volume). ${ }^{4}$

\section{Institutionalising the United Front}

United front theory and practice were resumed by the CCP in the early 1980s. In 1979, Deng Xiaoping redefined the united front as a 'patriotic' entity, implicitly different from the 'proletarian' one of the Maoist era. ${ }^{5}$ Since the 1980s, the notion of the united front has gained increasing importance for the CCP, as it concerns not only its political strategy but also its ideology and political theory.

More than ever before, in the reform era united front work has required a theoretical elaboration to provide ideological support for the activities of cadres. This elaboration has certainly been connected to the demise of class struggle as core notion of CCP's identity (see Russo's essay in the present volume), and to the adoption of nationalism as a fundamental tool of political and cultural legitimisation. However, it has also reflected the ambition and the need to enhance the ability of the Party to prevent and settle the conflicts generated by the increasing divergence in the economic interests and the cultural identities of different social constituencies in contemporary China.

Consequently, the united front has been increasingly connected to the so-called 'cultural work' of the Party, as it is in the realm of culture (broadly articulated) that it fully displays its effects, by creating relationships and seeking the cooperation of social and cultural elites outside the CCP. For instance, based on the vision of 'one country, two systems', developed during the 1980s, united front work has aimed at fostering support among local elites to facilitate the return of Hong Kong and Macao to PRC control. This has been accomplished by developing contacts and strengthening the personal links with the CCP through cooptation, while isolating potentially adversarial individuals and groups. ${ }^{6}$

The current discourse on a 'theory of the united front with Chinese characteristics' (you zhongguo tese de tongyi zhanxian lilun) is evidence that united front work is now being recognised as a structural element in the ideology and political identity of the CCP. In official Party literature, research and reflections on the united front have multiplied 
in the first decade of the twenty-first century, suggesting the need to systematise and offer guidance to the cadres engaged in this work, which is historically perceived as risky and not rewarding for one's political career. Party sources describe the ideological and intellectual genealogy of the 'united front with Chinese characteristics' after Mao, as included in Deng Xiaoping's theory of the primary stage of socialism, Jiang Zemin's notion of the Three Represents (san ge daibiao), and Hu Jintao's Scientific Development (kexue fazhan). But, from an institutional point of view, the most systematic attempt to organise and assign a new fundamental role to united front work is currently being done under Xi Jinping. ${ }^{7}$ On several occasions, Xi has emphasised the importance of united front work in order to accomplish the 'China dream and national rejuvenation' in the 'new era of socialism with Chinese characteristics.' In his view, the united front is connected to the need to modernise the governance of the CCP according to the perspective of the so-called Four Comprehensives (si ge quanmian) - the four political goals set out by the Party leadership in 2012, i.e. comprehensively build a moderately prosperous society, comprehensively deepen the reforms, comprehensively implement the rule of law, and comprehensively enhance Party discipline. ${ }^{8}$ Moreover, in Xi's view, united front is a strategic asset to implement Chinese-style consultative democracy, and to consolidate the interethnic and cultural unity of the country.

The importance that $\mathrm{Xi}$ attributes to this work is revealed by the organisation of several conferences on united front under his rule. Even more significantly, the complexity of goals now attributed to the united front has required that, for the first time in its history, the CCP established a regulatory framework for united front work. In 2015, the Party issued a set of 'United Front Work Trial Regulations' to clarify the realms of this activity. These Regulations define the united front as the 'alliance, under the leadership of the CCP, on the basis of the alliance of workers and peasants, of the patriots (aiguozhe)-comprehensive of all the socialist workers, the builders of socialism, the patriots who support socialism, the patriots who defend the unity of the motherland and spare no effort in the rejuvenation of the Chinese nation. ${ }^{9}$ Emphasising national cohesion under the CCP to achieve the double centenary goals (2021 for the CCP and 2049 for the PRC), the document lists the targets of the united front work. They include members of the so-called democratic parties, public figures with no party affiliation, non-Party intellectuals, influential members of the national minorities, religious leaders, business people, private entrepreneurs, and important members of the new social strata, students abroad and returned students, citizens of Hong Kong, Macao, Taiwan, and their relatives in mainland China, Chinese overseas and returned from overseas, and in the end all the people with whom it is necessary to make connections (lianxi) and unite (tuanjie).

The identification of these categories as the main targets is mirrored by the organisational chart of the United Front Work Department of the Central Committee of the CCP. ${ }^{10}$ Besides the General Affairs Office, the Theoretical Research Office, the Retired Cadres Office, and the Liaison Office for Mass Organisations, it comprises another nine highly specialised offices. Among these, two are specifically dedicated to Tibet and Xinjiang, and one to the relationship with public figures in new media, a sign of the gradual expansion of the political activities of the United Front Work Department. Currently, it is assumed that there are tens of thousands of cadres officially working in the various branches of the Department, though the number of people 
involved in the actual work is surely greater. United front work is expected to be carried out by cadres not only at every level of the Party's administration, but also in other key institutions, such as universities, research centres, and private corporations. Academic and specialised publications dedicated to the subject are numerous.

\section{From Local to Global}

Considering the revival of some aspects of Maoist governance and the importance attributed by $\mathrm{Xi}$ to enhancing the CCP's capacity to guide and control (using both ideology and legal tools) the different constituencies of Chinese society, this development is not surprising. At the same time, it has become urgent for the centre to increase its ability to control the work of local cadres involved in united front activities, in order to preserve the CCP's hegemony in the social and cultural realm. That this is a paramount concern is demonstrated by the fact that a so-called 'Central Leading Group for the United Front Work' (zhongyang tongyi zhanxian gongzuo lingdao xiaozu) has been established in the Politburo under the leadership of Xi himself.

The increasing social and cultural diversity of contemporary China and the impact of globalisation pose new challenges. As the wide spectrum of activities of the united front shows, it is evident that the CCP perceives potential threats as coming from very different constituencies-from religious organisations to ethnic communities, from private entrepreneurs to Chinese students and intellectuals abroad. Each context implies specific strategies and goals. For example, one goal of the united front work among private entrepreneurs is to ensure that they abide by the law and subordinate their personal ambitions to CCP's policies. The work among Chinese students and scientists abroad is addressed at persuading them not to abandon the motherland and cooperate for the development of the national academy and scientific improvement. On the whole, the overarching objective is to guarantee the loyalty towards the Party-state and a sense of belonging and identification with the Chinese nation as it is envisioned and understood by the CCP. In practice, the work of the united front aims at coopting selected figures within these constituencies, while isolating the individuals who do not conform. Unavoidably, this ends up causing a polarisation within these groups regarding their attitude towards the CCP.

Importantly, the Party leadership's use of the united front as an instrument of control often contradicts its stated goal of obtaining the support and collaboration of targeted individuals and communities. In the same vein, the activities of the united front within Chinese communities abroad have been perceived in several countries as a longa manus of the CCP in foreign affairs, raising worries about the attempt of the PRC to influence foreign public opinion and to conduct intelligence work through the cooperation of Chinese citizens abroad. ${ }^{11}$

In the domestic arena, in recent years united front work has also been increasingly connected to the idea that it is necessary to modernise CCP 'governance' (zhili), which in turn presumes the full accomplishment of a Chinese socialist 'consultative democracy' (xieshang minzhu), different from the Western-style electoral democracy. ${ }^{12}$ Centred on the pivotal role of the CPPCC as a distinctive Chinese political institution, the promotion of consultative democracy at any level is described as an important goal of united front activities, as the regular consultation with minor parties, targeted 
individuals, and specialised groups about local and national policies is envisioned as a necessary praxis to build wide support and consent for the Party. This 'consultative democracy' must be carried out 'seeking common grounds while putting aside differences,' a method that has a long history in CCP diplomacy and foreign relations. ${ }^{13}$ Regardless of how it presents itself abroad, it is worth remembering that within Chinese borders, the united front cannot be detached from the purpose of maintaining the CCP's political and cultural hegemony through social control.

Adopting a Gramscian perspective, Groot has argued that during periods of crisis, the Party-state relies on the united front as a strategy of 'passive revolution' to absorb potential oppositional elements and their elites into the state's hegemonic structure. ${ }^{14}$ From this perspective, the increasing importance attributed to united front work should be seen as a sign that the CCP is going through a critical stage of governance and political legitimisation. Nevertheless, the evolution of the united front has been also studied in light of the evolution of the corporatism of the Chinese state. ${ }^{15}$ In this sense, united front work must be seen as a structural aspect of the CCP's strategy to shape the relations between the Chinese state and various interest groups and to settle divergences within society. As economic development, social peace, and stability must be achieved by avoiding the possible conflicts generated by the different social and cultural claims, resorting to the theory and practice of the united front serves to revive a historical 'revolutionary' pedigree to cover up for that socialist state corporatism that seems to be an enduring facet of China's modernisation path. 
50

乌托邦
Utopia

OU Ning

(Translated by Christian SORACE)

C

hina today is defined by the rise of the so-called middle class, penetration of the market economy into all domains of life, and orientation toward practical benefit. Especially in the rash and ruthless populist undertones of online public opinion, the word 'utopia' is not only used to criticise the political catastrophe of the Mao era, but also to satirise and mock today's socially unrealistic deliriums and daydreams, monstrosities and abnormalities that run counter to the mainstream. In these days, people are ashamed to earnestly discuss utopia, let alone act on utopian ideas.

Times indeed have changed. Only when danger is imminent and everything is on the verge of collapse do people begin to urgently ponder and search for an alternative plan. Utopia calls to mind a cheerful earth that is elsewhere, a negation of reality. If people find this prospect dull, it is perhaps because their lives are calm and orderly, and it quite simply does not speak to their interests. Or, because it negates reality, perhaps it touches the red line of discourse before which people suppress their voices to protect themselves. In China, discussing utopia requires bravery; putting it into practice requires power.

\section{The Seeds of Utopia}

After learning of the Japanese author Saneatsu Mushanokōji's 'new village-ism' (atarashiki-mura, xincunzhuyi) through Zhou Zuoren in the early 1920s, the young Mao Zedong thought about organising a 'work-study mutual aid group' (gong $d u$ huzhu tuan) with his compatriots in order to build a new village utopia at the base of Mount Yuelu in Changsha. ${ }^{1}$ Due to the constraints of that particular time in history, this process never gained traction. Instead, Mao would have to wait until the 1950s- 
after he obtained the power to govern China by means of violent revolution-to act on his utopian impulse, which took the form of people's communes (renmin gongshe) (see Gao's essay in the present volume).

If Mao's ambition only resembled the small-scale utopian experiment pursued by intellectuals of the Shirakaba-ha (literally, 'White Birch Society') deep in the mountains of Miyazaki prefecture in Japan, the impact on society would be limited to the scale of a community. ${ }^{2}$ But propelled by Mao's power, people's communes sprung up in a vast political campaign and the entire country was transformed into a utopian experimental laboratory. By concentrating the means of production, militarising management, and enforcing collective labour, people's communes thoroughly eradicated the social structure of China's clan-based villages and the tradition of small peasant production methods. The laziness of human nature was indulged by imitating the system of 'communal feeding' (daguofan) of Zhang Lu, a Han Dynasty warlord, with its principle of 'setting up shelters for those in need of meat and drink' (qi yishe, zhi mirou). Although the construction of water conservation works left a legacy for collective agriculture, by the end of the 1970s fields were no longer cultivated and lay in waste. It was peasants from Fengyang county in Anhui province, who had suffered untold miseries during the Great Leap Forward, that finally sparked the bottom-up reform of 'fixing farm output quotas for each household' (baochandaohu) that eventually put an end to the era of the people's communes. ${ }^{3}$

Almost all utopian experiments on earth end in failure. Although the origins of Mao's utopian thinking can be traced back to small anarchist groups from the end of the nineteenth century, Mao magnified utopia at the national scale. When Mao in practice merged the communist principle 'from each according to ability, to each according to need' ( $g$ e jin suo neng, an xu fenpei) with Kang Youwei's explication of the Confucian idea of 'great unity' (datong) - that is, a utopian vision in which everything is in its proper place and peace prevails (see Craig A. Smith's essay in the present volume)-a disaster was born. ${ }^{4}$ In humanity's infancy, when population was scarce and natural resources were abundant, it was possible to form small-scale societies that practiced communist mutual aid and emphasised morality. But with the rapid increase of population, the proliferation of ethnic communities, and the growing diversification of interests, the ideal society of ancient times vanished into smoke. As early as the Warring States period (475-221 BCE), legalist thinker Han Fei wrote in the treatise Five Venoms: 'Men of high antiquity strove for moral virtue; men of middle times sought out wise schemes; men of today vie to be known for strength and spirit. ${ }^{5}$ To enlarge the ideals of a small society to the scale of a whole nation is like using one's childhood experience in the adult world. When such a brittle utopia collides with reality, it inevitably shatters into fragments.

\section{Utopian Traces in the World}

The Chinese word for utopia (wutuobang) has two synonyms: 'ideal state' (lixiang guo) and 'nowhere place' (wuyou xiang), meaning something nearly impossible to discern in the real world. For this reason utopia is in itself a discourse outside of time and space, an action that is unlikely to be realised. If utopia is put into action, it is destined to be connected with failure. Beginning with Sir Thomas Moore's sixteenth-century 
treatise Utopia, a school of utopian thought arose in England, culminating in Robert Owen's New Lanark experiment in Scotland and his commune in New Harmony, Indiana, in the early 1800 s. $^{6}$ Owen devoted his life to improving the environment for workers, nurturing their character, and creating a new society in which, to use once again the words of Han Fei, 'no rich rewards were doled out, no harsh punishments were administered.7 Throughout the rest of the nineteenth century, which was the age in which all kinds of experimentation were possible, numerous other efforts to build utopias arose, most of which were short-lived, but which nevertheless often had significant implications for society going forward.

In the United States, the Shaker Village (1805-1910) and the Oneida Community (1848-80) were distinguished by their rejection of the nuclear family and private ownership of property. This rejection manifested itself differently in each community, as asceticism in one, and complex marital arrangements in the other. ${ }^{8}$ However, these communities were unable to stave off the pressures from orthodox Christianity and the vigour of industrial capitalism. Entering the twentieth century, these formerly shocking practices were generally covered in dust and forgotten by mainstream society (despite the persistence of some like the Amish). After World War II, this kind of small-scale utopian project reappeared in two distinct responses to the crisis of Western society of that era: first in B. F. Skinner's novel Walden Two published in 1948, and later in the social movements of the 1960s and 1970s symbolised by the hippie commune. ${ }^{9}$ After Trump's rise to power in 2016, numerous books on utopian practices have been published. Even before this present crisis, globally there has been an intermittent accumulation of experimental small-scale ecological villages and intentional communities, which represent the evolution of utopia in the contemporary era. It would seem that the moment to discuss utopia is, once again, upon us.

\section{Utopian Violence}

At the time when Mao turned to violent revolution, there were still several intellectuals who attempted to improve society by other means. Although intellectuals involved in the Rural Reconstruction Movement (xiangcun jianshe yundong) of the 1920s and 1930s seldom invoked the discourse of utopia, the desire to challenge the cruelty of that period's realities had a certain shade of utopian thinking. Activists such as Y. C. James Yen and Liang Shuming attempted to transform China through mass education and moderate social experimentation. ${ }^{10}$ Although they shared the same starting point of dissatisfaction with the state of the world as Mao Zedong, they selected different paths. In response to historical conditions, Mao's belief in Marxism became an ideological pretext for revolutionary mobilisation; utopia was shelved as a remote ideal and the urgent needs of political reality became a 'you die, I live' factional struggle for power. Subsequently, the Rural Reconstruction Movement was abruptly cut short by the Japanese invasion of China. It ended in failure, whereas Mao's violent revolution succeeded.

After seizing state power, Mao had a free hand to start building his utopia. Liang Shuming remained in China only to be persecuted in ideological campaigns; Y. C. James Yen went to the Philippines where he strove to internationalise the Rural Reconstruction Movement. As described earlier, people's communes transformed China 
into a place in which the people had no way to survive. After Mao's death, the adoption of the Household Responsibility System (jiating lianchan chengbao zerenzhi) broke up collective agriculture and land-use rights were returned to the hands of farmers. For an ephemeral moment, there was vitality in the countryside, which was soon to be extinguished by the urbanisation movement that would swallow agricultural land and atomise the peasantry. In the new millennium, the problems of the countryside have returned, giving rise to a New Rural Reconstruction Movement (xin xiangcun jianshe yundong) (see Day's essay in the present volume). ${ }^{11}$ This new version originated among intellectuals outside of the state system, as a continuation of the historical experiments of Yen and Liang, in an attempt to find new methods to address contemporary problems.

In the Deng Xiaoping era, the tanks that rolled into Tiananmen Square cleared a path for neoliberal economics to enter China. After Deng Xiaoping's Southern Tour in 1992, China was transformed from a political society into a consumer society. The trauma of 1989 was forgotten as people threw themselves into the business of making money. The reform of state-owned enterprises plunged millions of workers into unemployment; due to the opening and expansion of real estate markets, farmers lost their land; economic construction consumed natural resources and intensified ecological destruction; and social wealth was redistributed resulting in a staggering gap between rich and poor. The concentration of China's population in megacities has hollowed out its villages. But China's growing urban middle class is filled with discontent over the struggle to find work, traffic congestion, air pollution, and competition over limited educational resources. In response, a trend of counterurbanisation (ni chengshihua) has begun.

\section{The Danger of Utopia}

The New Rural Reconstruction Movement was initiated by Wen Tiejun, a wellknown professor at Renmin University, as an attempt to reverse the dire realities of China's urban-rural situation. It proposes to reconstruct a positive and mutually interactive relationship between the rural and urban, motivate young people to return to the countryside, establish 'mutual aid societies' (huzhushe) in different village areas, develop ecological agriculture, and form community colleges that follow in the tradition of Yen's practice of mass education. ${ }^{12}$ In addition to taking care of people left behind in the villages, it also attaches importance to communities of migrant workers struggling to survive in the city. Aspects of this project have been extremely successful, while others have failed and been shut down. Although he does not define his efforts as utopian, and views himself as pragmatically working at the frontlines of rural communities, Wen Tiejun is associated with contemporary China's leftist intellectual pedigree because of his opposition to neoliberalism and pursuit of social fairness. For this reason, some of his 'failed' projects have dismissively been labelled as 'utopian.'

Whether in China or abroad, utopian experiments often take place in the countryside. The reason for this perhaps comes from the distance of rural life from the imagination of the urban mainstream: it is either wilderness or a place that has preserved the traces of humanity's infancy. In reality, an untouched 'place beyond civilisation' (huawai zhi di) already ceased to exist in ancient times, let alone in post-Mao China. Rural areas do 
not have fewer problems than cities, and are fully intertwined in the contradictions of Chinese society. For this reason, most efforts to improve rural areas in isolation from the city have been derided as 'utopian.'

Among the numerous approaches to practicing the New Rural Reconstruction Movement, the Bishan Project is perhaps the only one not to be ashamed to admit its utopian orientation. ${ }^{13}$ In 2010, this project took root in Bishan village, Yi county, Anhui province, beginning with the renovation of tattered old houses and their conversion into living and work spaces, as well as a newly established bookstore, library, and art centre. The project also conducted research on village history and traditional handicrafts, organised large-scale cultural and art activities, provided work opportunities for volunteers returning to the countryside, and helped villagers increase their incomes by using Taobao and Airbnb-until Beijing shut it down in 2016.

The Bishan Project was not the same as the Mao era's state-led mobilisation of youth and intellectuals to go 'down to the countryside' (xiaxiang) to work and reform themselves through labour. And its utopian direction was also distinct from the largescale people's communes of the Mao era. Rather, it was founded voluntarily after much consideration and reflection on the urbanisation crisis and agricultural situation. Moreover, it was based on a survey of the explorations of individuals and small groups in different historical periods from all over the world. That being said, Bishan was unable to incorporate some of the historical experiences and experiments in horizontal living arrangements from other places, which would be non-starters in China's atmosphere of political control.

In contemporary China there can be no genuine utopian practices, only utopian discourses. But sometimes even words themselves can disappear. 



\section{1 \\ 妇女解放 \\ Women's Liberation}

WANG Lingzhen

D

ifferent from the concept of women's liberation articulated and practiced within the capitalist system-which focuses on middle-class individualism, female independent consciousness, and equal political and legal rights between men and women-socialist women's liberation aims to dismantle the capitalist politicaleconomic structure that (re)produces not only gender hierarchy, but also class, racial, and regional inequalities. The socialist theory of women's liberation does not separate women's issues from other structural inequalities, arguing that women's oppression cannot be resolved if political-economic oppression continues. As an extraordinary feminist movement that eventually helped establish a socialist country where gender and class equality became the norm, Chinese socialist women's liberation particularly promoted an integrated, proletarian-oriented, and mass-participatory approach to the women's movement. In addition to class revolution and anti-feudal cultural revolution, Chinese socialist women's liberation is tied to the modern third world national independence movement and international socialist anti-imperialist endeavours. It endorses historical materialism, questioning any ahistorical naturalisation or culturalisation of women's oppression. Women's liberation, according to socialist theory and practice, is a long and complicated process because it is interlocked with liberation of all social subjects, which would amount to a total dismantlement and transformation of capitalist and other forms of patriarchal socioeconomic structures at both local and global levels.

Since the late 1970s and early 1980s, however, socialist feminist practice in generaland Chinese socialist women's liberation in particular-have been challenged by feminist scholars in both the West and China. Western Cold War ideology combined with the Western post-Second Wave feminist, especially radical feminist, repudiation of Marxist theory and the left-wing movement in the 1970s have played a powerful role in (re)orienting Western scholarship on women's liberation in the Chinese Revolution. 
In the Chinese context, the new ideology of economic reform implemented by the Party-state toward the end of the 1970s also, in its apparent de-legitimisation of the Cultural Revolution, swept aside some central socialist principles, including gender and class equality. The rise of the neoliberal trend of governance among both developed and developing countries-as well as the global intellectuals' general (re)turn to depoliticised cultural and 'bourgeois' values such as individual liberty, privacy, and justice in the 1980s-further undermined and discredited the socioeconomic and political achievements of socialist women's liberation in history. ${ }^{1}$

In this neoconservative and market-dominated transnational context, Western feminist scholarship started asking the question: 'Did socialism liberate women?' Or, more directly: 'Why has socialism not liberated women in China?'2 This quickly developed into a new scholarly trend, reversing the general direction of Western Second Wave feminist socioeconomic engagement in the 1960s and 1970s, especially retreating from its structural critique of capitalism. Whereas some scholars have argued that this reversal from idealisation to denigration of socialist China reflected more the changes in Western politics than anything directly to do with China, ${ }^{3}$ the rhetorical question of whether socialism can liberate women became transnational and pervasive in the 1980s and 1990s, and much feminist research in the United States and in China has directed itself to this question. ${ }^{4}$ This new trend by no means suggested a historical and geopolitical inquiry into the meaning and process of women's liberation in the Chinese Revolution. On the contrary, it worked to interrogate the socialist theory and practice of women's liberation from liberal, individualistic, separatist feminist and Cold War standpoints generated and practiced in the capitalist system. That is to say, the integrated, proletarianised, and institutionalised approach of Chinese socialist feminism to women's issues was dismissed as non-feminist both outside and inside China in the 1980s because it does not promote individualistic, autonomous, and essential female cultural values.

Starting from the early 1990s, when the end of the Cold War showcased the triumph of Western capitalism, accelerating the development of global neoliberalism and the transnational market, women's status and the feminist emancipatory vision of women's liberation have steadily deteriorated. At the same time, however, brought together by transnational capitalist forces, particularly the multilevel crisis produced by neoliberalism and marketisation at the global scale, feminist scholars and activists around the world have begun to probe the dangerous liaison between contemporary (post-Second Wave) feminist practices, neoliberalism, and free market fundamentalism. ${ }^{5}$ This served to reactivate the socioeconomic insight and international legacy of the Second Wave feminist movement, particularly socialist feminism. ${ }^{6}$ At this critical juncture, it is important to reassess the history and legacy, as well as the limitations of Chinese socialist women's liberation to renew systematic critiques of capitalism, to restore the integrated socialist emancipatory vision of the future, and to forge a transnational feminist alliance to confront global neoliberalism. A critical revisiting of the socialist theory and practice of women's liberation in history should also inspire us to combine feminist concerns of culture and ethics with politicaleconomic structural practice, projecting an alternative model for the post-Cold War world. 


\section{How Chinese Socialist Women's Liberation Came to Be}

The global spread of Western feminisms in the late nineteenth century, especially across China and other third world countries, was a direct result of Western imperialism, capitalist expansion, and colonial modernity. Not all feminist ideas and practices, however, would take root and grow under local conditions. A variety of feminisms, including liberal, anarchist, evolutionary and eugenic, and Marxist, appeared during China's transition from a dynastic system to a modern nation-state, yet only those feminisms that were institutionalised locally, or Sinicised through political, social, and economic practices, would become an integrated force in modern Chinese history.

Chinese socialist women's liberation developed from urban liberal and Marxist feminist discourses of the May Fourth Movement, embracing both individualist and socialist ideas about women's liberation. ${ }^{7}$ As a critical cultural discourse, Marxist feminism in the early May Fourth Movement called for women's participation in social production and political governance; the abolition of private property ownership and capitalism; transition from a middle class (bourgeois) women's rights movement to working class women's economic and gender liberation; and socialism as the sociopolitical foundation for women's liberation. ${ }^{8}$ It was, however, not until the establishment of the Chinese Communist Party (CCP) in July 1921 that Marxist and feminist ideas were adopted by a political organisation that unequivocally committed itself to socialist feminist practice.

The CCP, at its Second Congress in 1922, passed a 'Resolution on the Women's Movement, formal guidelines for organised feminist activities that highlighted the Chinese women's movement as an integral part of broader proletarian liberation as well as anti-imperialist and anti-feudal struggles. ${ }^{9}$ The Party continuously pursued this basic policy of uniting struggles for women's liberation with the socialist revolutionary movement. ${ }^{10}$ This theoretical and political clarification distinguished Chinese socialist feminism from all other feminist discourses imported into China at the time and paved the way for the institutional integration of Chinese women's liberation into the Communist Revolution. The Chinese socialist women's movement continued developing throughout the 1920s, directly engaging with the anti-imperialist movements, labour movements, and the Northern Expedition (1922-27), during which the Nationalists formed the First United Front with the CCP to exterminate regional warlords and reform political and economic institutions. In 1925, at the Fourth CCP Congress, a new 'Resolution on the Women's Movement' was stipulated, stressing the central role of women workers and peasants in Party-led women's movements. ${ }^{11}$ In 1927, however, the Nationalists and the CCP split violently. The subsequent terror inflicted upon the CCP and women activists marked a dramatic turn in the history of socialist feminism in China.

The late 1920s witnessed the Party's most significant theoretical and practical transformations, including serious reflections on its feminist policy and affiliations. The CCP repositioned itself in relation to China's large rural populations of women, rather than solely urban-based women workers. As part of the general Sinification of Marxist theory, this reflexive change ultimately reoriented Chinese socialist women's liberation. 
Mao Zedong's 1927 'Report on an Investigation of the Peasant Movement in Hunan, provided the initial and most important theoretical argument for both peasant revolution and socialist feminism in the Chinese context. In this document, Mao famously described how Chinese men (peasants) are oppressed by political authority, clan authority, and religious authority, while women, in addition to these three authorities, 'are also dominated by men [the authority of the husband].' The political authority of the landlord, according to Mao, underpinned the three other systems of authority. Therefore, dismantling these economic relations and overthrowing the power of the landlord marked the first step in the process of breaking down the traditional social system. For the first time in Chinese history, peasant women were represented as those most oppressed in China's political, economic, religious, and social systems, and were tied explicitly to the Chinese communist revolutionary cause. Moreover, being the most subjugated group, peasant women, together with peasant men, were perceived as historical agents in the proletarian revolution that would bring structural changes to China.

In 1928, the Sixth CCP Congress passed a resolution prioritising the development of a peasant women's movement. According to this resolution, because female peasants remained at the bottom of China's rural socioeconomic system, the CCP must 'recognise that peasant women were the most active revolutionary force' and therefore must recruit them into general peasant organisations. ${ }^{12}$ The recognition among CCP leaders of the potential power of peasant women helped establish women's liberation as a core component of future communist revolution.

By the time the Jiangxi-Fujian Soviet Republic, a Chinese communist base, was established in 1931, certain CCP members had formed a relatively coherent platform to address the combined issues of nationalism, class, and gender in the Chinese context, while keeping with general Marxist tradition. At this early stage, women's liberation began to be systematically institutionalised and integrated into the Chinese Communist Revolution. First and foremost, the Soviet Republic's Constitution, proclaimed by the first All-China Congress in Ruijin, Jiangxi, guaranteed equal rights for the working masses and the complete emancipation of women:

All workers, peasants, Red Army soldiers, and all toilers and their families, without distinction of sex, religion, or nationality shall be equal before the Soviet law, and shall be citizens of the Soviet Republic.

It is the purpose of the Soviet government of China to guarantee the thorough emancipation of women; it recognises freedom of marriage and will put into operation various measures for the protection of women, to enable women gradually to attain the material basis required for their emancipation from the bondage of domestic work, and to give them the possibility of participating in the social, economic, political, and cultural life of the entire society. ${ }^{13}$

The Soviet Republic also established concrete laws to enforce equality in status and participation. These new legal codes 'specifically affected the position of women in marriage and the family, and in their relationship to the land, the factory, and new 
political institutions. ${ }^{14}$ For the first time in modern Chinese history, women's social emancipation was promoted together with their economic and material emancipation. Implementation of these newly established laws was particularly emphasised, as the CCP fully understood 'it was not enough just to introduce new legislation, it had to be put into practice. ${ }^{15}$ Special women's departments were established in all Party organisations, along with local women's congresses to preside over women workers. Literacy classes and training courses were provided as well, to coach women activists in leadership techniques and to break down traditional gendered divisions of labour. Such opportunities enabled a significant number of women to step out of their homes and, for the first time, participate in political and economic activities. ${ }^{16}$ In short, the CCP's policies of 1931 and their implementation set the course for the institutionalisation and integrated development of the peasant women's movement in the soviet areas. ${ }^{17}$

During this same Soviet Republic period, the CCP also developed intensive, periodic mass campaigns to directly confront local resistance to the women's movement reinforcing its institutionalisation. The Jiangxi Soviet's particular circumstancesthat is, the establishment of a radically new and modern political power base in an underdeveloped and relatively isolated agrarian area-were extremely irregular. Deeply ingrained Confucian family values rendered certain feminist ideas, especially women's freedom to marry and divorce, completely alien even among peasant women themselves. The offensives of the Nationalist Party military further prevented long-term and orderly education and implementation of socialist feminist policies. As a result, short-term, intensive political campaigns and mass mobilisations were adopted as revolutionary practices, especially during politically and militarily unstable periods (see Li's essay in the present volume). ${ }^{18}$ This mass mobilisation approach developed into the mass line organisation and governance of the late 1930s and 1940s, a signature style of CCP leadership, which continued into the socialist period (see Lin Chun's essay in the present volume). Chinese socialist feminist institutionalisation from early on was accompanied by this unique mass mobilisation approach. Periodic mass campaigns might appear temporary and informal but in fact played a critical role in spreading socialist feminist ideas, challenging traditional gender perceptions among the rural masses and mobilising women to participate in the Party, politics, and production. ${ }^{19}$ In addition, mass campaigns also resulted in the CCP recalibrating political ideology and organisational tactics in response to inspiration from the masses. ${ }^{20}$ They further helped the CCP battle dogmatism, bureaucratism, and commandism within the Party, adjusting and revising its policies based on concrete historical situations.

Socialist feminist practice in the Jiangxi Soviet Republic was in many aspects experimental, testing an array of ideas, policies, legal implementations, and local conditions in a particular rural area of southern China. Nevertheless, the Republic's multilevel, institutional, and mass configuration created a model for feminist practice in socialist revolution that would continue after the People's Republic of China was established in $1949 .^{21}$

The recognition of the critical role of rural women in socialist revolution catalysed the Jiangxi Soviet's integrated institutionalisation of socialist feminism and the CCP's mass line, leading to the Party's continued reflections on and revisions of its policy and practice of the women's movement. To a large extent, Chinese women's liberation became a crucial criterion for the CCP to measure the effect and success of Chinese 
socialist revolution. In 1931, the Party conducted an extensive assessment of the women's movement in the Soviet area and discovered a great number of issues caused mostly by the reluctance of local intermediate and lower-level leadership in promoting the interests of peasant women, as well as their political and economic participation. New policies were thus implemented to change the situation, including the facilitation of better organising and recruiting of women into local leadership positions. ${ }^{22}$ In 1934, Mao Zedong, after investigating women's work in the Zhongyang district, criticised the local record. He concluded that women's specific interests were ignored in the general policymaking, and attention to women's education was insufficient, particularly with regard to efforts to explain new policies to peasant and working women. Mao then offered concrete suggestions for better attending to local women's needs and connecting their interests to other political problems. ${ }^{23}$

From 1937 to 1941, the women's movement in the more conservative and less developed northwestern Shan-Gan-Ning Border Region experienced certain setbacks. With the outbreak of the Second Sino-Japanese War (7 July 1937) and the subsequent formation of the Second United Front (1937-45) between CCP and the Nationalist Government, the overall revolutionary policy prioritised the war effort as well as the unification of different social classes and forces. ${ }^{24}$ In the late 1930s, however, the CCP already noticed stagnation in women's work and a 1939 Party resolution made an urgent request to recruit more women:

Women constitute half of the population of China. Without women's participation in the revolution, the revolution cannot succeed. The number of women workers in the Party is too small at present, primarily because not enough attention has been paid by the Party. The Party must today emphasise the task of absorbing into its ranks revolutionary peasant women and women intellectuals in great numbers $\ldots .^{25}$

By mid-1941, Party leaders had discovered more problems in the women's movement and the 1941 elections in the Shan-Gan-Ning Border Region were consequently coordinated with a campaign for women's rights. On 26 February 1943, as a part of both the Rectification Campaign against Dogmatism within the CCP and the CCP's effort to deploy the mass line approach to revolution, the Central Committee issued a new policy for women, actively addressing the existing problems and mobilising women to participate in economic production and war efforts. As Patricia Jackal wrote: 'There was a consistent effort throughout the Yan'an period to move women toward equality by bringing them out of the confines of their traditional lives and, in each stage, involving them in larger groups with broader concerns.. ${ }^{26}$ The CCP's continued reflection and revision of its revolutionary and feminist policy showcased the Party's recognition of the indispensability of the women's movement to the overall revolution. The integration of women's work into the socialist revolution was thus key to advancing both Chinese women's causes and communist revolution in modern China. 


\section{Interdependence between Chinese Socialist Revolution and Women's Liberation}

One fundamental topic that deserves additional emphasis in a critical review of Chinese socialist women's liberation concerns the interdependence and integration of the socialist revolution and the proletarian women's movement in modern China. This interdependence does not simply reflect the Marxist theoretical proposition that women's liberation is part of the overall proletarian revolution; more importantly, it reveals the broader geopolitical and socioeconomic condition that entailed the mutual support between Chinese socialist revolution and feminism for their survival and future success. Of all the major, modern revolutionary ideas introduced to rural China by the CCP in the late 1920s, feminism and women's liberation appeared most alien to Chinese peasants, both men and women. ${ }^{27}$ In the context of long-standing Confucian traditions, a devastated rural economy, and geographical and social isolation, granting women equal rights to social and public production, political participation, and governance was extremely radical. Local resistance first appeared as early as the beginning years of the Jiangxi Soviet period..$^{28}$ Adjustments to the implementation of socialist feminist policies were not a choice or bargain the CCP negotiated, but rather the only option presented by the historical reality. This conflict clearly demonstrates how gender issues and feminist questions cannot be addressed in isolation from other social, political, and economic conditions. In the China of the 1920s to 1940s, especially in rural areas, to stress the 'independence' and 'autonomy' of feminist movements would further estrange feminism from local populations, destining women's liberation to failure from the start. ${ }^{29}$ The integration of feminism into the Chinese socialist revolution, class struggle, nationalist revolution, and economic development, proved essential to the survival of feminism in the Chinese context.

The other side of this interdependence requires emphasis as well. The success of the Chinese socialist revolution would be inconceivable without the CCP's rigorous feminist policies and practice. Fully aware that the revolution needed both peasant men and women, rural-oriented CCP leaders at the turn of the 1920s and in the 1930s did not position themselves as external liberators of rural Chinese women. Rather, they reenvisioned male and female peasants as the Party's core revolutionary subjects. As Kathy LeMons Walker points out: 'The new direction in the women's movement was an essential part of the Party's general effort to integrate itself with the rural populace. ${ }^{30}$ Chinese socialist revolution would not have succeeded without the CCP's dedication to socialist women's liberation. Those who argue that the CCP simply compromised its feminist stance when conflicts arose with (peasant) men have ignored the crucial fact that neither class nor gender was dispensable for the Chinese socialist revolution. Class and gender equality constitutes the very goal of socialist revolution, and peasant and working men and women served as the central force in carrying out the revolution. A CCP document published in 1930 explicitly argued for the Chinese women's movement as 'an indispensable arm of the revolutionary struggle as a whole. ${ }^{31}$ Pressured by national crises, the Nationalists' military offensives, and conservative forces in various areas, the CCP sometimes had to 'compromise' on both class and gender issues, but such manoeuvrings do not suggest fundamental concessions. ${ }^{32}$ 
In practice, it was the CCP's dogmatic faction, which ignored Chinese conditions by stubbornly insisting on Marxist theories of urban working class struggle and Russian experiences, which had risked destroying the revolutionary force in the Jiangxi Soviet. ${ }^{33}$

While illustrating the interdependence between Chinese socialist feminism and socialist revolution, I also want to highlight the fact that Chinese socialist feminism had its own limitations. Theoretically, international socialist feminism has been both enabled and constrained by Marxist theory on gender, which stipulates that social production is key to women's liberation and that the elimination of private property would automatically address both class and gender issues. As feminist scholars have already pointed out, structural transformation brought about by the capitalist mode of production did challenge and shake the traditional gender division of labour, but it generated a new public form of patriarchy and a different gender division of labour. ${ }^{34}$ Even in the socialist period after the completion of nationalisation and collectivisation, traditional ideas and practices, although much reduced in the urban public and official space, remained active in some private and local rural areas. At the same time, Marxist theory's dismissal of women's roles in reproduction and domestic labour led to gender blindness in its materialist approach to history. This theoretical oversight resulted in the lack of adequate policies to address women's double burden in socialist society. Finally, Marxist theory, based on the European model, is limited in providing guidelines for anti-colonial, socialist, and feminist revolutions taking place in third world areas.

In the context of the Chinese socialist revolution, the combination of an underdeveloped agrarian economy, a largely illiterate rural population, and a deeply entrenched Confucian culture, all in a semicolonial state with endless wars and military conflicts, presented considerable local challenges to feminism in practice. The CCP encountered various kinds of obstacles and resistance including from its own members when it implemented certain policies to forward the women's movement. Clearly, feminist practices do not transcend their historical conditions, nor can they stand alone, independent from China's political, socioeconomic, and cultural transformations. Many of the limitations of socialist feminism, including those occurring in Mao's China, are tied to the limits of China's socialist revolution and the overall socioeconomic and geopolitical conditions. The idea that feminism(s) should independently address a universal set of issues across the globe, and the assumption that socialist revolution should solve all 'women's questions' raised from the universalised Western perspective regardless of historical conditions, only manifest an imperialist Cold War stance in transnational studies of women and socialist revolution.

\section{Nationalisation of Gender Equality and Mainstream Proletarian Feminist Culture}

With the consolidation of the communist victory in China after 1949, socialist women's liberation evolved into an officially promoted and mass participated mainstream discourse and practice. On 24 March 1949, shortly after the CCP took control of Beijing, the First Chinese National Women's Congress convened, and the formation of the All-China Federation of Democratic Women (ACDWF, later changed to ACWF in 1957) was announced. The Marxist materialist view of women's liberation, which espouses women's direct participation in social production, constituted one of the central principles of socialist China's feminist policy. ${ }^{35}$ Radical changes also followed 
the state's nationalisation of gender and class equality, as well as the redefinition of women's roles as socialist subjects in the early 1950s. More critically, Chinese socialist women's liberation constituted a central force in advancing all aspects of the newly established socialist system. In addition to guiding the promulgation and implementation of new marriage laws (1950-53), and championing multidimensional gender equality and women's special interests, socialist women's liberation also integrated itself into other major state movements, such as land reform and collectivisation (1950-53), the Korean War (1950-53), early industrialisation (1950-55), literacy campaigns (1950-56), and the Great Leap Forward (1958-62). In 1955, Mao Zedong put forward the slogan 'Chinese women can hold up half the sky.' The interconnectedness between feminism and other socialist practices also resulted in the emergence of a politically constructed proletarian public space that was essentially, and simultaneously, feminist and socialist.

Contrary to the conventional wisdom arising in the 1980s that claims Marxist or socialist feminism promotes socioeconomic redistribution and class equality at the expense of gender and cultural issues, Chinese socialist women's liberation not only achieved socioeconomic gender equality but also sustained the blossoming of socialist feminist mass culture. Socialist feminist culture explicitly targeted feudalist and capitalist patriarchies and Chinese traditional culture, transforming social ethics and constructing proletarian and socialist female model figures in 1950s China and beyond.

Chinese socialist feminist culture belonged to the political mainstream but grew from diverse international and domestic influences, changed over time, and produced various representations and aesthetics. ${ }^{36}$ In the widely circulated journal, Women in China (zhongguo funü), published by the All-China Women's Federation, socialist women articulated varying senses of agency and critical concerns, incorporating and transforming the May Fourth and left-wing feminisms. ${ }^{37}$ But variations in Chinese socialist feminist culture do not suggest a lack of a coherent, central agenda. The idea and practice of 'proletarianisation' distinguished Chinese socialist feminism from earlier Chinese feminisms, as well as from feminism practiced in other countries. ${ }^{38}$ Socialist public representation of new roles for working class women, such as tractor drivers, train dispatchers, and high pressure welders, illustrated 'the arrival of a socialist modernity contingent upon shattering the fetters of Confucian, feudal, and capitalist worldviews and their attendant patriarchal forms. ${ }^{39}$ The first group of working class women who embodied socialist gender equality, empowering themselves with modern knowledge of heavy machinery, also brought socialist Chinese women to 'the forefront of new national, international, and world orders. ${ }^{30}$

It is true that despite the abolition of private ownership and strong cultural campaigns against patriarchy, certain gender and class issues remained in socialist China. But this truth should in no way cancel out the extensive and unprecedented progress made in women's and proletarian liberations in world history. The development of Chinese socialist feminism in the post-1949 era was naturally a complex process, continuously manifesting a geopolitically constrained, socioeconomically conditioned, and culturally negotiated practice. Not all initiatives succeeded. The Cold War economic and technological sanctions launched against China, for example, directly led to structural inequality between rural and urban areas and the persistence of certain gendered divisions of labour. 
Socialist China's experience has clearly illustrated that women's liberation can by no means be achieved overnight or independently. The historical limitations of Chinese socialist feminism called for a continued, integrated, and expanded revolution even after the establishment of a socialist system. Today, as feminist movements have moved to restore a structural assault on the capitalist socioeconomic system, to forge transnational alliances over different geopolitical regions, and to develop an integrated emancipatory vision and approach, the practice of Chinese socialist women's liberation-both its achievements and limitations-can offer us critically relevant insights and alternative imaginations. 


\section{2 \\ 工作队 \\ Work Team}

Elizabeth J. PERRY

he common practice of deploying 'work teams' (gongzuodui or gongzuozu) to troubleshoot unexpected crises, implement developmental priorities, propagate official ideology, and monitor and discipline cadre corruptionamong other purposes-is a defining feature of Chinese Communist Party (CCP) governance. Perhaps because work teams straddle the boundary between formal and informal institutions, however, they have received scant analytical attention. Although work teams figure prominently in narratives of almost all the major mass campaigns of the Mao era-Land Reform, Thought Reform, Anti-rightist, Four Cleans, Cultural Revolution, and so on-their continued importance in the post-Mao era has seldom been emphasised. And even for the Mao period we lack a clear understanding of when, why, and how such units were differentially deployed. Yet, arguably it is this mechanism more than any other that exemplifies China's uniquely dexterous brand of authoritarian governance from its revolutionary days through to the present. ${ }^{1}$

\section{Putting the Mass Line into Practice}

Work teams are ad hoc units that are appointed and directed by higher-level Party and government organs to advance a specific mission and, following a stint of intensive training, are dispatched to lower levels of the political system for a limited period of time to carry out their assignment by means of mass mobilisation (see Li's essay in the present volume). Work teams are regarded as a key instrument for practicing the 'mass line'-Mao Zedong's injunction to involve ordinary people in the articulation and implementation of Party policy (see Lin Chun's essay in the present volume). The membership of these task forces, typically comprised of half a dozen or fewer people (but occasionally as small as a single individual or as large as a hundred or more), is designed to cut across normal bureaucratic and geographical lines. Work team 
members are supposed to be outsiders to the places where they operate, are usually drawn from a variety of different organisations, and generally possess a wide range of experiences and skills. In most cases they include a substantial representation of Party members from various official agencies along with a significant number of intellectuals (zhishifenzi, usually university students and professors) as well as grassroots activists (jijifenzi). After undergoing a training programme (often lasting several weeks or more), which includes the study of new policy documents, sharing of experiences from other work teams, and familiarisation with the problems and particulars of the place to which they will be sent, work team members decamp to a village, factory, university, or other targeted site of operation. One of their first onsite activities is to convene a mass meeting to introduce their centrally mandated assignment and to identify potential local activists to help achieve their mission.

Some of the most popular novels of the early People's Republic of China (PRC), such as Ding Ling's The Sun Shines over the Sangkan River (1954) and Zhou Libo's The Hurricane (1955), were based on the novelists' own experiences as members of a land reform work team. ${ }^{2}$ Our most detailed and dramatic English-language eyewitness accounts of the Chinese Revolution, William Hinton's Fanshen (1966) and Isabel and David Crook's Ten Mile Inn (1979), were also drawn from the authors' personal participation in work teams. ${ }^{3}$

These first-hand accounts by Chinese and foreigners alike suggest that work team members find their service to be a memorable-sometimes even transformativeexperience. Diaries, memoirs, novels, and other writings and interviews of former team members generally describe their stint in a village, school, or factory as an eyeopening adventure that enhanced understanding and empathy for the problems of ordinary people, increased appreciation of central policy goals, and heightened their sense of political engagement and efficacy. With so many of China's leading officials and intellectuals having participated in multiple work teams over the years, the positive contribution to regime loyalty and legitimacy would seem to be considerable.

But work teams are more than a means of generating support among the political and intellectual elites. The contributions of work teams to PRC governance are manifold. In addition to promoting a particular higher-level agenda, and enlisting grassroots participation in advancing it, the teams provide a direct (albeit temporary) channel of communication between state and society. Ordinary people gain awareness of state priorities and propaganda while upper-level officials in turn glean information and insight into the concerns of citizens at the grassroots. As outside emissaries who report directly to higher government and Party agencies, thereby bypassing local cadres, the work teams also act as a powerful check on grassroots officials. Often they are authorised not only to monitor, but also to reprimand local cadres. They therefore play a major role in Party rectification and anti-corruption campaigns as well as in initiatives to further economic and development objectives (see Mertha's essay in the present volume).

\section{Historical Origins}

First deployed on a massive scale in conjunction with the Land Reform Campaign of 1947-53, work teams have precedents that can be traced at least as far back as the 1920s, when the CCP-under the aegis of the First United Front with the Nationalist 
Party (guomindang, hereafter GMD) and in response to the encouragement of Soviet advisors-first began to develop a systematic strategy for rural mobilisation. At the Peasant Movement Training Institute (PMTI) in Guangzhou, established in the summer of 1923 as an official GMD entity reporting to its Peasant Bureau, early communist organisers such as Peng Pai and Mao Zedong instructed and assigned fellow revolutionaries in a manner that anticipated the later formation of work teams. ${ }^{4}$ After receiving several months of intensive classroom and infield training, successful PMTI graduates would be sent back to their native places as 'special emissaries' (tepaiyuan) whose mission was to incite the local peasants to revolutionary action. They were responsible for instigating much of the violence of the Red Terror that accompanied the joint CCP-GMD Northern Expedition of 1926-27.

These special emissaries prefigured the later practice of work teams in that they were selected and directed by an official agency-namely the GMD's Peasant Bureau-to carry out a specific, centrally designated mass mobilisation effort. They were expected to spend at least six hours a day in their assigned villages, conducting investigations, and undertaking propaganda and organisation work. They were required to submit weekly reports to the Peasant Bureau and to return to the bureau's headquarters in Guangzhou after each deployment to await instructions for the next assignment. The special emissaries differed from later work teams, however, in that they were for the most part single-person operations conducted by an 'insider' who had been chosen precisely because of his or her personal connections to the target sites.

The use of special emissaries was somewhat reminiscent of the ancient practice of imperial commissioners (qinchai dachen), in which the Chinese emperor might deputise a trusted official to handle a pressing matter in the provinces by exercising ad hoc powers that trumped those of the regular bureaucracy. However, the proximate origins of special emissaries more likely stemmed from Russian than Chinese roots. The Guangzhou PMTI had been founded on the suggestion of Mikhail Borodin and his fellow sovetniki (Soviet agents in China) who also lectured at the Institute on Russian revolutionary practices of agitation and propaganda. ${ }^{5}$ At the same time, hundreds of left-leaning Chinese were being trained at the Sun Yat-sen University of the Toilers of the East in Moscow. In short, there were multiple conduits for the transmission of Soviet mobilisation techniques to China. Among the most important Bolshevik methods was the use of so-called 'plenipotentiaries,' agent provocateurs who had played a key role in both the Revolution of 1917 and the Civil War that followed in its wake. In the Soviet Union, individual plenipotentiaries-augmented by mobile groups from the Youth League and Trade Union such as Komsomol brigades, 25,000ers, shock brigades, and the like-would again be deployed a decade later to carry out a brutal campaign of collectivisation and dekulakisation in the countryside.

\section{Transformation}

Whatever their origins, Chinese work teams underwent significant change over the course of Mao's revolution and its aftermath. During the 1930s, 'armed work teams' (wuzhuang gongzuodui) were dispatched from communist headquarters in Jiangxi and Yan'an to conduct grain confiscation and recruit soldiers for the Red Army. In the Land Reform of the late 1940s and early 1950s, work teams orchestrated the emotional 
'speak bitterness' struggles that preceded the liquidation of millions of landlords and rich peasants (see Javed's essay in the present volume). They also spearheaded attacks against alleged counterrevolutionaries in the Suppression of Counterrevolutionaries (1950) and Three and Five Antis (1951-52) Campaigns. The violence of these early PRC campaigns was reminiscent of the ruthlessness with which collectivisation had been conducted in the Soviet Union, where plenipotentiaries were known for drunkenness, beatings, and a litany of other bad behaviours. ${ }^{6}$ Precisely because of their callous and uncontrolled conduct, however, plenipotentiaries and other mobile units were phased out of Soviet governance practice in the 1950s, in favour of adhering to regular bureaucratic procedures. ${ }^{7}$ In this same period, especially following the Sino-Soviet rift, the PRC further expanded and systematised its own use of work teams. Chinese work teams, in stark contrast to their Soviet counterparts, were subject to increasingly stringent training regimens designed to teach them how to stir up mass enthusiasm and engagement without allowing locales to descend into unbridled disorder.

In the early years of the PRC, work teams were not only used for directing violence against designated 'class enemies.' They also successfully promoted a wide range of developmental efforts: public health initiatives such as small pox and schistosomiasis eradication, literacy campaigns, irrigation and flood control, and so forth. During the Four Cleans Campaign of the early 1960s, more than 3.5 million work team members were dispatched to villages across China to curb rural cadre corruption in the aftermath of the disastrous Great Leap Forward. In this period, virtually all upperclassmen at Chinese universities were mobilised to participate in Four Cleans teams. After undergoing a rigorous training programme, team members were sent to local sites to 'squat on a point' (dundian) while practicing the 'three togethers' (santong) of living, eating, and working with the local residents. ${ }^{8}$ Even today, the Four Cleans teams are still remembered fondly by many elderly villagers for having acted as disciplined and empathetic ambassadors of Party central. By pointing the finger of blame for the terrible Great Leap Famine at 'corrupt' grassroots officials, work teams helped to convince ordinary villagers that the root cause of their suffering rested with the malfeasance of their own local leaders, rather than with Chairman Mao or the CCP. Thanks in part to the earnest efforts of dedicated Four Cleans team members, the PRC proved able to weather one of the worst famines in world history.

The prominent role of work teams in the Four Cleans, operating under the aegis of then President Liu Shaoqi, became grounds for criticism a few years later during the Cultural Revolution. Work teams played a central part in the often violent 'twoline struggle' between 'left-wing' and 'right-wing' factions that afflicted schools, universities, factories, and other state agencies at the outset of the Cultural Revolution. The introduction in 1968 of Mao Zedong Thought Propaganda Teams, composed primarily of workers and soldiers, appeared for a time to have ended the practice of pragmatic Party-sponsored work teams in favour of a new ideological entity under the direct control of Mao and the military. Mao Zedong Thought Propaganda Teams promptly demobilised the unruly student Red Guards and helped to restore social order.

In the early post-Mao period, Deng Xiaoping declared an end to mass campaigns, implying that-much as in the later years of the Soviet Union-ad hoc mobile units would no longer be used to supersede regular bureaucratic procedures in implementing 
Party policy. In reality, however, work teams did not disappear from Chinese governance practice; they continued to play a key role in promoting a wide range of Party initiatives in post-Mao China. Family Planning Work Teams, Three Represents Work Teams, and New Socialist Countryside Work Teams, among others, served as critical conduits of policy implementation for Deng Xiaoping, Jiang Zemin, and $\mathrm{Hu}$ Jintao respectively. Under Xi Jinping, the deployment of work teams has been further expanded. Precision Poverty Alleviation Work Teams fan out across the countryside to deliver material and financial relief to impoverished villages while repeated rounds of Discipline Inspection Teams descend upon university campuses and government agencies to ferret out corruption and ideological impurity. In conducting their centrally mandated operations, work teams continue to circumvent the formal bureaucracy in favour of enlisting ordinary people to assist in advancing the Party's agenda. Although feared by local officials, work teams are generally welcomed by the populace at large as an effective means of checking grassroots governance abuses. The practice is surely not unrelated to the many public opinion surveys which reveal an extraordinary level of trust and support among ordinary Chinese for the central (as opposed to local) Party leadership.

\section{Achievements and Adaptation}

Scholars of Soviet and Central European communism such as Valerie Bunce have pointed to flaws in the institutional design of those political systems as a prime explanation for their collapse. ${ }^{9}$ In terms of formal political institutions, however, the contemporary PRC does not differ appreciably from the former Soviet Union and its client states. Like them, it is a generic communist party-state complete with a central committee, politburo, people's congresses, and so forth. Why then has the PRC not only survived, but even thrived? How has the CCP continued to govern with a flair for flexibility and responsiveness that eluded the European communist party-states?

In terms of governance, one of the most salient differences between the PRC and its erstwhile European counterparts is the CCP's effective deployment of well-trained work teams, capable of successfully communicating both top-down policies and bottom-up priorities. The teams allow the central leadership to cut through bureaucratic red tape and to establish direct contact with the people. The result is to accelerate the speed and spread of policy implementation while at the same time amplifying the centre's awareness of grassroots preferences. The Party is thus better able to calibrate its policies to match popular proclivities. And ordinary people, in turn, feel an unusually close connection with the central authorities that redounds to the legitimacy and longevity of the communist regime.

A practice imported from the Russian Revolution, yet much modified by Mao and his comrades over the course of the Chinese Revolution and its aftermath, work teams remain today one of the most important weapons in the CCP's governance arsenal. Their strategic and flexible application help explain the CCP's surprising ability to elude the fate that befell most formerly communist states, whose extinction is often attributed to their rigid and unresponsive political institutions. If, as Robert Putnam argues, vigorous civic engagement is what 'makes democracy work' by involving ordinary citizens in public life, then perhaps robust work teams are what 'make (Chinese) 
communism work' by incorporating the masses into the Party's itinerary..$^{10}$ Just as we debate whether American civil society is strong enough to withstand the formidable challenges that currently beset liberal democracy, so we may ponder whether the continued deployment of work teams will prove sufficient to sustain an otherwise ossified communist party-state. Whatever the future may hold, one cannot deny the contributions of Maoist-style ad hoc governance to the survival and success of the CCP over a century of surprising achievement and adaptation. 


\section{3 \\ 单位 \\ Work Unit}

Kevin LIN

$\mathbf{T}$

he work unit (danwei) was the quintessential urban institution of Chinese state socialism. For the generations living through the 1950s to the 1970s, the work unit was much more than simply a workplace. Most aspects of people's lives were deeply embedded in, and intimately connected to, a danwei, which structured not only their work, but also their benefits, housing, movement, and often their behaviour and thoughts. For many of them, the structural reform and closure of the work units in the 1980s and 1990s proved to be a traumatic experience, upending not only the certainties associated with lifelong employment and guaranteed incomes - the so-called 'iron rice bowl' (tiefanwan) - but in many cases also tearing apart the social fabric of their entire communities. However, to the surprise of many observers, and in contrast to the global trend of neoliberalism, some danwei have not only survived the demise of state socialism, but prospered in postsocialist China-reorganised into the powerful conglomerates known as 'central enterprises' (yangqi) that today dominate strategic sections of the Chinese economy.

\section{The Building Block of State Socialism}

Taken literally, danwei means 'unit', shorthand for 'work unit' (gongzuo danwei). Aptly named, it constituted the basic building block of economic organisation in urban China during the Mao era. In its broadest sense, danwei encompasses a diverse range of institutions, including industrial factories, public institutions such as schools and hospitals, government departments, and other workplaces. Among them, the industrial work units, especially those in heavy industry, stand out as the prototype of the socialist workplace and were privileged over all others for their role in building socialism through their contribution to state-led industrialisation. Despite the post- 
Mao reforms, the term has remained part of daily vocabulary; it is not uncommon for people to refer to their workplace as a danwei, even though the danwei of today barely resembles its predecessor from the Mao era.

As an institution of social and industrial organisation, work units emerged in the late 1950s, after the new state nationalised industries and pursued centralised economic planning and heavy industrialisation under the First Five-year Plan. It thus has been identified closely with both the Chinese state and its model of state socialism. But the danwei did not emerge from thin air. Aspects of the danwei, such as its functions and its authority relations, can be traced back to institutions of the first half of the twentieth century. From this perspective, rather than being an entirely new post-1949 socialist creation, multiple historical origins of the danwei-or at least close parallels-can be located in pre-communist financial institutions in the Republican era of the 1930s, in the labour movement led by skilled artisans between the 1920s and 1940s, in the rural revolutionary models of organisation in the communist base areas in the 1940s, and in the dominant communist industrial model available at the time: the Soviet industrial organisation. ${ }^{1}$ What emerged in the 1950 s can thus be seen as a composite institution that borrowed from a range of communist and non-communist sources. ${ }^{2}$

Despite the resemblances to a variety of institutions across time and space, the formation of the danwei in the Mao era represents something distinct. It simultaneously served as an economic, social, and political-ideological institution. To elaborate on a classic formulation of its functions, the work unit may be best understood as combining an economic role within a centrally planned economy by supplying public goods, services, and commodities; a non-market redistributive social role by administering labour insurance and social security provisions to employees; and a political role by representing and managing the interests of workers. ${ }^{3}$ In addition to this, we may also emphasise the ideological role of the danwei in monitoring and moulding workers' thoughts and behaviours in accordance with the official ideology, and mobilising employees for political campaigns.

This configuration of the work units reflects a non-capitalist form of social and economic organisation. In Chinese state socialism, economic relations were socially embedded in, and organised by, political institutions of the Party-state, rather than mediated by the market. These political institutions determined and regulated economic exchanges between economic units, as well as between economic units and individuals. According to Karl Polanyi, in a socially embedded economy, economic activity and the market operate within social institutions rather than social institutions being dominated by the market. ${ }^{4}$ Chinese state socialism is an extreme variant of such embedded economies. In work units, labour was not commodified: workers did not sell their labour power in a labour market as a commodity. Instead, labour was socially, as well as physically, embedded in the institution of the danwei. Workers' life-chances were neither determined by, nor dependent on, the market, but on the state and bureaucratic apparatus, and on the priorities governing the danwei and society at large. This held mixed blessings. 


\section{A Hidden Abode of Coercion and Exploitation}

In the work unit, non-capitalist social relations did not necessarily mean freedom from exploitation or coercion. Production processes in the industrial work units were hardly distinguishable from their counterparts in capitalist economies. Indeed, although everything else seemed to change around it, little needed to be reorganised in the production processes during the reform of the work units in the 1980s and 1990s. Even without management by capitalist bosses, workers in the danwei were under dual pressure from leaders who acted both as managers of a productive enterprise and political leaders enforcing political control and ideological norms. Furthermore, the lifetime tenure and the comprehensive benefits only ever applied to the core, permanent employees. While danwei did provide employment security, they also tied workers to their units. Jobs were assigned and employees were bound to their danwei, unable to voluntarily leave unless they obtained permission.

Moreover, substantive workplace democracy did not exist in the danwei. The trade unions from the 1950s onwards were tamed and subservient to the needs of economic efficiency (see Franceschini's essay in the present volume). The supposed organ of workplace democracy, the Staff and Workers' Representative Congress (zhigong daibiao dahui), ostensibly designed for employee consultations, rarely functioned as a mechanism of worker self-management. ${ }^{5}$ This is not to say that there were no constraints on leadership, or that workers could not exercise some degree of control. The state socialist ethos that privileged the historical role of the working class set limits on the disciplining and firing of workers by work unit leaders. What emerged in the danwei was a form of paternalism in which workers were dependent on their work units and management. ${ }^{6}$

Despite the high level of control in work units, it would be wrong to assume that there was never organised dissent. Throughout the Mao era, at least some groups of workers took advantage of political opportunities to raise their voices and, in some instances, pose serious challenges to both managers and Party leaders. Strikes and worker-led protests erupted in the mid-1950s during the Anti-rightist Campaign, then again during the Cultural Revolution (most prominently in Shanghai), and yet again in the wake of Mao's death. ${ }^{7}$ These groups demanded both economic improvement and a degree of political democracy. But the state ultimately proved to be intolerant of, and too powerful for, any independent organisation of workers against the authorities, and repeatedly crushed all such movements. By the end of the Mao era, despite their previously elevated symbolic status and economic position, workers lacked their own industrial and political organisations, and were ill-prepared for the subsequent reforms that would weaken their economic and social positions through the restructuring of the danwei.

\section{From Work Units to National Champions}

China's economic reforms fundamentally dismantled work units as an institution of state socialism. The state partially withdrew from direct control of the danwei, separating politics from economic management, and subjecting work units to competitive market pressures. ${ }^{8}$ Never designed to be an economic institution that 
could compete in a market economy, in the 1990s, many danwei went bankrupt, closed down, or were privatised. The work units that survived onslaught-often with a heavy dose of state support-still had to undergo internal restructuring that fundamentally changed how they operated, and what it meant to work for them. Lifetime employment was replaced by employment contracts, in a process of a progressive commodification of labour. Management became considerably more coercive toward workers. The state came to maintain control over labour relations in work units only indirectly, by means of industrial and labour policies and legislation, with much less direct intervention over the economy and society in general. ${ }^{9}$ The paternalism and organised dependency characteristic of the danwei in the Mao era was disrupted, with a more disorganised and despotic set of relations taking hold in the process of reform. ${ }^{10}$

What remains of the work unit today? The danwei has been transformed from an all-encompassing social, economic, and political-ideological institution embedded in a planned economy to a primarily economic institution. But those that remain stateowned and managed by state agencies — such as the State-owned Assets Supervision and Administration Commission of the State Council-continue to serve the goals of the Party-state, and often receive preferential treatment and protection. There are also some traces of the former paternalism. In general, contemporary work units provide better employment benefits and job security in strategic sectors than their counterparts in the private sector, but have also sharply increased the use of casual workers. It remains difficult for management to arbitrarily dismiss employees, and the state acts to intervene to protect these units from market pressures-albeit, to varying degrees depending on the significance of the units and sectors. For these reasons, the new work unit has been compared to the organisation-oriented, 'enterprise as community' Japanese employment system, ${ }^{11}$ and the current formation is a result of a state-led strategy to turn danwei into national champions based on the model of the South Korean developmental state. As such, the largest work units, regrouped as central state-owned enterprises (yangqi), are some of the most dominant companies with monopolistic power in China. Four decades after the end of state socialism, the new work units continue to be central to the Chinese economy, and are developing global reach, contributing to China's global strategy of infrastructure building and resource extraction. Yet, the danwei of state socialism is increasingly fading into the distance. 


\section{Afterword}

Jodi DEAN

W

hy is 'communist' unable to qualify political theory? We have democratic political theory, liberal political theory, republican political theory, conservative political theory, the indistinct placeholder 'normative' political theory-but communist political theory does not appear. Marxist political theory, Marxist-Leninist political theory, and even Marxist-Leninist-Maoist political theory are intelligible as types of inquiry, although in the twenty-first century they remain at the margins of most academic and activist discourse. The proper names Marx, Lenin, and Mao legitimate, to a degree, theorisations of political economy, concepts of political power, and analyses of the struggles of the oppressed-perhaps because their individuation of the knowledge gained through collective struggle makes them easier for those ensconced in the institutions and expectations of capitalist societies to swallow. Outputs of a man's brain, his thinking and writing, are more palatableand more easily dismissed-than the revolutionary courage of hundreds of millions of people willing to kill and die to end their own exploitation and colonisation. Hence the radicality of an insistence on Chinese communism: the people and their strugglestheir heroic victories, lessons learned, excesses, and defeats-take centre stage as the subject and object of communist political theory.

Radicality is risky. A specific challenge for communist political theory stems from the way its opponents (and some of its supporters) insist on reducing communist ideas to a few select historical examples. Inextricable from history, 'communist' fails to attain the level of abstraction necessary for a qualifier. It is inverted to refer to a state violence it aims to abolish. Gulags and famines take the place of the emancipatory egalitarian struggles of the oppressed. Pang Laikwan in this volume reminds us that Mao's version of dialectical materialism emphasises humans' struggle with history, so perhaps the stickiness of communism, its seemingly inescapable embeddedness in not just history but in a history written by the victors, its enemies, confirms Mao's point. 
Communists continue to battle with and over our histories. When anti-communists subsume working class victories under Cold War categories they inadvertently bear witness to the truth of communism. The struggle is real.

\section{Call Me by Your Name}

Language is a weapon in the arsenal of struggle. Communist names present the world differently from the way it is given in capitalist ideology. What was natural or traditional becomes a crime demanding redress. What workers learn through collective struggle takes form in slogans, demands, and concepts. In an era when anti-communism is the norm, the air, a mobilising theme for conservatives and liberals, and when capitalist individualism, self-interest, and cynicism reign, the language of communism can feel strange in our mouths. The terms seem not just outmoded but inauthentic. Were they ever more than propaganda designed to deceive the masses? Rebecca Karl's recovery of the emancipatory imperative of 'serve the people' in this volume illustrates this point. For Chinese communists 'serve the people' was a political injunction, social ideal, cultural expectation, economic norm, and concrete social practice, even if by the mid-1960s it had become rather empty and rote. By the 2000s, the phrase had lost its capacity to produce socialist meaning, more available for lampooning than ethical guidance. Karl excavates this capacity. She attends to Mao's initial use of the phrase in a tribute for Zhang Side, a beloved comrade. Born a peasant, Zhang was a soldier on the Long March. He died in a mining accident during the war against Japan. Mao's eulogy turned Zhang into an exemplar of socialist service. As Karl writes, 'the phrase Zhang's death inspired proposed a new form of social relation, a socialist organisation of time and society that was at once abstract and concrete, lived and "yet to be made," remembered and "not yet existing." To serve the people was to create the people, to enable the people to become present as a revolutionary unity. It was to undertake the work of dismantling old hierarchies and producing new kinds of social relations. Karl resurrects the theoretical and practical vitality of the expectation that socialists serve the people: only by serving the people are they part of the people; only by being served is the people revolutionary.

Serving the people names a process of subjectification: the people become present as the revolutionary subject they are by being served. ${ }^{1}$ Karl demonstrates the way that communist language produces the structure-the relations, understandings, and expectations - that makes it intelligible. This productive capacity is not absolute; it is entangled in a broad array of economic, political, social, and cultural forces. These forces are often antagonistic. Sometimes they align. Communist names rely on the antagonisms and alignments that imbue them with mobilising capacity. If an organisation instructs its members (or cadres, soldiers, workers, or students) to serve the people even as it promotes hierarchy, enables corruption, and enriches the few, the efficacy of the phrase will decline. But it may persist, for a while, as an ideal against which failures to uphold it are assessed. It may retain a symbolic authority that testifies to the struggles and sacrifices that it inspired and that inspired it. Even its cynical evocation relies on this prior authority-why else mock it? 
So what do we make of Mao's currency, the way he circulates as the face of Chinese capitalism, as money? The cynical response sees nothing but authoritarian capitalism, nothing but Foxconn and billionaires-even in the Party. Using Lacanian categories, one might say that in contemporary China capitalism is Real while communism is imaginary. But why not see the face of Mao as the sign of a struggle that cannot be erased, that lives on, that has social value? What could enable or support this properly symbolic perspective? The faces featured on money issued by the United States Treasury Department feature slave-owners. Their legacy lives on in the raced economic inequality, institutionalised white supremacy, and ongoing damage of racism that characterise US capitalism. That US money features slave-owners marks the fact that the wealth of the United States was produced by slaves as well as by exploited workers. US money registers how the value of labour in the US, like other commodities, is inseparable from slavery and its afterlives. Does the face of Mao make a mockery of the Foxconn workers assembling iPhones they cannot afford or does it haunt Chinese capitalism as a manifestation of an aspiration and a struggle that continues? The question is undecidable, which means political. So long as communist names have symbolic efficiency, they can touch the Real that ruptures them, keeping alive the possibility of its transformation. After all, capitalism is itself driven by and structured through class struggle. The Real of capitalism is the Real of a class antagonism that will lead to capitalism's own abolition, that is to say, capitalism from a communist perspective.

\section{Communism for Us}

Close to a decade ago, a number of leading European intellectuals gathered together for a conference on the 'Idea of Communism' at Birkbeck University in London. Initiated by the philosophers Slavoj Žižek and Alain Badiou, the conference attracted over a thousand people. It generated subsequent conferences in New York, Berlin, and Seoul as well as edited collections and follow-up books and articles. A goal of this endeavour is the reinvigoration and imagining of communism as a philosophical ideal and political project. Against the anti-communism that pervades three decades after communism's ostensible defeat, the desire for and affirmation of the truth of communism responds to the disaster of global capitalism, intensified economic inequality, rising fascism, and climate change. Emancipatory egalitarian struggle against the exploitation of people, nature, and the future is necessary for there to be a liveable future for most of the world's people.

Although in large part a theoretical project, the project for a new communism cannot be reduced to academic politics. The structures and expectations of the neoliberal academy work against thinking communism. Sometimes funding can be secured for projects that give the appearance of being sufficiently critical, artistic, or historicalsufficiently distant from politics, from the actuality of communism. Infiltration, using the meagre rewards of the university against its capitalist foundation, is better than nothing. Disciplinary norms regulate the production of what counts as knowledge, validating views that reinforce a capitalist status quo. Area studies reinforce borders: China separate from the so-called West, Latin America separate from Anglo America, the Middle East separate from everyone. In addition to supporting imperialism's ongoing fragmentation of the world to suit its own interests, these separations present 
real barriers to activists. They make it hard to learn from different experiences. They reinforce particularism and uniqueness-our struggle is like no other. They mitigate against the building of revolutionary international parties, organisations, and movements.

How does the project of reinvigorating the idea of communism here and now suggest a position from which we can put to use and redeploy the knowledge generated through Chinese communist struggle? What terms and ideals, what knowledge generated and lessons learned by the courageous work of Chinese comrades do we need today? Four interconnected notions stand out with particular power: mass line, people, class struggle, and revolution.

\section{Mass Line}

In its most fecund moments, Chinese communism has been vibrant and experimental, creating new modes of generating political energy and organising political being. Marxist-Leninist ideas took on new dimensions as Chinese communists made theoretical questions central to the practice of communism. 'Mass line' is the most significant of these conceptual innovations. A principle of participatory governance and political accountability, the mass line ties Party work to the people. The people have to be consulted; their will must be interpreted, and policies need to carry out this will-from the masses to the masses. As Lin Chun reminds us in this volume, not only does the mass line promote an ideal of popular sovereignty, but it also provides a novel adaptation of the Leninist principle of democratic centralism.' According to her, the mass line aims to balance deliberation and discipline while at the same time avoiding 'bureaucratic dogmatism and blind commandism.' Mindful of our present context of generalised dispossession, immiseration, and political despair, Lin highlights the emancipatory power of the mass line: 'Ordinary people can be proud of themselves as direct producers of both material and cultural wealth in the collective mastery of their own destiny'.

'Ordinary people' have today become a political cliché. Whether as voices of 'common sense' trotted out to symbolise that a given politician is in touch with the people or as 'slice of life' style television interviewees whose opinions take the place of actual news, ordinary people are ubiquitous. The recent turn to populism is but the latest political deployment of ordinary people. The differences between this cynical populism and the mass line are significant. In late neoliberal societies, ordinary people do not appear primarily as producers. They appear as singular national subjects, instantiations of the nation, representatives of a national interest as voices from a particular demographic position. Their source of pride arises from the way their demographic position is incorporated in the nation. Likewise, rather than collective, their capacities are individual-individual successes and failures, individual gains or losses, individual hopes and dreams. Detached from collective strength, ordinary people forfeit any possibility of mastery over their own destiny. The question is how they can cope with what life brings them. Have they prepared? Are they trained? All responsibility is downloaded onto them as individuals. Politics is either a matter of personal ethics and identity or so far removed from everyday life as to have become post-politcal. In fact, everybody knows that ordinary people have no political impact in societies run by and 
for billionaires. The presence of an ordinary person in a 'man on the street' interview or at an address by a US President is all for show, an instant of fame that vanishes at the moment it registers.

The mass line is indispensable to the return to communism, perhaps now more than it ever was. As Lin writes in this volume, against present individualism, it inspires a political vision that embeds 'individual worth and glory' in the work and struggle of a political collective. One is valuable as part of the revolutionary masses, as one of the people, and not for one's own individual insight, effort, or hot take. Ideally, parties and organisations committed to the mass line would practice a politics that exceeds empty horizontalism and participationism. There are leaders-but the leaders are leaders only insofar as they attend to the needs of the people. Lin details how through the mass line leadership pools the wisdom of the masses as it 'collects scattered views from below and turns them into systematic positions and experimental policies, the effects of which are then investigated, debated, and fed once again back into the system.' Political discussion is more than talk, more than sharing. It is tied directly to action for the benefit of the people. The mass line is radical democracy as communist practice, that is, a strategically minded practice with communism as its horizon.

\section{The People}

'The people' is the second concept from Chinese communism crucial to any contemporary reenvisioning of communist futures. Guan Kai in this volume takes up the notion of the people in Chinese history. Traditionally, 'ordinary people' were understood in contrast to rulers and government officials. The people are the 'material foundation for rule' even though they are not yet understood as themselves rulers, as sovereign. With the Chinese Communist Party's rise to political power, the people retained its place as one side of an antagonism, naming those who supported socialism over and against those who did not-the enemies of the people. Situating Chinese communism within the revolutionary line of the French Revolution and Paris Commune, Guan presents the people as 'the faintly discernible trace of revolutionary practice, a slogan that can be found everywhere, but the meaning of which is constantly changing.' The idea of the people is transformed through people's struggle, people's war. The sea in which the revolutionary swims is turbulent. Navigating it requires winning the people's hearts, which itself requires finding solutions to their problems.

The Chinese communist view of the people contrasts with the people of contemporary populism. Rather than given as a unity at the basis of a national project, it is a force with its own dynamics. The people is productive, active, and internally contradictory. Their engagement is the struggle, their support decisive for victory: 'The people, and the people alone, are the motive force in the making of world history' (quoted by Guan in the present volume). But they are not a unity and they are not invariable. Always comprised of contradictory elements, some of the people will be militant and disciplined. Others will not. The Party cannot take them for granted but must always be responsive, adaptive, and creative as it seeks to mobilise them-hence, the tight connection between the people and the mass line. 


\section{Class Struggle}

Chinese communism also provides an innovative view of class struggle. One objection that reappears in the contemporary discussion of communism turns on the idea of class. There is no working class in Europe and the United States, we are told. Instead we have multiple differentiated positions and identities with little relation to production. Class can no longer function as a revolutionary mode of political identity. This argument is not persuasive. Chinese communism lets us see why. First, as Wang Hui has observed, 'the identification of the working class as the leading class is a political statement rather than a positivist conclusion.' ${ }^{2}$ As he emphasises, 'class politics refers to movements against the contradictions created by the logic of capitalism and its derivative class inequality.' ${ }^{3}$ From a communist perspective, the classes engaged in class struggle are irreducible to demographic categories. They are positions in the antagonistic relations at the core of a society's mode of production. Second, in contrast to the workerist reductionism prevalent in European socialism and autonomist communism, the Chinese context gives us class struggle as creative experimentation. Work teams (Elizabeth Perry in this volume) and worker universities (Alessandro Russo in this volume) suggest new modes of developing accountability and subverting the technical division of labour. Third, class struggle has affective prerequisites; class consciousness cannot be reduced to a mindset that follows automatically from class position. Class feeling has to be engendered. Nourishing class feeling is itself a tactic of class struggle. Haiyan Lee in this volume brings out the ways Chinese cultural production sought to engineer a new structure of feeling whereby comradely love for one's class brothers and sisters supplants the rivals of kinship, romance, and pity. Fourth, Chinese communism gives us a class struggle that operates not just through the Party but that occurs within the Party. The Party is not a pure voice of the oppressed. It embodies all the contradictions already within the people and must include in itself capacities for learning and change. Contrasting the Chinese with the Soviet approach, Mao emphasises that class struggle is undertaken from the bottom to the top as well as from the top to the bottom. Pun Ngai concludes: 'The mass line and class struggle were always intertwined as the essential ingredients of the construction of socialism.'

\section{Revolution}

Finally, Chinese communism leaves a distinct legacy of revolution. Benjamin Kindler in this volume contrasts Lenin's and Mao's revolutionary temporalities. Lenin's was that of the moment, the decisive instant of rupture, revolution as event. Mao takes the long view. Kindler writes: 'For Mao, revolution is a moment of rupture within continuity and continuity amidst rupture-a transformation of the strategic terrain in which the nature of both the possibilities and the dangers undergo a marked change from one state to another, but where the conquest of power by no means marks the end of the revolutionary process.' Cai Xiang in this volume also highlights the impossibility of finality; there can always be reversals. Insofar as history is always the working through of contradictions, no victory is ever certain. Absent the fetishism of completion, of an end to history, that long plagued European communism, Chinese communism remained attuned to ongoing problems, combinations of radical advance and tactical 
retreat. To be sure, the long view brings its own challenges: when do compromises become betrayals? At what point do the measures designed to protect the revolution, by energising the economy, say, in fact defeat it? When can we say that counterrevolution has taken the place of people's revolution? Might it be when the interests of corporations and investors take the place of the people? When the people's own desires are too easily 'bound to the seductions of the commodity form,' as Kindler writes in this volume. When communism no longer appears as the horizon of our politics because its struggles have become blocked, repressed, outlawed?

And, perhaps, one final way Chinese communism may enable us to discern if our politics is revolutionary: it helps us ask whether ostensible efforts to serve the people fragment them into identity categories such that the people can no longer be seen as a revolutionary force. It compels us to consider whether our activists, organisers, and revolutionaries take the people as the way they are given under capitalism or work to transform them into agents of emancipatory egalitarian struggle. 
All men must die, but death can vary in its significance. The ancient Chinese writer Sima Qian said, 'Though death befalls all men alike, it may be weightier than Mount Tai or lighter than a feather.' To die for the people is weightier than Mount Tai, but to work for the fascists and die for the exploiters and oppressors is lighter than a feather.

Mao Zedong, 'Serve the People,' 1944

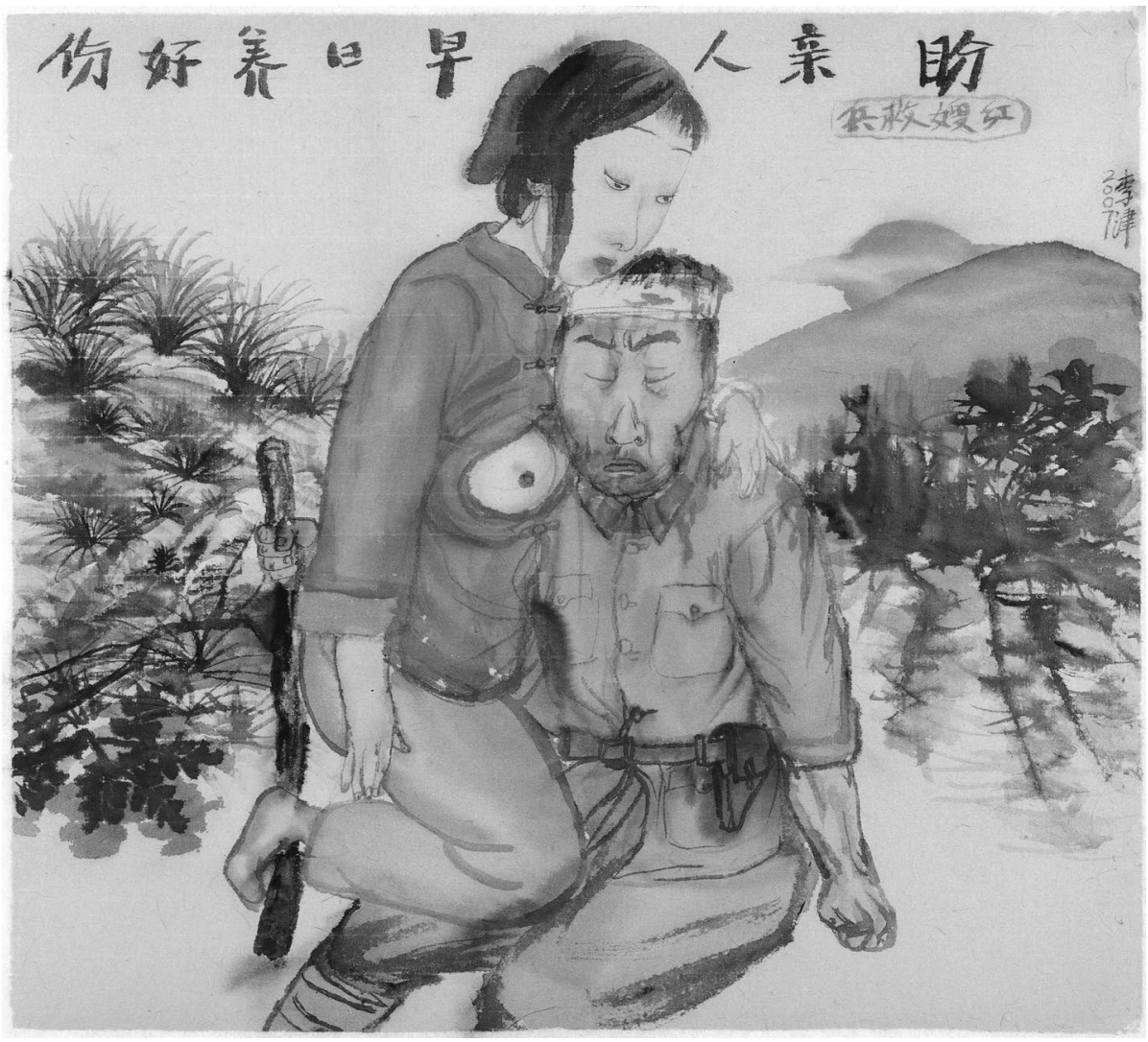




\section{Acknowledgements}

This edited volume has been a collective effort in the genuine and inspirational sense of the word. We are honored to have received contributions from so many talented thinkers and scholars of China. But a book is always more than its author(s) and editor(s). It is an archive of conversations, debates, and ideas, only a small fragment of which ever find their way onto the page. It is also a project that requires a lot of help along the way.

We would like to acknowledge our debt to The Australian National University's Centre on China in the World (ANU-CIW) for funding and hosting the Made in China Journal, which provided the origin and intellectual template for this edited volume. We would also like to thank Colorado College, especially the Political Science Department, Asian Studies Department, and Dean's Office, all of which have generously funded this project. The volume also received support from the European Union Horizon 2020 Research and Innovation Programme under the Marie Skłodowska-Curie Grant Agreement No 654852. Special thanks to Sharon Strange and Evyn Chesneau Papworth for their meticulous copy-editing work and constructive feedback.

This book would also not be possible without our publishers, Sebastian Budgen from Verso Books and Emily Hazlewood from ANU Press. We deeply appreciate their commitment to working together to create new modes of intellectual production and publication.

We are also grateful to Tommaso Facchin for his aesthetic touch and design of the book, and to Marco Verdugo Lopez for the spellbinding cover.

Finally, we would like to thank future readers for giving this book its own afterlives. 


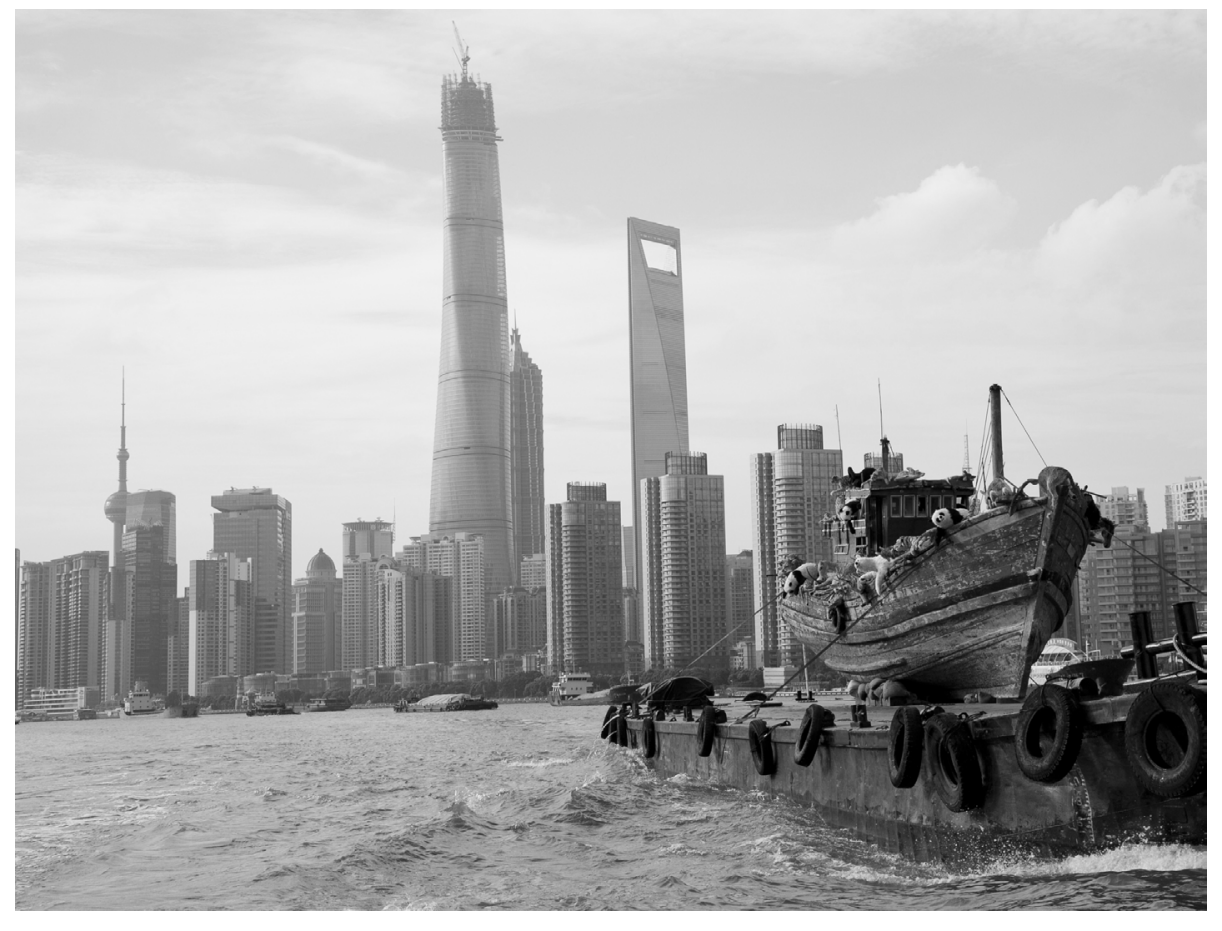

Cai Guo-Qiang, The Ninth Wave (2014) Photo by Wen-You Cai, courtesy Cai Studio 


\section{Contributors}

Joel ANDREAS is Associate Professor of Sociology at Johns Hopkins University, and studies political contention and social change in China. His first book, Rise of the Red Engineers: The Cultural Revolution and the Rise of China's New Class (Stanford University Press 2009), analysed the contentious merger of old and new elites following the 1949 Revolution. His forthcoming book, Disenfranchised: The Rise and Fall of Industrial Citizenship in China, traces radical changes that have fundamentally transformed industrial relations over the past seven decades. Currently, he is continuing to investigate changing labour relations and the ongoing transformation of China's rural society.

Judith BALSO is a French activist who has been successively involved in UCF(ml); Organisation politique; Rassemblement des collectifs des ouvriers sans papiers des foyers; and the collective Ouvriers du monde/Architectes de paix. Her books include Pessoa le passeur métaphysique (Le Seuil 2006) and Affirmation de la Poésie (Nous 2011). She is currently working on a new book project about Hölderlin. She is a founding member and co-headmaster of the Ecole des Actes, created in 2016 with the Théâtre de la Commune at Aubervilliers. There she teaches and learns from people-so-called 'migrants'-coming from Africa and Asia.

Tani BARLOW teaches Chinese modern history, intellectual history, and feminist history. Her publications include In the Event of Women (forthcoming with Duke University Press) and The Question of Women in Chinese Feminism (Duke University Press 2004). Barlow is starting a new research on a history of social logic and theory. She has been instrumental in founding long term collaborative projects, including Critical Asian Studies, a Rockefeller Foundation Grant, The Ephemera Project, a Luce Foundation Grant, Class Capital Class at the University of Washington, and has served as the founding Director of the Chao Center for Asian Studies at Rice University. She is Founding Senior Editor of positions: asia critique.

Marc BLECHER is James Monroe Professor of Politics and East Asian Studies at Oberlin College. His books include Micropolitics in Contemporary China: A Technical Unit During and After the Cultural Revolution (with Gordon White, M. E. Sharpe 1979); Tethered Deer: Government and Economy in a Chinese County (with Vivienne Shue, Stanford University Press 1996); and China Against the Tides: Restructuring through Revolution, Radicalism and Reform (Continuum 2003). His current book projects are Politology, or Political Analysis as a Science (with Philippe Schmitter) and A World to Lose: Working Class Formation and the Chinese State. He divides his time among London, New York, and Oberlin.

Urdayn E. BULAG is a Reader in Social Anthropology at Cambridge University. His interests broadly span East Asia and Inner Asia, especially China and Mongolia, the Mongolia-Tibet interface, nationalism and ethnic conflict, geopolitics, historiography, and statecraft. He is the author of Collaborative Nationalism: The Politics of Friendship on China's Mongolian Frontier (Rowman \& Littlefield 2010), The Mongols at China's Edge: History and the Politics of National Unity (Rowman \& Littlefield 2002), and Nationalism and Hybridity in Mongolia (Clarendon Press 1998). 
CAI Xiang is Professor of Chinese Literature and Director of the Research Institute for Contemporary Literature at Shanghai University.

William A. CALLAHAN is Professor of International Relations at the London School of Economics and Political Science. His recent books include China Dreams: 20 Visions of the Future (Oxford University Press 2015) and China: The Pessoptimist Nation (Oxford University Press 2010). His current book project is entitled Visualizing International Politics. He also makes documentary films: his China Dreams was broadcast on KCET (Los Angeles) in 2015; Toilet Adventures (2015) was shortlisted for a major award by the Arts and Humanities Research Council in the United Kingdom; and Great Walls (2019) juxtaposes Trump's wall with the Great Wall of China.

Roy CHAN is Associate Professor of Chinese in the Department of East Asian Languages and Literatures and is affiliated with the Department of Comparative Literature and the Program in Russian, East European, and Eurasian studies at the University of Oregon. His research focuses on modern Chinese and Russian literatures. His first monograph is The Edge of Knowing: Dreams, History, and Realism in Modern Chinese Literature (University of Washington Press 2017). He is currently working on a second monograph, A Reflection of Sovereignty: Transnational Figurations and Global Forms in Modern Chinese and Russian Literatures.

Timothy CHEEK is Director of the Institute of Asian Research and Professor and Louis Cha Chair in Chinese Research at the School of Public Policy and Global Affairs and Department of History at the University of British Columbia. His research, teaching, and translating focus on the recent history of China, especially the Chinese Communist Party and intellectual debate in China. He has contributed to scholarly and public conversations on the nature of CCP rule. His most recent book is The Intellectual in Modern Chinese History (Cambridge University Press 2015). In recent years, he has been working with some Chinese intellectuals to explore avenues of collaborative research and translation.

DAI Jinhua is Professor of Chinese Literature and Language at Peking University. She is the author of a number of books in Chinese and of two anthologies of essays translated into English: Cinema and Desire: Feminist Marxism and Cultural Politics in the Work of Dai Jinhua (edited with intro by Jing Wang and Tani E. Barlow, Duke University Press 2002); and, most recently, After the Post-Cold War: The Future of Chinese History (edited with intro by Lisa Rofel, Duke University Press 2018).

Gloria DAVIES is Professor of Chinese Studies at Monash University. She has published widely on modern Chinese intellectual politics and Chinese literary and cultural topics, including Worrying About China: On Chinese Critical Inquiry (Harvard University Press 2007) and Lu Xun's Revolution: Writing in a Time of Violence (Harvard University Press 2013). She is a regular contributor to the China Story Yearbook project based at the Australian Centre on China in the World, The Australian National University.

Alexander F. DAY is Associate Professor of History at Occidental College in Los Angeles. He studies the intellectual, social, and cultural history of peasants, food, and agrarian change in China. His first book, The Peasant in Postsocialist China: History, Politics, and Capitalism (Cambridge University Press 2013), centres on the question of why the peasant, and rural China more broadly, continually reappears as a figure of crisis in Chinese history. His second book project traces the labour and environmental history of a tea farm and factory in Guizhou province from the 1930s to the present. 
Laura DE GIORGI is Professor of Chinese History at the Department of Asian and North African Studies, Ca' Foscari University of Venice. She has published extensively on the history of media in modern and contemporary China and on political and cultural relations between Italy and China in the twentieth century. She is a member of the editorial board of several Italian academic journals, as well as of the board of the Italian Association of Chinese Studies and the European Association of Chinese Studies.

Jodi DEAN is Professor of Political Science at Hobart and William Smith Colleges in Geneva, New York. Her books include Democracy and Other Neoliberal Fantasies (Duke University Press 2009), The Communist Horizon (Verso 2010), Crowds and Party (Verso 2016), and Comrade: An Essay on Political Belonging (Verso 2019).

Michael DUTTON is Professor of Politics at Goldsmiths, University of London and Co-Director of the Goldsmiths Asia Centre. He is author of Policing and Punishment in China (Cambridge University Press 1992), Streetlife China (Cambridge University Press 1998), Policing Chinese Politics (Duke University Press 2005, for which he won the AAS Levenson Prize of 2007), and co-author of Beijing Time (Harvard University Press 2005). Characterised by a strong interest in China, theory, and Cultural Studies, his forthcoming work, entitled The Book of Politics, draws on these strands to rethink the concept of the political.

Ivan FRANCESCHINI is a Postdoctoral Fellow at the Department of Political and Social Change, Coral Bell School of Asia Pacific Affairs, The Australian National University. His research focuses on Chinese labour and civil society, but he is also interested in Chinese modern history and literature. He has published several books in Italian related to China, on topics ranging from human trafficking to digital activism, and from labour struggles to civil society. His articles have appeared in The China Journal, The China Quarterly, Journal of Contemporary Asia, Critical Asian Studies, and Postcolonial Studies, among other journals. With Tommaso Facchin, he co-directed the documentary Dreamwork China (2011).

Matthew GALWAY is the Hansen Trust Lecturer at the University of Melbourne. He was previously a Postdoctoral Fellow at the University of California, Berkeley, and a Lecturer at the University of British Columbia. His research focuses on radical intellectuals in Southeast Asia and Latin America who were inspired by Maoism. His manuscript project is on the reception, adaptation, and implementation of Maoism by Cambodian intellectuals. Other projects include a translation of Zhishi fenzi dui daotong de chengzai yu shiluo [Intellectuals as Bearers of Orthodoxy] by Zi Zhongyun, and intellectual biographies of Peruvian Marxist Jose Carlos Mariategui and Cambodian Maoist Phouk Chhay.

GAO Mobo is Chair of Chinese Studies at the Department of Asian Studies, University of Adelaide. Gao's research interests include studies of rural China, contemporary Chinese politics and culture, Chinese migration to Australia, and Chinese language. He has published several books and numerous book chapters and articles. Two of his books are case studies of the village that he came from. While The Battle for China's Past: Mao and the Cultural Revolution (Pluto Press 2008) is an reassessment of the Mao and the Cultural Revolution, his most recent book Constructing China: Clashing Views of the People's Republic (University of Chicago Press 2018) is a critique of the mainstream understanding of the People's Republic of China. 
GUAN Kai is a political scientist and anthropologist, and Professor and Vice-Dean at the School of Ethnology and Sociology, Minzu University of China. He received his $\mathrm{PhD}$ in anthropology from the Minzu University of China in 2009 and in 2015-16 was a Fulbright Visiting Scholar at the Fairbank Center of Chinese Studies, Harvard University. His research focuses on ethnic politics in contemporary China.

Jane HAYWARD is a research fellow at the Government Department of the London School of Economics and Political Science, and a teaching fellow at the Lau China Institute, King's College London. She researches China's agrarian question and related urban transformations in the context of China's internationalisation.

Denise Y. HO is Assistant Professor of twentieth-century Chinese history at Yale University. She is an historian of modern China, with a particular focus on the social and cultural history of the Mao period (1949-76). Her first book, Curating Revolution: Politics on Display in Mao's China, appeared with Cambridge University Press in 2018.

William J. HURST is Associate Professor of Political Science at Northwestern University and is the author of The Chinese Worker after Socialism (Cambridge University Press 2009) and Ruling Before the Law: the Politics of Legal Regimes in China and Indonesia (Cambridge University Press 2018). He has also edited three volumes and published more than two dozen articles and chapters on Chinese labour politics, political economy, contentious politics, urban politics, and local governance. Prior to moving to Northwestern in 2013, he held posts at the Universities of Toronto, Texas, and Oxford, after receiving his $\mathrm{PhD}$ in political science from the University of California, Berkeley, in 2005.

Yoshihiro ISHIKAWA is a Professor in the Institute for Research in Humanities, Kyoto University. Prior to working at Kyoto University, he taught at Kobe University from 1997 to 2001. In addition to his major research on the history of the Chinese Communist Party, he is currently focussing on the biography and images of Mao Zedong. His major publications include The Formation of the Chinese Communist Party (Iwanami 2001; China Social Sciences Press 2006; Columbia University Press 2012) and How Did the Red Star Rise? The Early Images of Mao Zedong (Rinsen 2016).

Jeffrey JAVED is a Postdoctoral Fellow at the Lieberthal-Rogel Center for Chinese Studies at the University of Michigan. He is completing a manuscript, entitled Righteous Revolutionaries, on massmobilised violence and state-building after the Chinese Communist Revolution. His other work on China examines Maoist nostalgia and judicial populism in the era of Xi Jinping. Outside of China, he is researching how American social media content shapes violent and discriminatory attitudes.

Rebecca E. KARL teaches at New York University. She is author, most recently, of The Magic of Concepts: History and the Economic in Twentieth-Century China (Duke University Press 2017) and Mao Zedong and China in the Twentieth-Century World: A Concise History (Duke University Press 2010). She is co-editor/co-translator, with Xueping Zhong, of Cai Xiang, Revolution and Its Narratives: China's Socialist Literary and Cultural Imaginaries, 1949-1966 (Duke University Press 2016); and, with Lydia Liu and Dorothy Ko, of The Birth of Chinese Feminism: Essential Texts in Transnational Theory (Columbia University Press 2013). Her forthcoming book, to be published by Verso, is tentatively entitled China's Revolutions: From Then to Now. 
Benjamin KINDLER is a $\mathrm{PhD}$ Student in Modern Chinese Literature at Columbia University. He is completing a project on the role of labour in the Chinese Revolution, focussed around the Maoist critique of the Soviet model of socialist development and associated problems of culture and political economy. His research interests further encompass the intellectual history of the early reform period, everyday life in socialist Shanghai, and the cultural history of Sino-Vietnamese solidarities. He has completed several article translations from Chinese together with Harlan Chambers, and is currently beginning work on a book-length translation project.

Tong LAM is an Associate Professor of History at the University of Toronto and a visual artist. He is the author of A Passion for Facts: Social Surveys and the Construction of the Chinese Nation-State, 1900-1949 (University of California Press 2011). As a visual artist, he has published photo-books and photo-essays, as well as exhibited his research-based photographic and video works internationally.

Fabio LANZA is Professor of Modern Chinese History in the Departments of History and East Asian Studies of the University of Arizona. He is the author of Behind the Gate: Inventing Students in Beijing (Columbia University Press 2010) and of The End of Concern: Maoist China, Activism, and Asian Studies (Duke University Press 2017). He also co-edited, with Jadwiga Pieper-Mooney, De-Centering Cold War History: Local and Global Change (Routledge 2013). He is currently working on a research project on Beijing urban space and the everyday under Maoism.

Haiyan LEE is a Professor of Chinese and Comparative Literature at Stanford University. She is the author of Revolution of the Heart: A Genealogy of Love in China, 1900-1950 (Stanford University Press 2007, winner of the 2009 Joseph Levenson Prize from the Association for Asian Studies), and The Stranger and the Chinese Moral Imagination (Stanford University Press 2014). In 2015-16, she was a Frederick Burkhardt Fellow at the Center for Advanced Study in the Behavioural Sciences, where she began research on a new project on Chinese visions of justice at the intersection of narrative, law, and ethics.

LI Zhiyu is an Associate Research Fellow in the Institute of Modern History at the Chinese Academy of Social Sciences. She received a PhD in history from the Institute of Qing History, Renmin University, in 2009. Her research focuses on politics and intellectuals in the Republic of China (1912-49). Her book Jing xian: Wang Jingwei de zhengzhi shengya [Jing Xian: The Political Life of Wang Ching-wei], published by Oxford University Press Hong Kong in 2014, is a new interpretation of Wang Jingwei, the leader of Chinese collaborators during the Anti-Japanese War (1937-45).

LIN Chun teaches at the London School of Economics and is the author of The British New Left (Edinburgh University Press 1993), The Transformation of Chinese Socialism (Duke University Press 2006), Reflections on China's Reform Trajectory (Sheke Wenxian Chubanshe 2008, in Chinese), and China and Global Capitalism (Palgrave 2013). She is also the editor of China I, II and III (Ashgate 2000), co-editor of Women: The Longest Revolution (Sanlian Chubanshe 1997, in Chinese) and Was Mao Really a Monster? (Routledge 2009).

Kevin LIN works on civil society development projects, and researches labour and civil society in China. His writings focus on labour and employment relations in China's state-owned industrial enterprises after restructuring, rural migrant workers' collective actions and labour activism, and the development of labour NGOs and civil society. 
Anna LORA-WAINWRIGHT is Professor of the Human Geography of China at the University of Oxford. Alongside Resigned Activism (MIT Press 2017), she is the author of Fighting for Breath: Living Morally and Dying of Cancer (University of Hawai'i Press 2013). She is the Director of the Leverhulme Trust Project 'Circuits of Waste and Value: Making E-waste Subjects in China and Japan.' She has a long-standing interest in rural China, its contemporary transformations, and the lived experience of development and its impacts. She was awarded the Philip Leverhulme Prize in Geography in 2013.

Nicholas LOUBERE is Associate Senior Lecturer in the Study of Modern China at the Centre for East and South-East Asian Studies, Lund University. His research examines microcredit and digital finance in rural China, and Chinese migration to Africa for resource extraction. His writing can be found in the Journal of Peasant Studies, Modern China, China Perspectives, International Migration, and Forum: Qualitative Social Research, as well as other outlets. Along with Ivan Franceschini, Nicholas is the co-chief editor of the Made in China Journal.

Andrew MERTHA is the George and Sadie Hyman Professor of China Studies and Director of the China Program at the Johns Hopkins School of Advanced International Studies. He is the author of The Politics of Piracy: Intellectual Property in Contemporary China (Cornell University Press 2005), China's Water Warriors: Citizen Action and Policy Change (Cornell University Press 2008), and Brothers in Arms: Chinese Aid to the Khmer Rouge, 1975-1979 (Cornell University Press 2014), as well as editor of May Ebihara's Svay: A Cambodian Village, with an Introduction by Judy Ledgerwood (Cornell University Press/Cornell Southeast Asia Program Press 2018). He has articles appearing in The China Quarterly, Comparative Politics, International Organization, Issues \& Studies, Cross-Currents, and Orbis, and chapters appearing in several edited volumes.

Covell MEYSKENS obtained his PhD in International History from the University of Chicago in 2015. He is an Assistant Professor in the Department of National Security Affairs at the US Naval Postgraduate School in Monterey. He is currently completing his first book on the Third Front and beginning his second book on the Three Gorges Dam. He runs the website 'Everyday Life in Maoist China' (everydaylifeinmaoistchina.org) which houses an ever-growing archive of images.

OU Ning is an artist, curator, and activist. As an artist, he is known for his documentary films San Yuan Li (2003) and Meishi Street (2006). He curated 'Get It Louder' (2005, 2007, 2010) and the 2009 Shenzhen \& Hong Kong Bi-city Biennale of Urbanism and Architecture. As an editor, he published Odyssey: Architecture and Literature (Zhongguo Qingnian Chubanshe 2009), South of Southern: Space, Geography, History and the Biennale (Zhongguo Qingnian Chubanshe 2014), and the literary journal Chutzpah! (2011-13). As an activist, he founded the Bishan Commune (2011-16) and School of Tillers (2015-16). He was a visiting professor at the Graduate School of Architecture, Planning and Preservation, Columbia University (2016-17).

PANG Laikwan is Professor of Cultural Studies at the Chinese University of Hong Kong. She is the author of several books, including The Art of Cloning: Creative Production During China's Cultural Revolution (Verso 2017), Creativity and Its Discontents: China's Creative Industries and Intellectual Property Rights Offenses (Duke University Press 2012), and The Distorting Mirror: Visual Modernity in China (University of Hawai'i Press 2007). Her latest manuscript, tentatively titled The Appearing Demos: Hong Kong During and Beyond the Umbrella Movement, is forthcoming with University of Michigan Press. 
Elizabeth J. PERRY is Henry Rosovsky Professor of Government at Harvard University and Director of the Harvard-Yenching Institute. A fellow of the American Academy of Arts and Sciences and the British Academy, she has served as President of the Association for Asian Studies and Director of Harvard's Fairbank Center for Chinese Studies. Perry's research focuses on the Chinese Revolution and its implications for contemporary politics. Her most recent publications include a co-edited volume with Sebastian Heilmann, Mao's Invisible Hand: The Political Foundations of Adaptive Governance in China (Harvard University Press 2011), and a single-authored monograph, Anyuan: Mining China's Revolutionary Tradition (University of California Press 2012).

Claudia POZZANA is an Associate Professor at the Department of History and Cultures of Bologna University, where she teaches Chinese language, literature, and culture. In the past, she was Visiting Professor and Research Fellow at the University of Washington-Seattle. Her research focuses on Chinese intellectual history of China in the early twentieth century, and on contemporary Chinese poetry. She has edited numerous anthologies of translations of contemporary Chinese poets.

Carlos ROJAS is Professor of Chinese Cultural Studies; Gender, Sexuality, and Feminist Studies; and Arts of the Moving Image at Duke University. He is the author, editor, and translator of numerous works, including Homesickness: Culture, Contagion, and National Transformation in Modern China (Harvard University Press 2015).

Alessandro RUSSO teaches Sociology at the University of Bologna, and has spent long periods of study and research in China. He was a Research Fellow in the Program in Critical Asia Studies at the University of Washington and a Visiting Professor at the Tsinghua Institute of Advanced Studies. He has published several studies on education in China and in Europe, and on the modern Chinese politics. His book Cultural Revolution and the Revolutionary Culture is forthcoming.

Sigrid SCHMALZER is Professor of History at the University of Massachusetts Amherst. Her research on the history of science in socialist China has produced two award-winning academic books-Red Revolution, Green Revolution: Scientific Farming in Socialist China (University of Chicago Press 2016) and The People's Peking Man: Popular Science and Human Identity in Twentieth-Century China (University of Chicago Press 2008) - along with a children's picture book. Her research also includes the history of science activism, and she has helped organise the revitalisation of the Science for the People movement in the United States. She is proud to serve as vice-president of the Massachusetts Society of Professors, the labour union for faculty and librarians at UMass Amherst.

Aminda SMITH specialises in the social and cultural history of Chinese Communism with broader interests in the global history of the left. Her first book, Thought Reform and China's Dangerous Classes (Rowman \& Littlefield 2013), examined the reformatories where agents of the state worked to transform vagrants and other outcasts into new socialist citizens. Her current work reexamines the Maoist Mass Line and the associated efforts to refashion individual consciousness through intense personal encounters. She is Associate Professor at Michigan State University and Co-Director of the PRC History Group. 
Craig A. SMITH is Lecturer of Translation Studies at the Asia Institute, University of Melbourne. Trained as a historian, his research focuses on the intellectual history of China in the early twentieth century. His writing on China-centred transnational regionalism has appeared in Twentieth-Century China, Cross-Currents, and Modern Chinese Literature and Culture. He also regularly translates contemporary Chinese and Japanese articles.

Christian SORACE is an Assistant Professor of Political Science at Colorado College. He is the author of Shaken Authority: China's Communist Party and the 2008 Sichuan Earthquake (Cornell University Press 2017). His articles have appeared in Public Culture, Critical Inquiry, Comparative Politics, The China Journal, and The China Quarterly among other journals. His current research focuses on urbanisation within the Mongolian steppe.

TENG Wei is a Professor at the School of Literature and Director of the Centre for Contemporary Cultural Studies at the South China Normal University. She received her PhD from Peking University and was a Harvard-Yenching Visiting Scholar in 2013-14. Her main research areas include hispanic literature and culture, Latin American studies, translation history, and cultural studies. She is also actively engaged in humanistic elementary education, and is the co-founder of the Magichanging Academy.

Patricia M. THORNTON is an Associate Professor in the Department of Politics and International Relations at the University of Oxford and Tutor in the Politics of China at Merton College. Her recent research focuses on the Chinese Communist Party, social movements, and Party-building. She is the author of several books, chapters, and articles on Chinese politics, the most recent of which is To Govern China: Evolving Practices of Power, edited with Vivienne Shue, and published by Cambridge University Press in 2017.

Luigi TOMBA is the Director of the China Studies Centre at The University of Sydney. He previously worked for 15 years at The Australian National University. He is interested in Chinese grassroots politics, political and social change, and urban transformation in China. His latest book is The Government Next Door: Neighborhood Politics in Urban China (Cornell University Press 2014), for which he won the Levenson prize in 2016. He was the co-editor of The China Journal for a decade until 2015.

Susan TREVASKES is a Professor of Chinese Studies in the School of Humanities, Languages, and Social Sciences at Griffith University. She has made contributions to the field of Chinese studies through her work on criminal law, punishment, and policing issues. Her research contributions have been recognised by a number of grants, which have resulted in papers, chapters, and books on criminal courts, policing serious crime, the death penalty, and the political nature of justice in China. Her most recent co-edited book is Justice: the China Experience (Cambridge University Press 2017).

WANG Ban is William Haas Professor in Chinese Studies in East Asian Languages and Cultures and Comparative Literature at Stanford University. His major publications include The Sublime Figure of History (Stanford University Press 1997), Illuminations from the Past (Stanford University Press 2004), and History and Memory (Oxford University Press in Hong Kong 2004, in Chinese). He has edited and co-edited seven books on Chinese film, revolution, socialism, and the New Left, including the most recent Chinese Visions of World Order (Duke University Press 2017). A Research Fellow with 
the National Endowment for the Humanities and the Institute for Advanced Studies at Princeton, he has taught at the State University of New York at Stony Brook, Harvard, Rutgers, East China Normal University, Yonsei, and Seoul National University.

WANG Lingzhen is Associate Professor at Brown University, specialising in modern Chinese literature, critical theory, film studies, and transnational feminist theory. She is the author of Personal Matters: Women's Autobiographical Practice in Twentieth Century China (Stanford University Press 2004) and Chinese Women Directing Films: History, Feminism, and Mainstream Culture in Modern China, 19491987 (forthcoming with Duke University Press), and the editor of Years of Sadness (Cornell East Asian Press 2009), Chinese Women's Cinema: Transnational Contexts (Columbia University Press 2011), and Other Genders, Other Sexualities: Chinese Differences (Duke University Press 2013). She is the co-editor of a Chinese book series, Gender, Theory, and Culture, the third volume of which, entitled Chinese Sex/ Gender: Historical Differences, came out from Shanghai Sanlian Press in 2016.

John WILLIAMS is an Associate Professor of History at Colorado College. His research interests range from the late imperial civil service examinations to rural mobilisation in the 1920s, and focus on the ways in which popular culture informed political and social institutions in late imperial and Republican China.

YANG Long is a DPhil Student in Oriental Studies at the University of Oxford. He completed his Master's Degree in Asian Studies at Lund University, Sweden. His published articles can be found in peer-reviewed journals such as Rural China and Twenty-First Century (ershiyi shiji). Based on previously unexamined archives, his current DPhil research centres on the social and local history of the Socialist Education Movement in north China between 1962 and 1966, with an emphasis on rural cadres' social relations.

YI Xiaocuo is a doctoral researcher who has lived in China and is now based in North America. The phrase yi xiao cuo in Chinese originally means 'a small bunch.' It is a recurring term in the Chinese Communist Party's historical discourse to denigrate critical voices. Writing on a wide range of topics such as the politics and history of China and borderlands, Yi Xiaocuo uses this pen name to reclaim the political stance of social justice that is often underrepresented and stigmatised by the state's propaganda machine. 



\section{References}

All references to Mao's writings and speeches that are clearly identified in the text are omitted from the reference list in order to streamline the endnotes. We include citations to Mao in the endnotes only when the text is not freely available online. The public translations of Mao can be found in Mao's Selected Works or by searching the online database www.marxists.org/reference/archive/mao/index.htm unless the translation was done by the author, in which case it is acknowledged. Finally, we adopted a consistent style throughout the text, including long-form quotations.

\section{INTRODUCTION}

[1] Barmé, Geremie. 1996. Shades of Mao: The Posthumous Cult of the Great Leader. Armonk: M. E. Sharpe; Li, Jie, and Enhua Zhang, eds. 2016. Red Legacies in China: Cultural Afterlives of the Communist Revolution. Cambridge, MA: Harvard University Press.

[2] Leys, Simon. 1974. Chinese Shadows, 59. New York: Penguin Books.

[3] Badiou, Alain (translated by David Macey and Steve Cocoran). 2010. The Communist Hypothesis, 269. London: Verso.

[4] Dean, Jodi. 2012. The Communist Horizon, 36. London: Verso.

[5] Žižek, Slavoj, and Costas Douzinas, eds. 2010. The Idea of Communism. London: Verso; Bosteels, Bruno, and Jodi Dean. 2014. Communist Currents, special issue of South Atlantic Quarterly 113 (4).

[6] Ghodsee, Kristen R., and Scott Sehon. 2018. 'Anti-anti-communism.' Aeon. aeon.co/essays/themerits-of-taking-an-anti-anti-communism-stance.

[7] Whitehead, Alfred North (edited by David Ray Griffin and Donald Shurburne). 1978. Process and Reality: An Essay in Cosmology, 226-27. New York: Free Press.

[8] Sorace, Christian. 2017. Shaken Authority: China's Communist Party and the 2008 Sichuan Earthquake, 59-80. Ithaca: Cornell University Press.

\section{AESTHETICS}

[1] Saussy, Haun. 2016. 'Music and Evil: A Basis of Aesthetics in China.' Paper presented at Political Enchantments: Aesthetic Practices and the Chinese State Conference, Melbourne, 15-16 December.

[2] Jameson, Frederic. 2016. An American Utopia: Dual Power and the Universal Army. London: Verso.

[3] People’s Daily. 1974. 'E'du de yongxin, beilie de shoufa: Pipan Andongniaoni paishe de ti wei "Zhongguo" de fanhua yingpian [Malicious Intentions, Despicable Techniques: Criticising Antonioni's Anti-Chinese Film “China”]. Renmin ribao [People's Daily], 30 January.

[4] Chu, Lan. 1974. 'Cong Andongniaoni qiren kan fanhua yingpian "Zhongguo" [Watching Antonioni’s Anti-Chinese Film "China”]. Guangming ribao [Guangming Daily], 13 February.

[5] Xiang, Alice. 2013. 'When Ordinary Seeing Fails: Reclaiming the Art of Documentary in Michelangelo Antonioni’s 1972 China Film Chung Kuo.' Sense of Cinema, July. 
[6] Wang, Ban. 1997. The Sublime Figure of History: Aesthetics and Politics in Twentieth-Century China. Stanford: Stanford University Press; Tang, Xiaobing. 2000. Chinese Modern: The Heroic and the Quotidian. Durham: Duke University Press.

[7] Rancière, Jacques (translated by Emiliano Battista). 2011. Althusser's Lesson. Durham: Duke University Press.

[8] Xi, Jinping. 2015. 'Zai weiyi gongzuo zuotanhui shang de jianghua [Speech at the Forum on Literature and Art].' Speech given on 15 October 2014, authorised for publication on 15 October 2015. news.xinhuanet.com/politics/2015-10/14/c_1116825558.htm; Boehler, Patrick and Vanessa Piao. 2015. 'Xi Jinping's Speech on the Arts is Released, One Year Later.' The New York Times, 15 October. sinosphere.blogs.nytimes.com/2015/10/15/xi-jinping-speech-arts-culture.

[9] Xinhua. 2017. 'China Embraces New "Principal Contradiction" When Embarking on New Journey.' Xinhua, 20 October. www.xinhuanet.com/english/2017-10/20/c_136694592.htm.

[10] Xinhua. 2016. 'President Xi Urges New Media Outlet to “Tell China Stories Well.” China Daily, 31 December.www.chinadaily.com.cn/china/2016-12/31/content_27832508.htm.

\section{BLOOD LINEAGE}

[1] Dikötter, Frank. 2015. The Discourse of Race in Modern China, 78. Oxford \& New York: Oxford University Press.

[2] Dutton, Michael. 2004. 'Mango Mao: Infections of the Sacred.' Public Culture 16 (2): 161-87.

[3] There are multiple terms to describe genealogical and political groupings in Kazakh society (for example ulus, ru, juz). These terms are inconsistently translated in English and Chinese sources, and were influenced by early British anthropology's ideological perceptions of the tribes and clans in Africa. The Chinese sources for this material used buluo, which in modern Chinese can be loosely translated as clan or tribe. However, as Morton Fried and Daniel Biebuyck argue, 'tribe' simplifies the innate complexity of a group's terms for social organisation. See Fried, Morton. 1966. 'On the Concepts of "Tribe" and 'Tribal Society." Transactions of the New York Academy of Sciences 28: 527-40; Biebuyck, Daniel P. 1966. 'On the Concept of Tribe.' Civilisations 16 (4): 500-15.

[4] Yu, Luoke. 2001. 'On Family Background.' Contemporary Chinese Thought 32 (4): 17-36.

[5] Byler, Darren. 2018. 'A Project Far More Extreme Than the Stanford Prison Experiment.' Sinopsis, 21 November. sinopsis.cz/en/xinjiang-specialist-darren-byler-for-sinopsis-a-project-farmore-extreme-than-the-stanford-prison-experiment.

[6] Hoshur, Shohret (translated by Alim Seytoff and Mamatjan Juma). 2018. 'Chinese Authorities Jail Four Wealthiest Uyghurs in Xinjiang's Kashgar in New Purge.' Radio Free Asia Uyghur Service, 5 January. www.rfa.org/english/news/uyghur/wealthiest-01052018144327.html.

[7] Human Rights Watch. 2018. 'China: Big Data Fuels Crackdown in Minority Region. Human Rights Watch, 26 February. www.hrw.org/news/2018/02/26/china-big-data-fuels-crackdownminority-region\#.

[8] Chin, Josh, and Clément Bürge. 2017. 'Twelve Days in Xinjiang: How China’s Surveillance State Overwhelms Daily Life.' The Wall Street Journal, 9 December. www.wsj.com/articles/twelve-days-inxinjiang-how-chinas-surveillance-state-overwhelms-daily-life-1513700355.

[9] Smith Finley, Joanne. 2013. The Art of Symbolic Resistance: Uyghur Identities and Uyghur-Han Relations in Contemporary Xinjiang. Leiden: Brill. 
[10] Wong, Edward. 2014. 'To Temper Unrest in Western China, Officials Offer Money for Intermarriage.' The New York Times, 2 September. www.nytimes.com/2014/09/03/world/asia/totemper-unrest-china-pushes-interethnic-marriage-between-han-and-minorities.html.

\section{CLASS FEELING}

[1] Lee, Haiyan. 2007. Revolution of the Heart: A Genealogy of Love in China, 1900-1950. Stanford: Stanford University Press.

[2] Wang, Ban. 2003. 'Revolutionary Realism and Revolutionary Romanticism: The Song of Youth' In The Columbia Companion to Modern East Asian Literature, edited by Joshua S. Mostow, 470-75. New York: Columbia University Press.

[3] Lee, Haiyan. 2011. 'Nowhere in the World Does There Exist Love or Hatred without Reason.' In Words and Their Stories: Essays on the Language of the Chinese Revolution, edited by Ban Wang, 149-70. Leiden: Brill.

[4] Alexander, Jeffrey C. 2017. The Drama of Social Life. Malden: Polity; Sun, Feiyu. 2013. Social Suffering and Political Confession: Suku in Modern China. New Jersey: World Scientific; Wu, Guo. 2014. 'Recalling Bitterness: Historiography, Memory, and Myth in Maoist China.' Twentieth-Century China 39 (3): 245-68.

[5] Dutton, Michael. 2009. 'Passionately Governmental: Maoism and the Structured Intensities of Revolutionary Governmentality'. In China's Governmentalities: Governing Change, Changing Government, edited by Elaine Jeffreys, 24-37. London \& New York: Routledge.

[6] Lee, Haiyan. 2014. The Stranger and the Chinese Moral Imagination. Stanford: Stanford University Press.

[7] Lee, Haiyan. 2011. 'Nowhere in the World Does There Exist Love or Hatred without Reason.'

[8] Perry, Elizabeth J. 2002. 'Moving the Masses: Emotion Work in the Chinese Revolution.' Mobilization: An International Quarterly 7 (2): 111-28.

[9] Hinton, William. 1966. Fanshen: A Documentary of Revolution in a Chinese Village. New York: Monthly Review Press.

[10] Arendt, Hannah. 1958. The Human Condition. Chicago: University of Chicago Press.

[11] Wang, Hui. 2006. 'The End of Politics? From East to West.' New Left Review 41: 29-45.

\section{CLASS STRUGGLE}

[1] Marx, Karl. 1852. 'Letter to Weydemeyer.' 5 March. www.marxists.org/archive/marx/works/ 1852/letters/52_03_05-ab.htm; Lenin, Vladimir. 1917. State and Revolution, Chapter 2, Section 3. www.marxists.org/archive/lenin/works/1917/staterev/ch02.htm\#s3.

[2] Marx, Karl. 1975. 'Critique of the Gotha Program.' www.marxists.org/archive/marx/works/1875/ gotha/.

[3] Althusser, Louis. 1970. 'Ideology and Ideological State Apparatuses.' On Ideology. Reprint, London: Verso Books, 2008.

[4] Schurmann, Franz. 1966. Ideology and Organization in Communist China. Berkeley: University of California Press.

[5] Russo, Alessandro. 2013. 'How Did the Cultural Revolution End? The Last Dispute Between Mao and Deng.' Modern China 39 (3): 239-97. 


\section{COLLECTIVISM}

[1] Gao, Mobo. 1999. Gao Village: A Portrait of Rural Life in Modern China. London: Hurst \& Co.

[2] Hinton, William. 1966. Fanshen: A Documentary of Chinese Revolution in Chinese Village. New York: Monthly Review Press.

[3] Gao, Mobo. 2018. Constructing China: Clashing Views of the People's Republic. London: Pluto.

[4] Hinton, William. 1990. The Great Reversal: The Privatization of China 1978-1989. New York: Monthly Review Press.

[5] Du, Runsheng. 2005. Du Runsheng zishu: Zhongguo nongcun tizhi biange zhongda juece jishi [A Record of the Major Decision in the Transformation of the Rural System in China]. Beijing: Renmin Chubanshe.

[6] Chen, An. 2015. The Transformation of Governance in Rural China: Market, Finance and Political Authority. Cambridge: Cambridge University Press.

[7] Lin, Justin Yifu. 1992. 'Rural Reforms and Agricultural Growth in China.' American Economic Review 82 (1): 34-51.

[8] Gao, Mobo. 2017. 'Wither Rural China: The Case of Gao Village.' The China Quarterly 229: 23-43.

\section{CONTRADICTION}

[1] Cohen, Arthur. 1961. 'Mao Tse-Tung and Historical Materialism: Part III, "Contradictions" in a "Socialist Society." Central Intelligence Staff Study, Central Intelligence Agency, 20 October.

[2] Žižek, Slavoj. 2007. 'Introduction.' In Slavoj Žižek Presents Mao on Practice and Contribution, 4. London: Verso Books.

[3] Starr, John Bryan. 1971. 'Conceptual Foundations of Mao Tse-Tung's Theory of Continuous Revolution.' Asian Survey 11 (6): 610-28.

[4] Yan, Lianke. 2004. Shouhuo. Shenyang: Chunfeng Wenyi Chubanshe, 2004. Translated by Carlos Rojas in 2012 as Lenin's Kisses. New York: Grove/Atlantic Press.

[5] Yan, Lianke. 2001. Jianying rushui. Wuhan: Changjiang Wenyi Chubanshe. Translated by Carlos Rojas forthcoming in 2020 as Hard Like Water. New York: Grove/Atlantic Press.

\section{CULTURE}

[1] Translator's Note: The 'socialist new person' (shehui zhuyi xinren), or, in Lenin's formulation from the early 1920s, 'new Soviet person,' was projected as the ideal figure who would create and emerge from the revolutionary remolding of human life and labour after the exploitative systems of capitalism were defeated: selfless, collective-minded, educated, seeking for equality, and so on. This became a central cinematic and literary motif in Chinese cultural production from the 1950s onwards.

[2] Translator's Note: This formulation derives from Mao Zedong's famous 1927 'Report on the Hunan Peasant Movement.' 


\section{CULTURAL REVOLUTION}

[1] Foster, Keith. 1986. 'Repudiation of the Cultural Revolution in China: The Case of Zhejiang.' Pacific Affairs 59 (1): 5-27.

[2] Russo, Alessandro. 2002. 'The Probable Defeat: Preliminary Notes on the Chinese Cultural Revolution.' In New Asian Marxism, edited by Tani E. Barlow, 311 and 313. Durham: Duke University Press.

[3] Hu, Weixiong. 2018. 'Mao Zedong xinminzhu zhuyi geming shiqi de jiaoyu shixian yu tansuo [Educational Practice and Exploration in the Era of Mao Zedong's New Democratic Thinking].' Mao Zedong yanjiu [Mao Zedong Research] 5: 69.

[4] People's Daily. 1947. 'Wusi yundong ershiba zhounian [The Twenty-eighth Anniversary of the May Fourth Movement].' Renmin ribao [People's Daily], 6 May.

[5] Bolajinsiji, 1947. 'Shiyue geming jiyule Sulian nongmin shenme? [What did the October Revolution give to the Soviet peasants?]'. Renmin ribao [People's Daily], 10 November.

[6] Kang, Sheng. 1957. 'Zhongguo geming shi weidade shiyue gemingde jixu [The Chinese Revolution Is the Continuation of the Great October Revolution].' Renmin ribao [People's Daily], 7 November.

[7] Pepper, Suzanne. 1996. Radicalism and Education Reform in Twentieth Century China, 289-90. Cambridge: Cambridge University Press.

[8] People's Daily. 1958. 'Wenhua geming kaishile [The Cultural Revolution has Begun].' Renmin ribao [People's Daily], 9 June .

[9] People's Daily. 1958. 'Yangjiang wenhua gongzuo zongjie [Summary of Yanjiang Culture Work].' Renmin ribao [People's Daily], December.

[10] 1958. 'Jixu da gao wenhua geming guanche dang de jiaoyu fangzhen [Continue to go full steam ahead implementing the Party's education direction],' 1-2. Guangdong Provincial Archives.

[11] Guangzhou Municipal Propaganda Department. 1958. 'Shiwei zi 275 hao [Municipal Party Committee No. 275],' 2, 29 August. Guangdong Provincial Archives.

[12] Nanfang Daily. 1958. Guangdong Provincial Archive file 217-1-455-1. Nanfang ribao [Nanfang Daily], 10 July.

[13] Guangzhou Municipal Cultural Bureau. 1958. Guangzhou gongren wenyi gongzuo shinian qingkuang [Ten Years of Literary Work among Guangzhou Workers], 15-16. Guangzhou Municipal Archives.

[14] Nee, Victor. 1969. The Cultural Revolution at Peking University, 20-27. London: Monthly Review Press.

[15] Central Committee. 1966. 'Circular of the Central Committee of the Communist Party of China on the Great Proletarian Cultural Revolution,' 16 May. www.marxists.org/subject/china/documents/ cpc/cc_gpcr.htm.

[16] Mao, Zedong. 1961-62. 'Reading Notes On The Soviet Text Political Economy'. www.marxists. org/reference/archive/mao/selected-works/volume-8/mswv8_64.htm.

[17] Central Committee. 1966. 'Circular of the Central Committee of the Communist Party of China on the Great Proletarian Cultural Revolution', 16 May. www.marxists.org/subject/china/documents/ cpc/cc_gpcr.htm.

[18] Gu, Yangmu, 2011. 'Hongweibing xiaobao xingwang lu [The Rise and Fall of Red Guards Broadsheets].' Wuhan wenshi ziliao [Wuhan Literary and Historical Materials] 9: 4.

[19] Bonnin, Michel, 2013. The Lost Generation: The Rustication of China's Educated Youth (19681980), 9-13. Hong Kong: The Chinese University of Hong Kong Press. 
[20] Wang, Hui (translated by Christopher Connery). 2006. 'Depoliticized Politics, Multiple Components of Hegemony, and the Eclipse of the Sixties', 684 and 690. Inter-Asia Cultural Studies 7 (4): 683-700.

[21] China Youth Daily Ideology and Theory Department. 1996. 'Realistic Responses and Strategic Options for China after the Soviet Upheaval.' Chinese Law \& Government, 29 (2): 13-31.

[22] Perry, Elizabeth J. 2017. 'Cultural Governance in Contemporary China: "Re-Orienting" Party Propaganda.' In To Govern China: Evolving Practices of Power, edited by Vivienne Shue and Patricia M. Thornton, 29. Cambridge: Cambridge University Press.

\section{DATONG AND XIAOKANG}

[1] Xi, Jinping. 2018. 'Secure a Decisive Victory in Building a Moderately Prosperous Society in All Respects and Strive for the Great Success of Socialism with Chinese Characteristics for a New Era.'Xinhua, 18 October. www.xinhuanet.com/english/download/Xi_Jinping's_report_at_19th_CPC_ National_Congress.pdf.

[2] Chen, Albert H.Y. 2014. 'The Concept of "Datong" in Chinese Philosophy as an Expression of the Common Good.' In The Common Good: Chinese and American Perspectives, edited by D. Solomon and P.C. Lo, 85-102. Dordrecht: Springer.

[3] Muller, Max, ed. 1885. The Sacred Books of the East, XXVII. Oxford: Clarendon Press.

[4] Couvreur, Séraphin. 1913. Li ki: ou, Mémoires sur les bienséances et les cérémonies. Ho Kien Fou: Imprimerie de la Mission Catholique.

[5] De Bary, Theodore, and Irene Cohen Bary, eds. 1999. Sources of Chinese Tradition: Volume 1: From Earliest Times to 1600. New York: Columbia University Press.

[6] Chen, Albert H.Y. 2014. 'The Concept of "Datong" in Chinese Philosophy as an Expression of the Common Good.'

[7] Mao, Zedong, quoted in Zhang, Airu. 2014. 'Cong "xiaokang" dao "quanmian xiaokang"-Deng Xiaoping xiaokang shehui lilun xingcheng he fazhan lunshu [From Xiaokang to Quanmian xiaokangThe Development and Discourse of Deng Xiaoping's Theory on Xiaokang Society]. Renminwang [People's Net]. cpc.people.com.cn/n/2014/0714/c69113-25279758.html.

[8] Hu, Jintao. 2012. 'Jiandingbuyi yanzhe Zhongguo tese shehuizhuyi daolu qianjin, wei quanmian xiaokang shehui er fendou [Hold High the Great Banner of Socialism with Chinese Characteristics and Strive for New Victories in Building a Moderately Prosperous Society in all Respects].' Zuguo [Motherland], November: 10-15.

[9] Wang, Hui. 2008. Quzhengzhihua de zhengzhi [The Depoliticisation of Politics]. Beijing: Xinzhi Sanlian Shudian.

\section{DIALECTICAL MATERIALISM}

[1] Marx, Karl, and Friedrich Engels (translated by Martin Milligan). 1988. 'Manifesto of the Communist Party. Economic and Philosophic Manuscripts of 1844. New York: Prometheus Books.

[2] Engels, Friedrich. 1883. Dialectics of Nature. www.marxists.org/archive/marx/works/download/ EngelsDialectics_of_Nature_part.pdf.

[3] Pang, Laikwan. 2016. 'Mao's Dialectical Materialism: Possibilities for the Future.' Rethinking Marxism 28 (1): 108-23. 
[4] Knight, Nick. 1997. 'The Laws of Dialectical Materialism in Mao Zedong's Thought: The Question of "Orthodoxy." Critical Perspectives on Mao Zedong's Thought, edited by Arif Dirlik, Paul Michael Healy, and Nick Knight, 84-116. New Jersey: Humanities Press.

[5] Stalin, Joseph. 1938. Dialectical and Historical Materialism. www.marxists.org/reference/archive/ stalin/works/1938/09.htm.

[6] Ai, Siqi. 1961. Bianzheng weiwu zhuyi lishi weiwu zhuyi [Dialectical Materialism, Historical Materialism]. Beijing: Renmin Chubanshe.

[7] Mao, Zedong. 1958. 'Introducing a Co-operative.' www.marxists.org/reference/archive/mao/ selected-works/volume-8/mswv8_09.htm.

[8] Schram, Stuart. 1989. The Thought of Mao Tse-Tung. Cambridge: Cambridge University Press.

[9] Knight, Nick, ed. 1990. Mao Zedong on Dialectical Materialism: Writings on Philosophy, 1937. Armonk \& London: M. E. Sharpe.

[10] Mao, Zedong. 1999. 'Gongzuo fangfa liushitiao (cao'an) [Sixty Articles of Work Methods (Draft)]'. Mao Zedong wenji [Mao Zedong Collected Works] Vol. 7. Beijing: Renmin Chubanshe.

[11] Mao, Zedong. 1974. 'Reading Notes on the Soviet Union's "Political Economics." Miscellany of Mao Tse-tung Thought (1949-1968) Part 2. Springfield, Virginia: Joint Publications Research Service.

[12] Adorno, Theodor W. 1981. Negative Dialectics. London: Bloomsbury Academic.

[13] Badiou, Alain (translated by Bruno Bosteels). 2009. Theory of the Subject. London: Continuum; Jameson, Fredric. 2010. Valences of the Dialectic. London \& New York: Verso.

[14] Pang, Laikwan. 2017. The Art of Cloning: Creative Production during China's Cultural Revolution. London \& New York: Verso.

\section{DIGNITY OF LABOUR}

[1] Lee, Ching Kwan. 2007. 'What Was Socialism to Chinese Workers? Collective Memories and Labor Politics in an Age of Reform.' In Re-Envisioning the Chinese Revolution, edited by Ching Kwan Lee and Guobin Yang, 141-65. Stanford: Stanford University Press.

[2] Snow, Edgar. 1944. Red Star Over China. New York: Modern Library.

[3] Marx, Karl (translated by Martin Nicolaus). 1973. Grundrisse: Foundations of the Critique of Political Economy. New York: Penguin.

\section{FORMALISM}

[1] Erlich, Victor. 1955. Russian Formalism: History-Doctrine, Fourth Edition, 135. The Hague: Mouton Publishers.

[2] Pang, Laikwan. 2017. The Art of Cloning: Creative Production During China's Cultural Revolution, 84-85. London: Verso Books.

[3] McGrath, Jason. 2010. 'Cultural Revolution Model Opera Films and the Realist Tradition.' The Opera Quarterly 26 (2-3): 343-76.

[4] Xi, Jinping. 2014. 'The Guiding Thoughts and Goals for the Program of Mass Line Education and Practice.' The Governance of China, 410-20. Beijing: Waiwen Chubanshe. 


\section{FRIEND AND ENEMY}

[1] Mao, Tse-Tung. 1965. 'Analysis of the Classes in Chinese Society (March 1926).' Selected Works, Vol. I, 13.

[2] After the Shanghai Massacre and the failure of the Autumn Harvest Uprising in 1927, the remnants of the Communist fighting forces fled to the remote bandit-ridden hideaway of Jinggangshan. They reached there in late 1927 and the process of rustication began as this formally city-based Party had to adapt to rural habits and mores.

[3] So says Leo Strauss in his famous commentary on Schmitt. See Strauss, Leo. 1996. 'Notes on Carl Schmitt.' In Carl Schmitt (translated by J. Harvey Lomax), The Concept of the Political, 85. Chicago: University of Chicago Press.

[4] For a detailed, empirically based description of its centrality to the Maoist revolution, see Dutton, Michael. 2005. Policing Chinese Politics: A History. Durham: Duke University Press.

[5] For the Party's own assessment, see 'Resolution on Certain Questions in the History of Our Party Since the Founding of the People's Republic of China.' Sixth Plenary Session of the Eleventh Central Committee of the Communist Party of China on 27 June 1981. The idea of Mao coming down from a sacred pedestal is drawn from the 1990 Hunan Xiang Yishu Chubanshe disco album called 'Cherishing your memories-Stepping down from the Sacred Pedestal of Mao Zedong.' This album contained 13 songs commemorating or remembering Mao. Set to a disco beat, these songs were a significant come down for a Chairman who had once been treated in a god-like fashion. Nevertheless, it proved to be a huge hit with over 100 million copies sold and forming part of the trinketisation and commodification of Mao's image that took place in the early 1990s Mao Craze.

[6] Just how influential this slogan was to the student movements of the 1960s is illustrated by the title of an article in the Asia Times celebrating the 50th anniversary of May 1968 by Pepe Escobar. The article was simply called '1968: The Legacy of Marx, Mao, and Marcuse.' Just how far Mao has fallen in those 50 years is noted by Escobar when he writes: 'Marx, arguably, may now be even more influential than Marcuse or Debord. It took a while for French intelligentsia to realize that then idealized Mao Zedong was a de facto rash Chinese emperor, issuing absurd edicts that destroyed the lives of millions.' See Escobar, Pepe. 2018. '1968: The Legacy of Marx, Mao, and Marcuse.' Asia Times, 12 May. www.atimes.com/article/1968-the-legacy-of-marx-mao-marcuse.

[7] The proliferation of comparisons of these dystopic figures has solidified the connection and is summed up well in the opening gambit of Ian Johnson's 2018 piece entitled 'Who Killed More: Hitler, Stalin, or Mao?' This piece, written in The New York Review of Books, begins as follows: 'In these pages nearly seven years ago, Timothy Snyder asked the provocative question: Who killed more, Hitler or Stalin? As useful as that exercise in moral rigor was, some think the question itself might have been slightly off. Instead, it should have included a third tyrant of the twentieth century, Chairman Mao. And not just that, but that Mao should have been the hands-down winner, with his ledger easily trumping the European dictators.' See Johnson, Ian. 2018. 'Who Killed More: Hitler, Stalin, or Mao?' The New York Review of Books, 5 February. www.nybooks.com/daily/2018/02/05/who-killed-morehitler-stalin-or-mao.

[8] Schmitt, Carl (translated by J. Harvey Lomax). 1996. The Concept of the Political, 26.

[9] Ibid.

[10] 'The political is the most intense and extreme antagonism, and every concrete antagonism becomes that much more political the closer it approaches the most extreme point, that of the friendenemy grouping.' Ibid., 29. 
[11] According to Jan-Werner Müller, Schmitt insisted that the political was 'purely a matter of intensity, so that any antithesis, if it was strong enough, could become political. Thus it was not the substance of enmity that mattered, but the intensity of an existential threat.' Quoted in Müller, JanWerner. 2003. A Dangerous Mind: Carl Schmitt in Post-War European Thought, 32-33. New Haven: Yale University Press.

[12] In discussing the question of intensity and the partisan, Schmitt states that 'with Mao there is still a concrete factor with reference to the partisan, whereby he came closer than Lenin to the core of the matter which made it possible for him to think the partisan through to the end. In short, Mao's revolution was more telluric.' See Schmitt, Carl (translated by G. L. Ulmen). 2007. The Theory of the Partisan: Intermediate Commentary on the Concept of the Political, 57. New York: Telos Press.

[13] Remnants of this can still be seen in Chinese policy today in a form that Sebastian Heilmann has called 'guerrilla style policy'. Interestingly, in China, this guerrilla policy style comes from the flexibility offered by what Zhai Xuewei has called tu zhengce and which could be translated as 'telluric policy.' For more details on both these policy concepts which tie grassroots policy operations back to the days of the telluric partisan, see Heilmann, Sebastian. 2011. 'Policy-Making Through Experimentation: The Formation of a Distinctive Policy Process.' In Maos Invisible Hand: The Political Foundations of Adaptive Governance in China, edited by Sebastian Heilmann and Elizabeth J. Perry, 62-101. Cambridge, MA: Harvard University Asia Center; Zhai, Xuewei. 2013. Renqing, mianzi yu quanli de zaishengchan [Face, Favour, and Reproduction of Power], 219-31. Beijing: Beijing Daxue Chubanshe.

[14] See People's Daily, 2 June 1966.

[15] Recent research by University College London makes the claim that the colonisation of the Americas at the end of the fifteenth century killed so many indigenous people, it disturbed Earth's climate, causing a 'Little Ice Age.' See Koch, Alexander, Chris Brierley, Mark M. Maslin, Simon L. Lewis. 2019. 'Earth System Impacts of the European Arrival and Great Dying in the Americas after 1492.' Quaternary Science Reviews 207 (1): 13-36.

[16] I offer a detailed elaboration of these points and other points in my new book, The Book of Politics (forthcoming).

\section{GLOBAL MAOISM}

[1] Wolin, Richard. 2010. The Wind from the East: French Intellectuals, the Cultural Revolution, and the Legacy of the 1960s. Princeton: Princeton University Press.

[2] Robcis, Camille. 2012. “China in Our Heads:” Althusser, Maoism, and Structuralism.' Social Text 30 (1): 51-69.

[3] Lanza, Fabio. 2017. The End of Concern: Maoist China, Activism, and Asian Studies. Durham: Duke University Press.

[4] Gurley, John G. 1970. 'Capitalist and Maoist Economic Development.' Bulletin of Concerned Asian Scholars 2 (3): 34-50.

[5] Newman, Robert P. 1992. Owen Lattimore and the 'Loss' of China. Berkeley: University of California Press.

[6] Reischauer, Edwin O., and John K. Fairbank. 1967. 'East Asia and Our Future.' Panel at Harvard University. vimeo.com/50776144.

[7] Pfeffer, Richard M. 1970. 'Revolution and Rule: Where Do We Go from Here'. Bulletin of Concerned Asian Scholars 2 (3): 88-95.

[8] Said, Edward. 1979. Orientalism. New York: Vintage. 
[9] Kagan, Leigh. 1968. 'Proposals.' Bulletin of Concerned Asian Scholars 1 (1): 7.

[10] Brown, Jeremy, and Matthew D. Johnson, eds. 2015. Maoism at the Grassroots: Everyday Life in China's Era of High Socialism. Cambridge, MA: Harvard University Press; Hershatter, Gail. 2011. The Gender of Memory: Rural Women and China's Collective Past. Berkeley: University of California Press.

[11] Smith, Aminda M. 2014. 'Lessons We Need to Learn.' The PRC History Review 1 (1): 17-19.

[12] Brown, Jeremy. 2010. 'Finding and Using Grassroots Historical Sources from the Mao Era.' Dissertation Reviews. 15 December. dissertationreviews.wordpress.com/2010/12/15/finding-andusing-grassroots-historical-sources-from-the-mao-era-by-jeremy-brown.

\section{IMMORTALITY}

[1] From an interview with the journalist, popular historian, and social critic Dai Qing in The Gate of Heavenly Peace. 1995. Film. Directed by Carma Hinton and Richard Gordon. Long Bow Group. tsquare.tv/film/transcript_open.php.

[2] Teiwes, Frederick C. 2010. 'Mao and his Followers', 130. In A Critical Introduction to Mao, edited by Timothy Cheek, 129-68. Cambridge: Cambridge University Press.

[3] Dai Qing in The Gate of Heavenly Peace, cit.

[4] Hartman, Geoffrey. 2007. Criticism in the Wilderness, 248. New Haven and London: Yale University Press.

[5] Wordsworth, William. 1876. 'Upon Epitaphs.' The Prose Works of William Wordsworth, Vol. 2. Edited by Alexander B. Grosart. www.gutenberg.org/files/16550/16550-h/16550-h.htm.

[6] Leys, Simon. 1999. The Angel and the Octopus, 16-17. Sydney: Duffy \& Snellgrover.

[7] Zhuangzi 27:1. Translation by the author.

[8] I draw here on Charles Taylor's argument that language, in its constitutive dimension, makes possible through 'certain expressions or enactments ... certain meanings and ways of being.' See Taylor, Charles. 2016. The Language Animal: The Full Shape of the Human Linguistic Capacity, 47-48. Cambridge, MA: Harvard University Press.

[9] Hu, Shi. 1998. 'Buxiu: Wo de zongjiao [Immortality: My Religion]? In Hu Shi wenji [Collected Works of Hu Shi], Vol. 2, edited by Ouyang Zhesheng, 525-32. Beijing: Beijing Daxue Chubanshe.

[10] Ibid., 532.

[11] In 1984, Orwell wrote: 'Every record has been destroyed or falsified, every book has been rewritten, every picture has been repainted, every statue and street and building has been renamed, every date has been altered. And that process is continuing day by day and minute by minute. History has stopped. Nothing exists except an endless present in which the Party is always right.' See Orwell, George. 1983. 1984, 147. Boston: Houghton Mifflin Harcourt.

[12] Yurchak, Alexei. 2005. Everything Was Forever, Until It Was No More: The Last Soviet Generation, 250. Princeton: Princeton University Press.

[13] This is likely because of the depth of identification with Mao's words that people had acquired in their formative years, through their memorisation and internalisation of quotations from Mao in the Little Red Book ('treasured red book' hongbaoshu).

[14] Schram, Stuart, Timothy Cheek, and Roderick MacFarquhar, eds. 2015. Mao's Road to Power: Revolutionary Writings, Vol. 8, 616. London \& New York: Routledge.

[15] One popular parody of the motto in the 2000s and since takes the form of the question: 'Are you serving the people or ...?' with the blank filled in by words such as 'Party', 'corrupt officials,' 'leaders', and 'yourself.' 
[16] The essay by Mao was: Mao, Zedong. 1919. 'Minzhongde dalianhe [Great Union of the Masses].' Xiangjiang pinglun [Xiang River Review]. 21 July. This translation is from the transcript of: The Gate of Heavenly Peace, www.tsquare.tv/film/transcript.html; The hunger strike manifesto 'Jueshi xuanyuan', 13 May 1989, is online at www.64wiki.com/viiv/viiv/eventinfo.php?id=484.

[17] Tencent Review. 2011. 'Lixiang guo di ba chang, Chen Danqing and Liang Wendao: Tantan daxue liaoliao lixiang [An Ideal Country, Eighth Session: Chen Danqing and Liang Wendao on Universities and Ideals]. Event organised to commemorate the 25th year of the establishment of Guangxi Normal University Press, in conjunction with the Imaginist [Lixiang guo] Humanities Cultural Salon. Held 21 November and published 6 December. view.news.qq.com/a/20111206/000040.htm.

[18] Morning Sun (Long Bow Group). September 2000. 'Long Life Without End.' Interview. www. morningsun.org/living/dying/mao.html.

[19] Arendt, Hannah. 1958. The Human Condition, 55. Chicago: University of Chicago Press.

[20] An annotated online copy of this poem appears on the People's Daily website at www.people. com.cn/GB/shizheng/8198/30446/30453/2220788.html.

[21] Mao, Zedong. 1958. 'Sixty Articles on Work Methods.' 2 February. www.marxists.org/reference/ archive/mao/selected-works/volume-8/mswv8_05.htm.

[22] Minzhu renshi is a Mao-era term referring to people who, during the Republican period, joined other political parties or were without political affiliations but who were 'patriotic' supporters of the Chinese communist cause. The year 1954 was also when Mao denounced Hu Shi and attacked Hu's former associates. Mao had, in earlier decades, admired Hu's writings.

[23] Quoted (among other places) in You, Heping. 2014. 'Mao Zedong zhongshi wenhua baohu [Mao Zedong Paid Attention to Cultural Preservation]'. Minzu fuxing wang [Ethnic Renaissance Net]. 21 May. www.mzfxw.com/e/action/ShowInfo.php?classid=18\&id=8790.

[24] My thanks to Warren Sun and Han Gang for providing this information.

[25] On Mao's influence and legacy in the first two decades after his death, see the absorbing study Barmé, Geremie R. 1996. Shades of Mao: The Posthumous Cult of the Great Leader. Armonk: M. E. Sharpe.

[26] Quoted and translated in Barmé, Geremie R. 2018. 'Homo Xinensis: Drop Your Pants! The Party Wants to Patriotise You All Over Again (Part iii).' China Heritage. 31 August. chinaheritage. net/journal/homo-xinensis.

\section{JUSTICE}

[1] Garlan, Edward N. 1941. Legal Realism and Justice, 3. New York: Columbia University Press.

[2] Hurst, William. 2018. Ruling Before the Law: the Politics of Legal Regimes in China and Indonesia, 29-30. Cambridge: Cambridge University Press.

[3] Tsou, Tang. 1976. 'Prolegomenon to the Study of Informal Groups in CCP Politics.' The China Quarterly 65: 98-114.

[4] Hurst, William. 2018. Ruling Before the Law, Chapter 1.

[5] Ibid., 103.

[6] Ibid., Chapter 2.

[7] Hurst, William. 2011. 'Politics, Society, and the Legal System in Contemporary China.' In Law, Wealth, and Power in China: Commercial Law Reforms in Context, edited by John Garrick, 72-88. London: Routledge. 
[8] Lubman, Stanley B. 1970. 'Methodological Problems in Studying Chinese Communist "Civil Law." In Contemporary Chinese Law: Research Problems and Perspectives, edited by Jerome A. Cohen, 248-55. Cambridge, MA: Harvard University Press.

[9] For instance, see Diamant, Neil J. 2001. 'Making Love Legible in China: Politics and Society during the Enforcement of Civil Marriage Registration, 1950-1966.' Politics and Society 29 (3): 477-80.

[10] Hurst, William. 2018. Ruling Before the Law, 61 and 89.

[11] For a discussion of the importance of defining enemies, and specifically hostes rather than inimici, see Schmitt, Carl (translated by George Schwab). 2007. The Concept of the Political, Expanded Edition, 28-30. Chicago: University of Chicago Press.

[12] Hurst, William. 2018. Ruling Before the Law, 113; Mühlhahn, Klaus. 2009. Criminal Justice in China: A History, 180-81. Cambridge, MA: Harvard University Press.

[13] Bennett, Gordon. 1976. Yundong: Mass Campaigns in Chinese Communist Leadership. Berkeley: Center for Chinese Studies Research Monographs; Hurst, William. 2018. Ruling Before the Law, 57.

[14] Hurst, William. 2011. 'Politics, Society, and the Legal System in Contemporary China', 80; Hurst, William. 2018. Ruling Before the Law, 59.

[15] In the reform era, heyiting have often also included a 'people's assessor' (renmin peishenyuan) alongside the shenpanzhang and a second professional judge.

[16] Hurst, William. 2018. Ruling Before the Law, 60.

[17] Ibid., 61.

[18] Ibid., 119-23.

[19] Mühlhahn, Klaus. 2009. Criminal Justice in China, 215-19; Hurst, William. 2018. Ruling Before the Law, 112-13.

[20] Hurst, William. 2018. Ruling Before the Law, 105-10.

[21] Liu, Sida, and Terence Halliday. 2016. Criminal Defense in China: The Politics of Lawyers at Work, 20-21. Cambridge: Cambridge University Press.

[22] Hurst, William. 2018. Ruling Before the Law, 106-10.

[23] Ibid., 125-26.

[24] Ibid., Chapters 4 and 5.

[25] Biddulph, Sarah. 2007. Legal Reform and Administrative Detention Powers in China. Cambridge: Cambridge University Press; Sapio, Flora. 2010. Sovereign Power and the Law in China. Leiden and Boston: Brill.

[26] Wang, Yuhua. 2015. Tying the Autocrat's Hands: The Rise of the Rule of Law in China. Cambridge: Cambridge University Press.

\section{LABOUR}

[1] Some representative works are: Walder, Andrew G. 1986. Communist Neo-Traditionalism: Work and Authority in Chinese Industry. Berkeley: University of California Press; Sheehan, Jackie. 1998. Chinese Labor: A New History, 13-155. London: Routledge; Frazier, Mark W. 2002. The Making of the Chinese Industrial Workplace: State, Revolution, and Labor Management, 149-233. Cambridge: Cambridge University Press. 
[2] For examples of these practices, see Li, Huaiyin. 2008. Village China Under Socialism and Reform: A Micro-History, 1948-2008, 23-266. Stanford: Stanford University Press; U, Eddy. 2007. Disorganizing China: Counter-Bureaucracy and the Decline of Socialism. Stanford: Stanford University Press; Li, Huaiyin. 2017. 'Everyday Power Relations in State Firms in Socialist China: A Reexamination.' Modern China 43: 288-321.

[3] Lenin, Vladimir. 1993. The State and Revolution, 16-21 and 75-92. New York: Penguin.

[4] An early treatment of this facet of Mao era propaganda can be found in Schwartz, Benjamin I. 1968. 'The Reign of Virtue: Some Broad Perspectives on Leader and Party in the Cultural Revolution.' The China Quarterly 35: 1-17. For a similar trend in Soviet cultural production, see Stites, Richard. 1989. Revolutionary Dreams. Utopian Vision and Experimental Life in the Russian Revolution. Oxford: Oxford University Press.

[5] On the urban-rural divide, see Brown, Jeremy. 2012. City Versus Countryside in Mao's China: Negotiating the Divide. Cambridge: Cambridge University Press. On the welfare state, see Lu, Xiaobo, and Elizabeth J. Perry, eds. 1997. Danwei: The Changing Chinese Workplace in Historical and Comparative Perspective. Armonk: M. E. Sharpe; Dillon, Nara. 2015. Radical Inequalities: China's Revolutionary Welfare State in Comparative Perspective. Cambridge, MA: Harvard University Press.

[6] On work-points, see Li, Huaiyin. 2008. Village China Under Socialism and Reform, 35-36, 99-100, 187-91, 194-98. On industrial wages see Walder, Andrew G. 1986. Communist Neo-Traditionalism, 76-81; Frazier, Mark W. 2002. The Making of the Chinese Industrial Workplace, 143-51.

[7] On radio, see Clark, Paul. 2008. The Chinese Cultural Revolution: A History, 180-81, 191, 194. Cambridge: Cambridge University Press.

[8] Sahlins, Marshall. 1972. Stone Age Economics, 193-94. London: Routledge.

[9] Marx, Karl (translated by Ben Fowkes). 1867. Capital: A Critique of Political Economy, Vol. 1, 342, 989-90. Reprint, Harmondsworth: Penguin Classics, 1976; Marx, Karl. 1849. 'Wage Labour and Capital.' Collected Works, Vol. 9, 213 and 215. Reprint, London, 1977.

[10] Pietz, David A. 2015. The Yellow River: The Problem of Water in Modern China, 130-257. Cambridge, MA: Harvard University Press; Li, Hou. 2018. Building for Oil Daqing and the Formation of the Chinese Socialist State. Cambridge, MA: Harvard University Press.

[11] On discipline and surveillance, see Walder, Andrew G. 1986. Communist Neo-Traditionalism; Bray, David. 2005. Social Space and Governance in Urban China: The Danwei System from Origins to Reform, 66-166. Stanford: Stanford University Press. On life chances, see Walder, Andrew G., Bobai Li, and Donald J. Treiman. 2000. 'Politics and Life Chances in a State Socialist Regime: Dual Career Paths into the Urban Chinese Elite, 1949 to 1996.' American Sociological Review 65 (2): 191-209.

[12] Cahill, James. 1982. The Compelling Image: Nature and Style in Seventeenth-Century Chinese Painting. Cambridge, MA: Belknap Press of Harvard University Press.

[13] Haraway, Donna J. 1997. Modest_Witness@Second_Millennium.FemaleMan_Meets_ OncoMouse: Feminism and Technoscience. London, Routledge.

[14] Bauman, Zygmunt. 1991. Modernity and Ambivalence, 20. Ithaca: Cornell University Press.

[15] Foucault, Michel. 2004. Security, Territory, Population, 125-30. New York: Picador.

[16] On privatisation, see Lee, Ching Kwan. 2007. Against the Law: Labor Protests in China's Rustbelt and Sunbelt, 125-30. Berkeley: University of California Press; Yan, Yunxiang. 2003. Private Life under Socialism: Love, Intimacy, and Family Change in a Chinese Village, 1949-1999. Stanford: Stanford University Press; Farquhar, Judith. 2002. Appetites: Food and Sex in Post-Socialist China. Durham: Duke University Press. 


\section{LARGE AND COMMUNITARIAN}

[1] Li, Ruiyang. 2011. 'Guanyu Mao Zedong chengshi renmin gongshe sixiang de lishi kaocha ji sikao [Historical Investigation and Analysis of Mao Zedong's Thoughts About Urban People Communes].' Dangdai shijie yu shehuizhuyi [Contemporary World and Socialism] 3: 162-66.

[2] Ibid.

[3] Engels, Friedrich. 1845. 'Speeches in Elberfeld.' In Marx and Engels Collected Works Vol. 4. marxists.anu.edu.au/archive/marx/works/1845/02/15.htm.

[4] Jin, Oubo. 1960. 'Jianzhu sheji bixu tixian daban chengshi renmin gong she de xin xingshi [Architectural Design Needs to Reflect the New Form of the Urban People's Communes].' Jianzhu xuebao [Architectural Journal] 5: 34-38.

[5] Qian, Shengzhi. 1958. 'Tan renmin gongshe hua tiaojian xia xian de chengshi guihua wenti [Discussing the Problem of Planning County Cities Under the Conditions of Communification].' Caijing yanjiu [Financial Research] 9: 15-18.

[6] Jin, Oubo. 1960. 'Architectural Design Needs to Reflect the New Form of the Urban People's Communes.'

[7] Ibid.

[8] Tomba, Luigi. 2017. 'Finding China's Urban: Bargained Land Conversions, Local Assemblages, and Fragmented Urbanization.' In To Govern China: Evolving Practices of Power, edited by Vivienne Shue and Patricia M. Thornton, 203-28. Cambridge: Cambridge University Press.

\section{LINE STRUGGLE}

[1] For a Japanese-language study on the early translation of the concept of 'line' in East Asia, see Eda, Kenji. 2013. 'Chūgoku Kyōsantōshi ni okeru honyaku gainen [Translated Concepts in the History of the Chinese Communist Party].' In Kindai higashi Ajia ni okeru honyaku gainen no tenkai [The Development of Translated Concepts in Modern East Asia], edited by Naoki Hazama and Yoshihiro Ishikawa, 343-72. Kyoto: Institute for Research in Humanities, Kyoto University. For an Englishlanguage study of the concept of 'line struggle, see Dittmer, Lowell. 1977. "Line Struggle" in Theory and Practice: The Origins of the Cultural Revolution Reconsidered.' The China Quarterly 72: 675-712.

[2] The term 'Li Lisan Course' first appeared in Ōtsuka, Reizō. 1931. 'Chūgoku Kyōsantō saikin no dōyō ni tsukite [On Recent Unrest in the Chinese Communist Party].' Sōgō shiryō [Collected Materials], 18 February. Mantetsu Chōsaka. Within months it also appeared in the popular journals of the time: Tanaka, Tadao. 1931. 'Shina kakumei no gensei to Shina Kyōsantō no naikō [The Current Situation of the Chinese Revolution and Discord within the Chinese Communist Party]. Chūō kōron [Central Review], April; Ōtsuka, Reizō. 1931. 'Shina kyōsantō no gensei [The Current Situation of the Chinese Communist Party]'. Kaizō [Reconstruct], July.

[3] Central Committee of the Communist Party of China Literature Research Office. 2011. Mao Zedong sixiang nianbian, 1921-1975 [Chronicle of Mao Zedong Thought, 1921-1975], 366-67. Beijing: Zhongyang Wenxian Chubanshe.

[4] Those ten line struggles were as follows: 1 . Chen Duxiu's right-opportunist line; 2. Li Lisan's left-adventurist line; 3. Qu Qiubai's left-deviationist line; 4. Luo Zhangnong's splittist line; 5. Zhang Guotao's splittist line; 6. Wang Ming's first left then right opportunist line; 7. Gao Gang and Rao Shushi's anti-Party clique splittist line; 8. Peng Dehuai's right-opportunist line; 9. Liu Shaoqi's capitalist 
headquarters; 10. Lin Biao's counter-revolutionary clique. See: Mao, Zedong. 1998. Jianguo yilai Mao Zedong wengao, di shisan ce [Mao Zedong's Writings Since the Founding of the People's Republic of China, Vol. 13], 241-50. Beijing: Zhongyang Wenxian Chubanshe.

[5] Ibid.

[6] Hu, Qiaomu. 1999. 'Guanyu minzhu he zhuanzhengde wenti (1980 nian qi yue shiba ri) [On the Question of Democracy and Dictatorship (18 July 1980)].' Hu Qiaomu tan zhonggong dangshi [Hu Qiaomu Discusses the History of the Communist Party of China], 85-86. Beijing: Renmin Chubanshe. This speech is a discussion of the drafting committee of the second resolution on history.

[7] Hu, Qiaomu. 1999. 'Guanyu "lishi jueyi" de jidian shuoming (1981 nian wu yue shijiu ri) [A Few Illustrations of the "Resolution on History"' (19 May 1981)]? Hu Qiaomu tan zhonggong dangshi [Hu Qiaomu Discusses the History of the Communist Party of China], 85-86. Beijing: Renmin Chubanshe. This speech was made at an Expanded Meeting of the CCP Politburo.

\section{MASS LINE}

[1] For a sampling of appreciation of the mass line in political theory in the West, see Lin, Chun. 2006. The Transformation of Chinese Socialism, Chapter 3, 143-48. Durham: Duke University Press.

[2] Marx, Karl. 1875. 'Critique of the Gotha Programme', Section I. www.marxists.org/archive/ marx/works/1875/gotha/ch01.htm.

[3] Mao, Zedong. 1959-60. 'On the Soviet Textbook of Political Economy'. cpc.people.com.cn/ GB/64184/64185/189968/11568297.html.

[4] Marx, Karl. 1867. Capital I, 874-75. Reprint, New York: Penguin, 1976.

[5] Mao, Zedong. 1964. 'The Editorial Note on "Khrushchev's Phony Communism and its World Historical Lessons." Renmin ribao [People's Daily], 14 July. His earliest warning in the similar wording was made in Mao, Zedong. 1962. 'Speech at the Extended Central Work Conference.' 30 January. Selected Works of Mao Zedong Since 1949, Vol. 10, 24-25. Reprint, Beijing: Central Party Literature Press, 1996.

[6] Xinhua. 2017. 'Highlights of Xi's Report to 19th CPC National Congress'. People's Daily, 18 October. en.people.cn/n3/2017/1018/c90000-9281682.html.

\section{MASS SUPERVISION}

[1] Sections of this chapter are based on chapters in a forthcoming book [Andreas, Joel. Forthcoming 2019. Disenfranchised: The Rise and Fall of Industrial Citizenship in China. Under Review] as well as a published chapter [Andreas, Joel, and Yige Dong. 2017. "Mass Supervision" and the Bureaucratization of Governance in China.' In To Govern China: Evolving Practices of Power, edited by Vivienne Shue and Patricia M. Thornton, 123-55. Cambridge: Cambridge University Press]. Yige Dong provided invaluable assistance in conducting the content analyses presented in the chapter. Research that informs this chapter also benefited from able assistance provided by Rachel Core, Chunyan Fan, Amy Han, Lingli Huang, Crystal Lee, Gloria Li, Peiyao Li, Yao Li, Yingyao Wang, Jaycee Yao, and Shaohua Zhan.

[2] Mao, Zedong, and Yanpei Huang. 1945. '1945 nian 7 yue 4 ri Mao Zedong yu Huang Yanpei tan 'lishi zhouqi lü’ [Mao Zedong and Huang Yanpei Discuss Historical Cycles], 4 July. cpc.people.com.cn/ GB/4162/64165/67447/67458/4555957.html. 
[3] Scholarship on the CCP's internal apparatus to monitor and discipline party cadres includes: Barnett, A. Doak. 1967. Cadres, Bureaucracy, and Political Power in Communist China. New York: Columbia University Press; Lü, Xiaobo. 2000. Cadres and Corruption: The Organizational Involution of the Chinese Communist Party. Stanford: Stanford University Press; Schurmann, Franz. 1968. Ideology and Organization in Communist China. Berkeley: University of California Press.

[4] Ocko, Jonathan. 1988. 'I'll Take It All the Way to Beijing: Capital Appeals in the Qing.' The Journal of Asian Studies 47 (2): 291-315; Fang, Qiang. 2013. Chinese Complaint Systems: Natural Resistance. New York: Routledge; Yang, Guobin. 2016. The Red Guard Generation and Political Activism in China, 26-27. New York: Columbia University Press.

[5] Andrle, Vladimir. 1988. Workers in Stalin's Russia: Industrialization and Social Change in a Planned Economy. New York: St. Martin's Press; Fitzpatrick, Sheila. 1994. 'Workers Against Bosses: The Impact of the Great Purges on Labor-Management Relations.' In Making Workers Soviet: Power, Class and Identity, edited by Lewis Siegelbaum and Ronald Grigor Suny, 311-40. Ithaca: Cornell University Press; Granick, David. 1954. Management of the Industrial Firm in the USSR: A Study in Soviet Economic Planning, 232-61. New York: Columbia University Press.

[6] Hinton, William. 1966. Fanshen: A Documentary of Revolution in a Chinese Village, 319-66, 446-75. New York: Monthly Review Press.

[7] Li, Fangchun. 2012. 'Mass Democracy, Class Struggle, and Remolding the Party and Government During the Land Reform Movement in North China.' Modern China 38 (4): 411-45; Teiwes, Frederick. 1976. 'The Origins of Rectification: Inner-Party Purges and Education Before Liberation.' The China Quarterly 65: 15-53.

[8] Li, Fangchun. 2012. 'Mass Democracy, Class Struggle, and Remolding the Party and Government During the Land Reform Movement in North China.'

[9] National People's Congress. 1954. 'Article 17.' Constitution of the People's Republic of China. www. npc.gov.cn/wxzl/wxzl/2000-12/26/content_4264.htm.

[10] On the Three Antis Campaign see Andreas, Joel. Forthcoming 2019. Disenfranchised; Gao, James Zheng. 2004. The Communist Takeover of Hangzhou: The Transformation of City and Cadre, 1949-1954. Honolulu: University of Hawaii Press; Lieberthal, Kenneth. 2009. Revolution and Tradition in Tientsin, 1949-1952. Stanford: Stanford University Press; Lü, Xiaobo. 2000. Cadres and Corruption, $51-62$.

[11] On the 1957 Party Rectification and the Anti-rightist Campaign, see Andreas, Joel. 2009. Rise of the Red Engineers: The Cultural Revolution and the Origins of China's New Class, 32-41. Stanford: Stanford University Press; Andreas, Joel. Forthcoming 2019. Disenfranchised; MacFarquhar, Roderick. 1960. The Hundred Flowers Campaign and the Chinese Intellectuals. New York: Praeger; MacFarquhar, Roderick. 1974. Origins of the Cultural Revolution, 1: Contradictions Among the People, 1956-1957. New York: Columbia University Press; Teiwes, Frederick. 1993. Politics and Purges in China: Rectification and the Decline of Party Norms, 1950-1965, Second Edition, 156-258. Armonk: M. E. Sharpe.

[12] CCP Central Committee. 1963. 'Decision About Some Current Problems in Rural Work (Draft).' In Ssu-ch 'ing: The Socialist Education Movement of 1962-1966, edited by Richard Baum and Frederick Teiwes, 58-71. Reprint, Berkeley: University of California Center for Chinese Studies, 1968.

[13] CCP Central Committee. 1965. 'Nongcun shehuizhuyi jiaoyu yundong zhong muqian tichu de yi xie wenti [Some Current Problems in the Village Socialist Education Movement]. baike.baidu.com/ view/3152593.htm\#2.

[14] Mao, Zedong. 1996. Jianguo yilai Mao Zedong wengao [Writings of Mao Zedong Since the Founding of the Republic], Vol. 11, 265-66. Beijing: Zhongyang Wenxian Chubanshe. 
[15] CCP Central Committee, 1965. 'Nongcun shehuizhuyi jiaoyu yundong zhong muqian tichu de yi xie wenti.'

[16] Andreas, Joel. Forthcoming 2019. Disenfranchised; Chan, Anita, Richard Madsen, and Jonathan Unger. 2009. Chen Village: Revolution to Globalization. Berkeley: University of California Press; Friedman, Edward, Paul Pickowicz, and Mark Selden. 2005. Revolution, Resistance and Reform in Village China. New Haven: Yale University Press; Hinton, William. 1983. Shenfan: The Continuing Revolution in a Chinese Village. New York: Random House.

[17] Mao, Zedong. 1965. 'Guanyu siqing yundong de yi ci jianghua [A Talk About the Four Cleans Movement].' In Mao Zedong sixiang wansui [Long Live Mao Zedong Thought], Vol. 5 (140): 277, 279. Reprint, Wuhan Chubanshe, 1968.

[18] Mao, Zedong. 1996. Jianguo yilai Mao Zedong wengao, 220.

[19] Mao, Zedong. 1966. 'Bombard the Headquarters: My First Big-Character Poster'. Peking Review 33. Reprint, 1967.

[20] Scholarship that focuses on factional conflict in China's workplaces during the Cultural Revolution includes: Andreas, Joel. Forthcoming 2019. Disenfranchised; Forster, Keith. 1990. Rebellion and Factionalism in a Chinese Province: Zhejiang, 1966-1976. Armonk: M. E. Sharpe; Liu, Guokai. 1986-87. 'A Brief Analysis of the Cultural Revolution.' Chinese Sociology and Anthropology 19 (2): 14-151; Perry, Elizabeth and Xun Li. 1997. Proletarian Power: Shanghai in the Cultural Revolution. Boulder: Westview Press; Walder, Andrew. 1996. 'The Chinese Cultural Revolution in the Factories: Party-State Structures and Patterns of Conflict.' In Putting Class in Its Place: Worker Identities in East Asia, edited by Elizabeth Perry, 167-98. Berkeley: Center for Chinese Studies, Institute of East Asian Studies, University of California; Wang, Shaoguang. 1995. Failure of Charisma: The Cultural Revolution in Wuhan. Oxford: Oxford University Press.

[21] Mao, Zedong. 1974. 'Talk at a Meeting of the Central Cultural Revolution Group, 9 January 1967. In Mao Talks to the People: Talks and Letters: 1956-1971, edited by Stuart Schram, 275-76. New York: Pantheon Books.

[22] Mao Zedong cited in Pang, Xianzhi, and Chongji Jin, eds. 2004. Mao Zedong zhuan (19491976)[Biography of Mao Zedong (1949-1976)], Vol. 4, 1468. Beijing: Zhongyang Wenxian Chubanshe.

[23] Andreas, Joel, and Yige Dong. 2017. "Mass Supervision” and the Bureaucratization of Governance in China'; He, Qin. 2009. 'Xin Zhongguo 60 nian lai qunzhong jiandu de lichen, qushi he jingyan [The Processes, Patterns, and Experiences of Mass Supervision During the Past Six Decades of New China]. Tansuo 5: 66-71; Huang, Yihua, and Shuyan Hu. 2010. 'Shilun xin Zhongguo chengli yilai dang de qunzhong jiandu si [The Party's Theory on Mass Supervision Since the Establishment of New China].' Zhonggong nanchang shiwei dangxiao xuebao [Journal of the Party School of the CCP Committee of Nanchang City] 8 (3): 23-26; Mo, Jiwu. 2002. Dangdai Zhongguo zhengzhi jiandu tizhi yanjiu [The Political Supervision System in Contemporary China]. Beijing: Zhongguo Shehui Kexue Chubanshe; Yang, Rong. 2010. 'Zhongguo san dai lingdaoren qunzhong jiandu sixiang de bijiao yanjiu [A Comparative Study on the Thinking of Three Generations of Chinese Leaders About Mass Supervision]'. Kexue shehuizhuyi [Scientific Socialism] 5: 139-41; Zhang, Hua, and Nengchang Wang. 2004. 'Lun woguo zhuanxing shehui zhong de qunzhong jiandu [Mass Supervision During China’s Social Transformation].' Qiushi 1: 57-58.

[24] Anonymous. 2011. 'Zhongguo molihua jihui zuzhizhe zhi quanguo renmin gongkaixin [Open Letter to People of the Whole Country by Organisers of the Chinese Jasmine Rallies].' www.boxun. com/news/gb/china/2011/02/201102230351.shtml. 


\section{MOBILISATION}

[1] Townsend, James, and Brantly Womack. 1986. Politics in China, 22-23. Boston: Little, Brown and Company.

[2] Tsou, Tang. 1986. The Cultural Revolution and Post-Mao Reforms, 266-67. Chicago: University of Chicago Press.

[3] Mao, Zedong. 1987. 'Zhongyang zhuanfa huabeiju guanyu zai dangzhengjun ge bumen tongyi zhankai sanfan douzheng baogode piyu [Comments on the North China Bureau Report on United Party, Government and Military-Led Implementation of the Three Anti Struggle, as Circulated by the Central Committee], 13 December 1951.' In Jianguo yilai Mao Zedong wengao [Mao Zedong's Manuscripts Since the Founding of the PRC], Vol. 2, 564-65. Beijing: Zhongyang Wenxian Chubanshe.

[4] Thornton, Patricia M. 2009. 'Crisis and Governance: SARS and the Resilience of the Chinese Body Politic.' The China Quarterly 61: 24-48.

[5] Sorace, Christian. 2017. Shaken Authority: China's Communist Party and the 2008 Sichuan Earthquake, Chapter 1. Ithaca: Cornell University Press.

[6] Davies, Gloria. 2016. 'Intellectual Hygiene/Mens Sana.' In China Story Yearbook 2015: Pollution, edited by Gloria Davies, Jeremy Goldkorn, and Luigi Tomba, 104-27. Canberra: ANU Press. doi.org/ 10.22459/CSY.09.2016.03

\section{MUSEUM}

[1] Shanghai Museum. 1952. Shanghai bowuguan chenliepin shuomingshu [Guide to Shanghai Museum Exhibits]. Shanghai: Shanghai Bowuguan.

[2] Chen, Qiuhui, ed. 2003. Shen Zhiyu wenbo lunji [Collected Writings by Shen Zhiyu on Cultural Relics and Museums]. Shanghai: Shanghai Guji Chubanshe.

[3] Bennett, Tony. 1994. 'The Exhibitionary Complex.' In Culture/Power/History: A Reader in Contemporary Social Theory, edited by Nicholas B. Dirks, Geoff Eley, and Sherry B. Ortner, 123-54. Princeton: Princeton University Press.

[4] Chen, Duanzhi. 1936. Bowuguanxue tonglun [General Survey of Museum Studies]. Shanghai: Shanghai Bowuguan.

[5] Lu, Tracey. 2014. Museums in China: Materialized Power and Objectified Identities. London: Routledge.

[6] Wang, Yeqiu. 1950. 'Sulian guoli geming bowuguan [The Soviet Museum of the Revolution].' Wenwu cankao ziliao [Cultural Relics Reference Materials] 10: 66-76.

[7] Ho, Denise Y. 2018. Curating Revolution: Politics on Display in Mao's China. Cambridge: Cambridge University Press.

[8] Perry, Elizabeth J. 2012. Anyuan: Mining China's Revolutionary Tradition. Berkeley: University of California Press.

[9] Denton, Kirk A. 2014. Exhibiting the Past: Historical Memory and the Politics of Museums in Postsocialist China. Honolulu: University of Hawaii Press.

[10] Yang, Guobin. 2007. “A Portrait of Martyr Jiang Qing:” The Chinese Cultural Revolution on the Internet.' In Re-envisioning the Chinese Revolution: The Politics and Poetics of Collective Memories in Reform China, edited by Ching Kwan Lee and Guobin Yang, 287-316. Washington, DC \& Stanford: Woodrow Wilson Center Press and Stanford University Press. 
[11] 1951. Jiedao lilong jumin shenghuo shouce [A Handbook for Neighbourhood Residential Life]. Shanghai: Xinwen Ribao Guan.

[12] Ho, Denise Y. 2018. Curating Revolution.

[13] Ibid.

[14] Lim, Louisa. 2014. The People's Republic of Amnesia: Tiananmen Revisited. Oxford: Oxford University Press.

[15] Ho, Denise Y., and Jie Li. 2016. 'From Landlord Manor to Red Memorabilia: Reincarnations of a Chinese Museum Town.' Modern China 42 (1): 3-37.

\section{NATIONALITY}

[1] Anderson, Benedict. 1991. Imagined Communities: Reflections on the Origin and Spread of Nationalism, 86. London: Verso.

[2] Gao, Quanxi. 2011. Lixian shike: Lun 'Qingdi xunwei zhaoshu' [The Constitutional Moment: On 'The Qing Imperial Edict of Abdication']. Guilin: Guangxi Shifan Daxue Chubanshe; Bulag, Uradyn E. 2012. 'Independence as Restoration: Chinese and Mongolian Declarations of Independence and the 1911 Revolutions.' The Asia-Pacific Journal 10 (3), Issue 52: 1-16.

[3] Guo, Hui, and Shan Liu. 2014. 'Yuan Shikai jiuren linshi da zongtong dianli yu quanli zhuanyi [Yuan Shikai's Provisional Presidential Inauguration Ritual and the Transfer of Power]. In Xinhai geming yu Yuan Shikai: Qingmo minchu shehui zhuanxing shiqi renwu yanjiu [Xinhai Revolution and Yuan Shikai: Studies on People at the Transitional Period from the late Qing to the early Republic], edited by Huateng Zhang, 419. Zhengzhou: Henan Daxue Chubanshe.

[4] Jiang, Zhongzheng. 1943. Zhongguo zhi mingyun [China's Destiny]. Chongqing: Zhongzheng Shuju.

[5] Bulag, Uradyn E. 2012. 'Good Han, Bad Han: The Moral Parameters of Ethnopolitics in China.' In Critical Han Studies: The History, Representation, and Identity of China's Majority, edited by Thomas S. Mullaney, James Leibold, Stéphane Gros, and Eric Vanden Bussche, 92-109. Berkeley: University of California Press.

[6] Leibold, James. 2013. Ethnic Policy in China: Is Reform Inevitable? Honolulu: East-West Center.

[7] Ma, Rong. 2013. 'A New Perspective in Guiding Ethnic Relations in the 21st Century: "DePoliticization" of Ethnicity in China.' In De-Politicization of Ethnic Questions in China, edited by Lizhong Xie, 199-217. Singapore: World Scientific.

[8] Hu, Angang, and Lianhe Hu. 2011. 'Dierdai minzu zhengce: Cujin minzu jiaorong yiti he fanrong [Second Generation Nationality Policies: Promoting Organic Ethnic Blending and Prosperity].' Xinjiang shifan daxue xuebao (zhexue shehui kexue bao) [Journal of the Xinjiang Normal University (Philosophy and Social Science)] 32 (5).

[9] Hao, Shiyuan. 2016. Zhongguo tese jiejue minzu wenti zhilu [Managing Ethno-national Issues of Road with Chinese Characteristics]. Beijing: Zhongguo Shehui Kexue Chubanshe.

\section{NEW DEMOCRACY}

$\left.{ }^{*}\right]$ The author wishes to acknowledge Chen Yaxiong for his excellent research assistance.

[1] Dirlik, Arif. 2012. 'Mao Zedong in Contemporary Chinese Official Discourse and History.' China Perspectives 21 (2): 17-27. 
[2] Meliksetov, Arlen. 1996. "New Democracy" and China's Search for Socio-Economic Development Routes (1949-1953).' Far Eastern Affairs 1: 75-92. Citation at p. 83.

[3] Galway, Matthew. 2017. 'From Revolutionary Culture to Original Culture and Back: "On New Democracy" and the Kampucheanization of Marxism-Leninism, 1940-1965.' Cross Currents: East Asian History and Culture Review 24: 132-58.

[4] Howland, Douglas. 2011. 'The Dialectics of Chauvinism: Minority Nationalities and Territorial Sovereignty in Mao Zedong's New Democracy.' Modern China 36 (2): 170-201.

[5] Dirlik, Arif. 2012. 'Mao Zedong in Contemporary Chinese Official Discourse and History'. 21-24.

[6] Chin, Steve S. K. 1982. 'Persevering in Socialism or Returning to New Democracy? A Case of the Certification of Mao Tse-tung Thought by Practice.' Journal of Oriental Studies 20 (2): 173-83.

[7] Hu, Sheng. 1999. 'Mao Zedong de xin minzhuzhuyi lun zai pingjia [A Reconsideration of Mao Zedong's Theory on New Democracy].' Zhongguo shehui kexue [Social Sciences in China] 3: 15.

[8] Ibid., 8. Hu was quoting Mao's report to the Second Plenary Session of the Seventh Party Central Committee.

[9] Zhang, Musheng. 2011. Gaizao women de wenhua lishiguan [Transforming Our Cultural Perspective on History]. Beijing: People's Liberation Army Military Academy of Sciences Press; Li, Cheng. 2016. Chinese Politics in the Xi Jinping Era: Reassessing Collective Leadership. Washington, DC: Brookings Institution Press, 326.

[10] Li, Cheng. 2016. Chinese Politics in the Xi Jinping Era. Citation at p. 326.

[11] Bandurski, David. 2011. 'Turning Back to "New Democracy"?' China Media Project, 19 May. chinamediaproject.org/2011/05/19/turning-back-to-new-democracy-2.

\section{PAPER TIGER}

[1] The first appearance of the term is in the 'Talk with the American Correspondent Anna Louise Strong' (August 1946); another in an excerpt from a 'Speech at the Moscow Meeting of Representatives of the Communist and Workers' Parties' (18 November 1957); and the final in Mao's declaration at a 'Meeting of the Political Bureau of the Central Committee of the Communist Party of China held at Wuchang' (1 December 1958). All quotations in the chapter come from Mao, Tse-tung. Selected Works of Mao Tse-tung. Beijing: Waiwen Chubanshe. www.marxists.org/reference/archive/mao/selectedworks.

[2] This citation comes from a leaflet and was published in La raison des ouvriers du monde, a selfpublished book written between 2009 and 2011 by inhabitants of Foyer Procession in Paris.

\section{PEASANT}

[1] Li, Shaogen, ed. 1996. Guocui yu xihua: Liu Shipei wenxuan, 208, 277-81. Shanghai: Shanghai Yuandong Chubanshe; Day, Alexander F. 2013. The Peasant in Postsocialist China: History, Politics, and Capitalism, 18-19. Cambridge: Cambridge University Press; Dirlik, Arif. 1991. Anarchism in the Chinese Revolution, 105-07. Berkeley: University of California Press.

[2] Meisner, Maurice. 1967. Li Ta-Chao and the Origins of Chinese Marxism, 71-89. Cambridge, MA: Harvard University Press. 
[3] Alitto, Guy. 1979. The Last Confucian: Liang Shu-ming and the Chinese Dilemma of Modernity. Berkeley: University of California Press; Douw, Leo. 1991. 'The Representation of China's Rural Backwardness: 1932-1937: A Tentative Analysis of Intellectual Choice in China, Based on the Lives, and the Writings on Rural Society, of Selected Liberal, Marxist, and Nationalist Intellectuals. PhD Dissertation. University of Leiden; Hayford, Charles W. 1990. To the People: James Yen and Village China. New York: Columbia University Press.

[4] Huang, Philip C. C. 1975. 'Mao Tse-Tung and the Middle Peasants, 1925-1928.' Modern China 1 (3): 271-96.

[5] Mao, Zedong. 1994. 'An Analysis of the Various Classes among the Chinese Peasantry and Their Attitudes Towards Revolution.' In Mao's Road to Power: Revolutionary Writings: 1912-1949, Vol. 2, edited by Stuart Schram. Armonk: M. E. Sharpe, 303.

[6] Mao, Zedong. 1965. 'Report on an Investigation of the Peasant Movement in Hunan.' Selected Works of Mao Tse-Tung, Vol. 1, 23-59. Beijing: Waiwen Chubanshe.

[7] Ibid., 27.

[8] Mao, Zedong (translated by Roger Thompson). 1990. Report from Xunwu. Stanford: Stanford University Press.

[9] Dirlik, Arif. 1978. Revolution and History: The Origins of Marxist Historiography in China, 19191937. Berkeley: University of California Press; Douw, Leo. 1991. 'The Representation of China’s Rural Backwardness: 1932-1937'. 176-82.

[10] Kelliher, Daniel. 1994. 'Chinese Communist Political Theory and the Rediscovery of the Peasantry.' Modern China 20 (4): 387-415; Harrison, James P. 1969. The Communists and Chinese Peasant Rebellions. Studies of the East Asian Institute, Columbia University, New York: Atheneum.

[11] Mao, Zedong. 1965. 'The Chinese Revolution and the Chinese Communist Party'. Selected Works of Mao Tse-Tung, Vol. 2, 305-34. Beijing: Waiwen Chubanshe.

[12] Schram, Stuart R. 1969. The Political Thought of Mao Tse-Tung, 341-42. New York: Praeger Publishers; Bo, Yibo. 2008. Ruogan zhongda juece yu shijian de huigu (shang) [A Review of Certain Major Policies and Events, Vol. 1], 147-48. Beijing: Zhonggong Dangshi Chubanshe.

[13] Brodsgaard, Kjeld Erik. 1983. 'Paradigmatic Change: Readjustment and Reform in the Chinese Economy, 1953-1981, Part I'. Modern China 9 (1): 37-83; Eckstein, Alexander. 1977. China's Economic Revolution. Cambridge: Cambridge University Press.

[14] Kelliher, Daniel. 1994. 'Chinese Communist Political Theory and the Rediscovery of the Peasantry, 396.

[15] Harrison, James P. 1969. The Communists and Chinese Peasant Rebellions.

[16] Ibid., 137, 187-89.

[17] Cai, Meibiao. 1961. 'Dui Zhongguo nongmin zhanzheng shi taolun zhong jige wenti de shangjue [Considerations of Several Questions Concerning the Discussion of Peasant Struggle History in China].' Lishi yanjiu [Historical Research] 4; Dirlik, Arif. 1977. 'The Problem of Class Viewpoint Versus Historicism in Chinese Historiography’ Modern China 3 (4): 465-88; Harrison, James P. 1969. The Communists and Chinese Peasant Rebellions, 136, 181.

[18] Wang, Xiaoqiang, and Nanfeng Bai. 1991. The Poverty of Plenty, 37. Hampshire and London: Macmillan.

[19] Su, Xiaokang, and Luxiang Wang. 1991. Deathsong of the River: A Reader's Guide to the Chinese TV Series Heshang, 169-70. Cornell East Asia Papers, Ithaca: Cornell University Press; The original translation rendered suzhi as 'makeup' and has been amended.

[20] Day, Alexander F. 2013. The Peasant in Postsocialist China, 39-43; Su, Xiaokang, and Luxiang Wang. 1991. Deathsong of the River, 187. 
[21] Day, Alexander F. 2013. The Peasant in Postsocialist China.

[22] Wen, Tiejun. 1999. Zhongguo nongcun jiben jingji zhidu yanjiu: 'Sannong' wenti de shiji fansi. Beijing: Zhongguo Jingji Chubanshe; Wen, Tiejun. 1999. “'Sannong wenti:" shiji mo de fansi.' Dushu 12: 3-11; He, Xuefeng. 2003. Xin xiangtu Zhongguo. Guilin: Guangxi Shifan Daxue Chubanshe; He, Xuefeng. 2007. Xiangcun de qiantu: xin nongcun jianshe yu Zhongguo daolu. Jinan: Shandong Renmin Chubanshe.

[23] Day, Alexander F. 2013. The Peasant in Postsocialist China: History, Politics, and Capitalism, Chapter 6.

[24] Day, Alexander F., and Mindi Schneider. 2017. 'The End of Alternatives? Capitalist Transformation, Rural Activism and the Politics of Possibility in China.' The Journal of Peasant Studies 45 (7): 1221-46. doi.org/10.1080/03066150.2017.1386179.

[25] Ibid.; Yan, Hairong and Yuan Chen. 2015. 'Agrarian Capitalization Without Capitalism? Capitalist Dynamics from Above and Below in China.' Journal of Agrarian Change 15 (3): 366-91; Qian, Forrest Zhang, and John. A. Donaldson. 2008. 'The Rise of Agrarian Capitalism with Chinese Characteristics: Agricultural Modernization, Agribusiness and Collective Land Rights.' The China Journal 60: 25-47; Qian, Forrest Zhang. 2015. 'Class Differentiation in Rural China: Dynamics of Accumulation, Commodification and State Intervention.' Journal of Agrarian Change 15 (3): 338-65.

[26] Chuang. 2018. 'Adding Insult to Injury: Beijing's Evictions and the Discourse of "Low-End Population," 9 January. chuangcn.org/2018/01/low-end-population.

\section{PEOPLE'S WAR}

[1] Translator's Note: Mao was responding to the reporter's question of what would happen if the United States uses the atom bomb against the Soviet Union (see also Balso's essay in the present volume). Mao, Zedong. 1946. 'Talk with the American Correspondent Anna Louise Strong,' August. www.marxists.org/reference/archive/mao/selected-works/volume-4/mswv4_13.htm.

[2] Translator's Note: The author uses different terms for 'subject' to inflect the shift from passively being ruled chenmin to the agent of rule zhuti effected through Rousseau's concept of popular sovereignty zhuquan zaimin.

[3] Laclau, Ernesto. 2014. The Rhetorical Foundations of Society. London: Verso.

[4] Translator's Note: These are song lyrics from the Xibaipo period (1947-48) where the CCP established its base after leaving Yan'an. It is a place laden with revolutionary significance.

[5] Translator's Note: The 'three-thirds system' was the creation of a united-front government combined of one-third Communists, one-third non-Communist left, and one-third middle/other elements, in order to fight the Japanese.

[6] Translator's Note: Nanniwan is a gorge southeast of Yan'an where the Eighth Route Army experimented in self-sufficient agricultural production in response to economic blockades in 1941; two years later, a popular revolutionary song was written about it. 


\section{PERMANENT REVOLUTION}

[1] Mao, Tse-tung. 1970. 'Sixty Points on Working Methods.' In Mao Papers: Anthology and Bibliography, edited by Jerome Chen, 57-76. Oxford: Oxford University Press; Mao, Zedong. 1967. 'Gongzuo fangfa liushitiao [Sixty Work Methods]' (31 January 1958). Mao Zedong sixiang wansui! [Long Live Mao Zedong's Thought], 1-14. Beijing: Red Guard Publication.

[2] Mao, Zedong. 1961. 'Carry On the Revolution Through to the End' (30 December 1948). Selected Works of Mao Tse-Tung, Vol. IV, 302. Beijing: Wawen Chubanshe. Emphasis added.

[3] Mao, Tse-tung. 1970. 'Sixty Points on Working Methods', 65.

[4] Dittmer, Lowell. 1987. China's Continuous Revolution: The Post-Liberation Epoch, 1949-1981, 210. Berkeley: University of California Press.

[5] Ibid., 408.

[6] Marx, Karl and Friedrich Engels. 1956. The Holy Family, or Critique of Critical Critique, 166. Moscow: Foreign Languages Press.

[7] Trotsky, Leon. 1965. The Permanent Revolution. New York: Pioneer Publishers. In passim.

[8] Schram, Stuart. 1966. Mao Tse-tung, 114-15, 123. New York: Simon \& Schuster. Mao received the Central Committee's letter on 4 June 1928, which contained a copy of the Comintern's February resolution condemning the theory of 'uninterrupted revolution' and the tactics of 'uninterrupted uprising.'

[9] Mao, Zedong. 1974. 'Speech at a Supreme State Conference' (28 January 1958). In Chairman Mao Talks to the People, edited by Stuart Schram, 91-95. New York: Pantheon. Liu Shaoqi popularised 'permanent revolution' as a term in May 1958. See Liu, Shaoqi. 1962. 'The Present Situation, the Party's General Line for Socialist Construction and Its Future Tasks' (5 May 1958). In Communist China 1955-1959: Policy Documents with Analysis, edited by Robert Bowie and John K. Fairbank, 425. Cambridge, MA: Harvard University Press.

[10] Mao, Zedong. 1961. 'Carry On the Revolution Through to the End', 302.

[11] Meisner, Maurice. 1999. Mao's China and After: A History of the People's Republic of China, Third Edition, 195. New York: The Free Press.

[12] Mao, Zedong. 1970. 'Sixty Points on Working Methods', 65-66.

[13] Mao, Zedong (translated by Moss Roberts). 1977. A Critique of Soviet Economics, 71. New York and London: Monthly Review Press; Starr, John Bryan. 1979. Continuing the Revolution: The Political Thought of Mao, xiii. Princeton: Princeton University Press.

[14] Mao, Zedong. 1999. 'Struggle to Win the Masses in Their Millions for the Anti-Japanese National United Front' (7 May 1937). In Mao's Road to Power: Revolutionary Writings, 1912-1949, Volume V-Toward the Second United Front, January 1935-July 1937, edited by Stuart Schram, 651-58. Armonk: M. E. Sharpe. Emphasis added (Page 57).

[15] Mao, Zedong. 1974. 'Speech at a Supreme State Conference,' 94.

[16] Mao, Zedong. 1967. 'Gongzuo fangfa liushitiao [Sixty Work Methods]', 5. Quoted in Starr, John Bryan. 1979. Continuing the Revolution, 159.

[17] Knight, Nick. 2007. Rethinking Mao: Explorations in Mao Zedong's Thought, 225-26. Lanham: Lexington Books. See also Schram, Stuart. 1971. 'Mao Tse-tung and the Theory of Permanent Revolution, 1958-1969'. The China Quarterly 46: 221-44.

[18] Starr, John Bryan. 1979. Continuing the Revolution, 300; Knight, Nick. 2007. Rethinking Mao, 238. 
[19] People’s Daily. 1967. 'Yanzhe shiyue shehuizhuyi gemìng kaipide daoluqianjin: Jinian weidade shiyue shehuizhuyi geming wushizhounian [Along the Path Opened by the October Socialist Revolution: Commemorating the 50th Anniversary of the Great October Socialist Revolution].' Renmin ribao [People's Daily], 6 November. cpc.people.com.cn/GB/64162/64165/72301/72307/4980 456.html.

[20] Starr, John Bryan. 1979. Continuing the Revolution, 303-04; Schram, Stuart. 1971. 'Mao Tsetung and the Theory of Permanent Revolution, 1958-1969', 244. See also 1985. Zhonggong zhongyang wenxian yanjiushi, guanyu jianguo yilai dangde ruoganlishi wentide jueyi zhushiben (xiuding) [Annotations of the Resolutions on Several Historical Issues of the Party since the Founding of the People's Republic of China (Revised)]. Beijing: Renmin Chubanshe.

[21] Zhang, Chunqiao. 1975. 'On Exercising All-Round Dictatorship of the Bourgeoisie.' Peking Review 14, 4 April: 5-11.

[22] Dirlik, Arif. 2005. Marxism in the Chinese Revolution, 193. Lanham: Rowman \& Littlefield. See also: Knight, Nick. 2007. Rethinking Mao, 219.

[23] Quoted in Ding, Wang, ed. 1971. Mao Zedong xuanji buyi [Supplement to Mao Zedong's Selected Works], Vol. III, 162. Hong Kong: Ming Bao Monthly Publishing.

[24] Schram, Stuart. 1971. 'Mao Tse-tung and the Theory of Permanent Revolution, 1958-1969, 231-33. Quote from Communist Party of China. 1981. Resolution on CPC History, 1949-1981, 84-85. Beijing: Waiwen Chubanshe.

[25] Guzmán, Abimael. 1995. 'We Are the Initiators (19 April 1980). In The Peru Reader: History, Culture, Politics, edited by Orin Starn, Carlos Ivan Degregori, and Robin Kirk, 325-26. Durham: Duke University Press. See also Comision de la Verdad y Reconciliacion (CVR). 2002. 'Interview with Abimael Guzmán and Elena Iparraguirre in Calla,' 28 May, 15; Guzmán, Abimael. 1992. 'Interview with Chairman Gonzalo by Luis Arce Borja and Janet Talavera.' A World to Win 18: 79.

[26] Comité Central Partido Comunista del Perú. 1988. Entrevista al Presidente Gonzalo, 5. Lima: Bandera Roja.

[27] Taylor, Lewis. 2006. Shining Path: Guerrilla War in Peru's Northern Highlands, 1980-1997, 9-20. Liverpool: Liverpool University Press. On Mariátegui's thought, see Mariátegui, José Carlos. 1971. Siete Ensayos de Interpretación de la Realidad Peruana. Lima, Peru: Empresa Editoria Amauta.

[28] Cleary, Edward L. 2004. 'New Voice in Religion and Politics in Bolivia and Peru.' In Resurgent Voices in Latin America: Indigenous Peoples, Political Mobilization, and Religious Change, edited by Edward L. Cleary and Timothy J. Steigenga, 52. New Brunswick: Rutgers University Press. Campesin (peasant) replaced indio (Indian) while Indigena (indigenous) was reserved for the people from the easternmost forest region. The Parties were the following: Comité Pro-Indigena Tawantinsuyo (Tawantinsuyo Pro-Indigenous Committee, 1920s); the centre-left Alianza Popular Revolucionaria Americana (American Popular Revolutionary Alliance, 1930s); radical Trotskyists (1940s); Fernando Belaúnde’s reformist Acción Popular (Popular Action, 1950s); and Velasco Alvarado's military regime (1960s-1970s). See Heilman, Jamie P. 2010. Before the Shining Path: Politics in Rural Ayacucho, 18951980. Stanford: Stanford University Press.

[29] Degregori, Carlos Iván. 2014. El Surgimiento de Sendero Luminoso: Ayacucho 1969-1979, 153-78. Lima: Instituto Estudios Peruanos; Rothwell, Matthew. 2013. Transpacific Revolutionaries: The Chinese Revolution in Latin America, 57-59. London and New York: Routledge.

[30] 2015. 'Oral Political Report at the Seventh National Congress of the Chinese Communist Party' (24 April 1945). Cited In Mao's Road to Power: Revolutionary Writings, 1912-1949, Volume VIII-From Rectification to Coalition Government, 1942-July 1945, edited by Stuart Schram and Timothy Cheek, 842-43. London and New York: Routledge. 
[31] Mao, Zedong. 'Yugongyishan [The Foolish Old Man Who Removed the Mountains]' (11 July 1945). www.marxists.org/chinese/maozedong/marxist.org-chinese-mao-19450611.htm.

[32] Comité Central Partido Comunista del Perú. 1988. Entrevista al Presidente Gonzalo, 5-6, $10-11,98$.

[33] Guzmán, Abimael, and Elena Iparraguirre. 2013. Memorias desde Némesis, 82-83. Lima: Punto De Encuentro; Roncagliolo, Santiago. 2007. La cuarta espada: La historia de Abimael Guzmán y Sendero Luminoso, 68-69, 78, 113-14, 119. Buenos Aires: Debate; Rothwell, Matthew. 2013. Transpacific Revolutionaries, 9.

[34] Starn, Orin. 1995. 'Maoism in the Andes: The Communist Party of Peru-Shining Path and the Refusal of History'. Journal of Latin American Studies 27 (2): 399-421. Carlos Degregori notes that on posters, Guzmán 'occupie[d] the center, dressed in a suit, wearing glasses, book in hand, surrounded by masses carrying rifles and flags,' so as to portray him as ever the intellectual and genius. Degregori, Carlos Iván. 1997. 'After the Fall of Abimael Guzmán: The Limits of Sendero Luminoso.' In The Peruvian Labyrinth: Polity, Society, Economy, edited by Maxwell Cameron and Philip Mauceri, 181. University Park, PA: Pennsylvania State University Press. Guzmán's lawyer and his 'ambassador' to London, Adolfo Olaechea, 'insisted that he [Guzmán] be addressed as Doctor Abimael Guzmán and that his status as an intellectual be recognized.' La Republica (17 September 1992), 2.

[35] Comité Central Partido Comunista del Perú. 1988. Entrevista al Presidente Gonzalo, 98. Emphasis added.

[36] Ibid., 98-99.

[37] Starn, Orin. 1995. 'Maoism in the Andes', 405.

[38] Anonymous, 'Oath of Loyalty (1989-90).' The Peru Reader, 351.

[39] Palmer, David Scott. 2014. 'The Influence of Maoism in Peru'. In Mao's Little Red Book: A Global History, edited by Alexander C. Cook, 130-46. Cambridge: Cambridge University Press.

[40] Brooke, James. 1992. 'Fugitive Leaders of Maoist Rebels Is Captured by the Police in Peru.' The New York Times, 14 September: 1.

\section{POETRY}

[1] Xiao, Kaiyu. 1998. 'Yidian ganxiang [A Few Reflections].' Jintian [Today] 1:213-15.

[2] Yang Lian raised this point in many interviews and lectures.

[3] Meng, Lang. 1997. 'Shiren zai "neibu” zhaoji [The Poet Is Restless Inside].' In Goutong: miandui shijiede Zhongguo wenxue [Communicate: Chinese Literature Facing the World], edited by Zhi Wan, 131-32. Stockholm: The Olof Palme International Center; Hong Kong: Social Thought Press.

[4] Forced to shut down in 1980, the group was re-founded abroad in June 1990.

[5] The poem is included Qin, Xiaoyu, and Xiaobo Wu. 2015. Wo de shipian: Dangdai gongren shidian [The Verses of Us: Contemporary Worker Poetry], 396. Beijing: Zuojia Chubanshe. Translation by the author.

[6] Ibid., 396. Translation by the author.

[7] Guo, Jinniu. 2015. 'Pangdade danshu [A Massively Single Number].' In A Massively Single Number, edited by Lian Yang, 152-53. Bristol: Shearsman Books. Translation by the author.

[8] Ibid.

[9] The poem can be found in Qin, Xiaoyu, and Xiaobo Wu. 2015. The Verses of Us, 170-72. Translation by the author. 
[10] Citations from Xing Huangtian's series of poems 'Xinling Shijian [Spiritual Facts].' In Qin, Xiaoyu, and Xiaobo Wu. 2015. The Verses of Us, 147-50. Translation by the author.

[11] Ibid.

[12] The poem, included in the 'Spiritual Facts' series can be found in Qin, Xiaoyu, and Xiaobo Wu. 2015. The Verses of Us, 149. Translation by the author.

[13] To use the expression put forward by Frank Ruda in his 2016 Abolishing Freedom: A Plea for a Contemporary Use of Fatalism. Lincoln, NE: University of Nebraska Press.

[14] Xu, Lizhi. 2015. 'Wo jiu nayang zhanzhe rushui [I Fell Asleep Standing So].' In Xin de yi tian [A New Day], edited by Xiaoyu Qin, 34. Beijing: Zuojia Chubanshe. Translation by the author.

[15] Marx, Karl (translated by Joseph O'Malley). 1970. Critique of Hegel's 'Philosophy of Right', Introduction. Oxford: Oxford University Press.

[16] The translations of Ji Zhishui's 'Rocks by the Road' and 'Migrant Workers' are both included in Goodman, Eleanor. 2016. Iron Moon: An Anthology of Chinese Migrant Worker Poetry. New York: White Pine Press, 170-71. Translation by Eleanor Goodman.

[17] Goodman, Eleanor. 2016. Iron Moon, 198. Translation by Eleanor Goodman, with a few adaptations by the author.

[18] Xu, Lizhi. 2015. 'I Fell Asleep Standing So'

[19] Mi, Jiuping, 2018. 'I Am with Us' is here proposed in the translation that appeared on the website Labor Notes. www.labornotes.org/blogs/2018/11/jasic-detainee-1-story-w. Chinese text is available at zhichishengyuan01.github.io/mjp.

[20] Xiao, Kaiyu. 1997. 'Risposte a un questionario.' In Nuovi poeti cinesi, edited by Claudia Pozzana and Alessandro Russo, 238. Torino: Einaudi.

\section{PRACTICE}

[1] For more on the intellectualism of Mao and Mao-era intellectuals, see Cheek, Timothy. 2016. The Intellectual in Modern Chinese History, 113-216. Cambridge: Cambridge University Press.

[2] Mao, Zedong. 1937. 'On Practice.' www.marxists.org/reference/archive/mao/selected-works/ volume-1/mswv1_16.htm.

[3] [Later attributed to Mao Zedong]. 1983. 'Zhongong zhongyang guanyu lingdao fangfa de jueding [Decision of the CCP Central Committee on Leading Methods].' In Mao Zedong ji [Collected Writings of Mao Zedong], Second Edition, Vol. 9, edited by Takeuchi Minoru, 25-31. Tokyo: Suososha. See also Schram, Stuart. 1989. The Political Thought of Mao Zedong, 315-17. Cambridge: Cambridge University Press.

[4] Mao's thought as infinite is from Alain Badiou, in Davidson, Miri. 2016. 'Alain Badiou: "Mao Thinks in an Almost Infinite Way." Verso Blog, 16 May. www.versobooks.com/blogs/2033-alainbadiou-mao-thinks-in-an-almost-infinite-way. The Mass Line as an endless ascending spiral is from Cao, Dahua. 2017. 'Xin zhi xin jue: Xie hao xin jieduan de shijian lun [New Knowledge, New Consciousness: Writing On Practice for the New Phase]'. Zhongguo Gongchandang Xinwenwang [CCP News], 17 August. theory.people.com.cn/n1/2017/0817/c40531-29475608.html.

[5] Anthony Garnaut, for example, raises this concern in 'The Mass Line on a Massive Famine, published in The China Story Journal on 8 October 2014. www.thechinastory.org/2014/10/the-massline-on-a-massive-famine.

[6] Cao, Dahua. 2017. 'New Knowledge, New Consciousness.' 


\section{PRIMITIVE ACCUMULATION}

[1] Marx, Karl. 1867. Capital: Volume 1, 874. Reprint, London: Penguin Books, 1990.

[2] Ibid., 876.

[3] Karl, Rebecca E. 2017. 'The Economic and the State: the Asiatic Mode of Production.' The Magic of Concepts: History and the Economic in Twentieth-Century China, 40-72. Durham \& London: Duke University Press.

[4] On the 'Sprouts of Capitalism' debates, see Dirlik, Arif. 1982. 'Chinese Historians and the Marxist Concept of Capitalism: A Critical Examination.' Modern China 8 (1): 105-32.

[5] Peng, Zeyi. 1962. 'Zhongguo ziben yuanshi jilei ruogan wenti de taolun [A Discussion of Several Questions Concerning the Primitive Accumulation of Capital in China].' Renmin ribao [People's Daily], 9 August.

[6] For example, see Dirlik, Arif. 1982. 'Chinese Historians and the Marxist Concept of Capitalism,' 111.

[7] Wen, Tiejun. 2014. Lecture at Renmin University of China. Beijing, 22 April.

[8] The version of universalist history now deployed was based on liberal modernisation theory, the ideology underpinning global capitalism, rather than a Marxist version of history rooted in class struggle. See Karl, Rebecca E. 2017. 'The Economic and the State', 40-72.

[9] Wen, Tiejun, 2004. 'Minjian ziben yuanshi jilei yu zhengfu xingwei [Human Capital Primitive Accumulation and Government Behaviour].' In Women daodi yao shenme? [What Do We Really Want?], edited by Tiejun Wen, 59-63. Reprint, Beijing: Huaxia Chubanshe. Originally in Jingjixue zhoubao [Economics Weekly], 1989. Originally in Jingjixue zhoubao [Economics Weekly], 1989.

[10] Wen, Tiejun. 2004. 'Guojia ziben zai fenpei yu minjian ziben zai jilei [State Capital Redistribution and Human Capital Re-Accumulation]. In Women daodi yao shenme? [What Do We Really Want?], edited by Tiejun Wen, 35-57. Reprint, Beijing: Huaxia Chubanshe.

[11] Ibid., 35.

[12] Wen, Tiejun. 2008. Sannong wenti yu zhidu bianqian [The Three Rurals Question and Systemic Change], 243. Beijing: Zhongguo Jingji Chubanshe.

[13] I am grateful to Rebecca Karl for this observation.

[14] Pun, Ngai, and Chris King-Chi Chan. 2008. 'The Subsumption of Class Discourse in China.' Boundary 235 (2): 75-91.

[15] Qin, Hui. 1998. 'Yetan yuanshi jilei-you "xiandaihua xianjing" shuokai qu [Discussing Primitive Accumulation-Starting from "The Pitfalls of Modernisation"]. Beijing zhengxie [Beijing Observation] 8: 37-38.

[16] For example, see Wang, Hui. 2008. 'Restructuring and the Historical Fate of China's Working Class: A Report on an Investigation into the Tongyu Textile Group of Jiangsu.' Critical Asian Studies 40 (2): 163-209.

[17] Li, Changping. 2003. 'The Crisis in the Countryside.' In One China, Many Paths, edited by Chaohua Wang, 198-218. London \& New York: Verso Books.

[18] Holmstrom, Nancy, and Richard Smith. 2000. 'The Necessity of Gangster Capitalism: Primitive Accumulation in Russia and China.' Monthly Review 51 (9): 1-15.

[19] For example, see: Wang, Yuqi. 1993. 'Xin "quandi yundong" yousi lu [Thoughts on the New Enclosure Movement].' Qiye jingji [Enterprise Economy] 8: 4-7.

[20] Qian, Forrest Zhang. 2015. 'Class Differentiation in Rural China: Dynamics of Accumulation, Commodification and State Intervention.' Journal of Agrarian Change 15 (3): 338-65. 
[21] Andreas, Joel, and Shaohua Zhan. 2016. 'Hukou and Land: Market Reform and Rural Displacement in China.' The Journal of Peasant Studies 43 (4): 798-827.

[22] Friedman, Eli. 2017. 'Evicting the Underclass.' Jacobin, 6 December. www.jacobinmag.com/ 2017/12/beijing-fire-migrant-labor-urbanization.

\section{RECTIFICATION}

$\left.{ }^{*}\right]$ I thank the editors and Steve Heder for comments on earlier drafts of this manuscript. Any remaining errors are mine.

[1] 1988. 'Report of Activities of the Party Center According to the General Political Tasks of 1976, December 20, 1976.' Translated by David Chandler in Pol Pot Plans the Future: Confidential Leadership Documents from Democratic Kampuchea, 1976-1977, edited by David Chandler, Ben Kiernan, and Chanthou Boua, 183. New Haven: Yale Southeast Asia Monograph Series 33.

[2] Mao, Zedong. 1995. Mao's Road to Power: Revolutionary Writings, 1912-49, Vol. 3: From the Jinggangshan to the Establishment of the Jiangxi Soviets, July 1927-December 1930. Edited by Stuart Schram and Nancy J. Hodes, 269. London: Routledge.

[3] Mao, Zedong. 1995. Mao's Road to Power, Vol. 3, lxiv, 587; Short, Philip. 2000. Mao: A Life, 267, 271. New York: Henry Holt.

[4] Guo, Xuezhi. 2012. China's Security State: Philosophy, Evolution, and Politics, 34. Cambridge: Cambridge University Press.

[5] Dutton, Michael. 2005. Policing Chinese Politics: A History, 46. Durham \& London: Duke University Press.

[6] Short, Philip. 2000. Mao, 267 and 271.

[7] Ibid., 279.

[8] Averill, Stephen C. 2006. Revolution in the Highlands: China's Jinggangshan Base Area, 391. New York: Rowman \& Littlefield.

[9] Guo, Xuezhi. 2012. China's Security State, 35.

[10] Ibid., 38-39.

[11] Dutton, Michael. 2005. Policing Chinese Politics, 54-67. Indeed, Dutton suggests that 'had it not been for the final success of Jiang Jieshi's fifth extermination campaign forcing the evacuation of the base camps and a reevaluation of Party policy, Mao's wry comments to Zhang Dingcheng about "cutting our own throats" may well have become prophetic' (66).

[12] Guo, Xuezhi. 2012. China's Security State, 42.

[13] Teiwes, Frederick C. 1994. Politics and Purges in China: Rectification and the Decline of Party Norms, 1950-65, Second Edition, 3. Armonk: M. E. Sharpe.

[14] Mao, Zedong. 2015. Mao's Road to Power: Revolutionary Writings, 1912-49, Vol. 8: From Rectification to Coalition Government, 1942-July 1945. Edited by Stuart Schram, Timothy Cheek, and Roderick MacFarquhar, xxxvi. London: Routledge.

[15] Mertha, Andrew. 2017. "Stressing Out": Cadre Calibration and Affective Proximity to the CCP in Reform-era China.' The China Quarterly 229: 64-85; Huang, Haifeng. 2015. 'Propaganda as Signaling.' The Journal of Comparative Politics 47 (4): 419-38.

[16] Teiwes, Frederick C. 1994. Politics and Purges in China, 3-4.

[17] Guo, Xuezhi. 2012. China's Security State, 42. 
[18] McDougal, Bonnie S. 1980. Mao Zedong's 'Talks at the Yan'an Conference on Literature and Art': A Translation of the 1943 Text with Commentary, 13. Ann Arbor: Michigan Monographs in Chinese Studies.

[19] Lifton, Robert Jay. 1963. Thought Reform and the Psychology of Totalism: A Study of Brainwashing in China. New York: Norton.

[20] Yang, Shangkun. 'Activities of the Trotskyite Wang Shiwei and Liberalism in the Party.' Dated 31 October 1942 and published in Dangde shenghuo [Party Life], it is translated in full in Dai, Qing. Wang Shiwei and 'Wild Lilies,' 135-45, as cited in Mao's Road to Power, Vol. 8, xliii.

[21] Mertha, Andrew. 2017. 'Stressing Out.'

[22] Although the Indochinese Communist Party/Vietnamese Communist Party was very heavily influenced and the Sino-Vietnamese rendering chinh phong exists in ICP/VCP speak, it is only to talk about China. In Thai Communist speak, the term exists ( $k \bar{a} r$ thảhīhthūk fxing), but similarly was never part of anything that was implemented. It is also in CPK-speak as dtomrong dtis, but again was not part of some intra-party campaign. I thank Steve Heder for this observation.

[23] Chandler, David, Ben Kiernan, and Chanthou Boua. Pol Pot Plans the Future, xii. On the uses of medical terminology to assess the political health of the regime, see Sorace, Christian. 2017. 'Communist Immunology', Chinoiresie, 20 June. www.chinoiresie.info/communist-immunology.

[24] Locard, Henry. 2004. Pol Pot's Little Red Book: The Sayings of Angkar, 210. Bangkok: Silkworm.

[25] The Associated Press. 2006. 'Ta Mok, Khmer Rouge Head Facing Genocide Trial, Dies.' The Associated Press, 21 July. I changed the wording to the more scatological term because Ta Mok would never use the word 'dung' when 'shit' would do.

[26] Chandler, David. 2000. Voices from S-21 Terror and History in Pol Pot's Secret Prison. Berkeley: University of California Press.

[27] Mertha, Andrew. 2014. Brothers in Arms: Chinese Aid to the Khmer Rouge, 1975-1979, Chapter 2. Ithaca: Cornell University Press.

[28] Short, Philip. 2000. Mao, 274.

[29] CNN. 1997. 'Pol Pot Reportedly on the Run after Slaughter.' CNN World News, 13 June. www.cnn.com/WORLD/9706/13/cambodia/index.html.

\section{RED AND EXPERT}

[1] China Youth Daily. 1957. 'Women de kouhao shi: You "hong” you "zhuan" [Our Slogan Is: Red and Expert].' Renmin ribao [People's Daily], 1 November: 2.

[2] Li, Zi. 1957. 'Tantan "hong yu zhuan" [A Discussion of "Red and Expert"].' Renmin ribao [People's Daily], 29 December: 7.

[3] MacFarquhar, Roderick. 1983. The Origins of the Cultural Revolution, Vol. 2, 28. New York: Columbia University Press.

[4] Cao, Cong. 2013. 'Science Imperiled: Intellectuals and the Cultural Revolution.' In Mr. Science and Chairman Mao's Cultural Revolution: Science and Technology in Modern China, edited by Chunjuan Nancy Wei and Darryl E. Brock, 122. Lanham: Lexington Books.

[5] Andreas, Joel. 2009. The Rise of the Red Engineers: The Cultural Revolution and the Origins of China's New Class. Stanford: Stanford University Press. 
[6] Sina. 2017. 'Jiaoyu buzhang: Peiyang you hong you zhuan de Zhongguo tese shehui zhuyi jiebanren [Minister of Education: Cultivate Red and Expert Successors for Socialism with Chinese Characteristics].' Xinliang [Sina.com], 9 May. news.sina.com.cn/c/nd/2017-05-09/docifyeychk7193961.shtml.

[7] Ju xinglong meitan (pseud.). 2017. 'You hong you zhuan yi ci dai you xianming de wenhua da geming de yinji [The Phrase Red and Expert Carries a Clear Imprint of the Cultural Revolution].' Baidu tieba [Baidu Web Forum], 17 May.

[8] Wu, DD. 2017. 'Why Did China Just Hear One More Mao-Era Phrase?' The Diplomat, 12 May. thediplomat.com/2017/05/why-did-china-just-hear-one-more-mao-era-phrase/.

[9] Lin, Aiyue. 2017. "You hong you zhuan" chonghui guanfang huayu tixi ["Red and Expert" Returns to Official Discourse].' Chawang, 13 May. www.cwzg.cn/politics/201705/35937.html.

[10] Mao, Zedong. 1992. Jianguo yilai Mao Zedong wengao [The Manuscripts of Mao Zedong Since the Nation's Founding], 52. Beijing: Zhongguo Wenxian Chubanshe.

[11] 'Zhong shiyantian-you hong you zhuan de daolu [Plant Experimental Fields, the Red and Expert Way].' Renmin ribao [People's Daily], 15 February: 1.

[12] Xiao, Long, and Tang Maolin. 1958. 'Jiushan hong zahuan daxue [Jiushan Red and Expert University].' Renmin ribao [People's Daily], 23 June: 7.

[13] 1960. 'Quanmin ban kexue, geng kuai deng gaofeng [All the People Do Science, Scaling High Peaks Even Faster]'. Renmin ribao [People's Daily], 7 June: 4.

[14] Schmalzer, Sigrid. 2016. Red Revolution, Green Revolution: Scientific Farming in Socialist China. Chicago: University of Chicago Press.

[15] Chambers, David Wade. 1979. Red and Expert: A Case Study of Chinese Science in the Cultural Revolution. Reprint, Victoria: Deakin University, 1984.

[16] Ibid., 9.

[17] Hongse Zhongguo: redchinacn.net; Chawang: www.cwzg.cn.

[18] Yan, Zuolei. 2018. 'Jishu faming zhuti zhi zheng yu 1970 niandai de kexue wenti [The Struggle Over Technological Inventions and the Question of Science in the 1970s].' Wenyi lilun yu piping [Theory and Criticism of Literature and Art] 1: 99-107.

[19] Peng, Guangcan. 2012. 'Mao Zedong gongye guanli sixiang jiqi xiandai yiyi [The Industrial Management Philosophy of Mao Zedong and its Modern Significance].' Hengyang shifan xueyuan xuebao [Journal of Hengyang Normal University] 2: 47-52. Circulated on 6 October, 2018 on Chawang (cwzg.cn) and recirculated on Red China (redchinacn.net).

[20] Schmalzer, Sigrid. 2018. 'Toward a Transnational, Trans-1978 History of Food Politics in China: An Exploratory Paper.' The PRC History Review 3 (1): 1-14.

[21] Chen, Tianyuan, and Kaijian Huang. 2006. 'Canyushi zhiwu yuzhong yu kechixu liyong shengwu duoyang xing-yi Guangxi yumi wei li [Participatory Plant Breeding and Sustainable Use of Biological Diversity: The Case of Maize in Guangxi].' Zhongguo nongxue tongbao [Chinese Agricultural Science Bulletin] 22 (7): 490-94.

\section{REMOVING MOUNTAINS AND DRAINING SEAS}

$\left.{ }^{*}\right]$ I thank the editors and Coraline Goron, Elizabeth Lord, and Yvan Schulz for their feedback on this piece.

[1] Shapiro, Judith. 2001. Mao's War against Nature: Politics and the Environment in Revolutionary China. Cambridge: Cambridge University Press. 
[2] It seems that the expression was first uttered by Xi in 2005 when he was Secretary of the Zhejiang Provincial Party Committee. See www.cecep.cn/g3621/s7631/t39494.aspx. Since then, it has been repeated on several occasions. For instance, see Xi, Jinping. 2016. 'Enhanced Partnership for Greater Momentum of Growth.' Keynote Speech by Chinese President Xi Jinping at the APEC CEO Summit, Lima, 19 November. www.globaltimes.cn/content/1019023.shtml.

[3] Elvin, Mark. 2004. The Retreat of the Elephants: An Environmental History of China. New Haven: Yale University Press.

[4] Shapiro, Judith. 2001. Mao's War against Nature.

[5] Ibid.

[6] Oi, Jean C. 1999. Rural China Takes Off: Institutional Foundations of Economic Reform. Berkeley \& Los Angeles: University of California Press; Wright, Tim. 2011. The Political Economy of the Chinese Coal Industry: Black Gold and Blood-Stained Coal. London \& New York: Routledge.

[7] Wright, Tim. 2011. The Political Economy of the Chinese Coal Industry; Tilt, Bryan. 2010. The Struggle for Sustainability in Rural China. New York: Columbia University Press.

[8] Economy, Elizabeth. 2004. The River Runs Black: The Environmental Challenge to China's Future. Ithaca \& London: Cornell University Press; Shapiro, Judith. 2012. China's Environmental Challenges. Cambridge: Polity Press; Weller, Robert. 2006. Discovering Nature: Globalization and Environmental Culture in China and Taiwan. Cambridge: Cambridge University Press.

[9] Goodman, David S. G. 2004. 'The Campaign to "Open Up the West": National, Provincial-level and Local Perspectives.' In China's Campaign to 'Open Up the West': National, Provincial-level and Local Perspectives, edited by David S. G. Goodman, 3-21. Cambridge: Cambridge University Press.

[10] Tilt, Bryan. 2010. The Struggle for Sustainability in Rural China; Van Rooij, Benjamin. 2006. Regulating Land and Pollution in China: Lawmaking, Compliance, and Enforcement: Theory and Cases. Leiden: Leiden University Press.

[11] Kostka, Genia, and Arthur P. J. Mol. 2013. 'Implementation and Participation in China’s Local Environmental Politics: Challenges and Innovations.' Journal of Environmental Policy \& Planning 15: 1, 3-16; Van Rooij, Benjamin, Qiaoqiao Zhu, Na Li, and Qiliang Wang. 2017. 'Centralizing Trends and Pollution Law Enforcement in China.' The China Quarterly 231: 583-606.

[12] Lord, Elizabeth. 2018. Building an Ecological Civilization Across the Rural/Urban Divide and the Politics of Environmental Knowledge Production in Contemporary China. Unpublished PhD Dissertation, University of Toronto.

[13] Chen, Jia-Ching, John A. Zinda, and Emily T. Yeh. 2017. 'Recasting the Rural: State, Society and Environment in Contemporary China.' Geoforum 78: 83-88; Lord, Elizabeth. 2018. Building an Ecological Civilization Across the Rural/Urban Divide and the Politics of Environmental Knowledge Production in Contemporary China.

\section{REVOLUTION}

[1] Lin, Chun. 2006. The Transformation of Chinese Socialism. Durham: Duke University Press.

[2] Translator's Note: The 'countryside surrounding the city' was Mao Zedong's revolutionary strategy of the 1930s and 1940s; the 'united front' refers to the policy of cross-class alliance in the War of Resistance against Japan (1937-45) (see De Giorgi's essay in the present volume); the mass line refers to Mao's hallmark theory of mass democracy (see Lin Chun's essay in the present volume). 
[3] Translator's Note: John King Fairbank (1907-91) was an historian of China based at Harvard University, known for the 'impact [of the West]-response [of China]' paradigm, which now is largely abandoned by historians. The point the author is making here, is that if 'impact-response' were a viable paradigm for thinking about modern Chinese history, then for the Chinese Revolution, one would have to expand the paradigm into 'impact-appropriation-response;' that is, there was not a clean acceptance of 'Western' or Soviet or Chinese traditional experience, but rather creative adaptations of all of it, thus an 'appropriation.'

[4] Translator's Note: The Paris Commune was a political and social revolution in 1870 in France. Its radical political and social egalitarianism became a touchstone in January 1967, during one of the high-tides of the proletarian commitment to the Cultural Revolution in Shanghai. This is known as the 'January Revolution' or the 'January Storm.'

[5] Translator's Note: Self-reliance and self-sufficiency in food were two of the major 'delinking' aspects of the Maoist years, intended to prepare China to survive global isolation, any nuclear or other devastating attack, or a US-led embargo (See Yang's essay in the present volume).

[6] Translator's Note: 'Successors' refers to what was called the 'revolutionary successors' problem: who or which social class was going to be the successor to the Mao Zedong-era of revolutionary activists? Was it going to be the technocrats (experts)? Or true believers (reds)? And who was going to train them?

[7] Translator's Note: There were sweeping efforts through the 1950s and 1960s to bridge the cultural-educational gap between rural areas and cities by allowing peasant children to 'enter the cities' while encouraging urban intellectual youths to 'return to the villages.' This effort reached its apogee during the Cultural Revolution.

[8] Translator's Note: Tang Tsou (1919-99) was a political scientist. Born in China, he made his career at the University of Chicago as an interpreter of Chinese politics. In 1986, he was recognised by Beijing University with an honorary position. Critical of the Communist Party but also a nationalist, Tang Tsou is one of the favoured 'Western-educated' Chinese often cited in Mainland China today. For Tang Tsou, 'all-round society' refers to what he deems to be the unindividuated nature of Chinese life, where state power and community lifeworlds interpenetrate in a way that is undifferentiated.

[9] Translator's Note: This was one of the opening documents of the Cultural Revolution in the form of a letter Mao wrote to Lin Biao, then the leader of the People's Liberation Army. In this directive, Mao Zedong indicated that the army was to become the 'great school of socialism' and that, essentially, education was to be productive and school-based, intellectual and manual.

[10] Translator's Note: Song-Ming neo-Confucianism was an abstruse set of textual doctrines and practices as well as a boiled-down, socially practical mode of instruction for the non-literate; it was propagated at the social levels through oral village instruction. The idealism of Wang Yangming (1472-1529) points to the unity of knowledge and action promoted by the philosopher and taken up by his followers ever since. It emphasises personal morality as the highest social good. It has been revived in recent years, with the retreat of Maoist collective ethics and the new ideological emphasis on individual responsibility.

[11] Translator's Note: Yao and Shun were mythical emperors of prehistorical times, to whose perfection all superior humans should aspire. The poem by Mao mobilises this thought to underscore the malleability and mutability of all human beings, if given the correct socio-political conditions in which to transform themselves. The poem from which this line derives was written in 1961.

[12] Translator's Note: The 'gentleman' or junzi ideal was a Confucian construction of the allround moral, ethical human being; in Confucianism, this was only expected to be achieved by literate superior men. 
[13] Translator's Note: Wang Meng (1934- ), is a major literary and cultural figure; he also served as China's Minister of Culture (1986-89). His works always skated along the line between officially sanctioned and prohibited. His legacy is thus quite complex, with some accusing him of Party sycophancy and others of heretical thinking. 'Avoiding glory', for him, indicated the 1980s and 1990s trend towards intellectuals relinquishing the social responsibility with which Mao had tasked them and becoming individuals again.

[14] Translator's Note: The economy as 'embedded' is an interpretive phrase derived from Karl Polanyi's The Great Transformation, which is a favoured text among some Chinese commentators, who are critical of capitalism but also of the Maoist economy that came before. Polanyi has seen a great revival among those looking for leftist but not Marxist analyses. See Polanyi, Karl. 1944. The Great Transformation. New York: Farrar \& Rinehart.

[15] Translator's Note: Datong, introduced above, is appropriated from Confucian thought to re-animate in today's China a collective ideal. It is not always meant to be equivalent to socialism (see Craig A. Smith's essay in the present volume), although Cai is here marking that possible equivalence. It has become a newly fashionable way to speak about a nativist socialist stream of thought that could become relevant again, even if Marxist socialism is no longer on the agenda.

\section{SELF-RELIANCE}

[1] Oxford English Dictionary Online. 2018. 'Self-reliance.' en.oxforddictionaries.com/definition/ self-reliance.

[2] Xinhua Dictionary Online. 2018. 'Zili gengsheng [Self-reliance].' xh.5156edu.com/html5/4214. html.

[3] Schoenhals, Michael. 1992. Doing Things with Words in Chinese Politics: Five Studies, 7-8. Berkeley: Institute of East Asian Studies, University of California, Berkeley.

[4] Zhonggong zhongyang wenxian yanjiushi, ed. 1993. Mao Zedong nianpu (1983-1949) [Chronological Biography of Mao Zedong (1983-1949)], Vol. 2, 341. Beijing: Zhongyang Wenxian Chubanshe.

[5] Mao, Zedong. 1939. 'Fantouxiang tigang [An Outline of Opposing Surrender].' www.marxists. org/chinese/maozedong/1968/1-116.htm.

[6] Chen, Yung-fa. 1986. Making Revolution: The Communist Movement in Eastern and Central China, 1937-1945, 213-15. Berkeley \& Los Angeles: University of California Press.

[7] Zhonggong zhongyang wenxian yanjiushi, ed. 1993. Chronological Biography of Mao Zedong (1983-1949), Vol. 2, 341.

[8] Mao, Zedong. 1945. 'The Situation and Our Policy after the Victory in the War of Resistance against Japan.' www.marxists.org/reference/archive/mao/selected-works/volume-4/mswv4_01.htm.

[9] Shen, Zhihua. 2002. 'A Historical Examination of the Issue of Soviet Experts in China: Basic Situation and Policy Changes.' Russian History 29 (2-4): 377-400; Lüthi, Lorenz. 2008. The Sino-Soviet Split: Cold War in the Communist World, 40 and 109. Princeton: Princeton University Press.

[10] Wu, Friedrich. 1981. 'From Self-Reliance to Interdependence? Developmental Strategy and Foreign Economic Policy in Post-Mao China.' Modern China 7 (4): 445-82.

[11] MacFarquhar, Roderick, and Michael Schoenhals. 2006. Mao's Last Revolution, 375. Cambridge, MA: The Belknap Press of Harvard University Press; Dikötter, Frank. 2016. The Cultural Revolution: A People’s History, 1962-1976, 226. London: Bloomsbury Press. 
[12] Dikötter, Frank. 2016. The Cultural Revolution, 219; Schmalzer, Sigrid. 2016. Red Revolution, Green Revolution: Scientific Farming in Socialist China, 142. Chicago: University of Chicago Press.

[13] Yahuda, Michael. 1983. Towards the End of Isolationism: China's Foreign Policy after Mao, 120-21. London: Palgrave Macmillan.

[14] He, Fang. 2005. 'Yan'an zhengfeng yu geren chongbai [The Yan'an Rectification Movement and Cult of Personality].' Modern China Studies 12 (1). www.modernchinastudies.org/us/issues/pastissues/87-mcs-2005-issue-1/895-2012-01-05-15-34-56.html.

[15] Yahuda, Michael. 1983. Towards the End of Isolationism, 198-225.

[16] Deng, Xiaoping. 1982. 'Zai Zhongguo gongchandang di shi'er ci quanguo daibiao dahui shang de kaimuci [Opening Speech at the Twelfth National Congress of the Communist Party of China].' 1982. www.gov.cn/test/2008-06/25/content_1027253.htm.

[17] Deng, Xiaoping. 1983. 'Luzi zoudui le, zhengce buhui bian [We are on the Right Track and Our Policies Will not Change],' 29; Deng, Xiaoping. 1984. 'Women de hongwei mubiao he geneben zhengce [Our Magnificent Goal and Basic Policies],' 78; Deng, Xiaoping. 1985. 'Zai junwei kuoda huiyi shang de jianghua [Speech at an Enlarged Meeting of the Military Commission of the Central Committee of the Communist Party of China],' 128; Deng, Xiaoping. 1989. 'Guojia de zhuquan he anquan yao shizhong fangzai diyiwei [First Priority Should always be Given to National Sovereignty and Security],' 349. In Deng Xiaoping wenxuan [Selected Works of Deng Xiaoping], Vol. 3. Beijing: Renmin Chubanshe.

[18] Jiang, Xiaoling. 2008. 'Banshi zhanshi ban shusheng: Ji Xia Zhengnong tongzhi [Half of him is a Soldier and Half Intellectual: A Brief History of Comrade Xia Zhengnong].' Jiefang ribao [Liberation Daily], 4 October. www.ewen.co/qikan/bkview.asp?bkid=162723\&cid=503896.

[19] Fifield, Anna. 2018. 'As China Settles in for Trade War, Leader Xi Emphasizes "Self Reliance." The Washington Post, 1 November. www.washingtonpost.com/world/asia_pacific/as-china-settles-infor-trade-war-leader-xi-emphasizesself-reliance/2018/11/01/2961b2b2-d8de-11e8-9559-712cbf726d1c story.html; Wildau, Gabriel. 2018. 'China’s Xi Jinping Revives Maoist Call for "Self-Reliance." Financial Times, 11 November. www.ft.com/content/63430718-e3cb-11e8-a6e5-792428919cee.

\section{SEMIFEUDALISM, SEMICOLONIALISM}

[*] Acknowledgement and gratitude to Aminda Smith for her kind reading of this essay.

[1] Lenin, Vladimir Ilyich. Imperialism, the Highest Stage of Capitalism, Chapter 6, 11. www. marxists.org/archive/lenin/works/1916/imp-hsc/ch06.htm. The term semi-colonialism is used only once, referring to China.

[2] Chen, Hongjin. 2017. 'Colonialism and Semi-Colonialism [Zhimindi yu banzhimindi].' In Rebecca Karl, The Magic of Concepts: History and the Economic in Twentieth Century China, 117-19. Durham: Duke University Press.

[3] Communist International. 1920. Congress of the Peoples of the East. September. Stenographic report translated and annotated by Brian Pearce. Reprint, London: New Park Publication, 1977. The term 'semi' covered conditions that were fuzzy. The transcript shows how theorists covered bets using the semi to indicate conditions in process. Terms included 'semi-colonial,' 'semi-feudal,' 'semiproletarian,' and 'semi-consciously'.

[4] MCLC. Undated. 'The White Haired Girl Film Script.' u.osu.edu/mclc/online-series/white.

[5] Chibber, Vivek. 2013. Postcolonial Theory and the Specter of Capital. London: Verso Books.

[6] Lowe, Donald M. 1966. The Function of 'China' in Marx, Lenin, and Mao. Berkeley: University of California Press. 
[7] Meisner, Maurice. 1982. Marxism, Maoism, and Utopianism: Eight Essays. Madison: University of Wisconsin Press.

[8] Brugger, Bill. 1995. 'Marxism, Asia and the 1990s.' Positions: East Asia Cultures Critique 3 (2): $630-41$.

[9] Dirlik, Arif. 1985. 'The Universalization of a Concept: "Feudalism" to "Feudalism" in Chinese Marxist Historiography.' The Journal of Peasant Studies 12 (2-3): 197-227.

[10] Mao, Zedong. 1937. “On Contradiction.” Mao Tse-tung Selected Works, 1937-38, Vol. 2, 25. Reprint, New York: International Publishers, 1954.

[11] Ibid., 33.

[12] Knight, Nick. 2007. Rethinking Mao: Exploration in Mao's Thought. Lanham: Lexington Books.

[13] The Dictionary of Sociology notes that semi-colonial would later become a category inside of which it became possible to count Iran, Thailand, Afghanistan, Yemen, and Ethiopia. See Dictionary of Sociology. 1998. Oxford: Oxford University Press. www.encyclopedia.com/social-sciences/dictionariesthesauruses-pictures-and-press-releases/semi-colonialism.

[14] The Maoist position on 'identity' appears in 'On Contradiction', in which 'identity of contradiction exists only under certain necessary conditions' without which there 'can be no identity whatsoever' (47).

[15] Mao, Zedong. 'Introductory Remarks to “The Communist."' Mao Tse-tung Selected Works Vol. 3, 64-65.

[16] Mao, Zedong. 'The Chinese Revolution and the Chinese Communist Party.' Mao Tse-tung Selected Works, Vol. 3, 72-105.

[17] Ibid., 80-110.

\section{SENDING FILMS TO THE COUNTRYSIDE}

$\left.{ }^{*}\right]$ The photography and research of this collaborative project (with Tina Chen and Thomas Lahusen) was funded by the Social Science and Humanities Research Council of Canada between 2012 and 2016.

[1] Lam, Tong. 2011. A Passion for Facts: Social Surveys and the Construction of the Chinese Nation State, 1900-1949. Berkeley: University of California Press; Merkel-Hess, Kate. 2016. The Rural Modern: Reconstructing the Self and State in Republican China. Chicago: University of Chicago Press.

\section{SERVE THE PEOPLE}

[1] Mao, Zedong. 1944. 'Serve the People.' www.marxists.org/reference/archive/mao/selectedworks/volume-3/mswv3_19.htm.

[2] Yan, Lianke (translated by Julia Lovell). 2005. Serve the People. Reprint, New York: Black Cat, 2007.

[3] Mao, Zedong. 1944. 'Our Study and the Current Situation.' www.marxists.org/reference/archive/ mao/selected-works/volume-3/mswv3_18.htm.

[4] Jacobs, Andrew. 2012. 'Chinese Heroism Effort Met with Cynicism.' The New York Times, 5 March. www.nytimes.com/2012/03/06/world/asia/lei-feng-day-draws-chinese-cynicism.html. 


\section{SOCIALIST LAW}

[1] Cited in Chen, Phillip M. 1973. Law and Justice: The Legal System in China 2400 B.C to 1960 A.D. New York \& London: Dunnellen Publishing Company.

[2] Yu, Xingzhong. 1989. 'Legal Pragmatism in the People's Republic of China.' Journal of Chinese Law 3 (1): 29-51.

[3] Chen, Phillip M. 1973. Law and Justice, 73.

[4] Trevaskes, Susan. 2007. Courts and Criminal Justice in Contemporary China. Lanham: Lexington Books.

[5] Trevaskes, Susan. 2017. 'Weaponising the Rule of Law in China.' In Justice: The China Experience, edited by Flora Sapio, Susan Trevaskes, Elisa Nesossi, and Sarah Biddulph 113-40. Cambridge: Cambridge University Press; Trevaskes, Susan. 2018. 'A Law Unto Itself: Chinese Communist Party Leadership and yifa zhiguo in the Xi Era.' Modern China 44(4): 347-73.

[6] Li, Ling. 2017. 'Anti-Corruption Campaign and the Transformation of the Central Commission of Discipline and Inspection in China (2013-2017).' Working Paper Series 1703. University of Vienna: Institute of Human Sciences; Lin, Delia, and Susan Trevaskes. 2018. 'Law-Morality Ideology in the Xi Jinping Era' (unpublished paper).

[7] Yin, Pumin. 2017. 'Constructive Measures: China Ramps Up Institution Building to Widen Anti-graft Campaign. Beijing Review, 16 February. www.bjreview.com/Nation/201702/t20170213 _ 800087083.html.

[8] Zhu, Jichai, and Leiji Qi. 2017. 'Jieshi jiancha tizhi gaige: Yong liuzhi qudai lianggui yiwei shenme? [Explaining Reforms to the Supervision System: What Are the Implications for Detention Replacing Shuanggui?].' Sina News, 23 October. news.sina.com.cn/o/2017-10-23/doc-ifymzksi1219829.shtml.

[9] Xinhua. 2017. 'Jiji tansuo shijian xingcheng baogui jinagyan, guojia jiancha tizhi gaige shidian gude shixiao: Guojia jiancha tizhi gaige shidian gongzuo zongsu [Actively Exploring and Practicing Valuable Experiences to Achieve Real Results in the Pilot Reform Project of the State Supervision System: A Summary of the Pilot Work on the Reform of the National Supervision System].' Xinhua News, 5 November. news.xinhuanet.com/politics/2017-11/05/c_1121908387.htm.

[10] Sina. 2016. 'Xi Jinping: Gaige he fazhi ru niao zhi liang chi, che zhi liang lun [Xi Jinping Likens "Reform" and "Rule of Law" to a Birds Two Wings or a Vehicle’s Two Wheels].' Sina News, 1 July. news. sina.com.cn/o/2016-07-01/doc-ifxtrwtu9635394.shtml.

[11] Trevaskes, Susan. 2018. 'A Law Unto Itself.'

[12] Chen, Jianfu. 2016. 'Out of the Shadows and Back to the Future: CPC and Law in China.' Asia Pacific Law Review 24 (2): 176-201.

[13] Wang, Liming. 2014. 'Yifa zhiguo fanglue shi zenyang xingcheng he fazhan de? [How Did

Governing the Nation in Accordance with the Law Take Shape and Develop?].' Qiushi [Seeking Truth], 1 November. www.qstheory.cn/dukan/qs/2014-11/01/c_1113046431.htm.

[14] Central Committee. 2014. 'Fourth Plenum Decision.' Central Committee Decision on Some Major Questions in Comprehensively Moving Forward Governing the Country According to Law, October. chinalawtranslate.com/fourth-plenum-decision/?lang=en/.

[15] Duan, Ruiqun. 2017. 'The Construction of a Rule of Law China and the Improvement of the Theoretical System of Human Rights in China.' China Society of Human Rights, 7 March. www. chinahumanrights.org/html/2017/MAGAZINES_0307/7571.html. 
[16] Xi, Jinping. 2015. 'Accelerating the Establishment of Socialist Rule of Law in China.' Qiushi [Seeking Truth] 7 (1), 16 March. english.qstheory.cn/2015-03/16/c_1114459319.htm; Duan, Ruiqun. 2017. 'The Construction of a Rule of Law China and the Improvement of the Theoretical System of Human Rights in China.'

[17] Ding, Xiaodong. 2017. 'Law According to the Chinese Communist Party: Constitutionalism and Socialist Rule of Law. Modern China 43 (3): 322-52.

[18] Lin, Delia, and Susan Trevaskes. 2018. 'Law-Morality Ideology in the Xi Jinping Era'; Trevaskes, Susan. 2018. 'A Law Unto Itself.'

[19] Ding, Xiaodong. 2017. 'Law According to the Chinese Communist Party'; Lin, Delia, and Susan Trevaskes. 2018. 'Law-Morality Ideology in the Xi Jinping Era.'

[20] Lin, Delia, and Susan Trevaskes. 2018. 'Law-Morality Ideology in the Xi Jinping Era'

[21] Yin, Pumin. 2017. 'Constructive Measures.'

[22] Yu, Gaizhi. 2018. 'Tuidong shehui zhuyi hexin jiazhi rufa rugui [Promote the embedding of socialist core values into law and regulations]. Guangming ribao [Guangming Daily], 25 May. epaper. gmw.cn/gmrb/html/2018-05/25/nw.D110000gmrb_20180525_2-11.htm.

[23] Rosenzweig, Joshua. 2017. 'State, Society, and the Justice Debate in Contemporary China.' In Justice: The China Experience, edited by Flora Sapio, Susan Trevaskes, Elisa Nesossi, and Sarah Biddulph, 26-66. Cambridge: Cambridge University Press.

\section{SPEAKING BITTERNESS}

[1] Perry, Elizabeth J. 2002. 'Moving the Masses: Emotion Work in the Chinese Revolution.' Mobilization: An International Journal 7 (2): 111-28.

[2] Sun, Feiyu. 2013. Social Suffering and Political Confession: Suku in Modern China, 45. New Jersey: World Scientific.

[3] Anagnost, Ann. 1997. National Past-times: Narrative, Representation, and Power in Modern China, 33. Durham: Duke University Press.

[4] Ibid., 4.

[5] Gao, Feng. 1998. 'Subei xingzheng qu er nian lai tudi gaige yundong jiben zongjie [A Basic Summary of the Land Reform Movement in the Northern Jiangsu Region Over the Past Two Years].' In Jiangsu sheng tudigaige yundong (1950-1952) [The Land Reform Movement in Jiangsu Province (1950-1952)], Winter 1952, edited by Jiangsu Provincial Archives and Nanjing Municipal Archives, 332. Nanjing: Zhonggong Jiangsu Shengwei Dangshi Gongzuo Bangongshi.

[6] Xu, Hongci (translated by Erling Hoh). 2017. No Wall Too High: One Man's Daring Escape from Mao's Darkest Prison. New York: Straus and Giroux.

[7] Singer, Tania, Ben Seymour, John O’Doherty, Holger Kaube, Raymond J. Dolan, and Chris D. Frith. 2004. 'Empathy for Pain Involves the Affective but Not Sensory Components of Pain. Science 303 (5661): 1157-62.

[8] Smith, Adam. 2016 (1759). The Theory of Moral Sentiments, 15. Reprint, Los Angeles: Enhanced Media.

[9] Fengyang County Party Committee. 1951. 'Fenglin qu (liu ge xiang) cunmin hui tongguo jieji chengfen jiehe zhongdian douzheng qingkuang zonghe huibao [Summary Report on the Situation of Village Associations Approving Class Labels and Linking with Key-point Struggles in Fenglin District]. Fengyang County Archives, Contemporary China Documents Center, file no. 1951XW11, 7 September, 82-85. 
[10] Fengyang County Party Committee. 1989. 'Yaowan xiang tugai gongzuo zongjie [Yaowan Township Land Reform Work Summary]'. In Xiangcun sanshi nian: Fengyang nongcun shehui jingji fazhan shilu (1949-1983) [Thirty Years of the Countryside: A True Record of the Socioeconomic Development of the Fengyang Countryside], October 1950, edited by Gengjin Wang, Xun Yang, Ziping Wang, Xiaodong Liang, and Guansan Yang, 43. Beijing: Nongcun Duwu Chubanshe.

[11] Rural Work Committee of the Southern Jiangsu Committee of the Chinese Communist Party. 1952. 'Sunan tudi gaige yundong zhong funü gongzuo de chubu zongjie [Initial Summary Report on Working with Women in the Southern Jiangsu Land Reform Campaign].' In Sunan tudi gaige wenxian [Documents on Land Reform in Southern Jiangsu], 10 May 1951, 469. Internal Publication.

[12] Gao, Feng. 1998. 'A Basic Summary of the Land Reform Movement in the Northern Jiangsu Region Over the Past Two Years,' 331.

[13] Crockett, M. J. 2017. 'Moral Outrage in the Digital Age.' Nature Human Behaviour 1 (11): 769-71.

[14] Huaining County Local Gazetteer Compilation Committee. 1996. Huaining xianzhi [Huaining County Gazetteer], 366. Hefei: Huangshan Shushe.

[15] Wu, Guo. 2014. 'Speaking Bitterness: Political Education in Land Reform and Military Training under the CCP, 1947-1951.' The Chinese Historical Review 21 (1): 14.

[16] For the full listing of 'classic' speaking-bitterness stories, see Jin-Cha-Ji Military District Political Department, ed. 1947. Suku fuchou [Speaking Bitterness and Seeking Vengeance], 1-32.

[17] Ibid., 44-45.

[18] Yu, Frederick T. C. 1964. Mass Persuasion in Communist China, 37. New York: Praeger.

[19] Anagnost, Ann. 1997. National Past-times, 31; Wu, Guo. 2014. 'Speaking Bitterness', 21.

[20] De Bary, William Theodore. 1981. Neo-Confucian Orthodoxy and the Learning of the Mind-andheart, 77. New York: Columbia University Press.

[21] Zhang, Daye (translated by Xiaofei Tian). 2013. The World of a Tiny Insect: A Memoir of the Taiping Rebellion and Its Aftermath, 67-68. Seattle: University of Washington Press.

[22] Lean, Eugenia. 2007. Public Passions: The Trial of Shi Jianqiao and the Rise of Popular Sympathy in Republican China. Berkeley: University of California Press.

[23] Anagnost, Ann. 1997. National Past-times, 28.

[24] Li, Lifeng. 2013. 'Mass Movements and Rural Governance in Communist China: 1945-1976. Journal of Modern Chinese History 7 (2): 166.

[25] DeMare, Brian J. 2015. Mao's Cultural Army: Drama Troupes in China's Rural Revolution, 98. Cambridge: Cambridge University Press.

[26] Thaxton, Ralph. 2016. Force and Contention in Contemporary China: Memory and Resistance in the Long Shadow of the Catastrophic Past, 38. Cambridge: Cambridge University Press.

[27] Sorace, Christian. 2019. 'Extracting Affect: Televised Cadre Confessions.' Public Culture 31 (1): $145-71$.

\section{SUGARCOATED BULLETS}

[1] For example, see Žižek, Slavoj. 2007. 'A Leninist Gesture Today: Against the Populist Temptation.' In Lenin Reloaded: Toward a Politics of Truth, edited by Sebastian Budgen, Stathis Kouvelakis, and Slavoj Žižek. Durham: Duke University Press.

[2] People’s Daily. 1949. 'Ba xiaofei chengshi biancheng shengchan chengshi [Transform Cities of Consumption into Cities of Production].' Renmin ribao [People's Daily], 17 March. 
[3] Zhang, Chunqiao. 1963. 'Zan "Nanjing lu shang hao ba lian" [Approving "The Good Eighth Company of Nanjing Road"].' Guangming ribao [Guangming Daily], 25 April.

[4] Holm, David. 1991. Art and Ideology in Revolutionary China. Oxford: Oxford University Press.

[5] Southern Daily Editorial Department. 1964. Xinfu guan taolun ji [Collection of Debates on the Concept of Happiness]. Guangzhou: Guangdong Renmin Chubanshe.

[6] Ibid., 167-69.

\section{SUPERSTITION}

[1] Liu, Lydia. 1995. Translingual Practice: Literature, National Culture, and Translated Modernity: China, 1900-1937. Stanford: Stanford University Press; Feuchtwang, Stephan. 1989. 'The Problem of "Superstition" in the People's Republic of China.' In Religion and Political Power, edited by Gustavo Benavides and W. M. Daly, 43-68. New York: SUNY Press.

[2] Shen, Zhiqi. 1995. Da Qing lüli jizhu [Annotated Statutes and Substatutes of the Great Qing Dynasty], 390. Shanghai: Shanghai Guji Chubanshe.

[3] Duara, Prasenjit. 1991. 'Knowledge and Power in the Discourse of Modernity: The Campaigns Against Popular Religion in Early Twentieth Century China.' Journal of Asian Studies 50 (1): 67-83.

[4] Chen, Duxiu. 1918. 'Kelinde bei [The Ketteler Monument]'. Xin qingnian [New Youth] 5 (5).

[5] Anagnost, Anna S. 1987. 'Politics and Magic in Contemporary China.' Modern China 13 (1): 41-61; Duara, Prasenjit. 1991. 'Knowledge and Power in the Discourse of Modernity'

[6] Wou, Odoric. 1994. Mobilizing the Masses: Building Revolution in Henan. Stanford: Stanford University Press; Perry, Elizabeth. 1980. Rebels and Revolutionaries in North China 1845-1950. Stanford: Stanford University Press.

[7] Morning Post. 1921. 'Henan faxian yingdu zhi xiejiao [Hardbelly Heterodoxy Discovered in Henan].' Chenbao [Morning Post], 24 July; Morning Post. 1923. 'Henan gexian xiejiao zhi liuxing [Prevalence of Heterodoxy in Henan Counties].' Chenbao [Morning Post], 15 February.

[8] Chen, Duxiu. 1926. 'Hongqianghui yu Zhongguo nongmin baodong [The Red Spear Societies and Chinese Peasant Insurrections]. Xiangdao zhoukan [Guide Weekly], 16 June.

[9] Secretariat of the Central Committee of the Chinese Communist Party, ed. 1980. Liu da yiqian: Dangde lishi cailiao [Before the Sixth Plenum: Party Historical Materials], 610-11. Beijing: Renmin Chubanshe.

[10] Duara, Prasenjit. 1991. 'Knowledge and Power in the Discourse of Modernity', 78.

[11] Feuchtwang, Stephan. 1989. 'The Problem of 'Superstition' in the People's Republic of China.'

[12] Smith, S. A. 2006. 'Talking Toads and Chinless Ghosts: The Politics of "Superstitious" Rumors in the People's Republic of China, 1961-65. American Historical Review 111 (2): 405-27.

[13] Chen, Boda. 1966. 'Hengsao yiqie niugui xieshen [Sweep Away All Demons and Monsters].' Renmin ribao [People’s Daily], 1 June.

[14] Feuchtwang, Stephan. 1989. 'The Problem of “Superstition” in the People's Republic of China'

[15] Anagnost, Anna S. 1987. 'Politics and Magic in Contemporary China'

[16] Permanent Committee of the National People’s Congress. 1999. 'Guanyu qudi xiejiao zuzhi, fangfan he chengzhi xiejiao huodong de jueding [Resolution on the Suppression of Heterodox Organisations, and the Prevention and Punishment of Heterodox Activities].' Zhongguo renda wang [China People's Congress Net], 30 October. www.npc.gov.cn/wxzl/gongbao/2000-12/05/ content_5004752.htm. 
[17] Zhang, Shaofeng, and Kong Qingpeng. 2005. Chongshang kexue, yuanli xiejiao [Revere Science, Leave Heterodoxy Behind]. Preface. Taiyuan: Shanxi Sheng Fanxiejiao Xiehui.

[18] Ibid., 20-25.

\section{SURPASS}

[1] For example, see 'Hu Angang: 2050 Zhongguo [Hu Angang: 2050 China].' Tsinghua University News, 24 April, 2017. www.tsinghua.edu.cn/publish/thunews/9945/2017/20170424185013498868920/ 20170424185013498868920_.html; Callahan, William A. 2015. China Dreams: 20 Visions of the Future. Oxford: Oxford University Press.

[2] Davies, Gloria. 2007. Worrying about China: The Language of Chinese Critical Inquiry. Cambridge, MA: Harvard University Press; Liu, Mingfu. 2010. Zhongguo meng: Hou meiguo shidai de daguo siwei zhanlue dingwei [The China Dream: The Great Power Thinking and Strategic Positioning of China in the Post-American Era], 9-13. Beijing: Zhongguo Youyi Chuban Gongsi.

[3] Yang, Jisheng (translated and edited by Edward Friedman, Stacy Mosher, and Jian Guo). 2012. Tombstone: The Great Chinese Famine, 1958-1962, 90. New York: Farrar, Straus, and Giroux.

[4] Cited in Hu, Angang. 2011. China in 2020: A New Kind of Superpower, 29. Washington, DC: Brookings Institution.

[5] Yao, Runtian. 2009. 'Gongheguo shishang: Ganchao kouhao de youlai yu yanbian [The Origin and Development of the 'Catch Up and Surpass' Slogan in the History of the Republic]'. Mao Zedong sixiang yanjiu [Research on Mao Zedong Thought] 26 (2): 5-11.

[6] Yang, Jisheng. 2012. Tombstone.

[7] Hu, Angang. 2013. Zhongguo daolu yu Zhongguo mengxiang [China Path and the China Dream], 191. Hangzhou: Zhejiang Renmin Chubanshe.

[8] Liu, Mingfu. 2010. The China Dream, 10-11, 13.

[9] Hu, Angang. 2011. China in 2020, 14; Hu, Angang. 2013. China Path and the China Dream, 191-209; 'Hu Angang: 2050 China'

[10] Hu, Angang. 2013. 'Mao Zedong de qiangguo meng: 60 nian chaobuguo meiguo ying kaichu quijian [Mao Zedong's Strong Nation Dream: If You Can't Surpass America Within 60 Years, Then You Should Be Read Off the Face of the Earth]' Renminwang [People's Net], 17 October. blog.people.com. cn/article/2/1382003195623.html.

[11] Hu, Angang. 2013. China Path and the China Dream, 191, 196, 208; 'Hu Angang: 2050 China.'

[12] Hu, Angang. 2011. China in 2020, 29.

[13] Lin, Justin Yifu, Fang Cai, and Zhou Li. 2003. The China Miracle: Development Strategy and Economic Reform, Revised Edition, Hong Kong: Chinese University Press.

[14] Hu, Angang. 2011. China in 2020, 27.

[15] Yao, Liwen, and Jianping Liu. 2011. 'Dayuejin shi fazhan weishenme "zhiming" [Why Great Leap Forward-Style Development Is "Deadly"]' Nanfang zhoumo [Southern Weekend], 29 September.

[16] Hu, Angang. 2011. China in 2020, 45.

[17] Zhang, Weiwei. 2012. The China Wave: Rise of a Civilizational State. Hackensack: World Century Publishing Corporation.

[18] Ibid., ix, 24-25, 26.

[19] Zhang, Weiwei. 2014. Zhongguo chaoyue: Yi ge "wenming xing guojia" de guangrong yu mengxiang [China Surpasses: The Glory and Dream of a "Civilization-State"]. Shanghai: Shanghai Renmin Chubanshe. 
[20] Zhang, Weiwei. 2012. The China Wave, xi; interview with Zhang Weiwei by the author, Oxford, UK, 10 June 2014.

[21] Callahan, William A. 2016. 'China’s “Asia Dream:” BRI and the New Regional Order.' Asian Journal of Comparative Politics 1 (3): 226-43.

\section{THIRD WORLD}

[1] Mao, Zedong. 1967. Mao Zedong xuanji: Hedingben [Selected Writings of Mao Zedong: Bounded Edition], 1089. Beijing: Renmin Chubanshe.

[2] Zhou, Enlai. 1997. Zhou Enlai nianpu (1949-1976): Xia juan [A Chronology of Zhou Enlai (19491976), Vol. 3], 494. Beijing: Zhongyang Wenxian Chubanshe.

[3] People's Daily, 23 January 1974.

[4] Mao, Zedong. 2013. Mao Zedong nianpu (1949-1976): Di liu juan [A Chronology of Mao Zedong (1949-1976), Vol. 6], 520. Beijing: Zhongyang Wenxian Chubanshe.

[5] Ibid., 521.

[6] People's Daily, 11 April 1974.

[7] Mao, Zedong. 2003. Mao Zedong zhuan [A Biography of Mao Zedong], 1695. Beijing: Zhongyang Wenxian Chubanshe.

[8] Translator's Note: The term zonghengshu, often translated as the 'School of Diplomacy' or the 'School of Vertical and Horizontal Alliances' refers to strategists of the Warring States Period. The 'vertical' supporters envisioned an alliance of the weak against the strongest state, while the 'horizontal' supporters encouraged the hegemony of the strongest state over the weaker states.

[9] Wu, Xingtan. 2003. "Sangeshijie" yu xiezuo banzi de huigu [The "Three Worlds" and the Memories of Writing Groups]. Dangdai shijie [Contemporary World] 9: 32-33, 41; Zhang, Guoxin. 2004. 'Lun Deng Xiaoping yu "sangeshijie" guafen lilun [On Deng Xiaoping and the Theory of the Division of the "Three Worlds"]. Zhonghua wenhua luntan [Chinese Cultural Forum] 3: 5-12.

[10] Chen, Xixi. 2012. 'Mao Zedong "sangeshijie" lilun de yishixingtaidiyunji Deng Xiaoping de chaoyue: Jianlun "sangeshijie" lilun de shidaijiazhi [The Intricacies of Ideology in Mao Zedong's Three Worlds Theory and the Value of Three Worlds Theory Today].' Shanghai jiaotong daxue xuebao: Zhexue shehui kexue ban [Journal of the Shanghai Jiaotong University: Philosophy and Social Sciences Edition] 5: 5-13.

[11] Hardt, Michael, and Antonio Negri. 2000. Empire, xiii. Cambridge, MA: Harvard University Press.

[12] Wang, Hui. 2009. 'Lishi de kenengxing: Xiangxiangyushijian [The Possibilities of History: Imaginaries and Practice].' Bieqiuxinsheng: Wang Hui fangtan lü [Don't Look for a New Voice: Interviews with Wang Hui], 76-79. Beijing: Beijing Daxue Chubanshe.

[13] Yin, Zhiguang. 2017. 'Guojizhuyi shike: Zhongguo geming shi yexia de Alabo minzu duli yu disanshijie zhi xuguan de xingcheng [The Time of Internationalism: Arabic National Independence from the Perspective of the Chinese Revolution and the Formation of the Concept of the Third World].' Kaifang shijie [Open World] 4: 110-33. 


\section{THOUGHT REFORM}

[1] Mao, Zedong (translated by Bonnie S. McDougal). 2015. 'Talks at the Yan'an Forum on Literature and Art.' In Mao's Road to Power: Revolutionary Writings, 1912-1949, Vol. 8, edited by Stuart Schram and Timothy Cheek, 106. London: Routledge.

[2] Xinhua. 2018. 'Zhonggong zhongyang zhuzhibu zhonggong zhongyang xuanchuanbu guanyu zai guangda zhishifenzi zhong shenru kaizhan "hongyang aiguo fendou jingshen, jiangong liye xin shidai" huodong de tongzhi [Notice of the Departments of Propaganda and Organisation of the Central Committee of the CCP on Carrying Out Activities to "Promote the spirit of patriotic struggle and make great contributions in the New Era" among the Broad Masses of Intellectuals]. Xinhua, 31 July. www.xinhuanet.com/politics/2018-07/31/c_1123204091.htm.

[3] The Relevant passages in the Liji appear in its 'Royal Regulations' section. This and the broader role of transformational political education are covered in Munro, Donald J. 2001. The Concept of Man in Early China. Ann Arbor: University of Michigan Press.

[4] Extracts from community compacts and their sacred edicts are translated in de Bary, Theodore William, and Richard Lufrano, eds. 2000. Sources of Chinese Tradition: From 1600 to the Twentieth Century, Second Edition, Vol. 2, 71-72. New York: Columbia University Press; Hsiao, Kung-chúan [Xiao Gongquan]. 1960. Rural China: Imperial Control in the Nineteenth Century. Seattle: University of Washington Press.

[5] Li, Laizhang. Preface dated 1705. 'Shengyu xuan-jiang xiangbao tiayue [Regulations for 'Community-Security' Sacred Edict Lectures].' Copy in the Harvard-Yenching Library.

[6] Sun, Yat-sen. 1923. 'Zhongguo geming shi [History of the Chinese Revolution].' Shenbao, 29 January. In this essay, Sun outlined his three-stage theory of revolutionary transformation: military government, political tutelage, and constitutional government. The best guide to these issues is Fitzgerald, Jonathan. 1997. Awakening China: Politics, Culture and Class in the Nationalist Revolution. Stanford: Stanford University Press.

[7] Liu, Wennan. 2013. 'Redefining the Moral and Legal Roles of the State in Everyday Life: The New Life Movement in China in the Mid-1930s.' Cross-Currents: East Asian History and Culture Review 7 , June. cross-currents.berkeley.edu/e-journal/issue-7/liu.

[8] Teiwes, Frederick C. 1993. Politics \& Purges in China: Rectification and the Decline of Party Norms, 1950-65, 51-62. Armonk: M. E. Sharpe.

[9] Sorace, Christian P. 2017. Shaken Authority: China's Communist Party and the 2008 Sichuan Earthquake. Ithaca: Cornell University Press. Especially Chapter 2: 'Party Spirit Made Flesh'

[10] Teiwes, Frederick C. 1993. Politics \& Purges in China, 36-37.

[11] Zhou, Yiliang (translated by Joshua A. Fogel). 2014. Just a Scholar: The Memoirs of Zhou Yiliang (1913-2001). Leiden: Brill.

[12] Fang, Lizhi (translated by Perry Link). 2016. The Most Wanted Man in China: My Journey from Scientist to Enemy of the State. New York: Henry Holt and Company.

[13] See, for example, Smith, Aminda M. 2012. Thought Reform and China's Dangerous Classes: Reeducation, Resistance, and the People. Boulder: Rowman \& Littlefield.

[14] 2013. Renmin ribao [People's Daily]. 27 November; 2007. 'Xi Jinping: Ideology Work is a Critical Task.' China Daily. 24 October; discussed in Lei, Ya-Wen. 2018. The Contentious Public Sphere: Law, Media \& Authoritarian Rule in China, Chapter 7, 171. Princeton: Princeton University Press. 
[15] 2018. 'Xinjiang weiwuer zizhiqu di shisan jie renmin daibiao dahui changwuyuanhui gonggao (di qi hao) [Third Session of the Xinjiang Uyghur Autonomous Region People's Congress Standing Committee, Report No. 7], 9 October. www.xjpcsc.gov.cn/1009/t4028e49 c665347630166588b8cf40001001.html.

[16] Scott, James C. 1990. Domination and the Arts of Resistance: Hidden Transcripts, Chapter 3, 45-69. New Haven: Yale University Press.

\section{TRADE UNION}

$\left[{ }^{*}\right]$ This essay draws from the author's paper: Franceschini, Ivan. 2015. 'The Broken Belt: The AllChina Federation of Trade Unions and the Communist Party in the People’s Republic of China.' Contemporanea 1: 67-90.

[1] Lenin, Vladimir I. 1964. “Left-wing Communism:” An Infantile Disorder. Lenin's Collected Works, Vol. 31, 17-118. Moscow: Progress Publishers.

[2] Lenin, Vladimir I. 1961. 'What's to Be Done?' Lenin's Collected Works, Vol. 5, 347-530. Moscow: Foreign Languages Publishing House.

[3] Quoted in Harper, Paul. 1969. 'The Party and the Unions in Communist China.' The China Quarterly 37: 84-119.

[4] Xinhua. 2013. 'Li Keqiang: Rang gaige fazhan chengguo huiji quanti renmin [Li Keqiang: Let the Achievements of the Reforms Extend to All People].' Xinhua, 21 October. news.xinhuanet.com/ politics/2013-10/21/c_117809444.htm; Xinhua. 2013. 'Xi Jinping yu zhonghua quanguo zonggonghui xin yi jie lingdao banzi jiti tanhua [Xi Jinping Holds a Collective Discussion with the New Leadership of the ACFTU].' Xinhua, 23 October. www.gov.cn/ldhd/2013-10/23/content_2513659.htm.

[5] 2018. 'Li Keqiang zai Zhongguo gonghui shiqida zuo jingji xingshi baogao [Li Keqiang Delivers the Report on the Economic Situation at the Seventeenth Union Congress].' Zhongyang renmin zhengfu [Central Government Website], 24 October. www.gov.cn/xinwen/2018-10/24/content_5334173.htm; Wang, Huning. 2018. 'Wang Huning: Zai Zhongguo gonghui di shiqi ci quanguo daibiao dahui shang de zhici [Wang Huning's Address at the Seventeenth Congress of the ACFTU]. Zhongguo gonghui xinwen wang [Chinese Union News], 22 October. acftu.people.com.cn/n1/2018/1022/c67560-30355671.html.

[6] Lee, Lai To. 1986. Trade Unions in China: 1949 to Present. Singapore: Singapore University Press.

[7] Chao, Kuo-chun. 1953. The Mass Organizations in Communist China, 4. Cambridge, MA: Centre for International Studies, Massachusetts Institute of Technology.

[8] The definition of the union is taken from the first article of the 1950 Trade Union Law; the definition of the CCP as vanguard of the Chinese working class is enshrined in the first line of the Party Constitution.

[9] Frazier, Mark. 2002. The Making of the Chinese Industrial Workplace, 112-14. Cambridge: Cambridge University Press.

[10] Harper, Paul. 1969. 'The Party and the Unions in Communist China', 91.

[11] Brugger, William. 1973. Democracy and Organization in the Chinese Industrial Enterprise (1948-1953), 81. Cambridge: Cambridge University Press.

[12] Deng, Zihui. 1950. 'Guanyu zhongnanqu de gonghui gongzuo [On the Trade Union Work in the Southern and Central Areas].' Gongren ribao [Workers' Daily], 4 August: 4.

[13] Li, Lisan. 1987. 'Xingzheng yu gonghui de guanxi [Relations between Administration and Union].' Li Lisan Lai Ruoyu lun gonghui [Li Lisan and Lai Ruoyu Discuss the Union], edited by the Chinese Institute of Industrial Relations, 146-49. Beijing: Dangan Chubanshe. 
[14] Li, Lisan. 1987. 'Guanyu xin minzhuzhuyi shiqi gonghui gongzuo zhong ji ge wenti de jueyi [Resolution on Some Issues regarding the Union Work in the Phase of the New Democracy].' In Li Lisan Lai Ruoyu lun gonghui, 150-55.

[15] Li. Lisan. 1987. 'Guanyu zai gonghui gongzuo zhong fasheng zhenglun de wenti de yijian xiang Mao zhuxi de baogao [Report to Chairman Mao on the Controversial Issues in Union Work].' In Li Lisan Lai Ruoyu lun gonghui, 156-58.

[16] Li, Fuchun. 1989. 'Zai gonghui gongzuo wenti shang de fenqi [Some Divergences of Opinion on Matters Related to Union Work]. In Jianguo yilai zhonggong zhongyang guanyu gongren yundong wenjian xuanbian [Selected Documents about the Labour Movement Issued by the Central Committee of the Party since the Foundation of the People's Republic], edited by the General Office of the ACFTU, 96-116. Beijing: Zhongguo Gongren Chubanshe.

[17] Gipouloux, François. 1986. Les cent fleurs a l'usine, 213. Paris: Edition de l'Ecole des Hautes Etudes en Sciences Sociales.

[18] Howe, Christopher. 1973. Wage Patterns and Wage Policy in Modern China, 1919-1972, 89-95. Cambridge: Cambridge University Press.

[19] Cited in Chang, Kai. 2005. 'Bagongquan lifa wenti de ruogan sikao [Some Thoughts on the Issue of the Legislation on the Right to Strike].' Xuehai 4: 43-55.

[20] Central Committee of the CCP. 1989. 'Zhonggong zhongyang guanyu chuli bagong, bake wenti de zhishi [Directive of the Central Committee of the CCP on How to Handle the Strikes by Workers and Students].' In Jianguo yilai zhonggong zhongyang guanyu gongren yundong wenjian xuanbian, $507-15$.

[21] Lai, Ruoyu. 1987. 'Gonghui zenyang duidai renmin neibu maodun? [How Does the Union Deal with Contradictions among the People?]' In Li Lisan Lai Ruoyu Lun Gonghui, 445-49.

[22] Ibid.

[23] Li, Xiuren. 1957. 'Gonghui gongzuo zouma guanhua ji [Cursory Notes on the Work of the Union].' Gongren ribao [Workers' Daily], 9 May: 12.

[24] Lai, Ruoyu. 1989. 'Guanyu dangqian gonghui gongzuo de ruogan wenti [Some Issues in the Current Work of the Union].' In Jianguo yilai zhonggong zhongyang guanyu gongren yundong wenjian xuanbian, 556-603.

[25] He, Bufeng. 2000. 'Wenhua dageming zhong quanguo zonggonghui tingzhi huodong de qianqian houhou [The Reasons Behind the Suspension of the Activities of the ACFTU during the Cultural Revolution].' In Zhongguo gongren yundonshi yanjiu wenji [Collection of Research Essays on the History of the Labour Movement in China], edited by Yanping Cao, 229-30. Beijing: Zhongguo Gongren Chubanshe.

[26] Deng, Xiaoping. 1978. 'Zai Zhongguo gonghui dijiuci quanguo daibiao dahui shang de zhici [Opening Speech at the Ninth National Congress of the Chinese Union].' In Zhongguo gonghui dijiuci quanguo daibiao dahui zhuyao wenjian [Fundamental Documents of the Ninth Congress of the Chinese Union], edited by the ACFTU, 1-6. Huhehuote: Neimenggu Renmin Chubanshe.

[27] Wilson, Jeanne. 1986. 'The People's Republic of China.' In Trade Unions in Communist States, edited by Alex Pravdaand Blair Ruble, 219-51. Boston: Allen \& Unwin; Morriss, Richard. 1985. 'Trade Unions in Contemporary China.' The Australian Journal of Chinese Affairs 13: 50-67.

[28] Zhao, Ziyang. 1988. 'Zai Zhongguo gonghui dishiyici quanguo daibiao dahui shang de zhici [Opening Speech at the Eleventh National Congress of the Chinese Union].' In Zhongguo gonghui dishiyici quanguo daibiao dahui wenjian huibian [Collection of Documents of the Eleventh Congress of the Chinese Union], edited by the ACFTU, 1-11. Beijing: Gongren Chubanshe. 
[29] ACFTU. 1988. 'Gonghui gaige de jiben shexiang [Basic Plan for the Reform of the Union].' In Zhongguo gonghui dishiyici quanguo daibiao dahui wenjian huibian, 54-70.

[30] Taylor, Bill, Kai Chang, and Qi Li. 2003. Industrial Relations in China, 111-12. Cheltenham: Edward Elgar.

[31] Walder, Andrew. 1992. 'Workers, Managers and the State: The Reform Era and the Political Crisis of 1989.' The China Quarterly 127: 467-92; Sheehan, Jackie. 1998. Chinese Workers: A New History, 195-209. London: Routledge.

[32] Much has been written about the workers' involvement in the 1989 movement, but the role of the official union has always been mentioned only cursorily. See, for instance Chan, Anita. 1993. 'Revolution or Corporatism? Workers and Trade Unions in Post-Mao China.' The Australian Journal of Chinese Affairs 29: 31-61; Wang, Shaoguang. 1992. 'Deng Xiaoping's Reform and the Chinese Workers Participation in the Protest Movement of 1989.' Research in Political Economy 13: 163-97; Wilson, Jeanne. 1990. 'Labour Policy in China: Reform and Retrogression.' Problems of Communism 39 (5): 44-65; Zhang, Yunmei. 2003. 'Lishun yu chongtu: Zhongguo gonghui yu dang-guojia de guanxi [Order and Conflicts: The Relations between the Union and the Party].' Ershiyi shiji [Twenty-first Century] 18. www.cuhk.edu.hk/ics/21c/supplem/essay/0308024g.htm.

[33] Li, Yun ed. 1989. Diankuang de shenian zhi xia [The Tumultuous Summer of the Year of the Snake], 114. Beijing, Guofang Keji Daxue Chubanshe.

[34] Worker’s Daily. 1989. ‘400 yu ming gonghui gongzuozhe youxing qingyuan [Over Four Hundred Union Workers Take the Street to Present a Petition].' Gongren ribao [Workers' Daily], 17 May: 1.

[35] Worker's Daily. 1989. 'Quanzong fuzhuxi Wang Houde dui benbao jizhe fabiao tanhua [Wang Houde, Vice-president of the ACFTU, Speaks with One of Our Journalists].' Gongren ribao [Workers' Daily], 18 May: 1 . The news of the donation was published on both Workers' Daily and People's Daily on 18 and 19 May 1989.

[36] ACFTU. 'Guanyu dangqian shitai de wu dian shengming [Five Declarations on the Present Situation].' Gongren ribao [Workers' Daily], 19 May: 1.

[37] Wang, Shaoguang. 1992. 'Deng Xiaoping's Reform and the Chinese Workers Participation in the Protest Movement of 1989.'

[38] On 'institutional conversion,' see Thelen, Kathleen. 2003. 'How Institutions Evolve: Insights from Comparative Historical Analysis.' In Comparative Historical Analysis in the Social Sciences, edited by James Mahoney and Dietrich Rueschemeyer, 208-40. Cambridge: Cambridge University Press; Ding, X. L. 2004. 'Institutional Amphibiousness and the Transition from Communism: The Case of China.' British Journal of Political Sciences 24: 293-318.

[39] Franceschini, Ivan. 2018. 'At the Roots of Labour Activism: Chinese and Cambodian Garment Workers in Comparative Perspective.' Journal of Contemporary Asia. Online first, doi.org/10.1080/00 472336.2018.1555272.

\section{UNITED FRONT}

[1] van Slyke, Lyman. 1967. Enemies and Friends: The United Front in Chinese Communist History. Stanford: Stanford University Press.

[2] Mao, Zedong. 1938. 'The Question of Independence and Initiative Within the United Front.' 5 November.

[3] U, Eddy. 2012. 'Dangerous Privilege: The United Front and the Rectification Campaign of the Early Mao Years.' The China Journal 68: 32-57. 
[4] Armstrong, David J. 1977. Revolutionary Diplomacy: Chinese Foreign Policy and the United Front Doctrine. Berkeley \& Los Angeles: University of California Press.

[5] Deng, Xiaoping. 1979. 'The United Front and the Tasks of the Chinese People's Political Consultative Conference in the New Period.' 15 June. Selected Works of Deng Xiaoping, Vol. 2 (19781982). www.chinadaily.com.cn/china/19thcpcnationalcongress/2010-10/15/content_29714545.htm.

[6] Lam, Wai-Man, and Kai Chi-yan Lam. 2013. 'China's United Front Work in Civil Society: The Case of Hong Kong. International Journal of Chinese Studies 4 (3): 301-25.

[7] Groot, Gerry. 2015. 'The Expansion of the United Front Under Xi Jinping.' In The China Story Yearbook 2015: Pollution, edited by Gloria Davies, Jeremy Goldkorn, and Luigi Tomba, 167-77. Canberra: ANU Press. doi.org/10.22459/CSY.09.2016.04A.

[8] Xi, Jinping. 2015. 'Guanyu xietiao tuijin "si ge quanmian" zhanlüe buju lun shuzhai bian [Selection on the Strategic Plan to Promote the "Four Comprehensive"].' Beijing: Zhongyang Wenxian Chubanshe.

[9] For the original text of the regulations, see cpc.people.com.cn/n/2015/0923/c64107-27622040. html.

[10] See the website of the United Front Department of the CPC Central Committee, www.zytzb. gov.cn/html/index.html.

[11] Brady, Anne-Marie. 2017. 'Magic Weapons: China’s political influence under Xi Jinping.' Wilson Center, 18 September 18. www.wilsoncenter.org/article/magic-weapons-chinas-political-influenceactivities-under-xi-jinping; Dreyer, June Teufel. 2018. 'Weapon Without War: China's United Front Strategy.' Foreign Policy Research Institute, 6 February. www.fpri.org/article/2018/02/weapon-withoutwar-chinas-united-front-strategy; Bowe, Alexander. 2018. 'China's Overseas United Front Work: Background and Implications for the United States.' Staff Research Report. 24 August. US-China Economic and Security Review Commission.

[12] Wang, Ray, and Gerry Groot. 2018. 'Who Represents? Xi Jinping's Grand United Front Work, Legitimation, Participation and Consultative Democracy'. The Journal of Contemporary China 27 (112): $569-83$.

[13] Li, Junru. 2018. 'Consultative Democracy, People’s Democracy'. China Today, 1 March. www. chinatoday.com.cn/ctenglish/2018/zdtj/201803/t20180301_800118954.html.

[14] Groot, Gerry. 2004. Managing Transitions: The Chinese Communist Party, United Front Work, Corporativism and Hegemony. New York: Routledge.

[15] Lam, Wai-Man, and Kai Chi-yan Lam. 2013. 'China’s United Front Work in Civil Society'; Groot, Gerry. 2004. Managing Transitions; Groot, Gerry. 2013. 'A Self-Defeating Secret Weapon? The Institutional Limitations of Corporatism on United Front Work.' In The Chinese Corporatist State: Adaptation, Survival and Resistance, edited by Jennifer Hsu and Reza Hasmath, 29-49. London \& New York: Routledge.

\section{UTOPIA}

[1] Shakhar, Rahav. 2015. The Rise of Political Intellectuals in Modern China: May Fourth Societies and the Roots of Mass-Party Politics. Oxford: Oxford University Press.

[2] Shūgo, Honda. 1960."'Shirakaba" ha no bungaku [The Literature of the "Shirakaba" School].' Shinchō Bunko; Itō, Sei. 1965. 'Modes of Thought in Contemporary Japan.' Japan Quarterly 12 (4).

[3] Huaiyin, Li. 2010. Village China Under Socialism and Reform: A Micro-History, 1948-2008. Stanford: Stanford University Press. 
[4] Callahan, William. 2015. 'History, Tradition and the China Dream: Social Modernization in the World of Great Harmony.' Journal of Contemporary China 24: 983-1001; Kang, Youwei. 2005. Datongshu [The Book of Great Harmony]. Shanghai: Shanghai Juji Chubanshe.

[5] Han, Feizi (translated by Burt Watson). 2003. Han Feizi: Basic Writings. New York: Columbia University Press.

[6] Moore, Thomas. 2016. Utopia. London: Verso; Owen, Robert. 1995. A New View of Society and Other Writings. London: Penguin Classics.

[7] Han, Feizi. 2003. Han Feizi.

[8] Wonderley, Anthony. 2017. Oneida Utopia: A Community Searching for Human Happiness and Prosperity. Ithaca: Cornell University Press; Stein, Stephen J. 1994. The Shaker Experience in America: A History of the United Society of Believers. New Haven: Yale University Press.

[9] Skinner, B. F. 2005. Walden Two. Indianapolis: Hackett Publishing Company.

[10] Merkel-Hess, Kate. 2016. The Rural Modern: Reconstructing the Self and State in Republican China. Chicago: University of Chicago Press.

[11] Day, Alexander. 2008. 'The End of the Peasant? New Rural Reconstruction in China.' Boundary 2 35 (2): 49-73; He, Xuefeng. 2007. 'New Rural Reconstruction and the Chinese Path.' Chinese Sociology and Anthropology 39 (4): 26-38.

[12] Wen, Tiejun. 2001. 'Centenary Reflections on the 'Three Dimensional Problem' of Rural China.' Inter-Asia Cultural Studies 2 (2): 287-95; Wen, Tiejun. 2007. 'Deconstructing Modernization.' Chinese Sociology and Anthropology 39 (4): 10-25.

[13] Sturgis, Sam. 2014. 'Inside China's 'Back to the Land' Movement.' CityLab, 14 December. www.citylab.com/life/2014/12/a-film-about-chinas-back-to-the-land-movement/383910; Wainwright, Olivier. 2014. “'Our Cities Are Insufferable:" Chinese Artists Go Back to the Land.' The Guardian, 2 December. www.theguardian.com/artanddesign/2014/dec/02/chinese-artists-rural-rebellion-xi-jinping; Poon, Linda. 2015. 'China's Villages Are Dying: A New Film Asks if They Can Be Saved'. National Public Radio, 5 January. www.npr.org/sections/goatsandsoda/2015/01/05/372491552/chinas-villages-are-dyinga-new-film-asks-if-they-can-be-saved; Ou, Ning. 2015. Bishan Commune: How to Start Your Own Utopia. Denmark: OVO Press.

\section{WOMEN'S LIBERATION}

[1] Harding, Harry. 1991. 'From China, with Disdain: New Trends in the Study of China.' In America Views China: American Images of China Then and Now, edited by Jonathan Goldstein, Jerry Israel, and Hilary Conroy, 244-72. London: Associated University Presses.

[2] Stacey, Judith. 1983. Patriarchy and Socialist Revolution in China. Berkeley: University of California Press.

[3] Harding, Harry. 1991. 'From China, with Disdain.'

[4] Rofel, Lisa. 1999. Other Modernities: Gendered Yearnings in China after Socialism, 21. Berkeley: University of California Press.

[5] Fraser, Nancy. 2013. Fortunes of Feminism: From State Managed Capitalism to Neoliberal Crisis. London: Verso.

[6] Fraser, Nancy. 2013. Fortunes of Feminism.

[7] Li, Jingzhi. 2011. Zhongguo funü yundong yanjiuwenji [Essays on Chinese Women's Movements]. Beijing: Shehui Kexue Wenxian Chubanshe. 
[8] Tong, Hua, and Peizhu Kang, eds. 2004. Makesizhuyi funülilun fazhanshi [Historical Development of Marxist Feminist Theory]. Beijing: Beijing Daxue Chubanshe.

[9] Li, Jingzhi. 2011. Essays on Chinese Women's Movements.

[10] Walker, Kathy LeMons. 1978. 'The Party and Peasant Women.' In Chinese Communists and Rural Society, 1927-1937, edited by Philip C. C. Huang, Lynda Schaefer Bell, and Kathy LeMons Walker, 57-82. Berkeley: University of California Press.

[11] Li, Jingzhi. 2011. Essays on Chinese Women's Movements.

[12] Ibid.; Croll, Elisabeth. 1980. Feminism and Socialism in China. New York: Schocken Books.

[13] Chinese Soviet Republic. 'Constitution of the Soviet Republic (November 7, 1931).' In Fundamental Laws of the Chinese Soviet Republic. New York: International Publishers, 1934.

[14] Croll, Elisabeth. 1980. Feminism and Socialism in China, 191.

[15] Ibid.

[16] Ibid.

[17] Walker, Kathy LeMons. 1978. 'The Party and Peasant Women.'

[18] Steiner, H. Arthur. 1951. 'Current 'Mass Line' Tactics in Communist China.' The American Political Science Review 2: 422-36.

[19] Walker, Kathy LeMons. 1978. 'The Party and Peasant Women.'

[20] Steiner, H. Arthur. 1951. 'Current “Mass Line” Tactics in Communist China.'

[21] Croll, Elisabeth. 1980. Feminism and Socialism in China; Cheng, Lucie. 1988. 'Women and Class Analysis in the Chinese Land Revolution.' Berkeley Women's Law Journal 4 (1): 62-93.

[22] Walker, Kathy LeMons. 1978. 'The Party and Peasant Women.'

[23] Croll, Elisabeth. 1980. Feminism and Socialism in China.

[24] Jackal, Patricia Stranahan. 1981. 'Changes in Policy for Yanan Women, 1935-1947'. Modern China 7 (1): 83-112.

[25] Croll, Elisabeth. 1980. Feminism and Socialism in China, 207.

[26] Jackal, Patricia Stranahan. 1981. 'Changes in Policy for Yanan Women, 1935-1947', 110.

[27] Saich, Tony. 1996. 'Introduction.' In The Rise to Power of the Chinese Communist Party: Documents and Analysis, edited by Tony Saich, xxxix-lxix. Armonk: M. E. Sharpe.

[28] Tang, Shuiqing. 2012. 'Xiangcun funü zaisuweiaigemingzhongde chayixing xuanze: Yizhongyangsuqu weizhongxinde kaocha [The Different Choices by Rural Women in the Soviet Revolution: An Investigation of the Central Soviet Area]. Zhonggong dangshi yanjiu [Research on the History of the Chinese Communist Party] 11: 85-94.

[29] Tang, Shuiqing. 2012. 'The Different Choices by Rural Women in the Soviet Revolution.'

[30] Walker, Kathy LeMons. 1978. 'The Party and Peasant Women', 60.

[31] 1988. 'Zhonggong zhongyang tonggao di 85 hao [Circular 85 of the Chinese Communist Party's Central Committee],' 21 July 1930. In Zhongguo funü yundong lishishiliao [Historical Materials on Chinese Women's Movements], 3: 63-64. Beijing: Renmin Chubanshe.

[32] Moise, Edwin E. 2008. Modern China: A History, Third Edition. New York: Longman; Saich, Tony. 1996. "Introduction'; Croll, Elisabeth. 1980. Feminism and Socialism in China.

[33] Moise, Edwin E. 2008. Modern China: A History.

[34] Sargent, Lydia, ed. 1981. Women and Revolution: A Discussion of the Unhappy Marriage of Marxism and Feminism. Boston: South End Press.

[35] Tong, Hua and Peizhu Kang, eds. 2004. Historical Development of Marxist Feminist Theory.

[36] Chen, Tina Mai. 2011. 'They Love Battle Array, Not Silks and Satins.' In Words and Their Stories: Essays on the Language of the Chinese Revolution, edited by Ban Wang, 263-82. Leiden: Brill. 
[37] Wang, Zheng. 2010. 'Creating a Socialist Feminist Cultural Front: Women of China (19491966). The China Quarterly 204: 827-49.

[38] Chen, Tina Mai. 2003. 'Female Icons, Feminist Iconography? Socialist Rhetoric and Women's Agency in 1950s China.' Gender and History 15 (2): 268-95.

[39] Ibid., 270.

[40] Ibid., 282.

\section{WORK TEAM}

[1] Heilmann, Sebastian, and Elizabeth J. Perry, eds. 2011. Mao's Invisible Hand: The Political Foundations of Adaptive Governance in China. Cambridge, MA: Harvard University Press. See also Perry, Elizabeth J. 2019. 'Making Communism Work: Sinicizing a Soviet Governance Practice.' Comparative Studies in Society and History 61 (3).

[2] Ding, Ling. 1954. The Sun Shines Over the Sangkan River. Beijing: Waiwen Chubanshes; Zhou, Libo. 1955. The Hurricane. Beijing: Waiwen Chubanshe.

[3] Hinton, William. 1966. Fanshen: A Documentary of Revolution in a Chinese Village. New York: Monthly Review Press; Crook, Isabel and David Crook. 1979. Ten Mile Inn: Mass Movement in a Chinese Village. New York: Pantheon.

[4] Museum of the Original Site of the Canton Peasant Movement Training Institute. 1987. Guangzhou nongmin yundong jiangxisuo ziliao xuanbian [Compilation of Materials on the Guangzhou Peasant Movement Training Institute], 27. Beijing: Renmin Chubanshe.

[5] Pantsov, Alexander. 2000. The Bolsheviks and the Chinese Revolution, 1919-1927, 164-69. Richmond: Curzon Press; Jacobs, Dan N. 1981. Borodin: Stalin's Man in China, 152. Cambridge, MA: Harvard University Press; Whiting, Allen S. 1954. Soviet Policies in China, 1917-1924, 245. New York: Columbia University Press.

[6] Viola, Lynne. 1999. Peasant Rebels under Stalin: Collectivization and the Culture of Peasant Resistance. Oxfordk: Oxford University Press.

[7] Miller, Robert F. 1970. One Thousand Tractors, 204-05. Cambridge, MA: Harvard University Press.

[8] Liu, Yanwen. 2009. Siqing gongzuodui gongzuo jizhi yanjiu [A Study of the Working Mechanisms of Work Teams in the Four Cleans]. MA Thesis. Beijing: Renmin Daxue Chubanshe.

[9] Bunce, Valerie. 1999. Subversive Institutions: The Design and the Destruction of Socialism and the State. Cambridge: Cambridge University Press.

[10] Putnam, Robert D. 1993. Making Democracy Work: Civic Traditions in Modern Italy. Princeton: Princeton University Press; Putnam, Robert D. 2000. Bowling Alone: The Collapse and Revival of American Community. New York: Simon \& Schuster.

\section{WORK UNIT}

[1] For some historical perspectives on the work unit in China see Danwei: The Changing Chinese Workplace in Historical and Comparative Perspective, edited by Xiaobo Lu and Elizabeth J. Perry. Armonk: M. E. Sharpe. See also Kaple, Deborah A. 1993. Dream of a Red Factory: The Legacy of High Stalinism in China. Oxford: Oxford University Press. 
[2] Frazier, Mark W. 2002. The Making of the Chinese Industrial Workplace: State, Revolution, and Labor Management. Cambridge: Cambridge University Press.

[3] Walder, Andrew G. 1988. Communist Neo-Traditionalism: Work and Authority in Chinese Industry. Berkeley: University of California Press.

[4] Polanyi, Karl. 2001. The Great Transformation: The Political and Economic Origins of Our Time. Boston: Beacon Press.

[5] Sheehan, Jackie. 2002. Chinese Workers: A New History. London \& New York: Routledge.

[6] Andreas, Joel. 2012. 'Industrial Restructuring and Class Transformation in China.' In China's Peasants and Workers: Changing Class Identities, edited by Beatriz Carrillo and David S. G. Goodman, 102-23. Cheltenham: Edward Elgar; Walder, Andrew G. 1988. Communist Neo-Traditionalism.

[7] Perry, Elizabeth J. 1997. Proletarian Power: Shanghai in the Cultural Revolution. Boulder: Westview Press; Sheehan, Jackie. 2002. Chinese Workers.

[8] Gallagher, Mary. 2005. Contagious Capitalism: Globalisation and the Politics of Labour in China. Princeton: Princeton University Press.

[9] Unger, Jonathan, ed. 2008. Associations and the Chinese State: Contested Spaces. Armonk: M. E. Sharpe.

[10] Lee, Ching Kwan. 1999. 'From Organized Dependence to Disorganized Despotism: Changing Labour Regimes in Chinese Factories.' The China Quarterly 157: 44-71.

[11] Chan, Anita. 1997. 'Chinese Danwei Reforms: Convergence with the Japanese Model.' In Danwei: The Changing Chinese Workplace in Historical and Comparative Perspective, edited by Xiaobo Lu and Elizabeth J. Perry, 91-113. Armonk: M. E. Sharpe; Unger, Jonathan, and Anita Chan. 2009. 'A Chinese State Enterprise under the Reforms: What Model of Capitalism?' The China Journal 62: 1-26; Dore, Ronald Philip. 1990. British Factory, Japanese Factory: The Origins of National Diversity in Industrial Relations. Berkeley: University of California Press.

\section{AFTERWORD}

[1] On subjectification, see Badiou, Alain (translated by Bruno Bosteels). 2009. Theory of the Subject, 241ff. London: Continuum.

[2] Wang, Hui. 2016. 'The Crisis of Representativeness and Post-Party Politics.' In The Idea of Communism, Volume 3, edited by Alex Taek-Gwang Lee and Slavoj Žižek, 19-40, citation at p. 25. London: Verso Books.

[3] Ibid., 25.

[4] Pun, Ngai. 2016. 'Chinese Communism Revisited: Still a Class Perspective, but Why?' In The Idea Of Communism, Volume 3, 42-61, citation at p. 58. 